Universidad de Lima

Facultad de Ingeniería y Arquitectura

Carrera de Arquitectura

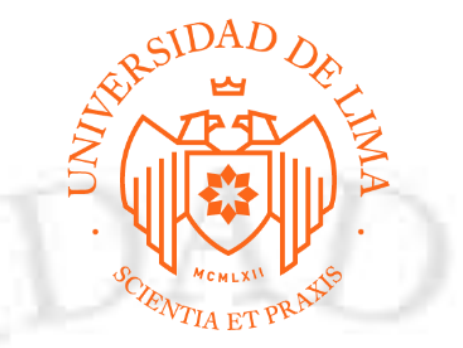

\title{
RESIDENCIA UNIVERSITARIA EN EL DISTRITO DE PUEBLO LIBRE
}

Trabajo de suficiencia profesional para optar el Título Profesional de Arquitecto

\section{Luis Alonso Montoro Vilela}

Código 20110814

Asesor

Fiorella Silvana Arispe Sevilla

Lima - Perú

02 de agosto del 2019 
INTRODUCCIÓN...................................................................................... 1

CAPÍTULO I: GENERALIDADES.......................................................... 3

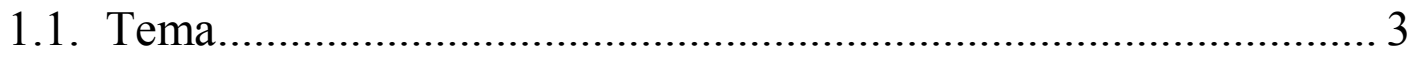

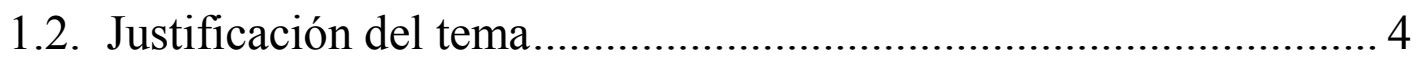

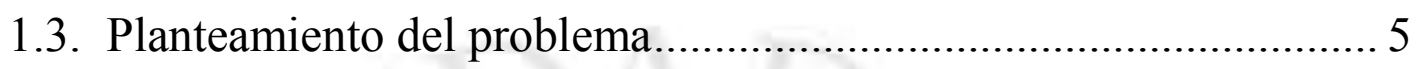

1.4. Objetivos de la investigación ......................................................... 5

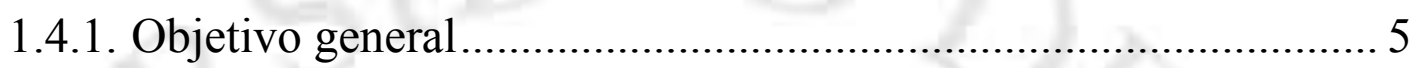

1.4.2. Objetivos específicos .............................................................. 5

1.4.3. Supuesto básico de la investigación .............................................. 6

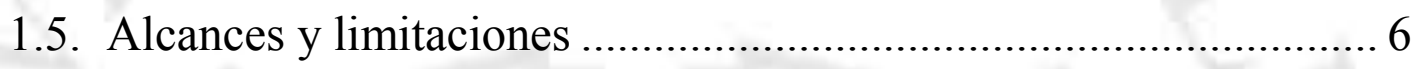

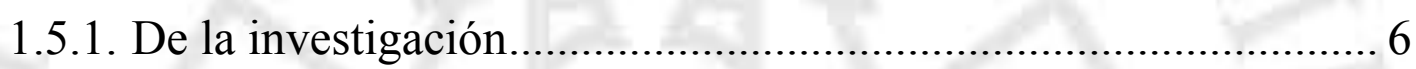

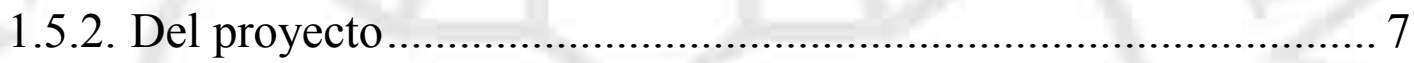

1.6. Diseño de la investigación .......................................................... 7

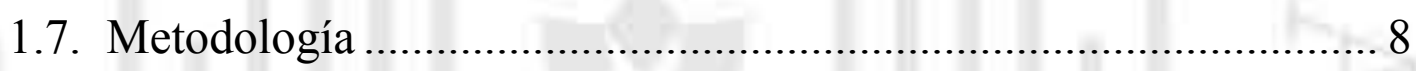

CAPÍTULO II: MARCO REFERENCIAL ..............................................9 9

2.1. Evolución de las residencias universitarias en el mundo a lo largo

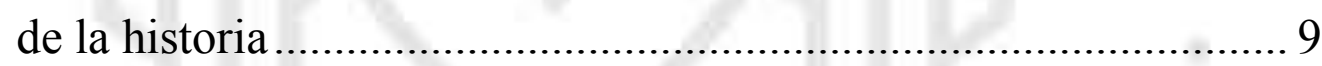

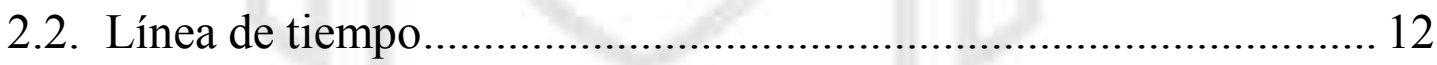

2.3. Indicadores de satisfacción de estudiantes universitarios en residencias universitarias tomados del estudio: Aspectos de satisfacción de los estudiantes de residencias universitarias: Un

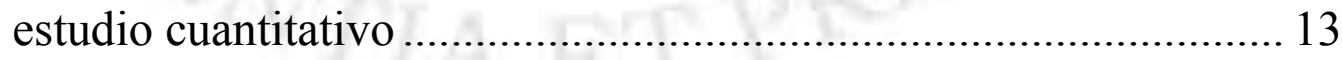

2.4. Estado actual de las residencias en Lima...................................... 17

2.4.1. Residencia universitaria en la Universidad Nacional Mayor de

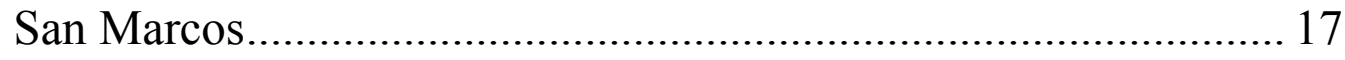

2.4.2. Residencia universitaria en la Universidad Nacional de Ingeniería 
2.4.3. Residencia universitaria en la Universidad Peruana La Unión .... 23

2.4.4. Conclusiones de las residencias investigadas ............................... 24

2.5. Población de estudiantes universitarios en el Perú ........................... 25

2.6. Demanda de las residencias Universitarias en Lima ....................... 34

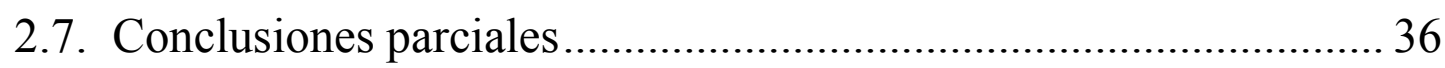

CAPÍTULO III: MARCO TEÓRICO ........................................................ 38

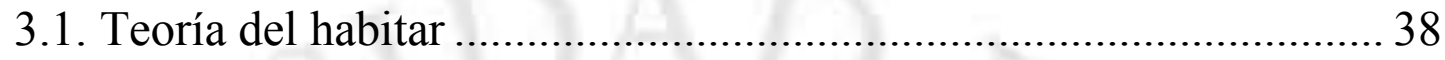

3.1.1. Flexibilidad, versatilidad y diversidad en recintos de la

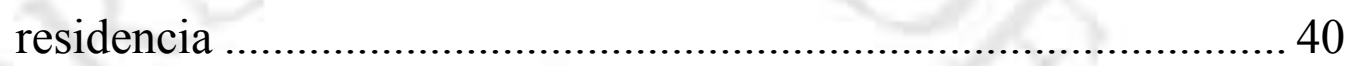

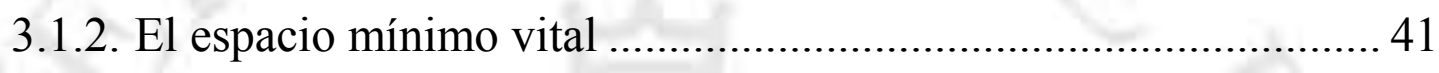

3.2. Teoría de los espacios "In between" ................................................. 41

3.2.1. Vivienda compartida en espacios mínimos ................................... 42

3.2.2. Espacio colectivo dentro de una comunidad ................................ 43

3.3. Concepto de la Residencia universitaria .......................................... 44

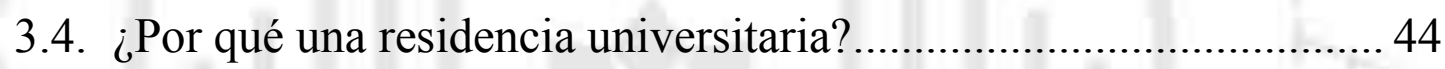

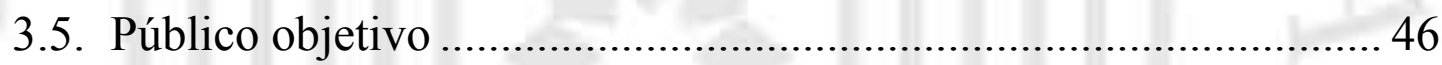

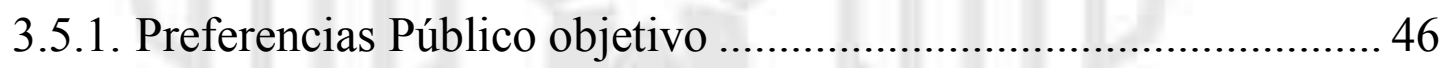

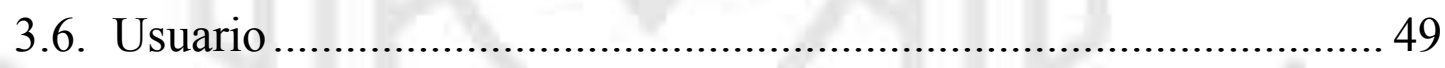

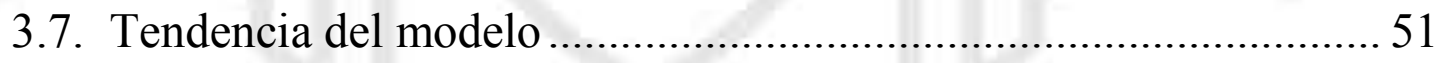

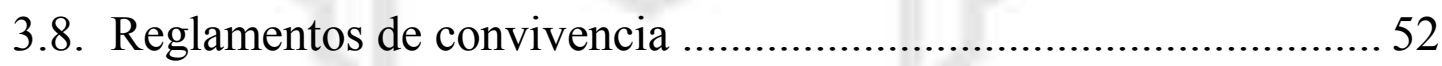

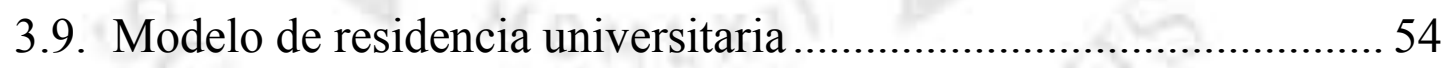

3.10. Servicios de la residencia universitaria........................................... 55

CAPÍTULO IV: MARCO NORMATIVO ................................................. 57

CAPÍTULO V: MARCO OPERATIVO .............................................6 61

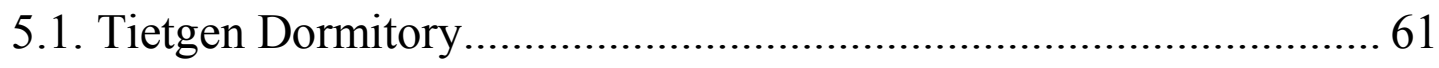

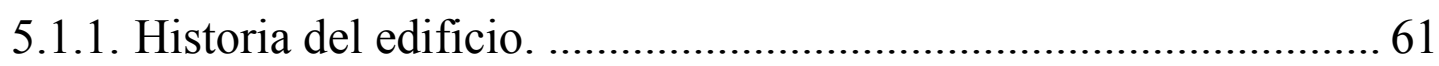

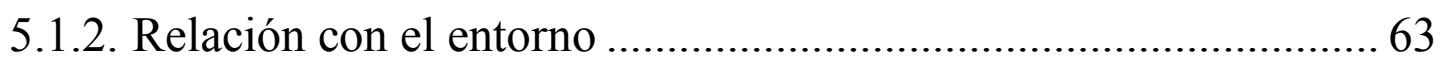

5.1.3. Programa y relaciones programáticas .......................................... 65

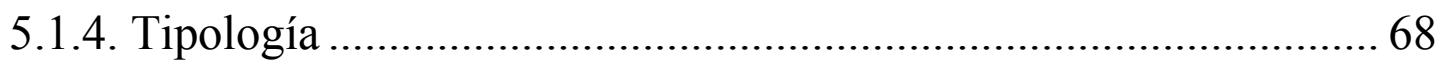




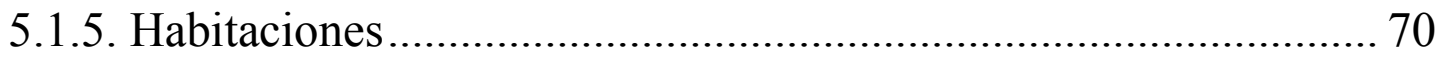

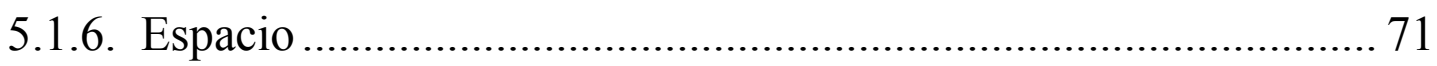

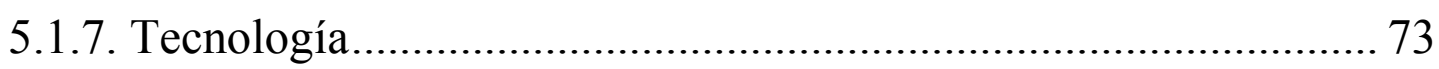

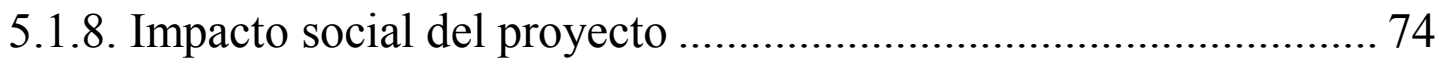

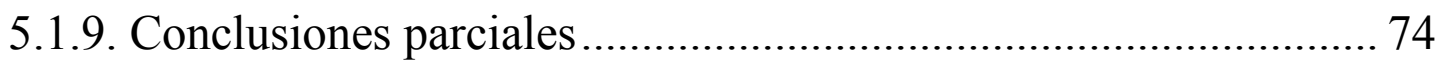

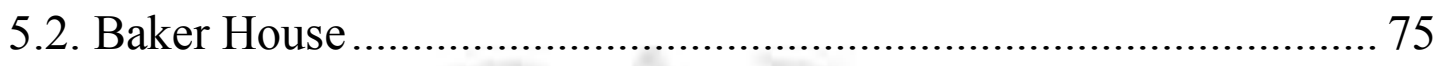

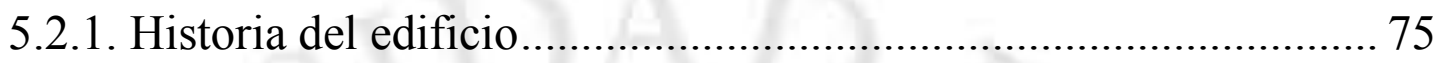

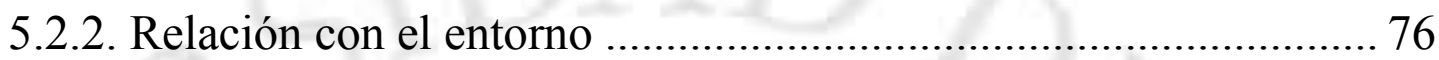

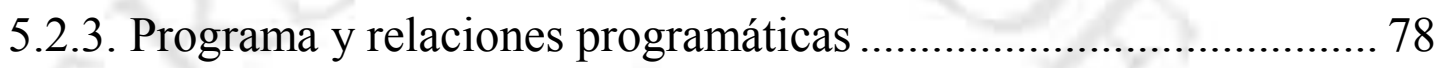

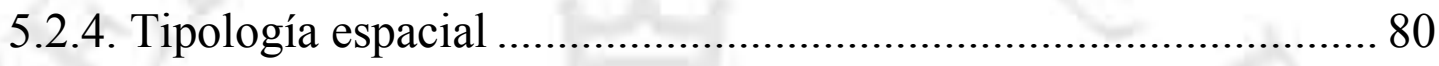

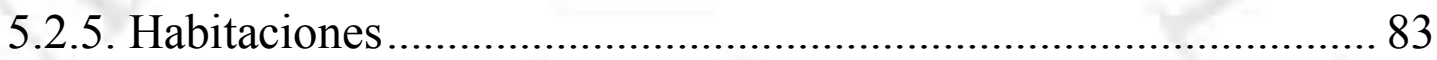

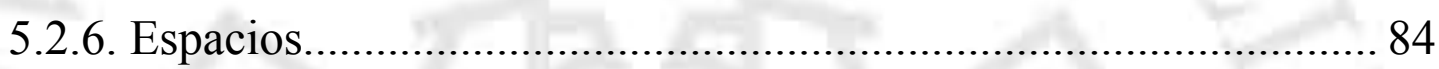

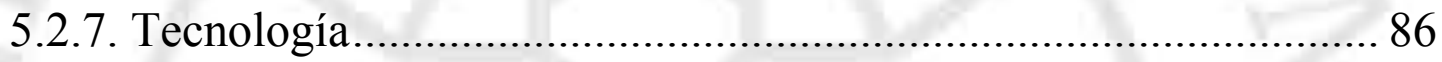

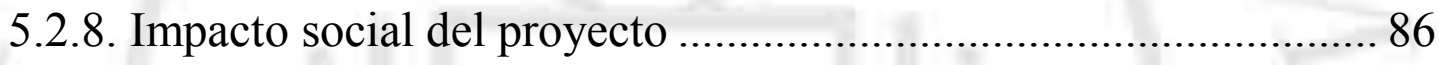

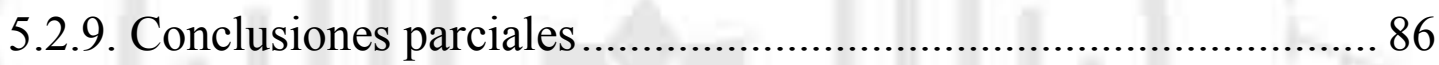

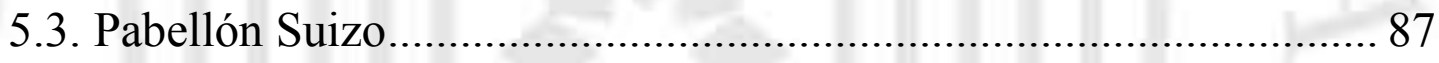

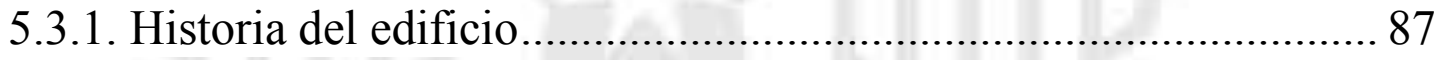

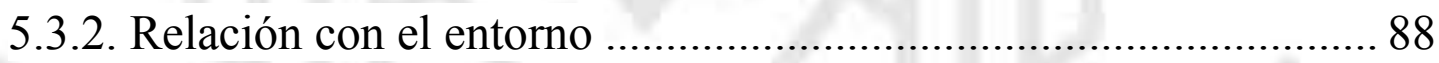

5.3.3. Relaciones programáticas .............................................................. 90

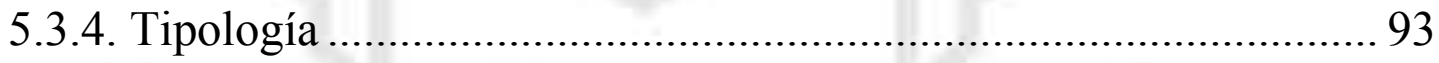

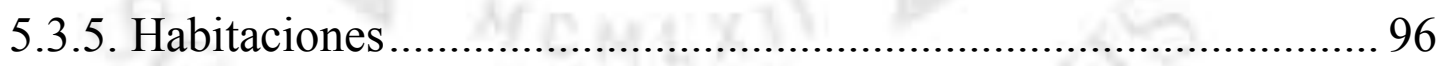

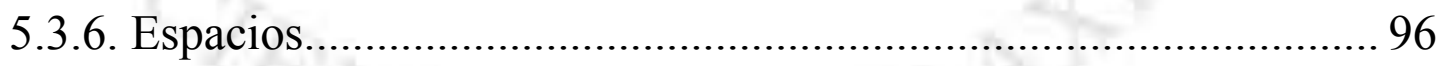

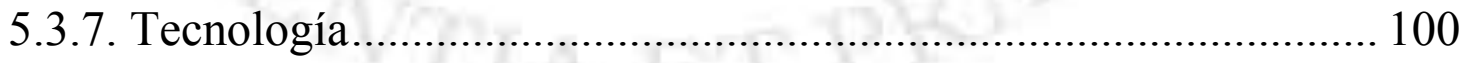

5.3.8. Impacto social del proyecto ........................................................ 100

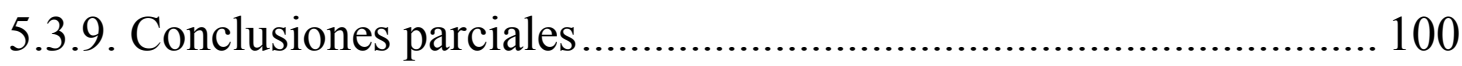

5.4. Nakagin Capsule Tower..................................................................... 101

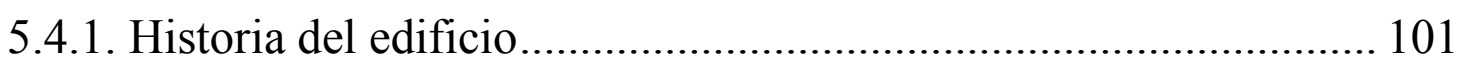

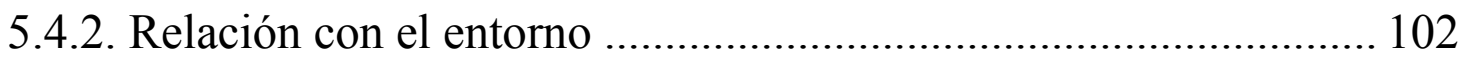

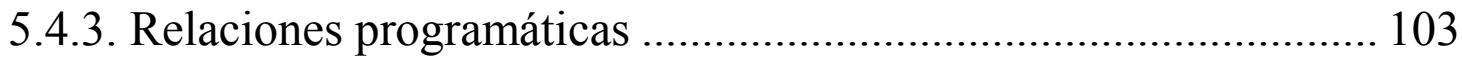




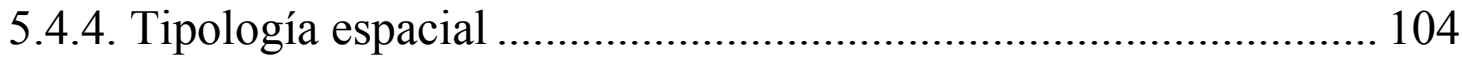

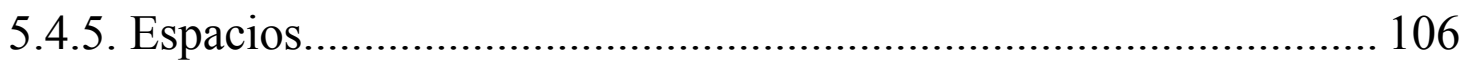

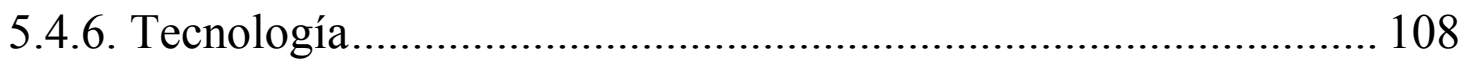

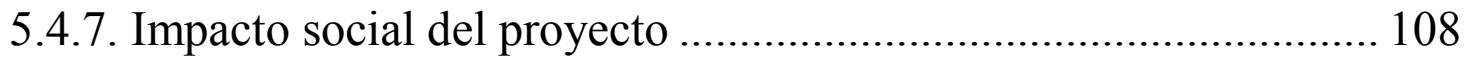

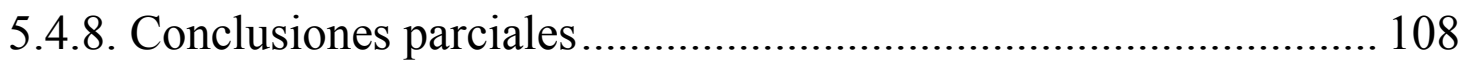

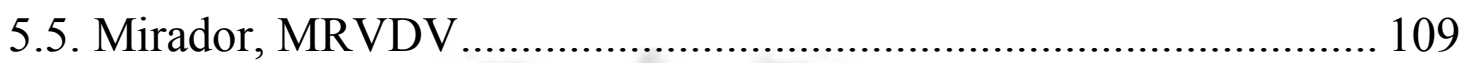

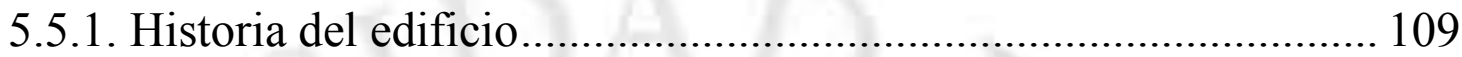

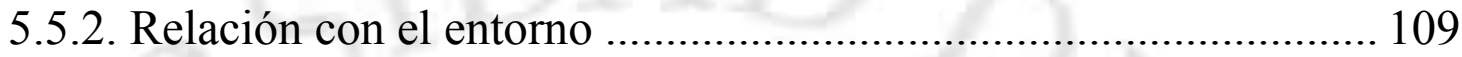

5.5.3. Programa y relaciones programáticas ............................................ 112

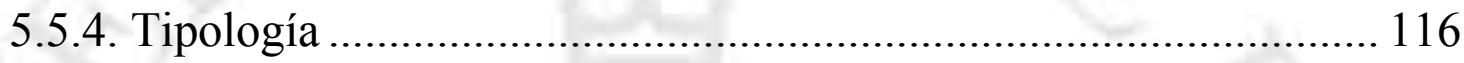

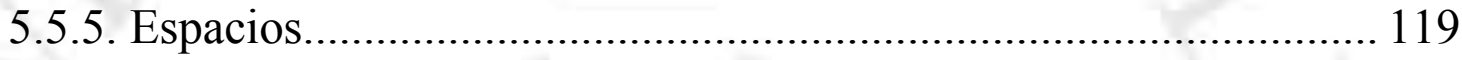

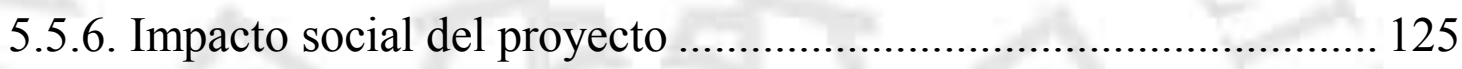

5.5.7. Conclusiones parciales .................................................................. 126

5.6. La Residencia Universitaria en la Universidad Nacional de

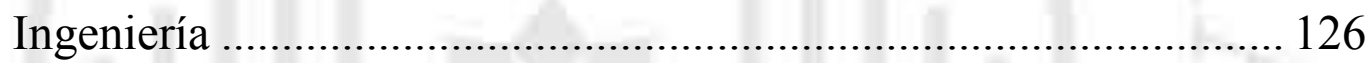

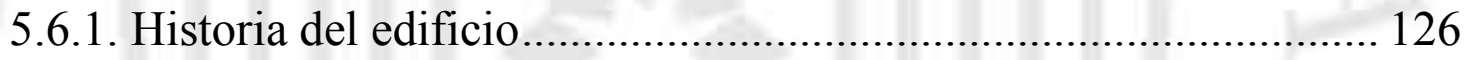

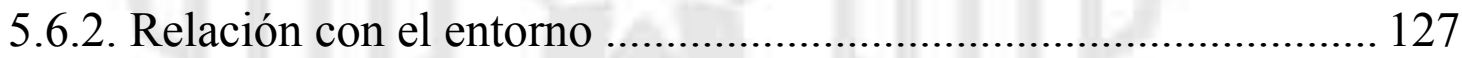

5.6.3. Programa y relaciones programáticas ............................................. 129

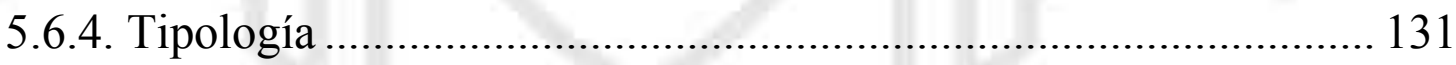

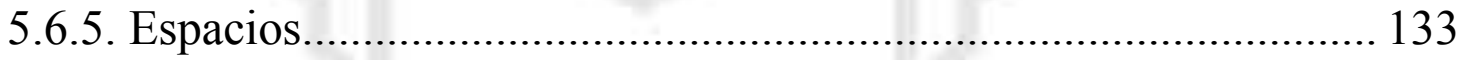

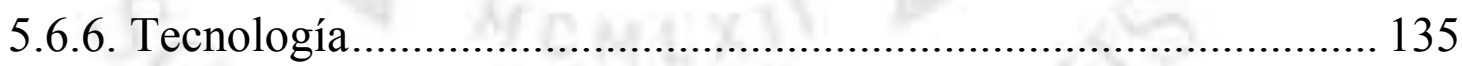

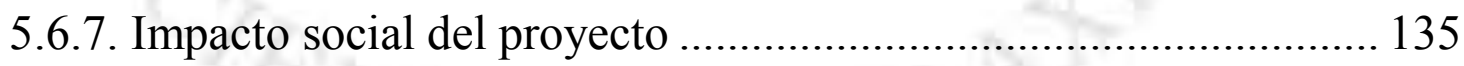

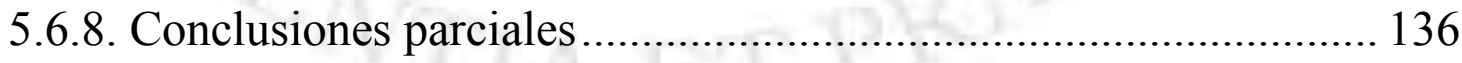

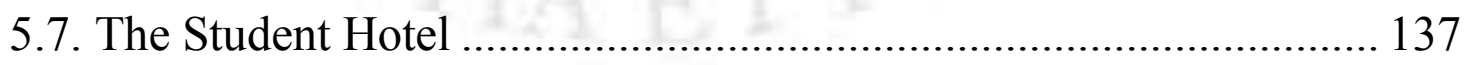

CAPÍTULO VI: MARCO CONTEXTUAL .................................................. 140

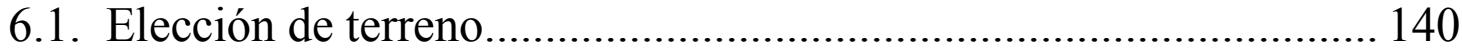

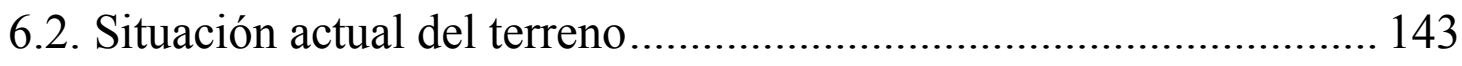

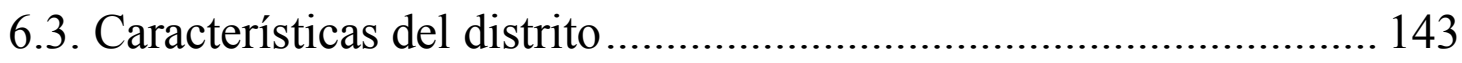

CAPÍTULO VII: PROYECTO.................................................................. 145 
7.1. Toma de partido y estrategias proyectuales

7.2. Programa arquitectónico ................................................................. 151

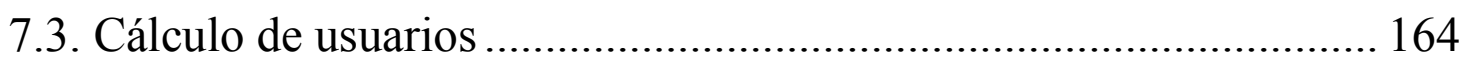

7.4. Programa con cabida .................................................................... 165

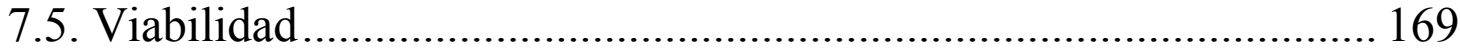

7.5.1. Propuesta de alquiler de locales comerciales............................... 169

7.5.2. Alquiler de habitaciones .......................................................... 175

CAPÍTULO VII: CONCLUSIONES FINALES......................................... 186

BIBLIOGRAFÍA ............................................................................................ 190 


\section{INTRODUCCIÓN}

Las residencias universitarias han ido evolucionando con el transcurrir del tiempo. Así, de ser simples lugares de albergue para los estudiantes, han pasado a ser lugares de convivencia con espacios complementarios en donde se estimula el aprendizaje y el desarrollo de habilidades blandas.

En Lima, el número de residencias es escaso para la gran cantidad de demanda estudiantil. Factores como la alta migración de provincias, el hecho que los estudiantes busquen cada vez más una independencia respecto de sus hogares o la distancia entre sus casas y las universidades hacen necesario el incremento de residencias, siendo esta una oportunidad para nuevas ofertas inmobiliarias.

Bajo este contexto y teniendo en consideración el gran número de estudiantes en el distrito de Pueblo libre al tener cerca la Universidad Católica del Perú, el proyecto a desarrollar considera la construcción de una residencia universitaria cerca a ambos centros de estudio.

En el Capítulo I, se abordan las generalidades que justifican el desarrollo de una residencia universitaria en Pueblo Libre acorde a la alta demanda de estudiantes e instituciones educativas, propuesta que busca además activar el entorno con espacios que beneficien a la comunidad.

En el Capítulo II, sobre el Marco Referencial, se efectúa una revisión del contexto histórico, analizándose la evolución de las residencias universitarias a lo largo de la historia a nivel mundial, sus inicios y las variaciones que sufrieron a través de los años, identificando los factores que las ocasionaron y cómo estos influyeron en las adaptaciones que efectuaron los proyectistas a efectos de adaptar las residencias a las nuevas sociedades.

Asimismo, se desarrollan diversos aspectos para reconocer las preferencias de los estudiantes mediante el análisis del estudio del autor Thomsen, J.E.

Se presenta también el levantamiento del estado actual de las tres residencias que existen en Lima, pudiendo apreciarse no sólo que su número es reducido (teniendo en consideración la población de estudiantes universitarios en Lima) sino que, además, no son lo suficientemente amplias como para suplir la demanda de los estudiantes que buscan alojamiento en ellas. 
El Marco Teórico es desarrollado en el Capítulo III definiendo los antecedentes de las residencias universitarias y su configuración programática a lo largo del tiempo; las teorías analizadas, las cuales van a servir para darle un enfoque al proyecto; un glosario con los términos relevantes; lo que constituye una residencia universitaria; el público objetivo al que va dirigido; cuáles son sus preferencias; la tendencia actual del modelo; la limitación del reglamento; y, finalmente el modelo o contenido del programa de residencia universitaria a desarrollar el mismo que es definido como un modelo no solo de alojamiento para los jóvenes estudiantes sino como uno de convivencia social basado en el desarrollo de los objetivos propuestos. Complementa este capítulo el desarrollo de los servicios con los que contará la residencia.

Ya en el Capítulo IV se desarrolla el Marco Operativo, en el cual se efectúa el análisis de las residencias internacionales que guardan cierta similitud entre sí (Tietgen Dormitory, Baker House, Pabellón Suizo y la residencia de la Universidad Nacional de Ingeniería) y luego se sacan conclusiones de porcentajes de áreas y zonificaciones para tomarlos como punto de partida en la organización programática de la nueva residencia.

En este contexto se analizan diversos aspectos importantes tales como la historia de estas residencias; su relación con el entorno; las relaciones programáticas; la tipología; tecnología; los espacios; $\mathrm{y}$, finalmente el impacto social del proyecto.

El Marco Contextual, que trata sobre el aspecto específico de la elección del terreno es desarrollado en el Capítulo VI, en el cual luego de hacerse la comparación de tres posibles lugares, se llega a la conclusión de cuál es el más adecuado para los fines de la presente investigación por su ubicación y tamaño como principales características, ya que permite el diseño de espacio público. Esto beneficia a la zona, que es uno de los puntos que busca el proyecto al querer funcionar como regenerador urbano.

Capítulo VII, explica cuál fue la toma del partido y las estrategias proyectuales utilizadas en torno a la residencia. Se describe todo el programa arquitectónico, utilizando una cabida por piso para la zonificación de áreas. También se realizó un estudio de los aforos, se muestra la viabilidad económica y se presentan las formas de financiamiento del proyecto.

La parte final de la presente investigación son las conclusiones a las que arribamos y que sustentan el desarrollo de la propuesta. 


\section{CAPÍTULO I: GENERALIDADES}

\subsection{Tema}

Se plantea como proyecto de investigación una residencia universitaria en el distrito de Pueblo Libre, cerca de las universidades ubicadas en la zona de San Miguel (Pontificia Universidad Católica del Perú, Universidad Nacional Mayor de San Marcos).

La cantidad de estudiantes matriculados en las universidades mencionadas anteriormente es de 62618 (INEI, 2011), lo que equivale al 20.04\% de la población total de estudiantes universitarios en universidades de Lima (p. 20-28). El proyecto de la residencia universitaria comprende a todos los estudiantes que vienen de provincias y del extranjero a Lima, quienes buscan un lugar de alojamiento durante el tiempo que cursarán sus estudios en este distrito. Se quiere suplir la demanda de estos estudiantes que buscan una residencia.

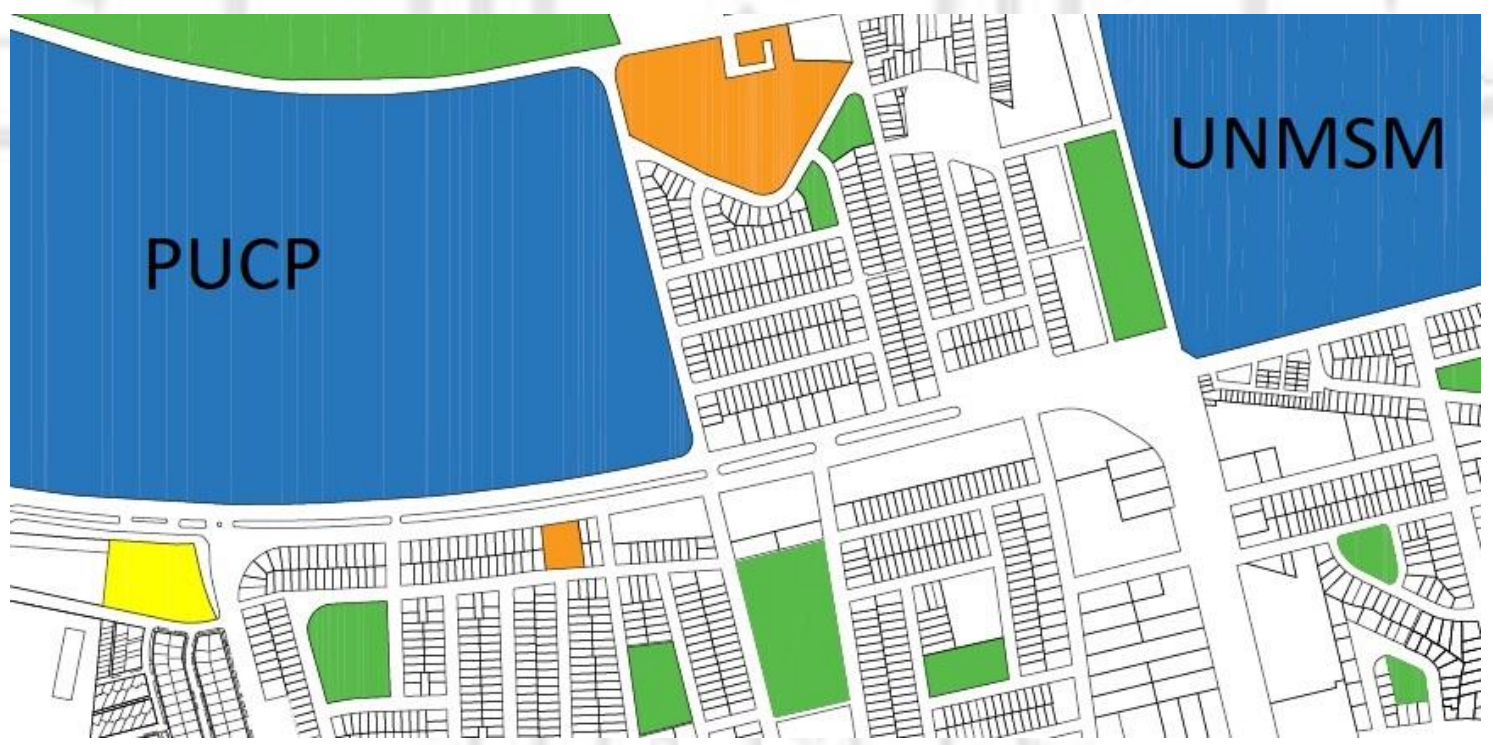
Imagen 1. Locación de universidades.

Fuente: Elaboración propia 


\subsection{Justificación del tema}

La presencia de una residencia universitaria en el límite distrital entre Pueblo Libre y San Miguel, cerca de las universidades de la zona, generaría un aporte a la ciudad ya que se supliría la demanda de estudiantes que buscan alojamiento, aumentarían las actividades sociales en la comunidad, y se reactivaría la zona urbana con un buen tratamiento y planteamiento del proyecto.

La residencia influye de manera positiva en el aprendizaje del estudiante al contar con todo lo necesario para un correcto desempeño en lo pedagógico durante los meses de estudio, ya que las instalaciones deben generar ambientes aptos para que los estudiantes puedan estudiar de manera cómoda cuando lo requieran.

Este proyecto permite la integración de la residencia a la zona debido a que se emplaza en toda una esquina, eliminando todos los muros ciegos y volviendo así más seguras las circulaciones y flujos peatonales del entorno inmediato.

Según el Instituto Nacional de Estadística e Informática (2011), la Universidad Nacional Mayor de San Marcos contaba con 28645 estudiantes en el 2010 con un crecimiento anual del 2.1\%, la Pontificia Universidad Católica del Perú contaba con 17531 estudiantes en el 2010 con un crecimiento anual del 3.1\%, siendo estas dos universidades las más representativas del distrito en cuanto a demanda.

El constante crecimiento anual de la población universitaria es un factor importante en la investigación para demostrar la viabilidad del proyecto.

Actualmente, en el Perú hay muy pocas residencias universitarias. Entre las residencias universitarias de Lima, podemos citar la de la Universidad Nacional Mayor de San Marcos que solo albergaba a 101 alumnos (Oficina General de Relaciones Públicas, 2002), la de la Universidad Nacional de Ingeniería y la de la Universidad Peruana Unión, cuyas vacantes solo están destinadas a estudiantes altamente destacados en esta universidad, así como las residencias Neptuno y Central que se encuentran ubicadas en Surco, que no están dentro del radio de influencia del distrito de San Miguel.

Como consecuencia de ello, los estudiantes tienden a alojarse en casas de estudio o alquilan departamentos entre un grupo de personas, con las cuales comparten los servicios. Como dice Thomsen (2010): Los estudiantes ya no quieren compartir un baño y una cocina, y están dispuestos a pagar más por una mejor ubicación, vista, y conexión a internet. (p. 278) [Traducción] Esto nos muestra la relevancia del proyecto 
en la exploración de alternativas de diseño que mejoren las condiciones de vida de los estudiantes.

Las residencias universitarias deben ofrecer todo lo necesario para que el estudiante se sienta a gusto con el lugar donde se está hospedando y pueda tener así un desarrollo académico mayor, ya que contará con servicios de estudio, además de un incremento de habilidades sociales con los otros estudiantes.

\subsection{Planteamiento del problema}

La falta de residencias universitarias en lugares céntricos de Lima, específicamente para el caso de estudio en el distrito de Pueblo Libre y alrededores, es un problema que afecta a los estudiantes universitarios de provincias, así como del extranjero que año a año vienen a Lima a continuar con sus estudios y no tienen un lugar adecuado donde hospedarse a lo largo de esta etapa de sus vidas.

Esto se debe a la falta de apoyo por parte del estado en el sector educación respecto a la necesidad de proveer a sus estudiantes de facilidades para el acceso a este tipo de viviendas y a un desinterés en el sector privado que hasta la fecha no ha evaluado el potencial de las residencias universitarias como un producto inmobiliario para renta con gran potencial.

\subsection{Objetivos de la investigación}

\subsubsection{Objetivo general}

Desarrollar un proyecto de residencia universitaria que considere variables del contexto y que satisfaga la demanda actual de estudiantes identificada en el distrito de Pueblo Libre, con un enfoque en la calidad de vida de los universitarios.

\subsubsection{Objetivos específicos}

- Estudiar los antecedentes de las residencias universitarias en el mundo y realizar una línea del tiempo.

- Analizar teorías referidas a los modelos de residencias universitarias y a residencias mínimas, y los servicios necesarios para su correcto funcionamiento. 
- Estudiar casos análogos a nivel nacional e internacional de residencias universitarias y elaborar un cuadro comparativo.

- Estudiar las variables y requisitos de una residencia universitaria para determinar el lugar más favorable para emplazar el proyecto.

\subsubsection{Supuesto básico de la investigación}

Si se implementara una residencia universitaria en el distrito de Pueblo Libre cerca de la Pontificia Universidad Católica del Perú, entonces se disminuiría la demanda de estudiantes que buscan una estadía durante el tiempo que llevarán sus estudios en esta zona y habría una activación urbana en el lugar.

\subsection{Alcances y limitaciones}

\subsubsection{De la investigación}

\section{Alcances}

- Realizar una investigación del porqué es viable desarrollar una residencia universitaria en el distrito de Pueblo Libre, como parte del marco contextual.

- Investigar y analizar estudios de mercado existentes.

- Analizar 3 casos análogos nacionales de residencias universitarias existentes con un levantamiento fotográfico propio y planos, con la finalidad de observar cómo funcionan y cuáles son los principales problemas que enfrentan para determinar criterios de diseño o conclusiones del programa y así poder elaborar un modelo adecuado a la zona de estudio.

Limitaciones

- Debido a la poca información de la historia de residencias en el Perú (ya que solo hay unas cuantas), analizaremos también la historia de casos en el extranjero para el tema de la evolución de las residencias universitarias en el mundo. 
- Debido a que no hay un reglamento de diseño arquitectónico de residencias universitarias en Perú, efectuaremos la revisión de su tratamiento a nivel internacional, con mayor énfasis en los utilizados por países vecinos como Chile o Argentina, algunos de cuyos alcances serán desarrollados y adaptados a nuestra realidad.

\subsubsection{Del proyecto}

\section{Alcances}

- Desarrollar una residencia universitaria a nivel anteproyecto.

- Suplir la demanda de estudiantes que buscan una residencia universitaria en la zona con este proyecto.

- Desarrollar planos de instalaciones eléctricas, sanitarias y estructurales a nivel esquemático.

- Desarrollar un espacio público en el proyecto que genere una activación en el contexto inmediato.

- Integrar un sistema de ciclovías en el área donde está ubicado el proyecto.

\section{Limitaciones}

- Como la investigación llega a nivel de anteproyecto, solo se podrá mostrar una viabilidad económica básica.

- No se desarrollará una residencia universitaria dentro de un campus como en otros países debido a que no hay espacio dentro de los campus de las universidades ubicadas en el distrito de San Miguel.

- Se pueden indicar limitaciones del terreno (Parámetros).

1.6. Diseño de la investigación

La investigación será principalmente de tipo descriptiva. Se determinará el objeto de estudio, el cual es una residencia universitaria ya que se pretende mostrar su importancia en la ciudad, sus características y los modelos de residencia que hay en el mundo. Se utilizarán fuentes primarias (estudios de mercado, censos) que permiten 
mostrarnos valores cuantitativos como la preferencia de modelo, la demanda, y la calidad de vida y espacio que debería brindarse.

\subsection{Metodología}

La información recopilada y presentada en esta investigación será obtenida de distintas tesis, artículos científicos, revistas y libros acerca de arquitectura, urbanismo y censos nacionales como los del INEI. También se consultarán fuentes recomendadas como EBSCO, PROQUEST y SCIENCE DIRECT, obtenidas de las bases de datos de la Universidad de Lima. Además, se visitará el lugar donde irá ubicado el proyecto para poder entender y relacionar el contexto con este.

Se trabajará un diagrama que comunique de mejor forma el proceso metodológico de la tesis como una secuencia de pasos. Se utilizarán encuestas para recoger información sobre el análisis de los gustos y preferencias de los usuarios. 


\section{CAPÍTULO II: MARCO REFERENCIAL}

Una residencia universitaria es un centro que proporciona alojamiento a los estudiantes universitarios. Se diferencia de otros tipos de hospedaje ya que busca una relación directa con las universidades, mejorando así el enfoque y nivel académico de los estudiantes. En este contexto se desarrollarán diversos puntos sobre los cuales se basará esta investigación:

- Evolución de las residencias universitarias en el mundo a lo largo de la historia.

- Indicadores de satisfacción de estudiantes universitarios en residencias universitarias.

- Estado actual de las residencias en Lima.

- Población de estudiantes universitarios en Lima.

- Demanda de las residencias Universitarias en Lima.

- Conclusiones parciales.

2.1. Evolución de las residencias universitarias en el mundo a lo largo de la historia

Este análisis nos ayudará a conocer los inicios de las residencias universitarias y sus variaciones a través de los años. En el pasado existieron muchos factores que ocasionaron cambios en los modelos de las residencias universitarias, lo cual influyó en cómo los proyectistas fueron adaptando las residencias a las nuevas sociedades.

"La evolución de la vivienda orientada a hospedar estudiantes, tienen sus orígenes con la vida monacal donde además de búsqueda de aislamiento, se dedica gran parte de la vida al estudio. Resulta interesante observar las similitudes entre la organización espacial y comunitaria que pueden encontrarse entre los monasterios y las residencias de estudiantes.” (Evolución de las residencias universitarias, s.f.).

Es así como los primeros alojamientos colectivos aparecen con las universidades entre los siglos XII y XIII, en Europa. Las comunidades universitarias se hicieron muy conocidas siendo las primeras las de Oxford y Cambridge, las cuales tenían una organización espacial muy similar a la de los monasterios, donde todos los edificios y programas funcionaban alrededor de un patio. Con este modelo, las facultades y los estudiantes vivían y trabajaban juntos en proximidad. Con la aparición de las mujeres en el ámbito universitario, las residencias universitarias se vieron en la obligación de 
sufrir ciertos cambios y aparecen otras necesidades. De esta manera los modelos de residencias universitarias comienzan a variar. (Evolución de las residencias universitarias, s.f.).

No es sino hasta el siglo XIX, donde comienzan a aparecer la mayor cantidad de residencias universitarias, comenzando por La Residencia de Estudiantes de Madrid (1910-1936), seguida de la Fundación Deutsch de la Meurthe (1925-1926) ${ }^{1}$. Ambas Residencias cuentan con edificios de vivienda alrededor de su pabellón central, modelo de residencia de aquella época.

En el año 1930, durante el período de guerras a inicios del movimiento moderno, Le Corbusier diseña el Pabellón Suizo en la Ciudad Internacional Universitaria de Paris, el cual es paradigmático ya que varía el modelo común de residencia universitaria. Plantea un edificio solo de habitaciones tradicionales con áreas comunes variando la distribución habitual, y un edificio separado con programas funcionales. Por primera vez se toman en cuenta los estacionamientos como parte del diseño. (Evolución de las residencias universitarias, s.f.).

Unas décadas después, se dio un aumento significativo de residencias universitarias. Estas no se enfocaban en el desarrollo del estudiante, sino en el mayor aprovechamiento posible del espacio (mayor cantidad de camas y dormitorios):

"Entre 1958 y 1970, no menos de 24 instituciones de educación superior en Estados Unidos desarrollaron al menos 42 residencias universitarias experimentales ${ }^{2}$, las cuales alojaron entre 100 y 3500 alumnos cada una". [Traducción] (Penven, Stephens, Shushok, y Keith, 2013, pág. 118).

Entre las décadas de 1970 y 1980, hubo una caída significativa en el planeamiento y desarrollo de residencias universitarias. Según Smith (1994): Esto se debió principalmente a tres factores: (a) grandes instituciones buscando crear comunidades de aprendizaje más pequeñas, (b) instituciones privadas usando opciones de residencia para alejar estudiantes de sus competidores, y (c) las instituciones del estado creaban más "comunidades compactas" para atraer estudiantes de áreas metropolitanas. (Como se citó en Penven, et al, 2013, p. 122)

A partir de la década de 1990 a la actualidad, el desarrollo de residencias universitarias volvió a crecer sobre todo en los países desarrollados, volviendo al

\footnotetext{
${ }^{1}$ Fue la primera residencia en la Ciudad Internacional Universitaria de París (1920), la cual cuenta con 40 residencias a lo largo del mundo actualmente.

2 Incluyen las primeras 5 residencias universitarias de la Universidad de Santa cruz, la residencia universitaria de la Universidad de Michigan y las 3 residencias universitarias en el Estado de Michigan.
} 
modelo antiguo de residencia universitaria como lo había mencionado Stewart Gordon ${ }^{3}$ en su artículo "Living and Learning in College" (1974). Las residencias universitarias vuelven a surgir debido a que la calidad de educación superior aumentó significativamente.

Para las instituciones, mejorar el aprendizaje del estudiante era uno de los enfoques principales, por lo que se centraron en desarrollar residencias dentro de los campus universitarios, y de esta manera crear oportunidades de mejorar el aprendizaje del alumno con un modelo en donde las residencias van "de la mano" con la institución.

"El conjunto de valores que llevaron a realizar las residencias urbanas experimentales en los 60's y 70's (el enfoque en vivir y aprender en un contexto que beneficie el desarrollo de la persona) ha reaparecido en la última década". (Penven, Stephens, Shushok, \& Keith, 2013, pág. 117).

Las universidades a lo largo del tiempo, dejaron de quedar relegadas y pasaron a formar parte de la ciudad, formándose un sistema mucho más integrado. Luego de diversos análisis y estudios, los proyectistas comienzan a tomar decisiones en la forma de llevar acabo la organización dentro de las residencias, ya que las posibilidades son muchas. Hay distintos grupos de estudiantes con preferencias heterogéneas, y se debe generar edificios "que combinan usos y deferentes tipos de dormitorio y departamentos, logrando soluciones heterogéneas con un carácter integrador." (Evolución de las residencias universitarias, s.f.).

Las residencias llevan más de 6 siglos en desarrollo y siempre se ajustan de acuerdo a lo que ocurre en la sociedad y a cómo va variando la educación, manteniendo siempre un carácter propio. Los servicios que se deben brindar, además de los ofrecidos por las viviendas y hospedajes tradicionales, deben ser de carácter educativo para elevar el rendimiento académico en los estudiantes. Así, es posible apreciar como las organizaciones de los programas van variando de acuerdo a los servicios ofrecidos.

Según Gordon (1974), la combinación de aprendizaje cognitivo y afectivo es el ideal de las nuevas residencias universitarias (p. 237). Esto se logra con un correcto planeamiento de la residencia para generar relaciones sociales entre los estudiantes.

\footnotetext{
${ }^{3}$ Stewart Gordon dedicó parte de su vida al estudio al valor que tienen las residencias universitarias y casas de estudio como lugares para el aprendizaje.
} 
2.2. Línea de tiempo

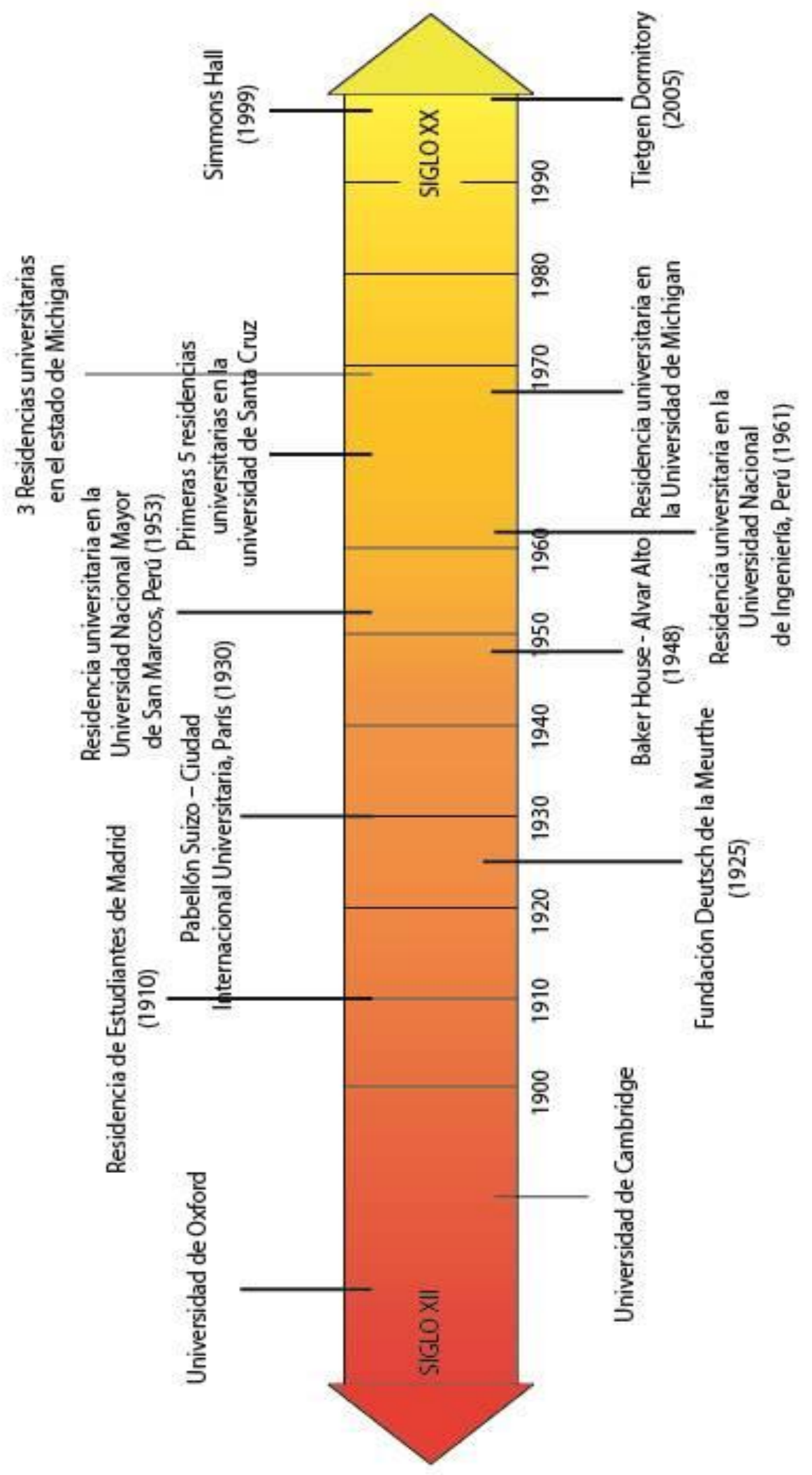

Imagen 1. Línea de tiempo

Fuente: Elaboración Propia 
2.3. Indicadores de satisfacción de estudiantes universitarios en residencias universitarias tomados del estudio: Aspectos de satisfacción de los estudiantes de residencias universitarias: Un estudio cuantitativo

Las preferencias $^{4}$ de los estudiantes a la hora de escoger una residencia universitaria es un tema muy importante a tomar en cuenta. Estas preferencias dependen mucho de la situación actual del alumno. Lo que se hace es comparar la situación de vivienda del estudiante con cómo le gustaría que sea a futuro. De esta manera se puede saber cuáles son las expectativas y exigencias de este, con qué está a gusto y qué le gustaría que se mejorara.

Los indicadores de satisfacción que presentamos a continuación pertenecen a estudiantes universitarios que residen en Noruega. Si bien no corresponden a nuestro contexto, hemos escogido aquellos que pueden ser aplicados a la realidad de nuestro país por tratarse de consideraciones generales que bien pueden ser tomadas en cuenta en cualquier realidad al momento de diseñar una residencia universitaria.

Según Gifford ${ }^{5}$ (2002): los estudiantes evalúan su satisfacción comparando sus preferencias con su situación de vivienda actual. Si estas tienen mucha diferencia, significa que están muy insatisfechos con el lugar donde viven en la actualidad. [Traducción] (Como se citó en Thomsen y Eikemo, 2010, p. 274)

Los indicadores de satisfacción que se evalúan de los cuáles se hablará más adelante, son cuatro puntos importantes: pertenencia del lugar donde se reside, aspectos demográficos, ubicación e importancia de las características de la residencia (tamaño del departamento, condiciones de luz, tamaño de habitaciones, etc.).

Según Statistics Norway6 (2006): "Estudiantes que viven en residencias de bajos estándares están más satisfechos que los que viven en el resto de residencias." (Como se citó en Thomsen y Eikemo, 2010, p. 275)

Esto significa que las personas de menores recursos esperan encontrar un alojamiento con características y servicios de acuerdo a lo que están pagando, mientras que los estudiantes de mayor capacidad económica buscan residencias con estándares muy altos. Luego del estudio, se llega a la conclusión que los primeros se sienten más

\footnotetext{
${ }^{4}$ Referido a tamaño de habitación, precio de renta, servicios a recibir, cercanía al campus, entre otros.

${ }^{5}$ Robert Gifford es un profesor con PhD. de psicología en la "University of Victoria” en Canadá.

${ }^{6}$ Central de estadísticas estudiantiles que funciona en Noruega
} 
satisfechos porque las residencias ofrecen mejores servicios y mayor calidad de lo esperado en sus instalaciones mientras que los estudiantes que pagan más, no consiguen lo que esperaban. Cuando se comparan las preferencias con la realidad, lo más importante según el estudio es la calidad de espacio que te puede brindar la residencia a comparación del lugar donde te encuentras viviendo en la actualidad.

Otro punto importante para definir el tipo de residencia adecuada es el formar grupos. Esto significa, que es importante identificar ideales comunes que ayuden a identificar grupos homogéneos de estudiantes con mismas tendencias y preferencias de residencias. Según Clapham (2005), "Este conocimiento es necesario, en primera instancia, para el planeamiento de residencias universitarias que encajen con los diferentes grupos en la sociedad”. [Traducción] (Como se citó en Thomsen y Eikemo, 2010, p. 274-275)

El hecho de que las residencias universitarias sean un hospedaje temporal para los estudiantes, genera que estos estén al tanto de aspectos como de la confianza y pertenencia que esta residencia les transmite y de la experiencia que les brinda como hogar. Hauge y Kolstad ${ }^{8}$, quienes estudiaron residencias en Noruega (2007), encontraron que los estudiantes de mediana edad se centran más en la búsqueda de un sentido de pertenencia a comparación de los estudiantes mayores. [Traducción] (Como se citó en Thomsen y Eikemo, 2010, p. 275)

Para que los alumnos se sientan satisfechos en estos alojamientos, las residencias deben hacerlos sentir cómodos en el lugar que se están hospedando (como si fuera su segundo hogar). Las preferencias de un estudiante en un hospedaje temporal son diferentes a las de un hospedaje permanente.

“También hay una conexión muy cercana entre la satisfacción por la residencia y la experiencia de un hogar. Un hogar es más que una vivienda física. Es un lugar donde la gente adquiere actitudes positivas o negativas. Adicionalmente, un hogar también está moldeado y ajustado a sus residentes para hacer que se sientan identificados". [Traducción] (Thomsen y Eikemo, 2010)

Las residencias universitarias en Noruega tienen características operativas parecidas a las que encontramos en Lima en la actualidad. Las residencias universitarias allí no son responsabilidad de las universidades, esto recae sobre organizaciones de

${ }^{7}$ David Clapham fue miembro del comité de coordinación de la red europea de investigación de residencies entre los años 1998 y 2006.

${ }^{8}$ Åshild Lappegard Hauge es una investigadoray Arnulf Kolstad un psicólogo social quienes trabajan en la Norwegian University of Science and Technology (NTNU). 
estudio de la ciudad ${ }^{9}$, quienes se encargan de suplementar a las residencias construidas por entidades privadas. Sin embargo, estas organizaciones no reciben el apoyo del Estado como para generar un incremento significativo en las residencias y liberar a las entidades privadas de tanta demanda. Las residencias planteadas por la organización de estudio de Noruega siempre poseen una alta demanda lo que demuestra la falta de residencias para suplir la cantidad de estudiantes del sitio. (Thomsen y Eikemo, 2010, p. 276)

Estas residencias albergan en su mayoría a estudiantes entre los 20 y 29 años, siendo las residencias con estudiantes de mayor edad las de menor demanda. El estudio realizado por Thomsen y Eikemo indica que los estudiantes tienen muy claro dónde y cómo vivir.

Los estudiantes ya no quieren seguir compartiendo las áreas de servicios (como baño y cocina) sino que buscan algo de más independencia, incluso acceden a pagar un poco más por obtener mejores servicios. Las residencias universitarias ya existentes son consideradas antiguas y poco populares, por lo que se buscan residencias con infraestructura moderna.

Una residencia universitaria fuera del campus es importante, ya que es fundamental para los alumnos que tengan independencia y que las instituciones tengan menos control sobre ellos, lo cual sucede al vivir dentro de un campus. Esto influye mucho a la hora que el estudiante debe decidirse por una residencia.

Otro punto a tomar en cuenta es la ubicación. Los estudiantes que viven cerca del campus se encuentran más satisfechos que los que no, esto influye incluso mucho más si tienen un costo de renta bajo. La distancia es muy importante ya que va más allá de lo individual, ya que está referida a un grupo de estudiantes que pueden influenciar mucho en el desarrollo urbano al encontrarse cerca de puntos importantes.

Las zonas de comercio como cafés o restaurantes e instalaciones culturales ayudan atrayendo estudiantes y volviendo el lugar más llamativo, activando así la residencia en un lugar, ya que estas zonas no serán utilizadas solo por los estudiantes, sino también por las personas de distintas partes de la ciudad.

Viendo un tema más específico dentro de la residencia, las características que ofrecen son algo muy importante a la hora de medir las preferencias del estudiante.

\footnotetext{
${ }^{9}$ Responsabilidad de Samskipnaden (Student Welfare Organization), organización que tiene el apoyo del ministerio de Educación. (Thomsen, 2010)
} 
Lo primordial para ellos es que el lugar donde se alojan tenga el espacio propio suficiente, ya que muchos se quejan que no tienen donde poner todas sus pertenencias lo cual hace que se sientan incómodos.

Según Kenyon ${ }^{10}$ (1999): "Las experiencias transicionales de residencia de los estudiantes muestran que el diseño de la residencia universitaria y la falta de arquitectura estética visual eran consideradas un obstáculo para que los estudiantes puedan aceptarlos como su hogar". [Traducción] (Como se citó en Thomsen y Eikemo, 2010, p. 288)

Cada estudiante debería poder personalizar su espacio, de esta manera se sentirían más a gusto en el lugar donde se encuentran y lo relacionarían con un hogar. Relacionado a esto, a los estudiantes no les gusta hospedarse en sitios que tengan un carácter institucional, como pasillos largos fuera de las habitaciones. Por ejemplo, ya que les hace recordar a las universidades y ellos prefieren no relacionarlo de esta manera en sus tiempos libres. Según Thomsen (2007):

"Los resultados de la encuesta muestran que los estudiantes no quieren vivir en una edificación donde la arquitectura tenga un carácter institucional. [...] Opciones contextuales y elementos arquitectónicos como fachadas, entradas, materiales, y organización espacial del edificio influencian nuestra percepción y categorización de edificios (p. 289).” [Traducción]

Como mostró el estudio, la importancia de los aspectos arquitectónicos incrementaría la posibilidad de crear un ambiente satisfactorio en la residencia, que complementaría la identidad del edificio y una experiencia de hogar. (Thomsen y Eikemo, 2010, p. 291)

En cuanto a las preferencias, se puede concluir que el deseo de tener una expresión de identidad, se ha vuelto muy importante en los estudiantes en la sociedad contemporánea. Estos toman en cuenta muchos factores a la hora de elegir una residencia, por lo que es importante realizar un estudio previo para adaptar la residencia de acuerdo a las necesidades de estos. Es importante tomar como referencia el contexto y el cómo se desarrollan las residencias en otras ciudades ya que puede haber cierta similitud con Lima, y de esta manera rescatar ciertos aspectos que puedan aplicarse a la zona de estudio.

\footnotetext{
${ }^{10}$ Elizabeth Kenyon escribió el artículo "Seasonal sub-communities: The impact of student households on residential communities" para la revista "The British Journal of Sociology".
} 


\begin{tabular}{|l|}
\hline \multicolumn{1}{|c|}{ INDICADORES DE PREFERENCIA } \\
\hline Pertenencia del lugar donde se reside \\
\hline Aspectos demográficos \\
\hline Ubicación \\
\hline Importancia de las características de la residencia \\
\hline Espacio propio \\
\hline Áreas de servicios compartidas \\
\hline Renta alta \\
\hline Estándares bajos de residencia \\
\hline Términos de contrato dudosos \\
\hline Falta de vacantes \\
\hline Residencias muy alejadas de los campus \\
\hline Zonas de comercio cercanas \\
\hline
\end{tabular}

Fuente: Elaboración Propia

2.4. Estado actual de las residencias en Lima

Actualmente sólo funcionan tres residencias en Lima, estas se encuentran en la Universidad Nacional Mayor de San Marcos, en la Universidad Nacional de Ingeniería y en la Universidad Peruana Unión. Estas tres residencias universitarias no son lo suficientemente amplias como para suplir la demanda de estudiantes que buscan un alojamiento y no poseen vivienda, ya que no son las únicas universidades a las cuales acuden los estudiantes. De estas centraremos el análisis en las dos primeras mencionadas.

\subsubsection{Residencia universitaria en la Universidad Nacional Mayor de San Marcos}

\subsubsection{Historia}

La Universidad Nacional Mayor de San Marcos cuenta con dos residencias universitarias: una ubicada en el mismo campus en la avenida Germán Amezaga s/n y la otra en la esquina de la avenida Grau con el jr. Prolongación Parinacochas, llamada Julio C. Tello.

La residencia ubicada en la ciudad universitaria empezó a construirse en el año 1950 durante el gobierno del Presidente Manuel Odría, sin embargo, sus avances fueron lentos. En el año 1953 sólo se había culminado de construir un ala de su pabellón y recién 3 años después, en el año 1956, se culminó la construcción total del primer bloque de la residencia. Con fecha 10 de enero de 1957 fueron inaugurados los dos 
pabellones que la conforman en la actualidad con la concurrencia de diversos funcionarios e importantes personalidades políticas y educativas debido a que esta residencia fue el primer edificio en construirse en la ciudad universitaria.

Lamentablemente el proyecto original que comprendía la construcción de varios pabellones con el correr del tiempo fue dejado de lado, reduciéndose los espacios de la residencia.

Por otro lado, la construcción de la residencia Julio C. Tello se inició en el año 1965 concluyendo con la construcción de un pabellón de 4 pisos en el año 1967, de los 4 que originalmente estaban planeados.

Durante mucho tiempo estas residencias universitarias no estuvieron a cargo de ninguna entidad sino de un grupo de estudiantes organizados que se dividían las tareas y el tiempo para que todo se mantuviera en orden (como la limpieza de los pabellones). Sin embargo, hubo un período de crisis en el año 1995. La junta de estudiantes formada para mantener el orden descuidó sus tareas y los servicios que brindaba la residencia colapsaron, la administración a cargo de la oficina de bienestar ya no tenía control y eran los mismos estudiantes quienes tomaban la decisión de quienes eran los que podían hospedarse en la residencia.

El terrorismo se estableció en estos lugares y la residencia recién comenzó una reorganización cuando este fue derrocado. Se procedió a retirar a los que no eran alumnos por medio de un censo, y de manera democrática se iban ocupando las vacantes (debían tener buen nivel académico como se mencionó anteriormente).

\subsubsection{Situación actual}

Actualmente, la sede dentro del campus de la universidad tiene capacidad para albergar a sólo 210 estudiantes mientras que la residencia Julio C. Tello alberga 90 estudiantes. Como se puede apreciar la capacidad de hospedaje en total entre las dos residencias es para 300 alumnos, cifra que es muy reducida teniendo en consideración que a julio 2018 el número de alumnos matriculados en esta universidad ascendía a 32,458 .

\subsubsection{Condiciones para el ingreso a la residencia}

Estos lugares se encuentran destinados solo para estudiantes de la misma universidad, y, además, se debe estar entre los primeros lugares con un alto nivel académico para tener acceso a ella, privándose así al resto de alumnos de la posibilidad 
de usar estas habitaciones. "Para acceder a la beca de vivienda, los sanmarquinos son sometidos a una rigurosa evaluación socioeconómica y académica, a cargo de trabajadoras sociales de la Oficina General de Bienestar Universitario, ente que se encarga de gestionar ambas viviendas.” (Obregón Dionisio, 2012)

Según Michael Armas Vega ${ }^{11}$, para poder ser admitido en la residencia, debes mostrar un buen nivel académico, además de mostrar un buen comportamiento dentro de la misma (como se citó en Obregón Dionisio, 2012)

En la actualidad las residencias universitarias de San Marcos son espacios que forman parte de la Unidad de Bienestar Universitario de dicha institución.

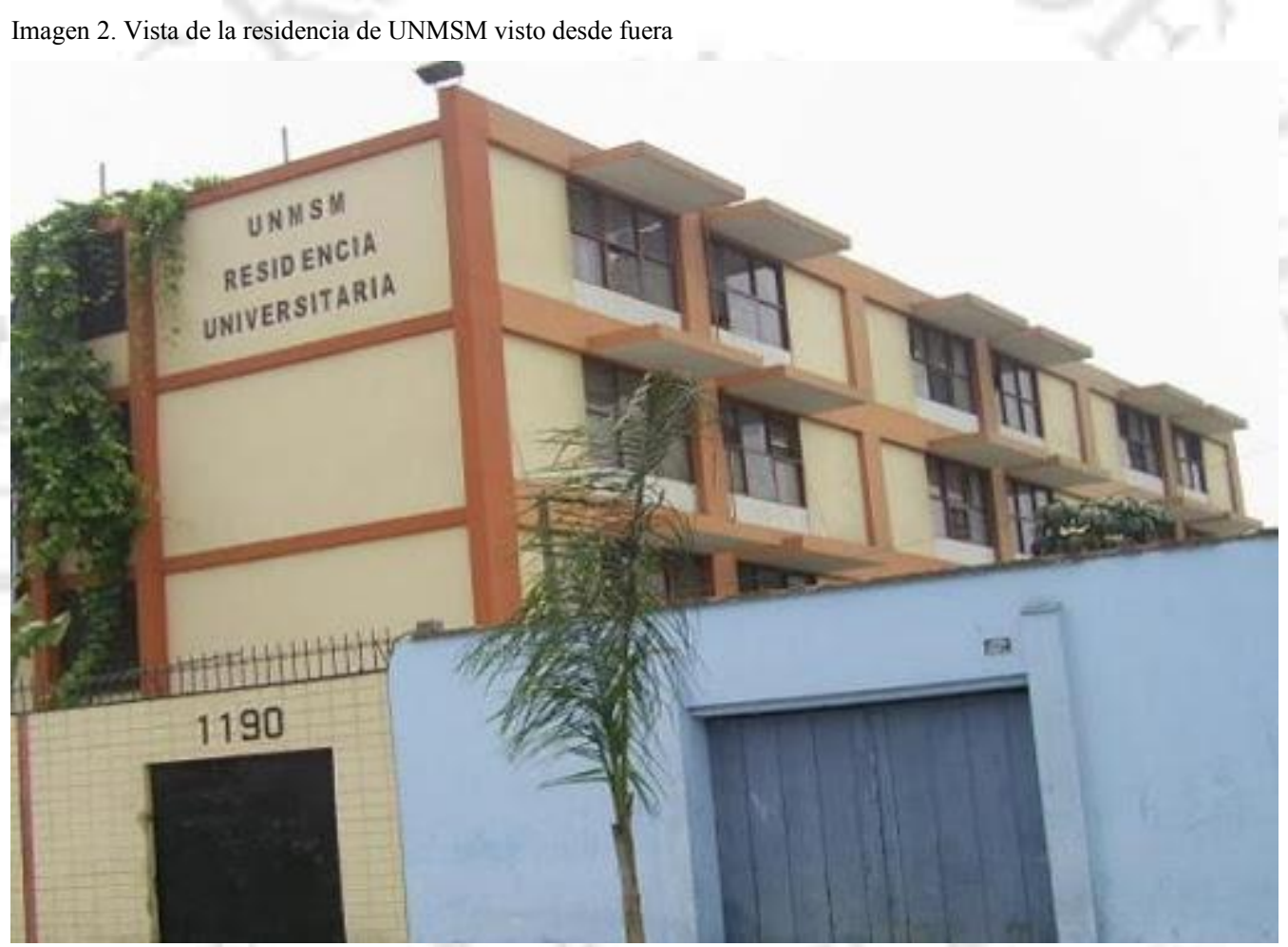

Fuente: Propia

2.4.2. Residencia universitaria en la Universidad Nacional de Ingeniería

\subsubsection{Historia}

La residencia universitaria tiene sus antecedentes en la construcción a inicios de los años 50 del Pabellón $\mathrm{M}$ en la Casa Estudiante. Funcionaba en base a becas residenciales y su administración interna estaba basada en el principio de autogobierno.

\footnotetext{
${ }^{11}$ Presidente de la Junta Directiva de la Residencia Julio C. Tello y estudiante de la Facultad de Letras y Ciencias Humanas (Paredes Albujar, 2012)
} 
Diez años después, el 8 de agosto de 1961 se inician las operaciones para la construcción e implementación del Pabellón P dentro del campus universitario para uso exclusivo de la residencia.

Inicialmente estas obras fueron encargadas al "Departamento Casa" y al "Comedor del Estudiante", siendo a partir del año 1966 el "Departamento de Residencia Estudiantil” y el "Comedor Universitario" los encargados respectivamente.

Carlos Meneses ${ }^{12}$ señaló que: El número de estudiantes alojados se elevó de 148 en 1961 a 238 en 1965. Para 1963, la casa del estudiante se había convertido en un espacio de intercambio entre los alumnos (p. 154). (Como se citó en López Soria, Ueda Tsuboyama, y Quiñones Tinoco (2012))

El alojamiento para estudiantes de la UNI ${ }^{13}$ además de servir de hospedaje para sus alumnos, servía también de alojamiento para alumnos becados de universidades y profesores extranjeros. En el año 1965, la Casa del Estudiante estaba distribuida de la siguiente manera: casino, sala de estudio, sala de administración, y tres pabellones con 238 equipos. (López Soria, Ueda Tsuboyama, \& Quiñones Tinoco, 2012).

La residencia se complementaba con un Comedor para estudiantes, el cual fue ampliando su capacidad conforme pasaban los años, y estaba dirigido y organizado por un grupo de estudiantes denominados "alumnos ayudantes". El comedor ofrecía una cierta cantidad de raciones sin costo alguno (inicialmente eran 400 en 1961 y en la decada del 80 se ofrecían 4420066 raciones) y los profesores y el personal también podían hacer uso de los servicios si es que pagaban.

"La vida estudiantil en este hogar de la UNI se desarrolla normal y confortablemente. Cuatro alumnos comparten un dormitorio, bastante espacioso y ventilado. La casa del estudiante, por otra parte, cuenta con una biblioteca en formación, la misma que se incrementa constantemente" (Como se citó en López Soria, Ueda Tsuboyama, \& Quiñones Tinoco, 2012, p. 154)

En el año 1965, la Casa del Estudiante ya contaba a dicha fecha con 238 estudiantes y se encontraba distribuida de la siguiente manera: casino, sala de estudio, sala de administración, y tres pabellones con 238 equipos.

En 1969 se decidió hacer mejoras para ambos espacios, y en el caso del alojamiento se solicitó la elaboración de un reglamento, se hicieron las reparaciones necesarias con un presupuesto de 145 mil soles, y la Oficina de Bienestar asumió la

\footnotetext{
${ }^{12}$ Carlos Meneses fue un ingeniero y el director de la UNI en el año 1961.

${ }^{13}$ Siglas para la Universidad Nacional de Ingeniería
} 
función de atender las solicitudes para cubrir las vacantes necesarias para dicha residencia. (López Soria, Ueda Tsuboyama, \& Quiñones Tinoco, 2012).

En la década de 1970, la residencia y el comedor fueron usados como espacios de protesta, con propósitos de clientelaje, dejándose de lado los quehaceres universitarios y perdiéndose la esencia de residencia.

Es así que a inicios de 1980 el Pabellón P fue tomado por los estudiantes, en su mayoría provincianos y de bajos recursos. Con el transcurrir de los años ese pabellón rebasó su capacidad llegándose a evidenciar una situación de hacinamiento en sus instalaciones. Ello trajo como resultado que en el año 1985 los alumnos tomaran el Pabellón "M" que venía funcionando como oficinas del Departamento de Matemáticas, restaurándose así su utilización como residencia estudiantil.

\subsubsection{Situación actual}

En la actualidad los pabellones $\mathrm{P}$ y $\mathrm{M}$ siguen destinados a albergar a los estudiantes.

En el Pabellón P existen 3 bloques de cuatro niveles cada uno con un total de 32 habitaciones. En cada habitación hay espacio para 3 residentes, por lo que en total se alberga a 96 estudiantes.

El Pabellón M, por su parte, tiene destinado solo el segundo y tercer nivel a la residencia de estudiantes, contando con 42 habitaciones con capacidad cada una de ellas para 3 alumnos, albergando en total a 126 alumnos. Respecto al primer nivel en un inicio fue concebido para espacios de uso común (sala de reuniones, música y juegos) siendo utilizado actualmente como comedor, sala de cómputo y kitchenette.

La residencia cuenta en la actualidad con un comedor en donde se brinda raciones de desayuno, almuerzo y cenas. También cuenta con dos salas de cómputo debidamente equipadas con servicio de internet, wifi y sistema de aire acondicionado.

Asimismo, hay una sala de estudios para los alumnos debidamente equipadas con mesas de estudio y buena iluminación y, los alumnos cuentan también con una lavandería equipada con seis lavadoras a cargo de dos trabajadores quienes se encargan de su manejo.

\subsubsection{Condiciones para el ingreso a la residencia}

En la actualidad el servicio de residencia es temporal y la adjudicación de las habitaciones se hace a través del otorgamiento de becas de alojamiento sujetas a una 
evaluación socioeconómica del estudiante, así como de su rendimiento académico y su desenvolvimiento social. Los que califiquen pueden acceder a utilizar la residencia, dándose prioridad a aquellos alumnos que carecen de vivienda, no cuentan con recursos económicos y que provienen del interior del país. En este contexto, se les otorga una habitación cuyo uso es personal e intransferible, debiendo el estudiante sujetarse al cumplimiento del reglamento de la residencia estudiantil.

Imagen 3. Vista de la residencia en la UNI desde el exterior

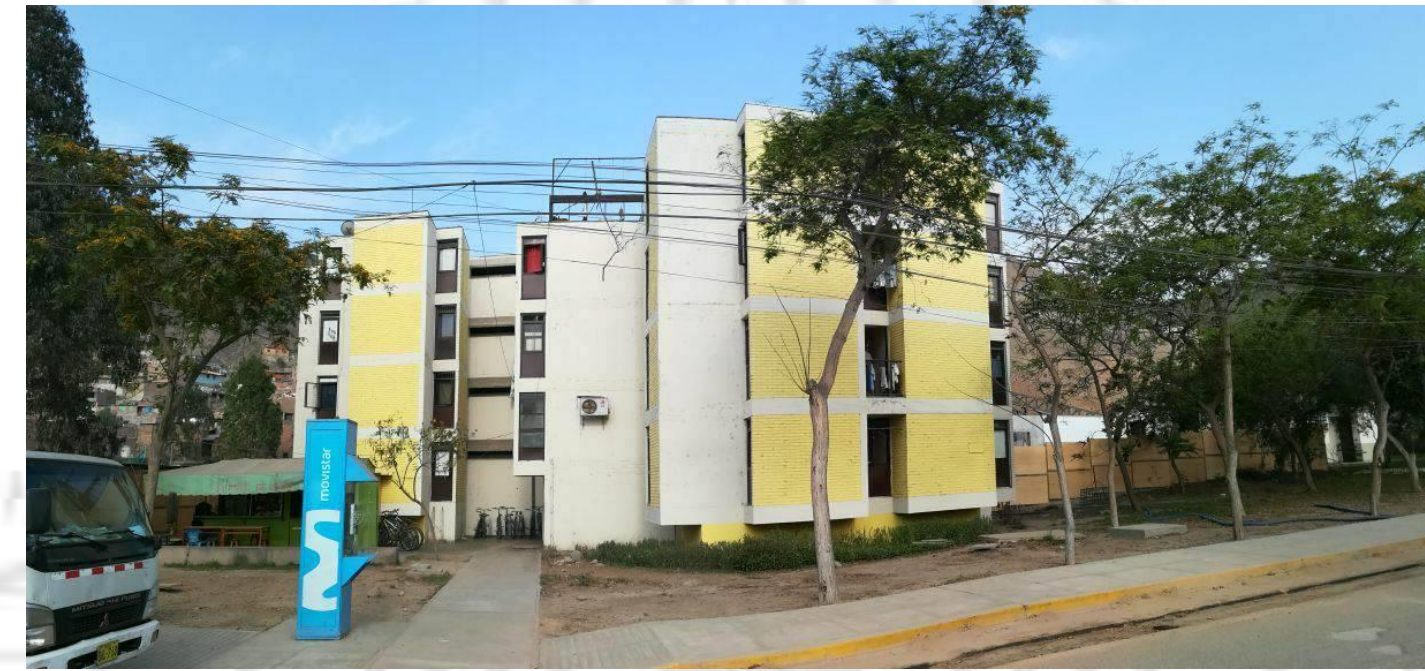

Fuente: Elaboración propia

Imagen 4. Vista de la residencia en la UNI desde el exterior

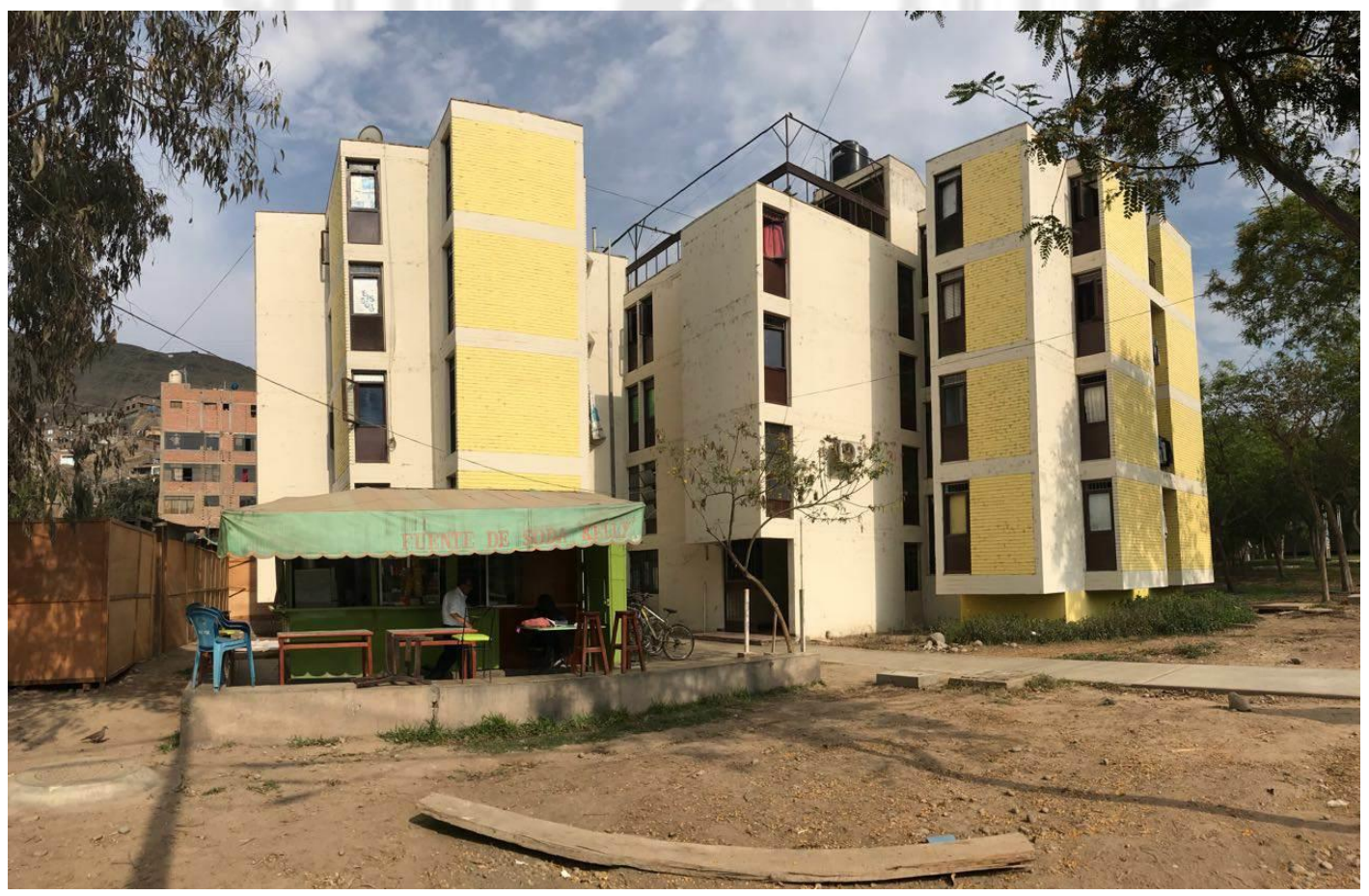

Fuente: Elaboración propia 


\subsubsection{Residencia universitaria en la Universidad Peruana La Unión}

\subsubsection{Historia}

La residencia fue creada en 1924 y remodelada en los años 2005 y 2007. Se encuentra ubicada dentro de la Universidad Peruana La Unión en la Carretera Central kilómetro 19.5, en Ñaña.

\subsubsection{Situación actual}

Esta universidad cuenta con una residencia de varones que se encuentra situada frente a la Facultad de Ciencias Humanas y Educación y una de damas ubicada frente al parque central de la universidad.

La residencia de varones tiene 36 habitaciones estándar -que cuentan con armarios personales y escritorios- así como 2 habitaciones VIP, para dos personas en cada cuarto, con balcón, baño propio, servicio de teléfono particular, e internet. En total cuenta con 150 alumnos varones.

Además, la residencia cuenta con un salón plateado multiusos, en donde se llevan a cabo diversas actividades culturales, seminarios y exposiciones. Este salón se encuentra adecuadamente equipado con servicio de Internet inalámbrico, Ecran y proyector multimedia.

La residencia tiene, asimismo, ambientes de recreación, sala de estudios, lavandería, sala de espera para los familiares de los estudiantes y un área de gimnasio. Dos son las personas encargadas de la administración de la residencia de varones, los que ofrecen atención personalizada de acuerdo a las necesidades de cada residente.

Por su parte, la residencia de damas tiene 66 habitaciones estándar, que cuentan con armarios personales y escritorios, así como 2 suites, que están compuestas por sala de estar, baño, servicio de teléfono particular e internet. Esta residencia en total cuenta con 230 estudiantes mujeres.

Tres son las personas encargadas de la administración de la residencia de damas, las mismas que son responsables de su correcto funcionamiento. Por otro lado, la seguridad de ambas residencias está a cargo de los vigilantes de la universidad.

\subsubsection{Condiciones para el ingreso a la residencia}

Los alumnos que se matriculan para cursar estudios en la universidad pueden elegir si van a estar internos en la residencia universitaria, en cuyo caso asumen un costo que está fijado en función a los tipos de habitaciones existentes. 


\subsubsection{Conclusiones de las residencias investigadas}

Los orígenes de las residencias universitarias reseñadas son antiguos y, con el transcurrir de los años, han sido objeto de modificaciones y ampliaciones.

Debemos tener en cuenta, luego de analizar la información anteriormente proporcionada, que dichos esfuerzos no han sido suficientes pues sus instalaciones no cuentan con la capacidad necesaria para albergar la alta demanda de alojamiento de sus estudiantes, tal como se muestra en el siguiente cuadro:

Cuadro 2. Estudiantes que residen en las residencias universitarias analizadas.

\begin{tabular}{lcc}
\multicolumn{1}{c}{ Universidad } & $\begin{array}{c}\mathbf{N}^{\circ} \text { de estudiantes } \\
\text { hospedados }\end{array}$ & $\begin{array}{c}\mathbf{N}^{\circ} \text { total estudiantes } \\
\text { pregrado }\end{array}$ \\
$\begin{array}{l}\text { Universidad Nacional } \\
\text { Mayor de San Marcos }\end{array}$ & \\
Julio C. Tello & 90 & \\
Campus Universitario & 210 & 32,458 \\
Total & 310 & \\
Universidad Nacional & & \\
de Ingeniería & & \\
Pabellón P & & \\
Pabellón M & 96 & 11,120 \\
Total & 126 & \\
Universidad Peruana & 222 & \\
La Unión & & 10,662 \\
Varones & & \\
Mujeres & 150 & \\
Total & 230 & \\
Elaboración propia & 380 & \\
& &
\end{tabular}

Como se puede apreciar, de un total de 54,240 alumnos estudiantes de pregrado en las 3 universidades reseñadas solo 912 residen en ellas por un tema de capacidad, es decir sólo el $1.68 \%$, lo que evidencia la falta de alojamiento.

Para efectos de la presente investigación el dato que nos interesa es el relacionado con la UNMSM, institución educativa que está ubicada en la zona del proyecto. Así, de un total de 32,458 estudiantes de pregrado sólo 310 se encuentran alojados en las dos residencias con las que cuenta la universidad, cifra que constituye un $0.95 \%$. 
Esto reafirma nuestra posición en el sentido que se hace necesario la construcción de una residencia universitaria que pueda suplir la demanda de alojamiento por parte de los estudiantes de la zona.

\subsection{Población de estudiantes universitarios en el Perú}

\subsubsection{Evolución y distribución de las universidades en nuestro país}

Desde la creación de la primera universidad en nuestro país, nos referimos a la Universidad Mayor de San Marcos en el año 1551, el número de universidades ha ido en constante aumento, tal como se puede apreciar en el gráfico siguiente:

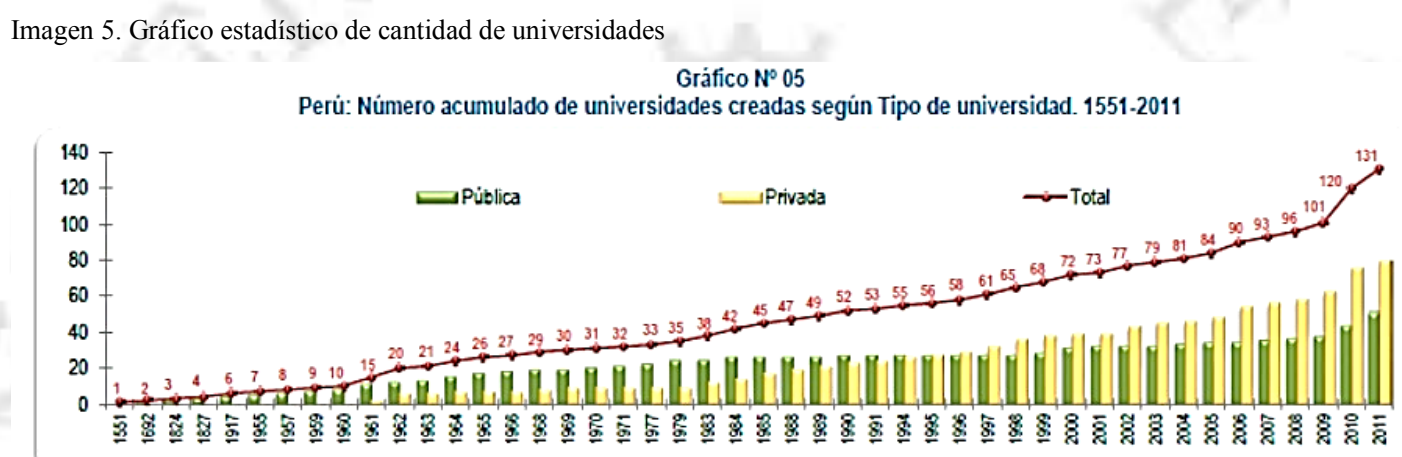

Fuente: Dirección de Estadística - ANR

Sin embargo, resulta conveniente precisar que ha sido recién en las últimas dos décadas que se ha presentado una elevación considerable de su número, llegándose éste a duplicar entre los años 1980 y el 2011, debido al incremento de la población universitaria en nuestro país -tema que será analizado más adelante- lo que conllevó a la creación de nuevas universidades.

En cuanto a su distribución, el Perú en el año 1996 contaba con 57 universidades (28 públicas y 29 privadas); catorce años más tarde, en el año 2010 nuestro país (último censo de estudiantes) contaba con 100 universidades (35 públicas y 65 privadas).

En el año 2012 el número de universidades se incrementó a 133 universidades tal como se aprecia en el Gráfico $\mathrm{N}^{\circ} 1$ : 
Imagen 6. Gráfico estadístico de cantidad de universidades según tipo.

\section{Gráfico $N^{0} 01$}

Perú: Número de Universidades por Tipo de universidad. Febrero 2012

\section{UNIVERSIDADES}

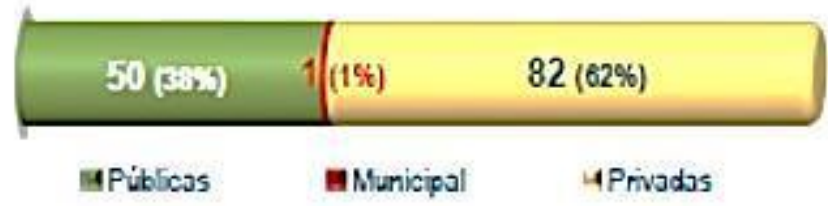

Fuente: Dirección de Estadística - ANR

En la actualidad existen en nuestro país 133 universidades, de las cuales 82 son privadas y 51 son públicas. El mayor número de universidades se concentra en la región Lima, con un total de 50 universidades, mientras que 78 están ubicadas en provincias, lo que denota la centralización existente en nuestro país.

\subsubsection{Evolución de la población universitaria}

Resulta necesario, para efectos de la presente investigación, efectuar un análisis acerca de cómo ha ido cambiando con el transcurrir de los años la población de estudiantes de pregrado en nuestro país. De esta manera se puede tener una idea de la demanda de alojamiento que se va a presentar a futuro, dependiendo de si va en aumento la población.

Tal como veremos a continuación la población universitaria en nuestro país ha crecido considerablemente. Así, el Perú en el año 1996 contaba con 57 universidades con un total de 335714 estudiantes; en el año 2010 contaba con 100 universidades con un total de 782970 estudiantes de pregrado.

Los datos antes reseñados nos muestran que hubo un aumento significativo del número de estudiantes, con una tasa de crecimiento anual de 4.2\%. (INEI, 2011). 
Cuadro 3. Población universitaria, por año censal y tasa de crecimiento anual, según tipo de universidad.

\begin{tabular}{|c|c|c|c|c|c|}
\hline \multirow{2}{*}{ TIPO DE UNIVERSIDAD } & \multirow{2}{*}{$\begin{array}{r}\text { NÚMERO DE } \\
\text { UNIVERSIDAD }\end{array}$} & \multicolumn{2}{|c|}{ ALUMNOS } & \multirow{2}{*}{$\begin{array}{r}\text { DOCENTES } \\
\text { UNIVERSITARIOS }\end{array}$} & \multirow{2}{*}{$\begin{array}{r}\text { PERSONAL } \\
\text { ADMINISTRATIVO Y } \\
\text { DE SERVICIOS }\end{array}$} \\
\hline & & PRE GRADO & POST GRADO & & \\
\hline & \multicolumn{5}{|c|}{ AÑO 2010} \\
\hline TOTAL & 100 & 782970 & 56358 & 59085 & 39017 \\
\hline PÚBLICAS & 35 & 309175 & 24591 & 21434 & 19961 \\
\hline \multirow[t]{2}{*}{ PRIVADAS } & 65 & 473795 & 31767 & 37651 & 19056 \\
\hline & \multicolumn{5}{|c|}{ AÑO 1996} \\
\hline TOTAL & 57 & 335714 & 10818 & 25795 & 16989 \\
\hline PÚBLICAS & 28 & 199943 & 7109 & 16096 & 11708 \\
\hline \multirow[t]{2}{*}{ PRIVADA } & 29 & 135771 & 3709 & 9699 & 5281 \\
\hline & \multicolumn{5}{|c|}{ TASA DE CRECIMIENTO ANUAL PERIODO 1996-2010 } \\
\hline TOTAL & 4,2 & 6,2 & 12,4 & 5,2 & 6,1 \\
\hline PÚBLICAS & 1,6 & 3,1 & 9,2 & 1,4 & 3,9 \\
\hline PRIVADA & 6,0 & 9,3 & 16,5 & 9,1 & 9,6 \\
\hline
\end{tabular}

NOTA: Incluye todas las universidades que vienen funcionando formalmente en el Sistema Universitario Peruano

Fuente: Instituto Nacional de Estadística e Informática, 2011

A julio de 2018 la data de población de estudiantes universitarios de pregrado matriculados a nivel nacional era de 1'383,217, con lo cual se evidencia que ésta sigue en crecimiento, al igual que en la región de Lima en la cual a julio de 2018 el número de estudiantes con las características reseñadas ascendía a 714,870 estudiantes.

\subsubsection{Características de la población universitaria de Lima Metropolitana}

La población universitaria de Lima es diversa en lo que respecta al lugar de origen de los estudiantes, universidad escogida, condiciones de alojamiento, medio de transporte utilizado, etc., por lo que analizaremos estos aspectos a efectos de conocer la realidad existente en nuestro medio.

\subsubsection{Alumnos que estudian en el lugar de su nacimiento}

Si bien es cierto la mayoría de jóvenes estudia en una universidad ubicada en su lugar de origen, existe un porcentaje constituido mayoritariamente por jóvenes de provincias que no lo hacen así, y que deciden estudiar en un lugar distinto. Usualmente estos jóvenes salen de su lugar de origen en búsqueda de una mayor variedad de carreras, mejor calidad en la enseñanza, infraestructura, facilidades de estudio, entre otros motivos. 
Para efectos del presente análisis en el cuadro siguiente se muestra que el porcentaje de jóvenes estudiantes de pregrado que han nacido en Lima Metropolitana y estudian acá es del 70.6\%, frente a un 29,4 por ciento que corresponde a jóvenes estudiantes de provincias y en menor número a extranjeros.

Cuadro 4. Porcentaje de estudiantes por género
\begin{tabular}{|lr|r|r|}
\hline \multirow{2}{*}{ ÁMBITO GEOGRÁFICO } & TOTAL & \multicolumn{3}{|c|}{ GÉNERO } \\
\cline { 4 - 5 } & & MASCULINO & FEMENINO \\
\hline TOTAL & 72.8 & 71.7 & 74.2 \\
Pública & 72.6 & 71.2 & 74.6 \\
Privada & 73.2 & 72.5 & 73.8 \\
\hline Lima Metropolitana & 70.6 & 68.5 & 73.1 \\
Pública & 63.4 & 60.6 & 67.8 \\
Privada & 75.9 & 75.7 & 76.2 \\
\hline Resto del País & 74.5 & 74.1 & 75.1 \\
Pública & 76.7 & 76.2 & 77.4 \\
Privada & 68.5 & 66.9 & 70.0 \\
\hline
\end{tabular}

Fuente: Instituto Nacional de Estadística e Informática - Censo Nacional Universitario 1996

El cuadro que presentamos a continuación nos muestra la información antes reseñada, pero con la especificación del departamento de origen del estudiante, su sexo, y si estudian en el mismo departamento o en otro. En él se evidencia que Arequipa es el Departamento con el porcentaje más alto de estudiantes oriundos con un 87,9 por ciento, seguidos por Lima con 87,1 por ciento. 
Cuadro 5. Porcentaje de estudiantes por género

\begin{tabular}{|l|ccc|c|c|c|}
\hline \multirow{2}{*}{ DEPARTAMENTO } & \multicolumn{5}{|c|}{ \% DE ALUMNOS QUE ESTUDIANEN: } \\
\cline { 2 - 7 } & EL MISMMO DEPARTAMENTO & \multicolumn{3}{|c|}{ OTROS DEPARTAMENTOS } \\
\cline { 2 - 7 } & TOTAL & HOMBRES & MUUERES & \multicolumn{1}{|c|}{ OOTAL } & HOMBRES & MUJERES \\
\hline Ancash & 55.0 & 51.1 & 59.9 & 46.8 & 48.9 & 40.1 \\
Apurímac & 34.3 & 29.6 & 40.5 & 65.7 & 70.4 & 59.5 \\
Arequipa & 87.9 & 87.3 & 88.6 & 12.1 & 12.7 & 11.4 \\
Ayacucho & 62.0 & 62.4 & 61.5 & 38.0 & 37.6 & 38.5 \\
Cajamarca & 48.7 & 49.8 & 46.9 & 51.3 & 50.2 & 53.1 \\
Callao & 11.3 & 14.1 & 8.2 & 88.7 & 85.9 & 91.8 \\
Cusco & 79.5 & 78.7 & 80.6 & 20.5 & 21.3 & 19.4 \\
Huancavelica & 34.1 & 31.5 & 38.0 & 65.9 & 68.5 & 62.0 \\
Huanuco & 77.7 & 77.6 & 77.8 & 22.3 & 22.4 & 22.0 \\
Ica & 77.4 & 77.5 & 77.2 & 22.6 & 22.5 & 22.8 \\
Junin & 51.2 & 50.5 & 51.9 & 48.8 & 49.5 & 48.1 \\
La Libertad & 78.1 & 76.0 & 80.3 & 21.9 & 24.0 & 19.7 \\
Lambayeque & 68.4 & 66.8 & 70.5 & 31.6 & 33.2 & 29.5 \\
\hline Lima & 87.1 & 86.1 & 88.4 & 11.7 & 12.8 & 10.2 \\
\hline Loreto & 73.8 & 72.2 & 75.6 & 26.2 & 27.4 & 24.4 \\
Moquegua & 11.5 & 10.1 & 13.0 & 88.5 & 89.9 & 87.0 \\
Pasco & 61.3 & 59.9 & 62.7 & 38.7 & 40.1 & 37.3 \\
Piura & 57.8 & 58.8 & 56.6 & 57.0 & 54.1 & 60.6 \\
Puno & 75.2 & 76.0 & 73.9 & 24.8 & 24.0 & 26.1 \\
San Martin & 38.9 & 38.7 & 39.2 & 61.1 & 61.3 & 60.8 \\
Tacna & 71.7 & 69.9 & 73.7 & 28.3 & 30.1 & 26.3 \\
Tumbes & 50.2 & 52.9 & 46.5 & 49.8 & 47.1 & 53.5 \\
Ucayali & 56.3 & 56.0 & 56.6 & 43.7 & 44.0 & 43.4 \\
\hline
\end{tabular}

Fuente: Instituto Nacional de Estadística e Informática - Censo Nacional Universitario 1996

\subsubsection{Alumnos por tipo de universidad}

Respecto al número total de estudiantes de pregrado en nuestro país $(782,970)$ según datos del Censo Nacional Universitario 2010, 309,715 alumnos, es decir el $39.50 \%$ estudian en universidades públicas y 473,795 , es decir el $70.60 \%$ lo hacen en universidades privadas de Lima Metropolitana.

Además, cabe precisar que del total de estudiantes de pregrado de nuestro país al 2010 el $40 \%$ es decir 312,409 alumnos estudiaban en Lima, mientras que el $70 \%$ de esta última población universitaria ha nacido en la ciudad capital (218,686 estudiantes), lo que nos permite señalar que 93,722 alumnos son nacidos en provincias o en el extranjero y viven en Lima. 


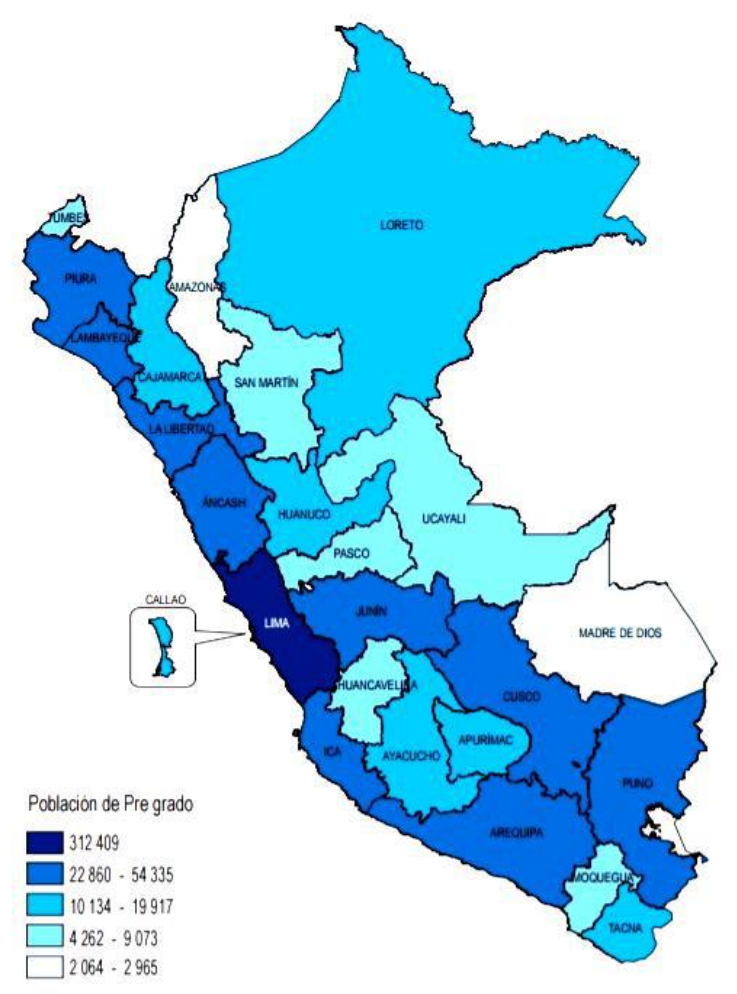

Cuad

ro 6 .

Departamento donde recibe la clase

Depa

rtame Categoria Casos $\%$ Acumulado \%

nto Amazona: $2064 \quad 00$

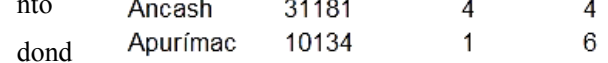

$\begin{array}{llll}\text { Arequipa } & 54335 & 7 & 12\end{array}$

e se Ayacuchc $13512 \quad 2 \quad 14$

$\begin{array}{llll}\text { recib Cajamarc } & 16964 & 2 & 16\end{array}$

$\begin{array}{llll}\text { Callao } & 13874 & 2 & 18\end{array}$

$\begin{array}{llll}\text { en } & \text { Cusco } & 31111 & 4\end{array}$

clases Huancave $5853 \quad 1 \quad 23$

$\begin{array}{lrrr}\text { Huánuco } & 19917 & 3 & 25\end{array}$

$\begin{array}{llll}\text { Ica } & 22860 & 3 & 28\end{array}$

Junín $\quad 34371 \quad 4 \quad 33$

La Liberte $\quad 45036 \quad 6 \quad 38$

Lambayer $32555 \quad 4 \quad 43$

Lima $\quad 312409 \quad 40 \quad 83$

$\begin{array}{llll}\text { Loreto } & 10890 & 1 & 84\end{array}$

Madre de $2965 \quad 0 \quad 84$

Moquegu: $5854 \quad 1 \quad 85$

$\begin{array}{llll}\text { Pasco } & 6558 & 1 & 86\end{array}$

$\begin{array}{llll}\text { Piura } & 34740 & 4 & 90\end{array}$

Puno $41308 \quad 569$

San Marti $\quad 9073 \quad 1 \quad 97$

Tacna $\quad 12443 \quad 208$

$\begin{array}{llll}\text { Tumbes } & 4262 & 1 & 99\end{array}$

Ucayali $\quad 8372 \quad 100$

Total $\quad 782641 \quad 100 \quad 100$

NSA : $\quad 235$

Ignorado 94

Fuente: Instituto Nacional de Estadística e Informática - Censo Nacional Universitario 2010

Estas cifras se incrementan en el año 2016 año según información de SUNEDU, ya que de un total de 1'382,932 alumnos estudiantes de pregrado en el país, el 73.43\% es decir 1'015,519 estudian en universidades privadas y el $26.57 \%$ es decir 367,413 alumnos lo hacen en universidades públicas. (INEI, 2010)

\subsubsection{Aspectos que influyen al momento de elegir una universidad}

Diversos son los aspectos que influyen en los estudiantes de pregrado al momento de elegir una universidad, entre ellos podemos mencionar la cercanía a su domicilio, el prestigio de la universidad, mejores expectativas económicas, entre otros.

Según la data del cuadro 2, el prestigio es el aspecto principal que influyó en los alumnos al momento de elegir una universidad - y que nos sirve como un alcance ya 
que hay ciertas similitudes a la hora de escoger una residencia universitaria- (la Universidad Católica del Perú y la Universidad Nacional Mayor de San Marcos son reconocidas a nivel latinoamericano) con un $54 \%$, mientras que quienes señalaron la cercanía a su domicilio constituyen solo el 10\%. Esta última preferencia es muy importante ya que nos señala que al $90 \%$ de la población universitaria no le importa la cercanía a su domicilio, lo que indica que la mayoría (sobretodo provincias y extranjero) están dispuestos a ir a una universidad que quede en cualquier sitio, y esto conlleva a que puedan optar por alojarse en una residencia universitaria que se ubique en la cercanía. Se aprecia claramente en el Cuadro $N^{\circ} 2$ que solo un mínimo porcentaje en las universidades tienen como preferencia la cercanía a su domicilio. (INEI, 2011)

Cuadro 7. Aspecto principal que influyó para elegir la universidad

TIPO Y NOMBRE DE UNIVERSIDAD

TOTAL

\section{PÚBLICAS}

UNIV. NAC. AGRARIA DE LA SELVA UNIV. NAC. AGRARIA LA MOLINA UNIV. NAC. DANIEL ALCIDES CARRIÓN UNIV. NAC. DE CAJAMARCA UNIV. NAC. DE EDUCACIÓN ENRIQUE GUZMAN Y VALLE UNIV. NAC. DE INGENIERIA UNIV. NAC. DE LA AMAZONIA PERUANA UNIV. NAC. DE MOQUEGUA UNIV. NAC. DE PIURA UNIV. NAC. DE SAN AGUSTIN UNIV. NAC. DE SAN ANTONIO ABAD UNIV. NAC. DE SAN MARTIN UNIV. NAC. DE TRUJILLO UNIV. NAC. DE UCAYALI UNIV. NAC. MAYOR DE SAN MARCOS PRIVADAS

PONTIF. UNN. CATÓLICA DEL PERÚ

\begin{tabular}{|c|c|c|c|c|c|}
\hline \multirow[b]{2}{*}{ TOTAL } & \multicolumn{5}{|c|}{$\begin{array}{l}\text { ASPECTO PRINCIPAL QUE INFLUYÓ } \\
\text { PARA ELEGIR LA UNIVERSIDAD }\end{array}$} \\
\hline & $\begin{array}{r}\text { PRESTI- } \\
\text { GIO DE } \\
\text { LA } \\
\text { UNIVER- } \\
\text { SIDAD }\end{array}$ & $\begin{array}{r}\text { ÚNICA } \\
\text { UNIVER- } \\
\text { SIDAD QUE } \\
\text { OFRECE } \\
\text { LA ESPE- } \\
\text { CIALIDAD } \\
\text { QUE } \\
\text { DESEA }\end{array}$ & $\begin{array}{r}\text { CERCA- } \\
\text { NIAA A } \\
\text { SU DOMI- } \\
\text { CILIO }\end{array}$ & $\begin{array}{r}\text { MEJORES } \\
\text { EXPEC- } \\
\text { TATIVAS } \\
\text { ECONÓ- } \\
\text { MICAS }\end{array}$ & OTRO \\
\hline 782970 & 423065 & 113035 & 82357 & 132197 & 32316 \\
\hline 309175 & 168085 & 44279 & 40767 & 46289 & 9755 \\
\hline 2726 & 1289 & 324 & 397 & 664 & 52 \\
\hline 4903 & 3245 & 1262 & 116 & 229 & 51 \\
\hline 6904 & 1891 & 1008 & 2878 & 994 & 133 \\
\hline 8851 & 4523 & 1392 & 1396 & 1305 & 235 \\
\hline 9178 & 4598 & 2257 & 1090 & 964 & 269 \\
\hline 11034 & 9854 & 501 & 103 & 419 & 157 \\
\hline 7216 & 4009 & 1618 & 407 & 1035 & 147 \\
\hline 689 & 74 & 213 & 188 & 191 & 23 \\
\hline 11907 & 6890 & 1948 & 483 & 2370 & 216 \\
\hline 24212 & 14127 & 2652 & 880 & 5278 & 1275 \\
\hline 16374 & 8302 & 3318 & 2344 & 1912 & 498 \\
\hline 4870 & 1763 & 978 & 981 & 1035 & 113 \\
\hline 15741 & 12528 & 1149 & 453 & 1410 & 201 \\
\hline 3890 & 1796 & 711 & 576 & 689 & 118 \\
\hline 28645 & 24878 & 1392 & 325 & 1573 & 477 \\
\hline 473795 & 254980 & 68756 & 41590 & 85908 & 22561 \\
\hline 17531 & 15912 & 862 & 241 & 308 & 208 \\
\hline
\end{tabular}


Cuadro 8. Total de alumnos de pre grado, por aspecto principal que influyó para elegir la universidad, según tipo de universidad

\begin{tabular}{|c|c|c|c|c|c|c|}
\hline \multirow[b]{2}{*}{$\begin{array}{c}\text { TIPO DE } \\
\text { UNIVERSIDAD }\end{array}$} & \multirow[b]{2}{*}{ TOTAL } & \multicolumn{5}{|c|}{ ASPECTO PRINCIPAL QUE INFLUYÓ PARA ELEGIR LA UNIVERSIDAD } \\
\hline & & $\begin{array}{r}\text { PRESTIGIO DE } \\
\text { LA } \\
\text { UNIVERSIDAD }\end{array}$ & $\begin{array}{r}\text { ÚNICA } \\
\text { UNIVERSIDAD } \\
\text { QUE OFRECE LA } \\
\text { ESPECIALIDAD } \\
\text { QUE DESEA }\end{array}$ & $\begin{array}{r}\text { CERCANIA A } \\
\text { SU DOMICILIO }\end{array}$ & $\begin{array}{r}\text { MEJORES } \\
\text { EXPECTATIVAS } \\
\text { ECONÓMICAS }\end{array}$ & OTRO \\
\hline TOTAL & 782970 & 423065 & 113035 & 82357 & 132197 & 32316 \\
\hline & 100,0 & 54,0 & 14,4 & 10,5 & 16,9 & 4,1 \\
\hline PÚBLICAS & 309175 & 168085 & 44279 & 40767 & 46289 & 9755 \\
\hline & 100,0 & 54,3 & 14,3 & 13,2 & 15 & 3,2 \\
\hline PRNADAS & 473795 & 254980 & 68756 & 41590 & 85908 & 22561 \\
\hline & 100,0 & 53,8 & 14,5 & 8,8 & 18,1 & 4,8 \\
\hline
\end{tabular}

NOTA: Incluye todas las universidades que vienen funcionando formalmente en el Sistema Universitario Peruano.

Fuente: Instituto Nacional de Estadística e Informática, 2011

\subsubsection{Condiciones de alojamiento}

Es importante también conocer con quienes viven los estudiantes ya que esto nos muestra cuanta población está dispuesta a vivir por su cuenta.

En la estadística del Cuadro 9 podemos apreciar que, en Lima, en el año 1996 el porcentaje de estudiantes que vivía con sus padres era de $81 \%$ y en el año 2010 bajó a $76 \%$, esto nos muestra que conforme pasan los años la cantidad de estudiantes que no vive con sus padres aumenta, por lo que se encuentran viviendo en algún otro lugar (ya sea departamentos o casas de estudio) y es viable que se hospeden en una residencia universitaria. A esto hay que agregarle a la demanda los estudiantes que vienen de provincia y del extranjero. 
Cuadro 9. Porcentaje de alumnos de pre grado que viven con sus padres según tipo de universidad y lugar donde recibe sus clases.

\begin{tabular}{|c|c|c|c|c|c|c|}
\hline \multirow{3}{*}{$\begin{array}{l}\text { TIPO DE UNIVERSIDAD Y } \\
\text { LUGAR DONDE RECIBE } \\
\text { SUS CLASES }\end{array}$} & \multicolumn{6}{|c|}{ AÑO CENSAL Y SEXO } \\
\hline & \multicolumn{3}{|c|}{ AÑO 1996} & \multicolumn{3}{|c|}{ AÑO 2010} \\
\hline & TOTAL & HOMBRE & MUJER & TOTAL & HOMBRE & MUJER \\
\hline TOTAL & 76,0 & 74,2 & 78,2 & 72,2 & 70,6 & 73,8 \\
\hline PÜBLICAS & 74,3 & 72,3 & 77,2 & 72,2 & 70,6 & 74,2 \\
\hline PRIVADAS & 78,5 & 77,5 & 79,5 & 72,1 & 70,5 & 73,6 \\
\hline LIMA METROPOLITANA & 81,2 & 79,7 & 83,0 & 76,3 & 75,1 & 77,6 \\
\hline PÚBLICAS & 79,9 & 77,5 & 83,5 & 78,4 & 76,9 & 80,5 \\
\hline PRIVADAS & 82,2 & 81,7 & 82,6 & 75,5 & 74,2 & 76,6 \\
\hline RESTO DEL PAIS & 71,9 & 69,9 & 74,4 & 69,5 & 67,7 & 71,4 \\
\hline PÚBLICAS & 71,8 & 69,9 & 74,5 & 69,6 & 67,9 & 71,7 \\
\hline PRIVADAS & 72,3 & 70,1 & 74,2 & 69,4 & 67,6 & 71,1 \\
\hline EXTRANJERO & - & - & - & 29,8 & 24,8 & 34,7 \\
\hline PÚBLICAS & - & - & - & 28,0 & 20,0 & 40,0 \\
\hline PRIVADAS & - & - & - & 30,0 & 25,5 & 34,3 \\
\hline NO ESPECIFICADO & - & - & - & 59,6 & 64,2 & 53,7 \\
\hline PÚBLICAS & - & - & - & 27,3 & 33,3 & 20,0 \\
\hline PRIVADAS & - & - & - & 63,9 & 68,1 & 58,3 \\
\hline
\end{tabular}

NOTA: Incluye todas las universidades que vienen funcionando formalmente en el Sistema Universitario Peruano.

Fuente: Instituto Nacional de Estadística e Informática, 2011

Esta estadística nos muestra qué porcentajes de estudiantes migran a Lima para poder realizar sus estudios, lo que nos indica el porcentaje de estudiantes que buscan un alojamiento (estadística resumida). 
Cuadro 10: Porcentaje de alumnos de pre grado nacidos en el mismo departamento de la universidad, por sexo, según tipo y nombre de la universidad.

\begin{tabular}{|c|c|c|c|}
\hline \multirow{2}{*}{ TIPO Y NOMBRE DE UNIVERSIDAD } & \multirow{2}{*}{ TOTAL } & \multicolumn{2}{|c|}{ SEXO } \\
\hline & & HOMBRE & MUJER \\
\hline TOTAL & 76,7 & 75,7 & 77,8 \\
\hline PÚBLICAS & 75,8 & 74,5 & 77,5 \\
\hline UNIV. NAC. AGRARIA DE LA SELVA & 50,2 & 47,3 & 54,5 \\
\hline UNIV. NAC. AGRARIA LA MOLINA & 75,0 & 72,5 & 77,7 \\
\hline UNIV. NAC. AMAZÓNICA DE MADRE DE DIOS & 65,4 & 62,7 & 68,6 \\
\hline UNIV. NAC. DANIEL ALCIDES CARRIÓN & 78,8 & 76,4 & 80,8 \\
\hline UNIV, NAC. DE CAJAMARCA & 87,5 & 88,9 & 85,5 \\
\hline UNIV. NAC. DE EDUCACIÓN ENRIQUE GUZMÁN Y VALLE & 66,5 & 62,0 & 69,1 \\
\hline UNIV. NAC. DE HUANCAVELICA & 84,5 & 84,5 & 84,5 \\
\hline UNIV. NAC. DE INGENIERIA & 67,0 & 66,3 & 72,3 \\
\hline UNIV. NAC. MAYOR DE SAN MARCOS & 74,9 & 73,7 & 76,4 \\
\hline PRIVADAS & 77,3 & 76,6 & 78,0 \\
\hline ASOCIACIÓN UNIV. PRIV. SAN JUAN BAUTISTA & 76,0 & 75,6 & 76,3 \\
\hline FACULTAD DE TEOLOGIA PONTIFICIA Y CIVIL DE LIMA & 47,1 & 48,1 & 42,6 \\
\hline PONTIF. UNIV. CATÓLICA DEL PERÚ & 76,2 & 74,3 & 78,5 \\
\hline UNIV. ADA A BYRON & 91,1 & 91,2 & 91,1 \\
\hline
\end{tabular}

NOTA: Incluye todas las univ ersidades que vienen funcionando formalmente en el Sistema Universitario Peruano.

Fuente: Instituto Nacional de Estadística e Informática, 2011

Tomando en cuenta las universidades en la zona de estudio (Pontificia Universidad Católica del Perú y la Universidad Nacional Mayor de San Marcos), se puede apreciar que entre el 25 y $33 \%$ de los estudiantes de estas universidades no son nacidos en el distrito de Lima, lo que puede significar que gran parte de ese porcentaje tampoco vive ahí.

\subsection{Demanda de las residencias Universitarias en Lima}

Teniendo en consideración datos extraídos de la Universidad Nacional Mayor de San Marcos (UNMSM) se nos posibilita conocer la cantidad de estudiantes que se hospedan en las residencias universitarias que esta universidad posee, con respecto al total de sus 
estudiantes de pregrado. También es posible conocer la cantidad de estudiantes que vienen de fuera de Lima, lo que permite calcular la demanda de las residencias por parte de alumnos de provincia y del extranjero.

De acuerdo al censo Universitario del año 2010 la UNMSM es la institución educativa que alberga la mayor cantidad de estudiantes de pregrado siendo su tasa anual de crecimiento de $2,1 \%$.

Según data al año 2015 la UNMSM contaba con una población universitaria de 31,802 alumnos (Universidad Nacional Mayor de San Marcos, 2015)

Cuadro 11: Estudiantes por lugar de nacimiento según facultad, 2017

3.12 ESTUDIANTES POR LUGAR DE NACIMIENTO SEGỦN FACULTAD, 2017

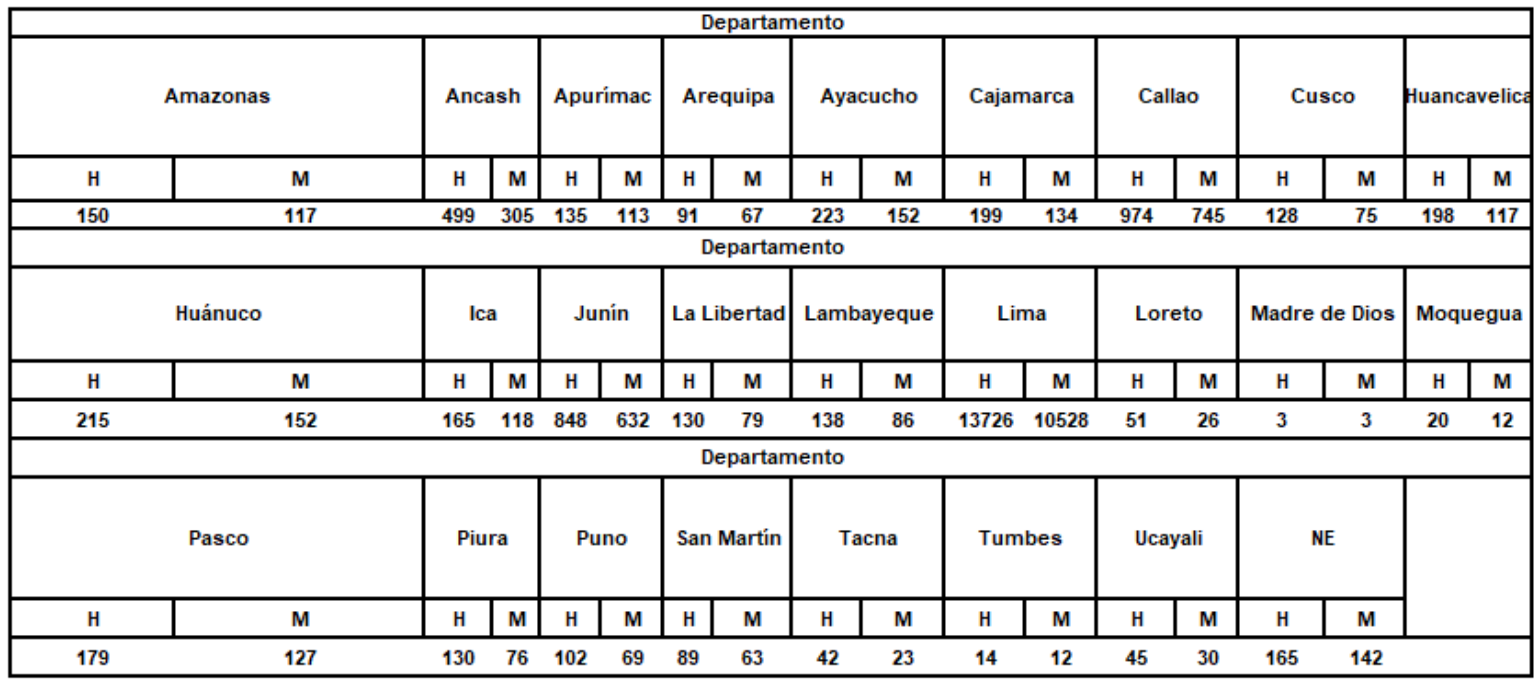

Fuente: Oficina General de Planificación UNMSM, 2018

y a julio de 2018 el número de estudiantes de pregrado se incrementó a 32,458, de los cuales 8408 vienen de provincias, lo que equivale al $26.44 \%$ del total.

Las residencias universitarias de la UNMSM albergan a 300 alumnos, lo que equivale al 0.92 por ciento del total de estudiantes de pregrado y al $3.57 \%$ de estudiantes cuyo lugar de nacimiento es en provincias, porcentaje que se ve limitado como consecuencia de la capacidad de la residencia.

En el caso de la PUCP, tuvo matriculados en el año 2017 un total de 23,381 alumnos: 369 del extranjero y 400 de provincias (de los cuales 200 son de la Red Peruana de Universidades). Dado que esta universidad no cuenta con una residencia universitaria, resulta por demás importante considerar las cifras antes reseñadas, ya que 
es una de las universidades a las cuales está dirigida la residencia universitaria que se piensa desarrollar en el distrito de Pueblo Libre.

Cuadro 12: Estudiantes de intercambio y nacionales. Datos actualizados a octubre del 2017

\section{Estudiantes de intercambio y nacionales}

\begin{tabular}{|l|c|c|c|}
\hline Nombre & 2017 & 2016 & 2015 \\
\hline Estudiantes provenientes del extranjero & 369 & 423 & 464 \\
\hline Estudiantes PUCP en el extranjero & 213 & 300 & 250 \\
\hline $\begin{array}{l}\text { Estudiantes provenientes de la Red Peruana } \\
\text { de Universidades }\end{array}$ & 200 & 192 & 177 \\
\hline Fuente: Dirección Académica de Relaciones Institucionales de la PUCP. & & & \\
\hline
\end{tabular}

\subsection{Conclusiones parciales}

Los primeros alojamientos colectivos de estudiantes aparecieron con las universidades entre los siglos XII y XIII, en Europa. Comenzaron como viviendas dentro de las universidades donde convivían alumnos y maestros, las cuales tenían una organización espacial muy similar a la de los monasterios, donde todos los edificios y programas funcionaban alrededor de un patio. Con el transcurrir del tiempo las residencias debían ir adaptándose a las necesidades y cambios que se iban presentando. Debido a esto el primer modelo cambió y fueron apareciendo muchos otros que se iban aplicando a diferentes universidades.

Esto indica que el planeamiento de las residencias universitarias no solo debe estar pensado para la situación actual, sino que deben tener flexibilidad a la hora de diseñarse de manera que pueda ir variando a futuro y se mantenga en funcionamiento durante mucho más tiempo. 
Tomando como base la historia de residencias universitarias de Lima, se pueden verificar algunas decisiones que se ejecutaron y que resultaron favorables para las mismas.

Las estadísticas nos dan un alcance de los factores que influyen en los diversos aspectos relacionados con la construcción de una residencia universitaria. Son análisis y estudios que nos muestran la viabilidad del proyecto y nos permiten ir sacando conclusiones acerca de cómo ir definiendo la residencia que se va a desarrollar.

En este contexto, la gran cantidad de estudiantes en las universidades del distrito de San Miguel -que colinda con el de Pueblo Libre lugar en donde está ubicado el terreno del proyecto- nos muestra que resultaría factible establecer una residencia universitaria cerca de la zona de estudio.

Además, actualmente existen solo tres (3) residencias universitarias en funcionamiento en Lima, cuya capacidad de hospedaje es limitada teniendo en consideración la cantidad de estudiantes que buscan un alojamiento.

Ello nos indica que la oferta de residencias universitarias es escasa para cubrir la demanda de hospedaje ya reseñada, por lo que la construcción de una nueva resultaría muy importante para los estudiantes que vienen de provincias o del extranjero, los cuales, para el caso específico de estudio, no se encuentran hospedados en la Residencia de la UNMSM que es la más cercana a la ubicación de nuestro proyecto.

Las preferencias de los estudiantes juegan también un papel importante, ya que de ellas depende la elección de una residencia universitaria. En este contexto, a través del análisis y estudio respectivo se identificarán cuáles son esas preferencias a efectos de poder desarrollar una residencia universitaria que cubra dichos requerimientos. 


\section{CAPÍTULO III: MARCO TEÓRICO}

\subsection{Teoría del habitar}

Los seres humanos habitamos por excelencia en cada momento de nuestras vidas. No existe un momento en el que una persona no habite y, además, ese habitar es siempre en comunidad.

El hecho que el habitar esté presente siempre y de manera constante hace que sea difícil reconocer que el mismo requiera una explicación o una teoría sobre sus alcances. Dicho de otro modo "la cercanía, o familiaridad del habitar tiene como consecuencia que no se adviertan sus incógnitas, sus opacidades, su compleja y velada estructuración". (Doberti, 2011)

Los sistemas de Hablar y Habitar, y específicamente su ejercicio, posibilitan el acceso a la condición humana, siendo el peldaño en el cual reside el orden primordial de la vida en sociedad.

El diseño por sus vinculaciones con las elaboraciones básicas de la sociedad y de la espacialidad está ineludiblemente ligado con las prácticas y los valores que asume una comunidad, con el pasado que recuerda y el futuro que anhela, en última instancia con el reconocimiento y la elaboración de su identidad. (Doberti, 2011)

Me baso en esta teoría ya que la acción de habitar es la esencia de la residencia universitaria. Su uso está destinado a los estudiantes quienes van a usarla como vivienda temporal, por lo que el habitar está presente en todo momento. Es importante destacar una diversidad en distintos espacios de las viviendas temporales, así como su flexibilidad y versatilidad, ya que todo esto es parte del habitar. 
Todo esto se encuentra relacionado con el dinamismo y la interactividad que se busca otorgar a los espacios de la residencia, volviéndola un sitio más completo en todos los aspectos. Según Heidegger en su libro Construir, habitar, pensar:

"El puente es, ciertamente, una cosa de un tipo propio, porque coliga la Cuaternidad de tal modo que otorga (hace sitio a) una plaza. Pero solo aquello que en sí mismo es un lugar puede abrir un espacio a una plaza. El lugar no está presente ya antes del puente. Es cierto que antes de que esté puesto el puente, a lo largo de la corriente hay muchos sitios que pueden ser ocupados por algo. De entre ellos uno se da como un lugar, y esto ocurre por el puente" (como se citó en Casanova, 2012, p. 15).

Según Casanova: Existen construcciones, tales como el puente, las que esencialmente constituyen lugares, otorgando espacio, haciendo sitio a plazas. Pero el espacio (Raum, en alemán) significa «lugar franqueado para población y campamento» (Heidegger, 1994: 114). Allí precisamente es en donde se constituye un lugar, según nuestro autor, «los espacios reciben su esencia desde lugares y no desde “el” espacio» (Heidegger, 1994: 114). (2012)

Como se ha podido apreciar, Casanova hace referencia a Heidegger quien explica que los espacios se empiezan a constituir a partir de los lugares donde se encuentren, y no netamente desde el "espacio" en sí. Es decir, los lugares no se construyen a expensas del espacio, sino que el espacio aparece de acuerdo a los lugares existentes o a construir. El espacio entonces como extensión, aparece mediante la constitución efectiva de lugares y estos se generan propiamente por el habitar del hombre.

Lo que la arquitectura busca es que los lugares que tienden a construirse sean habitados por el hombre y se les dé un uso específico. Según Heidegger: "La esencia del construir es el dejar habitar [...] Solo si somos capaces de habitar podemos construir" (como se citó en Casanova, 2012, p. 16). En este contexto, los espacios que buscamos para la residencia universitaria objeto de la presente tesis, solo serán factibles de acuerdo al lugar donde estén emplazados y de acuerdo al tipo de arquitectura bajo la cual se encuentren diseñados.

La definición de lugar según Lawrence es: "un espacio que se vuelve significativo por la ocupación o la apropiación humana; es un concepto cultural fundamental para describir las relaciones de los seres humanos con su ambiente" (como se citó en Casanova, 2012, p. 18). 
Tomando como base esta frase se llega a la conclusión de que los espacios adquieren un valor sobresaliente dependiendo del uso, la continuidad y la importancia que le den las personas que lo habitan en relación con el contexto que les rodea.

"El habitar es un hecho vincular, social y cultural, entre sujetos complejamente configurados y lugares no menos complejamente articulados. La teoría del habitar, entonces no puede ser quizá otra cosa que una tentativa hermenéutica que indague no solo con la observación de las conductas situadas del hombre, sino que escudriñe en el sentido que estas adopten para los sujetos involucrados" (Casanova, 2012).

Resulta pues importante el emplazamiento de la residencia universitaria ya que este determinará el desenvolvimiento de los estudiantes al momento de habitarla, ya que como bien dice Heidegger, el habitar es un hecho complejo en el que tanto el espacio como el contexto influyen para su viabilidad.

\subsubsection{Flexibilidad, versatilidad y diversidad en recintos de la residencia}

La flexibilidad se refiere al tipo de sistema y a la variedad de usos a utilizarse y que se pueden dar en el espacio residencial. También se refiere al tipo de diseño estructural a aplicarse (ya sea grandes luces, o minimización de la estructura para darle un mayor valor a los espacios a utilizar), el cual es de igual importancia que el diseño arquitectónico, ya que ambos deben ir de la mano. Hoy en día se busca mayor dinamismo en los espacios de la residencia, ya sea espacios contiguos, comunes, aulas de usos múltiples, y lugares de encuentro los cuales vuelven a la residencia un lugar más flexible.

Según Vargas (2012): "La versatilidad es ambivalencia y polivalencia". En la residencia puede, haber lugares ya sean públicos o semiprivados que sirvan para varias funciones, es decir, espacios multiplicadores que posean la facilidad y rapidez de adaptarse a diversas funciones. Por ejemplo, un área de uso común cerca de las habitaciones puede usarse como zona de estudio o como una zona para ver películas.

La diversidad se refiere a la cantidad de acontecimientos simultáneos que pueden darse en diversos espacios. Así, pueden notarse actividades individuales en lugares comunes como los espacios públicos o semiprivados, evidenciando lo singular en lo colectivo, "ya no como parte de un todo sino como especificidad interconectada con el todo" (Vargas, 2012). 


\subsubsection{El espacio mínimo vital}

Es importante tener en consideración el espacio mínimo que requiere un espacio para su diseño, ya que esto nos dará una visión más clara del espacio que necesita una persona para movilizarse por las áreas, para así establecer una relación directa entre las proporciones de los edificios y las del hombre, ya sean tanto en los espacios de las habitaciones, como en los espacios semiprivados y comunes, los cuales estarán abiertos a uso de todo el público.

- El modulor de Le Corbusier. Es una herramienta que permite aplicar la escala humana al espacio u objeto diseñado. Es importante considerarla para el diseño de la residencia universitaria pues nos dará una visión más exacta y clara del espacio lo cual nos permitirá diseñar de acuerdo a las necesidades de los estudiantes.

- Experiencia japonesa y su uso del espacio. Debido a la densidad de población en Japón, se ha aprendido a vivir en lugares haciendo un aprovechamiento al máximo del poco espacio que poseen las viviendas. Las limitaciones espaciales son un factor de inspiración y no de confusión. Los japoneses utilizan la luz, los huecos y las relaciones visuales, y las hacen funcionar en armonía como un conjunto, permitiendo mejorar la percepción del espacio.

\subsection{Teoría de los espacios "In between"}

Según Hertzberger, el espacio "In between" es un concepto que recupera la reciprocidad entre fenómenos duales aparentemente contrarios (individual-colectivo, unidad-diversidad, interior-exterior, ...)" (Lidón de Miguel, 2015).

El edificio debe convertirse en una casa para quienes lo habiten. Así, se busca eliminar los aislamientos de espacios y que aparezcan lugares colectivos que relacionen lo que ocurre dentro de la residencia con el contexto, generando relaciones con la comunidad. Los ocupantes pasarán la mayor parte de su tiempo ahí, por lo que deben sentirse íntegros con el lugar, dándole un sentido de pertenencia y no solo tomarlo como un lugar pasajero.

Los espacios In Between son espacios intermedios. Son importantes ya que representan la transición entre dos espacios diferentes. Estos pueden estar presentes en diferentes escalas dentro de un proyecto, ya sea entre la calle y el proyecto, entre espacios privados (oficinas, tiendas) y zonas públicas (plazas), o áreas comunes entre 
habitaciones (caso de residencias universitarias). Pueden ser de permanencia temporal o de paso.

"El edificio debía poder adaptarse al patrón de vida de sus ocupantes, pero sin caer en un exceso de flexibilidad, ya que esto conduciría a una falsa neutralidad y a la falta de identidad" (Lidón de Miguel, 2015).

\section{Respecto a la flexibilidad, Heidegger afirma que:}

"Ninguna solución es la correcta ni la definitiva porque se considera que el problema varía constantemente. Un diseño flexible es aquel capaz de cambiar para adaptarse a cualquier variación en el programa. Sin embargo, esto implica que, permitiendo un gran número de soluciones, nunca ofrece la mejor respuesta a una necesidad concreta (Analogía del guante de Van Eyck) conduce a la ausencia de identidad porque carece de características distintivas" (Lidón de Miguel, 2015).

Esta es una característica que debe estar presente en los espacios "In between", ya que nos ayuda a darle un enfoque al diseño y programación. Es importante que el diseño sea flexible ya que permite adaptarse a los distintos cambios que se vayan dando conforme pase el tiempo, y permitiendo buscarles una solución de acuerdo a lo que se necesite entre dos espacios adyacentes.

\subsubsection{Vivienda compartida en espacios mínimos}

"Se debería de producir el doble de bienestar con la mitad de recursos para aumentar la eficacia de nuestro entorno. El espacio habitable es un recurso escaso, y tiene un alto valor económico. Por ello se podría impulsar la construcción de viviendas y edificios en los que sus usuarios (principalmente jóvenes) compartan sus recursos para disfrutar de más espacio con una menor inversión" (Vargas, 2012).

Esto nos da el enfoque que se le quiere dar a la programación a desarrollar en la residencia. Comúnmente las habitaciones en residencias cuentan con una cierta cantidad de implementos (lavadoras, televisores, mesas, muebles, etc), de los cuales solo se utilizan hasta un $10 \%$ de su rendimiento. Se busca optimizar la ubicación y uso de los espacios entre habitaciones o comunes, para darles un uso más preciso con muchos menos recursos y cantidad de espacio, aprovechando de esta manera cantidad de área en otras zonas de la residencia para diferentes usos. 
Es importante que las habitaciones establezcan relaciones dinámicas con otras habitaciones, y todo esto en cada nivel, utilizando áreas comunes. Así es como puedes tener un nivel de cierta cantidad de metros cuadrados, pero tiene un uso efectivo de casi el doble de la cantidad de espacio debido a los espacios comunes que utilizarían las personas.

"Entre un espacio individual, aislado, propio de una persona, y los espacios comunes o espacios públicos, se dan los espacios compartidos. Con el fin de permitir por un lado más interacción social, y por el otro lado, eficacia en el sistema, para que las personas tengan más espacio para su uso propio. Cabe definir lugares compartidos que estén en directa relación con los espacios privados de las personas.” (Vargas, 2012).

\subsubsection{Espacio colectivo dentro de una comunidad}

Permite la realización de actividades relacionadas con la vida comunitaria y que la vida no se desarrolle en espacios ni construcciones aisladas porque lo único que eso hace es segmentar a la comunidad basándose en sus actividades diarias, lo cual no pasaría si hay puntos de encuentro donde también pueden ejercerse las mismas.

Se buscan estos espacios colectivos debido a que en la zona hay una escasez de espacios compartidos dentro de las residencias, las cuales solo están destinadas a ofrecer hospedaje y servicios de menor importancia. Ya no se ven lugares en las edificaciones donde las personas puedan juntarse para socializar, como áreas comunes en proporciones adecuadas a las residencias, o áreas donde la gente pueda realizar actividades colectivas en las cuales también pueda formar parte la comunidad cercana ubicada en el contexto inmediato de estos edificios.

Debido a la carencia de estos espacios, la gente tiende a utilizar zonas de circulación u otros espacios de recorrido para suplir estas necesidades, por lo que esto debería ser resuelto. Se necesitan espacios de encuentro social donde la gente pueda pasar tiempo fuera de las horas de estudio.

14“"Las propias viviendas se están convirtiendo en células herméticas e independientes donde cada individuo se relaciona con el mundo exterior y lejano a través de las sofisticadas redes de telecomunicaciones, pero es incapaz de entablar un contacto franco y directo con las personas más próximas de su entorno. Se salta sin transición de la esfera personal al universo genérico de la globalización”.

14 GIMENEZ, Antonio. "Vivienda colectiva”. Valencia: Editorial Pencil, 351 pag. 


\subsection{Concepto de la Residencia universitaria}

En sentido estricto las residencias universitarias vendrían a ser centros que proporcionan alojamiento a estudiantes nacionales -en cuyo caso comprenden a aquellos que son de la ciudad en la que se encuentra ésta ubicada, así como a los que vienen de provincias-, y extranjeros. En sentido extenso, además del tema del alojamiento son lugares que promueven la formación de los estudiantes y les brindan una serie de servicios tendentes a facilitar su desarrollo integral.

"Los servicios con los que cuentan las residencias universitarias suelen ir desde el alojamiento y la manutención hasta los servicios de lavandería y biblioteca. Además, según la categoría de estas residencias, también contarán con servicios complementarios como cine, salas de juegos, planificación de excursiones o actividades deportivas". (residenciasen.com, 2014, párr. 3)

Además una de las características de las residencias universitarias es fomentar la socialización entre los estudiantes alojados. En este contexto, una residencia universitaria es algo más que una mera estructura física para vivir, es una pequeña comunidad donde se aprende a vivir en grupo, a respetar las diferencias individuales, a aceptar éstas y a desarrollar un mayor grado de tolerancia. (Decanato de estudiantes, 2002)

\section{4. ¿Por qué una residencia universitaria?}

El porqué de la importancia de la elección de una residencia universitaria como tema para la investigación de la tesis, viene de algunos puntos a tomar en consideración, los cuáles también sirven para el diseño de la misma.

Fuera del horario de clases, los estudiantes desarrollan su vida dentro de la residencia, lo cual indica que esta juega un rol vital tanto en el aspecto social como en el cultural de estos estudiantes, ya que debería ser la encargada de brindarles todas las herramientas necesarias para su correcto desempeño.

Los hospedajes para estudiantes en Lima no brindan paquetes de estadía (cobran por noche) y muchas veces no cuentan con los servicios adecuados y necesarios a sus requirimientos, teniendo en consideración que sus necesidades son distintas a las de cualquier otro grupo de personas. 
Es por eso que resulta necesaria la creación de una residencia universitaria, porque esta se centra en brindar al estudiante todo lo que necesita durante el tiempo que se dirige a la universidad, así como durante sus días libres o sus horas de ocio.

La residencia universitaria brinda, asimismo, un aporte a la zona donde se emplaza. Los estudiantes se encuentran en un ambiente acorde a sus necesidades, la comunidad gana densidad de población y también se da un aumento en la economía local.

De acuerdo a información obtenida de encuestas a estudiantes y comunidades, se utilizan cuatro puntos importantes que suplen los deseos de los estudiantes:

- Determinar locación: Los estudiantes escogen la proximidad a sus centros de estudio y a las tiendas como principales factores al momento de elegir una residencia. Los estudiantes también buscan un lugar seguro, y con la propuesta de una residencia universitaria, se propone un aumento de flujo de personas al integrar el proyecto a la zona, lo que aumente la seguridad en la residencia y alrededores.

- Como usar e implementar el contexto existente: Cuando la locación para la residencia universitaria es escogida, es importante reconocer cómo el proyecto influye positivamente en los alrededores, permitiendo desarrollarse nuevas mejoras e implementaciones en estructuras o espacios públicos que potencien el lugar a largo plazo.

El aumento de flujo de personas gracias a la residencia universitaria, brinda potencial a zonas del contexto tales como parques y lugares de comercio, reactivando de una manera más positiva y ordenada el lugar.

- Diseño para una vida pública: Para que una residencia universitaria sea aceptada por la comunidad, debe tener un diseño integrador, que permita al público recorrer la residencia (cierta permeabilidad), convirtiéndose en parte en un espacio público para su uso. La permeabilidad en el diseño de la residencia contribuye a la revitalización de la zona, mediante movimiento, conexiones visuales y encuentros sociales.

La residencia universitaria incentivaría además a los negocios locales a posicionarse cerca de la zona debido al incremento del flujo de personas que se producirá al realizarse el proyecto, lo cual repotenciará el área.

- Diseño funcional de la residencia: Este es un punto importante ya que la residencia debe recoger las preferencias de sus estudiantes en cuanto a 
infraestructura, de forma tal que resulte un lugar cómodo para alojarse y que cuente con todos los servicios necesarios.

\subsection{Público objetivo}

El proyecto está dirigido en su mayoría a estudiantes de provincias y extranjeros que vienen a Lima a cursar sus estudios en la Universidad Nacional Mayor de San Marcos y en la Pontificia Universidad Católica del Perú, así como a aquellos que si bien residen en Lima lo hacen en zonas alejadas a los campus reseñados. En este sentido sólo estará dirigido a este grupo de estudiantes, puesto que lo que se pretende es que sean las universidades a las que pertenecen las que financien la residencia universitaria ya que son las que se verían beneficiadas a largo plazo al cubrir dicha carencia de alojamiento, que les permitiría contar con un mayor número de estudiantes.

La demanda y la cantidad de estudiantes de estas universidades, es de 62618 alumnos, siendo alrededor de 1600 alumnos los que vienen de provincia y del extranjero.

\subsubsection{Preferencias Público objetivo}

Tomando como referencia encuestas realizadas en otras residencias universitarias de Estados Unidos y Europa, se llegaron a importantes conclusiones respecto a cuáles son las preferencias más comunes entre sus estudiantes al momento de decidir alojarse en alguna de ellas, encontrándose que en general los resultados son muy similares. Para efectos del presente estudio, tomaremos en consideración aquellas que por sus características resultan aplicables en Lima.

Así la preferencia más importante en todas es aquella relacionada con el costo del alojamiento. Las residencias universitarias existentes en Lima están caracterizadas por ofrecer estadía becando a estudiantes con alto rendimiento y de bajos recursos. Entonces es importante poner un bajo costo al servicio que se va a ofrecer para que no diste mucho de lo que se ofrece en la actualidad.

Los estilos de vida universitaria atraviesan todos los grupos sociales, de ahí la importancia de revisar la data de cuatro universidades -aun cuando dos de ellas no forman parte del tema central de la presente investigación- que albergan un continuum 
social $^{15}$ a nivel socioeconómico (Arellano, 2010): la Universidad del Pacífico (UP), la Pontificia Universidad Católica del Perú (PUCP), la Universidad San Martín de Porres (USMP) y la Universidad Nacional Mayor de San Marcos (UNMSM). La UP alberga principalmente estudiantes de nivel socioeconómico A1 y B1, la PUCP alberga principalmente estudiantes del nivel socioeconómico $\mathrm{B}$ y $\mathrm{C}$, la USMP alberga principalmente estudiantes del nivel socioeconómico B2 hasta D1, y la UNMSM alberga a estudiantes del nivel socioeconómico C a D2. (Matthew, Kogan, Sánchez, y Villa, 2014, p. 7)

Esto nos ayuda a conocer a que público de estudiantes se encuentra orientada cada universidad de acuerdo al nivel socioeconómico al que pertenecen sus estudiantes, lo que ayudará a determinar el costo de alquiler que debería utilizar la residencia universitaria.

En segundo lugar, otro aspecto que toman muy en cuenta los estudiantes es que la residencia universitaria se encuentre relativamente cerca de las universidades donde estudian. Es por esto que se escogieron dos universidades, entre las cuales existe una corta distancia.

Normalmente los estudiantes que vienen de provincia y del extranjero no poseen un transporte particular motorizado, por lo que mayormente se desplazan caminando o en transporte público. Es por esto que la residencia universitaria no debería estar a más de 20 minutos a pie de las universidades cercanas. De esta forma se minimizan los costos de viaje y los estudiantes ahorran más dinero el cual lo pueden utilizar en otros servicios.

Otro punto que se puede ver ha cambiado mucho en la actualidad es la privacidad. Los estudiantes ya no quieren compartir los servicios básicos (baño y cocina), e incluso buscan que su habitación cuente con un ingreso independiente (lo cual es ostentoso y elevaría el costo). La cantidad de estudiantes por habitación aceptado por los estudiantes según las encuestas analizadas es de 3 personas como máximo, ya que cuando comienza a aumentar este número los estudiantes empiezan a mostrar disconformidad.

Una característica muy pedida es que la habitación donde se aloja el estudiante tenga el espacio suficiente, ya que muchos se quejan de no tener lugar para poner todas sus pertenencias, lo cual hace que se sientan incómodos. Referido a esto, algunos

15 "La teoría del "continuum social o continuo social" intenta demostrar la realidad de que los seres humanos pertenecemos a la lógica global de lo social” (Rucrespo, 2012). 
estudiantes sugirieron que las habitaciones posean una altura mayor a la normal, de esta manera ellos pueden utilizar el espacio vertical para almacenar cosas y aprovecharlo al máximo.

A pesar de que es una estadía temporal, los estudiantes tratan de tener un estilo personal, modificando sus habitaciones de manera que se sientan cómodos en el lugar donde se encuentran hospedados y poder darle una identidad muy similar a la de su hogar.

Algo que influye mucho al momento de decidirse por una residencia universitaria, es que esta no posea un carácter institucional, esto quiere decir que la residencia no debe albergar características propias de una universidad, como por ejemplo pasillos largos de habitaciones (similar a la de los salones de clase en las universidades).

Los estudiantes pasan muchas horas al día en su centro de estudios y lo que no quieren es llegar al lugar donde se encuentra alojados y sentirse de la misma manera como si estuvieran de vuelta en la universidad. La residencia debe mantener un carácter propio y de descanso, completamente distinto al de una universidad. Además, debe haber una pertenencia del lugar donde se reside, para que se pueda apreciar una identificación de la residencia en la zona.

\section{CO-LIVING}

El término co-living hace referencia a soluciones innovadoras que permiten desarrollar proyectos donde los espacios y servicios compartidos se encuentran unidos y relacionados a las áreas privadas (dormitorios) para generar una experiencia más integradora.

Hampton (2016), al referirse al co-living como método innovativo precisa:

La tendencia hacia servicios académicos compartidos y áreas comunes se alinea bien con las expectativas anticipadas de futuros estudiantes. Hemos estado observando una serie de rasgos que afectan la forma en que pensamos sobre el diseño.

--Comunidad: los estudiantes buscan recopilar experiencias, no cosas. Como tal, los servicios compartidos que benefician al grupo más grande y ofrecen una mayor variedad son más atractivos que una oferta más pequeña dedicada al individuo. 
- Conexión: los estudiantes son altamente sociales y están orientados a grupos. Ya sea dentro o fuera de línea, los estudiantes priorizan el trabajo grupal y forman una comunidad muy unida.

- Adaptabilidad: los estudiantes quieren flexibilidad y elección en sus vidas diarias. Cuanto más se puedan adaptar los espacios y permitir múltiples funciones, más probabilidades habrá de que se utilicen de manera uniforme.

Este concepto ofrece una mejora en los servicios actuales brindados en lo que es hospedaje temporal. Los estudiantes quieren un espacio para colaborar, aprender, jugar y conocer gente, espacios que van a mejorar la vida social, los cuales apoyen y mejoren el crecimiento personal y académico. (Hampton, 2016)

Las habitaciones se encuentran configuradas alrededor de cocinas, espacios compartidos como salas de estar, centros de juego y áreas de estudio, las cuales promueven la colaboración e interacción entre los estudiantes.

En un proyecto de Gensler, en la Universidad de Biola, estos espacios compartidos fueron configurados y diseñados no solo para socializar, sino como método de aprendizaje colectivo, los cuales son importantes para propósitos académicos. (Hampton, 2016)

\subsection{Usuario}

Para efectos del presente estudio al 2017 la PUCP cuenta con 21,933 estudiantes de pregrado mientras que la UNMSM con 32,458.

Estas dos universidades cuentan con una gran variedad de carreras, así como con un destacado plantel de docentes y además con personal administrativo y de servicios. En este contexto, podemos señalar que 4 serían los tipos de usuarios de las residencias: alumnos de pre grado, post grado, personal docente y personal administrativo. Sin embargo, si bien es cierto este público podría aplicarse para la residencia, es mejor segmentar los tipos de usuario objetivos.

\subsubsection{Estudiante universitario}

Respecto a los estudiantes nacionales, el tipo de usuario predominante que albergará la residencia será el estudiante de provincia, debido a la cada vez mayor demanda de 
estas personas que vienen de lugares alejados para estudiar y que no tienen donde hospedarse, por lo que buscan un lugar donde vivir.

Entre las Universidades del Consorcio ${ }^{16}$, la PUCP ocupa el segundo lugar de preferencia por los alumnos que proceden de provincias y en primer lugar la Universidad Peruana Cayetano Heredia, probablemente por el reconocimiento que tiene la Facultad de Medicina. Ellos provienen de distintos departamentos del Perú siendo en gran cantidad los alumnos de Junín, Ancash, Ica, Cuzco, Lambayeque y Cajamarca; pero también hay alumnos de Ucayali, Tacna, San Martín, Puno, Loreto, Pasco, Huánuco, Apurímac, Amazonas y Moquegua. Entre las carreras elegidas por los estudiantes de provincia están: Arquitectura, Derecho, Letras y Ciencias Humanas, Educación, arte, entre otras. (PUCP, puntoedu)

En el caso de estudiantes extranjeros, estos llegan por iniciativa propia o, en mayor cantidad debido a convenios que tienen las universidades con instituciones del exterior. Así, por ejemplo, la PUCP en el año 2015 recibió a 464, en el 2016 a 423 y en el 2017 a 369 estudiantes del extranjero. (Dirección Académica de Relaciones Institucionales, 2017)

\subsubsection{Empresas del Coworking}

Las empresas de Coworking son otro usuario objetivo, ya que serán las operarias de esta parte del proyecto. No son el usuario predominante pero también generan aportes e ingresos a la residencia.

\subsubsection{Locatarios patio de comidas}

El patio de comidas al ser una parte importante de la parte comercial del proyecto, necesita locatarios para todas las islas a desarrollarse, quienes serán los encargados de operar esta zona de la residencia.

3.6.4. Locatarios de otros locales comerciales

\footnotetext{
16 Conformado por Pontificia Universidad Católica del Perú, Universidad de Lima, Universidad Cayetano Heredia y Universidad del Pacífico. Su objetivo principal es unir los esfuerzos institucionales individuales, de forma que la actuación conjunta de las cuatro universidades aporte en el desarrollo integral del país.
} 
3.6.5. La comunidad y los universitarios interesados en locales comerciales

Este público es el que mantiene la zona pública activa, utilizando los locales comerciales y los espacios públicos del proyecto, por lo que su presencia es importante en el día a día. Comprende a los estudiantes de las universidades cercanas, quienes pueden aproximarse al proyecto en sus horas libres, y a la comunidad en general que puede utilizar la zona comercial para su necesidad.

\subsubsection{Trabajadores}

Si bien este usuario objetivo no genera ingresos, son parte de la totalidad de la residencia, quienes permiten que todo esto funcione y por lo tanto son indispensables en este proyecto.

\subsection{Tendencia del modelo}

Las residencias universitarias han sido diseñadas de manera tal que posean un espacio en común que reúna a todas las personas hospedadas, ya sea un comedor, un espacio público, hasta una biblioteca, como se puede apreciar en la Tietgen Dormitory con la plaza que posee al interior, el comedor que presenta el Pabellón Suizo de Le Corbusier y la Baker House de Alvar Aalto, y analizando los casos nacionales, la biblioteca central de la UNI que se encuentra frente a la residencia de estudiantes y el comedor que se ubica cerca de la residencia de la UNMSM.

Se aprecia que a pesar de que los estudiantes manifestaron que prefieren no tener largos corredores en la residencia que desemboquen en habitaciones porque les hace recordar a los mismos pabellones de su universidad, las residencias universitarias poseen estos, pero a diferencia de lo mencionado anteriormente, en cada nivel poseen áreas comunes las cuales organizan la planta y dan una mayor calidad al espacio, al no volverlo tan monótono.

En el caso de las residencias universitarias que se encuentran emplazadas en terrenos con áreas públicas alrededor, se busca una configuración horizontal, de tal 
manera que no se perciba de manera vertical, y que no se pierdan las proporciones del edificio y de la zona.

Una tendencia más actual es a la construcción de complejos arquitectónicos conformados por edificios de residencias universitarias cuyo objeto es aprovechar el espacio vertical para poder dar albergue a un mayor número de estudiantes, tal es el caso del complejo de la Universidad de los Andes en Bogotá Colombia, que comprende 3 torres con capacidad para dar cabida a 1700 estudiantes y que fueron inauguradas en el 2017. (Newsletter Semana, 2017)

Asimismo, en la actualidad el diseño de las residencias universitarias pone énfasis en las áreas comunes, las mismas que incluyen salas de trabajo y estudio, terrazas, gimnasio y en algunos casos como en el de la Residencia Claudio Coello en Madrid, España, piscina.

Cabe precisar, además, que se evidencia un creciente número de residencias universitarias mixtas, a diferencia de la concepción un tanto tradicional en donde se construían por separado las de varones y mujeres, como es el caso en nuestro país de la residencia de la Universidad Peruana La Unión.

La organización de las residencias normalmente se le da a un grupo de estudiantes alojados, a los cuales se les brinda beneficios para que se encarguen de la administración de la zona. No todas las residencias colocan personal, sino que las tareas son encargadas a los diferentes estudiantes los cuales se organizan por su propia cuenta.

\subsection{Reglamentos de convivencia}

Es usual que en las residencias universitarias rija un reglamento en el cual se contemplen las normas a seguir por los estudiantes que las habitan, tal como se establece en el Reglamento General de Residencias Universitarias de Puerto Rico(z) en donde se precisa que su objetivo es "establecer normas y disposiciones reglamentarias en el sistema de Residencias Universitarias Estudiantiles, de modo que se promueva y se fortifique la convivencia social saludable entre los residentes, y a la vez proveer los procedimientos que se seguirán en caso de violaciones al mismo".

Las regulaciones contenidas en los textos de estos Reglamentos versan sobre temas comunes tales como los derechos y deberes de los estudiantes, las normas de admision, orden institucional, medidas de seguridad, régimen disciplinario, el costo de los servicios, el tiempo máximo de permanencia, entre otros aspectos. 
Encontramos, además, que la tendencia en los Reglamentos revisados es que la asignación de habitaciones se encuentra a cargo de una persona designada para tales efectos, y que la misma se hará en función a características especiales de los estudiantes.

Tal es el caso específico del Reglamento de las Residencias Universitarias de Puerto Rico antes reseñado en donde se puede apreciar la distribución de sus alumnos en grupos, en base a determinados criterios. (Decanato de estudiantes, 2002)

Así, encontramos:

- Estudiantes especiales

- Estudiantes de intercambio

- Estudiantes sub graduados (por años)

- Estudiantes graduados

- Estudiantes transitorios

Al respecto consideramos que el uso de diversos criterios de agrupación tiene tanto aspectos positivos como negativos. Por ejemplo, agrupar a los estudiantes que tienen alguna discapacidad o problema físico podría resultar conveniente pues facilitaría la realización de ajustes razonables en el área designada para ellos.

Sin embargo, el hecho de que separen a los estudiantes de intercambio no parece una buena solución. Tomando como referencia otras ciudades de Lima en cuanto a hospedaje (hoteles o backpackers en ciudades turísticas), lo que se hace es compartir habitaciones entre personas de distintos países (extranjeros con nacionales), lo cual genera reacciones favorables para todos. Las personas de la habitación comienzan a desarrollar nexos sociales y se sienten a gusto conociendo otras culturas. De esta manera se podría integrar áreas comunes para que todos los estudiantes de la residencia se mantengan en contacto en un punto en común del establecimiento.

En el caso de los estudiantes de pregrado el hecho que estos se encuentren agrupados por años puede resultar en algo positivo. De esta manera tienen temas académicos en común de los cuales pueden hablar e intercambiar ideas, a diferencia de un grupo de alumnos de distintos años, por lo que también es importante agruparlos de acuerdo a la rama de carrera que tengan en común.

Los estudiantes que se encuentran graduados pueden ir en una agrupación aparte, ya que normalmente tienen otros intereses académicos destinados por ejemplo a las maestrías o trabajo. 
Los estudiantes transitorios al quedarse hospedados incluso menor tiempo que un estudiante normal (la residencia universitaria se caracteriza por brindar un hospedaje temporal), deberían estar en otro grupo de distribución ya que pasarán menos tiempo en la residencia y su vínculo con el resto de estudiantes y participación en la sociedad será menor. Esto no quiere decir que no mantendrán nexos con los otros estudiantes durante su estadía cuando pasen por las salas comunes.

\subsection{Modelo de residencia universitaria}

Luego de tener en claro las preferencias de los estudiantes, podemos arribar a las conclusiones respecto al contenido del programa de la residencia universitaria. La educación debe estar ligada al quehacer social y a la actividad humana.

Según Gómez Pérez, A. (2006), actualmente se evidencia la necesidad de desarrollar una propuesta que aúna la capacitación profesional con un aprendizaje para la vida y la coexistencia con las demás personas. Es decir, se debe impulsar el crecimiento de habilidades que nos permitan vivir de manera óptima, vale decir, a través de la creación de ciudadanos involucrados y responsables.

Por lo tanto, el modelo de residencia que desarrollamos no intenta de forma exclusiva solucionar la dificultad de vivienda de los estudiantes, sino que busca además ser un modelo de convivencia social, basada en el desarrollo de los objetivos propuestos.

Consideramos que no podría ser de otra forma dada las características del ser humano, como ente social. La inserción de los estudiantes de la residencia universitaria en el medio en el que viven, de forma tal de lograr relaciones interpersonales satisfactorias, resulta necesaria a efectos de que puedan desarrollarse plenamente, no solo desde el punto de vista de sus estudios sino también respecto de los diversos aspectos sociales que implica su crecimiento como personas.

En segundo lugar, respecto a las relaciones hacia afuera, es decir entre los estudiantes y los habitantes de la zona, como señala Gómez Pérez (2006) ello puede ser una buena oportunidad para el aprendizaje de convivencia de los jóvenes estudiantes.

Por otro lado, los conocimientos aprehendidos por los jóvenes en la universidad, sus experiencias y valores pueden de una $u$ otra forma ser transmitidos a los habitantes de la zona en el manejo diario de las relaciones existentes entre ellos. 
En este contexto, la presencia de los estudiantes en la zona de estudio tiene una implicancia positiva en diversos aspectos, lo que puede contribuir a su progreso.

Es así que el hecho que el primer piso de la residencia universitaria proyectada cuente con tiendas comerciales con ingresos por ambos lados siendo accesibles desde el exterior y desde el interior de la residencia, permite su utilización no sólo por los estudiantes sino también por las personas vecinas y transeúntes de la calle, situación esta última que genera una mayor movilidad de personas por la zona. Asimismo, el contar con múltiples accesos y locales comerciales en los frentes, permite una mayor interacción entre el exterior y la plaza de la residencia.

Todo ello genera mayor seguridad en la zona ya que como señala Jacobs "Se requiere de equipamientos, buen diseño y demarcación de espacios para generar más movimiento y actividad en la calle y así inconscientemente aparecen "ojos mirando a la calle" supervisando y colabora en la seguridad de la ciudad" (1973).

\subsection{Servicios de la residencia universitaria}

Se procede a analizar en primer lugar el tema de la vida en la residencia universitaria y la necesidad de dinamizarla. En este sentido se deberán ofrecer servicios de limpieza de las zonas comunes, seguridad y vigilancia, y se debe albergar equipamiento y servicios comunes como: biblioteca, sala de informática, aulas de usos múltiples, salas de exposiciones, y salas multiusos.

Asimismo, se deberá ofrecer los servicios de: cafetería y comedor; lavandería y planchado.

La residencia universitaria debe contar con una zona de comercio, ya que esto además de atraer más estudiantes, permite ahorrarles tiempo y costo de viaje al tener que movilizarse a otras zonas a realizar distintos tipos de compra. El área de comercio es un punto importante de encuentro por parte de los estudiantes, donde se desarrollarán nexos sociales al pasar una buena cantidad de tiempo allí. Esto permitirá activar la zona urbana, ya que no solo es para los estudiantes sino para la gente del barrio. Además, la zona de comercio sirve de complemento para la residencia universitaria junto con los otros servicios mencionados que esta brinda.

Por otro lado, resulta también conveniente la instalación de un comedor para que los estudiantes puedan proveerse de la alimentación que necesitan. 
Es necesario, asimismo, la implementación de un taller de arquitectura para los estudiantes de esta carrera, ya que ellos destinan una gran cantidad de horas en sus proyectos, incluidas las madrugadas, por lo cual parece pertinente darles un espacio propio, de tal manera que no generarían incomodidad en el resto de estudiantes hospedados en la residencia.

Debe haber una cantidad considerable de áreas comunes a lo largo de toda la residencia para fomentar las relaciones sociales dentro de esta. Se debe buscar la implementación del "Street learning" ${ }^{17}$ mediante un buen diseño del espacio público en la residencia, de modo que este sirva de nexo entre todos los edificios de la residencia.

Estos servicios permiten brindar facilidades al alumno de tal manera que su permanencia en la residencia sea placentera y los hagan sentir cómodos con lo que están pagando y cómodos con el lugar donde se encuentran hospedados.

${ }^{17}$ Aprendizaje adquirido fuera del horario de clases, mientras se está en un espacio público. 


\section{CAPÍTULO IV: MARCO NORMATIVO}

Basándome en los parámetros urbanísticos del lote obtenidos en la Municipalidad distrital de Pueblo Libre:

- Edificación Residencial Densidad Alta (RDA)

- Usos permitidos: Multifamiliar / Conjunto Residencial

- Densidad Neta Máxima: Multifamiliar $\left(300 \mathrm{~m}^{2}\right) \quad-2250$ hab / Ha

Conjunto Residencial $\left(450 / 2500 \mathrm{~m}^{2}\right)-2250 \mathrm{hab} / \mathrm{Ha}$

- Retiros Municipales: $\quad$ En avenidas: 5 metros

En calles o jirones: 3 metros

Imagen 7. Terreno seleccionado con retiros. 


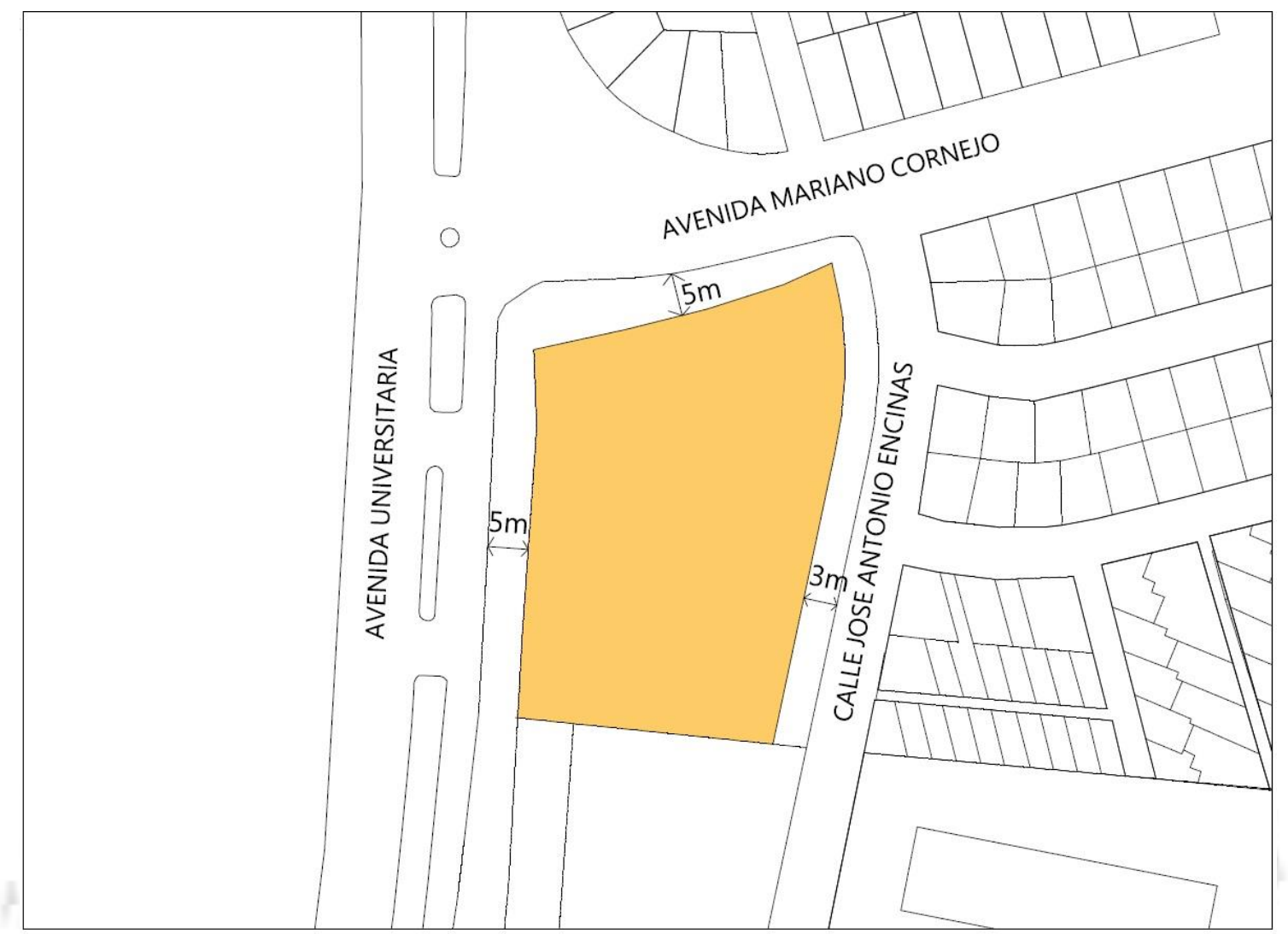

Fuente: Elaboración propia

- Altura de edificación (máxima): Multifamiliar $\left(300 m^{2}\right)$ - 8 pisos

Multifamiliar $\left(450 \mathrm{~m}^{2}\right)-1.5$ (ancho vía+retiros)

- Área libre (min) dependiendo del área del lote: 35\% multifamiliar $\left(300.00 \mathrm{~m}^{2}\right)$ $40 \%$ multifamiliar $\left(450.00 \mathrm{~m}^{2}\right)$

Imagen 8: Plano de zonificación 


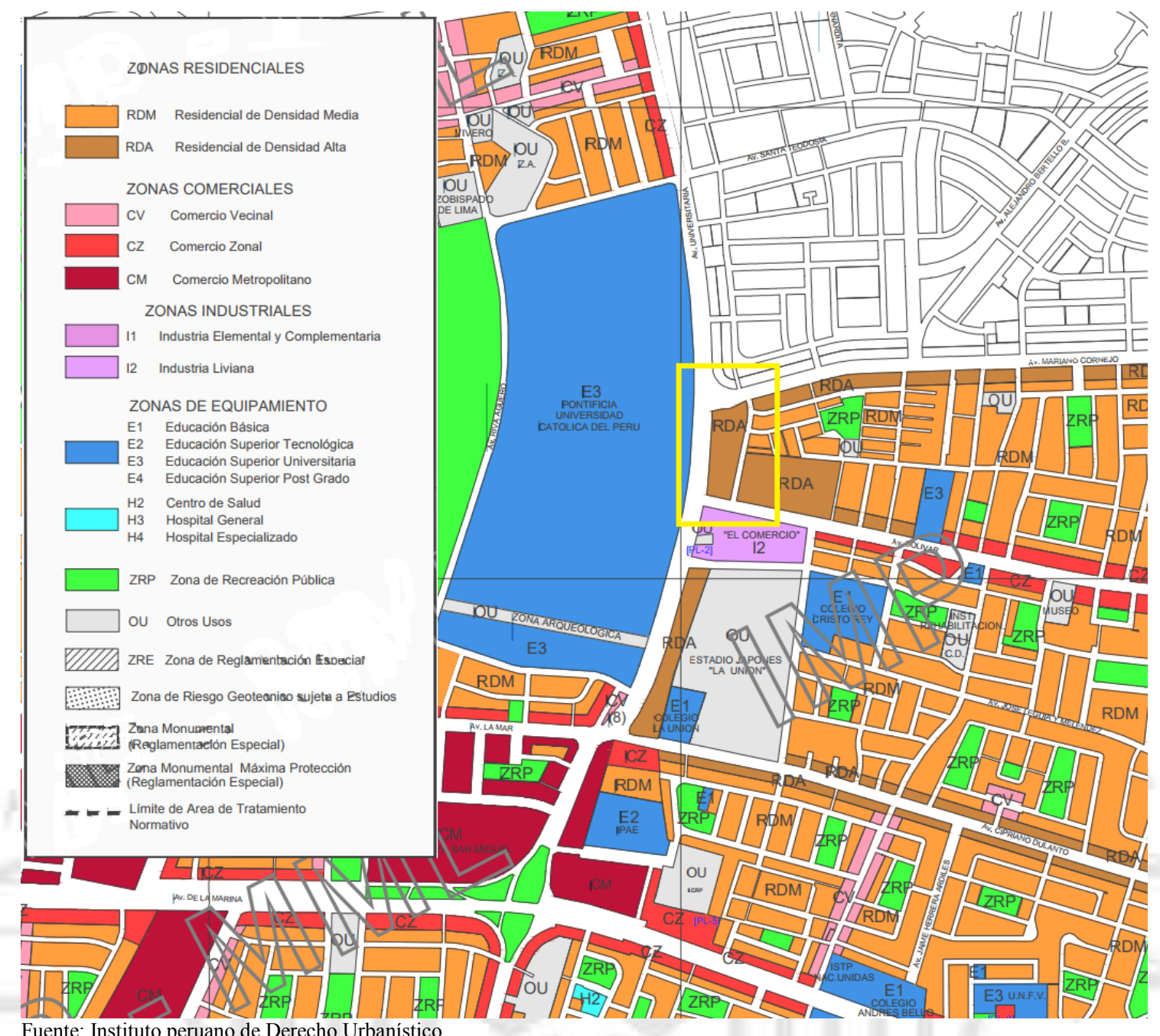

Fuente: Instituto peruano de Derecho Urbanístico

- Índice de espacios de estacionamientos: 1 cada 1.5 viviendas

- Artículo 3 Ordenanza N 360-MPL: Considerar para los lotes con frente a dos calles paralelas y cruzados por una "línea límite de zonas", cada zona afectará al terreno en áreas proporcionales a los fondos del lote normativo. Sólo cuando una de las dos zonificaciones sea comercial, y se utilice el $100 \%$ para uso residencial, a criterio de la Comisión Técnica podrá optarse por el uso residencial compatible en su totalidad, con los parámetros normativos establecidos en el Cuadro $\mathrm{N}^{\circ} 1$ - RESUMEN DE ZONIFICACIÓN RESIDENCIAL de la Ordenanza N 1076-MML. 


\section{$\rightarrow$ \\ PUUEMELPALIDADDERE \\ GERENCIA DE DESARROLLO URBANO Y DEL AMBIENTE \\ Subgerencia de Obras Privadas y Habilitaciones Urbanas \\ CERTIFICADO DE PARÁMETROS URBANÍSTICOS Y EDIFICATORIOS N`296-2016-MPL-GDUA/SGOPHU}

La Subgerencia de Licencias de Obra de conformidad con el Plano de Zonificación del distrito aprobado mediante Ordenanza N ${ }^{\circ}$ 1017-MML, certifica que el predio ubicado en:

\begin{tabular}{|c|c|c|c|c|}
\hline Via Púbtica & Numero & interior & Lote & Sub lote \\
\hline $\begin{array}{l}\text { AV. UNIVERSITARIA SUR ESQ. AV. MARIANO CORNEJO (EX } 28 \text { DE JULIO) / CA. } \\
\text { JOSE ANTONIO ENCINAS }\end{array}$ & & $\cdots . .$. & & -...... \\
\hline Urbanizacion & \multirow{2}{*}{\multicolumn{4}{|c|}{ Referenia }} \\
\hline FUNDO PANDO 8 VA. ETAPA & & & & \\
\hline
\end{tabular}

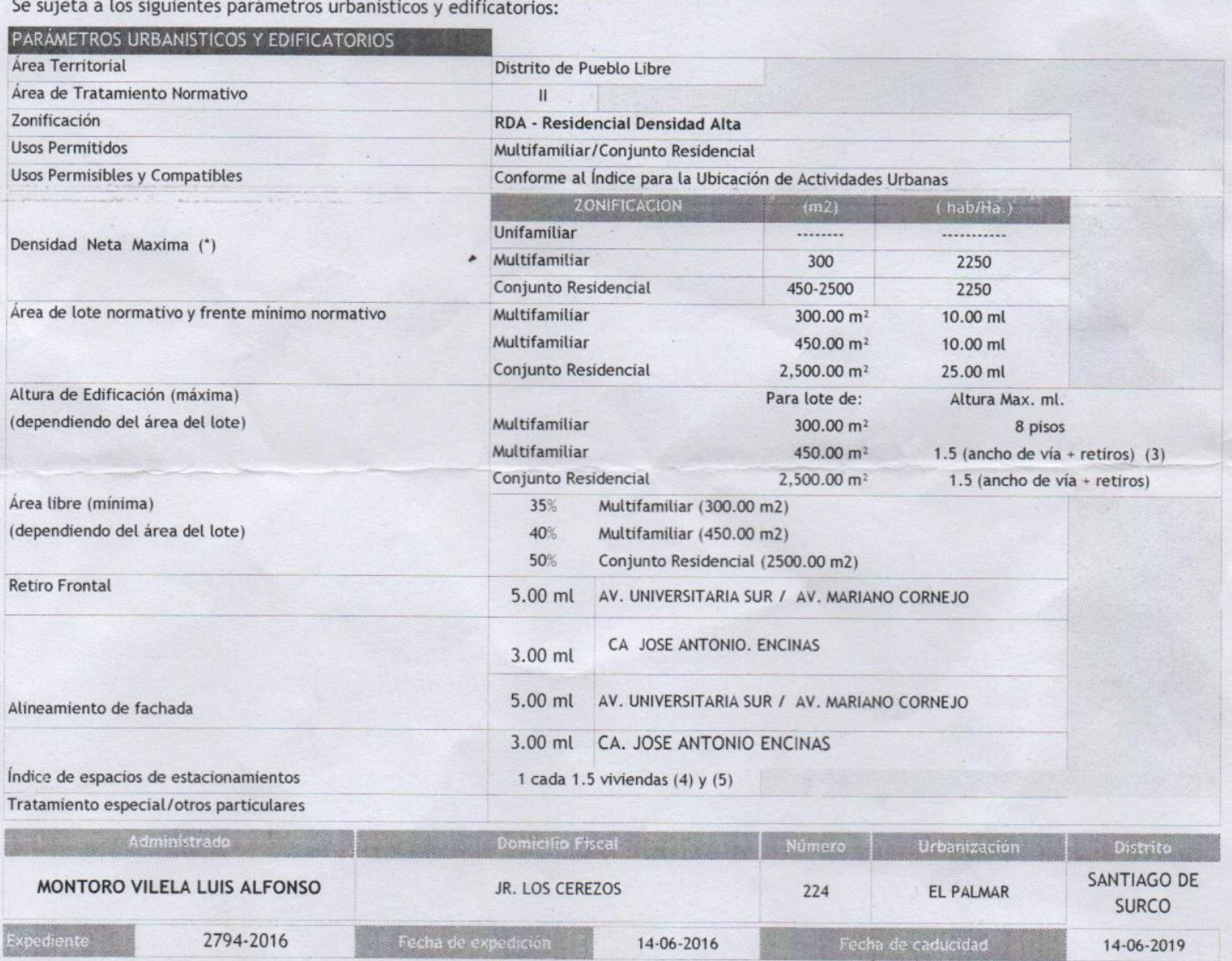

\section{REFERENCIAS:}

(3) Frente a Avenidas con ancho mayor de $20 \mathrm{ml}$. Frente a Parques.

(4) Incluye a los proyectos desarrollados bajo el Reglamento de Habilitación y Construcción Urbanallespecial - MI VIVIENDA (Art. 3 Ord. $\left.\mathrm{N}^{\circ} 337-\mathrm{MPL}^{\circ}\right)$

(5) Para Conjuntos Residenciales se aplicara lo dispuesto en la Ordenanza N'360-MPL. (11.06.11)

NOTAS:

a. Se considera un área mínima de $75 \mathrm{~m}^{2}$ para departamentos de 3 dormitorios, se podrán incluir departamentos de 2 y 1 dormitorio con áreas y en porcentajes a definir, se contará como dormitorio todo ambiente cuyas dimensiones permitan dicho uso.

b. En zonas residentes se podrá construir viviendas unifamiliar en cualquier lote superior a $90 \mathrm{~m} 2$.

c. Se permite el uso de Azotea sobre la altura maxima (Ver Ord(s) $\mathrm{N}^{-}-330$-MPL y $\mathrm{N}^{-}-347-\mathrm{MPL}^{-}$

d. Todos los proyectos que se acojan al Reglamento de Habilitacion y Construccion Urbana Especial-MI VIVIENDA, deberan cumplir lo dispuesto en los Decretos Supremos $N^{*}$ 053-98-PCM, N 030-2002-MTC, y N 013-2013-VIVIENDA, excepto el requerimiento de estacionamiento que se rige por lo establecido en la Ordenanza $\mathrm{N}^{*} 337-\mathrm{MPL}$

(") Ordenanza N*369-MPL

El presente certificado no constituye autorización para el inicio o ejecución de obras

Se expide el presente certificado a solicitud del administrado para los fines que estime pertinentes.

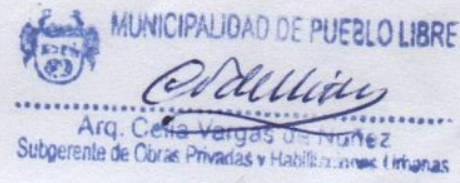




\section{CAPÍTULO V: MARCO OPERATIVO}

\subsection{Tietgen Dormitory}

Imagen 9. Tietgen Dormitory

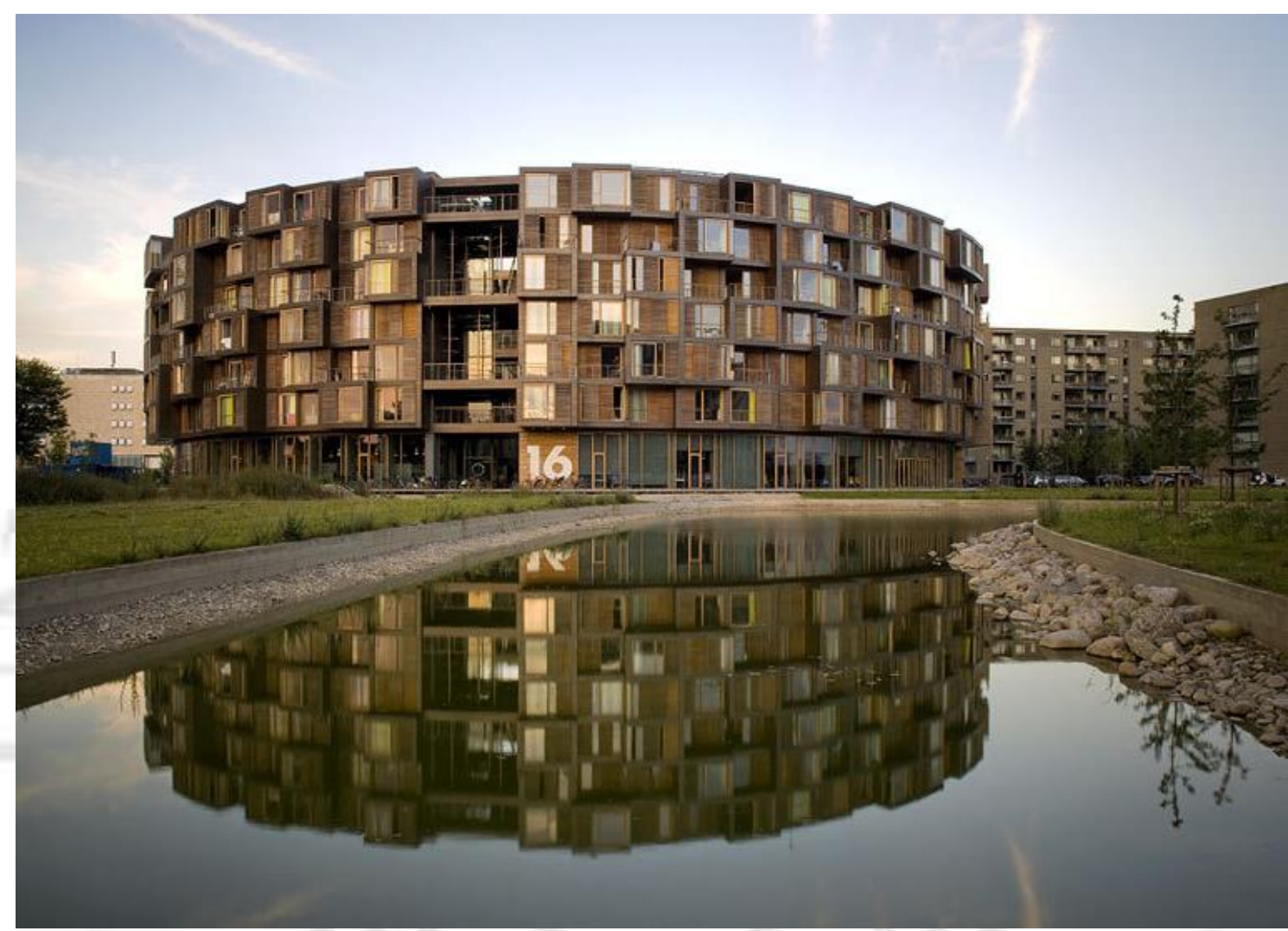

Nota: Vista de la residencia desde el exterior

Fuente: http://www.arcspace.com/features/lundgaard--tranberg-/tietgen-dormitory/

\subsubsection{Historia del edificio.}

El Tietgen Dormitory fue un proyecto diseñado por los arquitectos daneses Lundgaard and Lene Tranberg en el año 2006 sobre la base de una idea visionaria de lo que vendría a ser una residencia del futuro conformada por viviendas para 400 alumnos.

Se ejecutó gracias a una donación de la Fundación Nordea Dinamarca y está localizado en Rued Langgaards Vej 10, 2100, cerca de la Universidad de Copenhague, en Orestad Norte, Copenhague, Dinamarca. (Hites, Archdaily, 2014)

El edificio tiene forma circular y, además está compuesto por pequeños bloques (habitaciones), vidrios y estructura de acero. Fue diseñado tomando como referencia los 
edificios tradicionales en forma de círculo Tulou o también llamados "edificios de tierra", de la provincia sudoriental de Fujian en China.

La forma circular del Tietgen Dormitory hace que se integre perfectamente con el contexto urbano y, a su vez, con los elementos individuales representados por las residencias de los estudiantes, logrando así una dinámica y un balance destacables que lo hacen muy funcional. Esta forma permite integrar tanto el diseño individual como el colectivo, al generar un espacio público central el cual es una de las vistas de los espacios comunes del edificio que se encuentran ubicados alrededor de toda esta plaza.

Hay un balance entre los espacios privados y todas las facilidades de áreas comunes que un estudiante necesita. El "Street learning" es aplicado aquí ya que al ser un espacio cerrado de encuentro entre estudiantes y al tener los servicios comunes como salas de estudio, se fomenta el aprendizaje en la plaza.

Es una nueva propuesta de arquitectura en el lugar donde la forma rompe con el contexto lineal, emplazándose entre dos canales y rodeado de área libre, por lo que el cambio de forma en el lugar, no afecta la visual del proyecto.

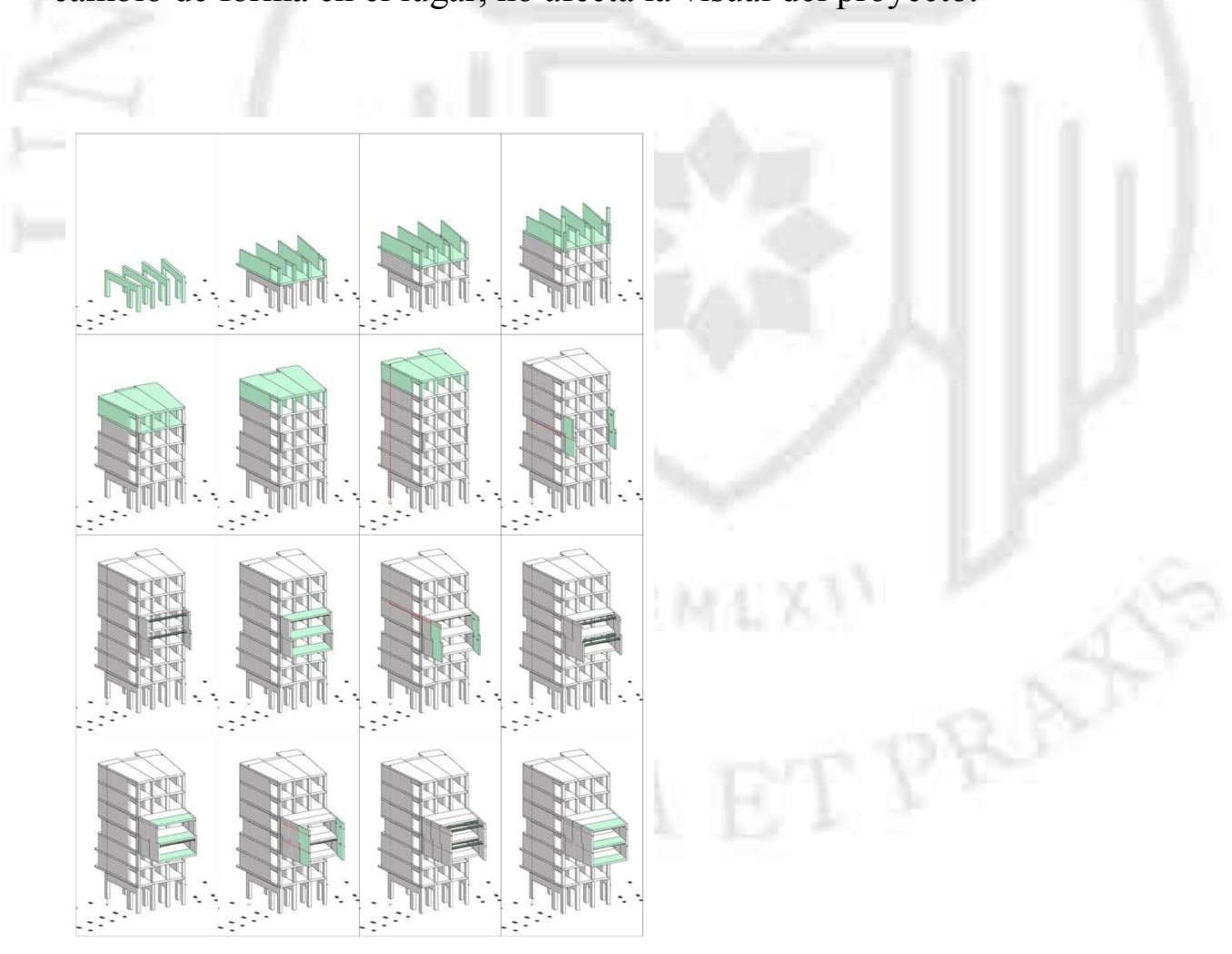

Imagen 10. Etapas de construcción del proyecto

Fuente: (Hites, 2014) 


\subsubsection{Relación con el entorno}

Imagen 11. Contexto macro

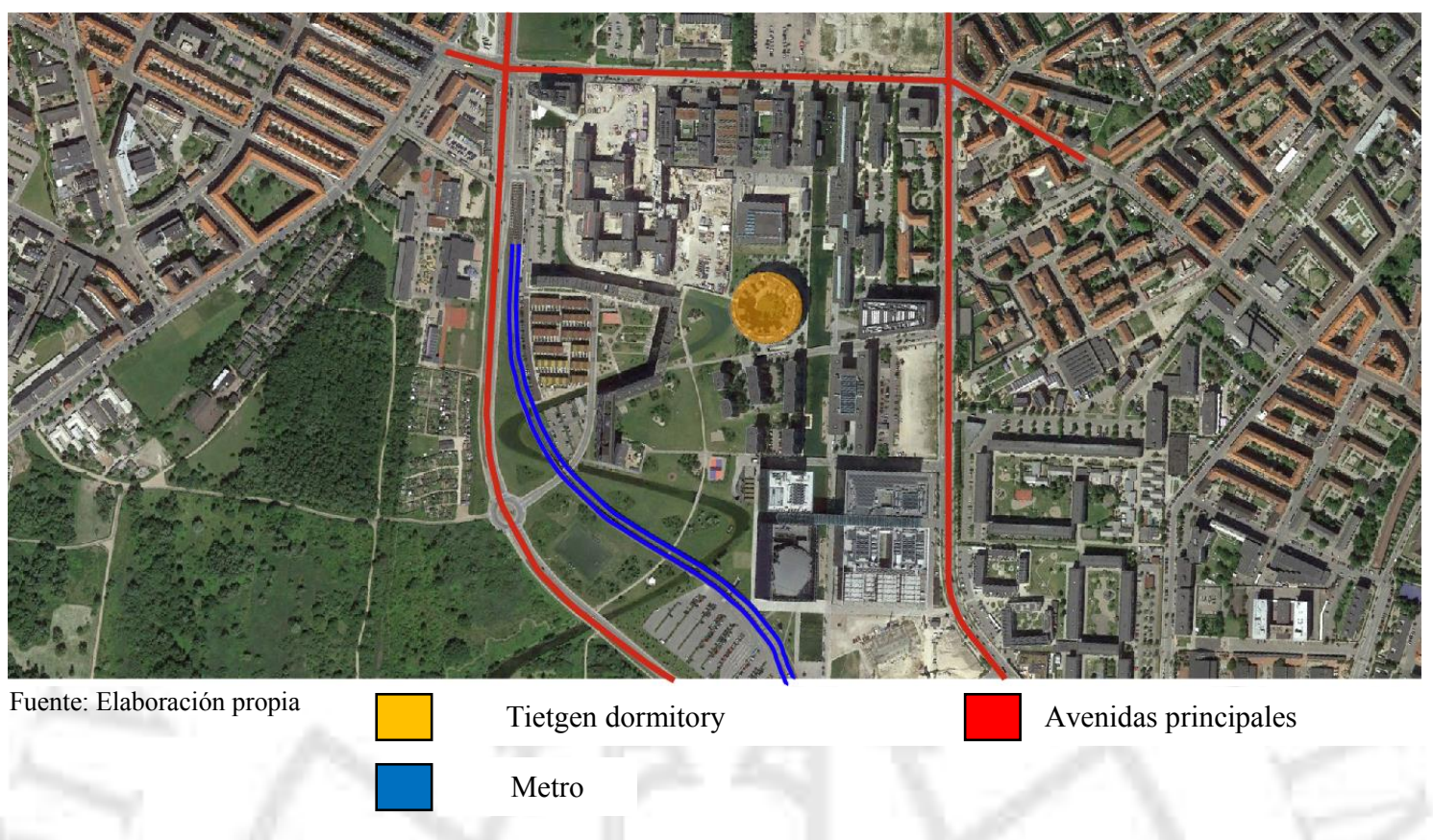

El sitio en donde se ejecutó el proyecto es un barrio creciente y muy bien planificado, que cuenta con varios canales y edificaciones sólidas y consistentes. Está situado cerca de la famosa isla recreacional Brygge y de importantes edificaciones como la National Danish Broadcasting Corporation, la Universidad de Copenhage, así como también el metro.

La forma de las habitaciones, en donde se desfasa cada residencia individual, hace que la forma cilíndrica pierda fuerza desde afuera, otorgándole a la fachada una identidad propia y fuera de lo común. El edificio combina la forma de cajas de las habitaciones con la forma circular de toda la residencia.

El edificio se organiza en torno a un gran patio central, de forma circular. Las habitaciones en todos los niveles se encuentran ubicadas en todo el perímetro exterior del edificio, conectadas por la circulación, con las áreas comunes al frente de cada bloque, orientadas hacia el patio interior. Todas las habitaciones tienen variaciones de tamaño y profundidades a lo largo de la planta, de manera tal que se genera una armonía en las fachadas y da la sensación de movimiento. Al mostrarse cada una de la forma de las habitaciones desde fuera y poder distinguir que son únicas, se logra perder la monumentalidad de la forma cilíndrica del edificio, lo que genera su neutralización con el entorno. 


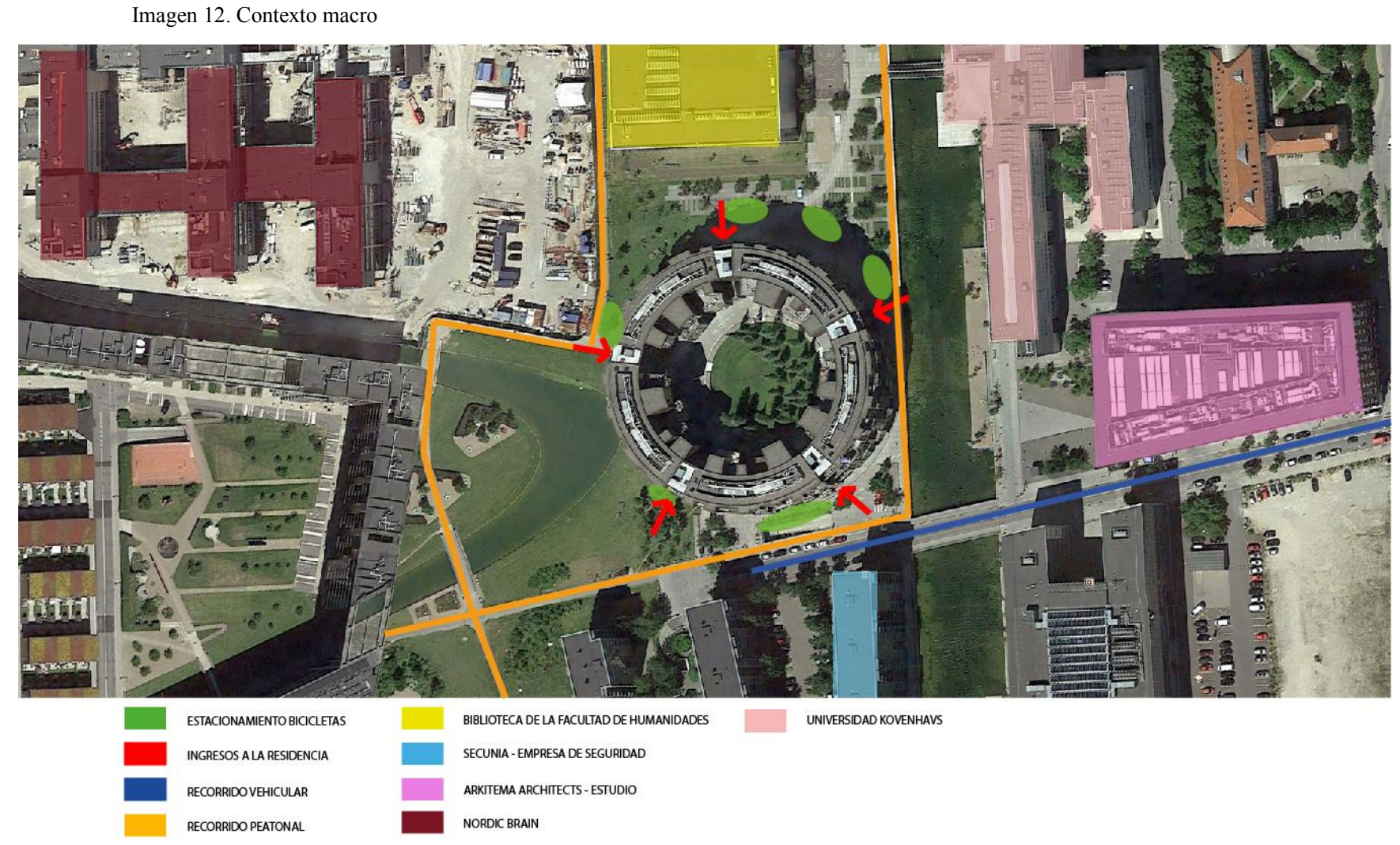

Fuente: Elaboración propia

En la planta baja, el ingreso al edificio se da por las 5 entradas divididas en los cinco bloques que posee el edificio, las cuales derivan al patio interior. En estos ingresos se ubican las circulaciones verticales del edificio, las cuales te llevan a los 6 niveles superiores. Cada bloque está compuesto por 12 residencias las cuales se organizan en torno a un área común y una cocina. Todos los servicios e instalaciones comunes se organizan en el primer nivel del edificio.

Los niveles superiores se organizan con 360 unidades habitacionales a lo largo del perímetro y las funciones comunes están orientadas hacia el patio interior. Los servicios comunes del edificio se agrupan a nivel del suelo, entre los cuales están una cafetería, un auditorio, una lavandería, salas de reuniones, salas de estudios, salas de computadoras, sala de música, auditorio y parqueo de bicicletas.

El edificio está compuesto por 7 niveles. Hay 5 lineas verticales que dividen el edificio tanto visual como funcionalmente en secciones y también sirven como pasajes continuos que proveen el acceso desde fuera hacia al patio central y otras áreas. Todos los departamentos tienen fachada y una visual de los alrededores. Las cocinas comunes, 
cuartos auxiliares, lounges, y las terrazas están ubicadas en el patio central, juntando de esta manera a todos los estudiantes.

El concepto se enfoca en cómo el ordenamiento puede ayudar a reforzar tanto el desarrollo personal como social en los estudiantes. El patio refuerza la idea de comunidad. También genera un cambio en los corredores, ya que, si normalmente son monótonos, estos se vuelven interesantes espacialmente y al ser un edificio circular se vuelven infinitos, uniendo todas las habitaciones de cada piso.

En total hay 360 habitaciones, 36 de las cuales (el 10\%) fueron diseñadas para alumnos de intercambio. La residencia es circular, con 7 pisos y habitaciones organizadas en bloques de 12. Cada habitación tiene su baño y hay 4 tamaños de cuartos:

\section{$-26 m 2$ \\ $-29 m 2$ \\ $-33 m 2$ \\ $-42 \mathrm{~m} 2$}

Cada bloque comparte una cocina y una sala de estar, la cual cuenta con mobiliario único en cada bloque.

\subsubsection{Programa y relaciones programáticas}

\subsubsection{Zonificación}

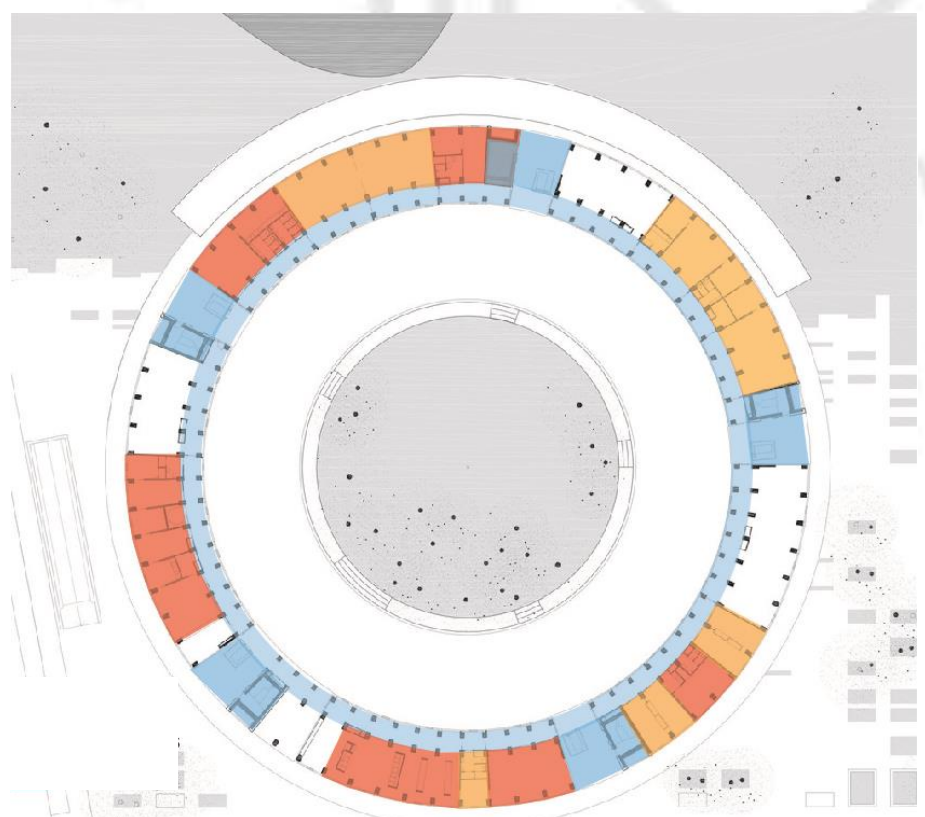

Imagen 13. Contexto macro

Fuente:https://www.archdaily.pe/pe/02334957/tietgen-dormitory-lundgaard-andtranberg-architects

Servicios comunes

Áreas comunes

Circulación 


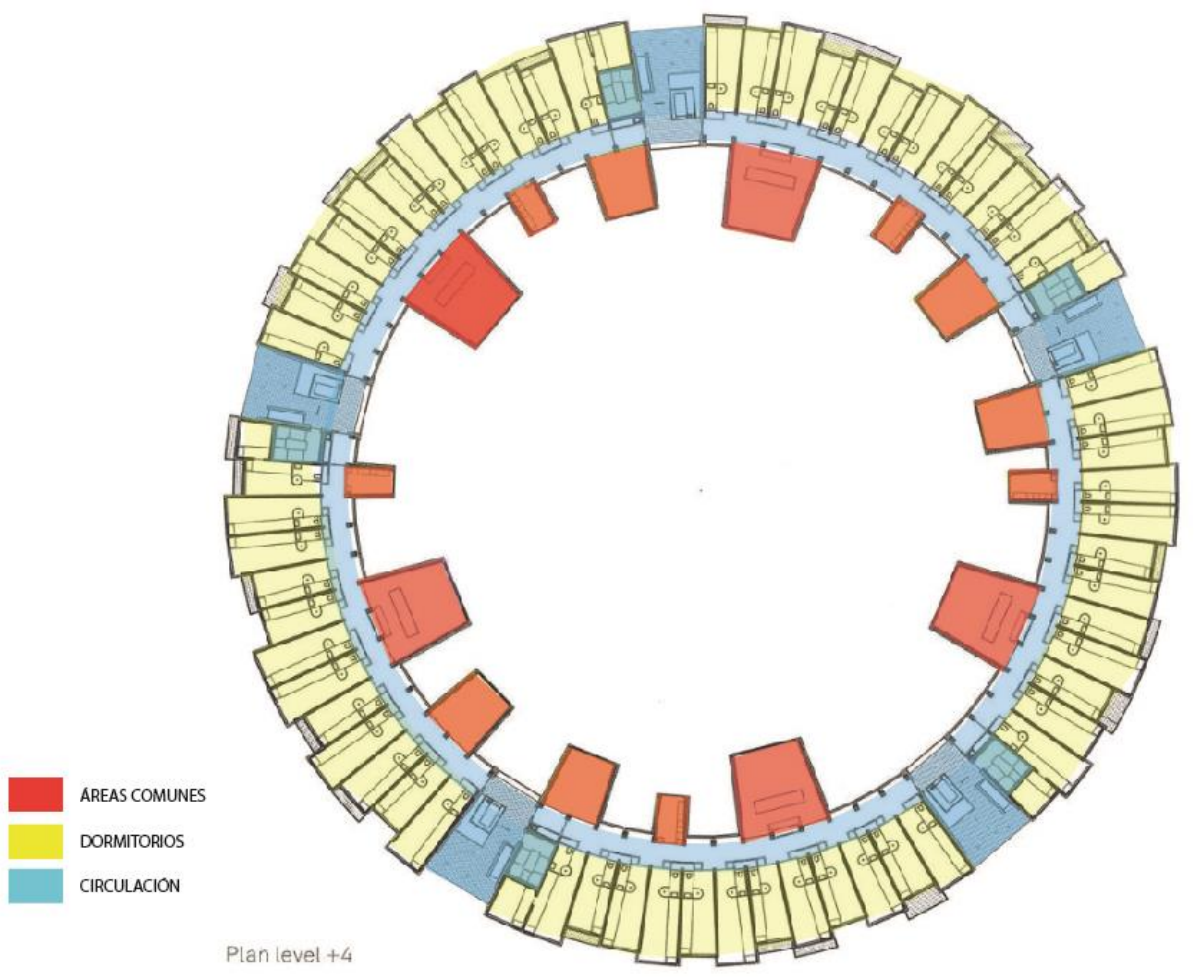

Fuente: https:/www.archdaily.pe/pe/02-334957/tietgen-dormitory-lundgaard-and-tranberg-architects

\subsubsection{Paquetes programáticos}

La residencia universitaria Tietgen Dormitory tiene una organización radial la cual se distribuye en función a una plaza central. Esta plaza abarca el 52.9\% del total del área del edificio. En el primer nivel, además, se ubica parte de las áreas comunes de la residencia. El resto de facilidades se encuentran a partir del segundo nivel.

Los dormitorios también ocupan un área importante del terreno con el 35.2\% del total. Están distribuidos de tal manera que todos tengan vista hacia el exterior, desfasados pudiendo ver la individualidad de cada alojamiento. La residencia está dividida en 5 bloques, esto genera espacio entre ellos y circulaciones verticales en 5 puntos, las cuales forman parte de la circulación total que abarca un $11.93 \%$ del área total. 
5.1.3.3. Cuadro de Áreas

6. Cuadro 13. Áreas

\begin{tabular}{|c|c|c|}
\hline Ambiente & Área aprox. & Aporte \\
\hline Dormitorios & $2531.73 \mathrm{~m}^{2}$ & $35.18 \%$ \\
\hline Áreas comunes (planta \\
típica, adicional al 100\%)
\end{tabular}

Fuente: Elaboración propia

\subsubsection{Organigrama}

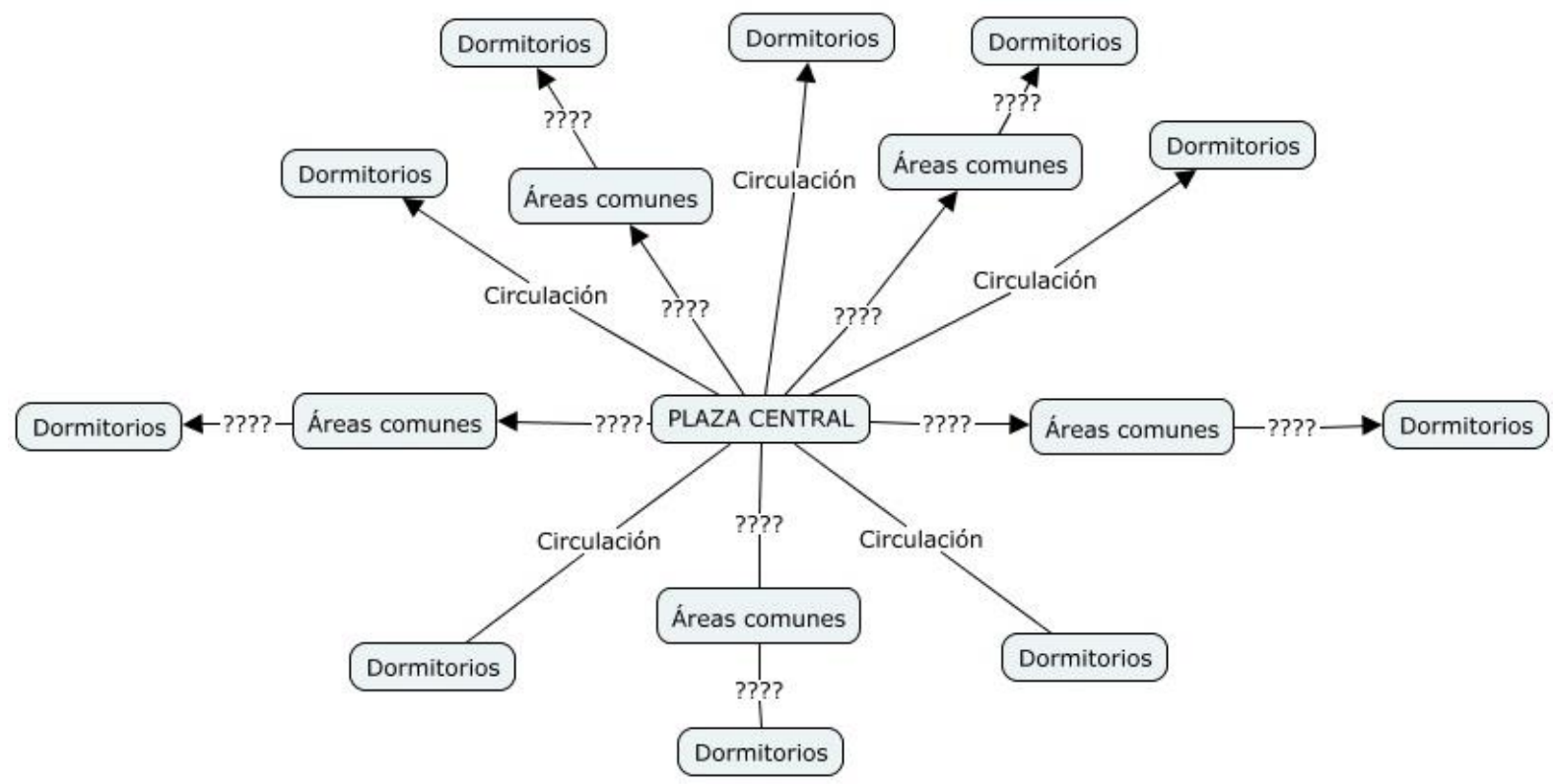




\subsubsection{Tipología}

Para analizar la tipología del edificio, nos basaremos en el libro "Arquitectura: Forma, espacio y orden”, escrito por D.K. Ching.

\subsubsection{Forma y espacio}

La residencia está organizada en torno a un patio el cual funciona como espacio de reunión para los estudiantes y la gente de la zona.

Imagen 16: Casa Patio

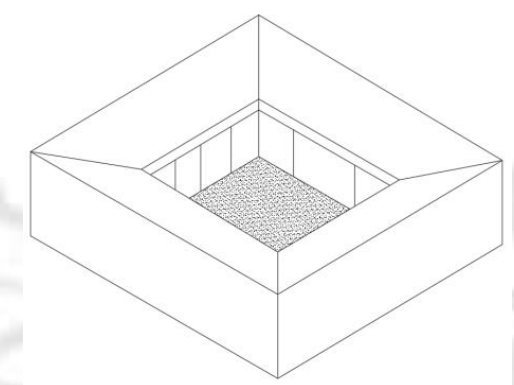

Fuente: Elaboración propia

\subsubsection{Organización centralizada}

La Tietgen Dormitory se caracteriza por tener módulos iguales en cada planta, pero distribuidos de distinta manera, lo que genera movimiento en sus fachadas. el centro se convierte en el espacio principal, y los servicios comunes frente a los dormitorios los espacios secundarios como parte de la configuración del edificio.

Imagen 17: esquema de organización
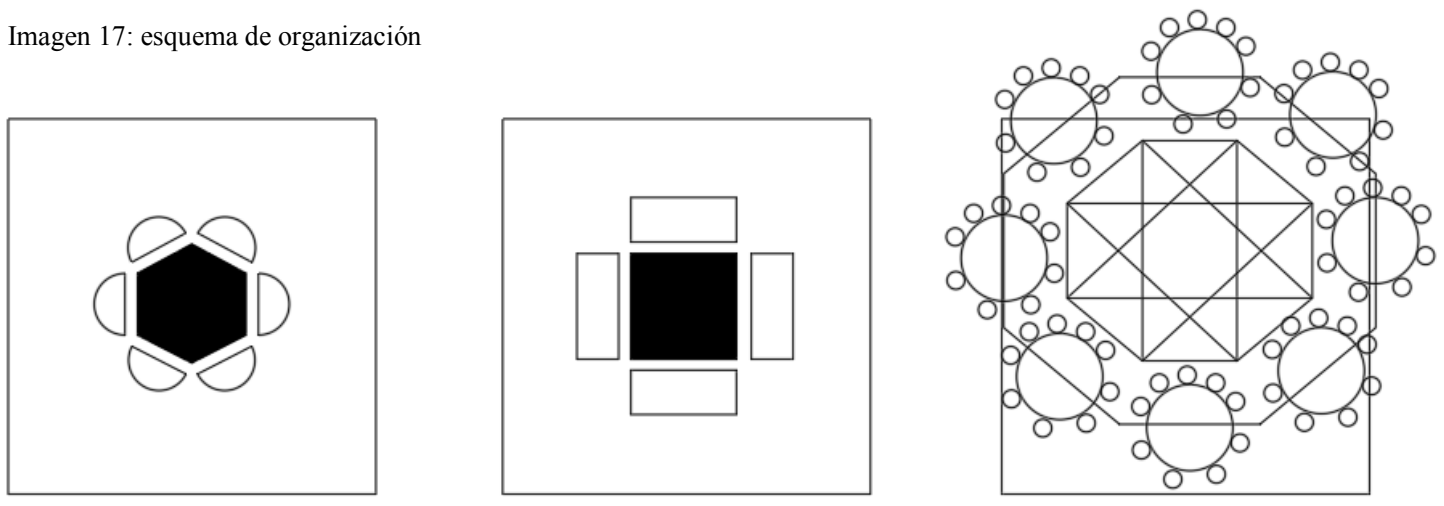

IGLESIA IDEAL, LEONARDO DA VINCI

Fuente: Digitalizada del libro “Arquitectuı.. . . v. . a, espacio y orden”, escrito por D.K. Ching. 


\subsubsection{Aproximación al edificio}

Frontal: El recorrido previo al ingreso del edificio comienza al terminar el recorrido vehicular, situándonos frente al edificio de manera directa. El edificio posee otros cuatro ingresos los cuales tienen en su contexto solamente recorrido peatonal, y que embocan desde distintas ubicaciones como por ejemplo el campus.

Imagen 18: Aproximación al edificio

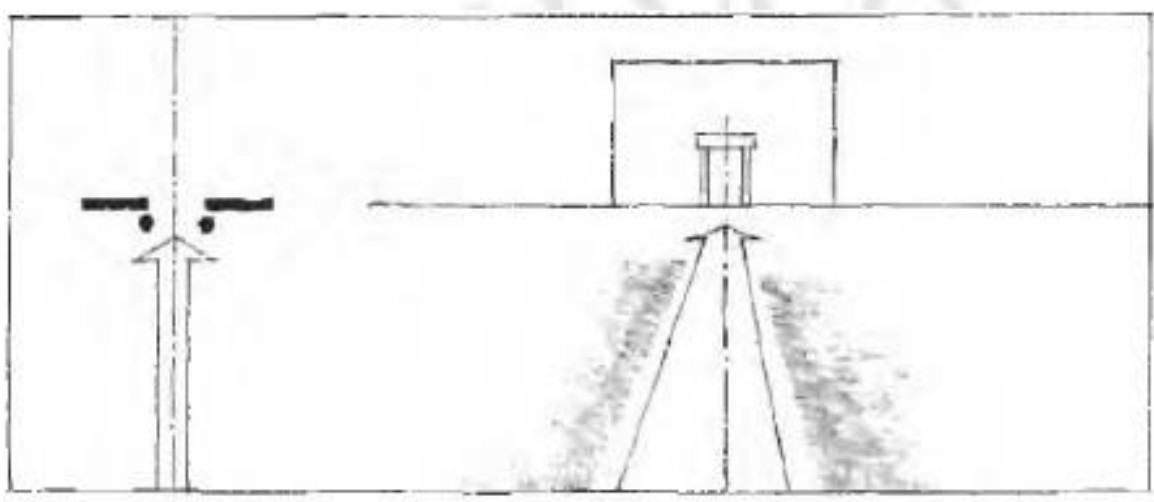

Fuente: Digitalizada del libro “Arquitectura: Forma, espacio y orden”, escrito por D.K. Ching.

\subsubsection{Configuración del recorrido}

Lineal: Tietgen Dormitory tiene claramente un recorrido circular. Este recorrido es el elemento organizador de los espacios, ya que al edificio ser simétrico, necesitaba un recorrido lineal el cual te lleva a todos los espacios sin ramificarse.

Imagen 19: Configuración del recorrido

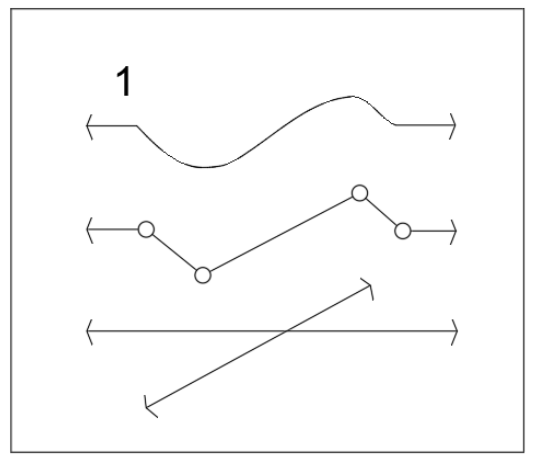

Fuente: Digitalizada del libro “Arquitectura: Forma, espacio y orden”, escrito por D.K. Ching. 


\subsubsection{Relación recorrido-espacio}

Pasar entre espacios:

- Se conserva la integridad de cada espacio

- La configuración del recorrido es flexible

- Para vincular el recorrido con los espacios es posible el empleo de otros intermedios

Imagen 20: Recorrido-espacio

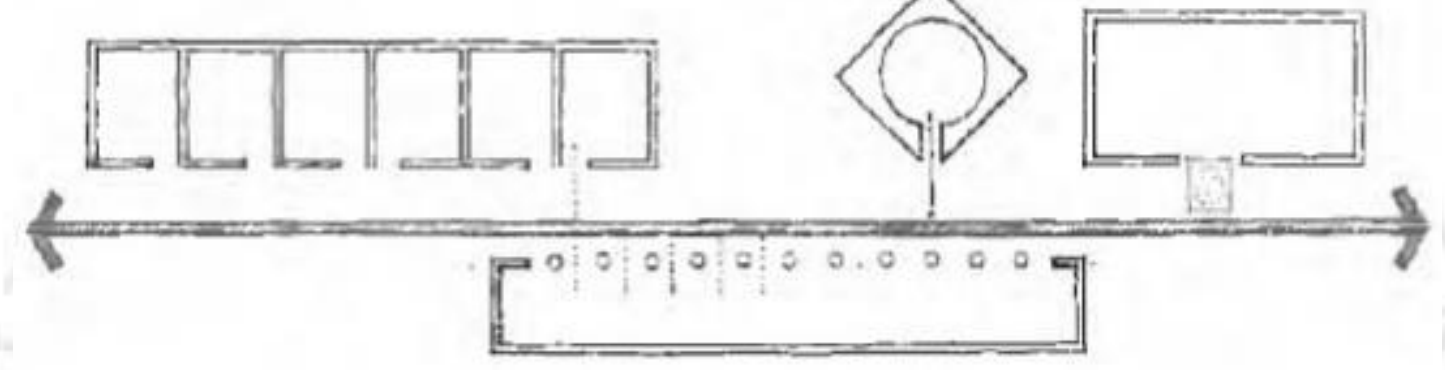

Fuente: Digitalizada del libro “Arquitectura: Forma, espacio y orden”, escrito por D.K. Ching

\subsubsection{Habitaciones}

Imagen 21: Habitación en Tietgen Dormitory
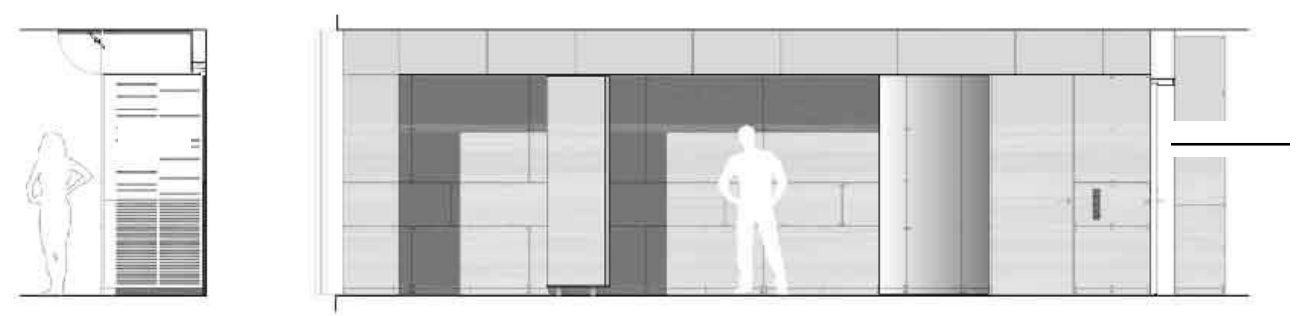

MUEBLE FLEXIBLE

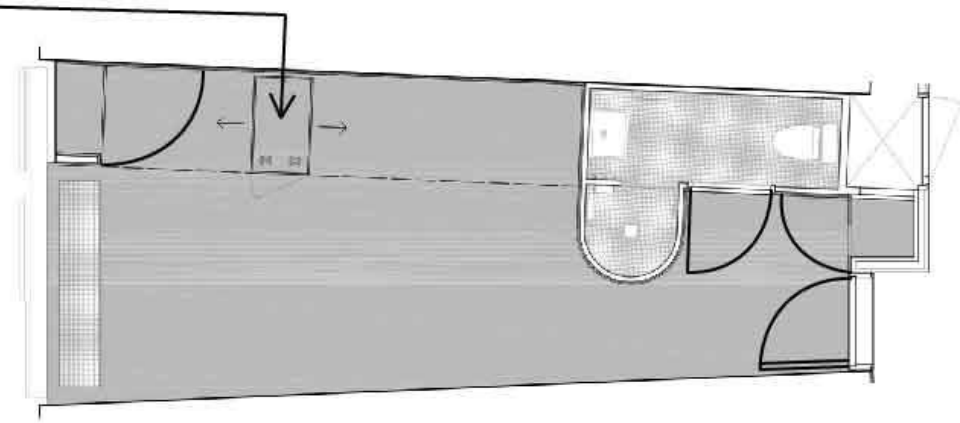

Fuente: https://www.archdaily.pe/pe/02-334957/tietgen-dormitory-lundgaard-and-tranberg-architects 


\subsubsection{Espacio}

\subsubsection{Relaciones espaciales}

- Primera planta
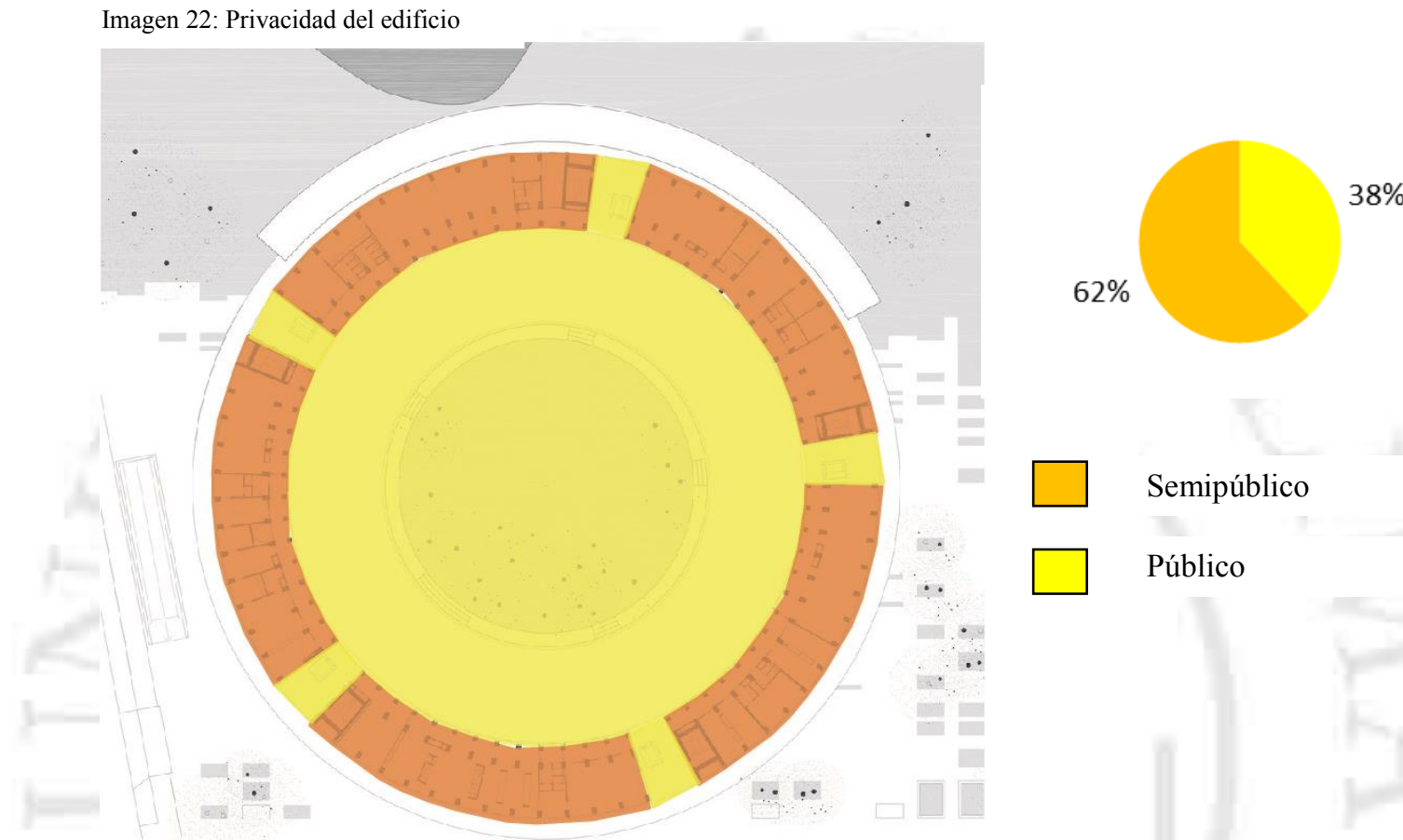

Fuente: Elaboración propia

\section{- Planta típica}

\section{Imagen 23: Privacidad del edificio}

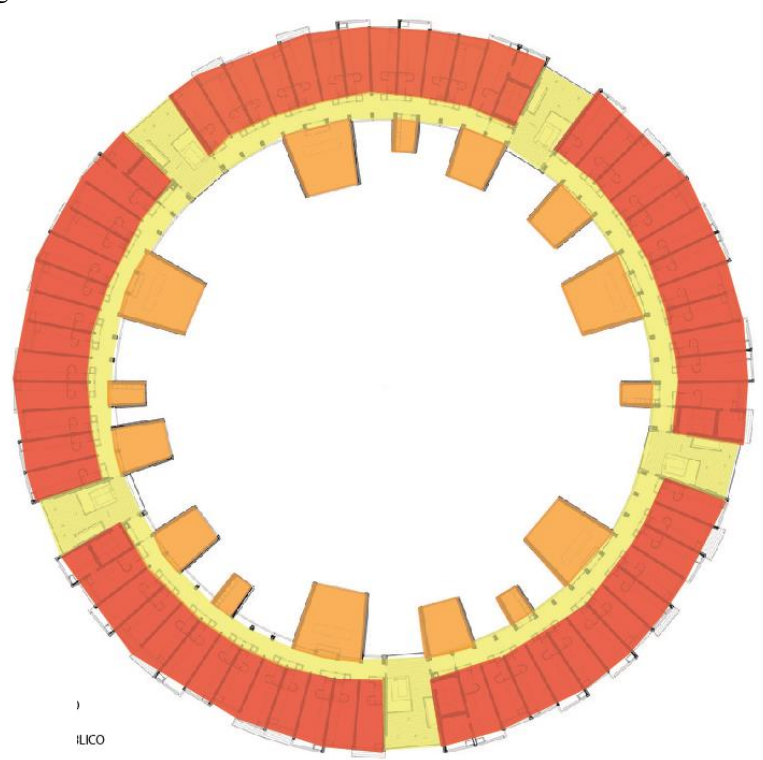

$26 \%$

$15 \%$

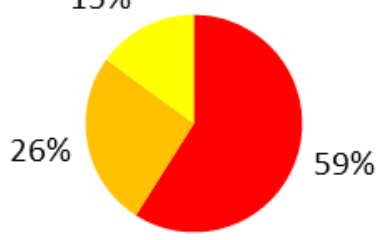

Público

Semipúblico

Privado 
5.1.6.2. Flujos y circulaciones

- Primera planta

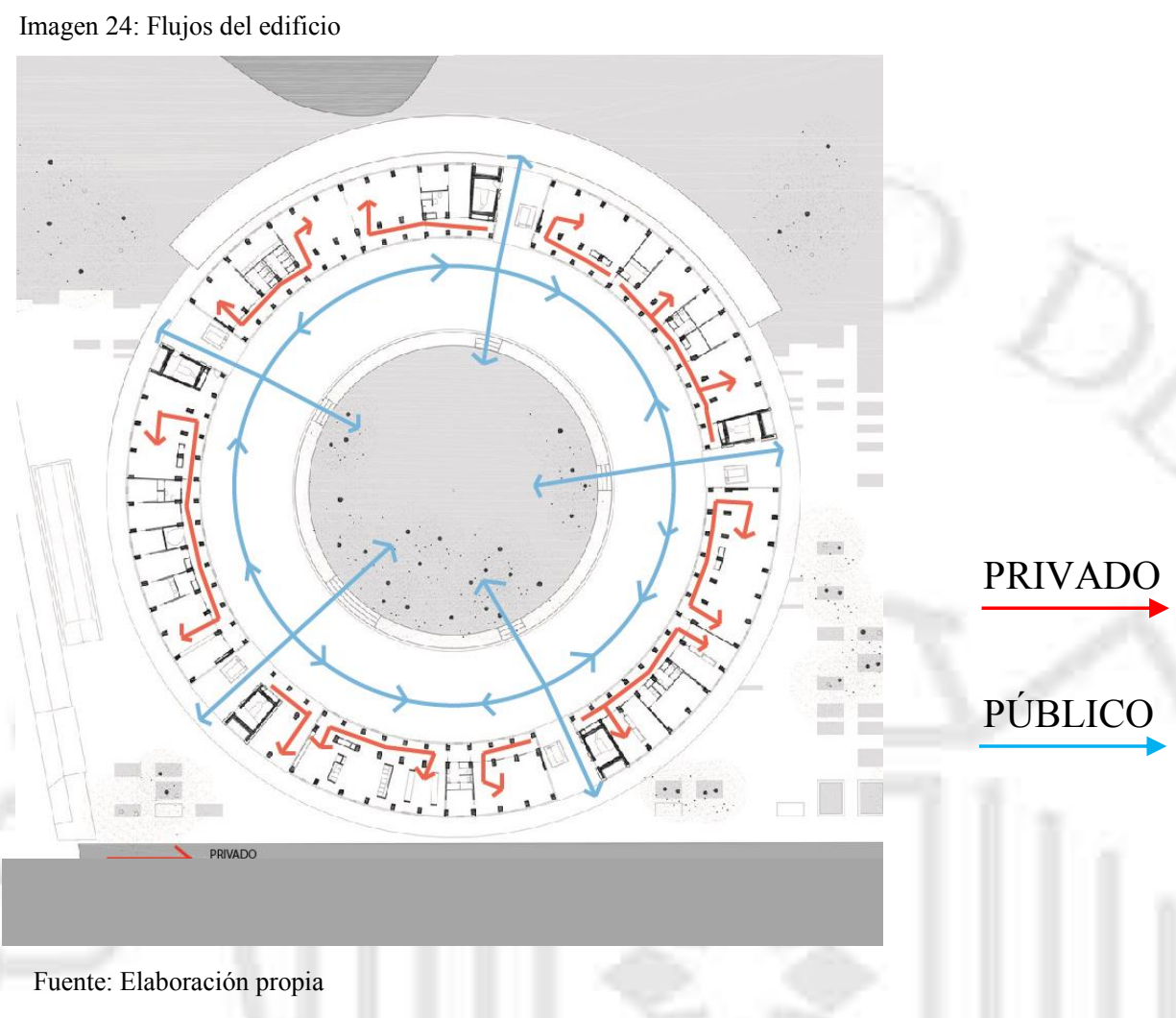

- Planta típica

Imagen 25: Flujos del edificio

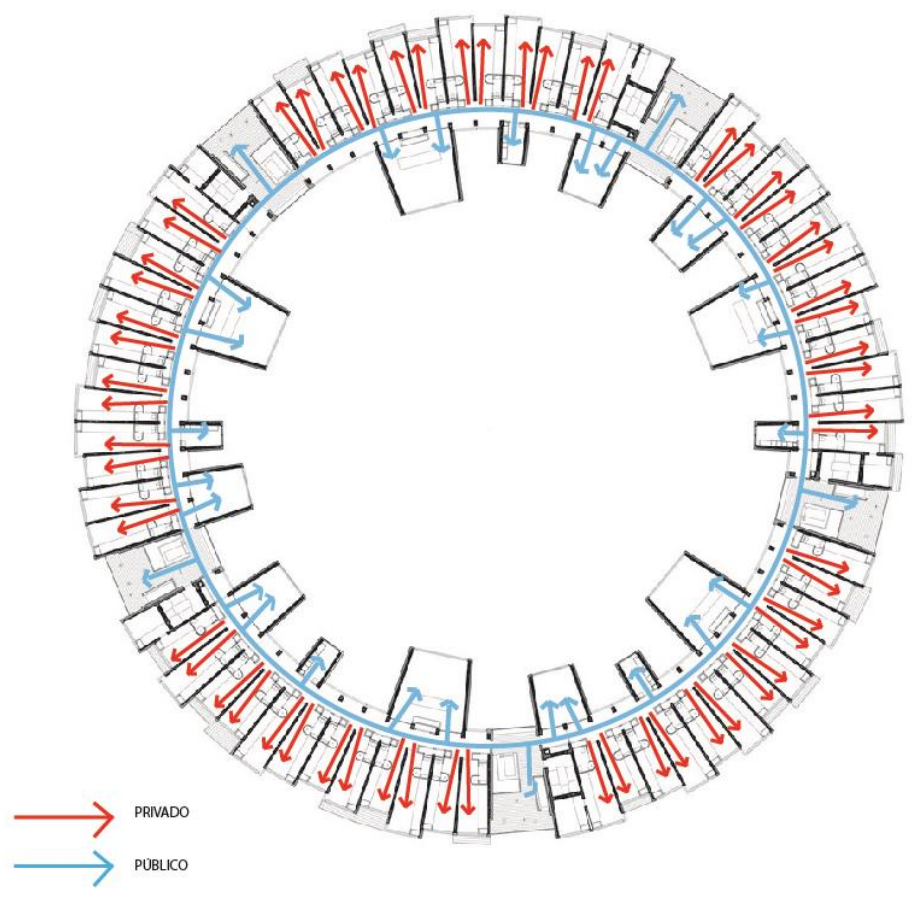


5.1.6.3. Área techada - libre
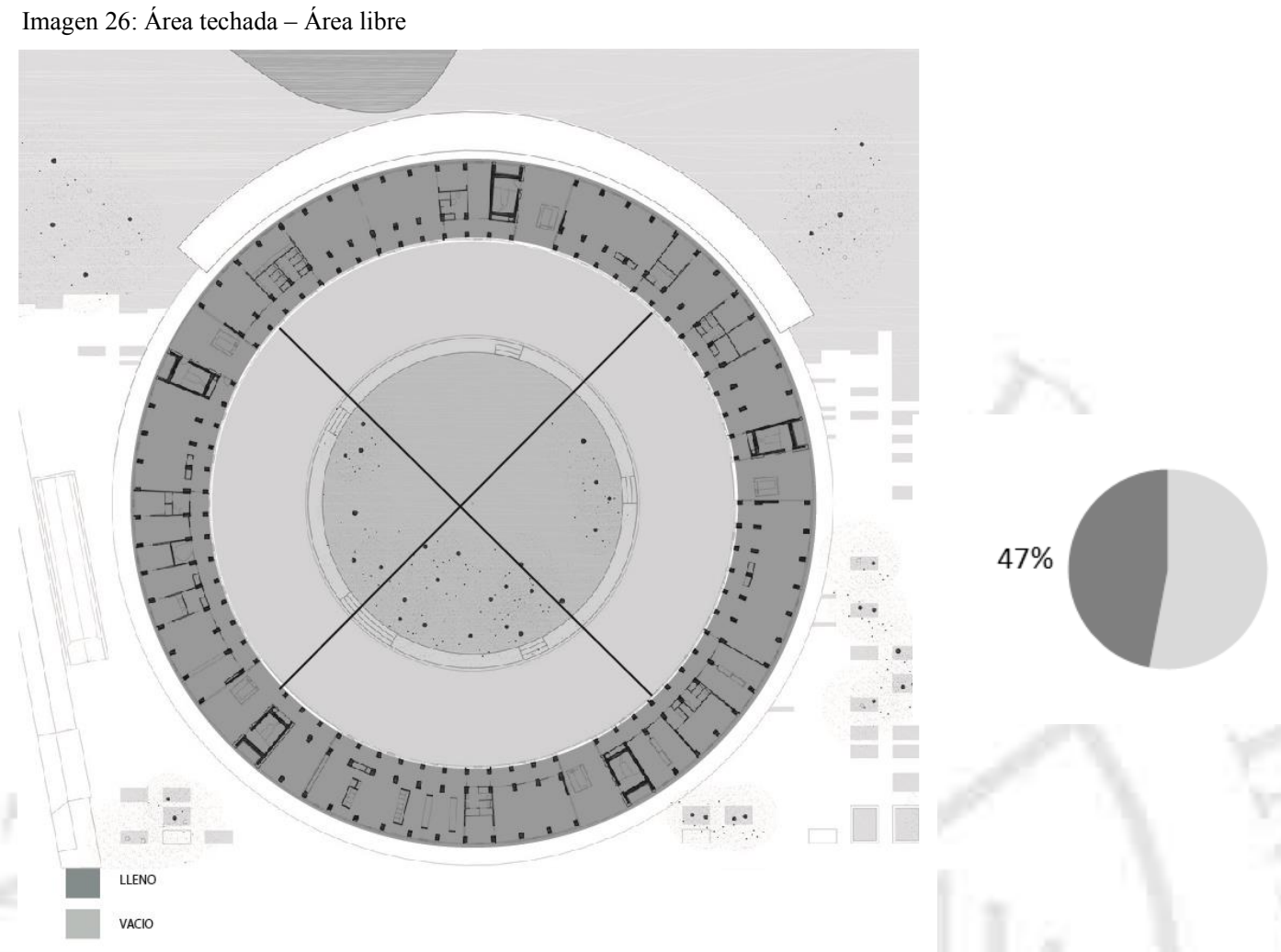

Fuente: Elaboración propia

\subsubsection{Tecnología}

La fachada de la residencia con paneles de aleación de cobre se complementa con una mampara de cristal y un sistema de celosías de madera. El interior del edificio se caracteriza por una estructura de concreto expuesto y madera contrachapada revestida.

Imagen 27. Detalle constructivo de balcón

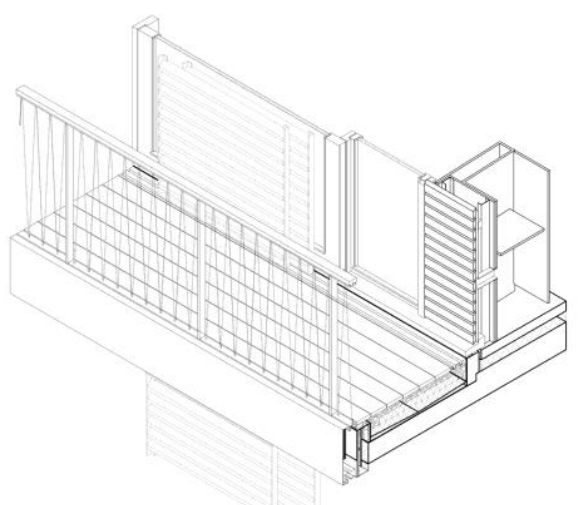

Fuente: (Hites, 2014) 
Hay interiores como el del detalle constructivo (Véase imagen 27) que poseen una terraza en las áreas comunes, con barandas de metal, y cerramientos de madera. Las losas están hechas de concreto armado.

\subsubsection{Impacto social del proyecto}

Esta residencia influye positivamente en el lugar ya que se encuentra ubicada cerca de la universidad de Copenhague, atrayendo así a más estudiantes. Este proyecto obedece al plan maestro realizado en Orrestad, brindando alojamiento a un total de 400 estudiantes extranjeros y de provincia, de manera que les soluciona el problema de alojamiento que se presentaba anteriormente, dentro de una ciudad que busca destinar el $20 \%$ de sus actividades al desarrollo universitario. Así, el conjunto toma lugar en un contexto de planificación urbana de esta gran zona de desarrollo estratégico, ya que se encuentra ubicado entre el centro de Copenhague y el aeropuerto internacional.

Tietgen Dormitory es una respuesta urbana al contexto con su forma simple y circular, emplazándose entre los edificios ortogonales generando armonía. Incrementa el espacio público de la comunidad al permitir que su plaza pública central sirva de encuentro no solo para los estudiantes de la residencia, sino también para el resto de personas de la zona.

\subsubsection{Conclusiones parciales}

Esta residencia universitaria se encuentra distribuida en torno a un espacio central. Utiliza un zócalo de servicios que consta de 1 nivel, mientras que el resto de pisos son netamente dormitorios para estudiantes. Se utilizan espacios comunes en todos los pisos, como espacios de reunión y descanso entre las habitaciones hacia el espacio interior. Se utiliza el mismo módulo de habitación en toda la residencia, en el que solo varía el tamaño de la habitación. Estas estrategias proyectuales funcionan de manera homogénea a lo largo de toda la residencia debido a su forma circular. 


\subsection{Baker House}

Imagen 28: Fachada de Baker House

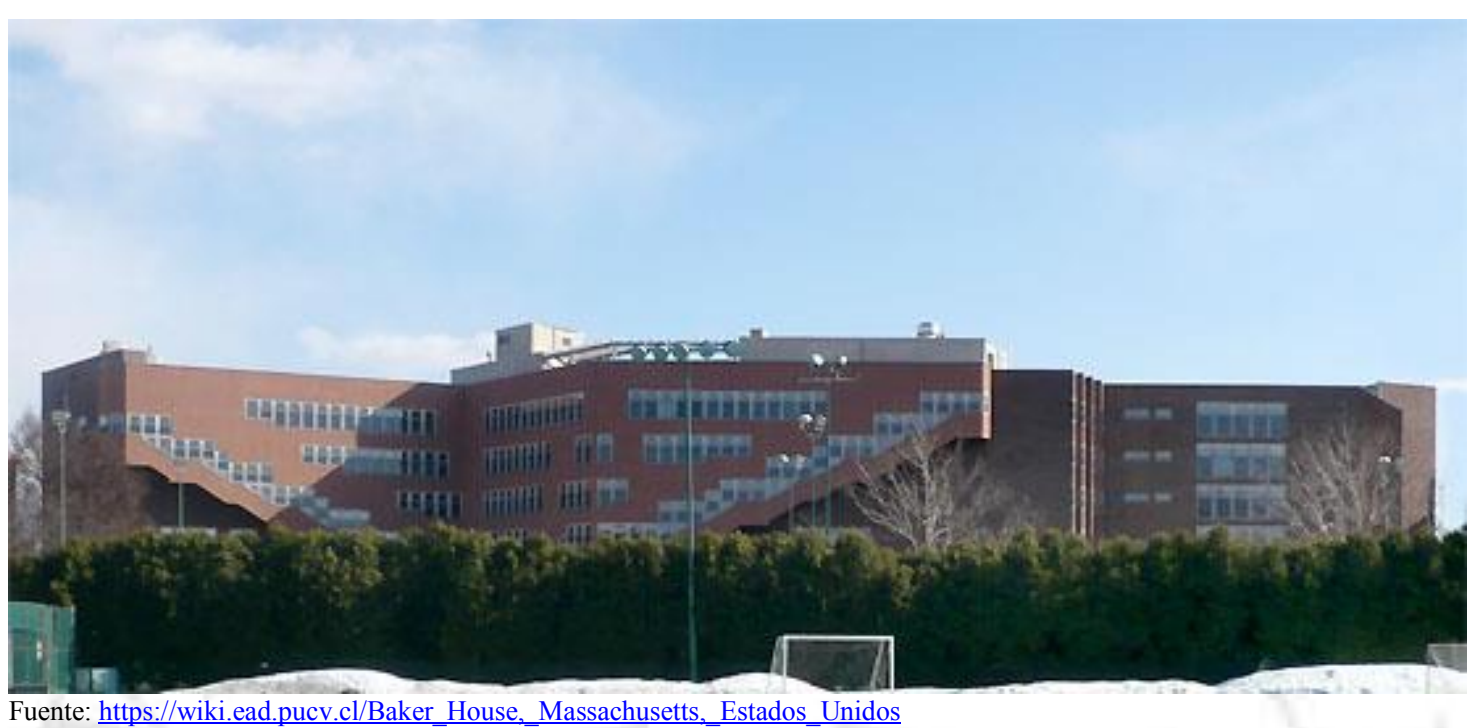

\subsubsection{Historia del edificio}

La Baker House se encuentra ubicada en Boston, Massachusetts, Estados Unidos. El arquitecto finlandés Alvar Aalto, quien fue profesor de arquitectura de dicha casa de estudios, fue el encargado en el año 1946 del proyecto consistente en diseñar una residencia para el Instituto Tecnológico de Massachusetts (MIT según sus siglas en inglés). El concepto de vivienda temporal prima en este edificio construido para brindar alojamiento a las personas que vienen a estudiar desde otras ciudades.

El edificio fue construido durante los años 1947-1948, en ladrillo rojo y sus ventanas cuentan con marcos de madera. Esta residencia de estudiantes fue bautizada en 1950 como la casa Baker en recuerdo a Everett Moore Baker, decano de los estudiantes del MIT. 


\subsubsection{Relación con el entorno}

El entorno natural que circunda la residencia es de tal atractivo, que Alvar Aalto decidió idear el proyecto "articulando el habitar, entregando la mayoría de vistas del río y salas de exposición indirecta al tráfico". (casiope, 2014)

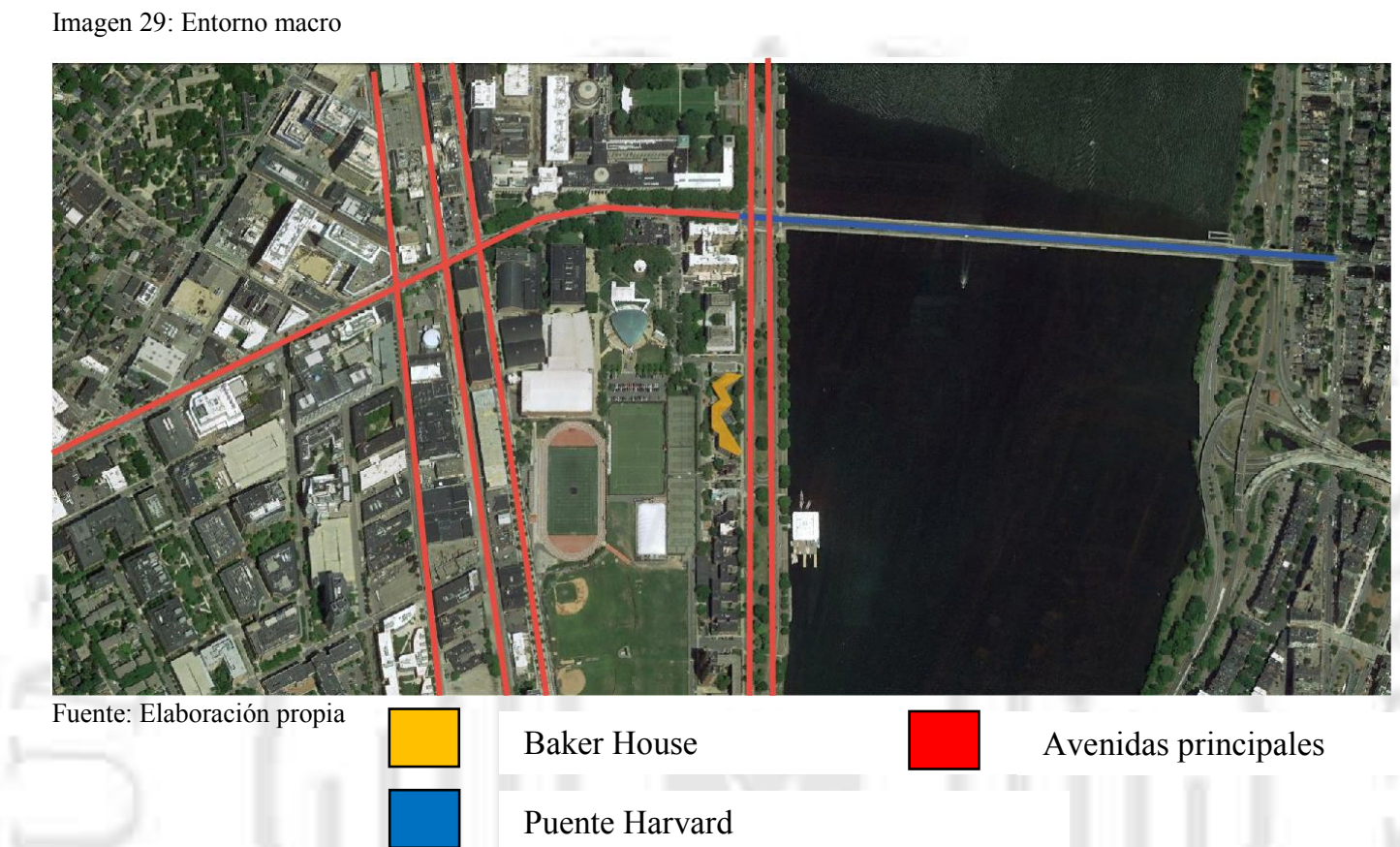

Asimismo, empleó diversos recursos para lograr romper la uniformidad de la extensión del edificio y el programa que le fuera solicitado. Para tales efectos, la fachada de la residencia fue diseñada de forma curva, no como decoración, sino con el objeto que desde todas las habitaciones se tuviera una vista del río Charles pero sin que desde cada una de ellas se viera toda la extensión del edificio. "Esta ingeniosa forma permite, asimismo, que la gran mayoría de habitaciones sean muy luminosas, al contar con una exposición al sol hacia el sur, y su orientación en ángulos oblicuos disminuye el ruido del Memorial Drive". [Traducción] (BAKER HOUSE, 2011)

Giedion, Sigfried señala:

"Igualmente alternó la capacidad y la forma de las habitaciones y combinó las formas y disposiciones de los espacios comunes, incluidas las escaleras, que sobresalen de la fachada posterior; así, todas las habitaciones son distintas y mientras unas miran río arriba, otras lo hacen río abajo" (2009). 
La residencia se ubica frente al Rio Charles, lo que le da un ambiente tranquilo ya que no hay congestión sonora por tráfico; solo una avenida pasa por la residencia y a la espalda se encuentran las canchas deportivas del campus.

"Escaleras colgantes sirven de acceso vertical, proporcionando una visión cada vez más dramática del MIT a medida que se asciende, y el pabellón del comedor con sus "luces de jardín de la luna" ofrecen vistas maravillosas del río Charles." [Traducción] (BAKER HOUSE, 2011)

La residencia no posee muchas calles peatonales. Las únicas son las del espacio libre del lote y el resto del campus. Luego el entorno está configurado con calles pequeñas para autos y un par de avenidas principales.

Imagen 30. Entorno inmediato

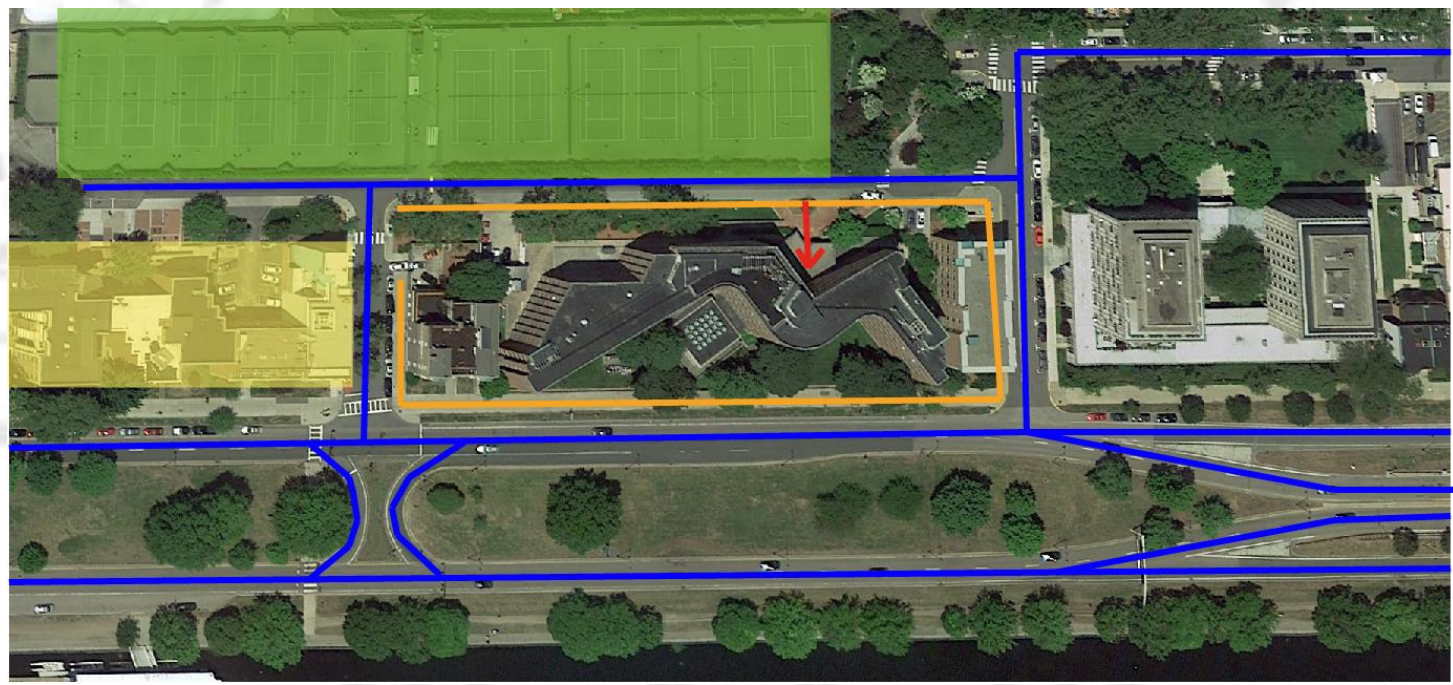

Fuente: Elaboración propia

Campus MIT

Ingresos a la residencia

Recorrido vehicular
Recorrido peatonal

PI BETA PHI University 
Imagen 31. Visuales en planta de las fachadas de la Baker House

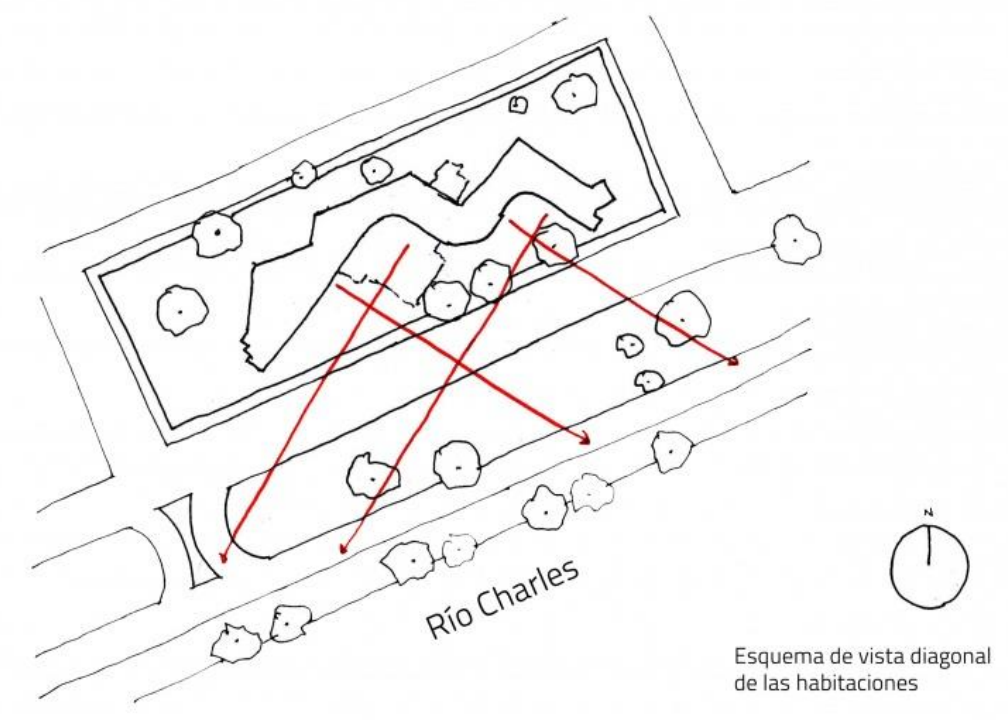

Fuente: https://wiki.ead.pucv.cl/Baker_House,_Massachusetts,_Estados_Unidos

\subsubsection{Programa y relaciones programáticas}

\subsubsection{Zonificación}

Imagen 32. Distribución en planta de la Baker House

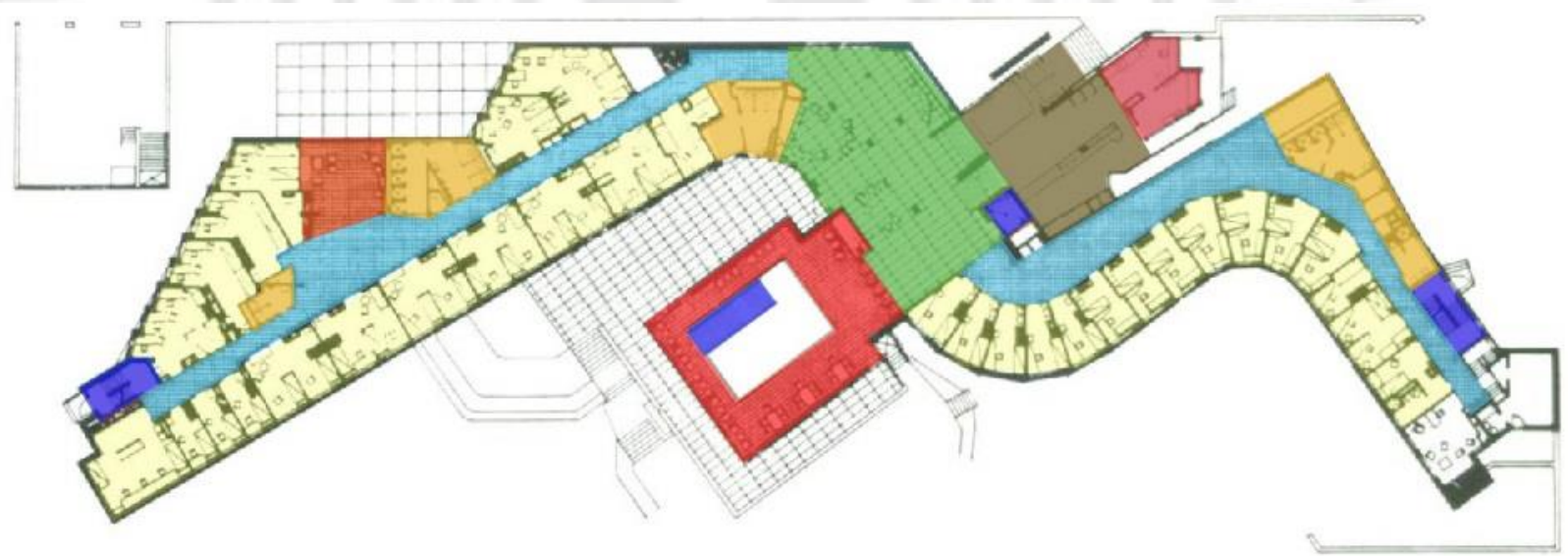

CIRCULACION VERTICAL
Hall

Fuente: Elaboración propia 


\subsubsection{Paquetes Programáticos}

La residencia universitaria Baker House está conformada por un programa que se repite en cada planta. La recepción, la cual cuenta con el 5.2\% del total de la residencia, es el ingreso al edificio, y se encuentra ubicada en la fachada a la espalda del río Charles. Esta recepción lleva a la zona cultural de la residencia que cuenta con el 10.5\% del área. La zona cultural se encuentra en el medio de toda la residencia universitaria, la cual te ordena y te lleva hacia los distintos lugares del edificio.

Frente a la zona cultural se ubica la primera área común del edificio la cual forma parte del 10.3\% que ocupan estas áreas. Esta zona posee en el medio una escalera con un vano significativo la cual lleva a los niveles superiores, las otras 2 escaleras se encuentran ubicadas en los extremos de la residencia para que haya una distancia equitativa entre estas. La circulación vertical ocupa el 3\% del edificio. Los dormitorios ocupan la mayor parte del edificio con un $37.15 \%$ y se encuentran ubicados a los lados, la mayoría con vista hacia el río Charles.

Los servicios ocupan el 7.5\% del área y se encuentran repartidos a lo largo de las habitaciones para que puedan ser usados por todos. La circulación te lleva a lo largo de todo el edificio y te reparte a los dormitorios, ocupando así el 12.25\% del área total.

\subsubsection{Cuadro de áreas}

Cuadro 14. Áreas del edificio

\begin{tabular}{|c|c|c|}
\hline Ambiente & Área aprox. & Aporte \\
\hline Circulación vertical & $80.57 \mathrm{~m}^{2}$ & $3.05 \%$ \\
\hline Circulación & $321.81 \mathrm{~m}^{2}$ & $12.25 \%$ \\
\hline Recepción & $135.62 \mathrm{~m}^{2}$ & $5.2 \%$ \\
\hline Dormitorios & $976.77 \mathrm{~m}^{2}$ & $37.15 \%$ \\
\hline Servicios & $197.26 \mathrm{~m}^{2}$ & $7.5 \%$ \\
\hline áreas comunes & $270.28 \mathrm{~m}^{2}$ & $10.30 \%$ \\
\hline Cultural & $274.87 \mathrm{~m}^{2}$ & $10.45 \%$ \\
\hline Total & $2631 \mathrm{~m}^{2}$ & $100 \%$ \\
\hline
\end{tabular}

Fuente: Elaboración propia 


\subsubsection{Organigrama}

Imagen 33. Organigrama

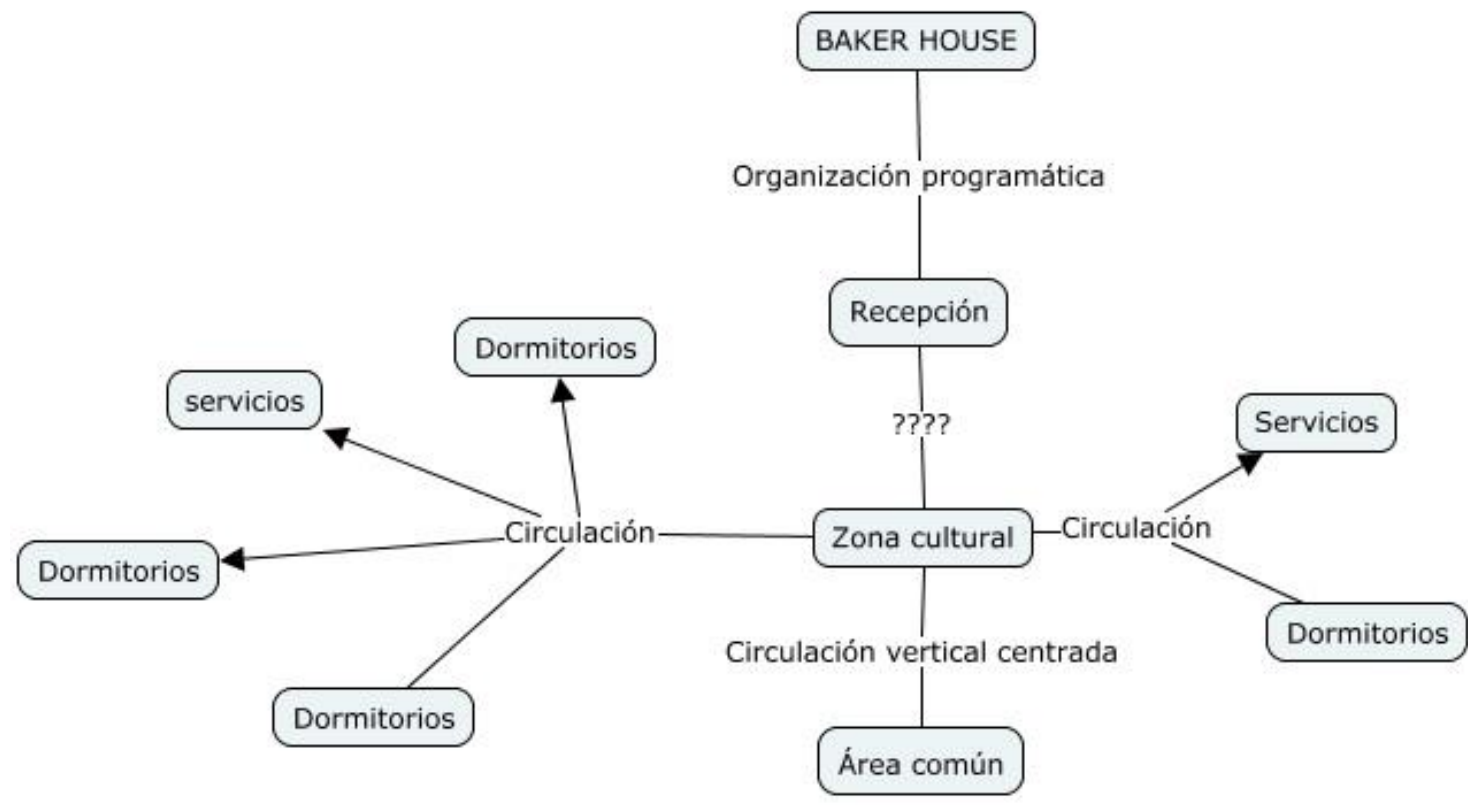

Fuente: Elaboración propia

5.2.4. Tipología espacial

Para analizar la tipología del edificio, nos basaremos en el libro "Arquitectura: Forma, espacio y orden", escrito por D.K. Ching.

\subsubsection{Organización lineal}

El terreno tiene una configuración lineal, la cual puede solucionar distintas condiciones de emplazamiento que se presenten. Una construcción ondeada también es considerada construcción lineal ya que no se pierde la continuidad, como en el caso de la residencia universitaria Baker House. Fue diseñada de modo que sus fachadas tuvieran visual al río y para que sus habitaciones tuvieran una orientación favorable de acuerdo al sol. La residencia se organiza horizontalmente a través del emplazamiento, para así aprovechar y desarrollar el espacio público en el resto del terreno. 

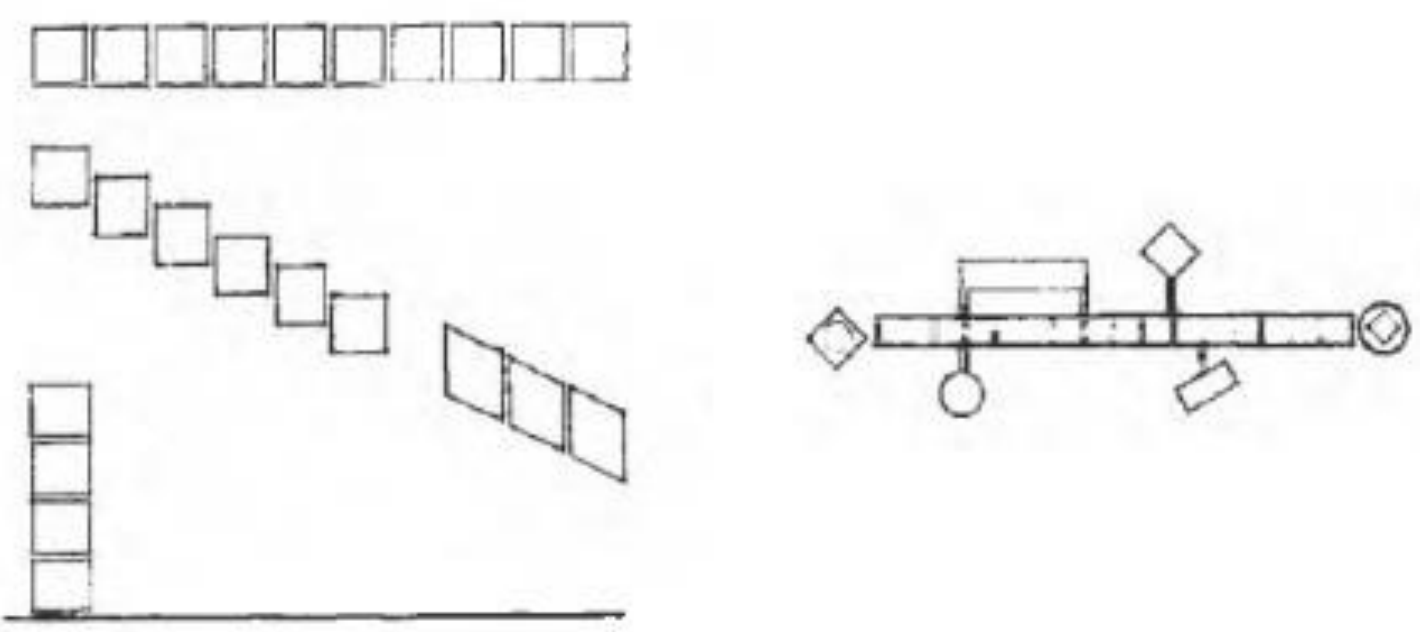

Fuente: Digitalizada del libro “Arquitectura: Forma, espacio y orden”, escrito por D.K. Ching.

\subsubsection{Aproximación al edificio}

Oblicua: La aproximación a la Baker House no es directa, se tiene que bordear la residencia si es que se llega por la avenida principal, ya que el ingreso se encuentra ubicado en una de las calles que da la espalda al río. Este recorrido permite darle mayor valor al edificio ya que se pueden apreciar los espacios públicos y la arquitectura de la residencia antes de ingresar a esta.

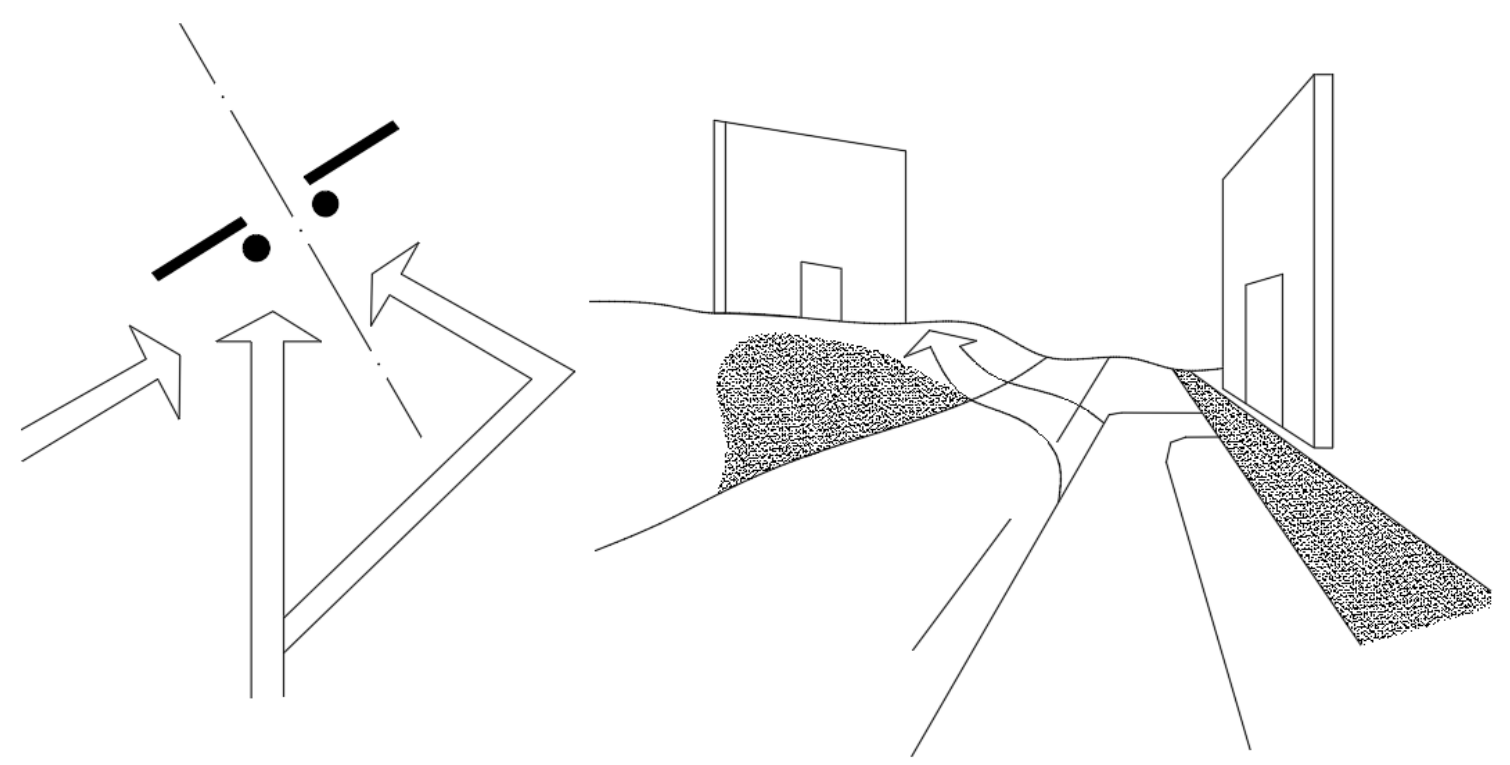

Fuente: Digitalizada del libro “Arquitectura: Forma, espacio y orden”, escrito por D.K. Ching. 


\subsubsection{Configuración del recorrido}

Lineal: Esta residencia posee un área común como inicio del recorrido al salir de la recepción, para luego continuar de forma lineal a las habitaciones y demás áreas y servicios comunes. La circulación vertical se encuentra ubicada al centro y a los extremos de la residencia.

Imagen 36: Configuración del recorrido

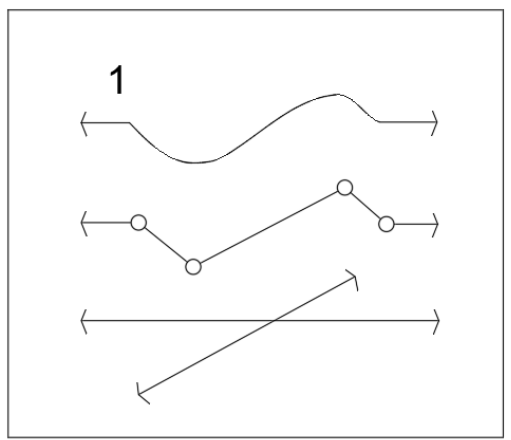

Fuente: Digitalizada del libro “Arquitectura: Forma, espacio y orden”, escrito por D.K. Ching.

\subsubsection{Relación recorrido-espacio}

Pasar entre espacios:

- Se conserva la integridad de cada espacio

- La configuración del recorrido es flexible

- Para vincular el recorrido con los espacios es posible el empleo de otros intermedios

Imagen 37: Relación recorrido-espacio

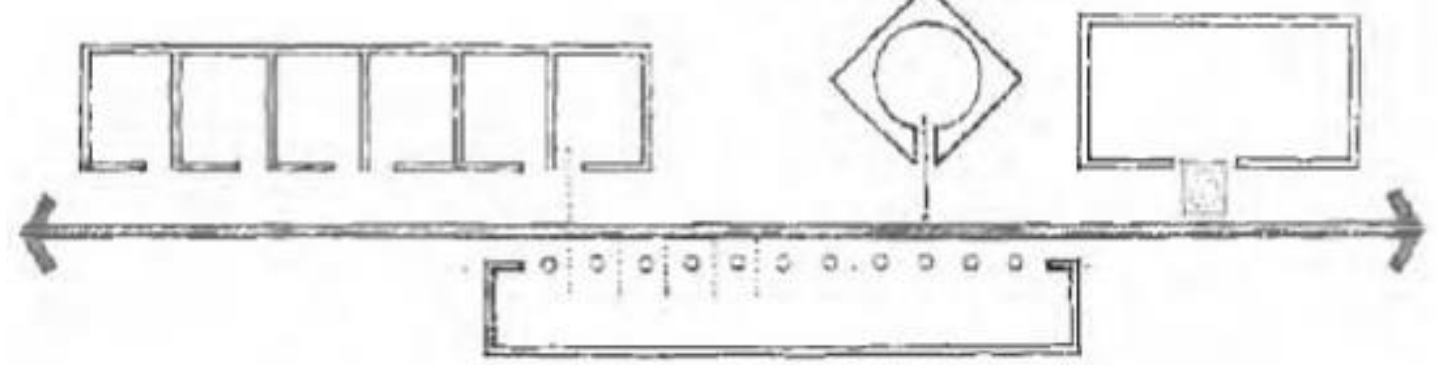

Fuente: Digitalizada del libro “Arquitectura: Forma, espacio y orden”, escrito por D.K. Ching. 


\subsubsection{Habitaciones}

Imagen 38: Habitación tipo 1

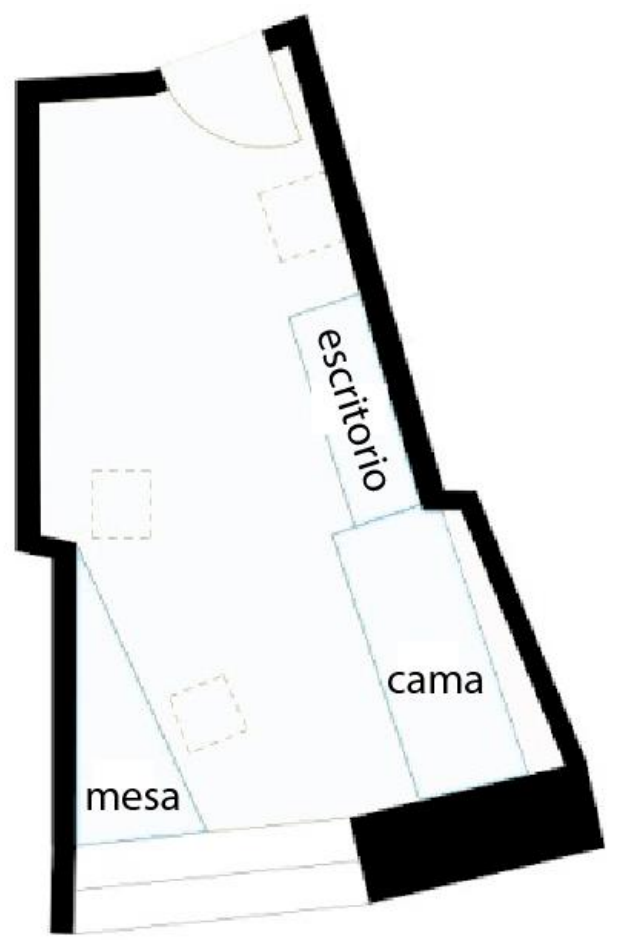

Nota: Habitación para 1 persona con escritorio

Imagen 40: Habitación tipo 3

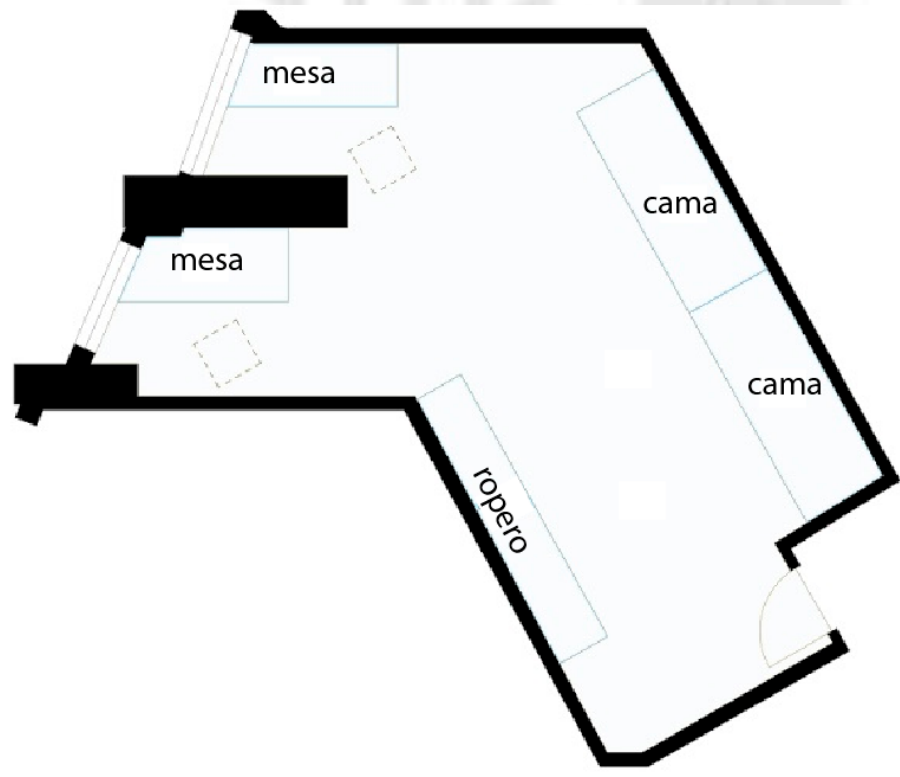

Nota: Habitación para 2 persona con mesas y roperos
Imagen 39: Habitación tipo 2

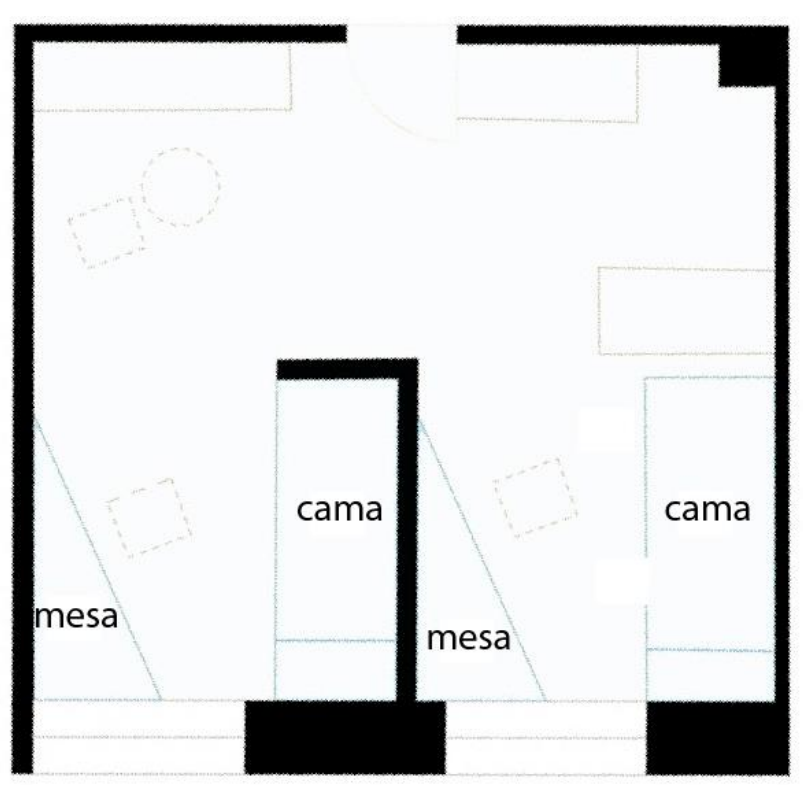

Nota: Habitación para 2 persona con mesas

Imagen 41: Habitación tipo 4

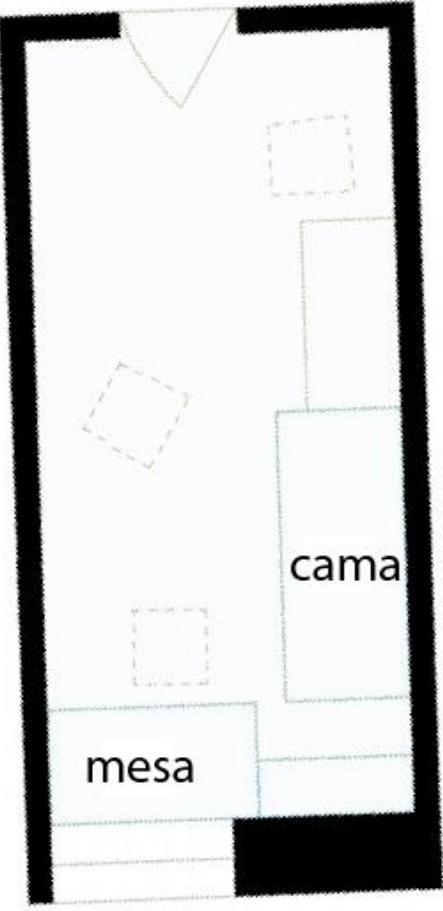

Nota: Habitación para 1 persona con mesa 


\subsubsection{Espacios}

\subsubsection{Relaciones espaciales}

Imagen 42. Distribución de priv/pub en planta de la Baker House

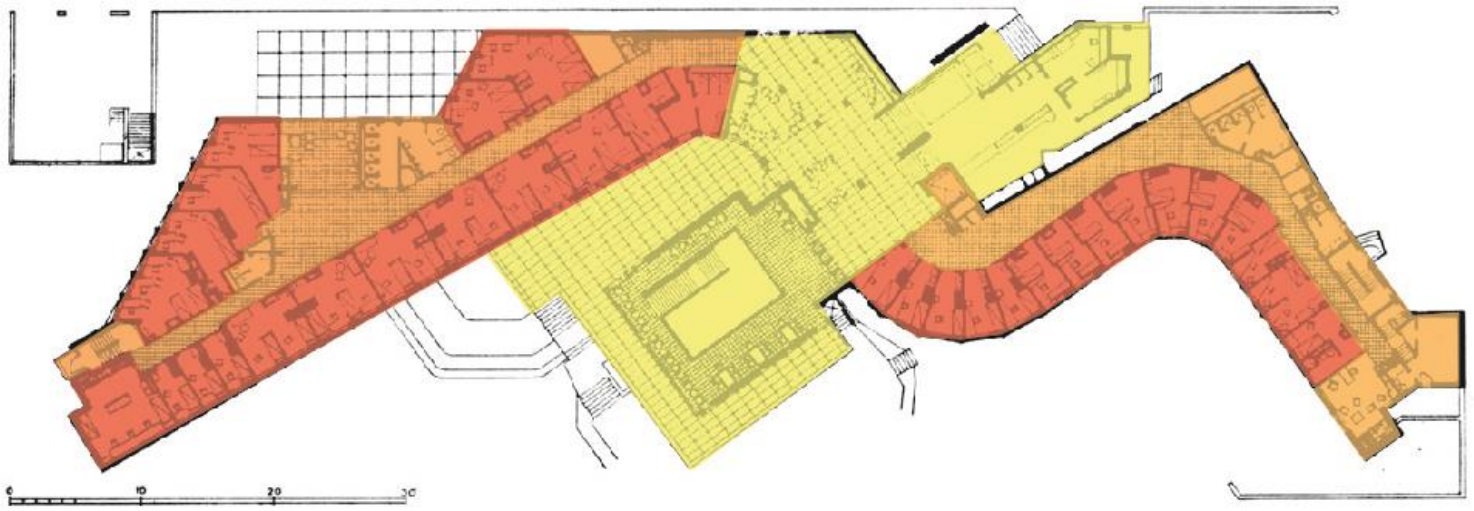

PRIVADO

SEMIPUBLICO

PUBUCO

Fuente: Elaboración propia

$24 \%$

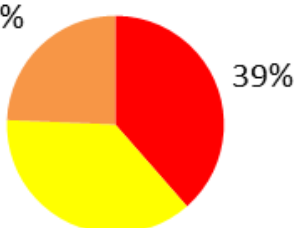

$37 \%$

Imagen 43. Distribución de priv/pub en corte de la Baker House

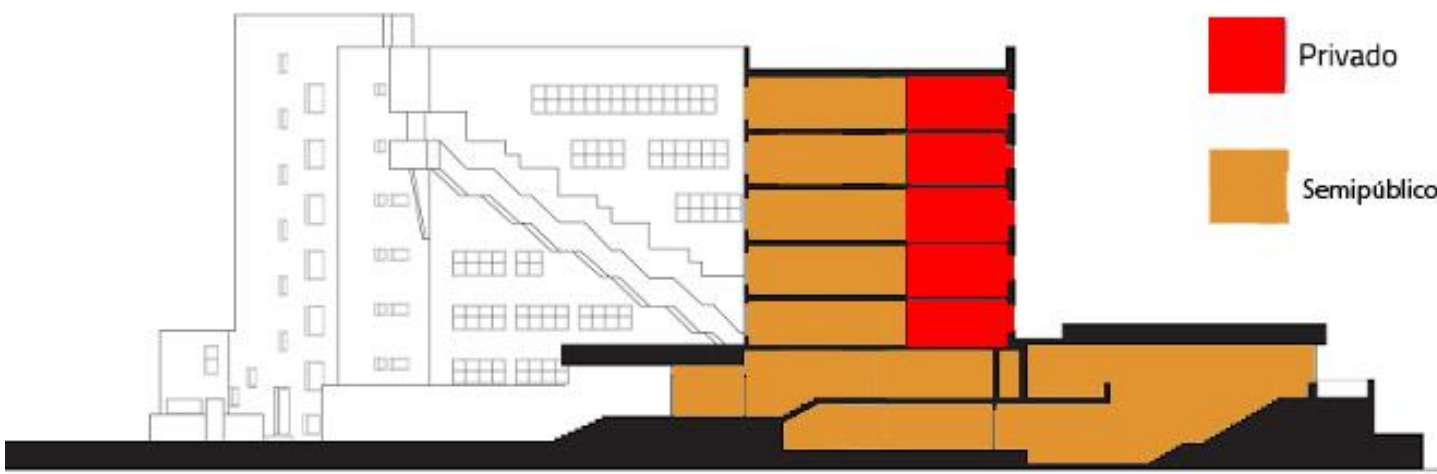

Fuente: Elaboración propia 


\subsubsection{Flujos y circulaciones}

Imagen 44. Circulaciones en la Baker House
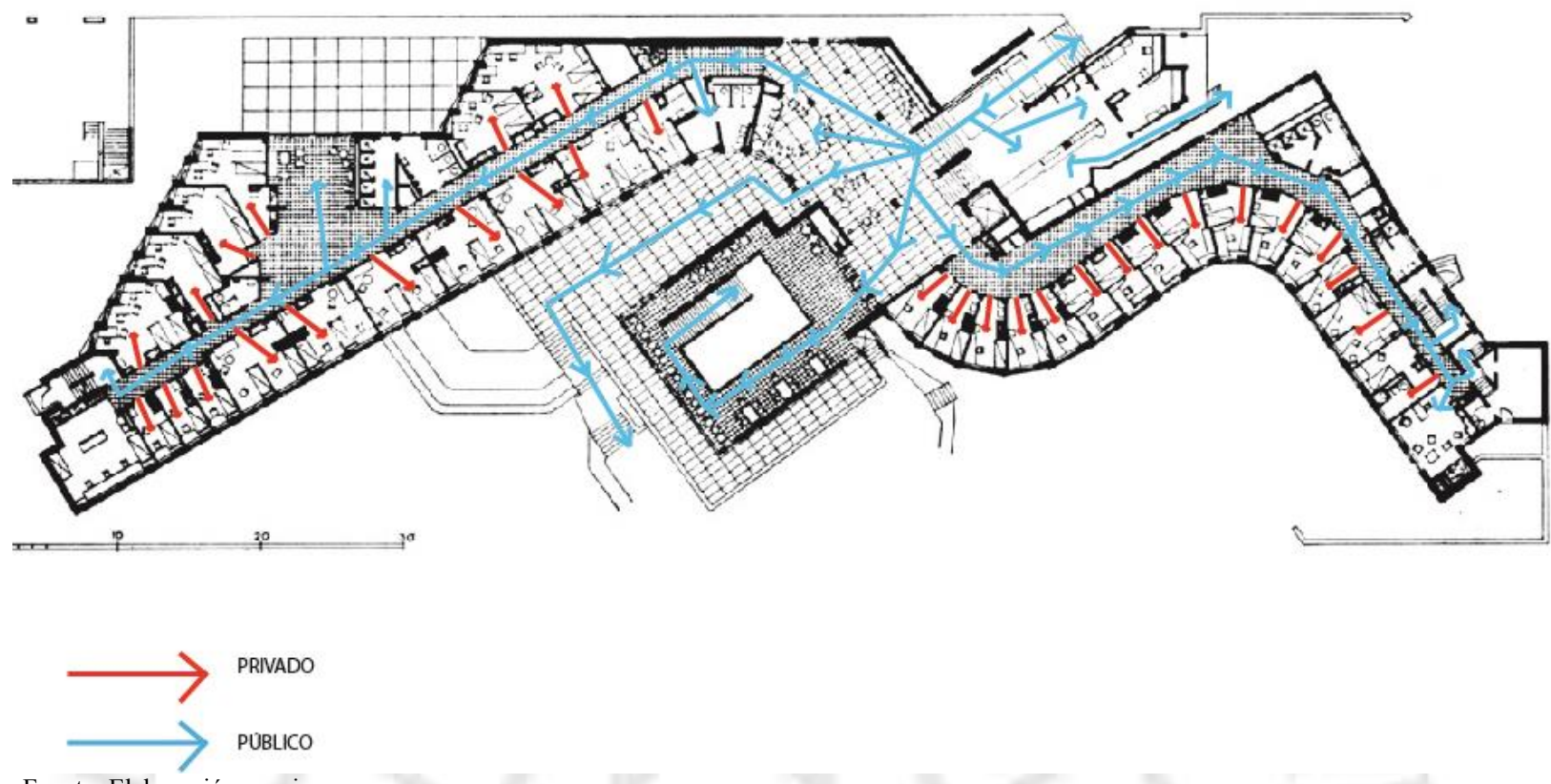

Fuente: Elaboración propia

\subsubsection{3. Área techada - libre}

Imagen 45. Lleno y vacío en la Baker House
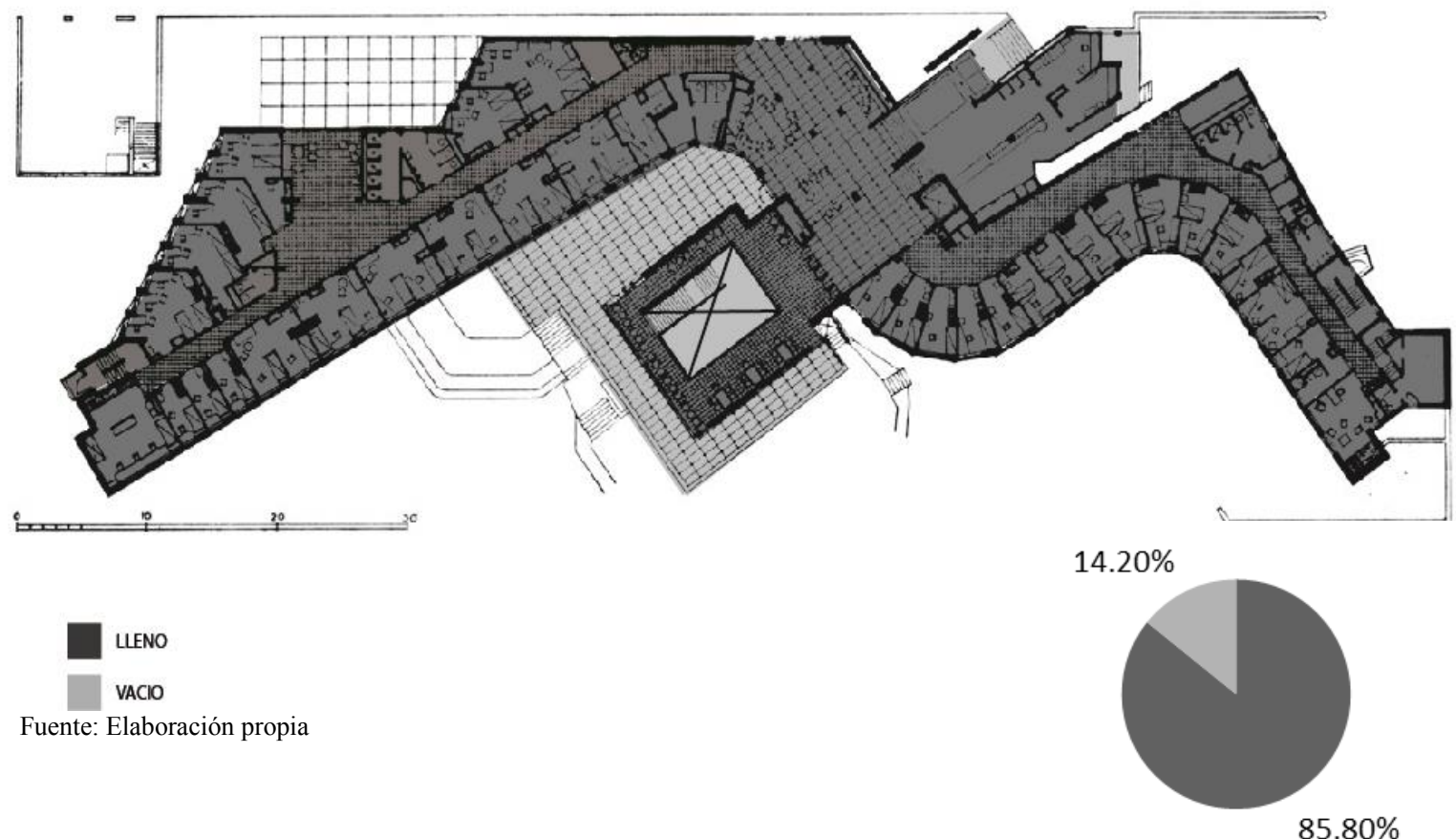

$85.80 \%$ 


\subsubsection{Tecnología}

La Baker House utiliza mampostería con ladrillo en todo el edificio, por lo que no se aporta nada innovador al proyecto

\subsubsection{Impacto social del proyecto}

El proyecto brinda áreas verdes y espacio público, además de equipamiento para la sociedad. Solo se ha construido la tercera parte del lote, dejando así $2794 \mathrm{~m}^{2}$ de área verde y $200 \mathrm{~m}^{2}$ de espacio público. Además de esto, la residencia brinda una cafetería y una lavandería como equipamientos, que pueden ser utilizados por la comunidad. Uno de los servicios que brinda la residencia son las salas de estudio y estar, las cuales "potencian la vida "pública" o en comunidad, mirando el conjunto a otra escala". (casiopea, 2014)

Tiene un radio de influencia alrededor de 10 manzanas, lo cual es todo lo que abarca el MIT, al cual esta orientada la residencia. La calidad de vida de la residencia es alta, esto se debe al diseño y organización espacial de sus espacios. Sumado a esto, se ubica frente a un río, lo cual es uno de los factores que mejora la calidad de vida al ser una buena visual.

\subsubsection{Conclusiones parciales}

Baker House utiliza estrategias proyectuales de diseño basándose en el entorno y adecuándose a este, para definir la forma, y la ubicación de las áreas comunes y de servicio. Las habitaciones se encuentran a lo largo de uno de los frentes con un pasillo central que va de extremo a extremo de la edificación. 


\subsection{Pabellón Suizo}

Imagen 46. Pabellón Suizo

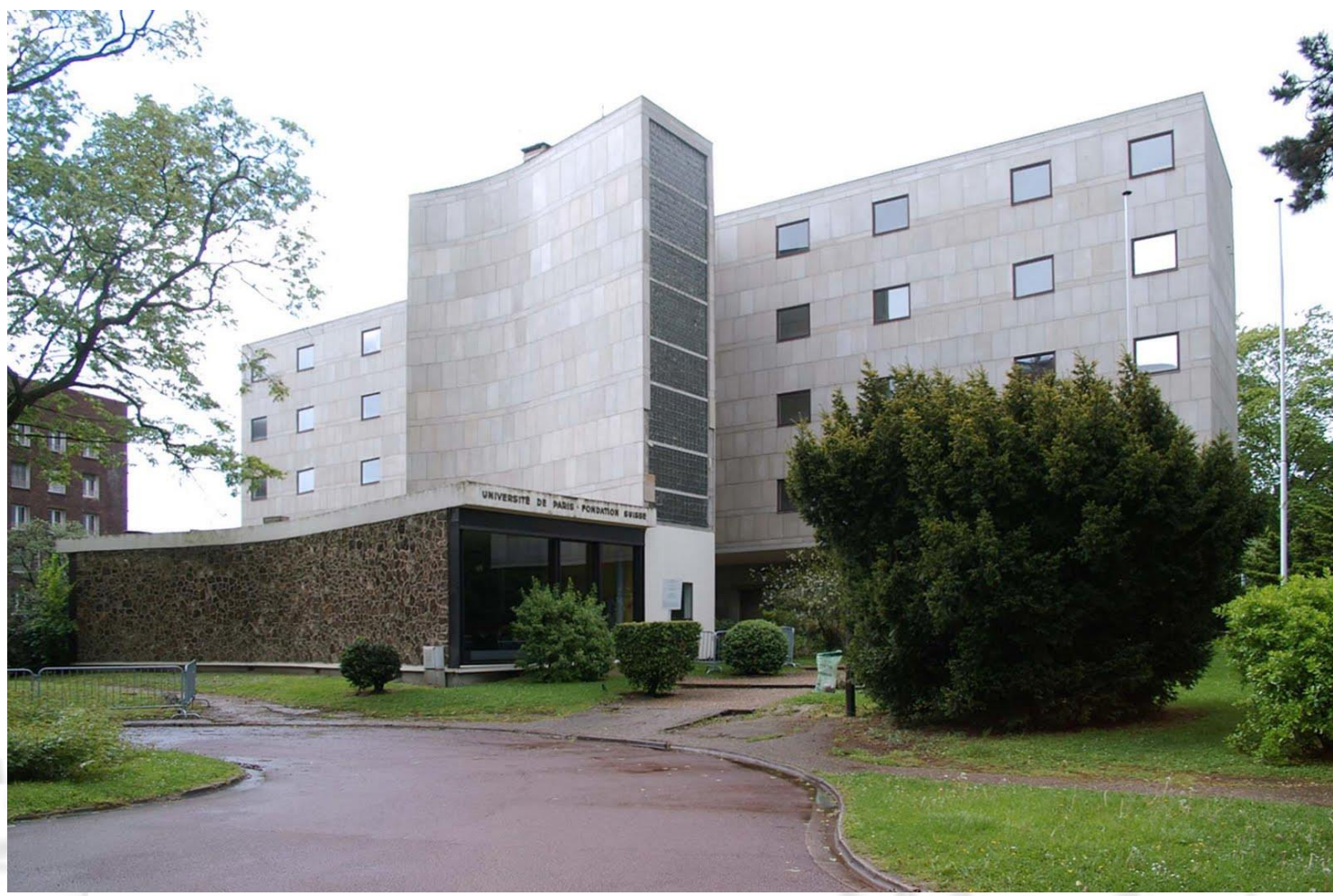

Fuente: Pavillon Suisse, Cité Internationale Universitaire, Paris

Foto: Olivier Martin-Gambier 2005

\subsubsection{Historia del edificio}

En 1930 el arquitecto Le Corbusier, recibe el encargo de la Fundación Suiza de realizar un proyecto de alojamiento para jóvenes universitarios suizos en París, en cuyo diseño también colaboró su primo el arquitecto Pierre Jeanneret.

La obra estaría ubicada dentro de la Ciudad Universitaria Internacional de París con el objeto que los jóvenes pudieran mejorar sus condiciones de alojamiento y alimentación, así como participar de las actividades del campus.

Inicialmente el programa constaba de 46 habitaciones, un comedor y un salón. La obra fue construida entre los años 1930 y 1933 en circunstancias difíciles por el bajo presupuesto con el que contaban y por el tema del tipo de suelo en el que se construyó. 


\subsubsection{Relación con el entorno}

El contexto en que se da la creación de esta residencia está relacionado con la carencia de alojamientos para los estudiantes suizos en París, lo que hacía que estos habitaran en lugares de bajas condiciones en el barrio latino de París. El pabellón se construye dentro del campus universitario de forma tal que brinda acceso a los jóvenes, según Naja, R.: "no sólo a una vivienda digna y alimentación a precios razonables, sino también a las instalaciones deportivas y culturales de la naciente Ciudad Universitaria Internacional de París (CIUP).” (2013)

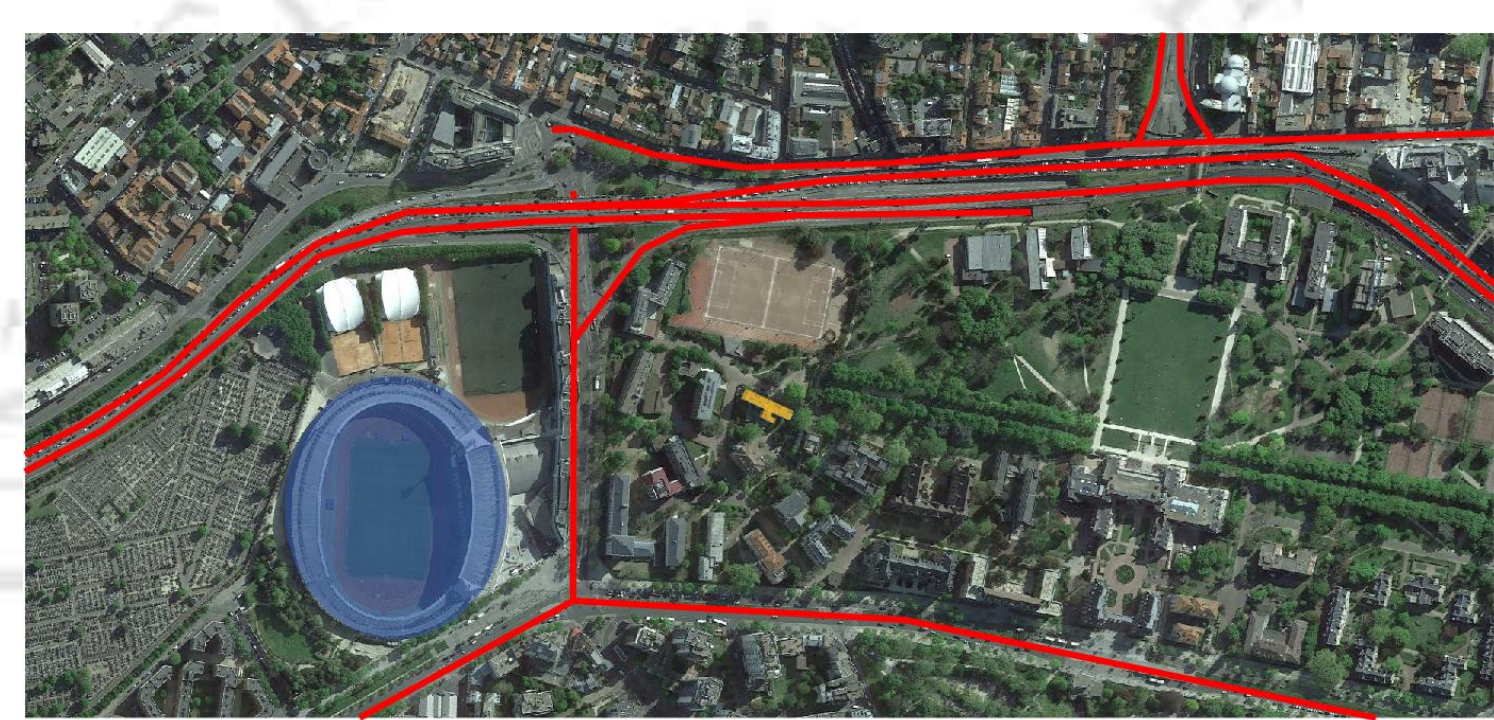

Fuente: Elaboración propia

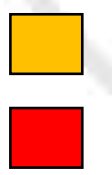

Pabellón Suizo

Estadio

Avenidas Principales

"El Pabellón Suizo de la Ciudad Universitaria es un acabado paradigma del énfasis del movimiento moderno en que las formas sean representativas de las diferentes funciones (form follows function) y a la vez, sean objeto de un tratamiento plástico tanto en su gestación como en su integración al conjunto". (es.wikiarquitectura, 2015) 


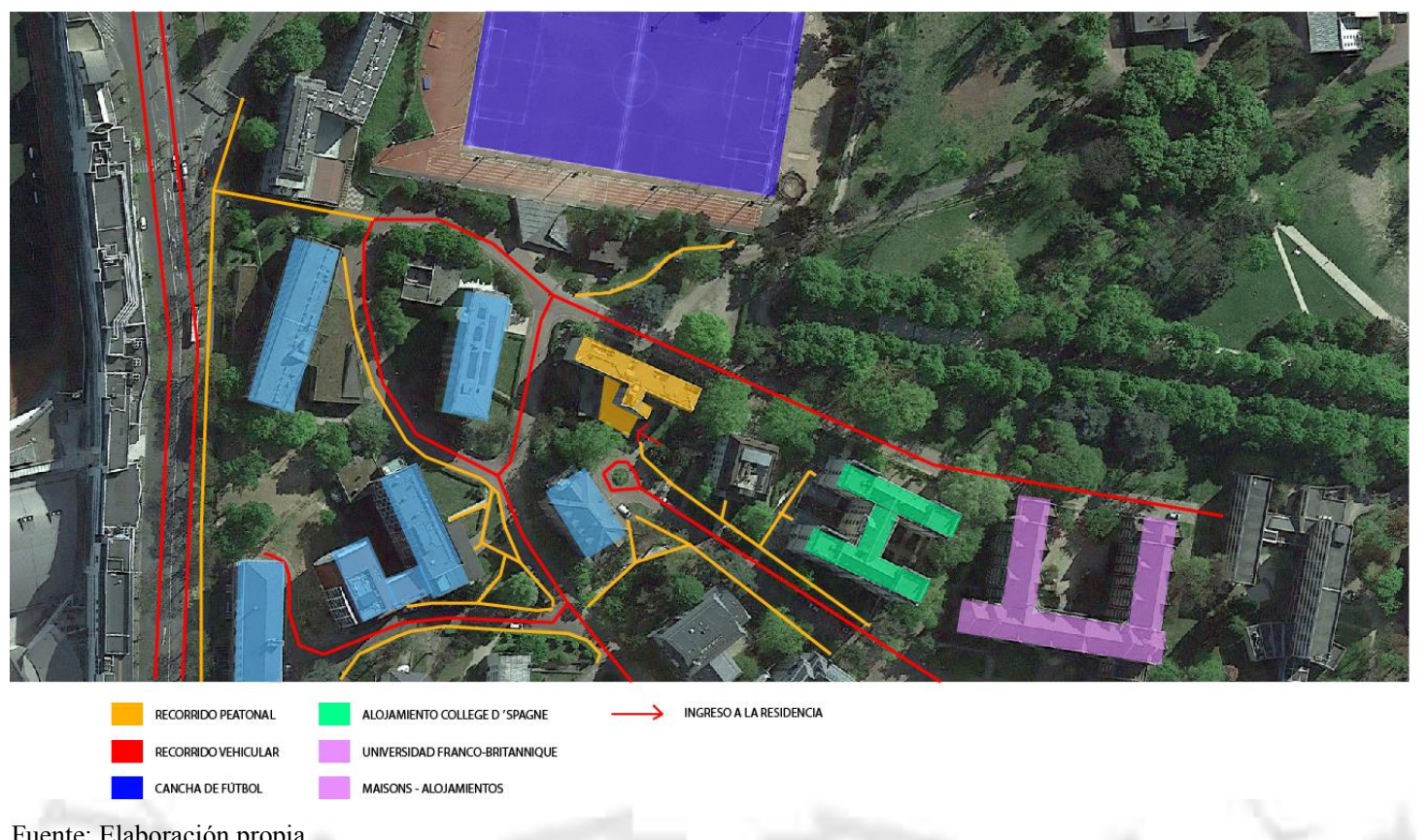

Fuente: Elaboración propia

El pabellón tiene forma de T. Su diseño es sencillo y conciso. Debido a los requerimientos de su cliente, que quería que las funciones públicas se dieran en la planta baja, Le Corbusier ideó el diseño del pabellón en dos zonas o volúmenes bien diferenciados:

a) La zona de alojamiento, que comprende 4 pisos y tiene forma de un prisma de $49 \mathrm{~m}$ por $9 \mathrm{~m}$. En ella se ubican las habitaciones de $24 \mathrm{~m} 2$ las cuales se encuentran orientadas hacia el sur.

Estas habitaciones se apoyan cerca del centro del edificio sobre una serie de pilares de hormigón que lo elevan sobre el suelo, acentúan su efecto de "flotación", y permiten la circulación bajo el edificio.

"Expresa claramente esta característica de 'edificio como agrupación de células' a través de su fachada sur, compuesta por un módulo de carpintería que se repite indefinidamente en correspondencia con la serie de los cuartos. Pero el frente calado correspondiente a la terraza aparece para enmarcar equilibradamente este conjunto de carpinterías modulares. La fachada norte como corresponde a la orientación más fría- se materializa a través de un muro sólo horadado por pequeñas ventanas puntuales que proveen de iluminación las circulaciones horizontales" (arq.com.mx, 2013)

b) La planta baja, en donde se ubican la recepción y áreas comunes (espacio social). "Esta zona de servicios se organiza de forma más libre y está compuesta por de 
dos volúmenes curvados, una torre vertical de comunicación y un volumen más bajo revestido en piedra donde se encuentra el acceso" $(\mathrm{K})$

Según la página web arq.com.mx, el volumen vertical central que contiene los servicios funciona como nexo con el cuerpo bajo que contiene los ámbitos comunes, el cual es en esencia, un gran espacio tratado con una gran libertad formal, cuyas poéticas curvas contrastan con la austeridad de líneas del primer volumen. (2013)

"La planta libre se controla con elementos arquitectónicos como escaleras, así como muebles, ya sean fijos o sueltos. La vista y la penetración de la luz también tienen su impacto en la organización de la planta abierta, al haber sido controladas por la fachada”. (Naja, R., 2013)

Existe, asimismo, una tercera zona, la pieza que asume las funciones de conexión y comunicación vertical. En la azotea se ubica un jardín y es concebida como una terraza accesible para los residentes del edificio.

La fachada del edificio es libre y abierta y la fachada sur, a diferencia de la norte, está completamente acristalada.

\subsubsection{Relaciones programáticas}

\subsubsection{Zonificación}

- Planta de servicios

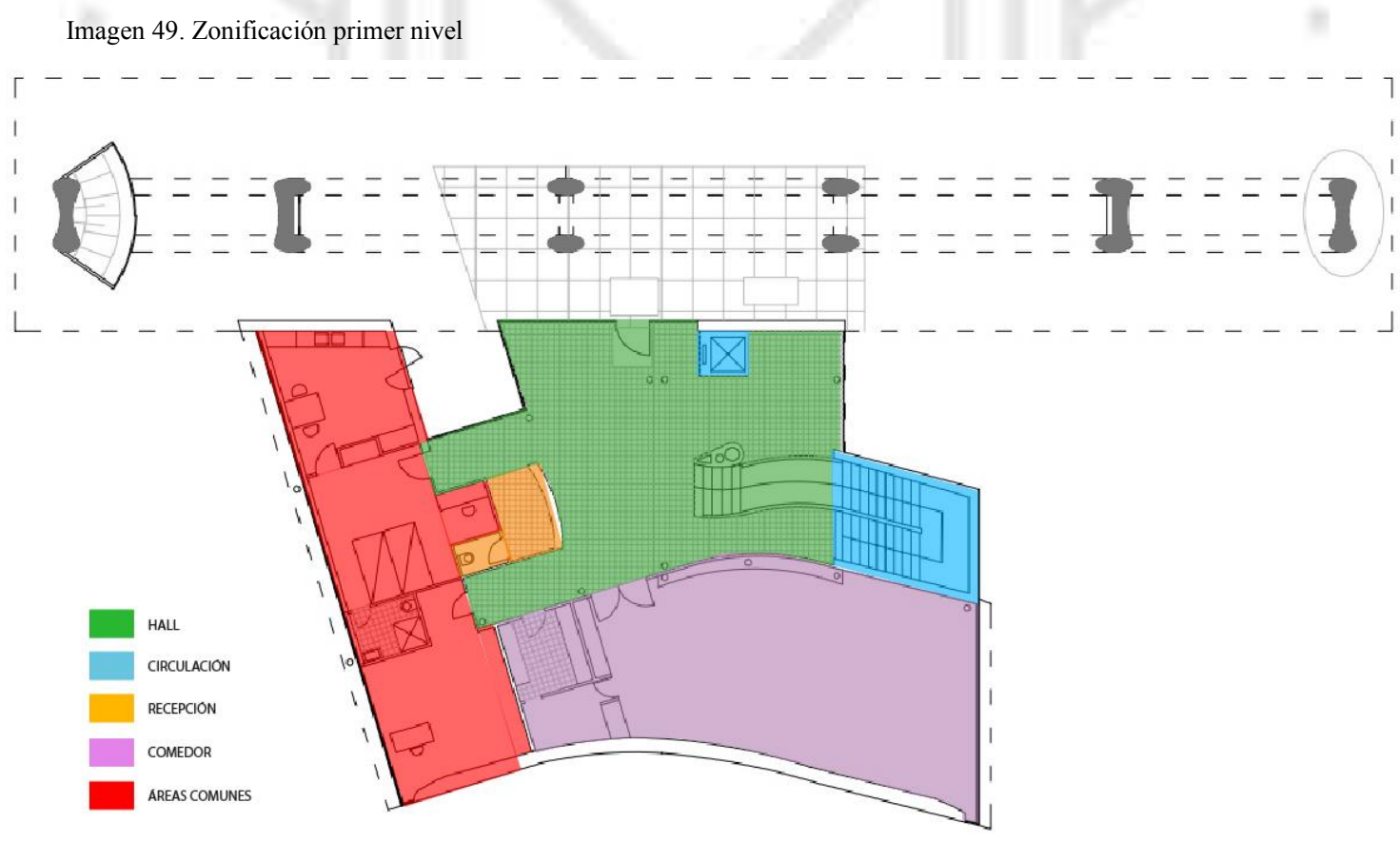


- Planta típica

Imagen 50. Zonificación planta típica

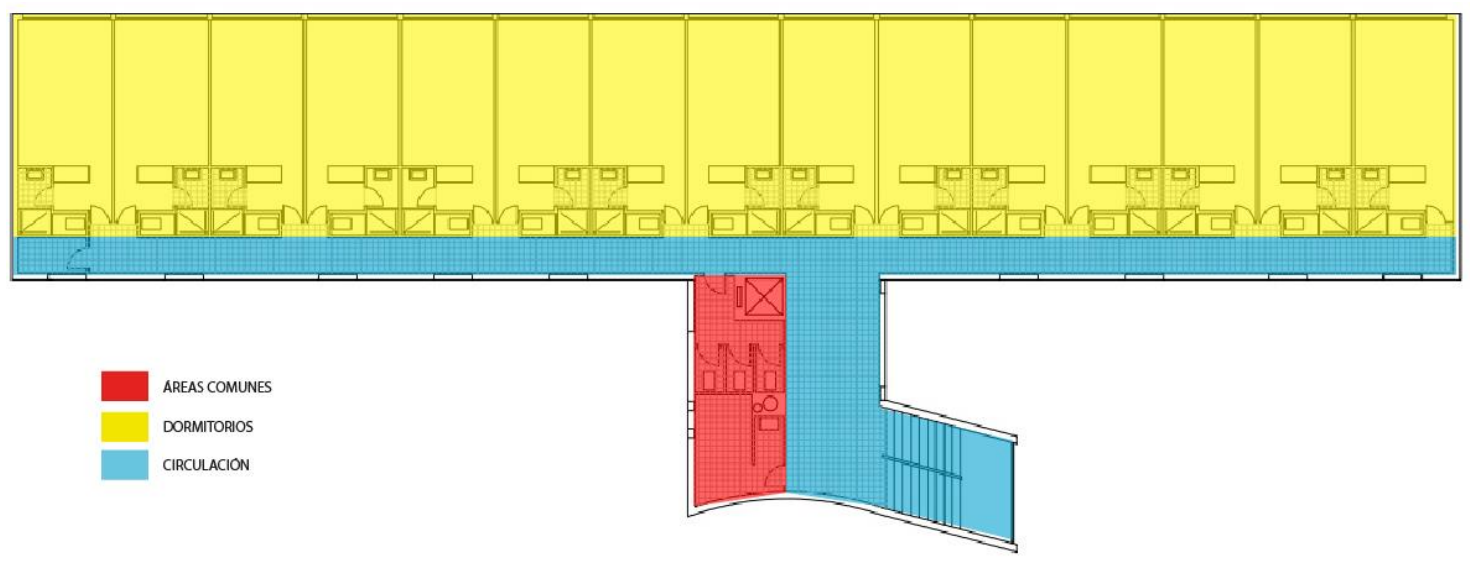

Fuente: Elaboración Propia

- Última planta

Imagen 51. Zonificación última planta

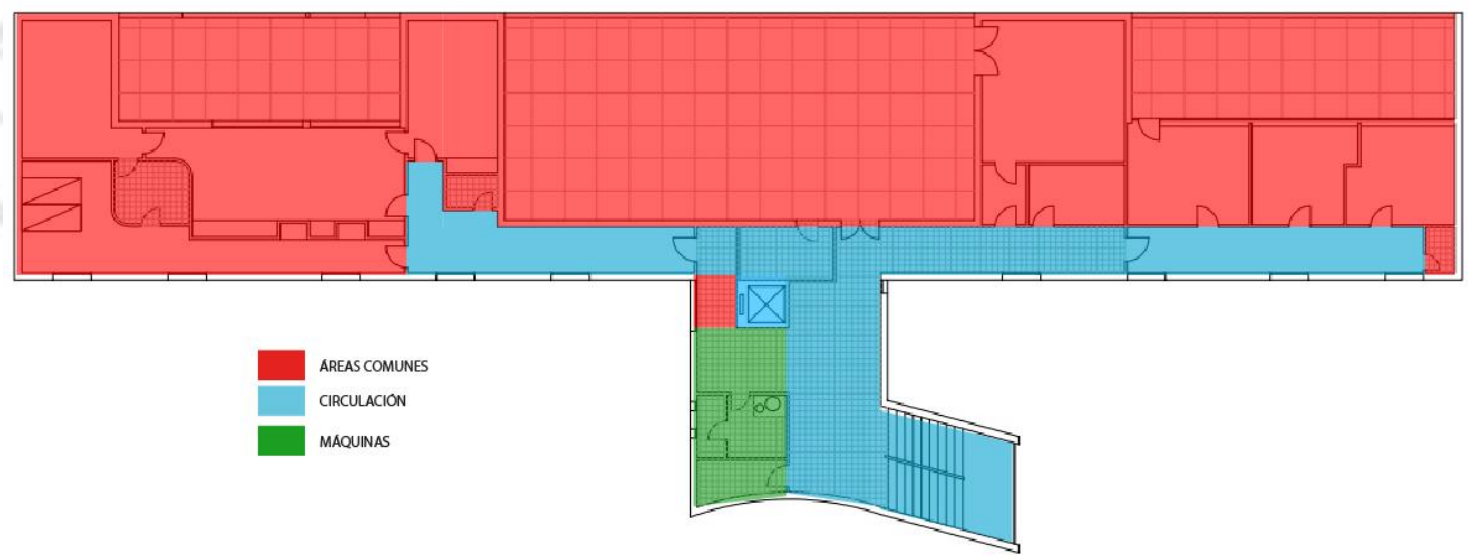

Fuente: Elaboración Propia

\subsubsection{Paquetes programáticos}

El pabellón suizo en Francia está conformado por un programa que se divide en tres bloques. El primer bloque está ubicado en la primera planta donde se encuentran todos los servicios. Posee un Hall con un $2.67 \%$ del total del área construida, el cual te lleva a la recepción que ocupa el $0.22 \%$. Detrás de la recepción aparece una habitación que es para el personal del pabellón que se encarga del cuidado. Además, en el primer nivel también se ubica el comedor de estudiantes, el cuál ocupa el 2.74\% (tamaño similar al hall). Este da a una de las fachadas del pabellón. 
El segundo bloque es un área no construida en el primer nivel, al lado del hall, el cual amarra el bloque de servicios con el de áreas privadas. El ascensor se ubica en esta zona. Al lado del ingreso se encuentra la ubicación vertical (tanto las escaleras como el ascensor. Estas circulaciones te llevan a las plantas superiores típicas, las cuales son un pasillo largo, el cual reparte las habitaciones a lo largo de la fachada. Estas habitaciones ocupan el 51.39\% del edificio, el cual es un aporte de más de la mitad a la construcción.

En el quinto y último nivel dejan de aparecer habitaciones para dar paso a las áreas comunes, las cuales ocupan más del $70 \%$ de la planta.

\subsubsection{Cuadro de áreas}

Cuadro 15. Áreas

\begin{tabular}{|c|c|c|}
\hline Ambiente & Área aprox. & Aporte \\
\hline Hall & $96.78 \mathrm{~m}^{2}$ & $2.67 \%$ \\
\hline Circulación & $776.96 \mathrm{~m}^{2}$ & $21.44 \%$ \\
\hline Recepción & $8.27 \mathrm{~m}^{2}$ & $0.22 \%$ \\
\hline Comedor & $98.17 \mathrm{~m}^{2}$ & $2.74 \%$ \\
\hline Áreas comunes & $780.23 \mathrm{~m}^{2}$ & $21.54 \%$ \\
\hline Dormitorios & $1861.8 \mathrm{~m}^{2}$ & $51.39 \%$ \\
\hline Total & $3622.21 \mathrm{~m}^{2}$ & 100 \\
\hline
\end{tabular}

Fuente: Elaboración propia 


\subsubsection{Organigrama}

Imagen 52: Organigrama

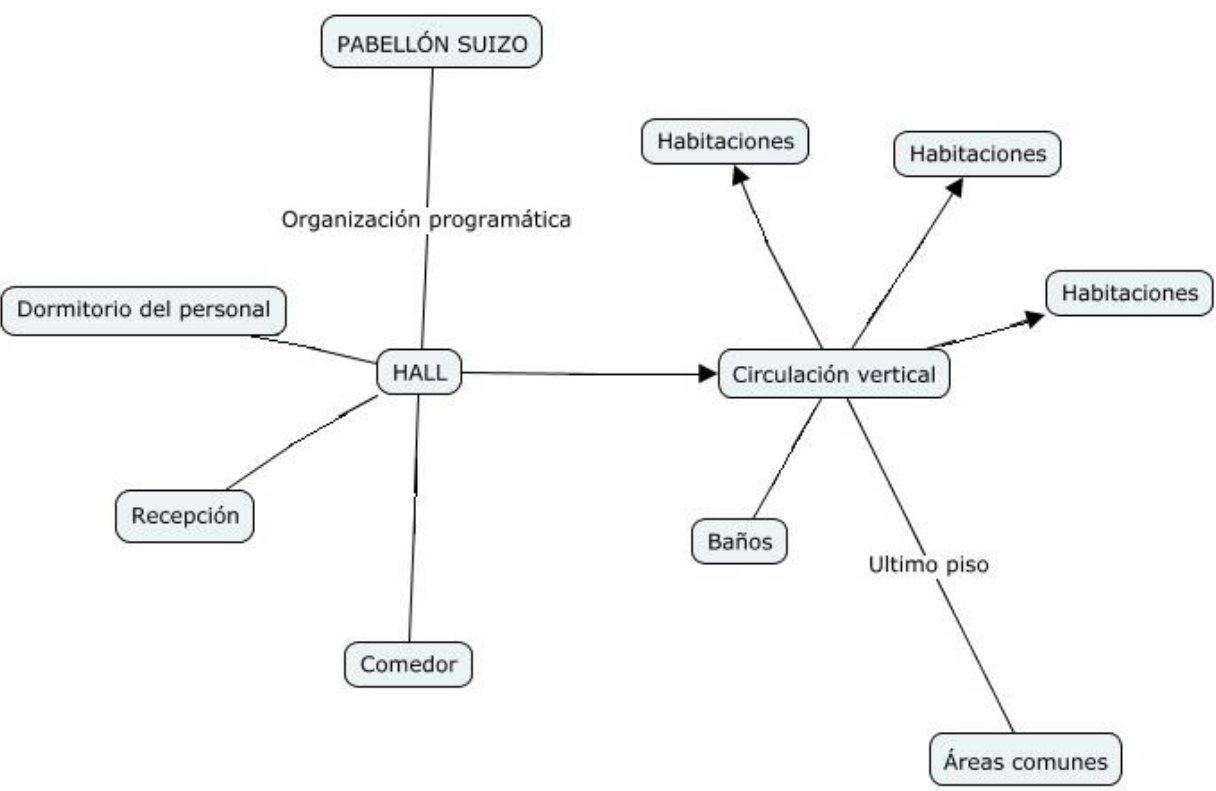

Fuente: Elaboración propia

5.3.4. Tipología

Para analizar la tipología del edificio, nos basaremos en el libro "Arquitectura: Forma, espacio y orden", escrito por D.K. Ching.

\subsubsection{Organización lineal}

El Pabellón Suizo, el cual está conformado por 2 bloques, posee una organización lineal como edificio, teniendo una forma cuadrada el primer bloque, y rectangular el segundo, emplazándose a lo largo del terreno el cual deriva en una pequeña rotonda. El edificio se adecúa al terreno ya que se encuentra ubicado en una esquina con una forma no ortogonal, y busca una buena orientación de fachadas para aprovechar el asoleamiento. 

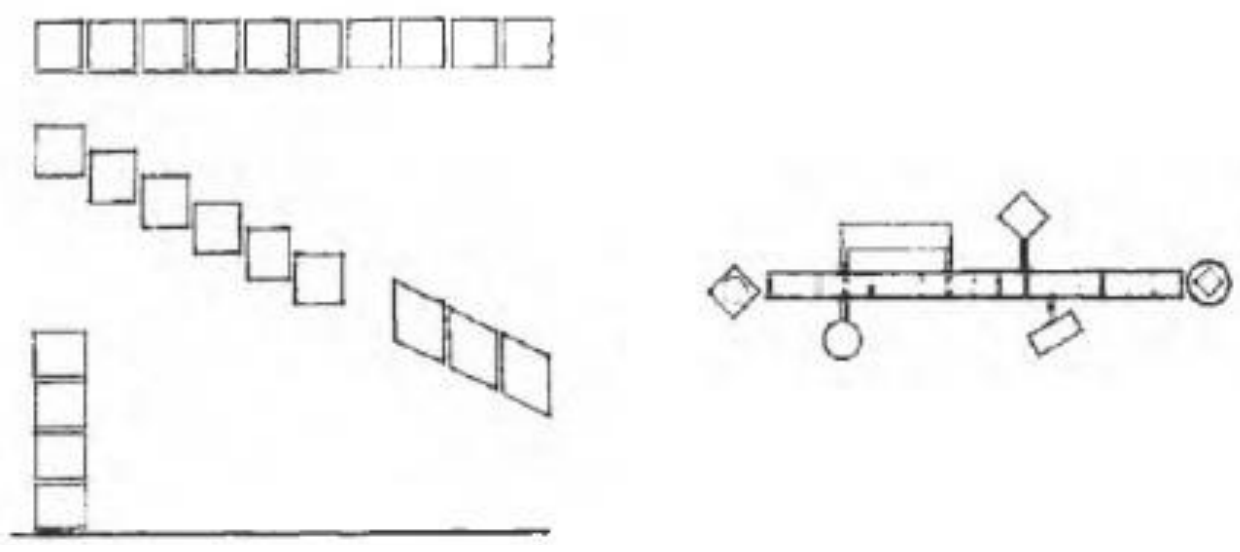

Fuente: Digitalizada del libro “Arquitectura: Forma, espacio y orden”, escrito por D.K. Ching.

\subsubsection{Aproximación al edificio}

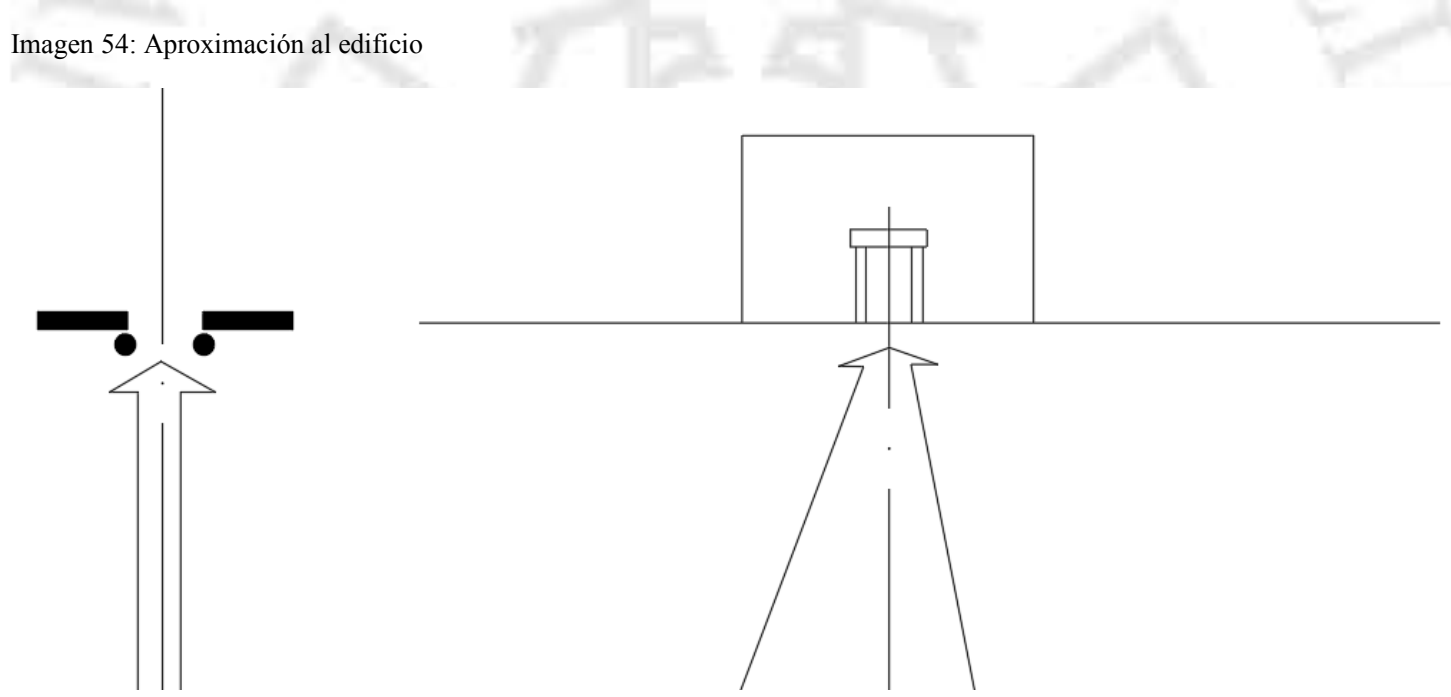

Fuente: Digitalizada del libro “Arquitectura: Forma, espacio y orden”, escrito por D.K. Ching.

Frontal: Posee una aproximación frontal al edificio al cual se accede a pie luego de que termina el recorrido vehicular en la rotonda. Primero se aprecia el bloque cuadrado como ingreso para luego ver el bloque rectangular de mayor altura que se ubica en la parte trasera.

\subsubsection{Configuración del recorrido}

El Pabellón Suizo está conformado por 2 bloques, en el primero se encuentran los servicios, el cual posee un recorrido céntrico, porque el hall comunica al resto de 
espacios; mientras que el segundo donde se encuentran todas las áreas privadas posee un recorrido lineal, teniendo un solo corredor que te lleva a todas las habitaciones.

Imagen 55: Configuración del recorrido

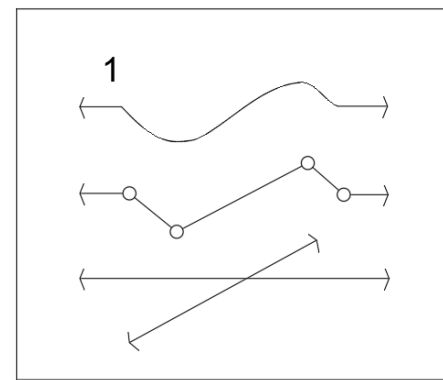

Fuente: Digitalizada del libro "Arquitectura: Forma, espacio y orden”, escrito por D.K. Ching.

\subsubsection{Relación recorrido-espacio}

Pasar entre espacios:

- Se conserva la integridad de cada espacio

- La configuración del recorrido es flexible

- Para vincular el recorrido con los espacios es posible el empleo de otros intermedios

Imagen 56: Relación recorrido-espacio

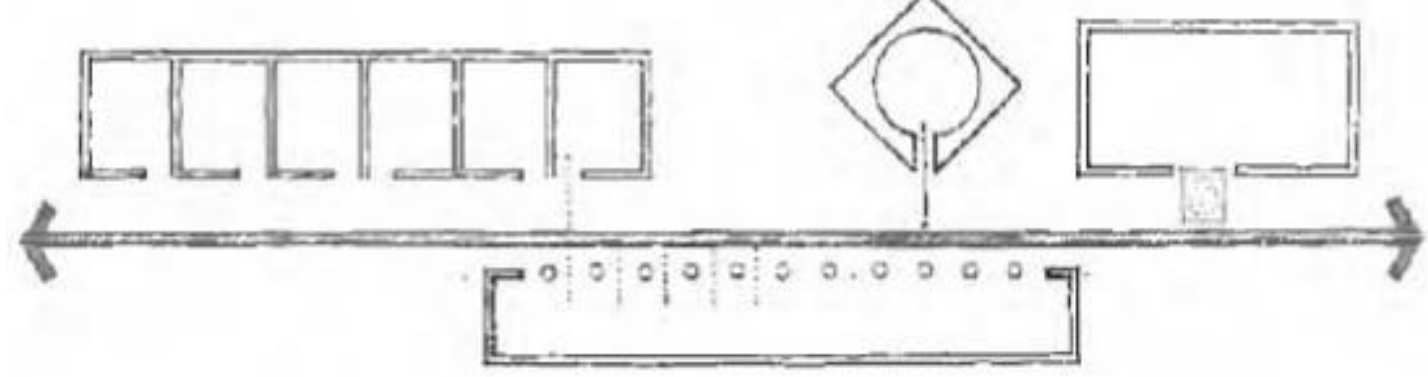

Fuente: Digitalizada del libro “Arquitectura: Forma, espacio y orden”, escrito por D.K. Ching. 


\subsubsection{Habitaciones}

Imagen 57: Habitación modelo de la residencia

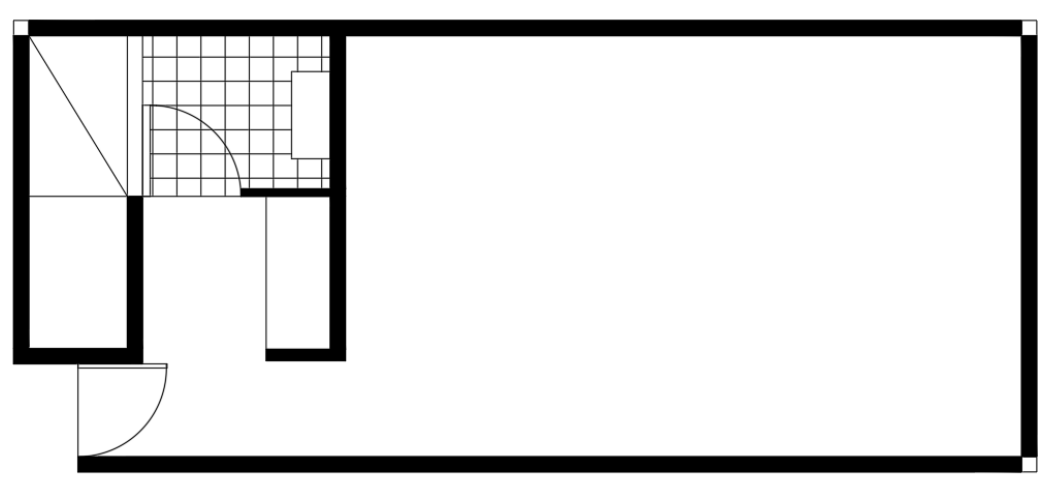

\subsubsection{Espacios}

\subsubsection{Relaciones espaciales.}

- Planta de servicios

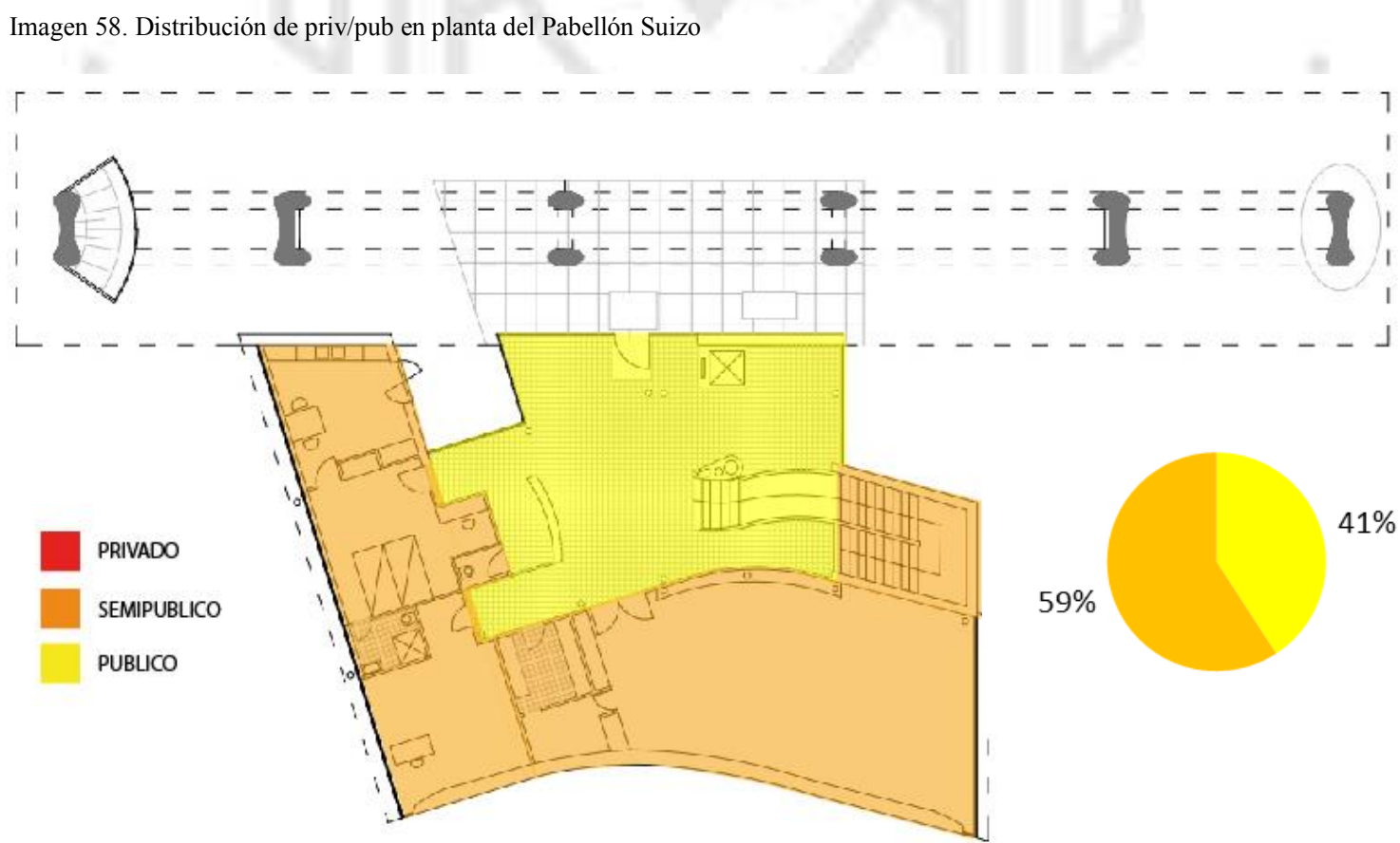

Fuente: Elaboración Propia 


\section{- Planta típica}

Imagen 59. Distribución de priv/pub en planta típica del Pabellón Suizo

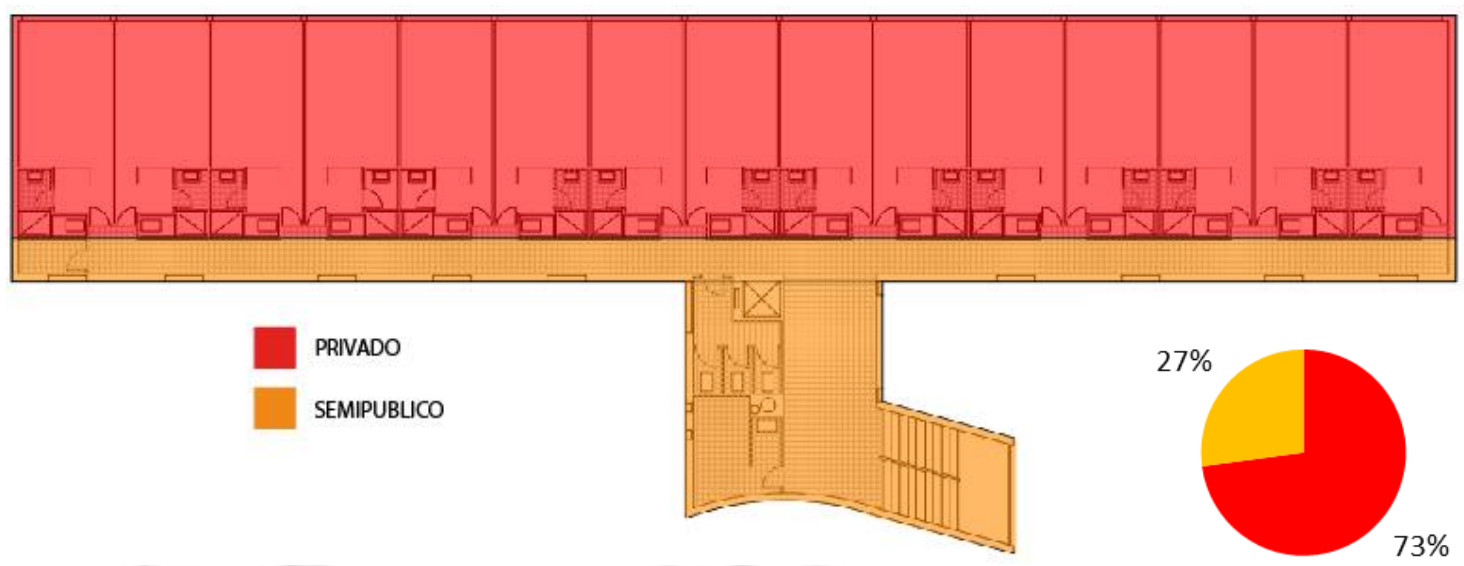

Fuente: Elaboración Propia

\section{- Última planta}

Imagen 60. Distribución de priv/pub en última planta del Pabellón Suizo

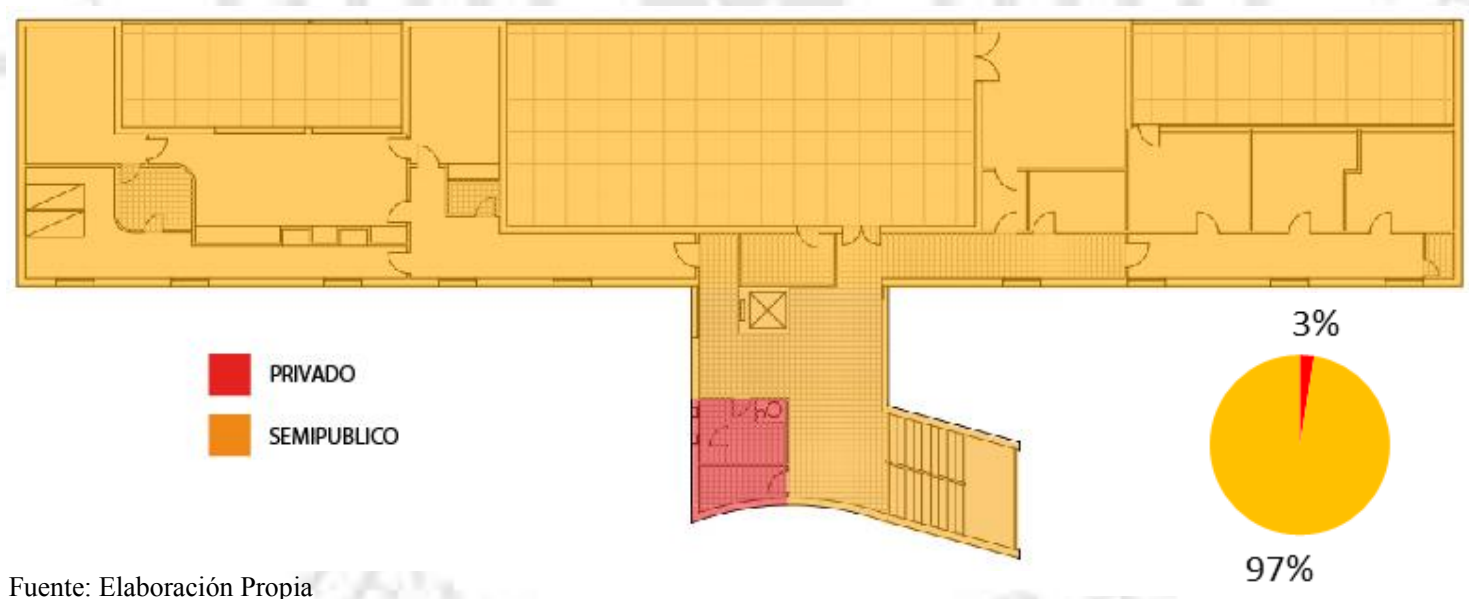


5.3.6.2. Flujos y circulaciones

\section{- Primera planta}

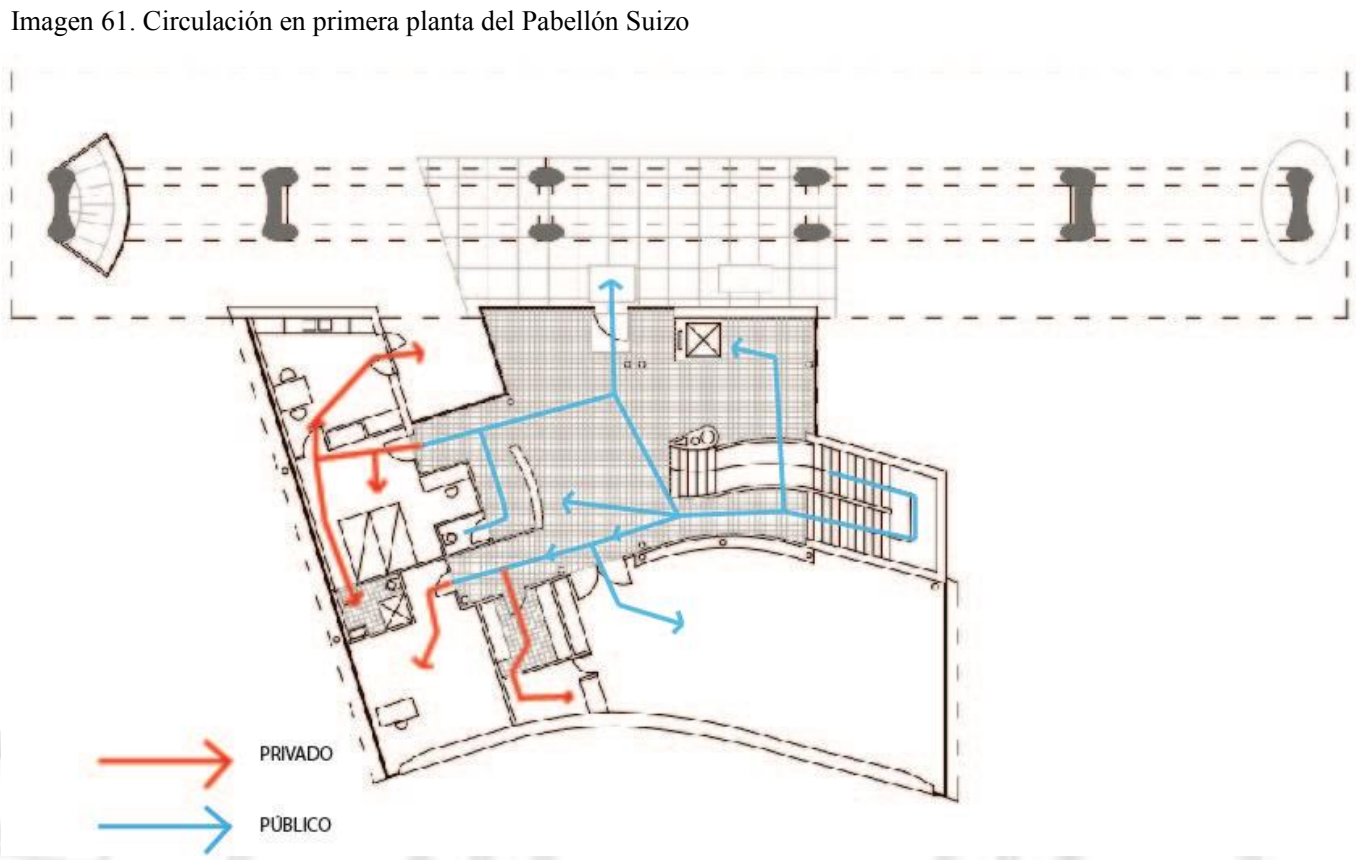

Fuente: Elaboración Propia

- Planta Típica

Imagen 62. Circulación en planta típica del Pabellón Suizo

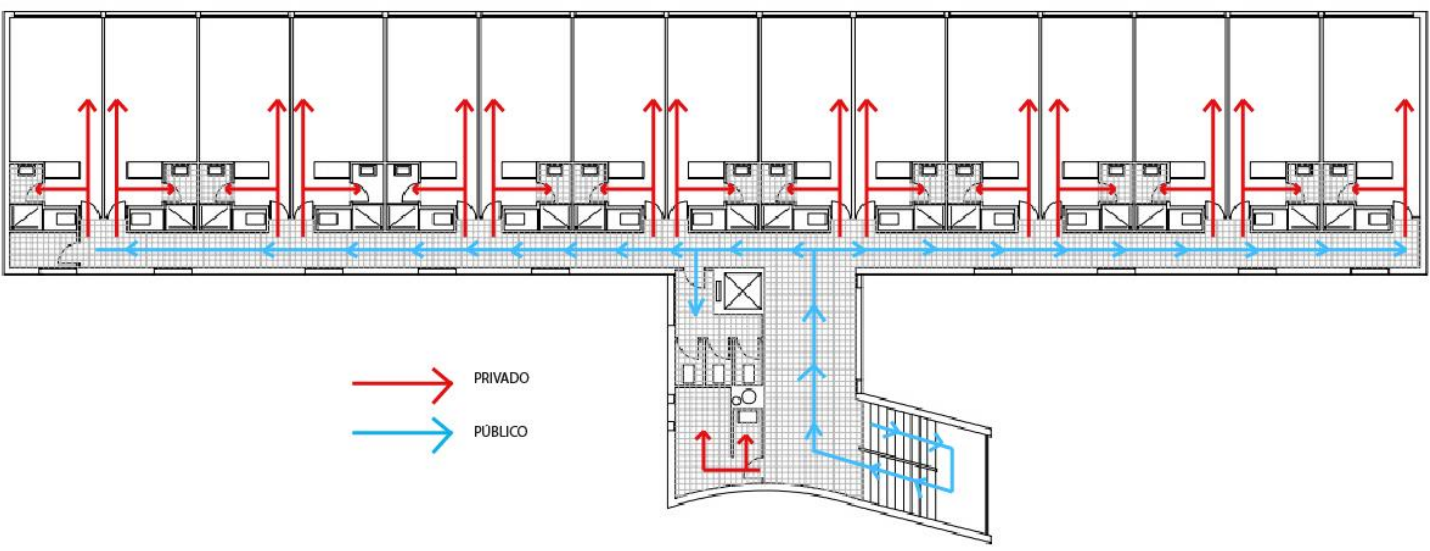

Fuente: Elaboración Propia 


\section{- Última planta}

Imagen 63. Circulación en última planta del Pabellón Suizo

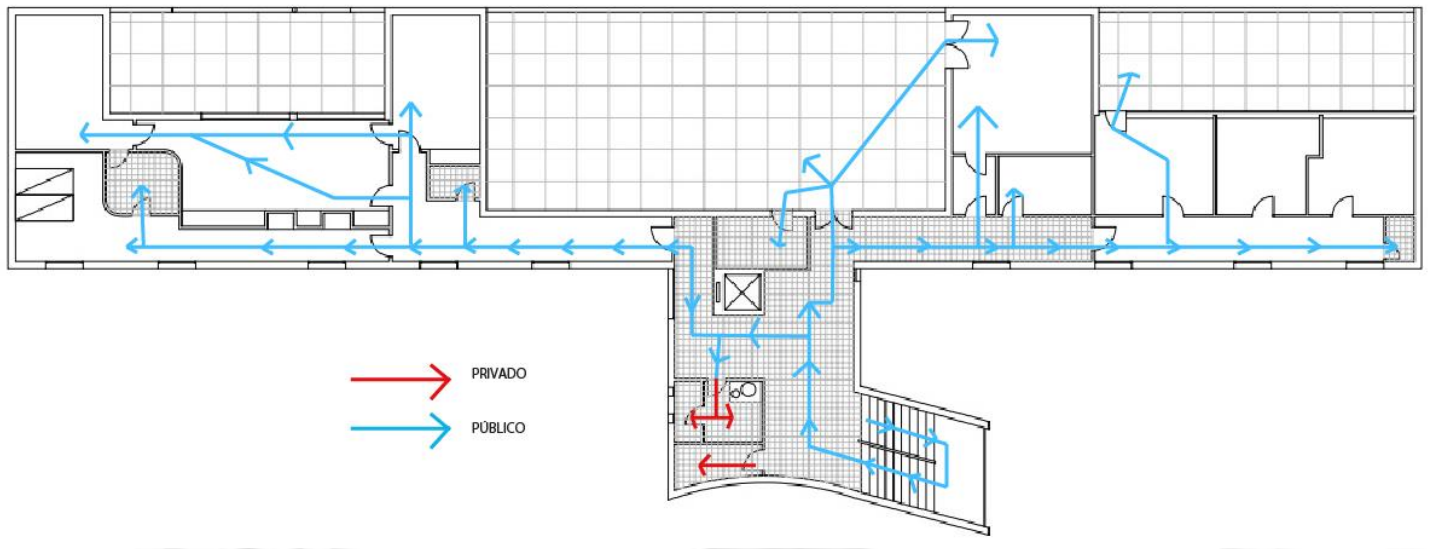

Fuente: Elaboración Propia

\subsubsection{3. Área techada - libre}

Imagen 64. Área techada del Pabellón Suizo

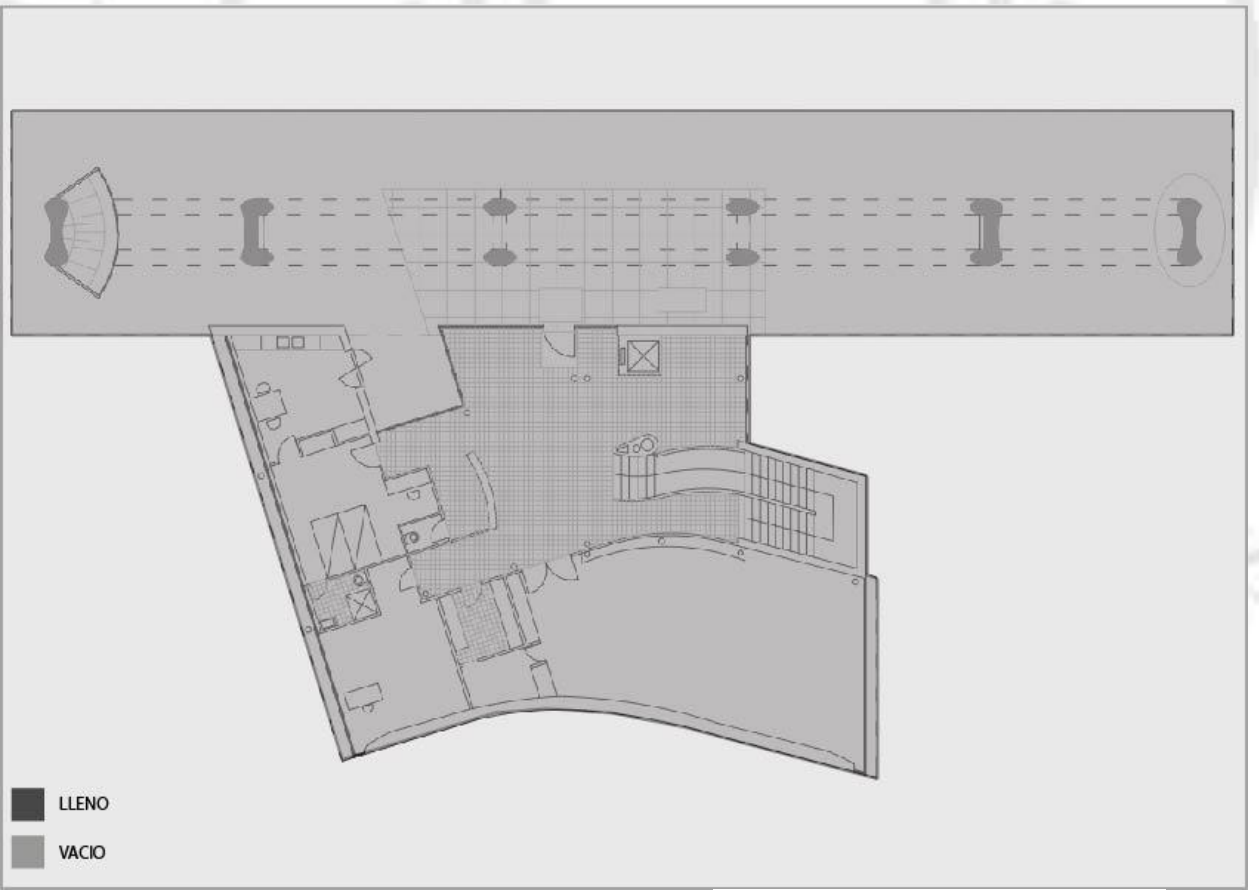

Fuente: Elaboración Propia 


\subsubsection{Tecnología}

Le Corbusier aplica los 5 puntos de la arquitectura a este proyecto: planta libre, ventanas corridas, techo jardín, pilotes, y fachada libre. Esto le permitió tener un diseño flexible en el primero nivel, ubicando el mobiliario a su gusto. Utiliza elementos estructurales sencillos, como el concreto y el acero. La fachada fue diseñada de tal manera que controle la vista y la penetración de la luz.

\subsubsection{Impacto social del proyecto}

Mejora de la calidad de vida de los estudiantes universitarios suizos, los cuales se hospedaban en residencias universitarias de baja calidad de vida. Tiene un radio de influencia de 7 a 8 cuadras, ya que está ubicado en una zona rodeada de universidades, permitiendo a los estudiantes transitar a pie hasta sus centros de estudio.

\subsubsection{Conclusiones parciales}

Este proyecto emplea las mismas estrategias proyectuales que los anteriores, pero con una distribución distinta. Todas las habitaciones se encuentran agrupadas por niveles mientras que las áreas comunes y servicios están agrupadas en el primer y último nivel. Notándose una agrupación por paquetes y una alineación de fachada frente a la calle principal. 
Imagen 65. Foto del edificio Nakagin Capsule Tower

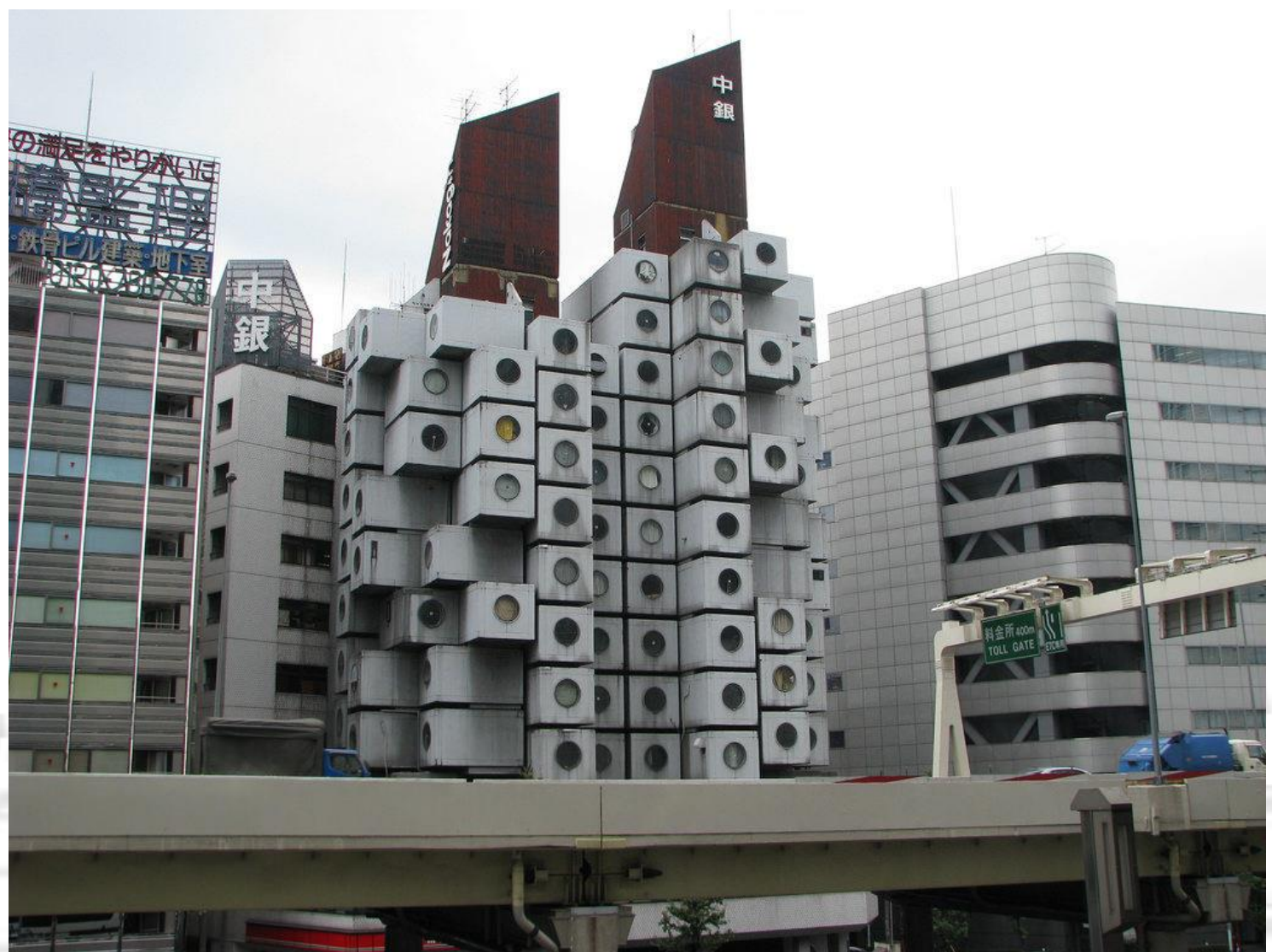

Fuente:http://www.slate.com/blogs/atlas_obscura/2013/12/02/nakagin_capsule_tower_in_tokyo_is_a_ claustrophobe_s_nightmare.html

\subsubsection{Historia del edificio}

La Nagakin Capsule Tower es el primer edificio construido basado en la idea de los habitáculos cápsulas en 1972. Su arquitecto, Kisho Kurokawa, concibió este proyecto como una megaestructura en la que se insertan los módulos habitables prefabricados, mostrando a través de su diseño las ideas de intercambiabilidad, reciclabilidad y sostenibilidad en las obras arquitectónicas.

A diferencia de la arquitectura tradicional japonesa, la Nagakin Capsule Tower no es una arquitectura acabada o completa, sino que se plantea como un edificio cambiante en el tiempo. Pese a ello, no deja de lado completamente la tradición, ya que en la pequeña escala del diseño de las cápsulas se encuentra la proporción del tatami japonés. (Wikiarquitectura, s.f.) 


\subsubsection{Relación con el entorno}

El Proyecto se ubica en uno de los barrios más caros de la ciudad. Se encuentro frente a un centro comercial y un edificio de una empresa importante como lo es Panasonic. Tiene una estación de tren cercana como transporte público importante. La Nakagin Capsule Tower también cuenta con un parque extensor a unas cuadras.

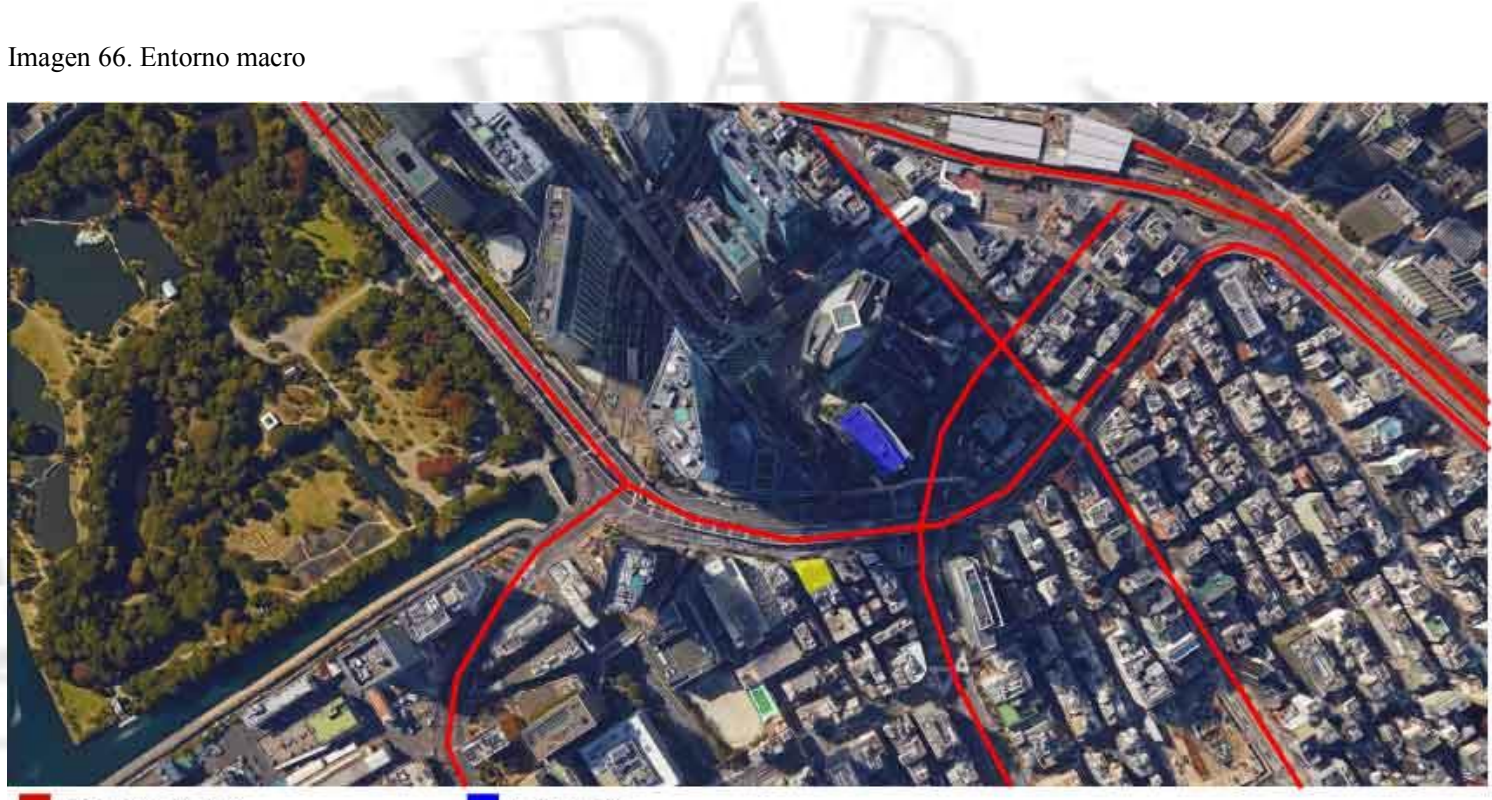

vías principales Panasonic

Nakagin Capsule Tower

Fuente: Elaboración Propia

El proyecto de la Nagakin Capsule Tower se compone de dos torres o núcleos estructurales de once y trece pisos de altura que incorporan los servicios e instalaciones; a los que se adosan 140 cápsulas de 8 tipologías diferentes. El conjunto se completa con una planta baja que ubica una cafetería y una primera planta donde se encuentran oficinas. 
Imagen 67. Entorno inmediato

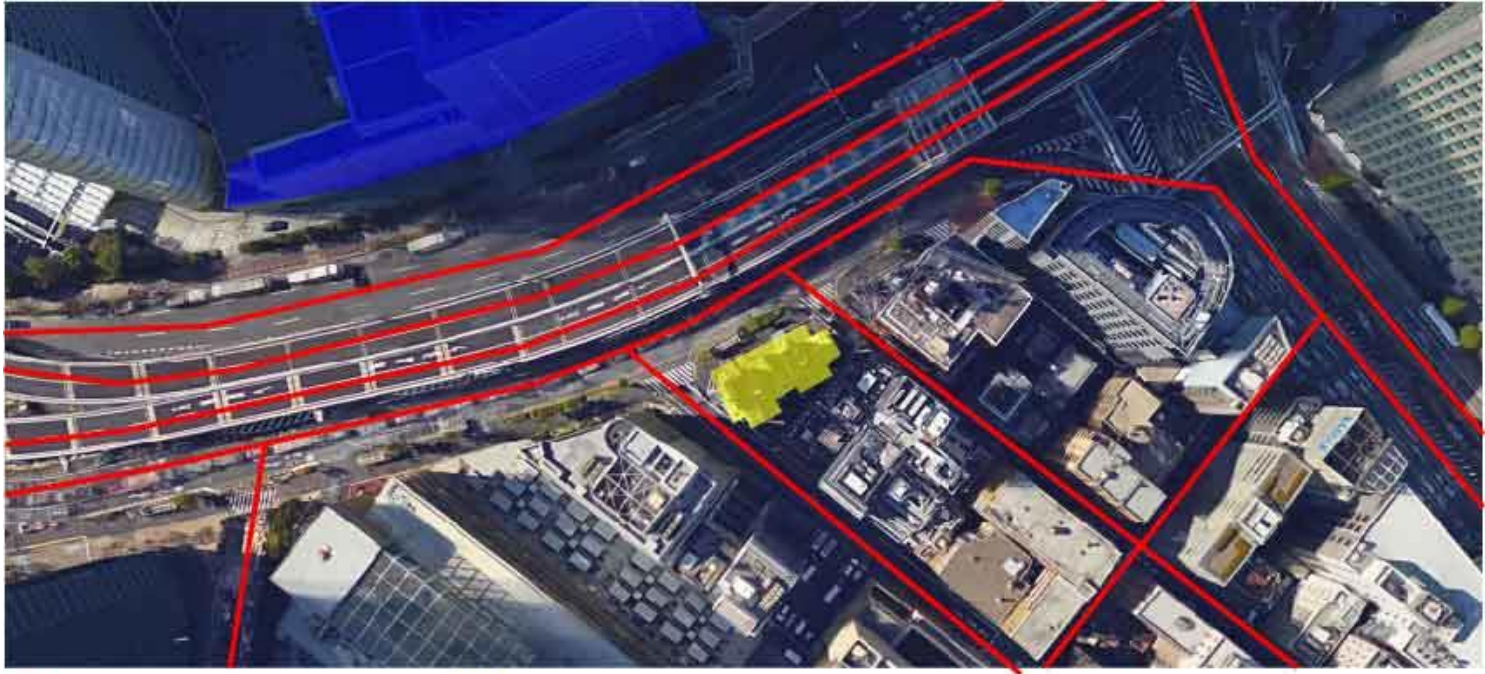

vías principales

Centro Comercial

Nakagin Capsule Tower

Fuente: Elaboración Propia

\subsubsection{Relaciones programáticas}

\subsubsection{Zonificación}

Imagen 68. Zonificación planta típica

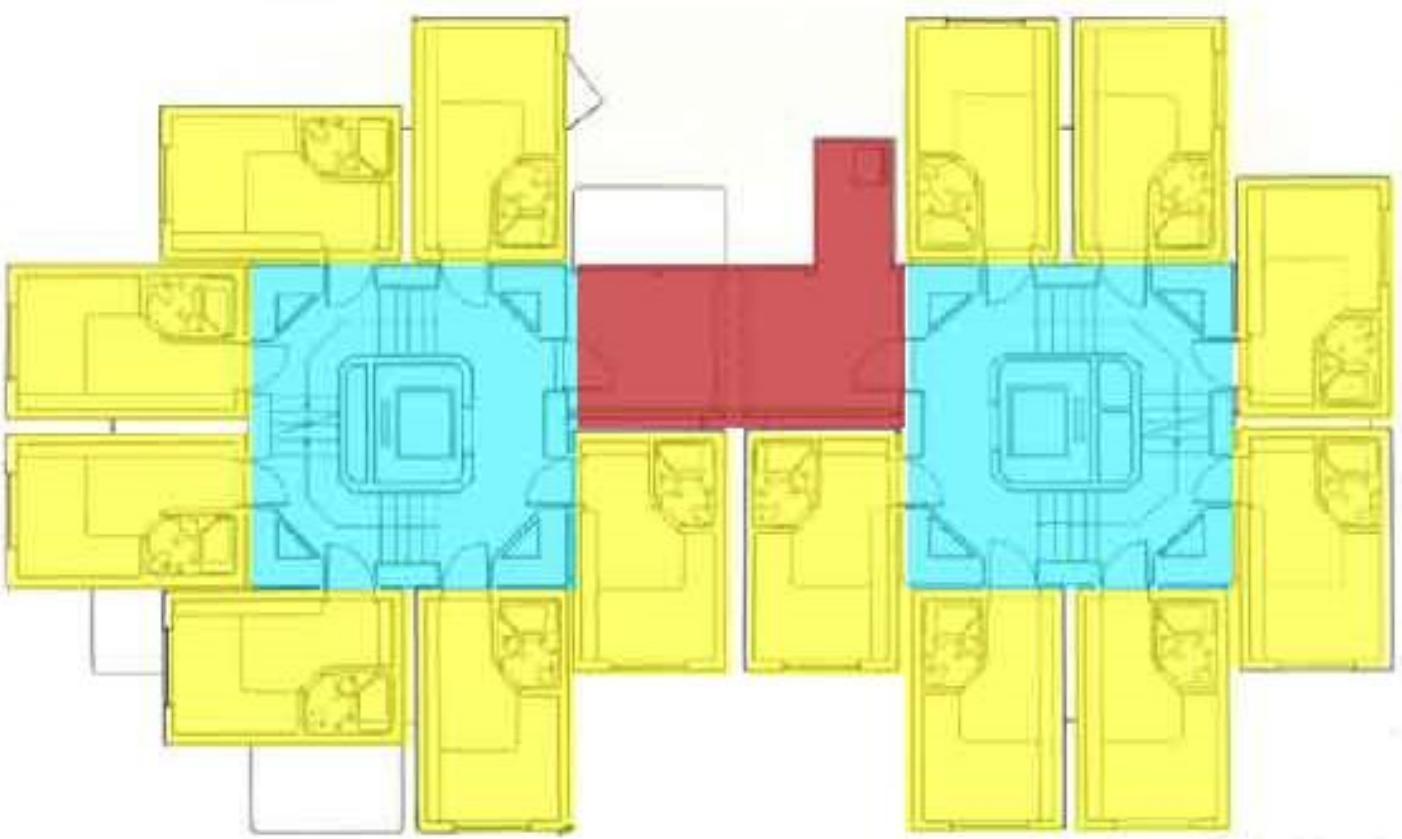

Sancbra thoor plar

\section{Servicios}

Dormitorios

Fuente: Elaboración Propia 


\subsubsection{Paquetes programáticos}

El proyecto de la Nagakin Capsule Tower se compone de dos torres o núcleos estructurales de once y trece pisos de altura que incorporan los servicios e instalaciones; a los que se adosan 140 cápsulas de 8 tipologías diferentes. El conjunto se completa con una planta baja que ubica una cafetería y una primera planta donde se encuentran oficinas. (Wikiarquitectura, s.f.)

Posee planta típica en donde la circulación ocupa el $25.02 \%$ del espacio. Los dormitorios ocupan la mayor parte de la planta con un $63.38 \%$ con módulos que cambian en los distintos pisos. Los servicios ocupan el $11.6 \%$ de la planta.

\subsubsection{Cuadro de áreas}

Cuadro 16. Cuadro de áreas por planta típica

\begin{tabular}{|c|c|c|}
\hline Ambiente & Área aprox. & Aporte \\
\hline Circulación & $67.5 \mathrm{~m}^{2}$ & $25,02 \%$ \\
\hline Dormitorios & $171.08 \mathrm{~m}^{2}$ & $63.38 \%$ \\
\hline Servicios & $31.33 \mathrm{~m}^{2}$ & $11.6 \%$ \\
\hline Total & $269.91 \mathrm{~m}^{2}$ & $100 \%$ \\
\hline
\end{tabular}

Fuente: Elaboración propia

\subsubsection{Tipología espacial}

Para analizar la tipología del edificio, nos basaremos en el libro "Arquitectura: Forma, espacio y orden", escrito por D.K. Ching.

\subsubsection{Organización agrupada}

La organización agrupada de la residencia universitaria de la Nakagin Capsule Tower es apreciada por los bloques de dormitorios simétricos, los cuales se organizan 
en torno al pasillo y a la circulación vertical. Otra característica que define la organización de esta residencia es la simetría, la cual puede verse al situarse en el hall intermedio.

\subsubsection{Forma y espacio}

La residencia está organizada en torno a una circulación vertical al centro.

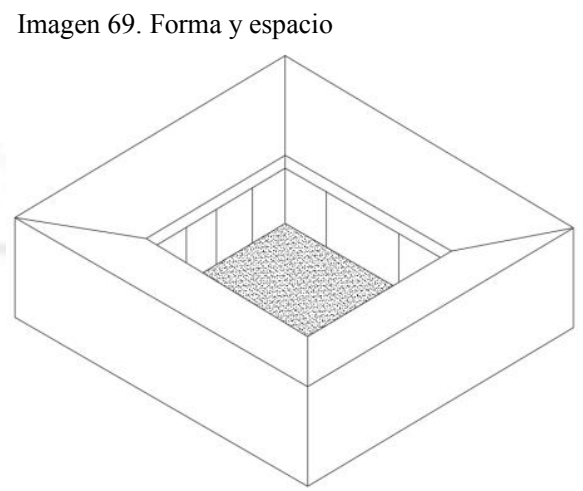

Fuente: Digitalizada del libro "Arquitectura: Forma, espacio y orden", escrito por D.K. Ching.

\subsubsection{Organización centralizada}

La Nakagin Capsule Tower se caracteriza por tener módulos iguales en cada planta, pero distribuidos de distinta manera, lo que genera movimiento en sus fachadas. el centro se convierte en la única circulación semiprivada, y los servicios comunes frente a los dormitorios son los espacios secundarios como parte de la configuración del edificio.

Imagen 70. Organización centralizada
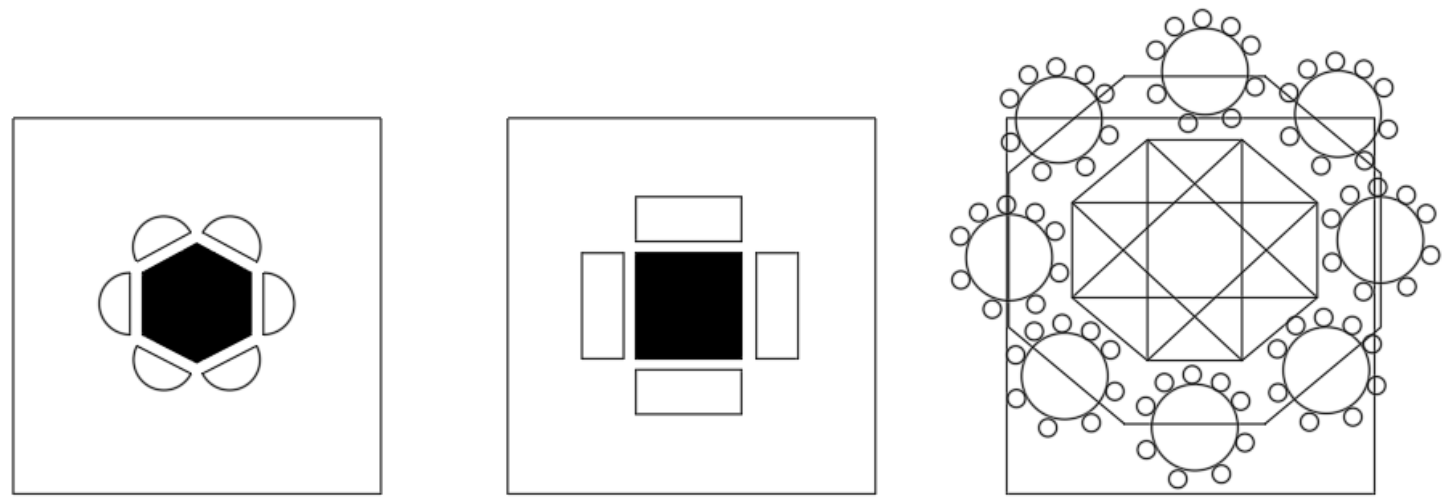

IGLESIA IDEAL, LEONARDO DA VINC

Fuente: Digitalizada del libro “Arquitectura: Forma, espacio y orden”, escrito por D.K. Ching. 


\subsubsection{Frontal:}

La aproximación al edificio es frontal. La fachada de ingreso se puede apreciar desde una distancia considerable, y se llega luego de pasar un área común en el área libre del terreno. Se llega de manera directa sin tener que desviarse en algún momento del recorrido.

Imagen 71. Aproximación al edificio
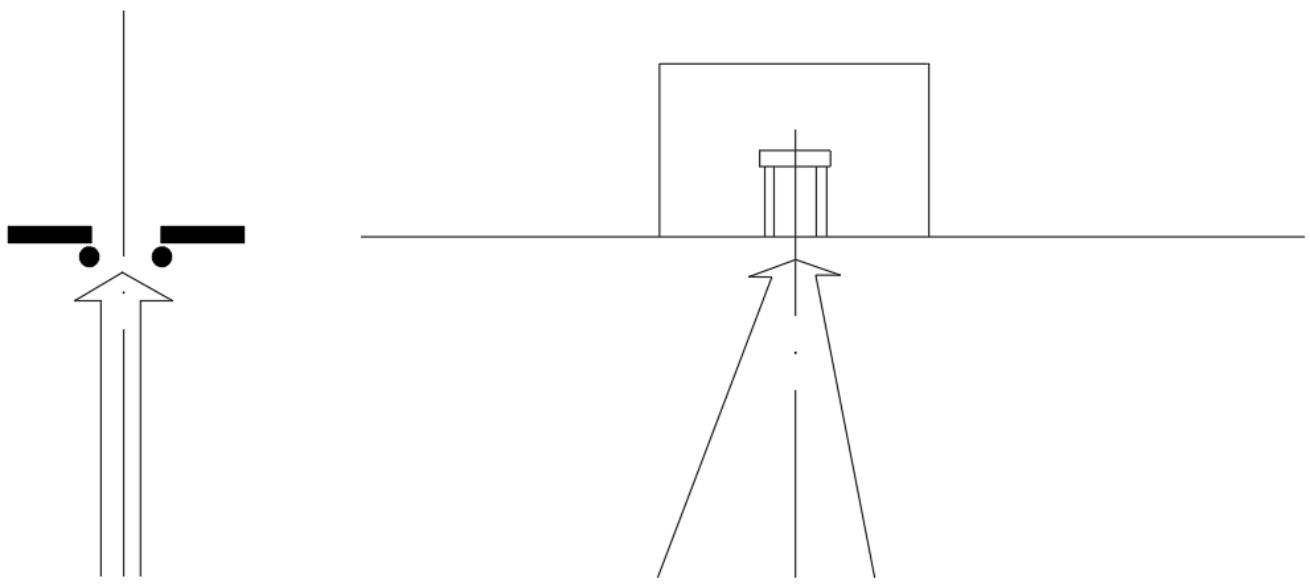

Fuente: Digitalizada del libro “Arquitectura: Forma, espacio y orden”, escrito por D.K. Ching.

\subsubsection{Espacios}

\subsubsection{Relaciones espaciales}

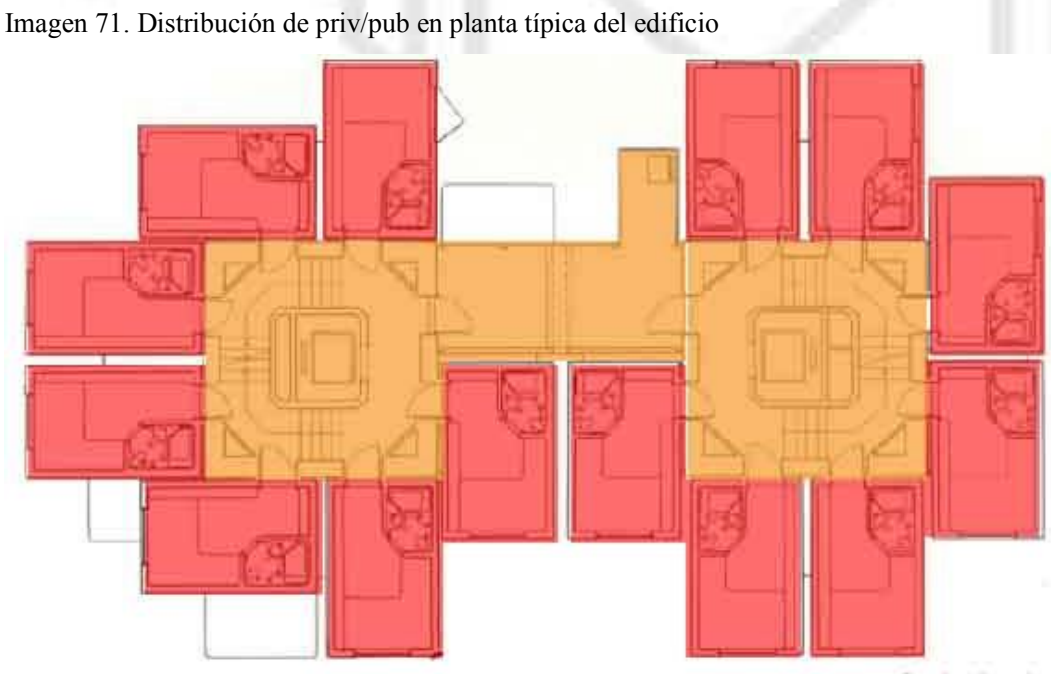

Privado

Semiprivado

Fuente: Elaboración Propia 


\subsubsection{Flujos y circulaciones}

Imagen 72. Circulación en planta típica del edificio
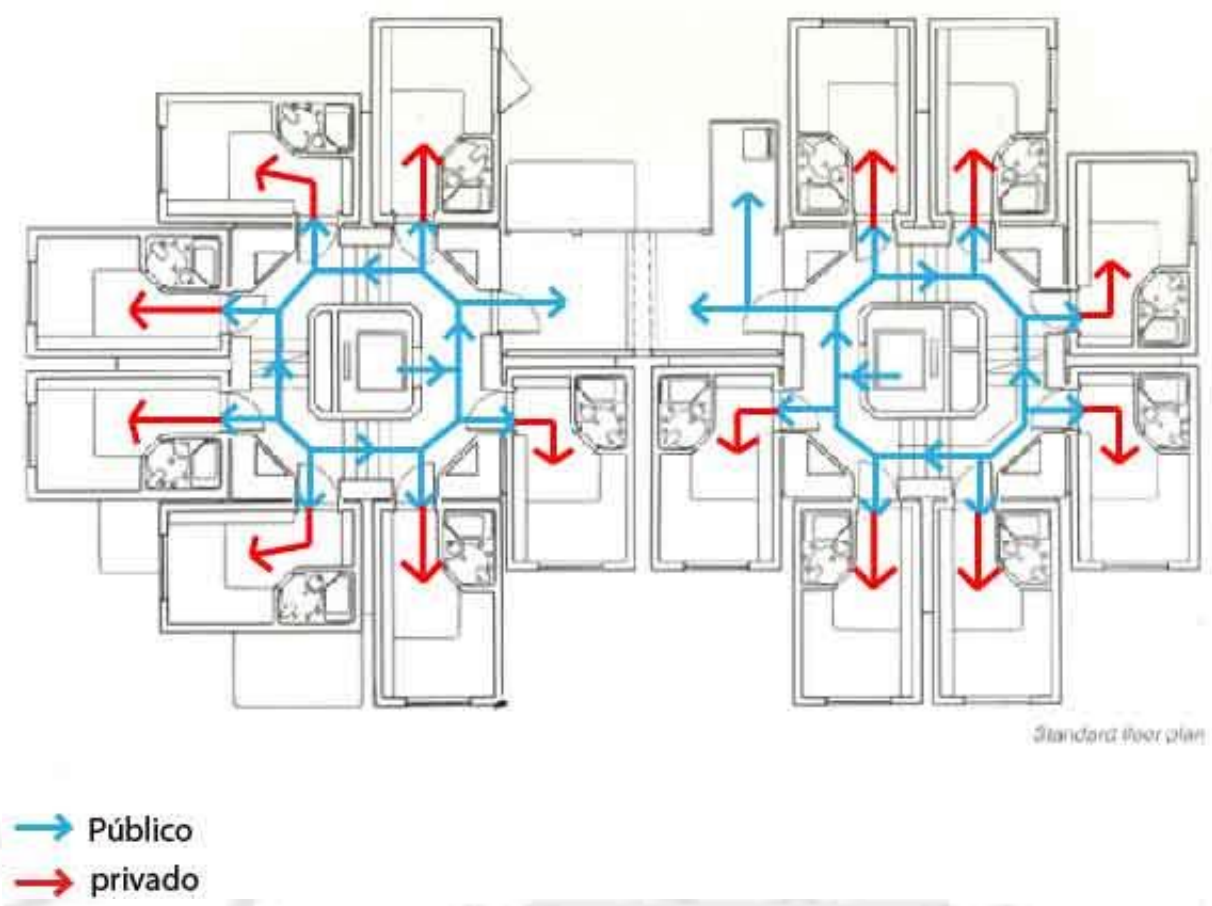

Fuente: Elaboración Propia

\subsubsection{3. Área techada y libre}

\section{Imagen 73. Área techada en planta típica del edificio}

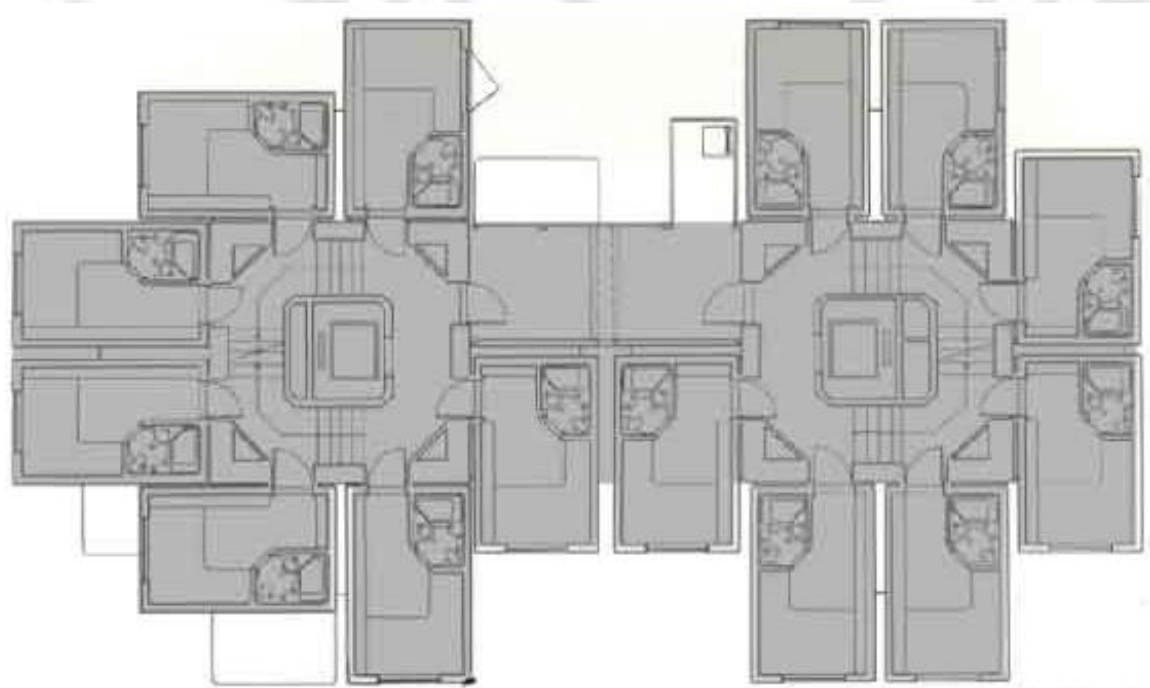

Jtandang ther plas

\section{Techado \\ Vacío}

Fuente: Elaboración Propia 


\subsubsection{Tecnología}

Las cápsulas se idean como módulos que cubren las necesidades básicas de un habitáculo. Son concebidas como una pieza económica que será construida en fábrica y transportada al emplazamiento del edificio para ser insertada in situ, por lo que deben ser fácilmente transportables y ligeras. Dado que se prevé una duración aproximada de las cápsulas de veinte años como máximo, éstas también deben ser fácilmente reemplazables.

Estas células prefabricadas tienen unas dimensiones de 4 x 2,5 m. Se proyectan ocho tipologías de cápsulas en función de la posición de su ventana, la disposición de la entrada, la colocación del mobiliario y los materiales de los acabados. Como resultado de estas tipologías surgen cápsulas super-deluxe, deluxe y estándar. (Wikiarquitectura, s.f.)

\subsubsection{Impacto social del proyecto}

Debido a su emplazamiento en uno de los barrios de más actividad económica de la ciudad de Tokio, Japón, el edificio fue pensado especialmente para aquellas personas que trabajaban en el centro de Tokio pero que vivían en los suburbios, a distancias considerables, o incluso en otras ciudades, pero que por negocios tenían que permanecer en el centro de Tokio. Por ello el proyecto tenía la función de servir como hotel, edificio dormitorio o estudio. (Wikiarquitectura, s.f.)

\subsubsection{Conclusiones parciales}

Este proyecto posee una estrategia proyectual homogénea. Son dos torres de circulación vertical a las cuales van adosadas los módulos de habitaciones, las cuales pueden cambiar de posición. Es una estrategia interesante porque permite la diversidad de opciones a realizarse dentro del proyecto, de acuerdo a las condiciones del entorno. El uso de módulos de habitaciones en el proyecto es lo que permite dar un sentido único a la fachada brindando dinamismo en todos sus frentes. Esta estrategia puede aplicarse en el proyecto a realizar, utilizando los módulos que serán diseñados para generar una fachada interesante, así como también relaciones espaciales al interior del proyecto entre los distintos niveles de habitaciones. 


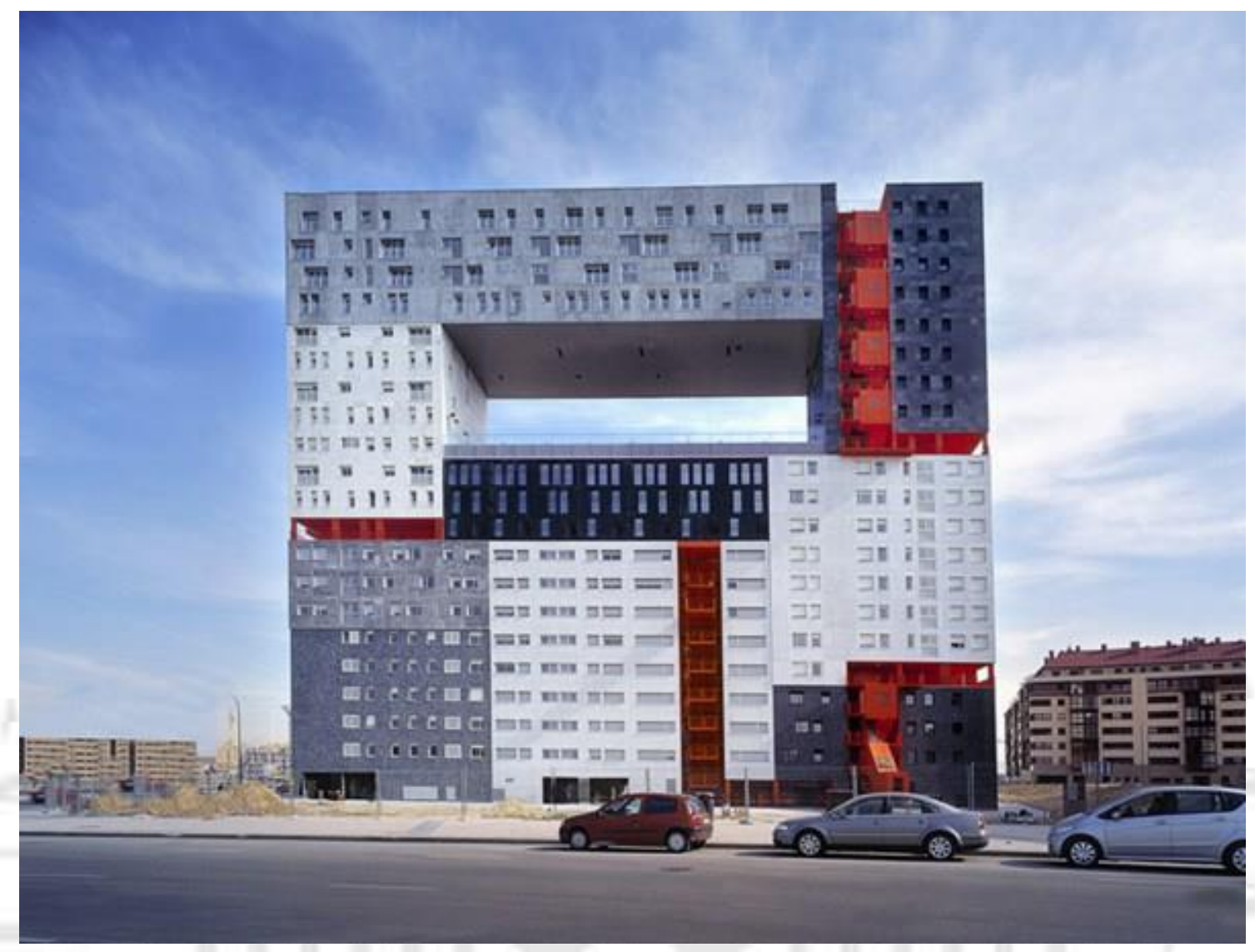

Fuente: http://www.3dsign.es/los-mejores-arquitectos-mvrdv/

\subsubsection{Historia del edificio}

El proyecto de viviendas en altura, proyectado por los arquitectos holandeses en colaboración con la arquitecta madrileña Blanca Lleó, quiere romper la excesiva homogeneidad del trazado previsto por el planeamiento, que contempla, en la casi totalidad de las parcelas residenciales, la configuración de manzana cerrada de 6 plantas. Sin embargo, el volumen proyectado para la parcela TR-22, se desarrolla en 21 plantas y emerge como referente para la ciudad y el territorio. (Wiki Arquitectura, 2001)

\subsubsection{Relación con el entorno}

En resumen, la propuesta quiere abrir la arquitectura doméstica al entorno de la ciudad 
nueva, al territorio próximo [los nuevos barrios, las redes de circulación, la sierra de Guadarrama] y también, porque no, al contexto mediático que nos rodea.

La plaza de la edificación en altura libera será un espacio colectivo. En este jardín abierto, la escultora Cristina Iglesias llevará a cabo una singular pieza de relieve y agua que además de dotar de un valor singular al entorno urbano, establecerá un especial diálogo con el edificio: la dimensión de esta escultura tiene las medidas del mirador y hace referencia a él como reflejo de un espacio desplazado y reflejado en altura. Se trata de jugar con la movilidad del agua introduciendo un elemento de relación con el tiempo y la vida del espectador, el paseante y el habitante. (arquitectura blanca, 2006)

Por otra parte, el gran mirador situado a 36,850 metros del suelo, ofrece a los vecinos un jardín comunitario y un espacio al aire libre en altura, donde encontrarse y gozar de las vistas.

El edificio es un encuadre y un observatorio del horizonte lejano. La construcción proyectada, al elevarse, permite liberar en gran parte la ocupación de la parcela; así se hace posible la cesión de una parte del terreno privado en beneficio del disfrute social colectivo. Se contribuye de este modo a la generación del espacio público necesario que la ciudad contemporánea demanda. (EcuRed, 2005)

Se puede apreciar que el edificio se encuentra ubicado frente a un óvalo, el cual es el desemboque de las 4 avenidas principales que hay alrededor de la zona. Como complemento, se tienen las calles radiales en torno al óvalo, que van configurando las manzanas y generando calles adicionales. Toda la zona es residencial, no hay servicios ni universidades cerca, salvo un par de tiendas.

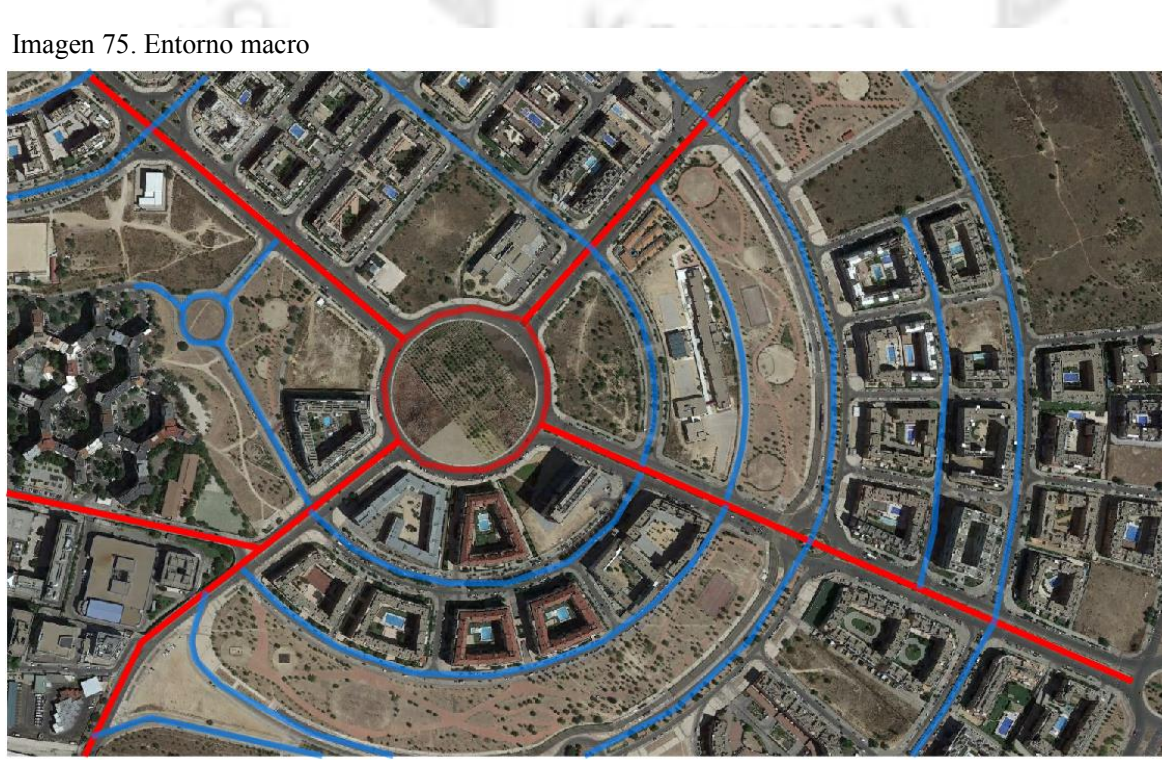

Avenidas Principales

$\square$ Calles conectoras

Fuente: Elaboración

Propia 
Tomando el contexto más cercano, se puede ver que las manzanas van posicionándose de manera radiar en torno al óvalo, siendo el terreno del edificio el más libre de todos, ya que aprovecha una mínima parte de este para su construcción, generando un área pública importante en lo que resta del terreno.

Imagen 76. Entorno inmediato

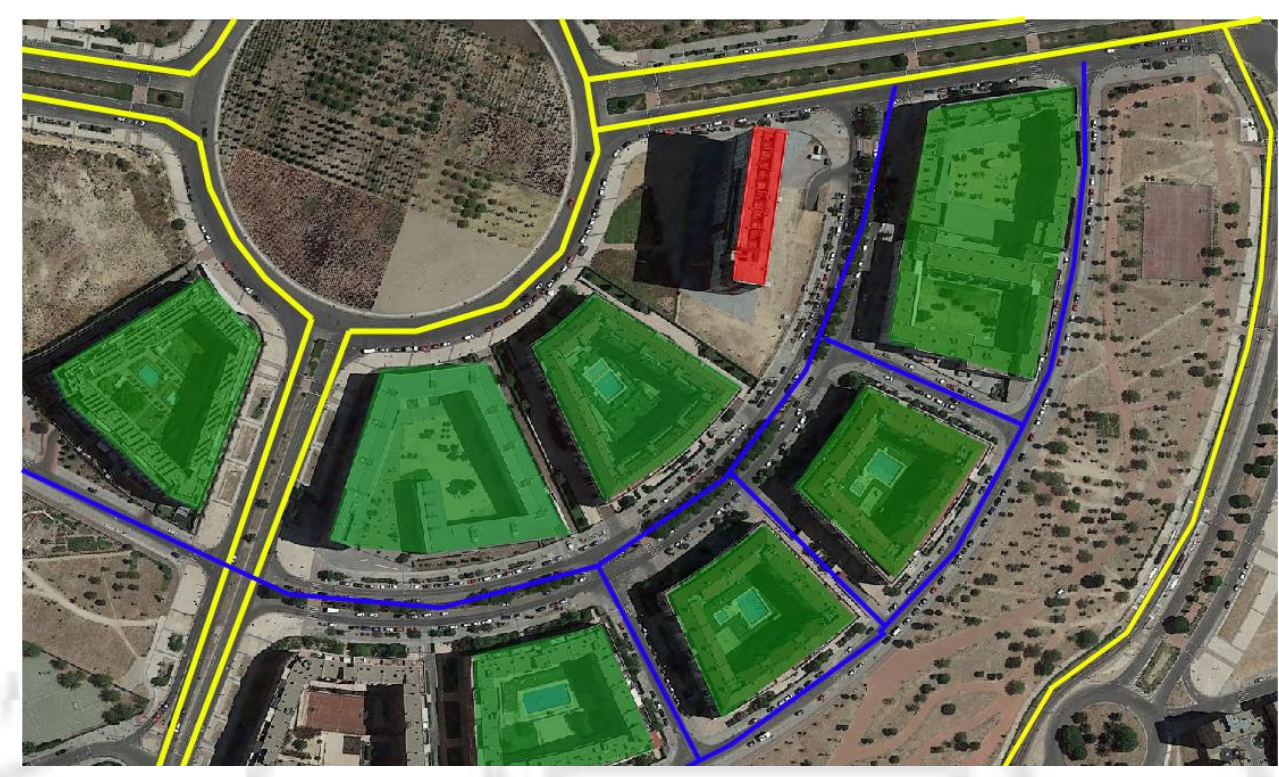

Fuente: Elaboración Propia

Avenidas Principales

Residencias

Calles conectoras

Edificio Mirador 
5.5.3. Programa y relaciones programáticas

\subsubsection{Zonificación}

- Planta 3 y 4

Imagen 77. Zonificación planta 3 y 4
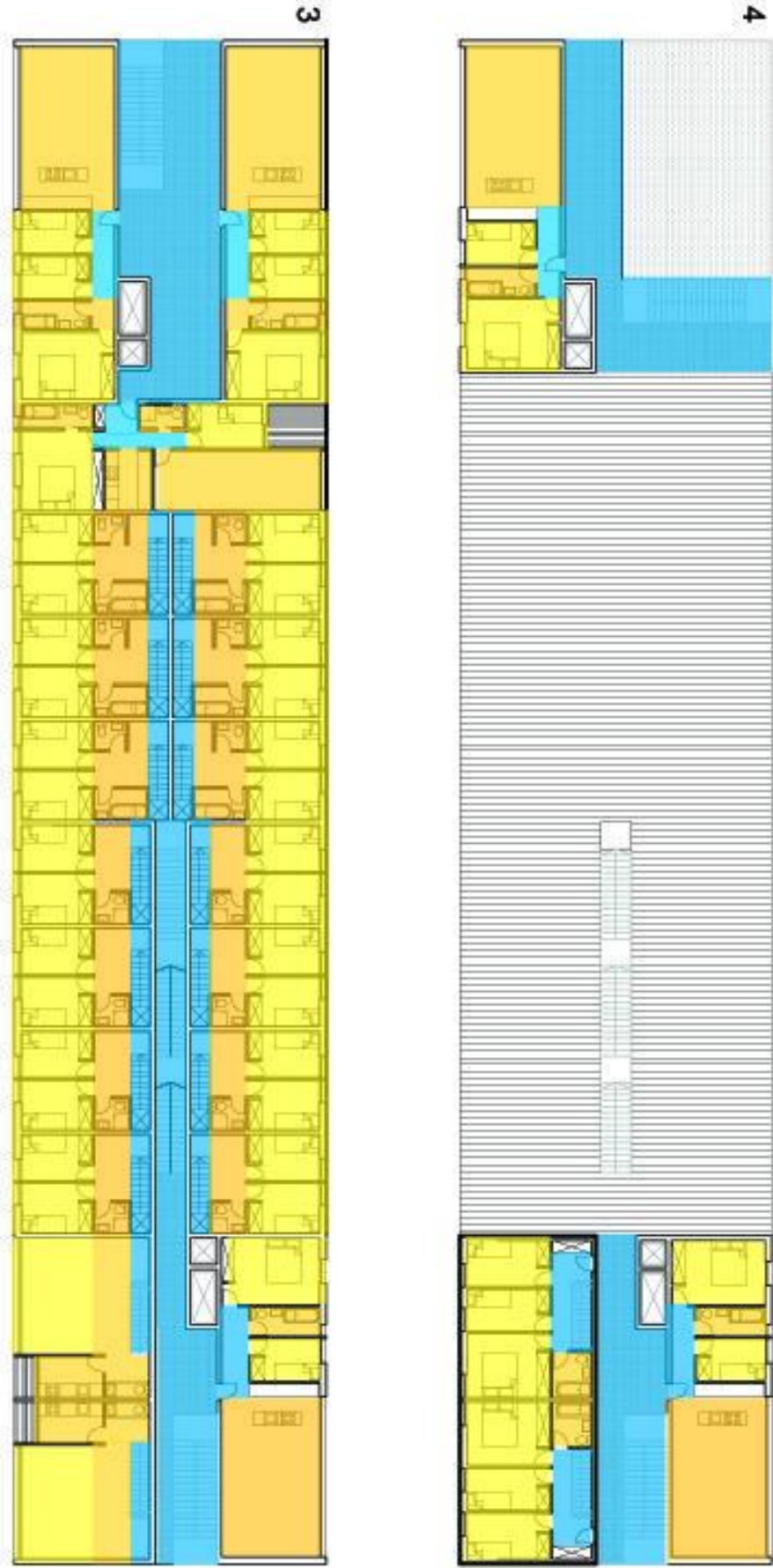

AREAS COMUNES

DORMTOFIOS

GARCULACION

Fuente: Elaboración propia 
- Planta 4 y 5
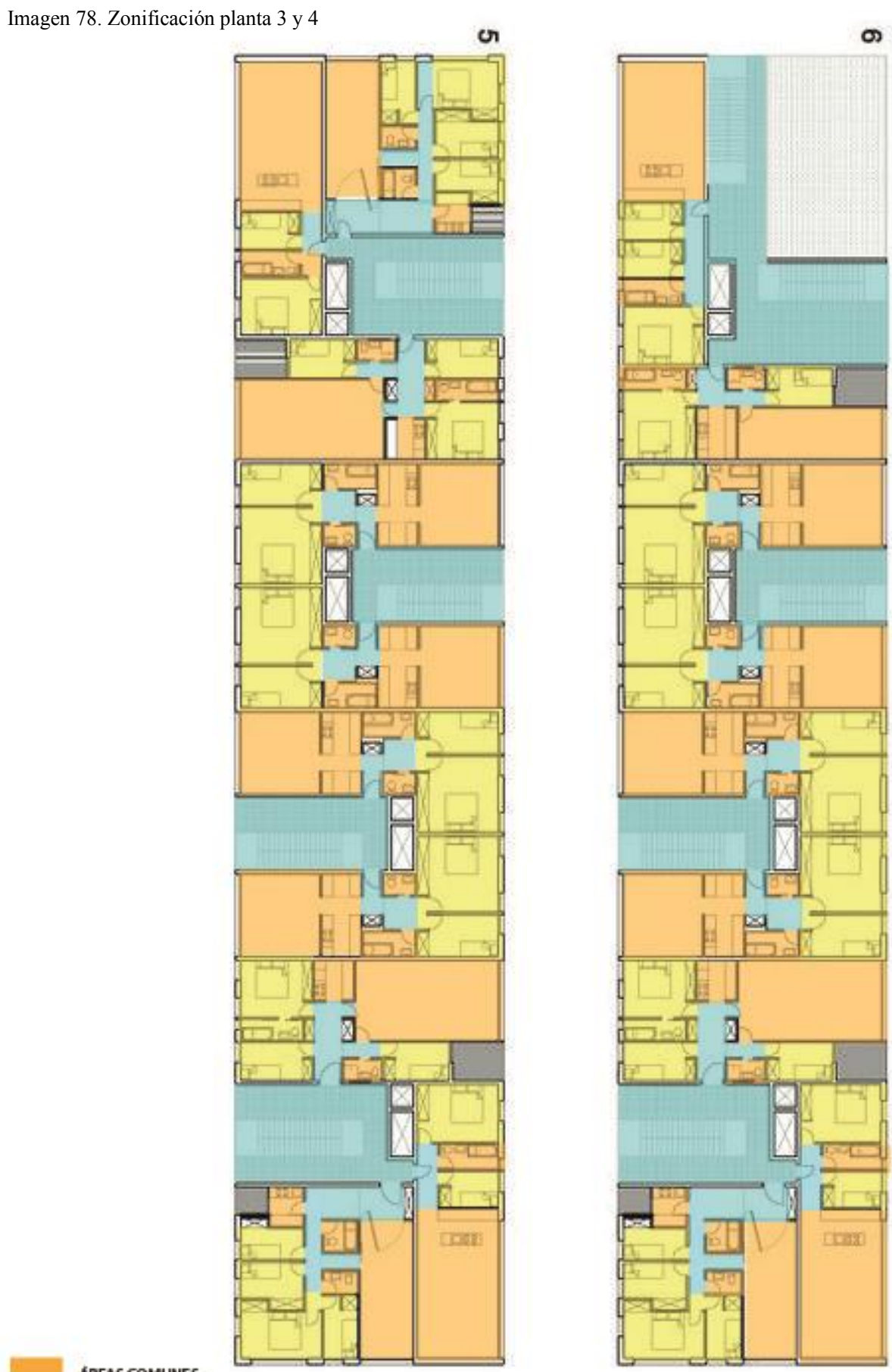

DORMTOPOS

CIRCULACION 
- Planta 21 y 22

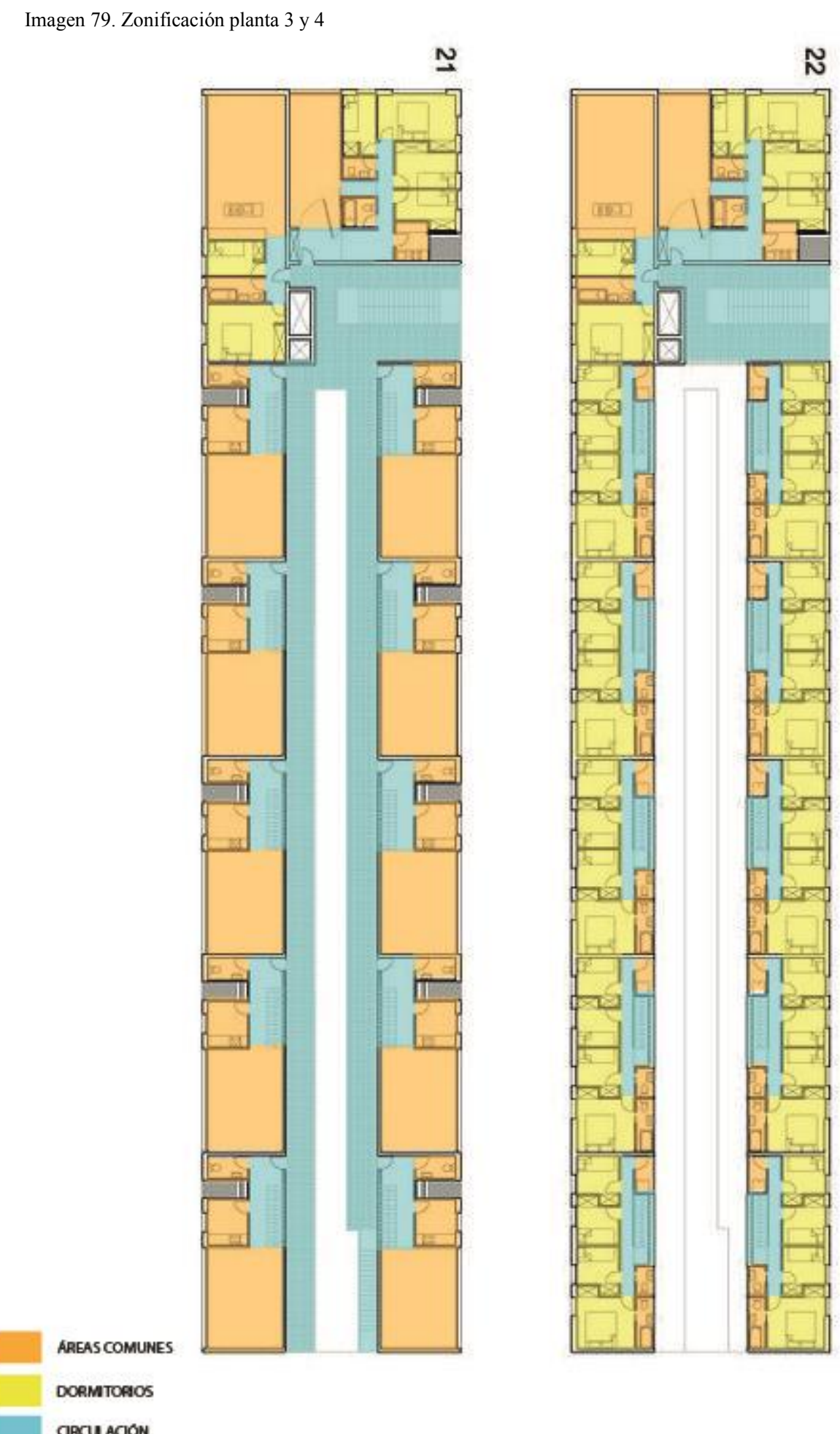

Fuente: Elaboración propia 


\subsubsection{Paquetes programáticos}

El edificio Mirador de MVRDV se encuentra ubicado frente a un óvalo. Se accede de manera frontal al edificio por la zona pública del terreno hasta llegar a un corredor de circulación. Esta no es una circulación ordenada ya que se reparte por todo el edificio, tanto la circulación horizontal como la vertical. Los departamentos se encuentran ubicados a ambos frentes del edificio. Hay en total 156 viviendas repartidas alrededor de todos los pisos.

El edificio cuenta con un área común que se encuentra ubicada en la gran ventana configurada por el diseño del edificio, la cual es una planta amplia concurrida por los habitantes del edificio. Este también sirve de mirador.

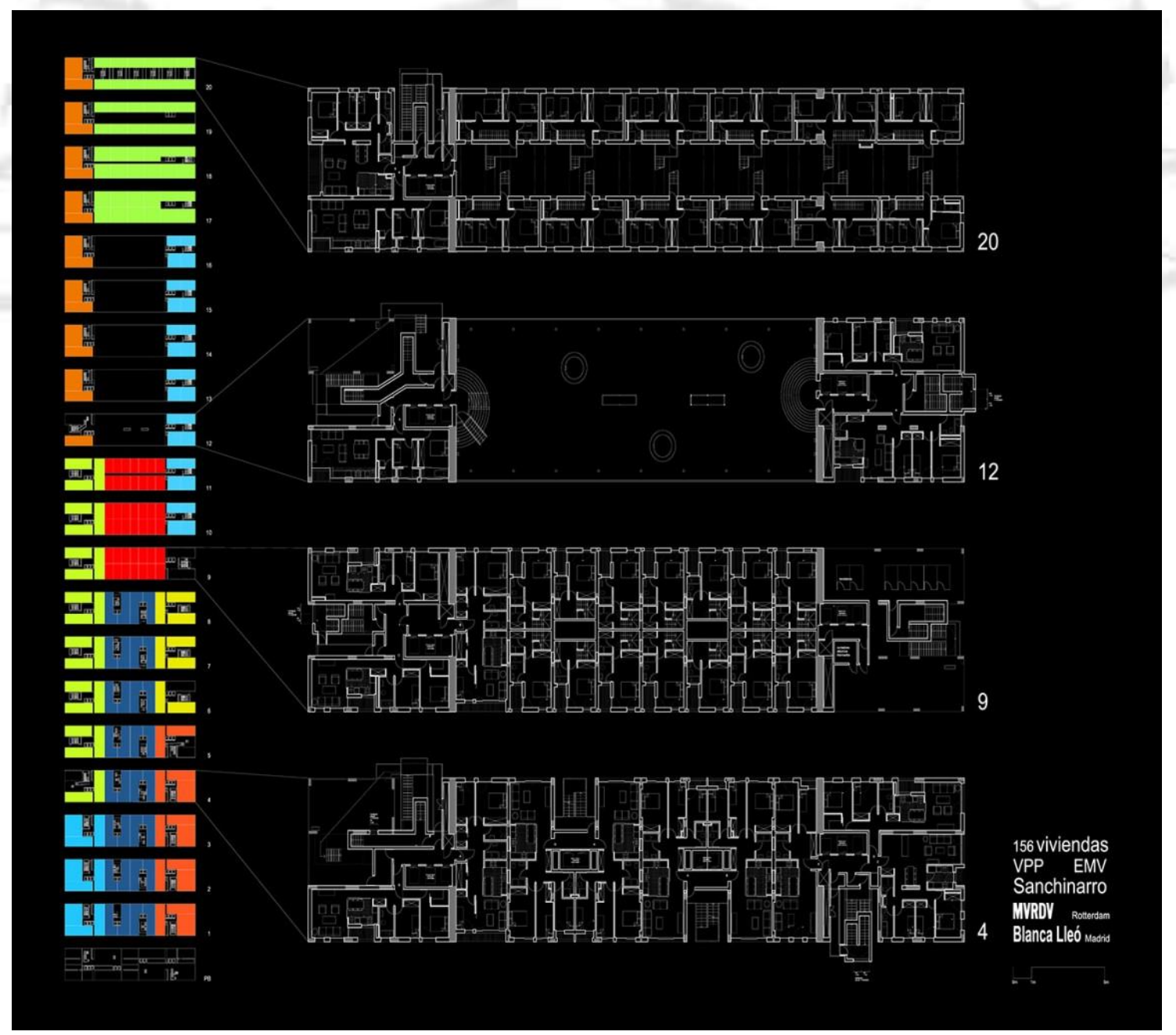

Fuente: http://blancalleo.com/es/edificio-mirador-4/ 


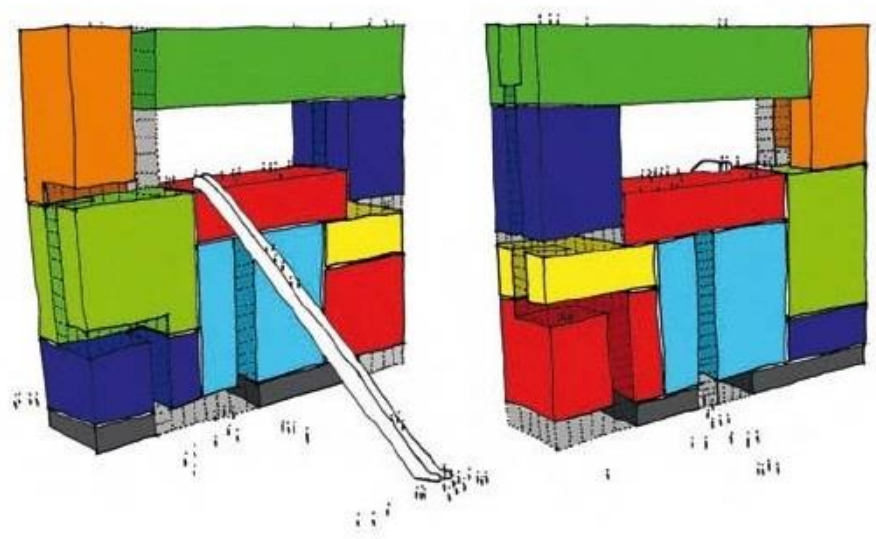

Edificio organizado alrededor de un jardin comunitario situado en la cara horizontal del hueco del propio edificio, evocando a un observatorio donde contemplar la ciudad.

Fuente: https://es.slideshare.netobservatoriothnuevas-formas-de-habitar-tipologia-de-casa

\subsubsection{Organigrama}

Imagen 82. Organigrama

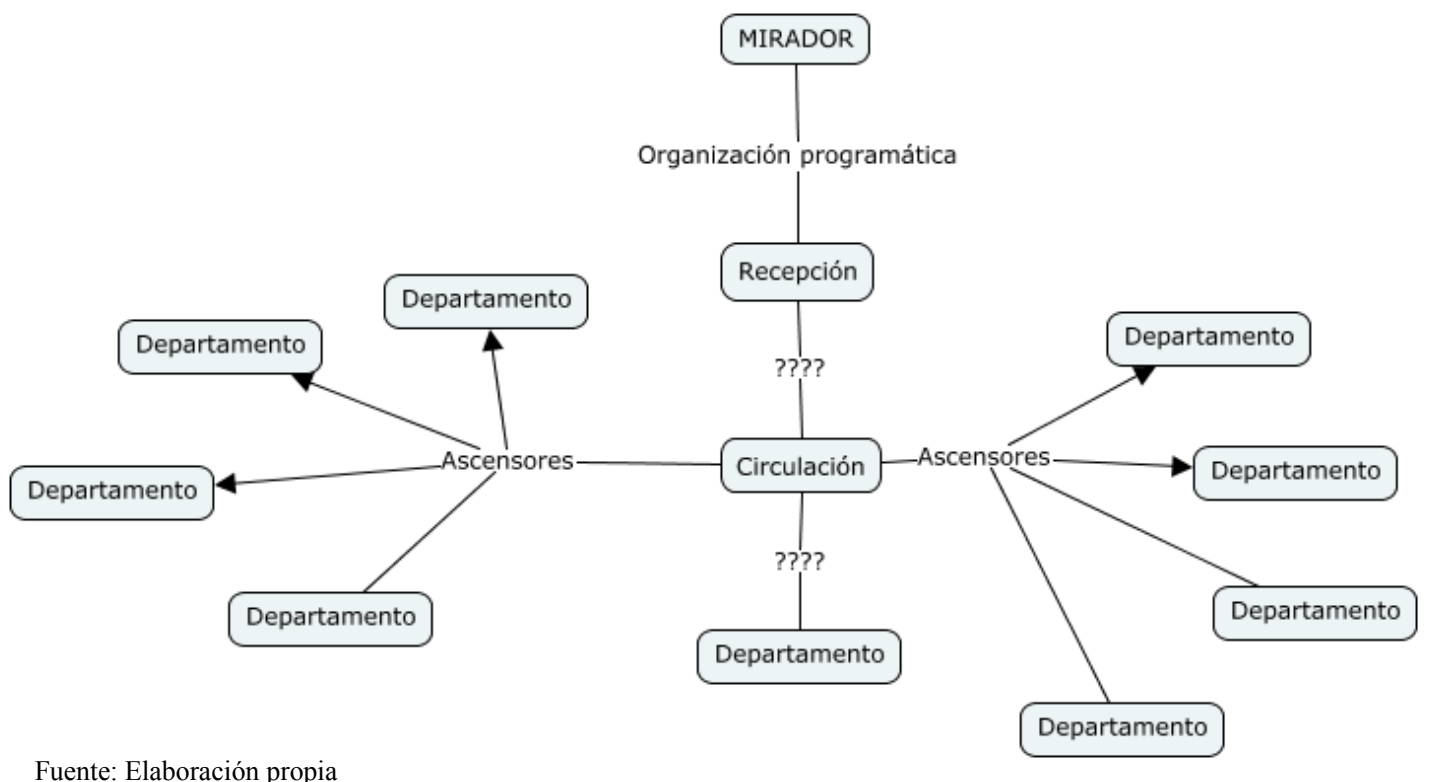

Fuente: Elaboración propia

\subsubsection{Tipología}

Para analizar la tipología del edificio, nos basaremos en el libro "Arquitectura: Forma, espacio y orden”, escrito por D.K. Ching. 


\subsubsection{Organización agrupada}

El Mirador cuenta con plantas simétricas a cada lado (distintas cada piso), por lo que los departamentos comparten una forma en común en cada piso. Se organizan en torno al eje horizontal con el que cuenta el edificio, a partir del cual se van agrupando a lo largo del recorrido lineal.

Imagen 83. Organización agrupada

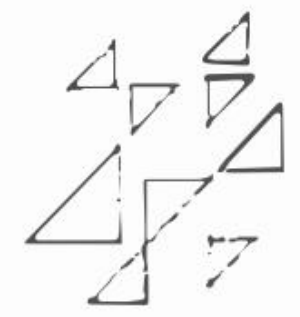

Comparten un forma

corrun

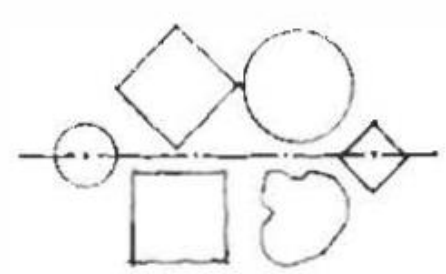

Organización segín

un eje

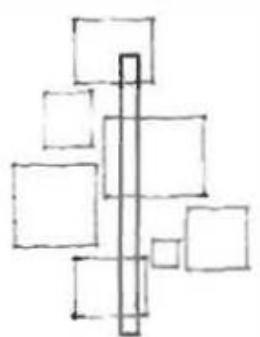

Agrupación a lo largo de un recorrido

Fuente: Digitalizada del libro “Arquitectura: Forma, espacio y orden”, escrito por D.K. Ching.

\subsubsection{Aproximación al edificio}

Frente al óvalo se configura un gran espacio público, desde donde se accede al edificio, el cual es un gran hito en la zona. Tiene una entrada directa y frontal, justo en el medio, para luego pasar a una distribución interior más compleja.

Imagen 84. Aproximación al edificio

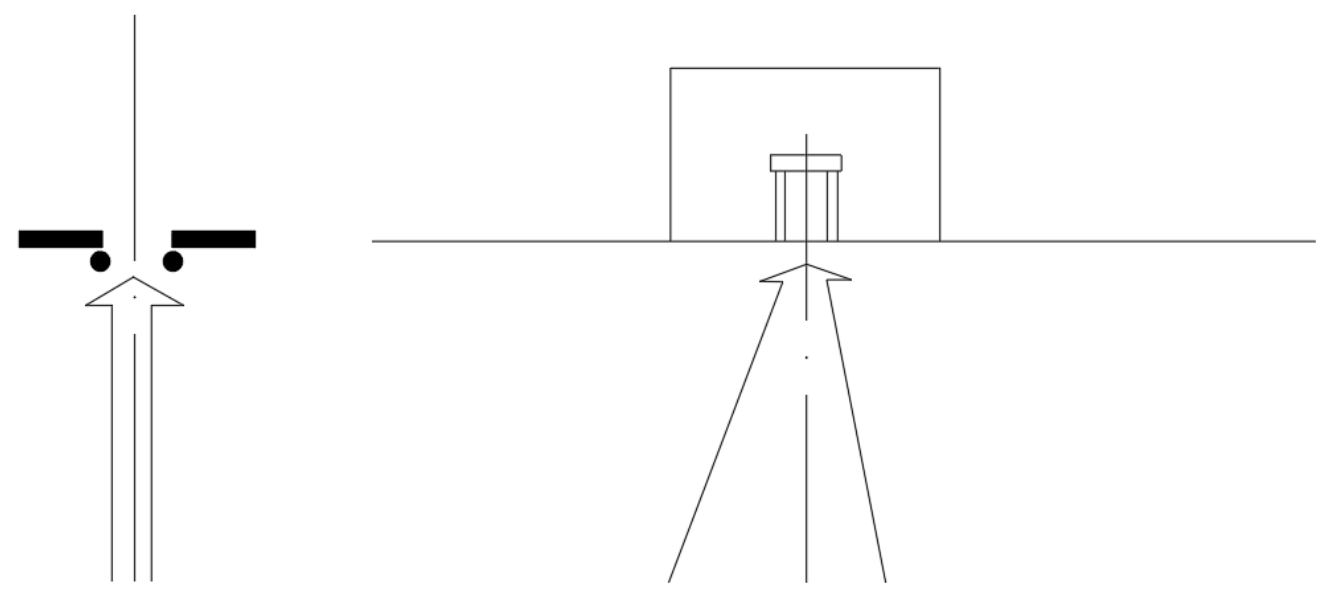

Fuente: Digitalizada del libro “Arquitectura: Forma, espacio y orden”, escrito por D.K. Ching. 


\subsubsection{Configuración del recorrido}

El edificio tiene un recorrido horizontal con escaleras y ascensores a ambos extremos, sin embargo, la circulación cambia dependiendo de la planta, lo cual hace a la circulación interesante. En cierto punto de la circulación vertical, se desemboca en una planta de área libre, la cual es el mirador y sirve de espacio común para los residentes.

Imagen 85. Aproximación al edificio

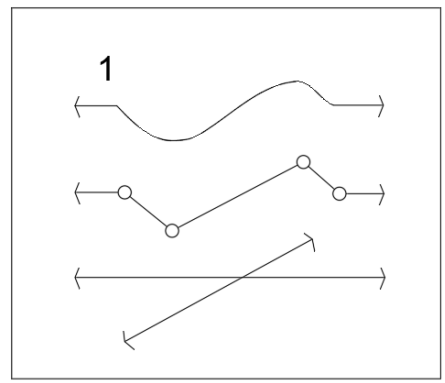

Fuente: Digitalizada del libro “Arquitectura: Forma, espacio y orden”, escrito por D.K. Ching.

\subsubsection{Relación recorrido-espacio}

Los departamentos se encuentran distribuidos a lo largo de la circulación horizontal en cada piso, siendo posible el ingreso directamente desde los pasillos.

Imagen 86. Aproximación al edificio

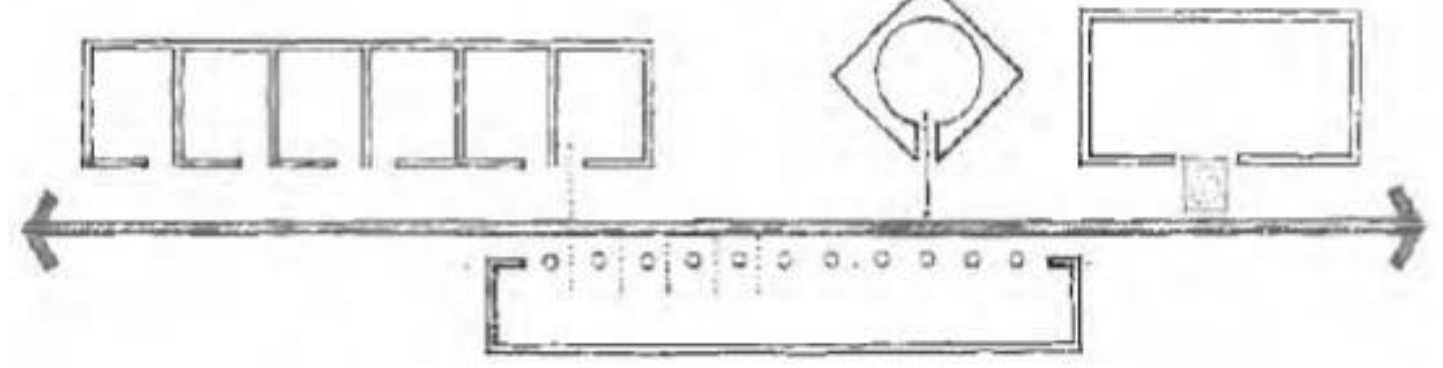

Fuente: Digitalizada del libro “Arquitectura: Forma, espacio y orden”, escrito por D.K. Ching. 


\subsubsection{Espacios}

\subsubsection{Relaciones Espaciales}

- Plantas 3 y 4

Imagen 87 . Distribución de priv/pub en planta 3 y 4 del Mirador

$\omega$
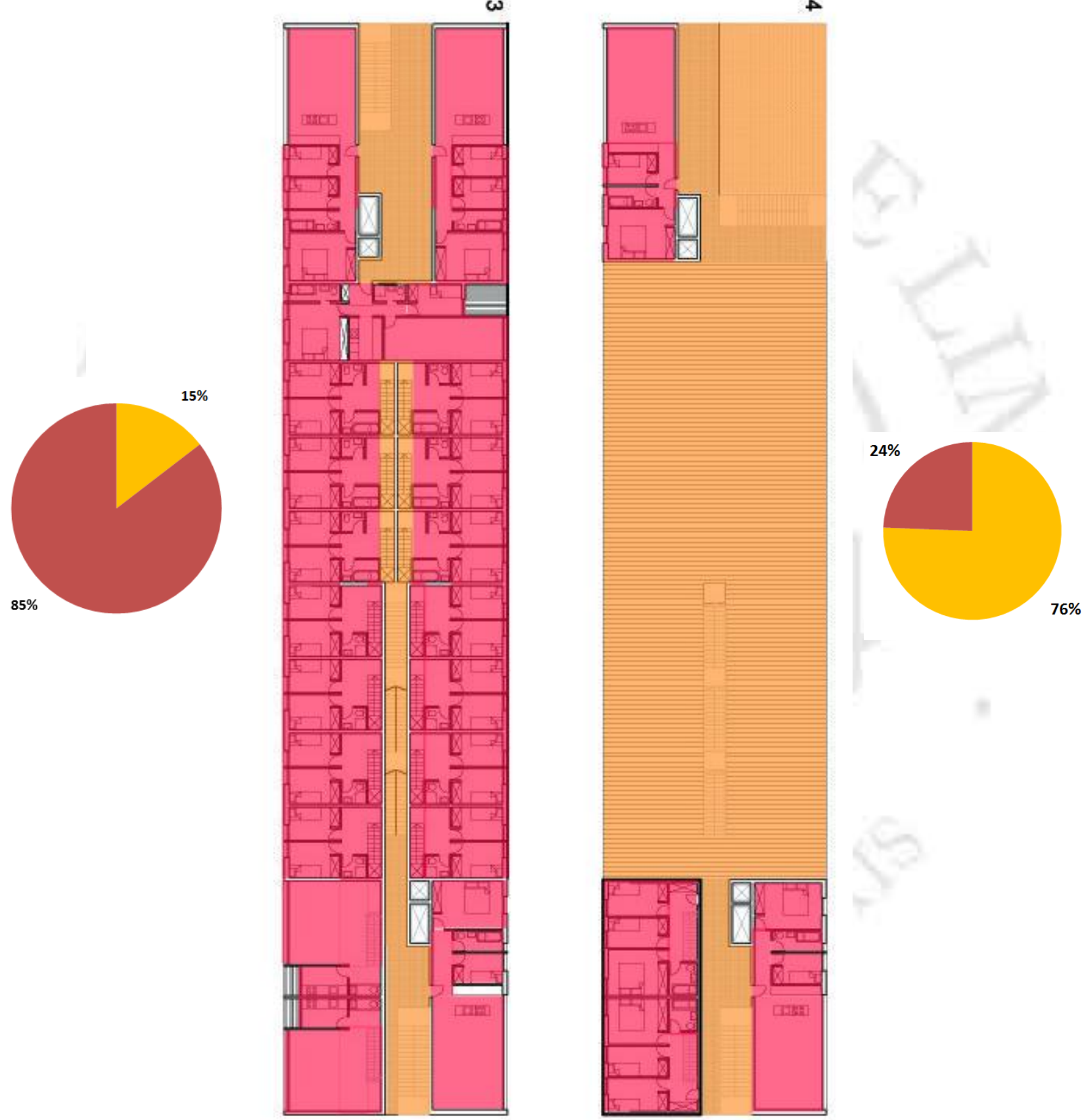

SEMIPORUICO

PRIVADO

Fuente: Elaboración propia 
- Plantas 5 y 6

Imagen 88. Distribución de priv/pub en planta 5 y 6 del Mirador

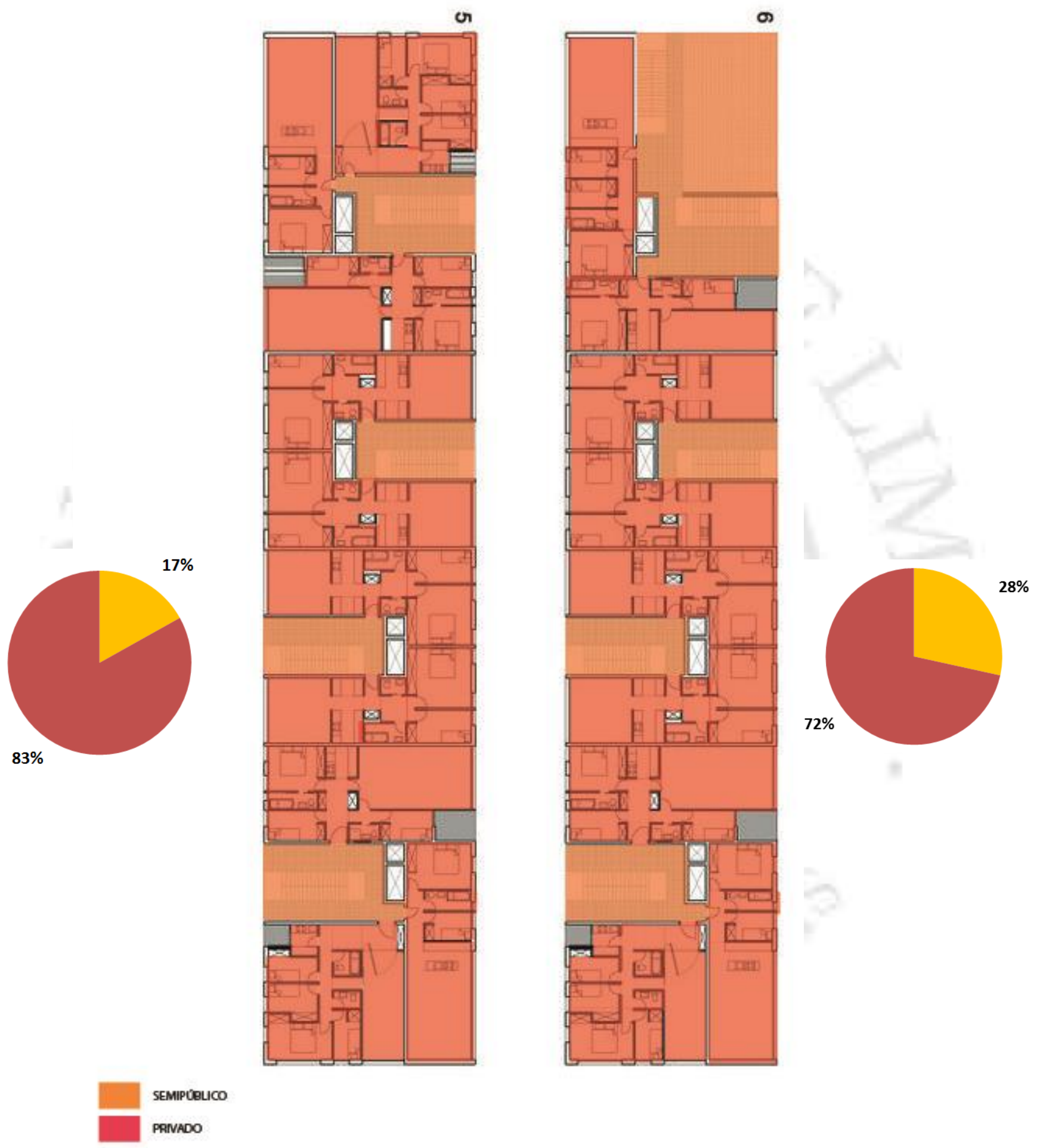

Fuente: Elaboración propia 
- Plantas 21 y 22

Imagen 89. Distribución de priv/pub en planta 21 y 22 del Mirador

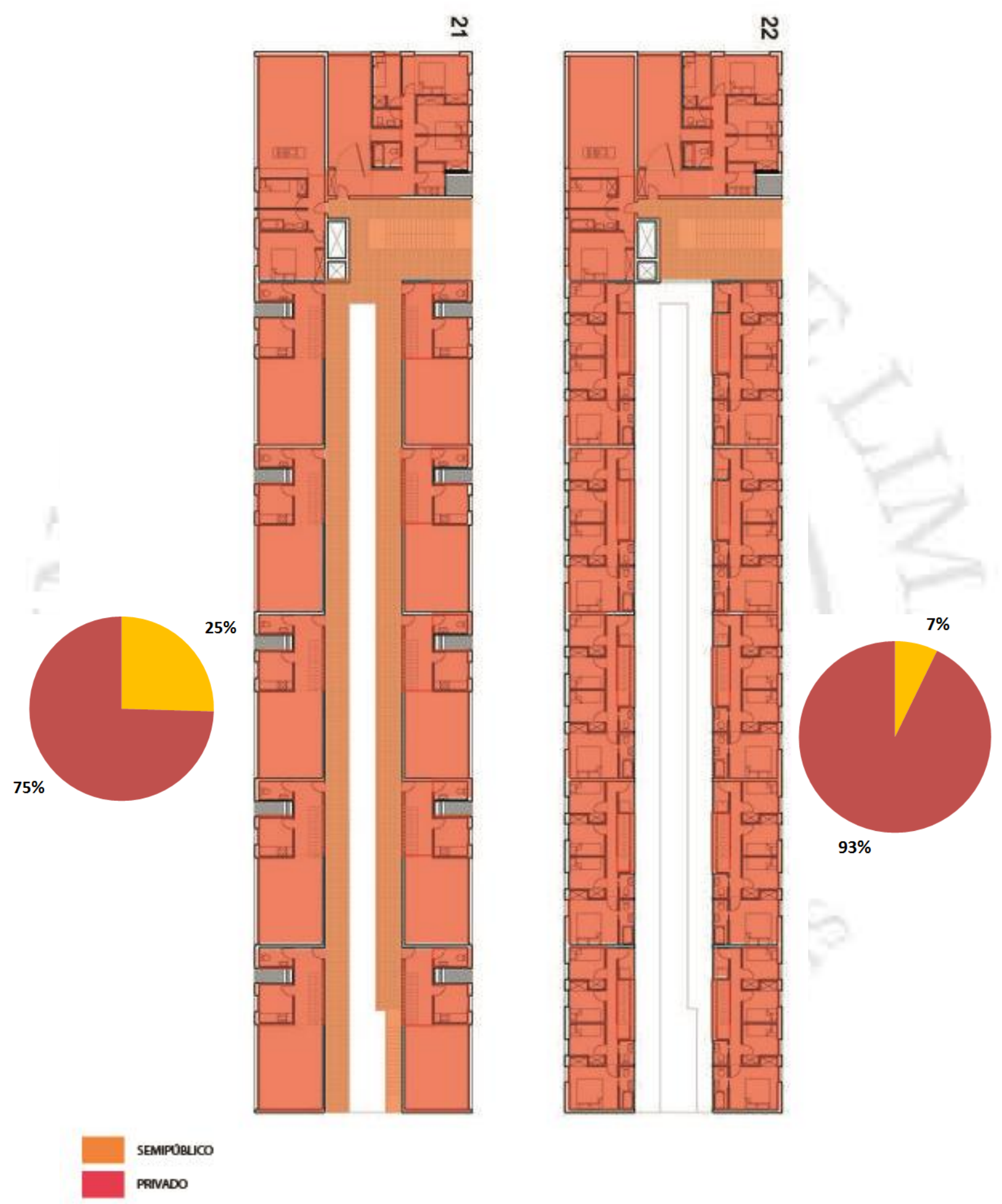

Fuente: Elaboración propia 


\subsubsection{Flujos y circulaciones}

- Plantas 3 y 4

Imagen 90. Circulación en planta 3 y 4 del Mirador

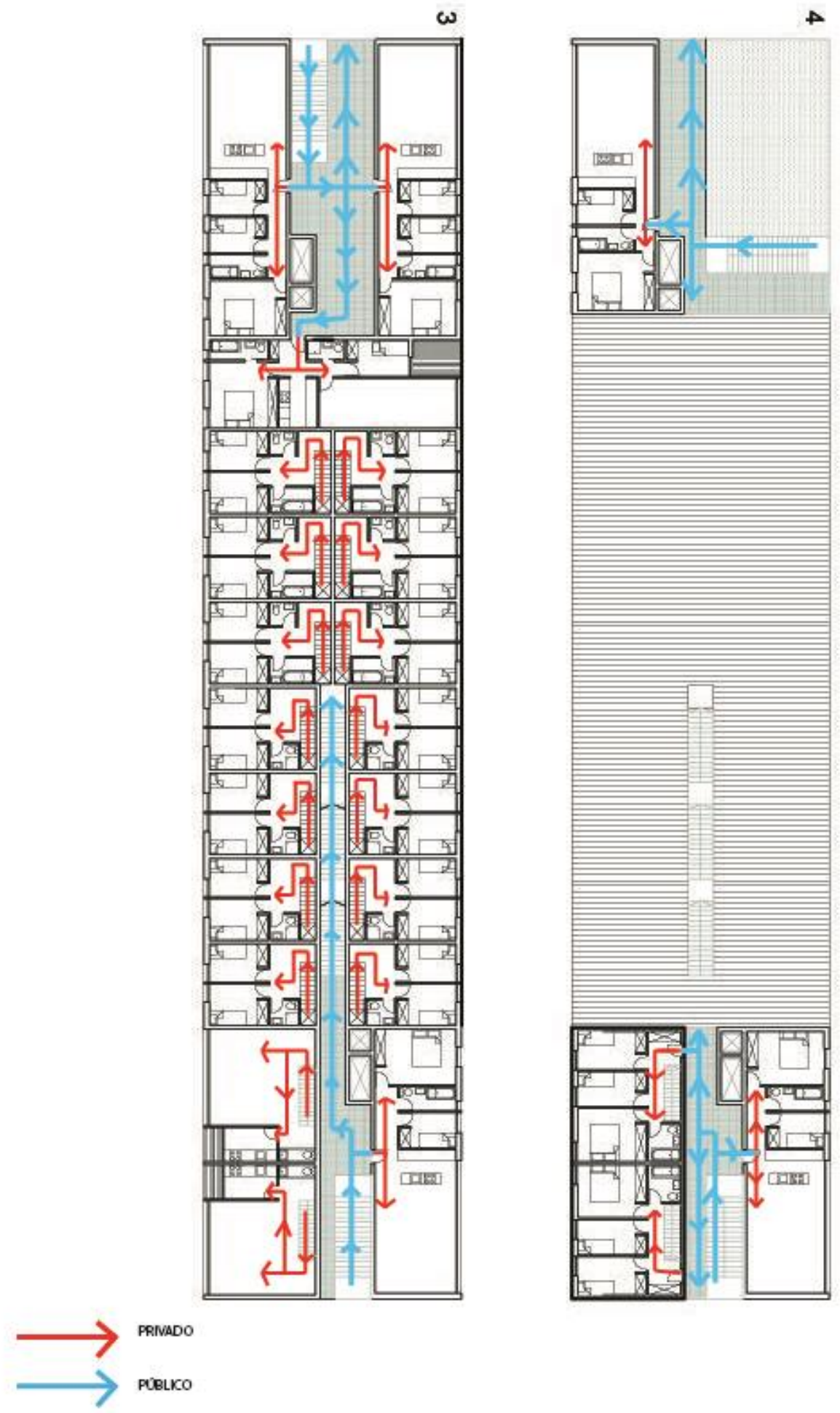

Fuente: Elaboración propia 
- Plantas 5 y 6

Imagen 91. Circulación en planta 5 y 6 del Mirador
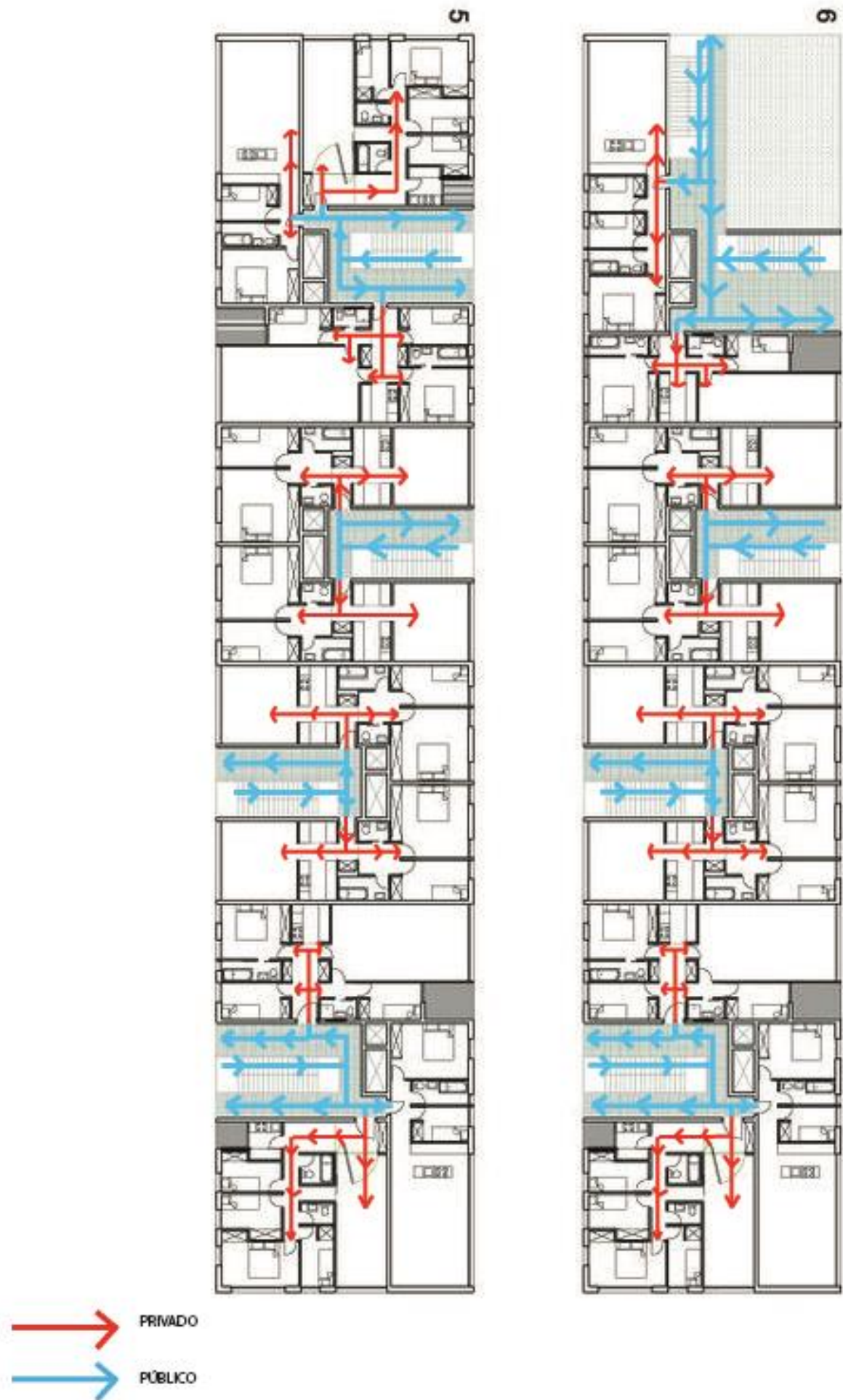

Fuente: Elaboración propia 
- Plantas 21 y 22

Imagen 92. Circulación en planta 21 y 22 del Mirador

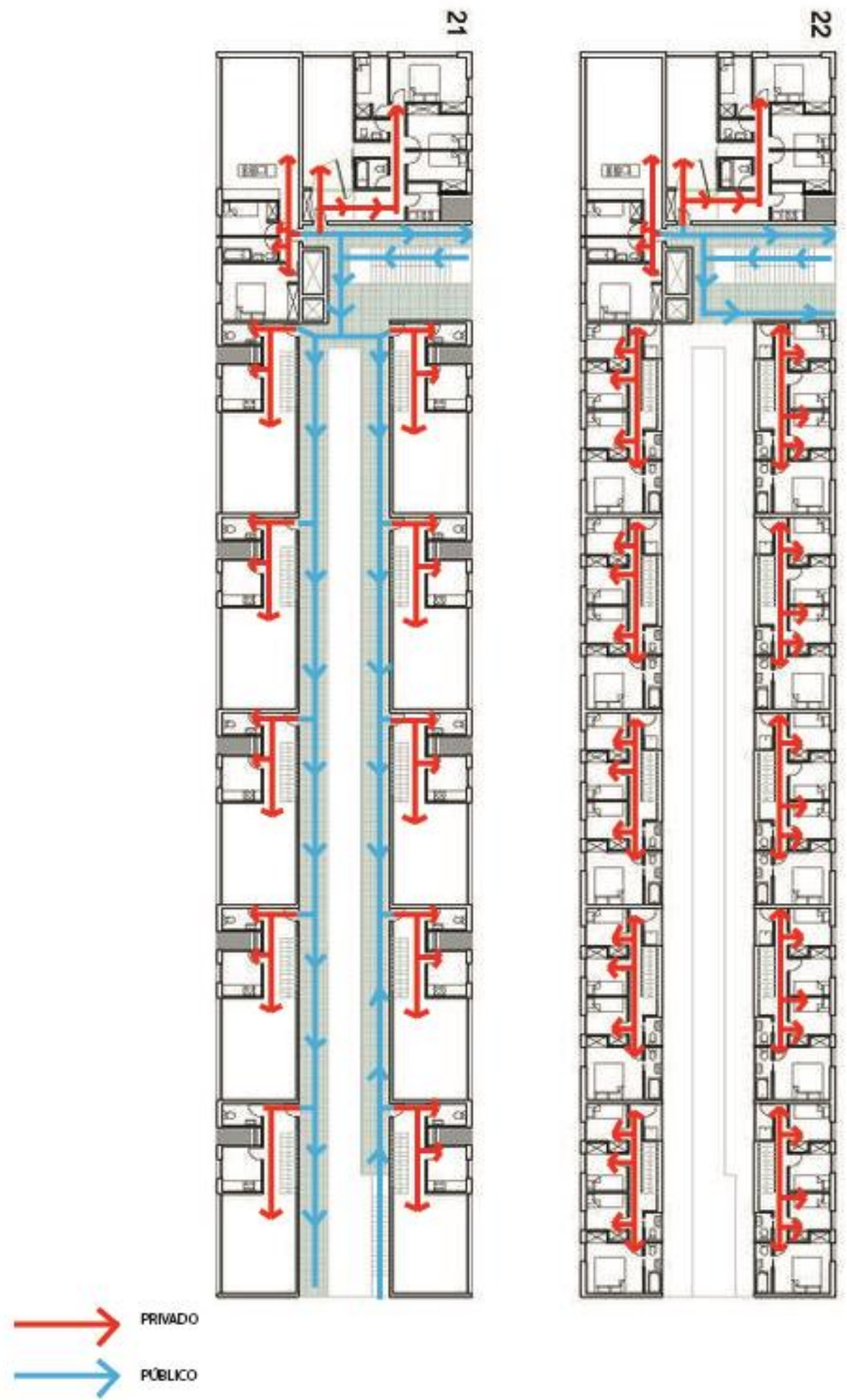

Fuente: Elaboración propia 


\subsubsection{3. Área Techada}

Imagen 93. Área techada del Mirador

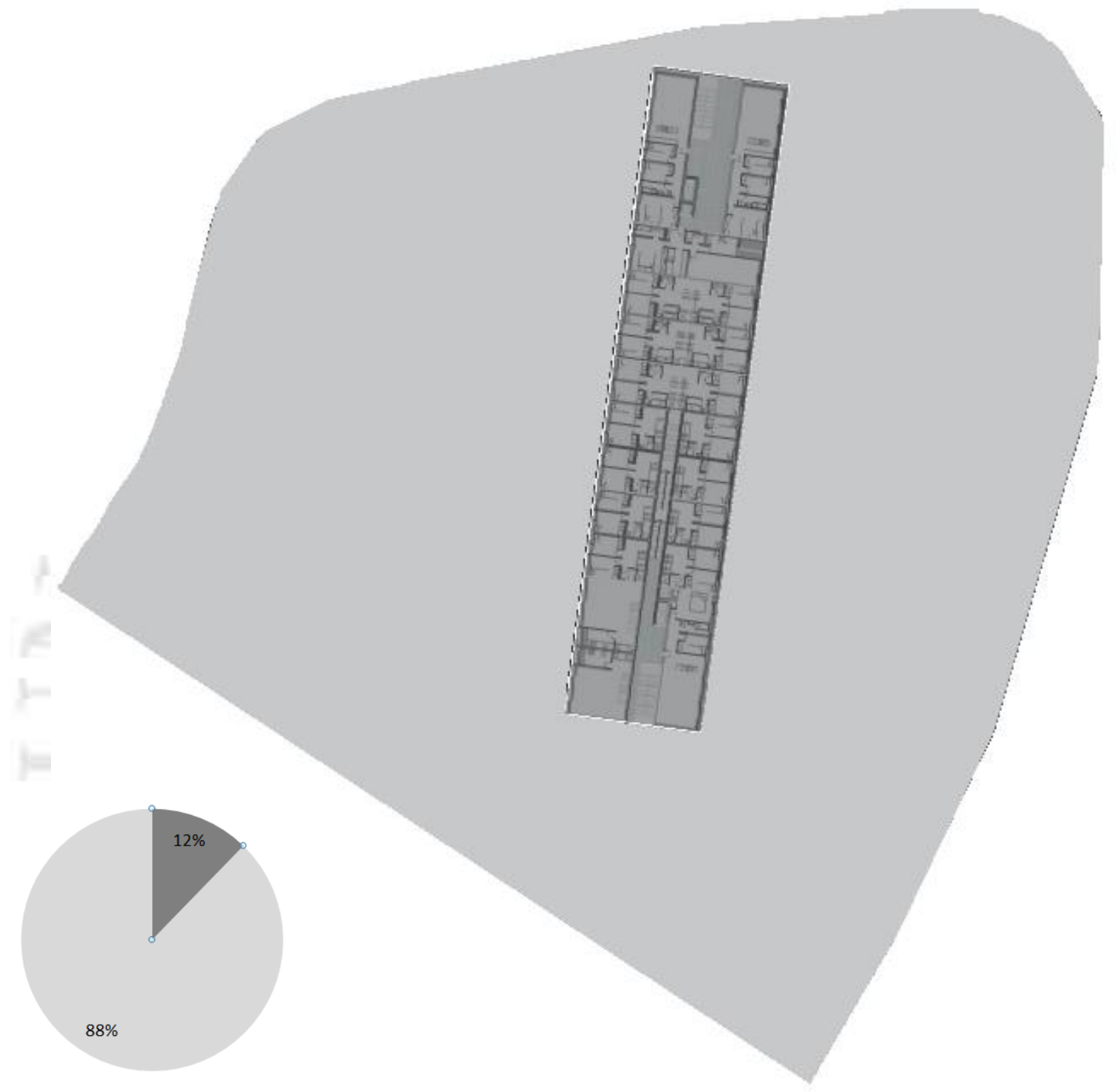

Fuente: Elaboración propia

5.5.6. Impacto social del proyecto

El proyecto alberga una cantidad considerable de familias, las cuales tienen una cercanía gracias al espacio colectivo que ofrece el edificio, el cual a su vez sirve de mirador hacia la ciudad.

También genera un espacio público importante en la zona adyacente al edificio, dentro del mismo terreno, ya que su área libre es más del $80 \%$ del total. 


\subsubsection{Conclusiones parciales}

Este proyecto cuenta con una configuración proyectual de módulos de dormitorio interesante. Se puede ver que hay distintos tipos de módulos que van encajando en la forma del edificio de manera que no quede todo homogéneo, sino que hay distintas variables en todo el edificio. Esta configuración puede aplicarse en el proyecto a realizar, teniendo los dormitorios ubicados de manera adyacente a las zonas comunes, y al ser un edificio vertical, se cuenta también con un gran espacio comunitario que vendría a ser la planta central totalmente libre.

\subsection{La Residencia Universitaria en la Universidad Nacional de Ingeniería}

Imagen 94. Residencia de la UNI

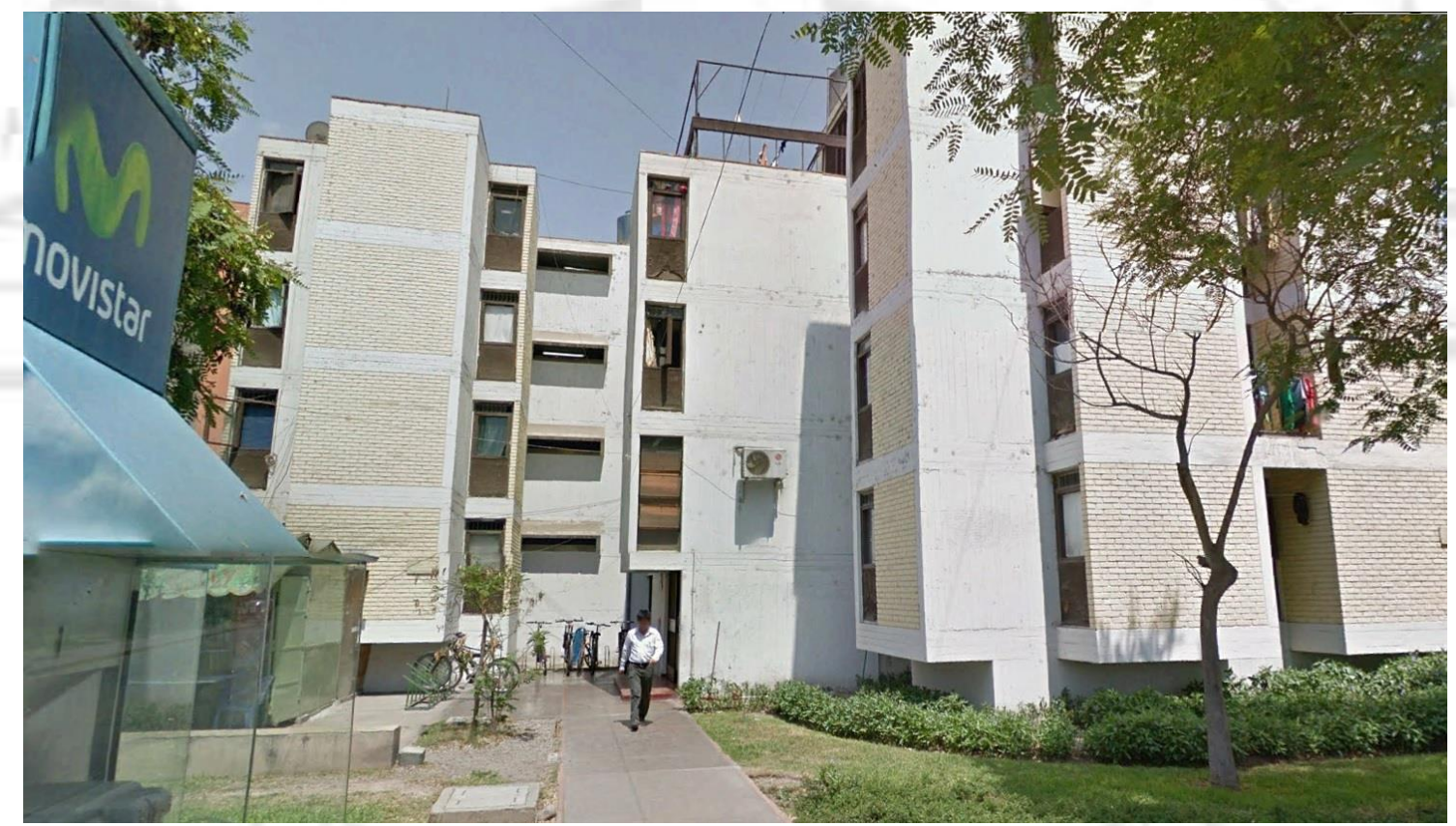

Fuente: Google Earth

\subsubsection{Historia del edificio}

En los años 50 se iniciaron las operaciones para la construcción del Pabellón $\mathrm{M}$ en la Casa del Estudiante y en 1961 se iniciaron las operaciones para la construcción del Pabellón P dentro del campus universitario, a cargo del Departamento de Casa y Comedor del Estudiante y a partir de 1966 de la División de Bienestar Universitario.

$\mathrm{La}$ residencia universitaria funcionaba en base a becas residenciales y su administración interna estaba basada en el principio de autogobierno. 
El alojamiento para estudiantes de la UNI servía de hospedaje no solo para sus alumnos, sino tambièn para alumnos becados de universidades y profesores extranjeros. Según los redactores de UNI, Boletín informativo:

En 1969 se decidió efectuar mejoras para tanto en la residencia universitaria como en el comedor.

Lamentablemente en la década de 1970, la residencia y el comedor fueron usados como espacios de protesta perdiéndose así su verdadera esencia, la misma que se restauró en la década de los años 80 en la cual tanto el Pabellón P como el M volvieron a funcionar como alojamiento para los estudiantes.

\subsubsection{Relación con el entorno}

La residencia universitaria de la UNI se encuentra ubicada dentro del campus, el cual está en la avenida Túpac Amaru s/n, Rímac. Esta universidad se encuentra en una buena posición ya que está próxima a una zona totalmente urbana, donde viven muchos de sus estudiantes. Hay 4 avenidas principales que cruzan la universidad, que son la avenida Túpac Amaru la cual va a lo largo de la universidad, y las avenidas Eduardo de Habich, Honorio Delgado, y Fray Bartolomé De Las Casas.

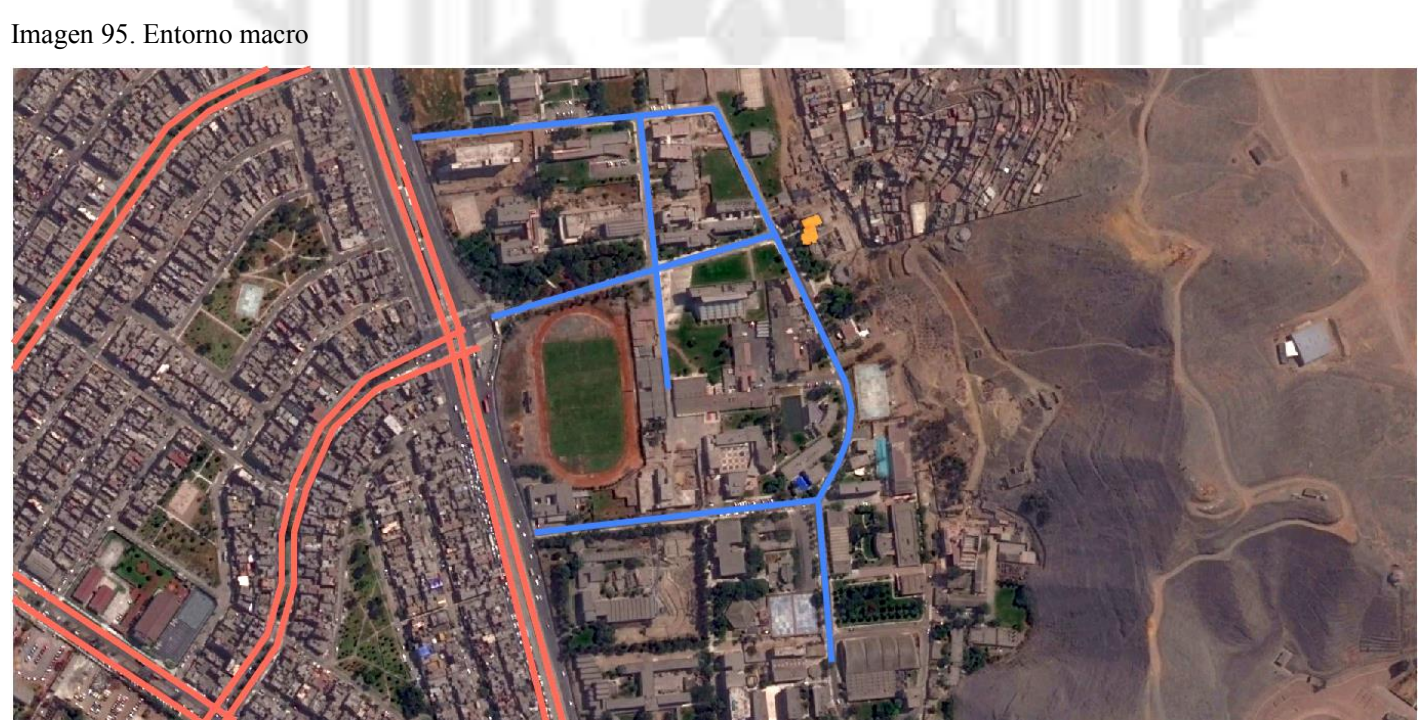

Avenidas Principales

Calles dentro de la Universidad Nacional de Ingenieria

Fuente: Google Earth 
Dentro de la universidad, los estudiantes también se pueden trasladar en vehículos, ya que las calles vehiculares, las cuales también pasan por la residencia, tienen un recorrido a lo largo de todos los pabellones de manera eficiente.

La residencia universitaria está ubicada a la misma distancia de ambos extremos de la universidad, por lo que se encuentra en una buena posición. Tiene a la facultad de Ingeniería Mecánica al frente, la biblioteca central de la UNI a una cuadra y el comedor para estudiantes a 2 cuadras. Toda la universidad posee calles peatonales, por lo que los estudiantes pueden transitar tranquilamente, estando máximo a 15 minutos de sus salones de clase.

Hay equipamientos de la universidad muy cerca de la residencia, como son las canchas de fulbito, el comedor, y algunas plazas donde se reúnen los estudiantes, zonas donde se desarrollan, en su mayoría, las relaciones sociales de la universidad.

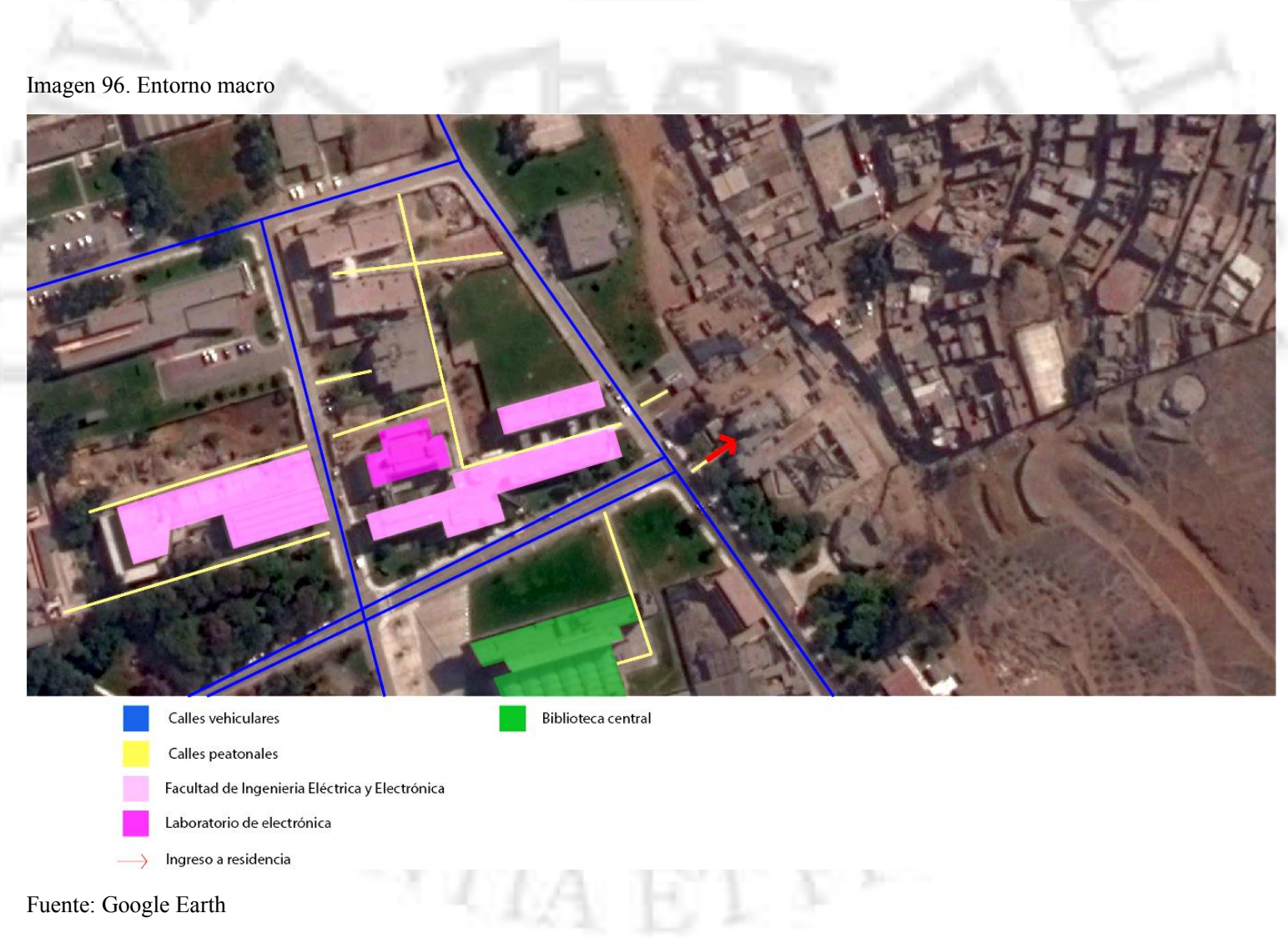


5.6.3. Programa y relaciones programáticas

\subsubsection{Zonificación}

- Planta típica

Imagen 97. Distribución planta típica

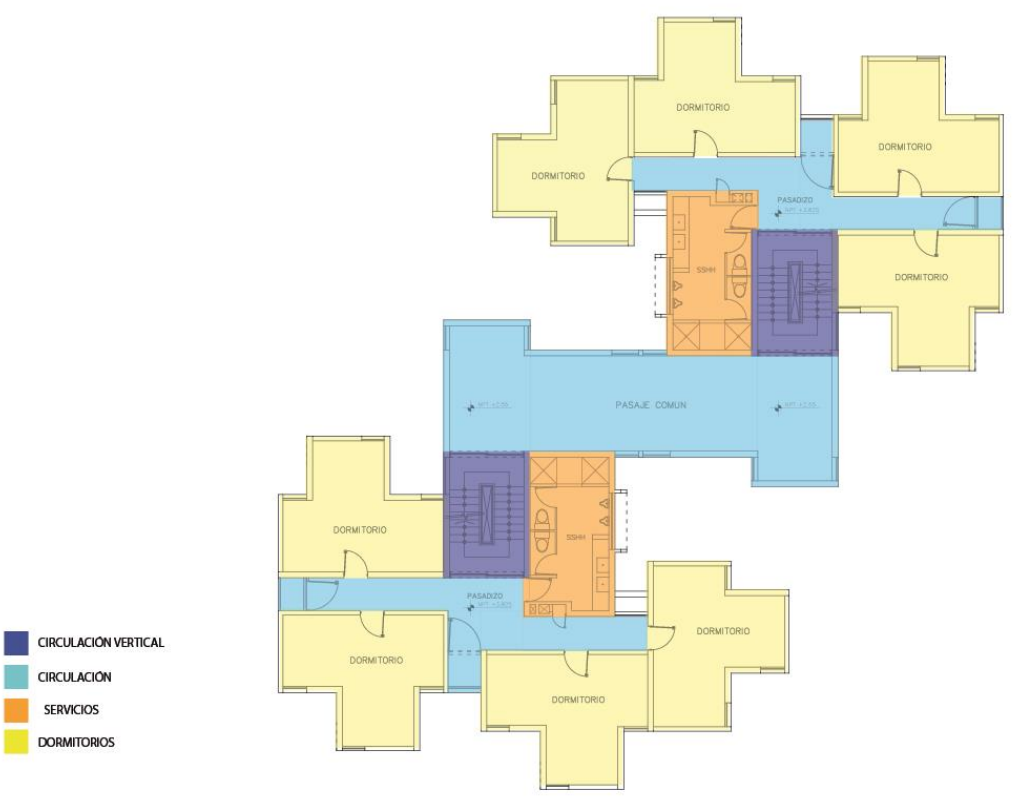

Fuente: Elaboración propia

5.6.3.2. Cuadro de áreas

Cuadro 17. Cuadro de áreas

\begin{tabular}{|c|c|c|}
\hline Ambiente & Área aprox. & Aporte \\
\hline Circulación vertical & $88.44 \mathrm{~m}^{2}$ & $7.13 \%$ \\
\hline Circulación & $309.108 \mathrm{~m}^{2}$ & $24.92 \%$ \\
\hline Dormitorios & $678.68 \mathrm{~m}^{2}$ & $55.72 \%$ \\
\hline Servicios & $151.687 \mathrm{~m}^{2}$ & $12.23 \%$ \\
\hline Total & $1240.02 \mathrm{~m}^{2}$ & $100 \%$ \\
\hline
\end{tabular}

Fuente: Elaboración propia 


\subsubsection{Paquetes programáticos}

La residencia universitaria se encuentra dentro del campus de la Universidad Nacional de Ingeniería. Se accede de manera frontal al edificio hasta llegar a un corredor de circulación. Esta ocupa en el edificio el $24.92 \%$ del total del área construida. Esta circulación de planta siempre desemboca en la circulación vertical que ocupa el 7.13\% de área.

Desde el primer nivel hasta el último piso se pueden encontrar los dormitorios repartidos en las fachadas laterales, los cuales ocupan el 55.72\% de área, que es más de la mitad de todo el proyecto. Los únicos servicios de la residencia son los baños, que ocupan el $12.23 \%$, ya que cuentan con una biblioteca y un comedor cerca a esta.

\subsubsection{Organigrama}

\section{Imagen 98. Organigrama}

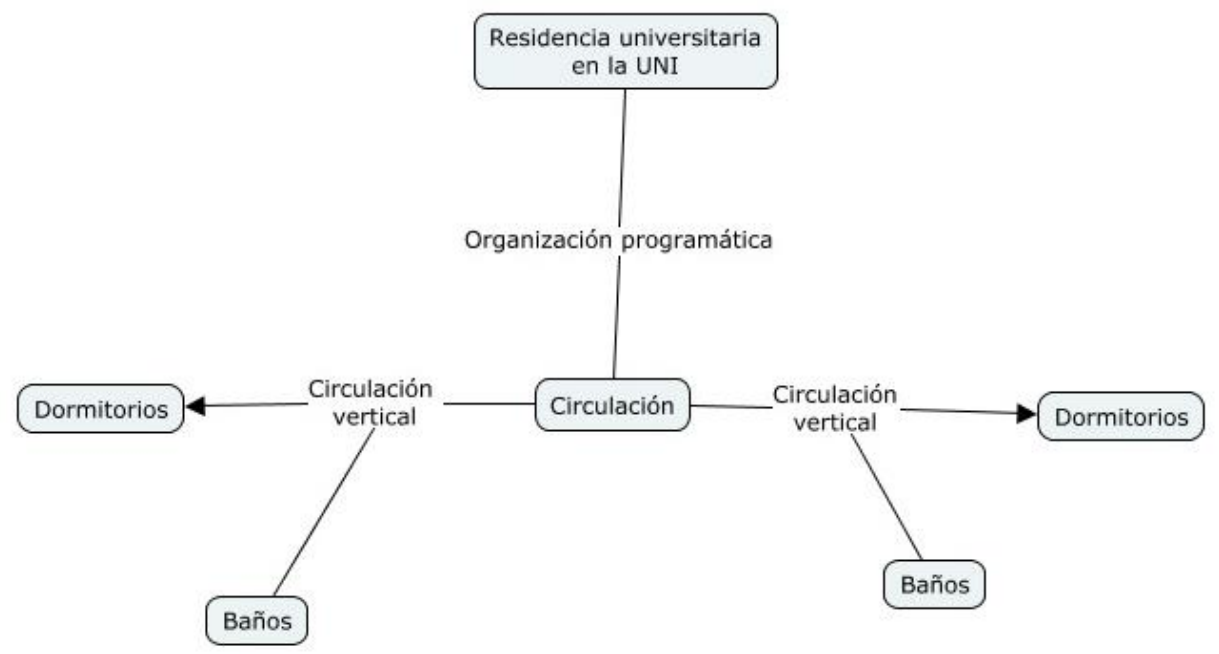

Fuente: Elaboración propia 


\subsubsection{Tipología}

Para analizar la tipología del edificio, nos basaremos en el libro "Arquitectura: Forma, espacio y orden”, escrito por D.K. Ching.

\subsubsection{Organización agrupada}

La organización agrupada de la residencia universitaria de la UNI es apreciada por los bloques de dormitorios simétricos, los cuales se organizan en torno al pasillo y a la circulación vertical. Otra característica que define la organización de esta residencia es la simetría, la cual puede verse al situarse en el hall intermedio.

Imagen 99. Organización agrupada

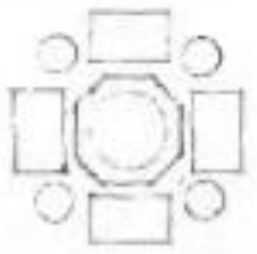

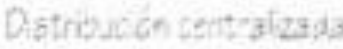
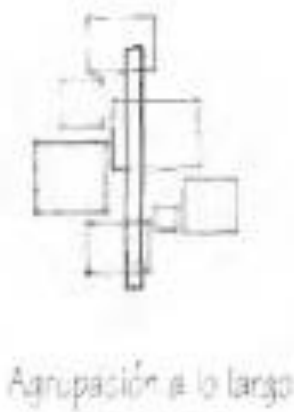

de ur recortide

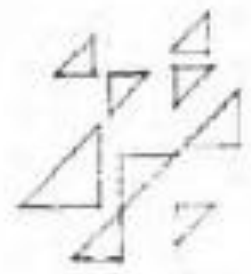

Comparten un fertha comin

Fuente: Digitalizada del libro “Arquitectura: Forma, espacio y orden”, escrito por D.K. Ching.

\subsubsection{Aproximación al edificio}

Frontal: La aproximación al edificio es frontal. La fachada de ingreso se puede apreciar desde una distancia considerable, y se llega luego de pasar un área común en el área libre del terreno. Se llega de manera directa sin tener que desviarse en algún momento del recorrido. 

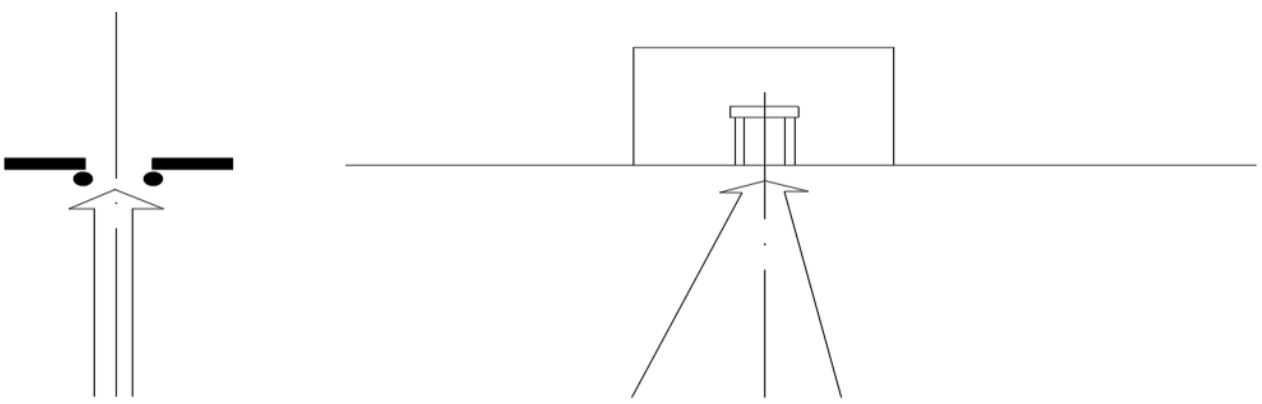

Fuente: Digitalizada del libro “Arquitectura: Forma, espacio y orden”, escrito por D.K. Ching.

\subsubsection{Configuración del recorrido}

La residencia universitaria de la UNI, al igual que el resto Imagen 101. Configuración del de residencias analizadas, poseen una configuración lineal de recorrido. Al no ser una planta muy grande, el recorrido termina en el pasillo de las habitaciones, e inicia en el área común al centro de la planta, donde se encuentran los alumnos. Si bien esta configuración de recorrido lineal es cortada por las circulaciones verticales, la esencia se mantiene al ver la planta completa.

recorrido

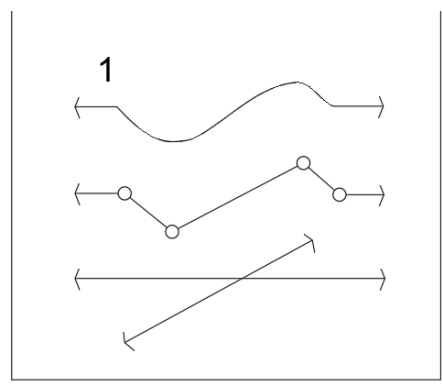

Fuente: Digitalizada del libro "Arquitectura: Forma, espacio y orden", escrito por D.K. Ching.

\subsubsection{Relación recorrido-espacio}

Pasar entre espacios:

- Se conserva la integridad de cada espacio

- La configuración del recorrido es flexible

- Para vincular el recorrido con los espacios es posible el empleo de otros intermedios

Imagen 102. Relación recorrido-espacio.

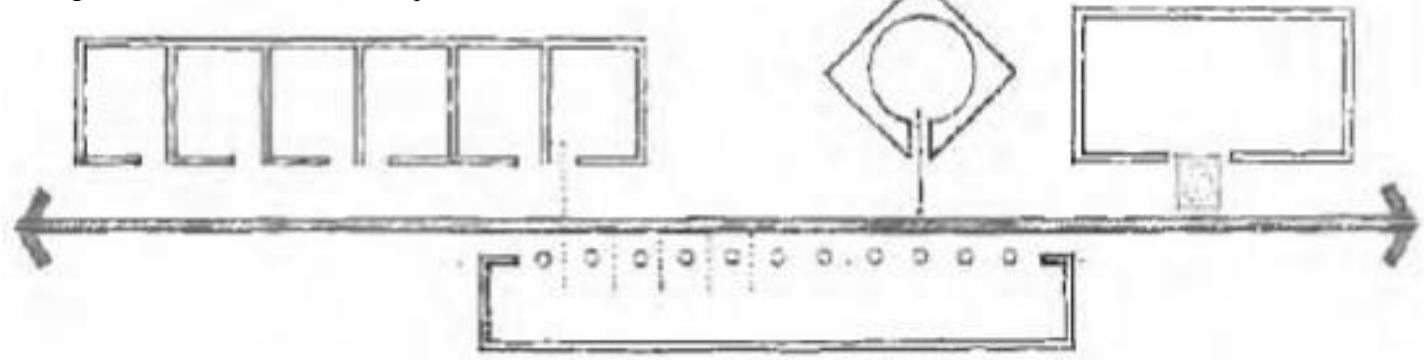

Fuente: Digitalizada del libro “Arquitectura: Forma, espacio y orden”, escrito por D.K. Ching. 


\subsubsection{Espacios}

\subsubsection{Relaciones espaciales}

- Primer nivel

Imagen 103. Distribución de priv/pub en primera planta del edificio

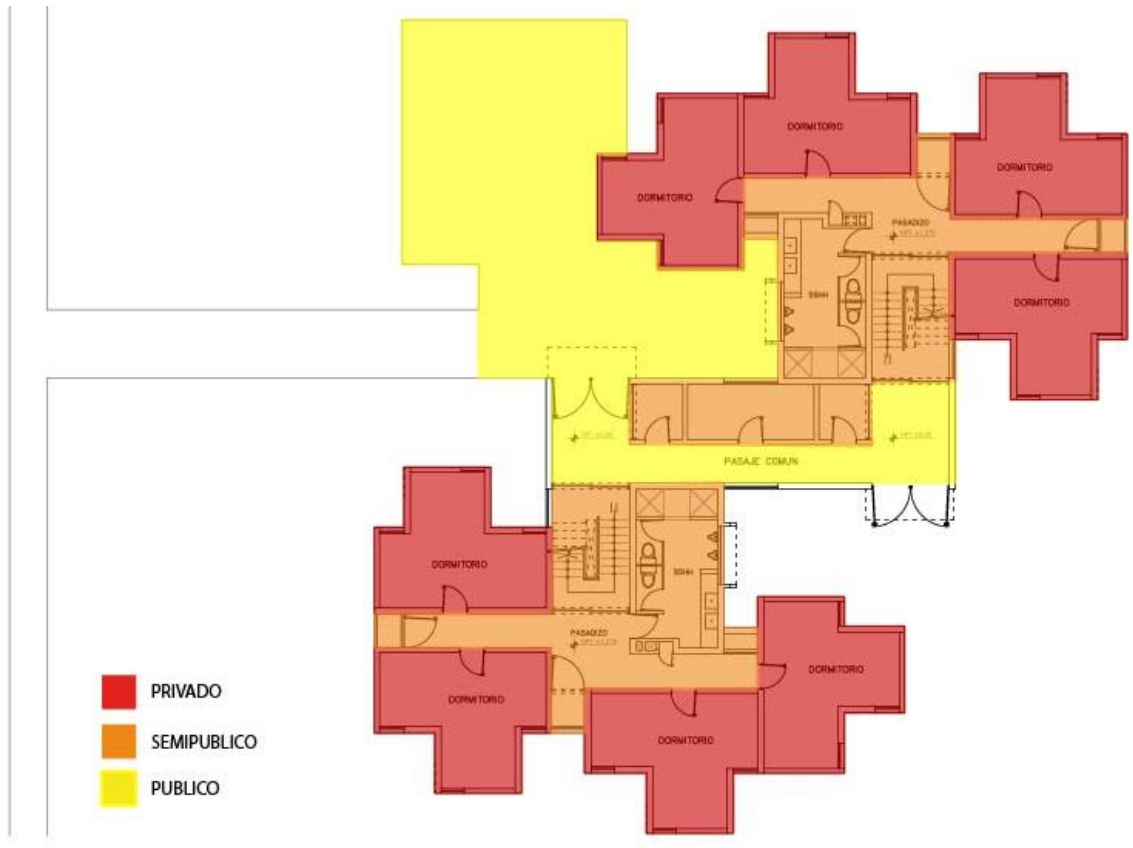

$19 \%$

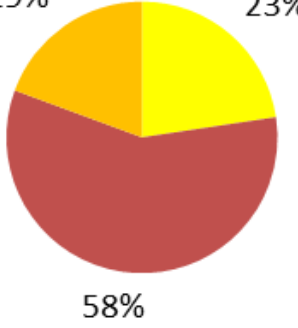

Fuente: Elaboración Propia

- Planta típica

Imagen 104. Distribución de priv/pub en planta típica del edificio

PRIVADO

SEMIPUBLICO
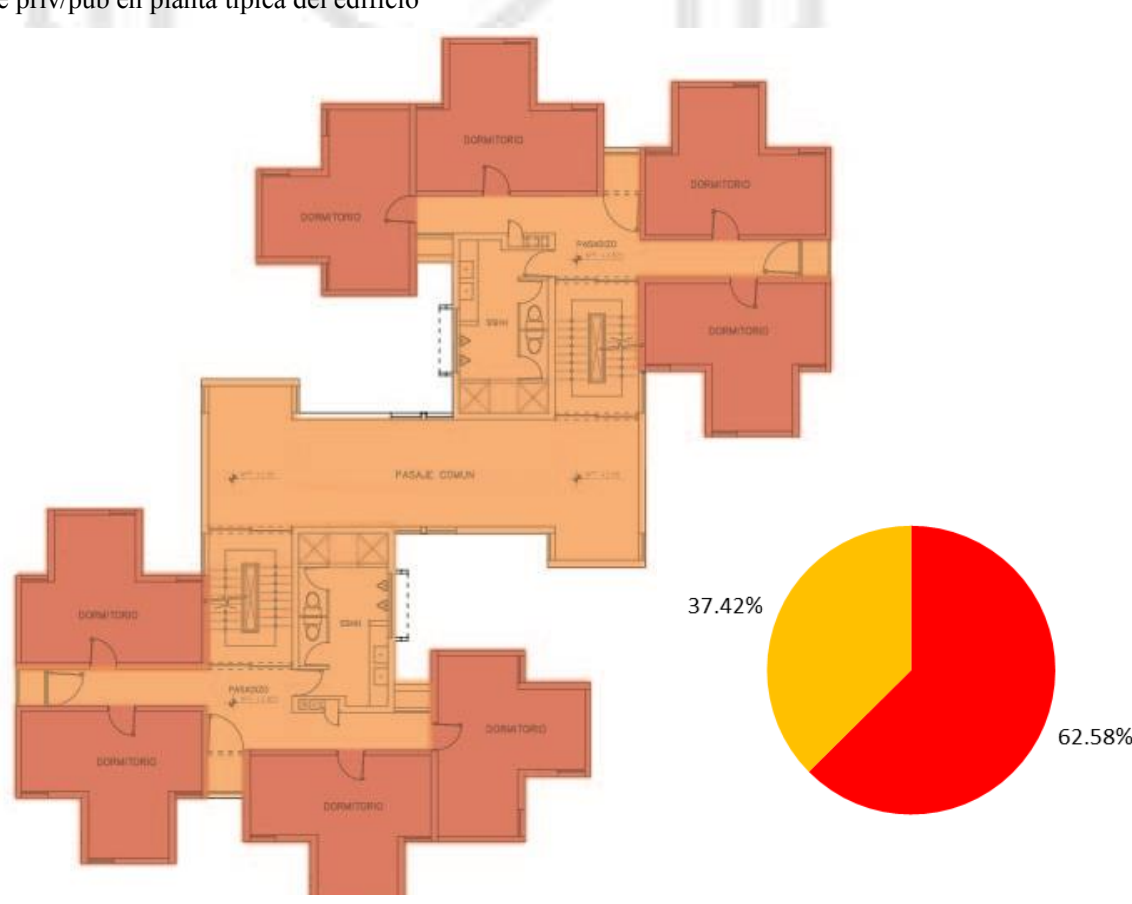
5.6.5.2. Flujos y circulaciones

\section{- Primera planta}

Imagen 105. Circulación en primera planta del edificio

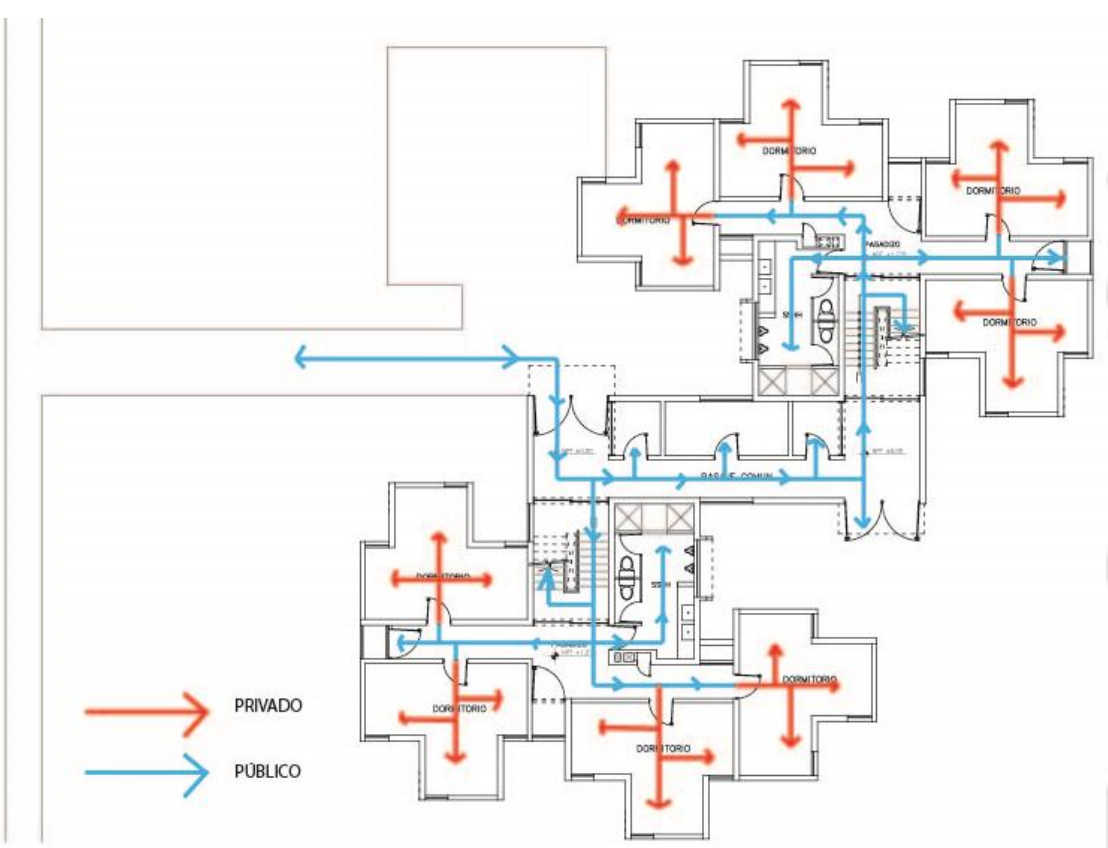

Fuente: Elaboración Propia

- Planta típica

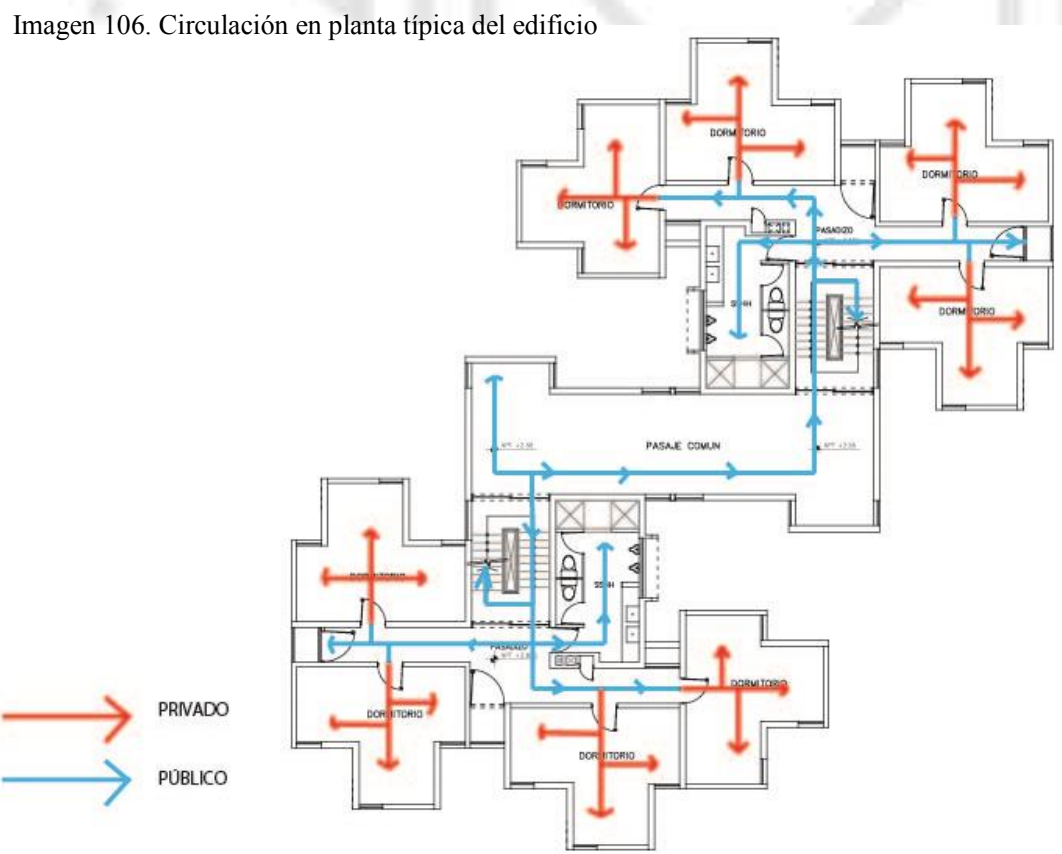

Fuente: Elaboración Propia 
5.6.5.3. Área techada

Imagen 107. Área techada del edificio
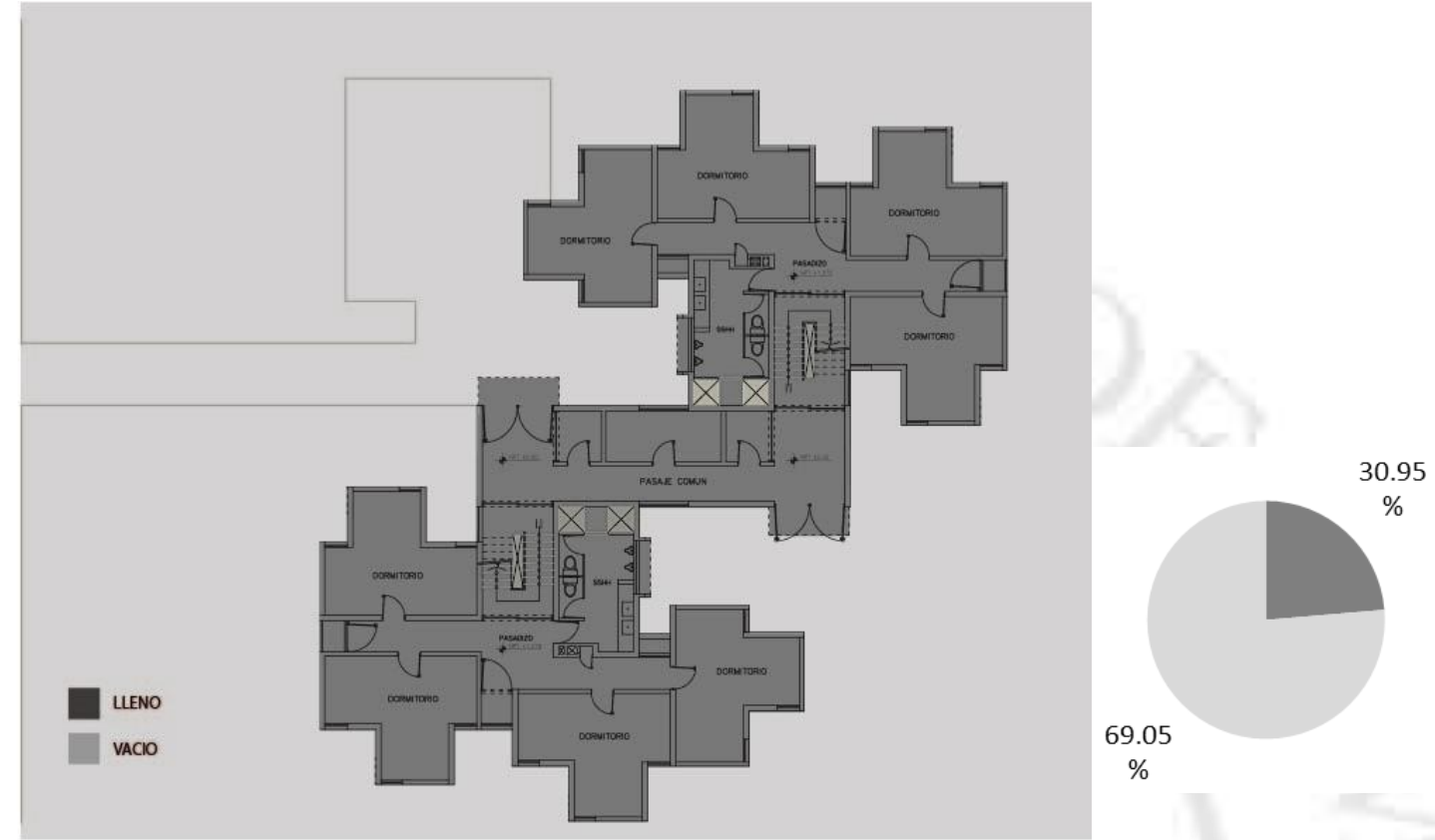

Fuente: Elaboración Propia

\subsubsection{Tecnología}

La residencia universitaria de la UNI utiliza concreto armado para toda la edificación, posee una construcción tradicional y no hay nada innovador.

\subsubsection{Impacto social del proyecto}

El proyecto no tiene un impacto social fuera de la universidad, pero dentro juega un rol muy importante. La residencia al permitir que alumnos vivan dentro de la universidad permite que desarrollen una relación social mayor al resto de estudiantes, ya que les permite debatir sobre distintos temas y generar diversas labores sociales que beneficien a la universidad. Además de esto, la universidad se ve beneficiada al albergar estudiantes de provincia y del extranjero porque así se evita que vayan a otras universidades solo por el factor de la distancia. 
Otro factor importante es que hay estudiantes que quieren quedarse en la residencia incluso si ya están estudiando en esta universidad, pero la residencia al solo admitir estudiantes con altos grados académicos, incita a los alumnos a esforzarse más en sus estudios y así poder postular a una vacante en este pabellón.

\subsubsection{Conclusiones parciales}

La residencia de la UNI es un edificio dividido en 2 partes simétricas, en donde la circulación se encuentra ubicada al centro junto con las pequeñas áreas comunes que poseen. Es la única residencia analizada que se encuentra dentro del campus universitario. 


\subsection{The Student Hotel}

Imagen 107. The Student Hotel

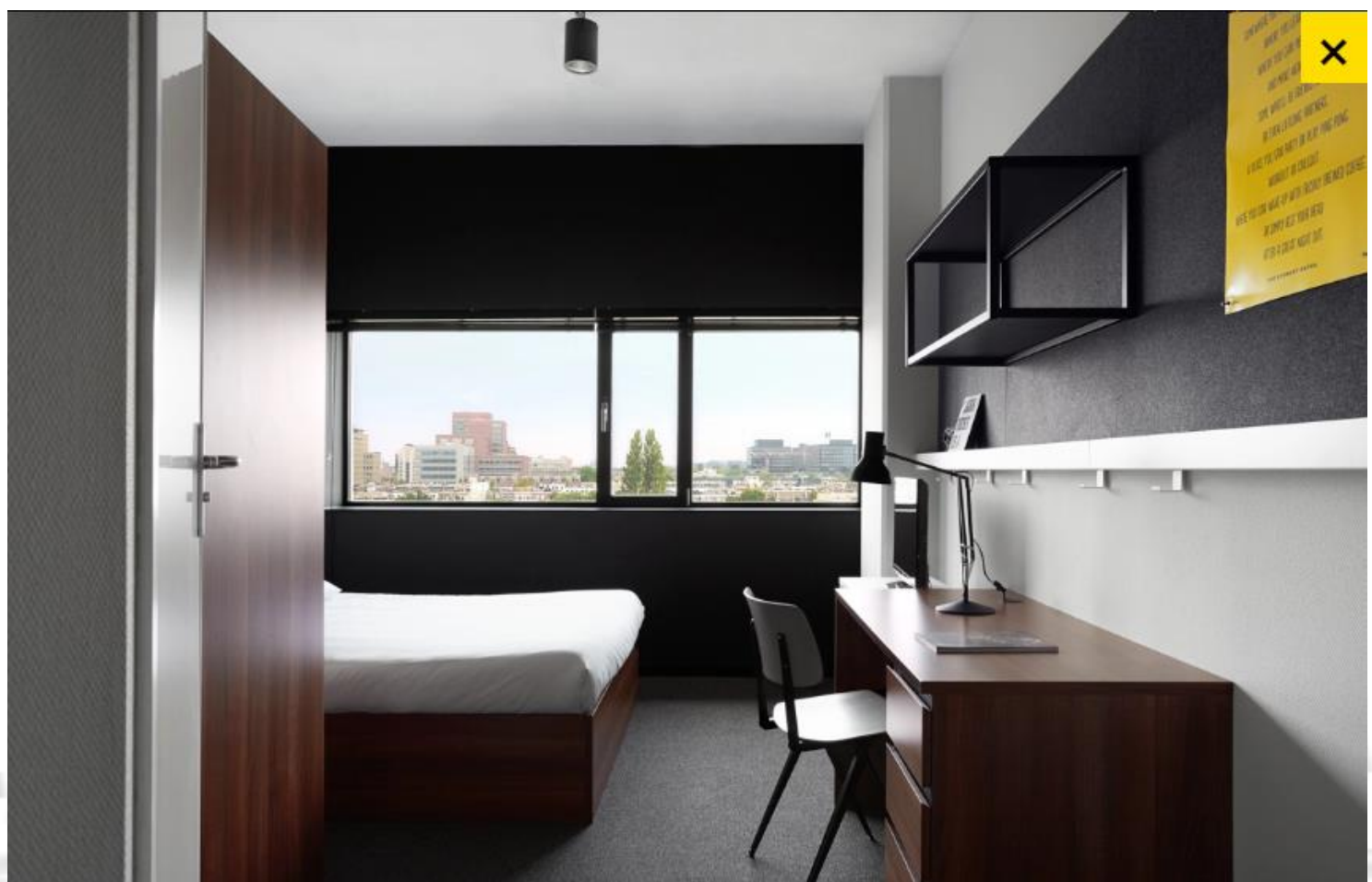

Fuente: https://www.thestudenthotel.com/es/

Se toma como referencia a la empresa The Student Hotel, analizando sobretodo la calidad de espacios y servicios que se le brinda a los estudiantes. The Student Hotel inició en 2006, en Amsterdam, Holanda, cuando los fundadores vieron la falta de residencias en el país, y la lista de espera para que estos pudieran tomar una habitación en las ya existentes.

Esta empresa brinda facilidades de alojamiento a los estudiantes en distintas ciudades del mundo. Sus instalaciones tienen carácter juvenil y están muy bien equipadas. Cuentan con zonas de estudio, bibliotecas, bares, zonas de comida, lavandería, gimnasio y zonas de esparcimiento dentro de sus hoteles.

The Student Hotel ofrece distintas formas de alojamiento, como alquileres por día, semanales, mensuales, por semestre e incluso anuales, variando los precios dependiendo de la opción elegida.

Cuentan con amplias habitaciones para una o dos personas. Están equipadas con baño privado, TV por satélite, aire acondicionado y calefacción, espacios de trabajo y armarios para cada persona, y con acceso a la cocina compartida. También brindan servicio de wi-fi. 
Imagen 108. Habitación de The Student Hotel para dos personas

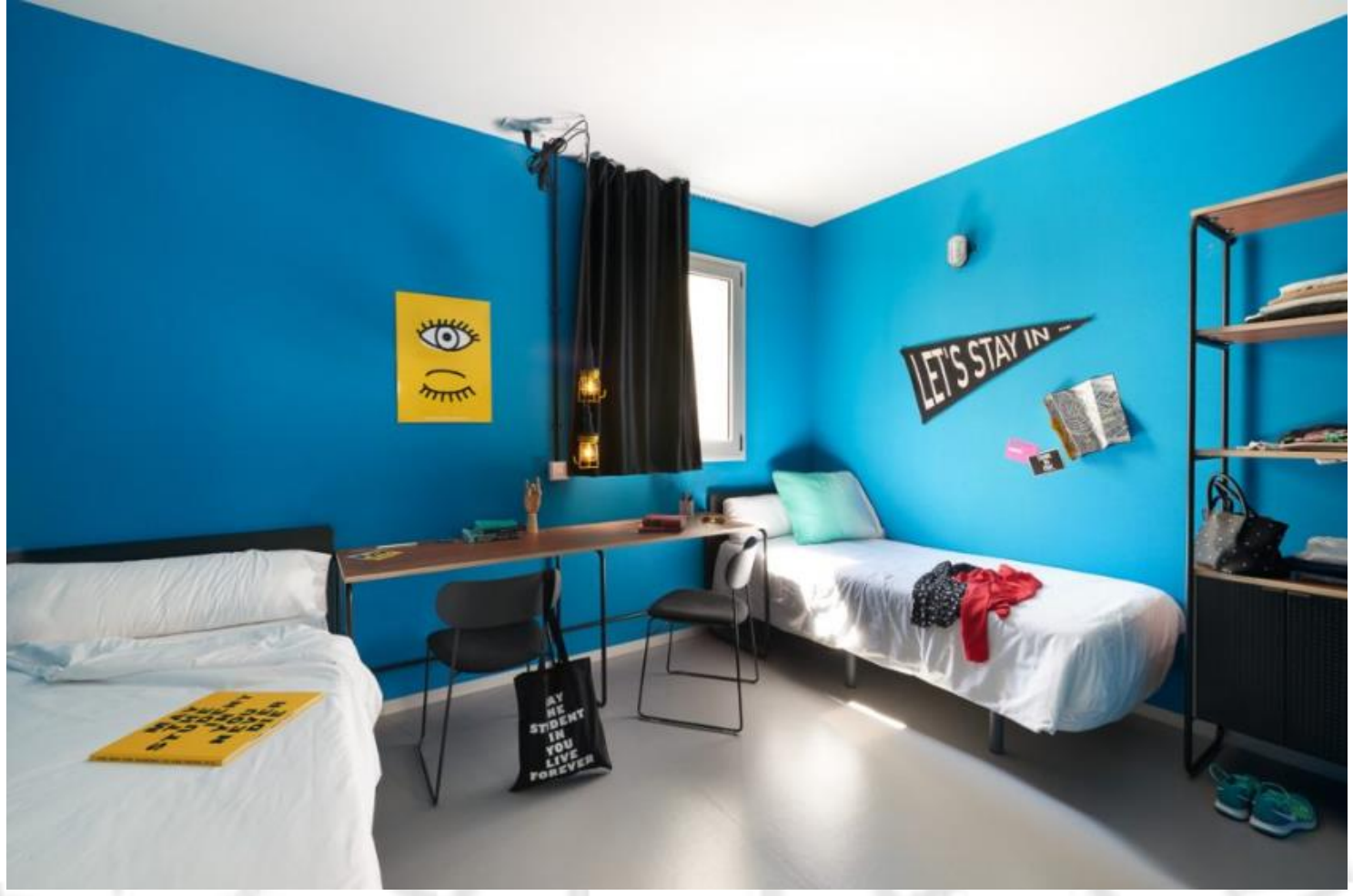

Fuente: https://tshlife.thestudenthotel.com/

Los precios de las habitaciones van desde los 600 euros al mes (compartidas) hasta los 1330 euros mensuales (habitaciones exclusivas individuales). Estos precios van a corde con los servicios que brinda el Hotel, así como también el mantenimiento.

Todas las ubicaciones comparten un concepto básico: estudios y habitaciones equipados, cocina (compartida o privada), coworking flexible, área chill-out, biblioteca, cabinas TedTalks, mesas de ping pong, gimnasio, restaurante abierto todo el día, bicicletas de diseño, lavandería, salas de reuniones, auditorio, programa de eventos, piscina (ubicaciones concretas), espacios comunes y una enorme planta baja donde la gente puede conocerse y estar a gusto. ("THE STUDENT HOTEL", 2015)

Es importante ver la manera en que este tipo de alojamiento opera ya que es uno de los más grandes del mundo respecto a su rubro, y tomarlo como modelo es importante ya que sigue con su plan de expansión por todo Europa, dando a notar el excelente servicio que ofrecen. 


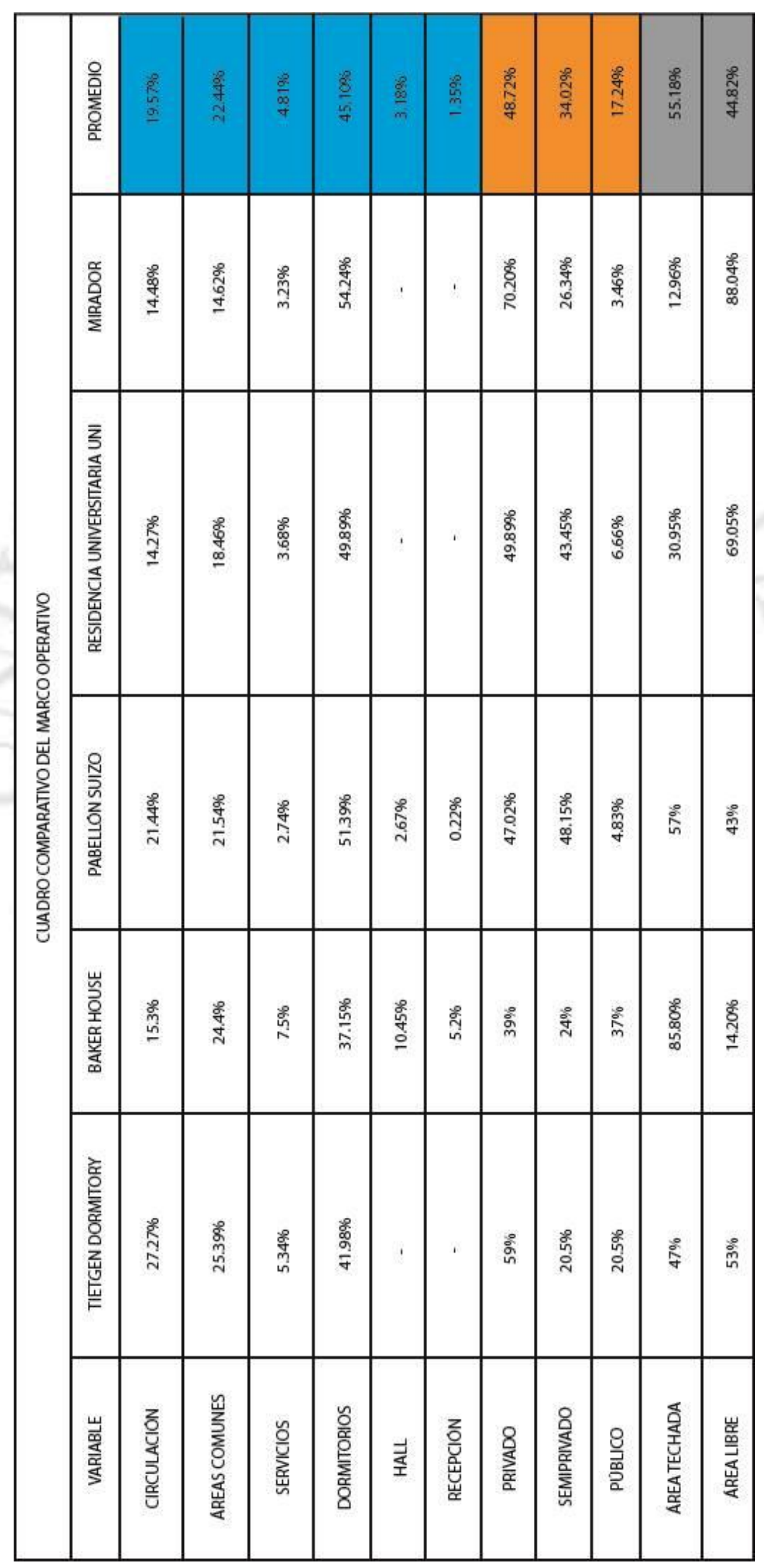




\section{CAPÍTULO VI: MARCO CONTEXTUAL}

\subsection{Elección de terreno}

Para decidir dónde se va a emplazar el proyecto se procedió a escoger tres terrenos tentativos, los cuales fueron comparados para poder determinar cuál es el terreno más conveniente a utilizar.

El primer terreno le pertenece a la Universidad Católica y se encuentra ubicado en una esquina, en el cruce de la avenida Universitaria con la avenida Mariano Cornejo. Es el terreno más grande de los tres y cuenta con 3 frentes. Frente al terreno se encuentra la PUCP y la UNMSM a 6 cuadras. Este terreno beneficia mucho a los alumnos de la PUCP ya que solo tendrían que cruzar la avenida para llegar a sus centros de estudio.

El segundo terreno está en venta actualmente y se encuentra ubicado en una esquina, en el cruce de la avenida Universitaria con la calle Tulipanes. El terreno se encuentra a 2 cuadras de la PUCP y a 4 cuadras de la UNMSM, por lo que está casi a la misma distancia de las 2 universidades. Los alumnos pueden llegar caminando a ambas sin necesidad de tomar transporte público a pesar de que hay un paradero al frente.

Este terreno rectangular es de menor extensión con dos frentes, y cuenta con negocios vecinales en toda la cuadra, lo cual genera mucha actividad en esta.

El último terreno es el más pequeño de los tres y se encuentra al final de la misma cuadra del segundo terreno. Se encuentra entre a ambas universidades a tres cuadras de cada una, con edificios residenciales a su alrededor.

Luego de hacer las comparaciones se llega a la conclusión que el terreno más adecuado es el primero. Si bien los tres terrenos podrían utilizarse para la residencia universitaria, el primero destaca por su ubicación y tamaño como principales características, ya que permite el diseño de espacio público. Esto beneficia a la zona, que es uno de los puntos que busca el proyecto al querer funcionar como regenerador urbano. 
Imagen 109. Ubicación de terrenos en el área

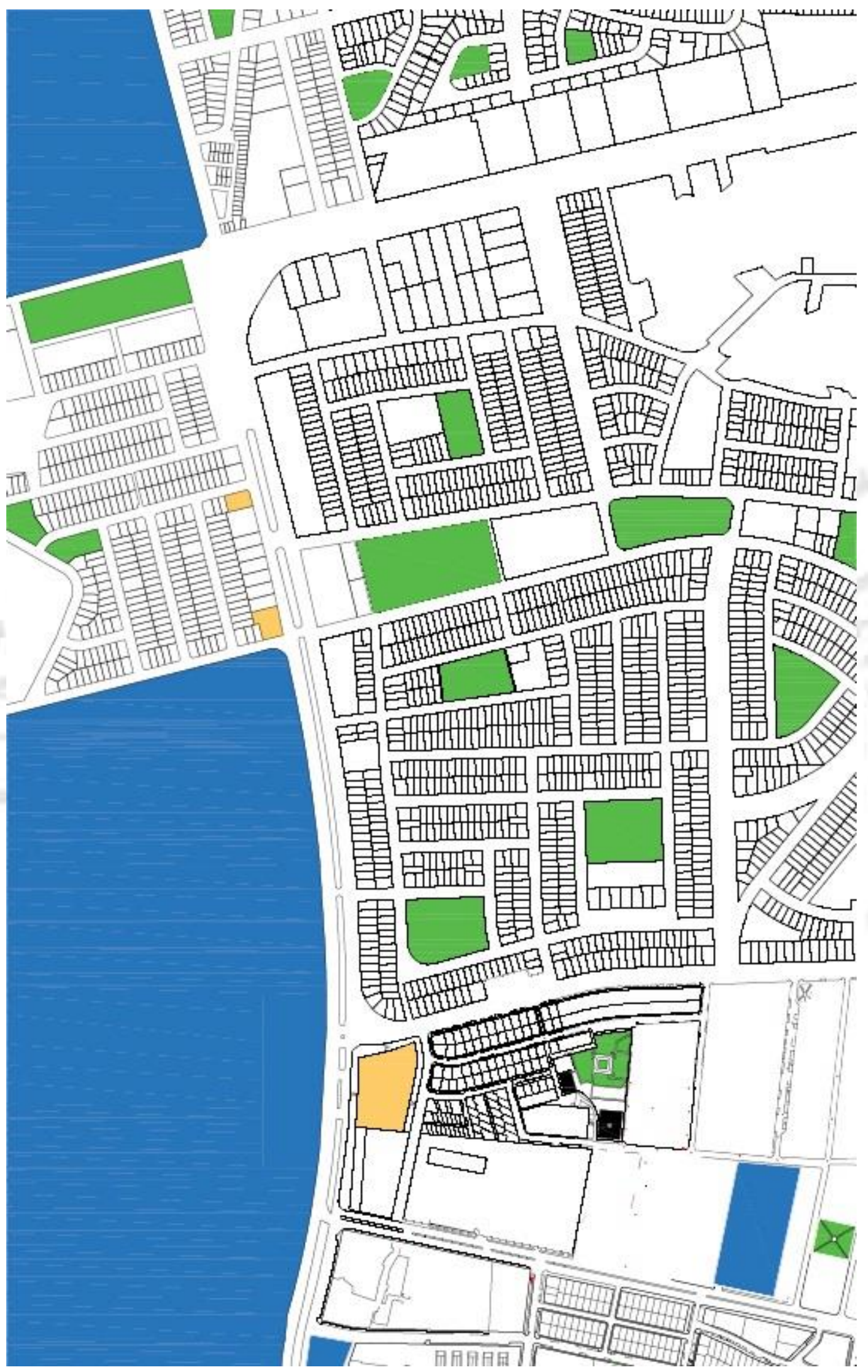

$\square$ Opciones de terrenos

$\square$ Parques

Fuente: Elaboración Propia 


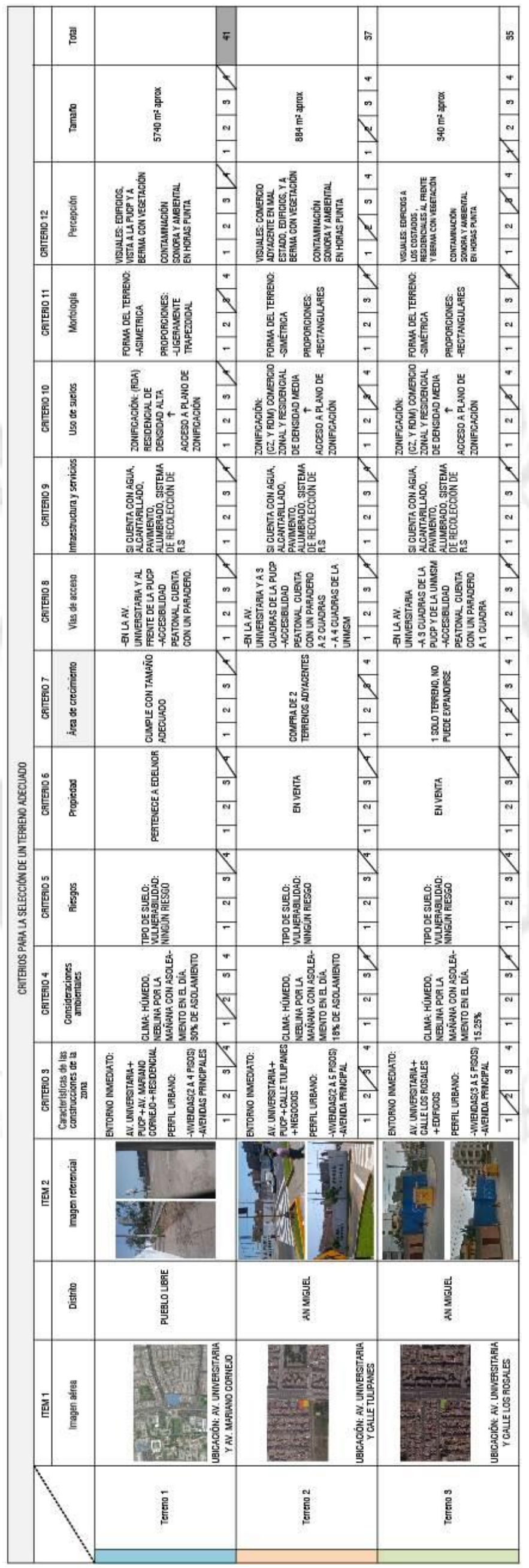




\subsection{Situación actual del terreno}

En la manzana a intervenir se encuentra un paradero formal de transporte público. Al lado del terreno se ubican lotes de pequeñas dimensiones las cuales son usadas netamente para comercio local. Estos lotes van a tender a crecer verticalmente en un futuro ya que sus parámetros urbanísticos se lo permiten.

En el caso del terreno en sí, hay una subestación perteneciente a Edelnor, la cual, luego de hacer las investigaciones correspondientes, es posible reubicarla para poder hacer uso del terreno. Aparte de esto, el terreno se encuentra totalmente libre para poder comenzar con la obra. El terreno pertenece a la Universidad Católica del Perú.

En cuanto al uso del terreno, podemos ver que solo es un muro ciego en los 3 frentes de la manzana (limita con 2 esquinas), lo cual es perjudicial para el peatón. Al utilizar el terreno se recuperará esta zona y se reactivarán estas calles que no inspiran seguridad.

Actualmente dentro del terreno hay postes con anuncios publicitarios de gran envergadura, los cuales deberán ser retirados y reubicados en algún punto de la zona que se les permita y que sea factible a su vez.

\subsection{Características del distrito}

Pueblo Libre es un distrito principalmente residencial. Se encuentra en el Noroeste de la Provincia de Lima.

Latitud: -12.0833

Longitud: -77.0667

Altitud: 93 Msnm

Limites:

- Norte: Cercado de Lima y distrito de Breña

- Sur: Distrito de Magdalena del Mar

- Este: Distrito de Jesús María

- Oeste: Distrito de San Miguel 
Extensión: El territorio distrital comprende $462.34 \mathrm{Ha}$, totalmente consolidadas y de uso predominantemente residencial, donde se desarrollan también actividades comerciales y de servicios a escala distrital con tendencias a mantener su carácter residencial y turístico-cultural. El carácter residencial se ve reflejado por mantener una densidad poblacional estable de 240 a 246 hab. / Ha. En relación a Lima metropolitana se encuentra entre los distritos de mediana densidad (entre 200 a 250 hab./Ha.). (Municipalidad distrital de Pueblo Libre, 2010)

Vegetación: El distrito de Pueblo Libre cuenta con moderada cantidad de vegetación, la cual sirve de ornamentación y, además, garantiza el equilibrio del ecosistema distrital. Las especies que predominan en el distrito son:

- La ponciana regia

- El álamo chileno

- El ciprés

- El eucalipto

- Los laureles

- Los geranios

- El pino estrella

Aspectos Climáticos: El clima del distrito es semi-cálido, subtropical, en términos generales podría decirse que el distrito goza de agradable clima todo el año.

Vientos: El viento se presenta predominantemente del Sur y de Sur-oeste hacia el norte. Su velocidad media es de $3.9 \mathrm{~m} / \mathrm{seg}$, son vientos rápidos debido a la escasez de cerros de mediana altura y arboledas que generan un agradable microclima. Por consiguiente, las condiciones meteorológicas en Pueblo Libre presentarán una mejor sensación térmica, disminuyendo la frecuencia de nieblas y neblinas; las lloviznas matutinas y nocturnas aún seguirán presentándose, aunque de intensidad leve. (Municipalidad distrital de Pueblo Libre, 2010) 


\section{CAPÍTULO VII: PROYECTO}

\subsection{Toma de partido y estrategias proyectuales}

La idea de la residencia universitaria es desarrollar un proyecto que permita formar una comunidad para los estudiantes brindando facilidades dentro sin aislarlos del exterior. El concepto nace a partir de las relaciones de los seres humanos con su ambiente, y como estos se relacionan tanto fuera como dentro de la residencia. Es importante la presencia de espacios significativos a los cuales los estudiantes les atribuyan un valor dependiendo del uso que se le quieran dar.

Entre las estrategias aplicadas figuran:

\section{A) Permeabilidad}

La permeabilidad es uno de los elementos de la urbanidad material que constituye una respuesta espacial equivalente a movimiento y representa secuencias espaciales dinámicas y articuladas. Una buena solución de la permeabilidad consiste en fusionar sutilmente las plantas bajas de las edificaciones con el espacio público contextual. (Quintero, 2015)

La residencia es un proyecto cuya permeabilidad permite tener un acceso a la plaza central desde las avenidas principales que dan hacia la calle. No solo se puede percibir esta permeabilidad espacialmente sino también visualmente debido a la altura de $5 \mathrm{~m}$ del primer nivel, lo que permite ver el interior del proyecto desde afuera. El proyecto presenta permeabilidad visual ya que está diseñado para que los edificios tengan distintas alturas, de manera que las visuales no se vean interrumpidas hacia la avenida principal. La calle Jose Antonio Encinas tiene un frente más reservado ya que es una calle residencial, donde se decidió colocar la parte administrativa y de servicios para mantener la tranquilidad de esta calle. Hay tres niveles de permeabilidad en la primera planta, los ingresos amplios en cada avenida, la visual del exterior con el interior gracias a las fachadas vidriadas, y los recorridos controlados por el patio de comidas que conectan la plaza central con la parte exterior del proyecto. 


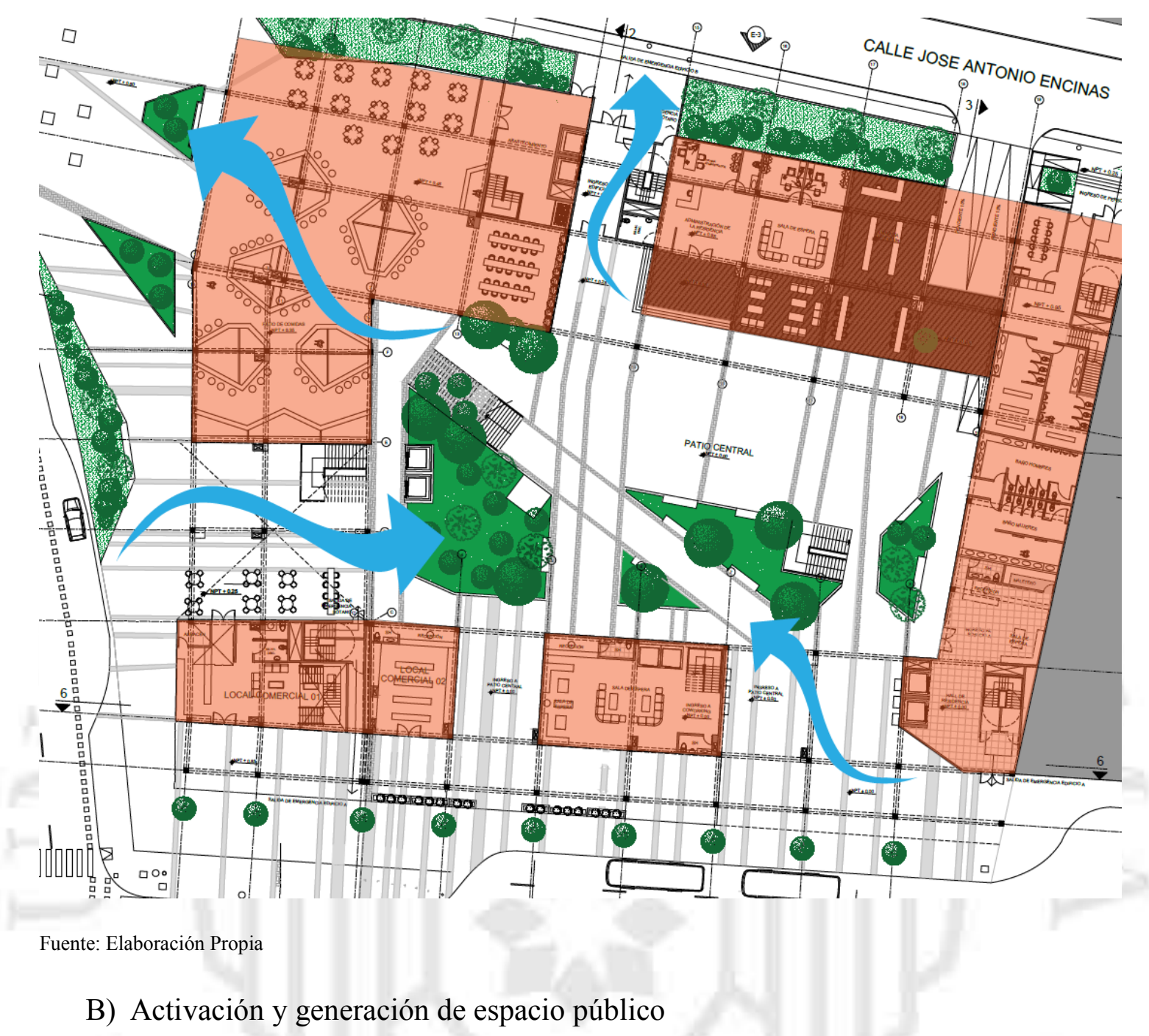

El terreno se encuentra actualmente cercado por muros ciegos, hay poca iluminación y no hay mucho tránsito peatonal, lo que genera inseguridad en el sitio. Con el emplazamiento del proyecto, se activa el lugar, generando espacio público que previamente era inexistente. El retiro de los muros del lote brinda espacios más propensos a ser habitados y recorridos por la gente. Las veredas se ensanchan hacia el interior del proyecto, con dimensiones más orientadas hacia el peatón. La parte pública del proyecto activa los distintos frentes del terreno. El patio de comidas permite la concentración de gente en el cruce de las avenidas Mariano Cornejo con la calle Jose Antonio Encinas. Esta esquina es liberada para el peatón, la cual sirve de ingreso a esta parte del proyecto. La esquina más importante es la que se encuentra en la avenida Universitaria con la avenida Mariano Cornejo. Aquí se encuentra ubicado un Café, el cual sirve de tienda ancla para que las personas lo tomen de punto de referencia. En este frente, el camino es ensanchado para que sea aprovechado por los peatones. También se 
ubica el ingreso a la plaza central, la cual es el principal lugar de activación del proyecto donde va a concentrar la mayor cantidad de gente.

Imagen 111. Interior del proyecto

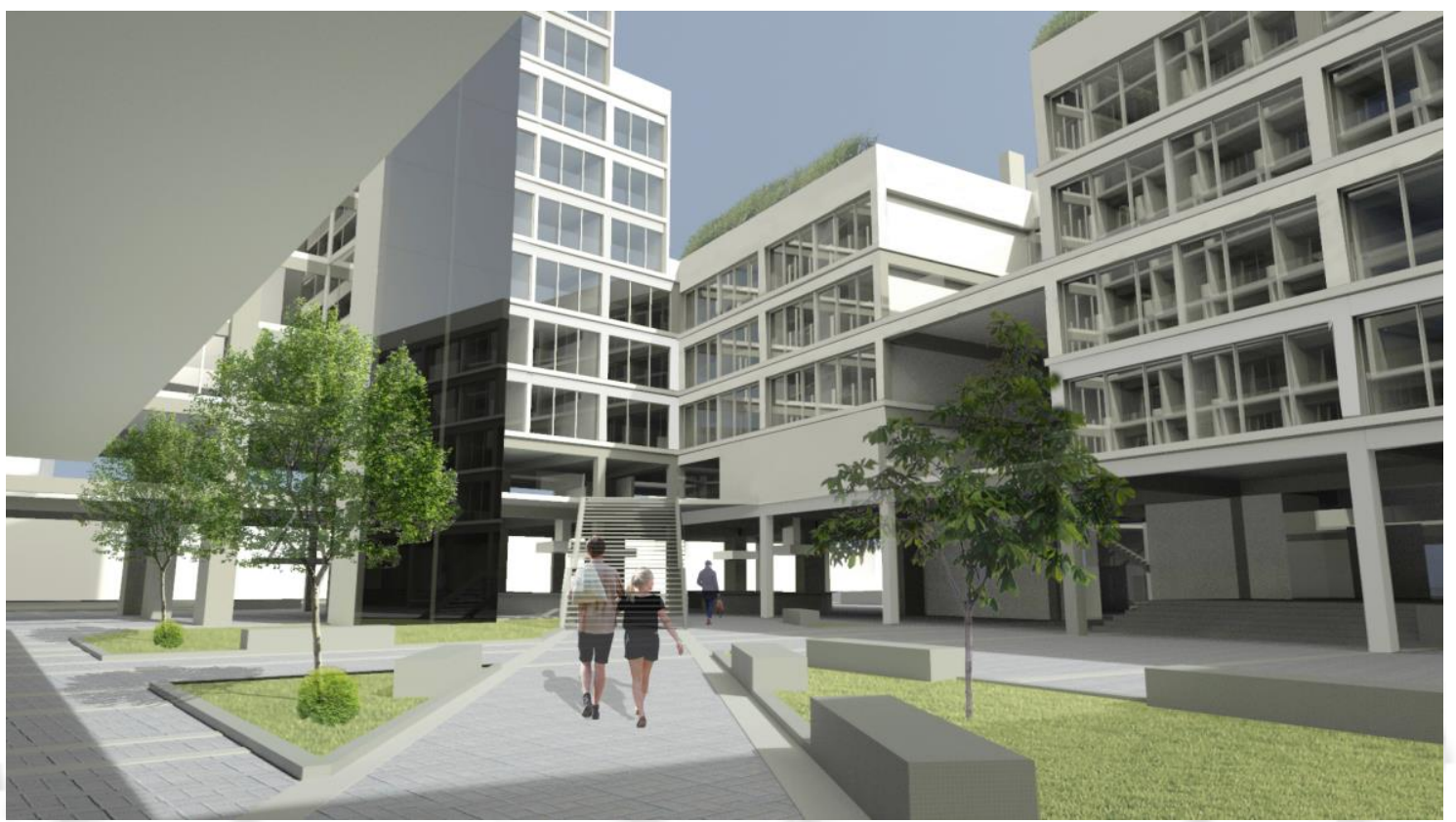

Fuente: Elaboración propia

El proyecto parte de la idea de estar configurado en torno a una plaza central, tal como se puede apreciar en Tietgen Dormitory, el proyecto ubicado en Copenhague. La residencia está diseñada de tal manera que te dirija a los distintos locales que ofrece esta en los niveles inferiores. Las áreas verdes y las distintas texturas de materiales en el suelo te trazan distintos recorridos posibles en el centro del proyecto. La plaza es considerada multiuso, presenta una zona libre la cual sirve para diversos usos, ya sea una exposición de arte, manualidades, un pequeño concierto, entre otros, lo cual podría ser apreciado desde cualquier punto de los edificios.

Imagen 112. 3D del terreno cercado por muros

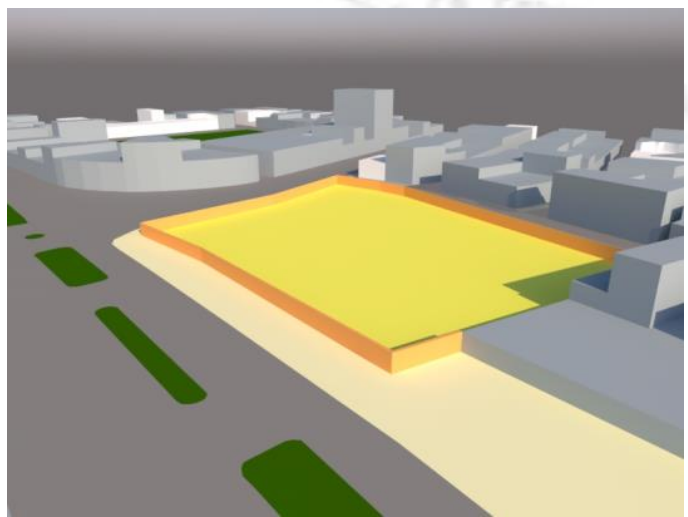

Fuente: Elaboración Propia
Imagen 113. Muro que cerca el terreno

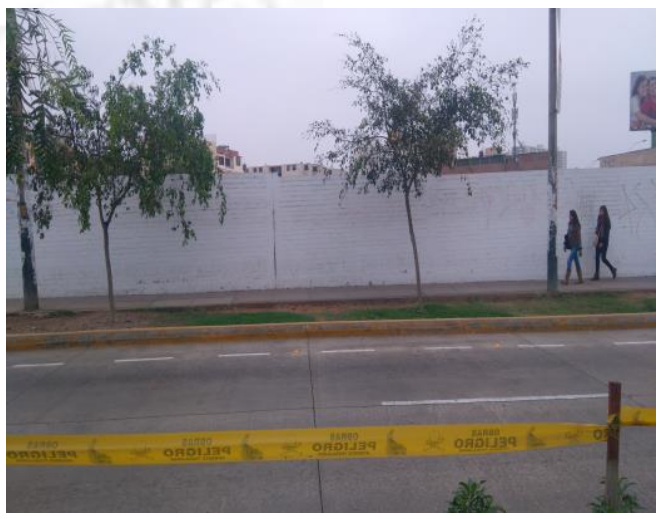

Fuente: Foto propia 
Imagen 114. Primera planta del proyecto con eliminación de cerco del terreno.

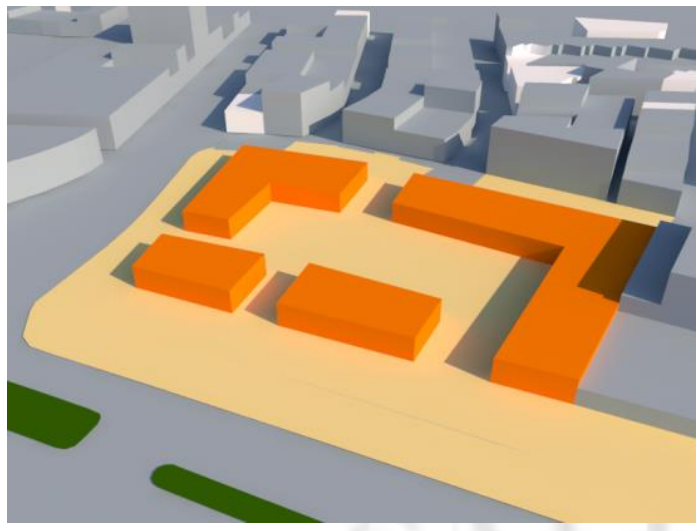

Fuente: Elaboración Propia

C) Relaciones espaciales verticales para mayor conexión

Al implementar relaciones verticales, se otorga una mayor conexión entre espacios de manera indirecta. A nivel perceptual, estas amplifican el espacio, brindando una sensación de continuidad de manera visual.

Las zonas de dormitorios, cuentan con espacios intermedios entre habitaciones, los cuales son las salas de estar. Estas salas están repartidas de manera equitativa en todos los pisos. Las salas de estar que presentan dobles alturas generan conexión entre niveles al encontrarse relacionadas verticalmente, generando dinamismo y volviendo a las fachadas más interesantes.

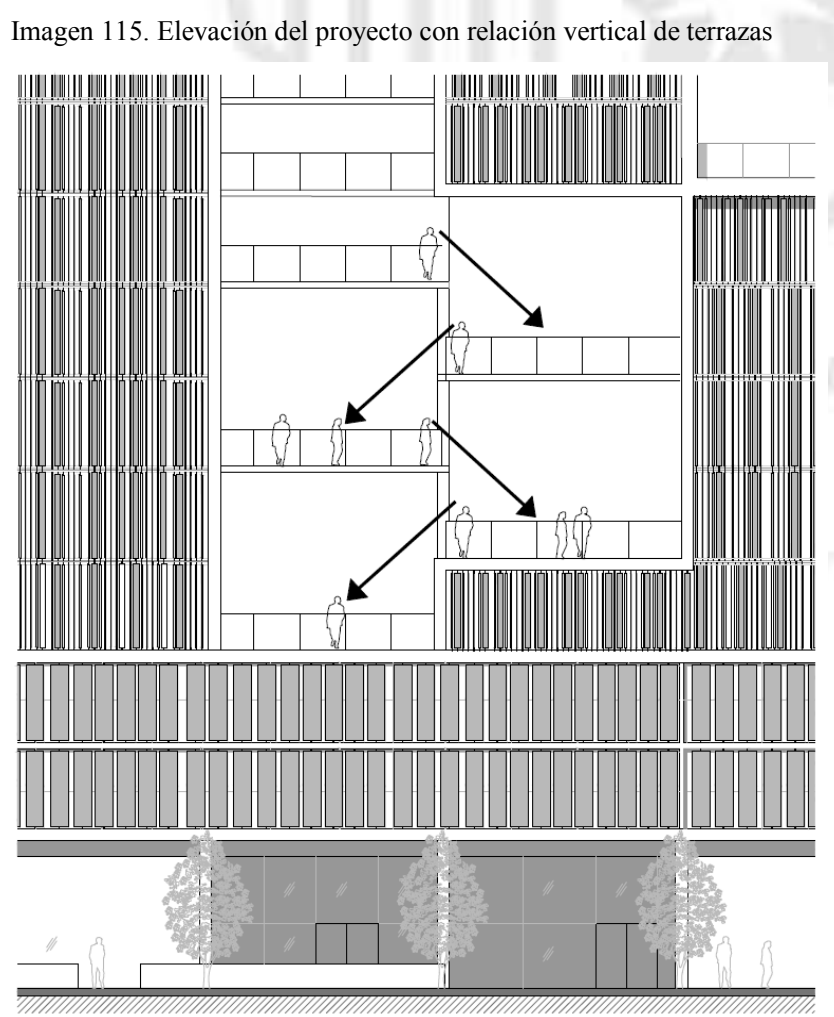

Fuente: Elaboración Propia 
D) Aprovechamiento de áreas techadas para terrazas y espacios de conexión

La residencia cuenta con 3 zonas de terrazas importantes en distintas ubicaciones. La primera es la que pertenece a la zona de coworking en el bloque A, la cual sirve como un espacio de ocio para los trabajadores. La segunda terraza se ubica en el quinto nivel en el bloque D, arriba de las zonas de estudio para los estudiantes. Esta terraza sirve como puente para conectar el bloque A Y C, y es un espacio de zona común para todos los residentes, con vista al patio central. La tercera terraza y la más significativa es la que se ubica en el techo del bloque $\mathrm{C}$ de la residencia. Esta pasa a ser un techo verde con zonas de esparcimiento, como espacios para parrilla y bancas repartidas en toda su extensión.

Imagen 116. Ubicación de terrazas

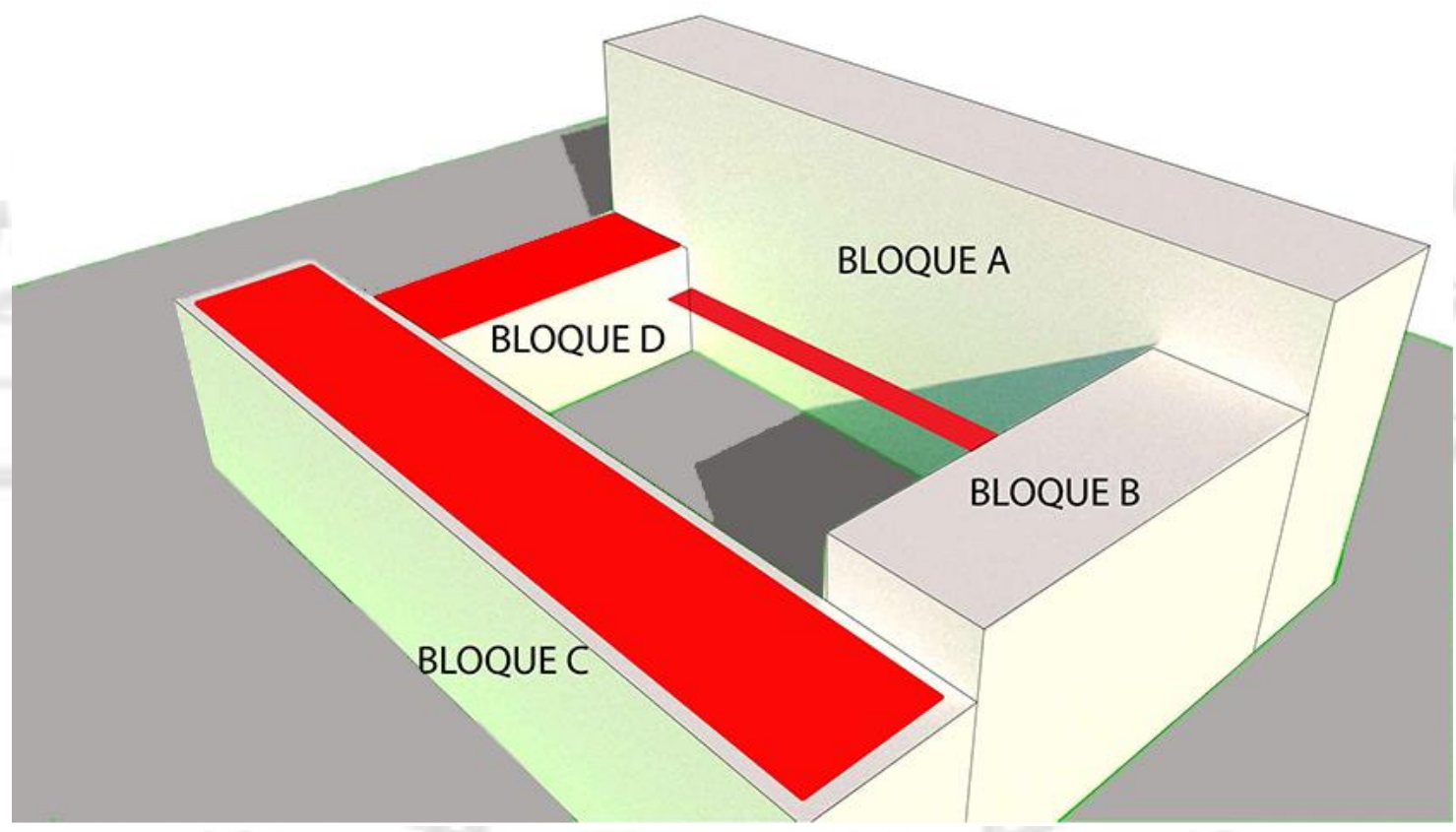

Fuente: Elaboración Propia 


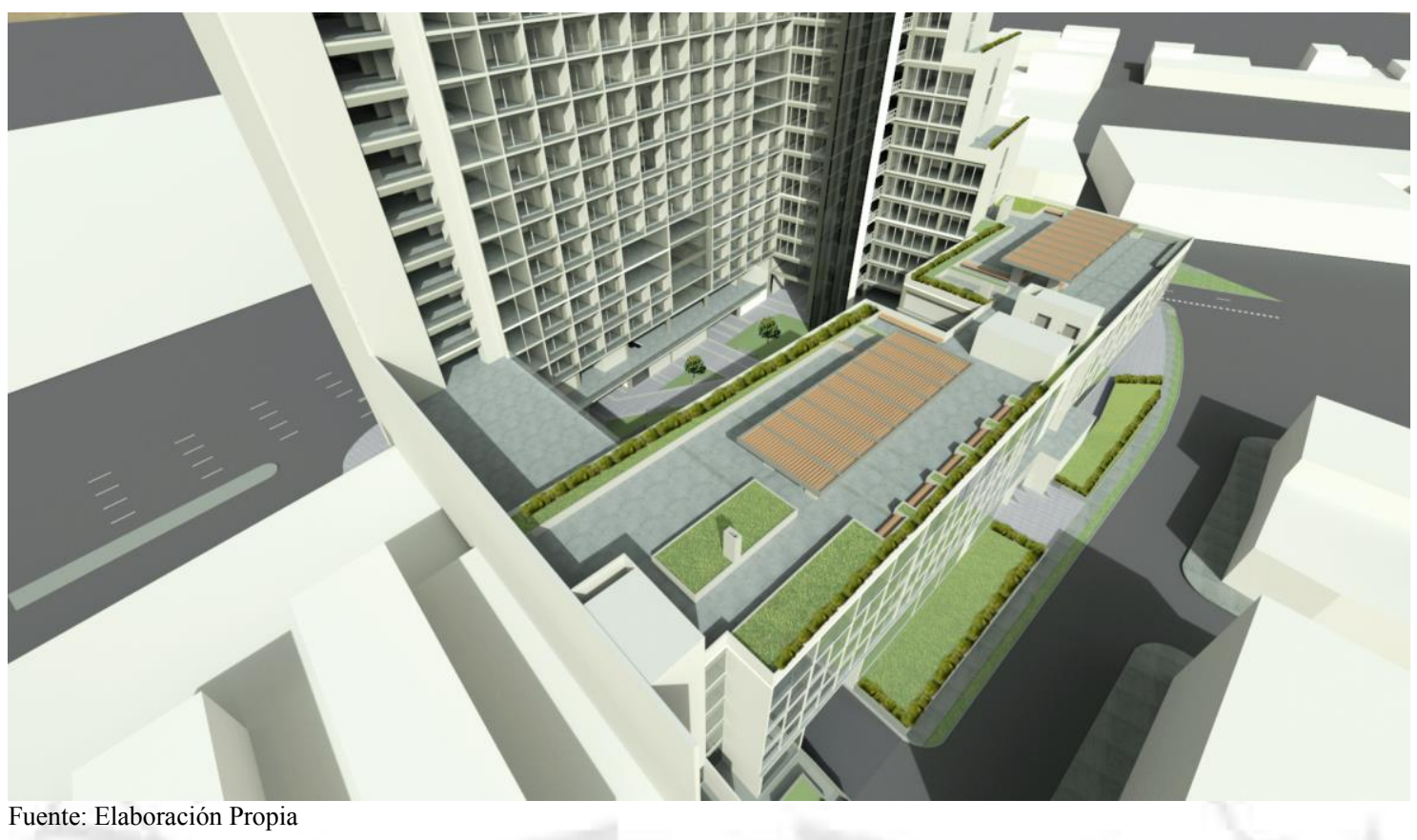

E) Edificio poli-funcional para activación de lugar en beneficio de los habitantes y la comunidad

El proyecto es diseñado para ser un edificio poli-funcional ya que cuenta con distintos tipos de servicios y locales. Cuenta con la zona comercial en el zócalo del edificio, área de coworking en el frente de la avenida universitaria y por último la zona de residencia en los pisos superiores.

Esto trae muchas ventajas tanto a los residentes como a la gente de fuera. El ahorro de tiempo por proximidad de comercio - oficina - vivienda incrementa, siendo más viable tener todo en un mismo sitio sin tener que movilizarse por mucho tiempo, y evitando el uso del automóvil.

Se genera un ahorro de costo ya que se dividen ciertos pagos entre todos, como por ejemplo los alimentos para las kitchenettes. La seguridad en la zona aumenta drásticamente, ya que dejan de ser caminos pequeños para convertirse en un espacio público donde hay mucho movimiento a distintas horas del día.

Este tipo de estrategia es la que genera muchos aportes al entorno ya que es pensado como un proyecto en su totalidad y no visto solo desde la planta. 


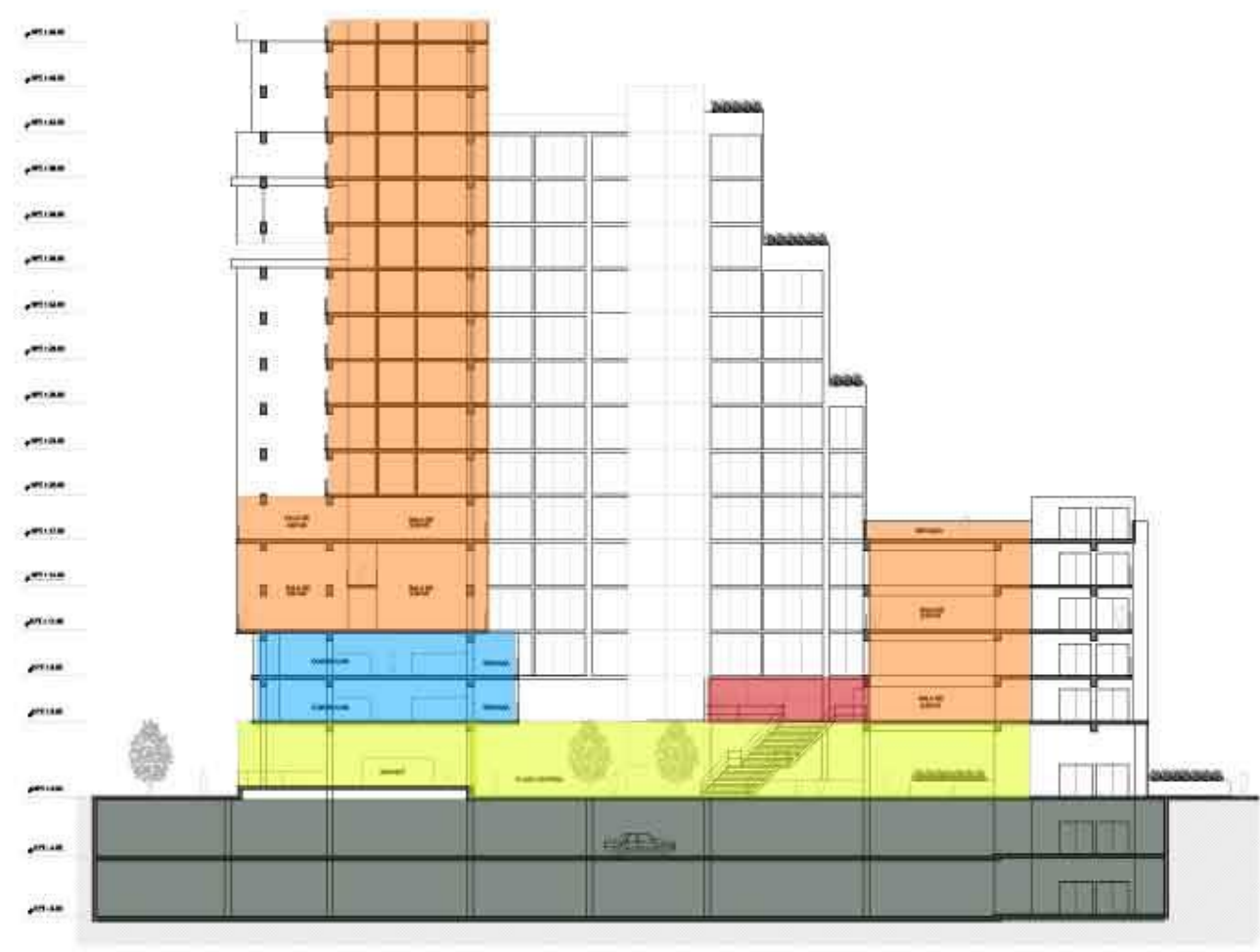

Sótano

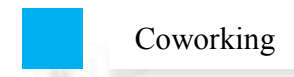

Vivienda

Comercio

Gimnasio

Fuente: Elaboración Propia

\subsection{Programa arquitectónico}

La residencia universitaria es un edificio poli-funcional, que cuenta con tiendas comerciales, un gimnasio, oficinas y el sector más importante que son las habitaciones. Tiene, asimismo, dos sótanos con 211 estacionamientos en total, además de almacenes para las diferentes tiendas del nivel superior, habitaciones para las cisternas, bombas y aparatos eléctricos.

Este nivel cuenta con un frente principal de ingresos y locales entre los cuales tenemos un café y el ingreso a la zona de coworking. Estas tiendas permiten la concurrencia de gente en los alrededores.

Entre estos dos programas se encuentra la salida de una de las escaleras de emergencia. Ubicado en este mismo frente se encuentran 3 ingresos. Este ingreso lleva a los 2 pisos superiores los cuales contienen este programa. Luego se encuentra el ingreso a la plaza central del proyecto, acompañada de cajeros automáticos a los lados del corredor para su uso por las personas que los necesiten. En el límite del proyecto se 
encuentra la salida de una de las escaleras de emergencia, la cual solo se puede abrir desde dentro.

Por el frente de la avenida Mariano Dulanto funciona una ciclovía la cual ha sido integrada al proyecto anchando la vía por la cual circulan los ciclistas.

Imagen 119. Proyecto fachada

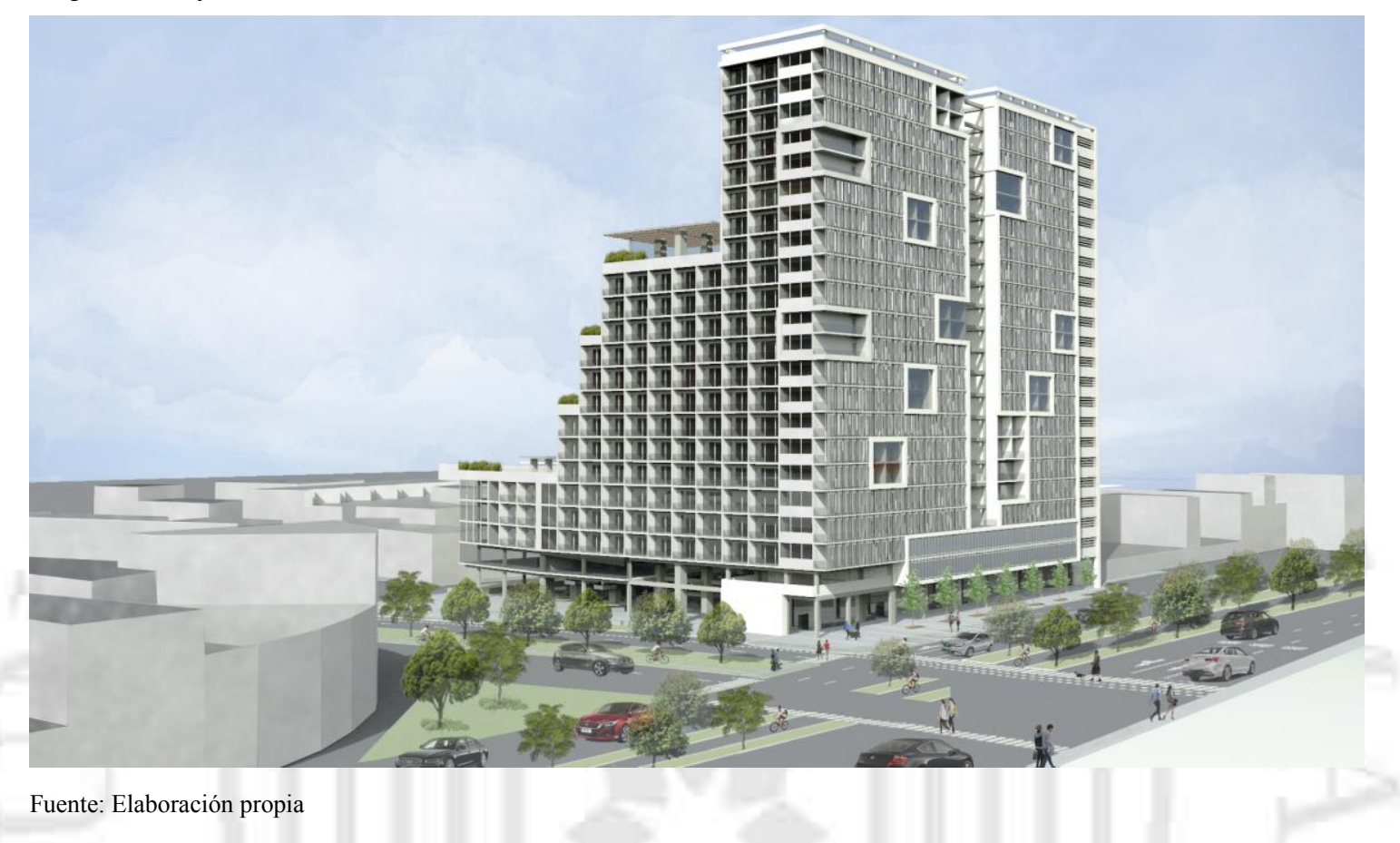

\section{Zona Comercial}

\subsection{Plaza central}

La plaza central es una zona de permanencia que te dirige a los distintos establecimientos, incluido el sótano con los estacionamientos. Tiene un área de $1738 \mathrm{~m}^{2}$ y cuenta con una escalera grande que lleva hacia el gimnasio en el segundo nivel. El piso tiene distintas texturas y zonas de vegetación que marcan los caminos y lugares por los cuales la gente puede recorrer. La plaza tiene ingreso por cada avenida, y cuenta con una zona de baños al lado de la zona del personal. 
Imagen 120. Ubicación de la plaza central del proyecto

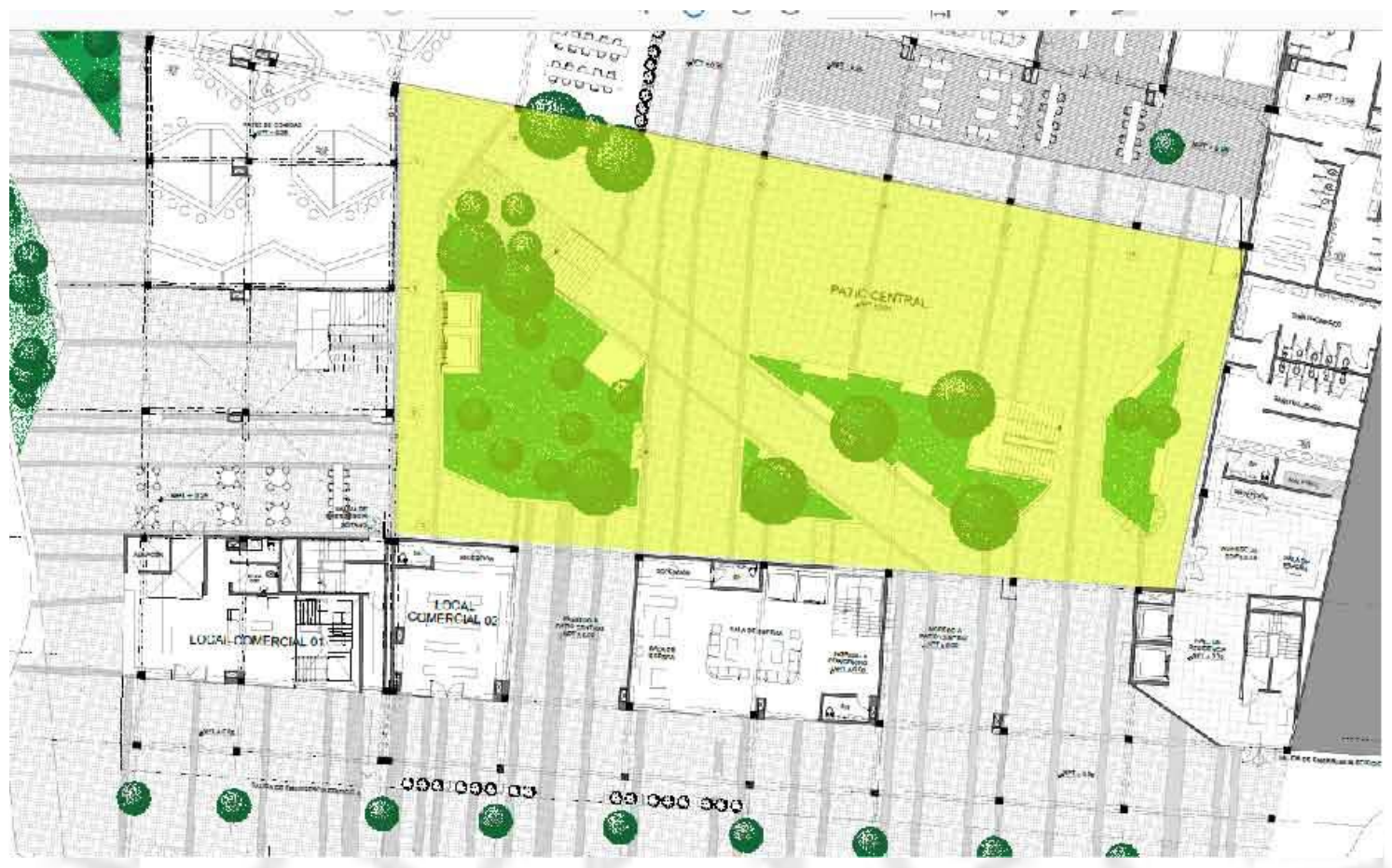

Fuente: Elaboración Propia

Imagen 121. Vista interior de la plaza

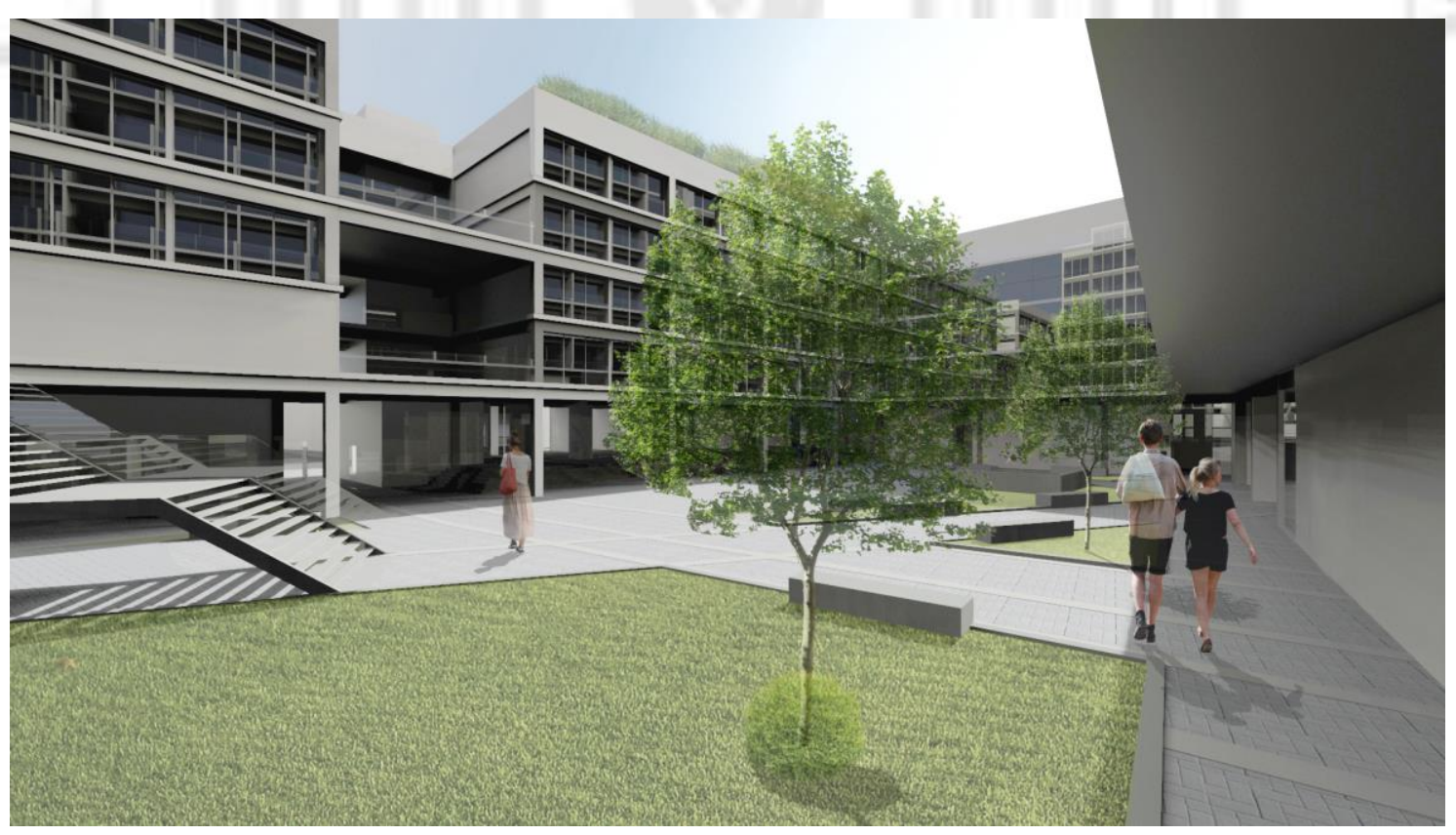

Fuente. Elaboración propia 


\subsection{Patio de comidas}

La residencia cuenta con una zona de comidas con un área de $743 \mathrm{~m}^{2}$ la cual abarca todo el frente de la avenida Mariano Dulanto, exceptuando la esquina del café y el ingreso hacia la plaza entre ambos. Esta zona de comidas cuenta con 15 islas de comida, las cuales permiten a la gente tener variedad de opciones a elegir. El diseño de las islas define los caminos a recorrer por las personas. El ingreso al lado de esta zona cuenta con una escalera que lleva hasta el segundo piso, el cual es el nivel hasta donde llega la zona pública de la residencia. El otro cruce de calles es aprovechado para utilizarlo como ingreso al estacionamiento en el sótano, tanto para los vehículos como para los proveedores, donde tienen los suministros para los distintos puestos.

Imagen 122. Vista al patio de comidas en el primer nivel

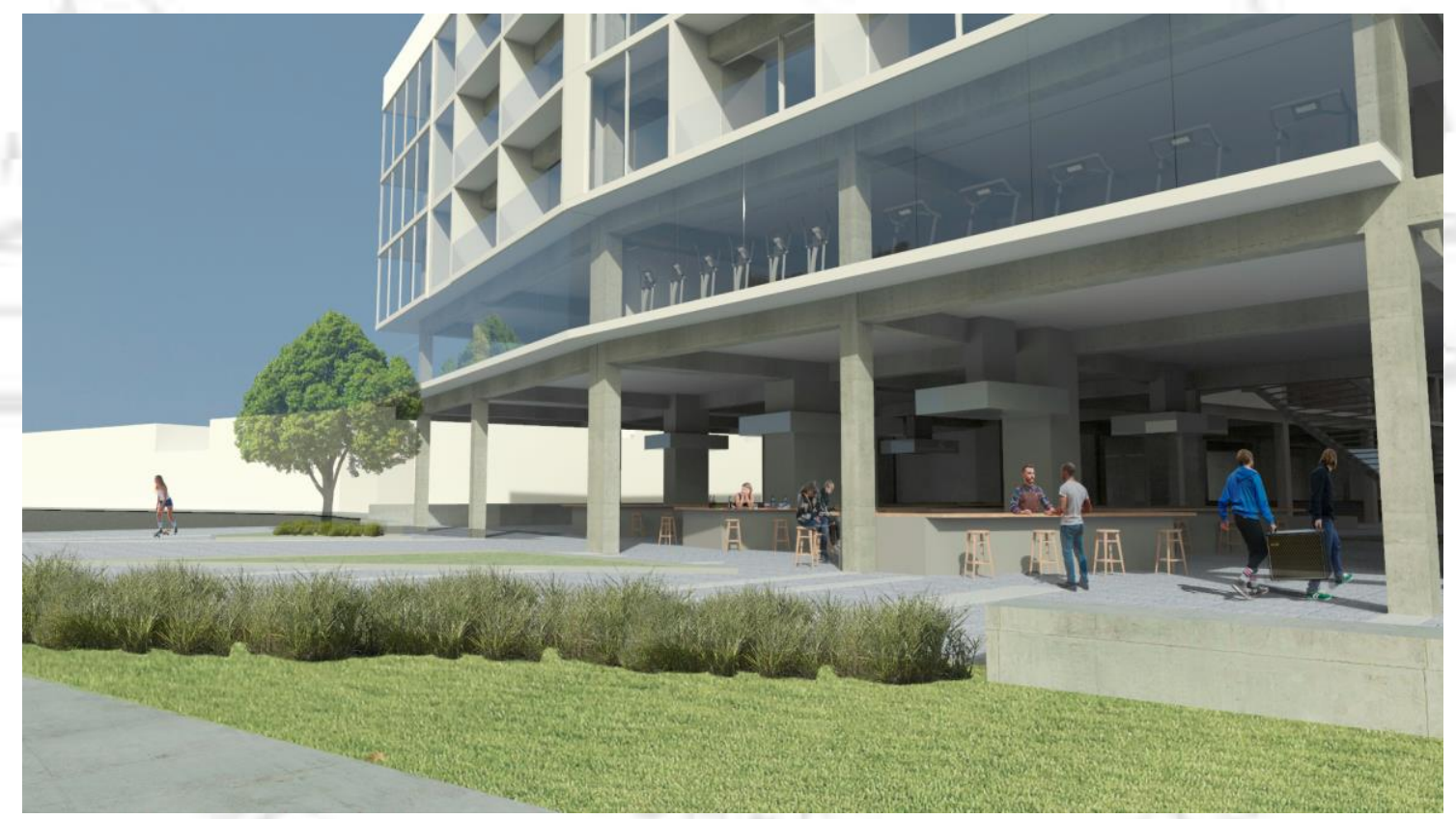

Fuente. Elaboración propia

\subsection{Minimarket}

Al lado se encuentra ubicado un minimarket, lo que permite a los estudiantes, tanto de la Universidad Católica como a los estudiantes hospedados en la residencia, abastecerse de lo que requieran sin tener que movilizarse fuera de esta. Además de estos, también es de uso público para toda la gente de los alrededores. Este minimarket tiene un área de $79 \mathrm{~m}^{2}$, y funciona como espacio de transición entre la calle y la plaza, al 
ser un espacio intermedio. Cuenta con ingresos hacia ambos lados y las fachadas son transparentes.

Imagen 123. Ubicación del minimarket

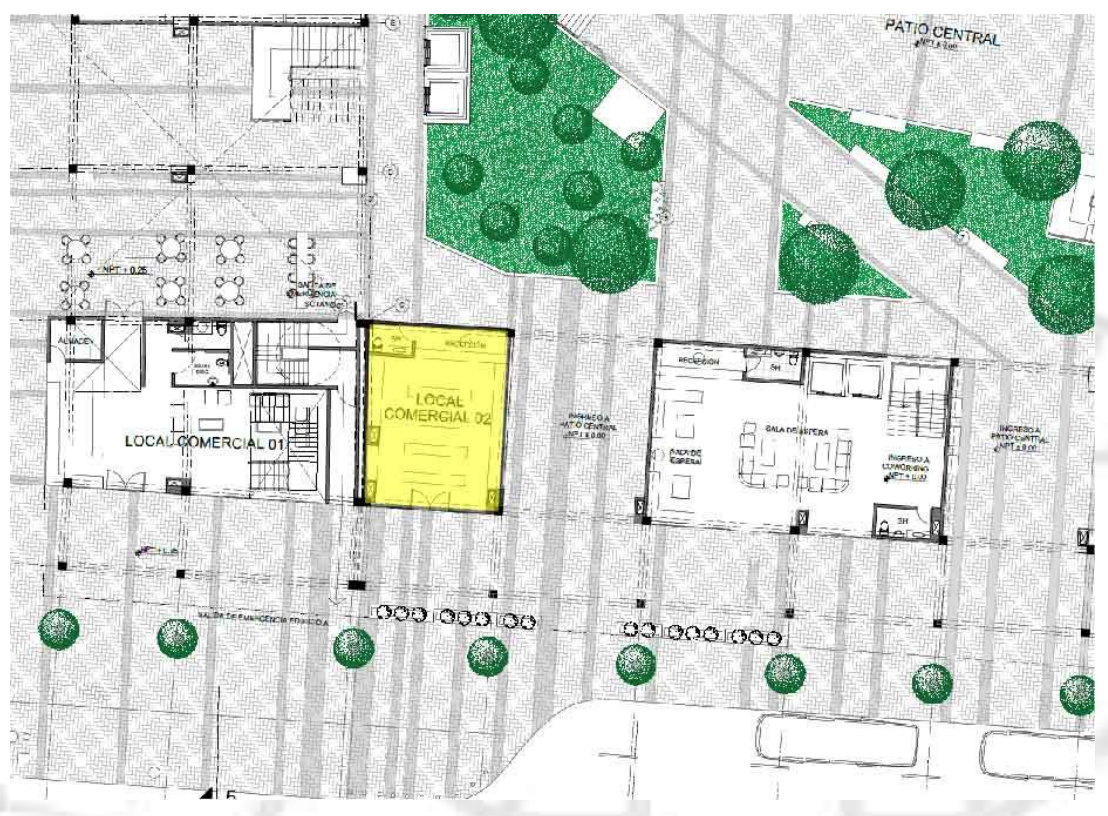

Fuente: Elaboración Propia

\subsection{Café}

La esquina de la residencia con un área en el primer nivel de $217 \mathrm{~m}^{2}$ se encuentra en el cruce de dos avenidas (Avenida Universitaria y avenida Mariano Dulanto). Se aprovechó para establecer un café de dos niveles, el cual tiene su acceso desde la calle y sirve de abasto para el entorno inmediato.

Imagen 124. Ubicación del café

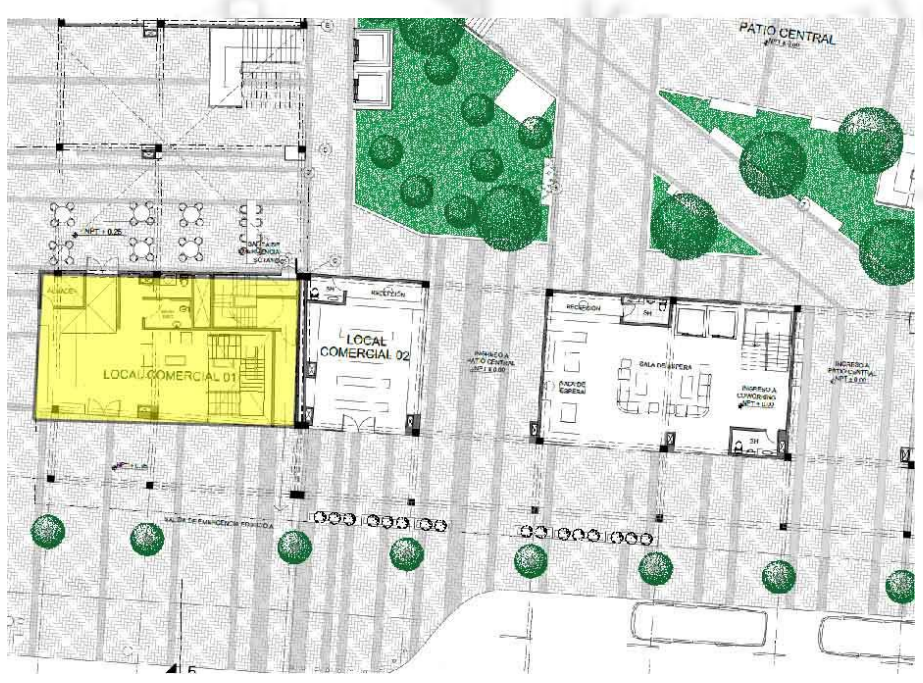

Fuente: Elaboración Propia 


\subsection{Lavandería}

El proyecto incorpora una lavandería ubicada en el primer sótano. Esta cuenta con atención, sin embargo, también es de autoservicio y presenta una zona de espera. La lavandería es de uso privado para la residencia y tiene un área de $120 \mathrm{~m}^{2}$.

Imagen 125. Ubicación de la lavandería

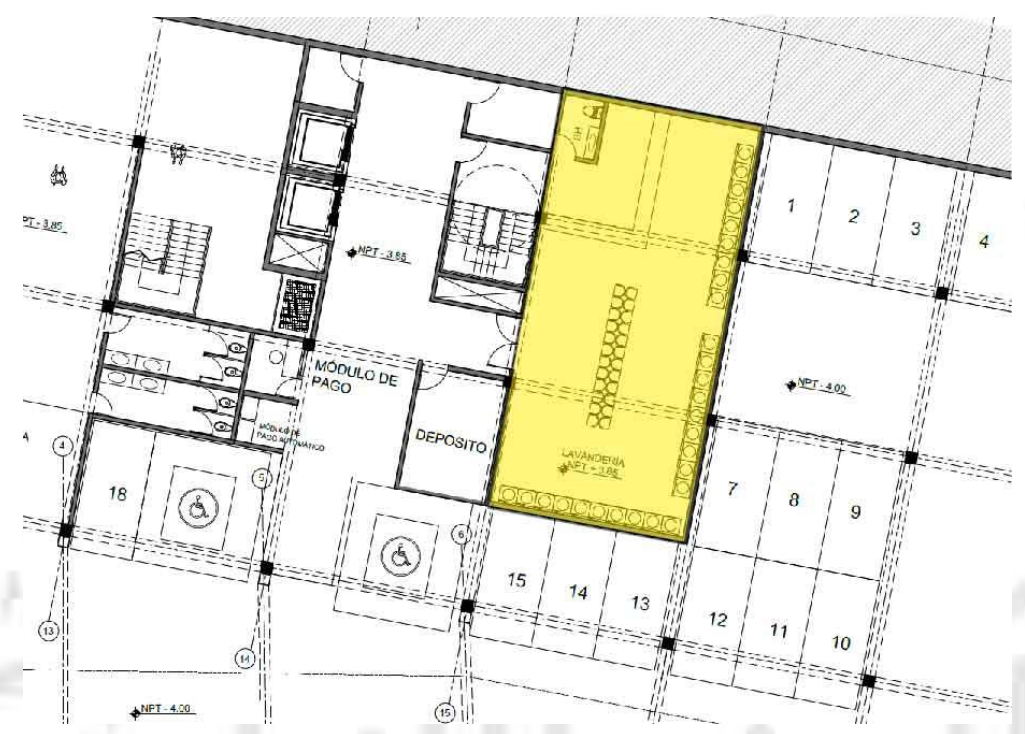

Fuente: Elaboración Propia

\section{Sótanos}

El proyecto tiene dos sótanos para suplir la demanda de estacionamientos requeridos.

Cuadro 18: Dotación de estacionamientos:

\begin{tabular}{|l|r|r|r|r|r|}
\hline \multicolumn{7}{|c|}{ Aforo } & Aforo & Personal & Público & Factor & $N^{\circ}$ de estacionamientos \\
\hline Café & 224 & 1 & 12 & 9,1 & 10 \\
\hline Convinience & 54 & 1 & 4 & 3,5 & 4 \\
\hline Patio de comidas & 144 & 2 & 6 & 5,6 & 6 \\
\hline Administración & 20 & 1 & 2 & 2,1 & 3 \\
\hline Librería & 28 & 1 & 2 & 2,1 & 3 \\
\hline Lavandería & 12 & & 1 & 0,7 & 1 \\
\hline Zona de personal & 14 & 1 & & 0,7 & 1 \\
\hline Mantenimiento de piso & 3 & 1 & & 0,7 & 1 \\
\hline Gimnasio & 263 & 1 & 26 & 18,9 & 19 \\
\hline Coworking & 170 & 3 & 17 & 1 & 20 \\
\hline Habitaciones & 604 & & & 0,2 & 121 \\
\hline \multicolumn{7}{|c|}{ Total } & & & 189 \\
\hline
\end{tabular}

Fuente: Elaboración propia 


\subsection{Depósitos}

En el sótano del proyecto hay una zona de depósitos destinada tanto a los locales comerciales como al patio de comidas. El número de depósitos es igual al número de locales e islas presentes en la zona comercial. Estos tienen una extensión total de $407 \mathrm{~m}^{2}$. También hay una zona destinada al área de coworking del segundo y tercer nivel. La zona de viviendas de la residencia también cuenta con un área general de depósitos.

Imagen 126. Ubicación de los depósitos en el sótano

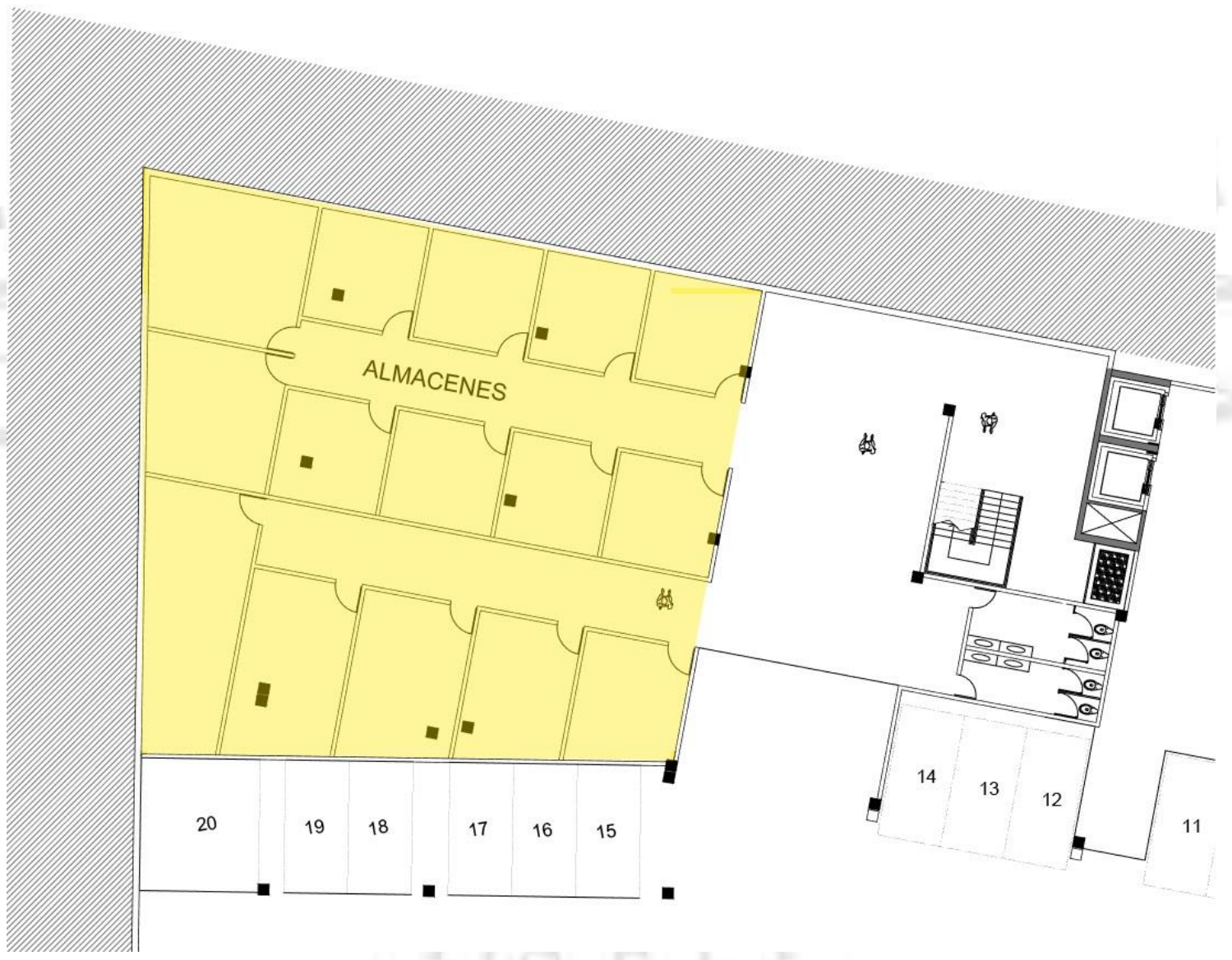

Fuente: Elaboración Propia 


\section{Gimnasio}

El gimnasio posee un área de $796 \mathrm{~m}^{2}$ y se ubica en el segundo nivel de la torre $\mathrm{C}$, con vista hacia Mariano Cornejo, al cual se puede acceder mediante las escaleras que están en la plaza o mediante el ascensor., Este presenta zonas de máquinas de doble altura, y tiene un énfasis en planta libre para ejercicios funcionales y zona de baile. Hay oficinas de nutrición, depósitos y servicios para los clientes.

Imagen 127. Ubicación del gimnasio

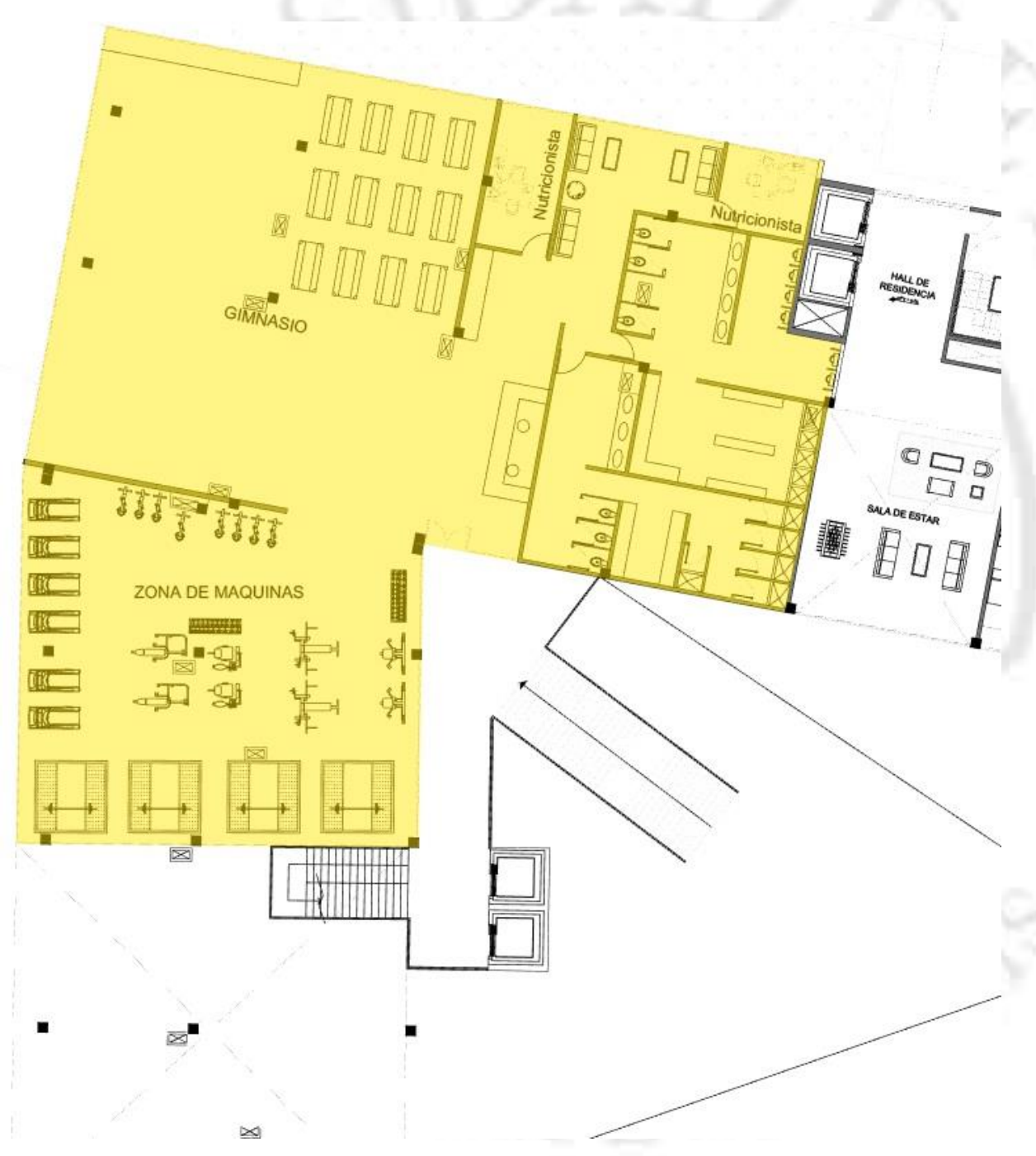

Fuente: Elaboración Propia 


\section{Zona de Coworking}

Imagen 128. Ubicación del coworking

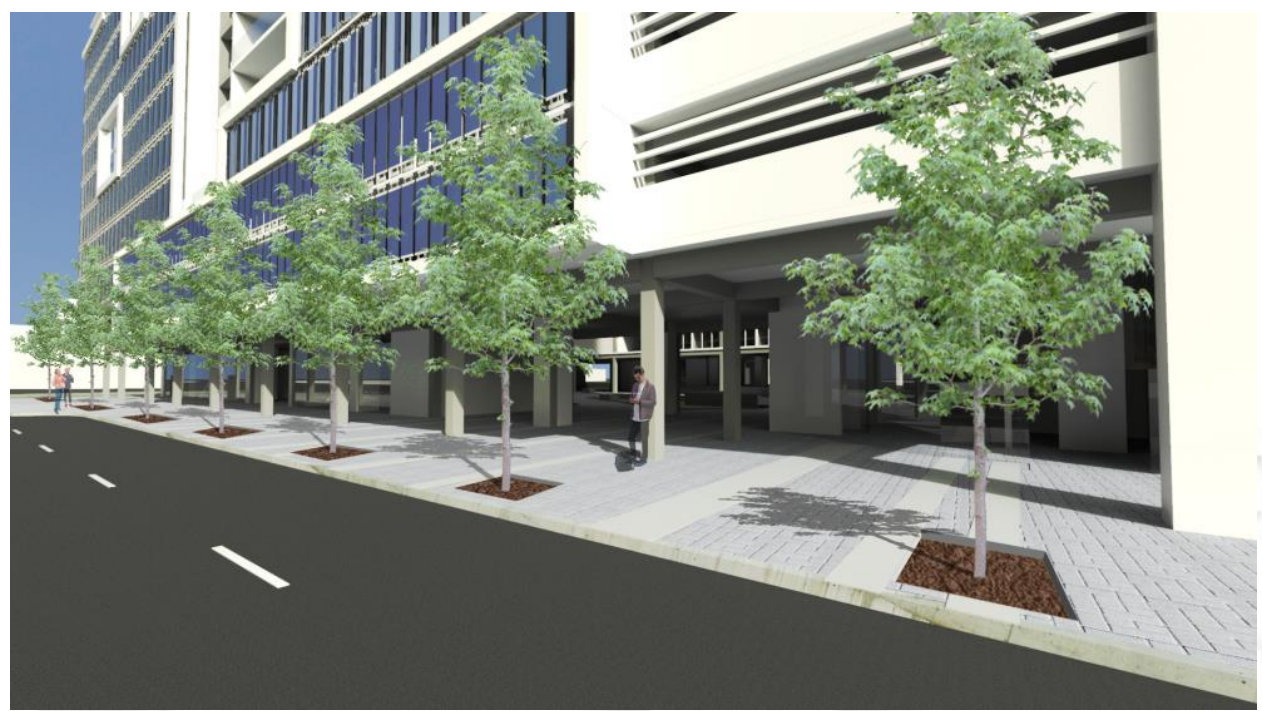

Fuente: Elaboración propia

Las oficinas de coworking se ubican en la torre A y cuentan con tres niveles. En el primer nivel se encuentra el ingreso y posee un área de $141 \mathrm{~m}^{2}$. Este ingreso lleva a los 2 pisos superiores mediante una escalera y ascensor privados.

La distribución interna de las oficinas está equipada con escritorios en conjunto, cubículos separados, privados y una sala de juntas. Presenta dos salas multiuso que pueden unirse para volverse una sala de conferencia. También se cuenta con servicios higiénicos y una kitchenette en cada nivel para que los trabajadores puedan calentar y prepararse lo que necesiten. La zona de coworking en el segundo y tercer nivel tienen con una terraza hacia la plaza central con áreas comunes de esparcimiento.

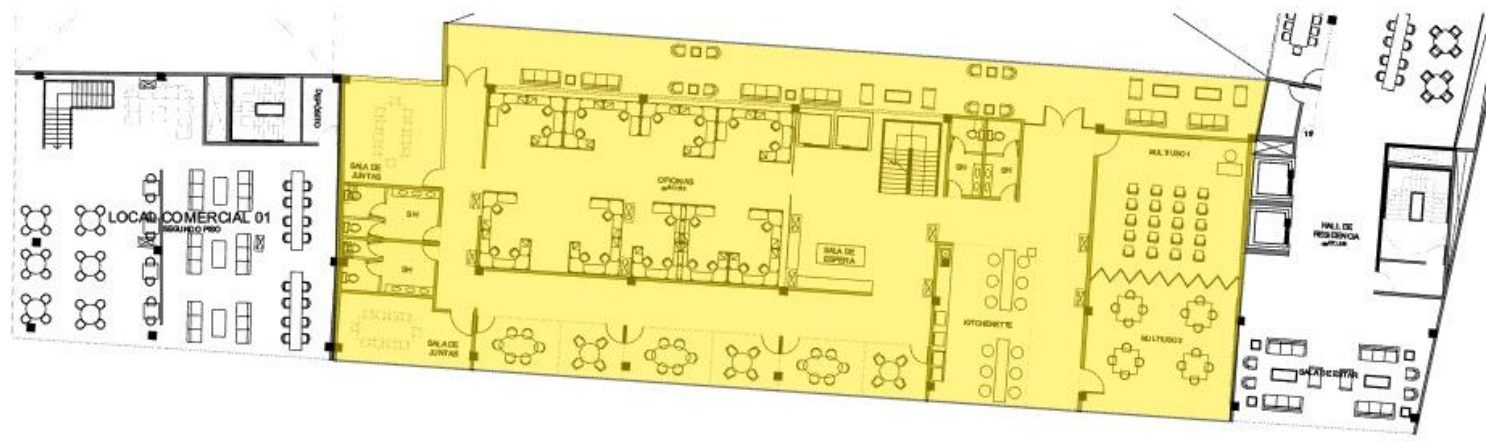

AV. UNIVERSITARIA

Fuente: Elaboración Propia 


\section{Vivienda de estudiantes}

\section{1. $\quad$ Planta de vivienda}

Uno de los ingresos que hay dentro de la plaza es una de las entradas a la zona de habitaciones de la residencia, la cual tiene un control para su acceso en el primer nivel con una zona de espera. En los niveles superiores se encuentran las plantas típicas, salvo el frente de la avenida universitaria en el segundo y tercer nivel, los cuales están ocupados por el coworking. En las plantas superiores se aplicó el concepto de In Between, generando una transición de espacios ubicando áreas comunes entre las habitaciones, evitando también de esta manera pasillos largos en el proyecto. Estos niveles cuentan con kitchenettes (utilizando el mismo concepto) ubicadas de manera equidistante en puntos estratégicos de la planta, para que puedan suplir a todas las habitaciones, zona donde los residentes pueden guardar, calentar y preparar los alimentos que les sea necesario. También se utilizó la conexión entre niveles, generando dobles alturas y comunicaciones verticales mediante las áreas de estar.

Imagen 130. Ubicación del coworking

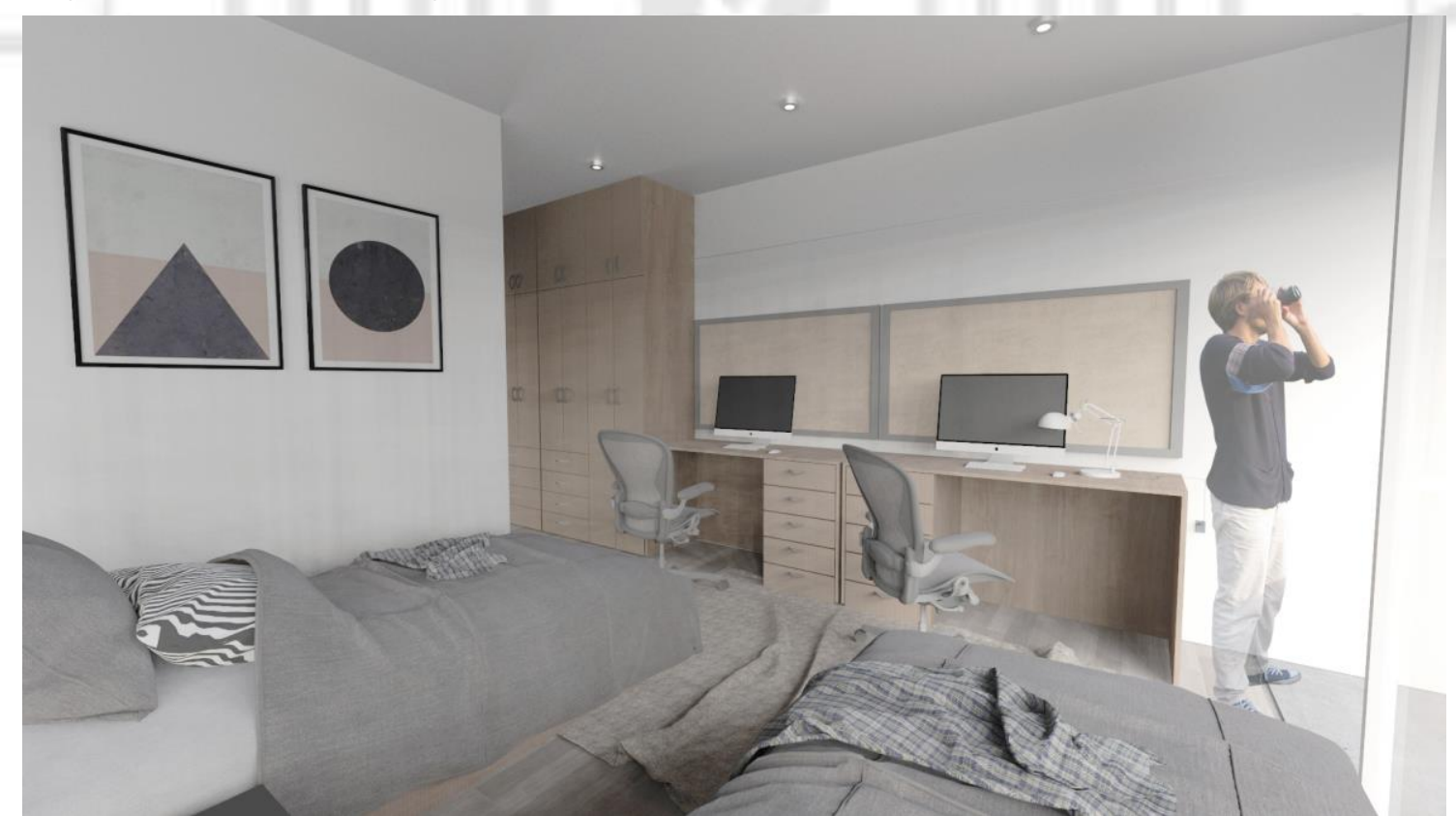

Fuente: Elaboración Propia

En el lado colindante con el predio de al lado, se encuentra ubicada la zona de estudio, un área diseñada para que los estudiantes puedan usarla a cualquier hora sin incomodar al resto de estudiantes en las habitaciones. Esta área se encuentra en todos 
los niveles., con mesas compartidas y cubículos privados para el uso que se requiera, de uso exclusivo para los estudiantes

La residencia cuenta con tres circulaciones verticales que llevan a los distintos frentes de las habitaciones. A partir del sexto nivel, el frente que da hacia la parte posterior se convierte en una terraza de uso privado (los parámetros no permiten que siga creciendo) para quienes se encuentran alojados, mientras que el resto de frentes sigue aumentando en pisos con más habitaciones.

Imagen 131. Planta 3 de la residencia

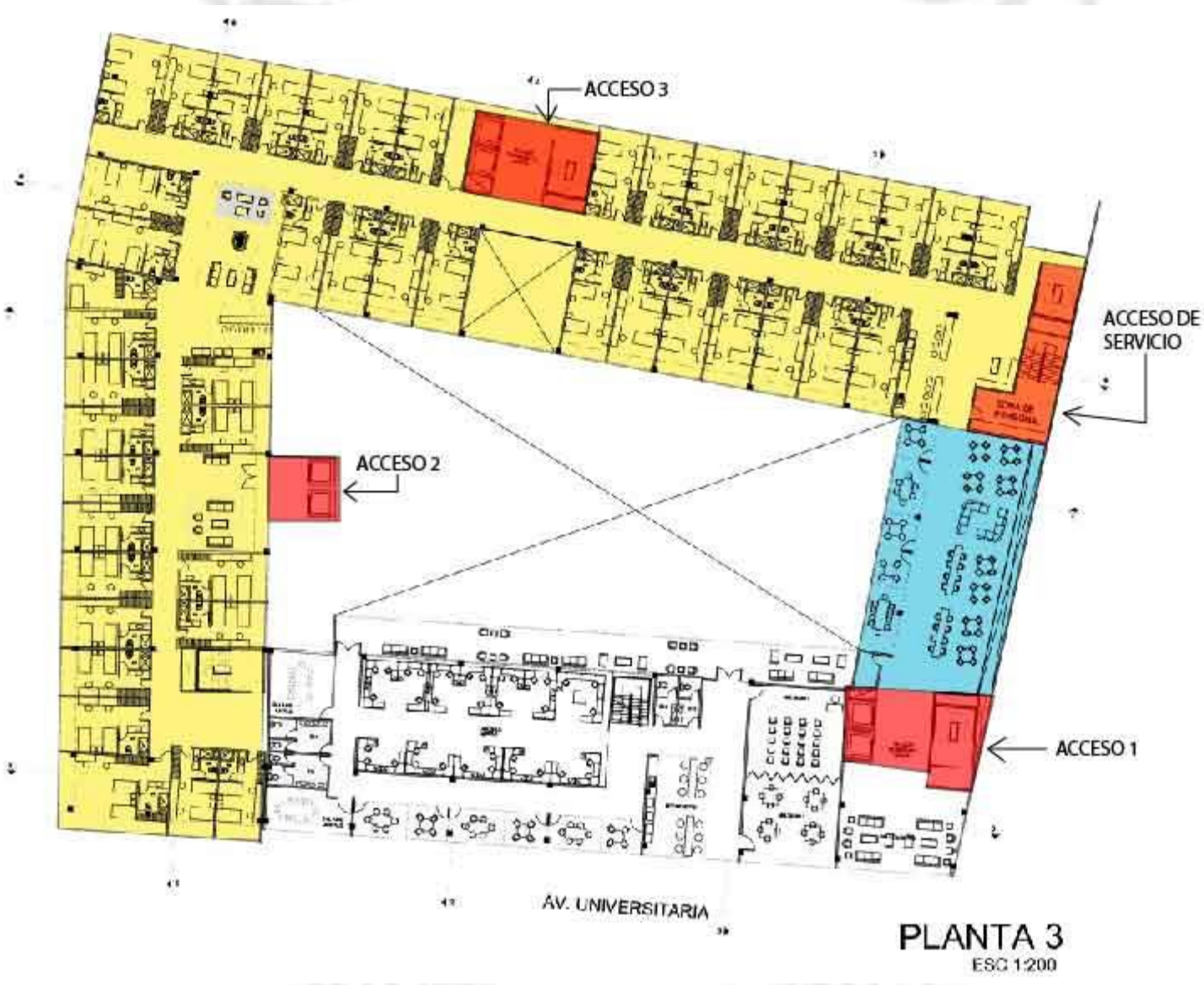

Fuente: Elaboración Propia 


\subsection{Administración}

Se tiene la zona administrativa de la residencia con un área de $161 \mathrm{~m}^{2}$, la cual cuenta con tres oficinas al lado del ingreso con la circulación vertical y una de las escaleras de emergencia. Cuenta con un hall, una recepción y una sala de espera. El frente de la torre $\mathrm{C}$ en el primer nivel tiene un murete de $1 \mathrm{~m}$ de altura con vegetación para darle mayor privacidad a lo que sucede en el interior ya que esta parte del programa tiene su funcionamiento desde el interior.

Imagen 132. Ubicación de la administración del edificio

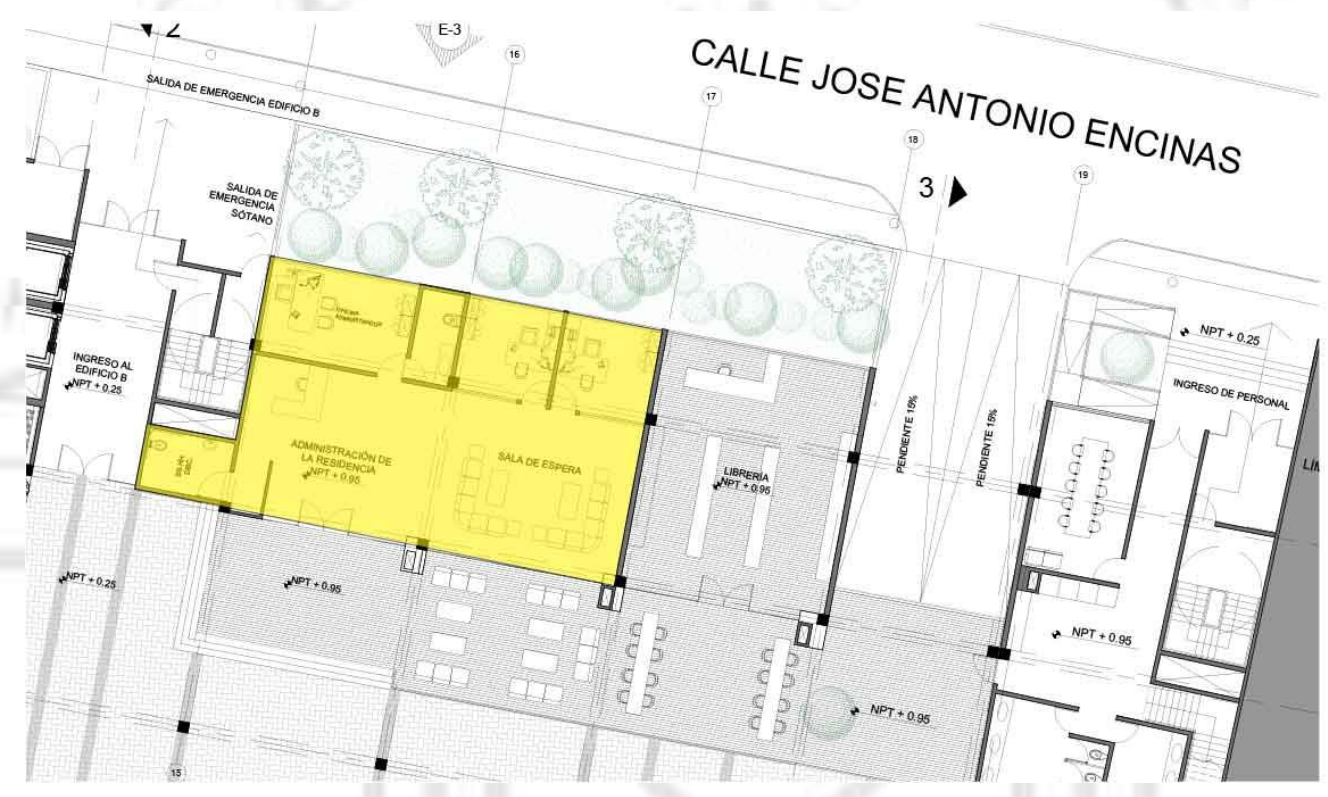

Fuente: Elaboración Propia 


\subsection{Servicios}

El extremo de la residencia que da hacia los lotes colindantes es aprovechado para el personal de servicio con un área de $190 \mathrm{~m}^{2}$, donde cuentan con un comedor, zona de control, baños y vestidores. La escalera de emergencia se encuentra ubicada en el extremo del proyecto.

\section{CALLE JOSE}

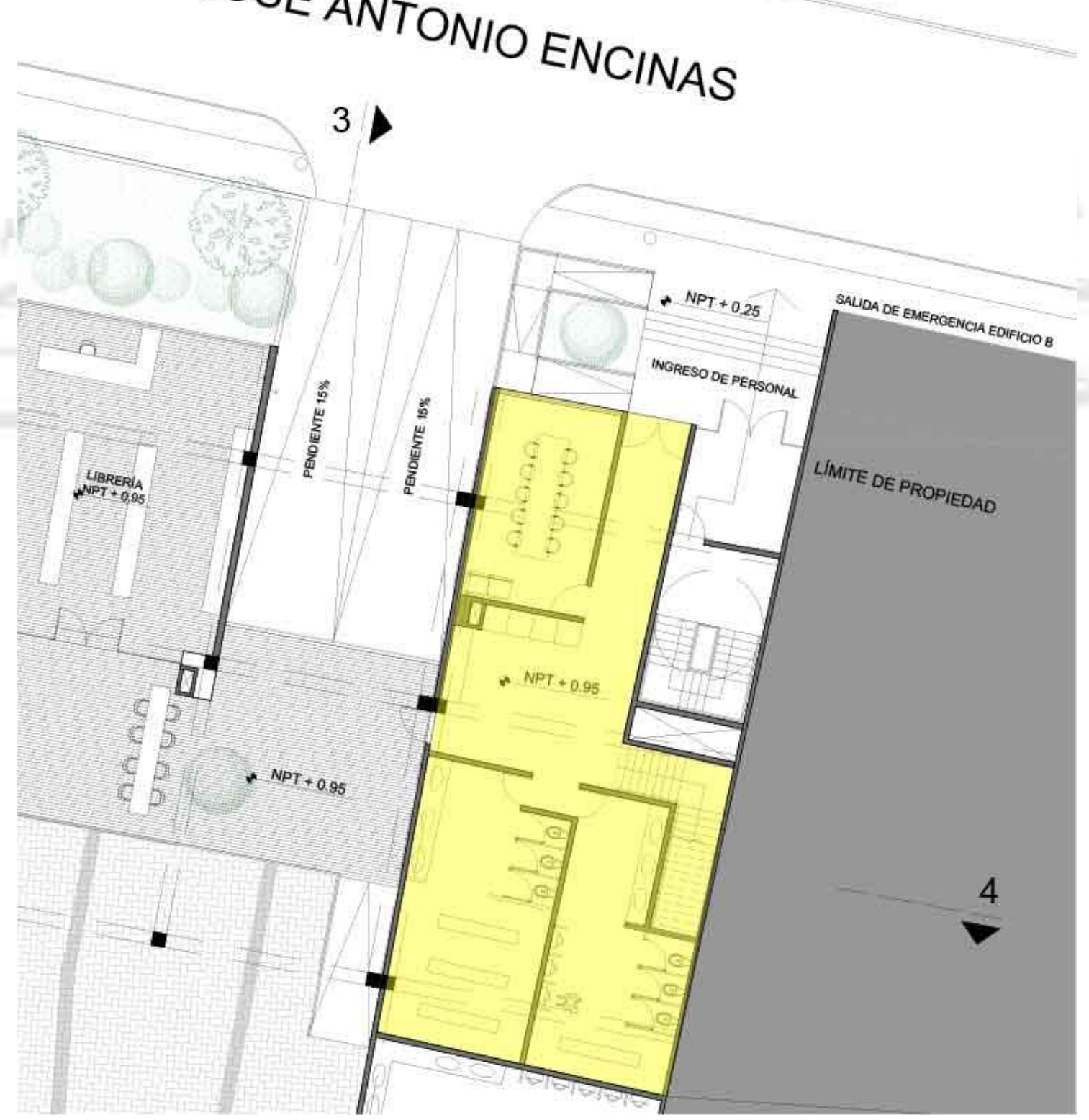

Fuente: Elaboración Propia 
7.3. Cálculo de usuarios

\begin{tabular}{|c|c|c|c|c|c|c|}
\hline PISO & & ograma & Aforo & Personal & Total & \\
\hline \multirow{11}{*}{ Primer nivel } & \multicolumn{2}{|r|}{ Café } & 99 & 2 & 101 & \multirow{11}{*}{402} \\
\hline & \multicolumn{2}{|c|}{ Convinience } & 54 & 3 & 57 & \\
\hline & \multicolumn{2}{|c|}{ Sala de espera coworking } & 10 & 1 & 11 & \\
\hline & \multicolumn{2}{|c|}{ sala de espera residencia } & 10 & 1 & 11 & \\
\hline & \multicolumn{2}{|c|}{ Patio de comidas } & 114 & 30 & 144 & \\
\hline & \multicolumn{2}{|c|}{ administración } & 16 & 4 & 20 & \\
\hline & \multicolumn{2}{|c|}{ Librería } & 27 & 1 & 28 & \\
\hline & \multicolumn{2}{|c|}{ Lavandería } & 12 & 0 & 13 & \\
\hline & \multicolumn{2}{|c|}{ Plaza } & & & $*$ & \\
\hline & \multicolumn{2}{|c|}{ Zona de personal } & 14 & 0 & 14 & \\
\hline & \multicolumn{2}{|c|}{ Mantenimiento de piso } & 0 & 3 & 3 & \\
\hline \multirow{4}{*}{ Segundo nivel } & \multicolumn{2}{|c|}{ Gimnasio } & 263 & 4 & 267 & \multirow{4}{*}{416} \\
\hline & \multicolumn{2}{|c|}{ coworking } & 131 & 1 & 132 & \\
\hline & Habitaciones & Habitación doble & 16 & 0 & 16 & \\
\hline & \multicolumn{2}{|c|}{ Mantenimiento de habitaciones } & 0 & 1 & 1 & \\
\hline & \multicolumn{2}{|c|}{ Coworking } & 131 & 1 & 132 & \multirow{3}{*}{181} \\
\hline \multirow[t]{2}{*}{ Tercer nivel } & Habitaciones & Habitación doble & 46 & 0 & 46 & \\
\hline & \multicolumn{2}{|c|}{ Mantenimiento de habitaciones } & 1 & 2 & 3 & \\
\hline \multirow{3}{*}{ Cuarto nivel } & \multirow{2}{*}{ Habitaciones } & Habitación simple & 1 & \multirow{2}{*}{0} & 1 & \multirow{3}{*}{66} \\
\hline & & Habitación doble & 62 & & 62 & \\
\hline & \multicolumn{2}{|c|}{ Mantenimiento de habitaciones } & 1 & 2 & 3 & \\
\hline \multirow{3}{*}{ Quinto nivel } & Habitaciones & Habitación simple & 1 & 0 & 1 & \\
\hline & & Habitación doble & 58 & & 58 & 62 \\
\hline & Mantenimiel & to de habitaciones & 1 & 2 & 3 & \\
\hline & Hahitacionoc & Habitación simple & 0 & 0 & 0 & \\
\hline Sexto nivel & - & Habitación doble & 30 & 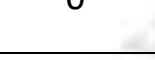 & 30 & 32 \\
\hline & Mantenimiel & to de habitaciones & 0 & 2 & 2 & \\
\hline & Hahitaciones & Habitación simple & 0 & 0 & 0 & \\
\hline Séptimo Nivel & manicacturtes & Habitación doble & 28 & & 28 & 28 \\
\hline & Mantenimie & to de habitaciones & 0 & 2 & 2 & \\
\hline & Habitaciones & Habitación simple & 0 & 0 & 0 & \\
\hline Octavo nivel & & Habitación doble & 28 & & 28 & 28 \\
\hline & Mantenimiel & to de habitaciones & 0 & 2 & 2 & \\
\hline & & & & & TOTAL & 1541 \\
\hline
\end{tabular}

*No incluye flujo interno de la plaza central 
7.4. Programa con cabida

Cuadro 20: Programa con cabida

\begin{tabular}{|c|c|c|c|}
\hline Primer piso & Cantidad & Área unitaria & Área total $\left(\mathrm{m}^{2}\right)$ \\
\hline Stand 1 & 1 & 8,66 & 8,66 \\
\hline Stand 2 & 1 & 8,75 & 8,75 \\
\hline Stand 3 & 1 & 10,72 & 10,72 \\
\hline Stand 4 & 1 & 10,92 & 10,92 \\
\hline Stand 5 & 1 & 8,81 & 8,81 \\
\hline Stand 6 & 1 & 9,71 & 9,71 \\
\hline Stand 7 & 1 & 7,42 & 7,42 \\
\hline Stand 8 & 1 & 8,93 & 8,93 \\
\hline Stand 9 & 1 & 7,16 & 7,16 \\
\hline Stand 10 & 1 & 10,27 & 10,27 \\
\hline Stand 11 & 1 & 11,72 & 11,72 \\
\hline Stand 12 & 1 & 11,67 & 11,67 \\
\hline Stand 13 & 1 & 11,68 & 11,68 \\
\hline Stand 14 & 1 & 11,65 & 11,65 \\
\hline Stand 15 & 1 & 8,05 & 8,05 \\
\hline Café 1 - primer piso & 1 & 217 & 217 \\
\hline Convinience & 1 & 217,21 & 217,21 \\
\hline Hall a plaza & 1 & 74,29 & 74,29 \\
\hline Tay Loi & 1 & 79,57 & 79,57 \\
\hline Administración & 1 & 157,28 & 157,28 \\
\hline Hall de ingreso & 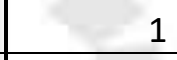 & 120,8 & 120,8 \\
\hline Patio central & 1 & 1738,25 & 1738,25 \\
\hline Hall oficinas & 1 & 70,63 & 70,63 \\
\hline Área de personal & 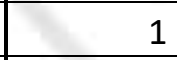 & 219,4 & 219,4 \\
\hline Baños públicos & 1 & 94,27 & 94,27 \\
\hline Escaleras & 4 & 17,85 & 71,4 \\
\hline Ascensores & 3 & 10,74 & 32,22 \\
\hline Área libre & 1 & 1545,46 & 1545,46 \\
\hline & & & $6159,69 \mathrm{~m}^{2}$ \\
\hline
\end{tabular}




\begin{tabular}{|c|r|r|c|}
\hline Segundo Piso & Cantidad & Área unitaria & Área total $\left(\mathrm{m}^{2}\right)$ \\
\hline Café 1 - Segundo piso & 1 & 206,47 & 206,47 \\
\hline Gimnasio & 1 & 796,05 & 796,05 \\
\hline área de estudio & 1 & 239,65 & 239,65 \\
\hline Coworking & 1 & 793,76 & 793,76 \\
\hline Habitación 1 & 9 & 25,83 & 232,47 \\
\hline Habitación 2 & 7 & 30,96 & 216,72 \\
\hline Circulación & 1 & 341,62 & 341,62 \\
\hline Sala de espera & 1 & 68,53 & 68,53 \\
\hline Sala de estar & 1 & 57,93 & 57,93 \\
\hline Zona de personal & 1 & 54,38 & 54,38 \\
\hline Kitchenette & 1 & 25,56 & 25,56 \\
\hline Escaleras & 4 & 17,85 & 71,4 \\
\hline Ascensores & 3 & 10,74 & 32,22 \\
\hline & & & 3104,54 \\
\hline
\end{tabular}

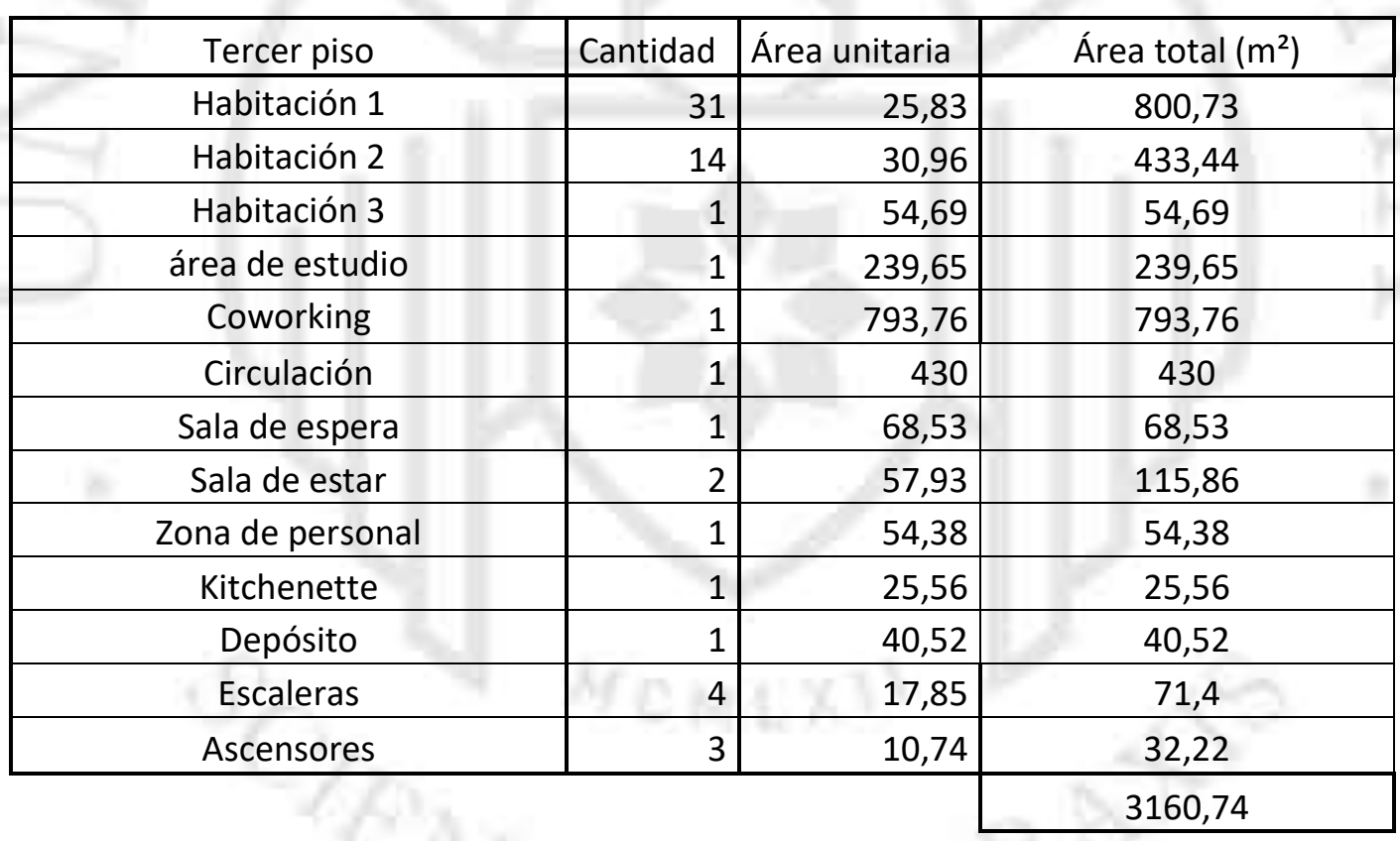




\begin{tabular}{|c|r|r|c|}
\hline Cuarto piso & Cantidad & Área unitaria & Área total $\left(\mathrm{m}^{2}\right)$ \\
\hline Habitación 1 & 47 & 25,83 & 1214,01 \\
\hline Habitación 2 & 14 & 30,96 & 433,44 \\
\hline Habitación 3 & 1 & 54,69 & 54,69 \\
\hline Habitación 4 & 1 & 21,65 & 21,65 \\
\hline área de estudio & 1 & 239,65 & 239,65 \\
\hline Circulación & 1 & 524,03 & 524,03 \\
\hline Sala de espera & 1 & 68,53 & 68,53 \\
\hline Sala de estar & 6 & 57,93 & 347,58 \\
\hline Zona de personal & 1 & 54,38 & 54,38 \\
\hline Kitchenette & 4 & 25,56 & 102,24 \\
\hline Depósito & 1 & 40,52 & 40,52 \\
\hline Escaleras & 4 & 17,85 & 71,4 \\
\hline Ascensores & 3 & 10,74 & 32,22 \\
\hline & & & 3204,34 \\
\hline
\end{tabular}

\begin{tabular}{|c|r|r|c|}
\hline Quinto piso & Cantidad & Área unitaria & Área total $\left(\mathrm{m}^{2}\right)$ \\
\hline Habitación 1 & 43 & 25,83 & 1110,69 \\
\hline Habitación 2 & 14 & 30,96 & 433,44 \\
\hline Habitación 3 & 1 & 54,69 & 54,69 \\
\hline Habitación 4 & 1 & 21,65 & 21,65 \\
\hline Terraza & 1 & 239,65 & 239,65 \\
\hline Circulación & 1 & 524,03 & 524,03 \\
\hline Sala de espera & 1 & 68,53 & 68,53 \\
\hline Sala de estar & 5 & 57,93 & 289,65 \\
\hline Zona de personal & 1 & 54,38 & 54,38 \\
\hline Kitchenette & 4 & 25,56 & 102,24 \\
\hline Depósito & 1 & 40,52 & 40,52 \\
\hline Escaleras & 4 & 17,85 & 71,4 \\
\hline Ascensores & 3 & 10,74 & 32,22 \\
\hline & & & 3043,09 \\
\hline
\end{tabular}

\begin{tabular}{|c|r|r|c|}
\hline Sexto piso & Cantidad & Área unitaria & Área total $\left(\mathrm{m}^{2}\right)$ \\
\hline Habitación 1 & 29 & 25,83 & 749,07 \\
\hline Habitación 3 & 1 & 54,69 & 54,69 \\
\hline Circulación & 1 & 271,61 & 271,61 \\
\hline Sala de espera & 1 & 68,53 & 68,53 \\
\hline Sala de estar & 4 & 57,93 & 231,72 \\
\hline Kitchenette & 3 & 25,56 & 76,68 \\
\hline Techo & 1 & 1372,72 & 1372,72 \\
\hline Escaleras & 4 & 17,85 & 71,4 \\
\hline Ascensores & 3 & 10,74 & 32,22 \\
\hline & & & 2928,64 \\
\hline
\end{tabular}




\begin{tabular}{|c|r|r|c|}
\hline Séptimo - Octavo piso & Cantidad & Área unitaria & Área total $\left(\mathrm{m}^{2}\right)$ \\
\hline Habitación 1 & 27 & 25,83 & 697,41 \\
\hline Habitación 3 & 1 & 54,69 & 54,69 \\
\hline Circulación & 1 & 264,39 & 264,39 \\
\hline Sala de espera & 1 & 68,53 & 68,53 \\
\hline Sala de estar & 4 & 57,93 & 231,72 \\
\hline Kitchenette & 3 & 25,56 & 76,68 \\
\hline Terraza & 1 & 53,23 & 53,23 \\
\hline Escaleras & 2 & 17,85 & 35,7 \\
\hline Ascensores & 2 & 10,74 & 21,48 \\
\hline & & & 1503,83 \\
\hline
\end{tabular}

\begin{tabular}{|c|r|r|c|}
\hline 9 piso - 11 PISO & Cantidad & Área unitaria & Área total $\left(\mathrm{m}^{2}\right)$ \\
\hline Habitación 1 & 25 & 25,83 & 645,75 \\
\hline Habitación 3 & 1 & 54,69 & 54,69 \\
\hline Circulación & 1 & 256,8 & 256,8 \\
\hline Sala de espera & 1 & 68,53 & 68,53 \\
\hline Sala de estar & 4 & 57,93 & 231,72 \\
\hline Kitchenette & 1 & 25,56 & 25,56 \\
\hline Terraza & 1 & 55,75 & 55,75 \\
\hline Escaleras & 2 & 17,85 & 35,7 \\
\hline Ascensores & 2 & 10,74 & 21,48 \\
\hline & & & 1395,98 \\
\hline
\end{tabular}

\begin{tabular}{|c|r|r|c|}
\hline 12 piso - 14 PISO & Cantidad & Área unitaria & Área total $\left(\mathrm{m}^{2}\right)$ \\
\hline Habitación 1 & 23 & 25,83 & 594,09 \\
\hline Habitación 3 & 1 & 54,69 & 54,69 \\
\hline Circulación & 1 & 256,8 & 256,8 \\
\hline Sala de espera & 1 & 68,53 & 68,53 \\
\hline Sala de estar & 4 & 57,93 & 231,72 \\
\hline Kitchenette & 1 & 25,56 & 25,56 \\
\hline Terraza & 1 & 55,75 & 55,75 \\
\hline Escaleras & 2 & 17,85 & 35,7 \\
\hline Ascensores & 2 & 10,74 & 21,48 \\
\hline & & & 1344,32 \\
\hline
\end{tabular}




\begin{tabular}{|c|r|r|c|}
\hline 15 piso -22 piso & Cantidad & Área unitaria & Área total $\left(\mathrm{m}^{2}\right)$ \\
\hline Habitación 1 & 22 & 25,83 & 568,26 \\
\hline Habitación 3 & 1 & 54,69 & 54,69 \\
\hline Circulación & 1 & 256,8 & 256,8 \\
\hline Sala de espera & 1 & 68,53 & 68,53 \\
\hline Sala de estar & 4 & 57,93 & 231,72 \\
\hline Kitchenette & 1 & 25,56 & 25,56 \\
\hline Terraza & 1 & 55,75 & 55,75 \\
\hline Escaleras & 2 & 17,85 & 35,7 \\
\hline Ascensores & 2 & 10,74 & 21,48 \\
\hline & & & 1318,49 \\
\cline { 4 - 4 } & & &
\end{tabular}

Fuente: Elaboración propia

\subsection{Viabilidad}

El método de financiamiento que se va a utilizar para este proyecto, es teniendo a la Pontificia Universidad Católica como único inversor, donando además el terreno que les pertenece. Se consideran ingresos provenientes del alquiler de locales y de habitaciones.

7.5.1. Propuesta de alquiler de locales comerciales

Iniciando por el primer y segundo nivel, que tienen un incremento del $5 \%$ y $2.5 \%$ respectivamente, del costo de alquiler por la ubicación, tenemos a las tiendas de locales comerciales, el gym y las oficinas de Coworking. Todas estas tiendas tienen un precio distinto dependiendo si tienen vista hacia el interior (más económico) o hacia el exterior (incremento de hasta un 5\%). 
Cuadro 21: Precio de alquiler de locales

Porcentajes de influencia de los atributos en el precio final de alquiler.

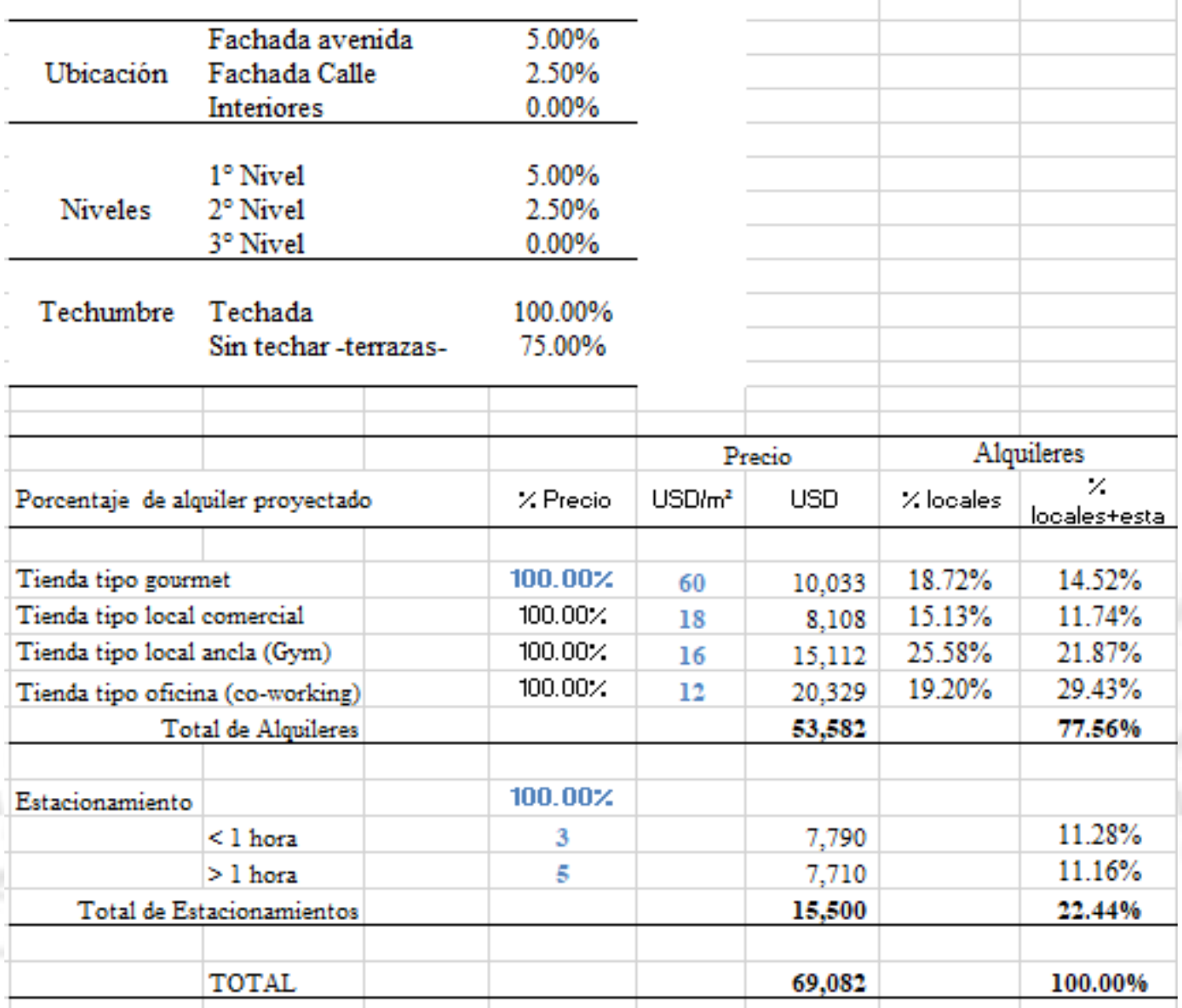

Fuente: Elaboración propia

El proyecto cuenta con 2 sótanos de estacionamientos. La residencia, al estar enfocada en el alquiler de habitaciones para estudiantes universitarios, tiene como público objetivo para los estacionamientos a las personas que planean utilizar los locales comerciales en su mayoría. El precio del estacionamiento de un vehículo ha sido considerado de 3 soles para menos de 1 hora, y 6 soles para más de una hora de estancia. 
Cuadro 22: Precio de alquileres mensuales de locales

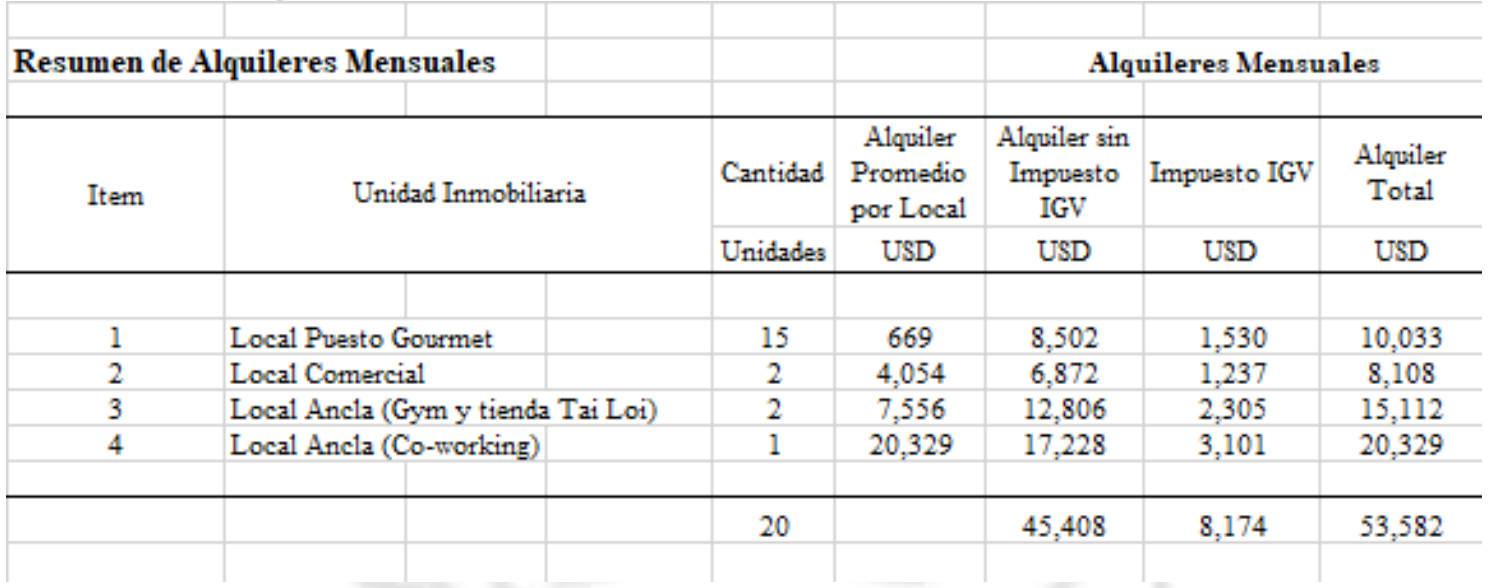

Fuente: Elaboración propia

- Alquiler de locales comerciales y Coworking

Un punto importante a considerar para la corrida financiera del proyecto, es el porcentaje de ocupación del proyecto durante el año. Se ha considerado un promedio de ocupación del 90\% de alquileres de locales del proyecto durante el año, basándome en durante los últimos años. Las tiendas comerciales de comida, han considerado un porcentaje de ocupación del 65\% el primer año, y un 100\% durante los siguientes 4 años, para luego repetir el mismo ciclo, tomando en consideración que el alquiler del espacio puede cambiar de dueño cada 5 años. Las tiendas comerciales de otros rubros, si inician en el año 1 con el 100\% de ocupación, igual con un ciclo de 5 años, iniciando el sexto con $65 \%$.

El alquiler de estacionamientos varía entre un $78 \%$ y un $98 \%$ en promedio durante el año, durante las horas del día en que está permitido su uso. 


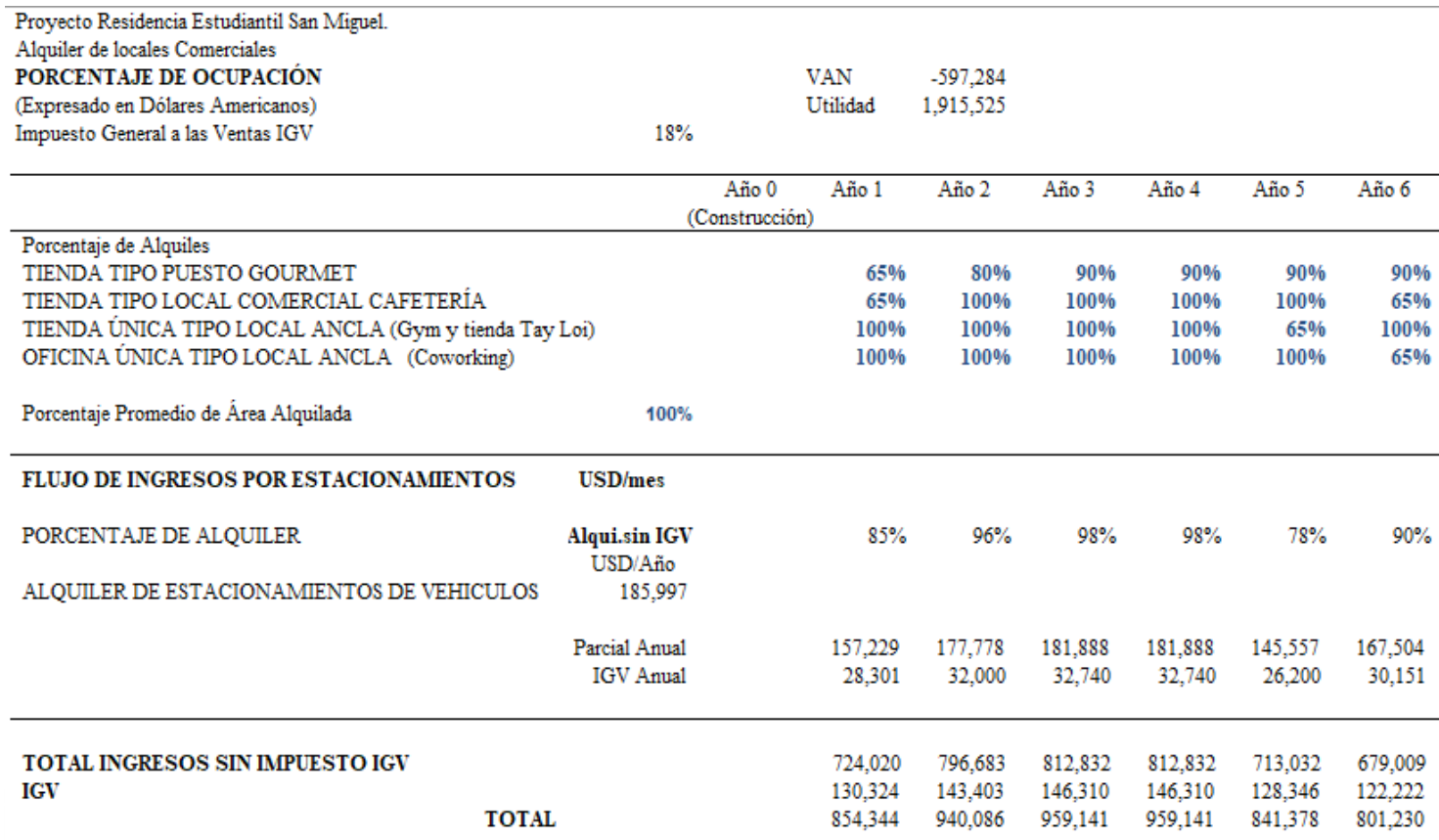

Fuente: Elaboración propia

\section{- Gastos operativos 1}

Independientemente de los gastos de construcción directos e indirectos, aparecen también los gastos operativos, que son los encargados de mantener el proyecto a lo largo de los años.

Aquí se han considerado los gastos administrativos, de publicidad, limpieza, seguridad, de mantenimiento y gastos de servicios públicos y municipales. Durante la construcción del proyecto. 


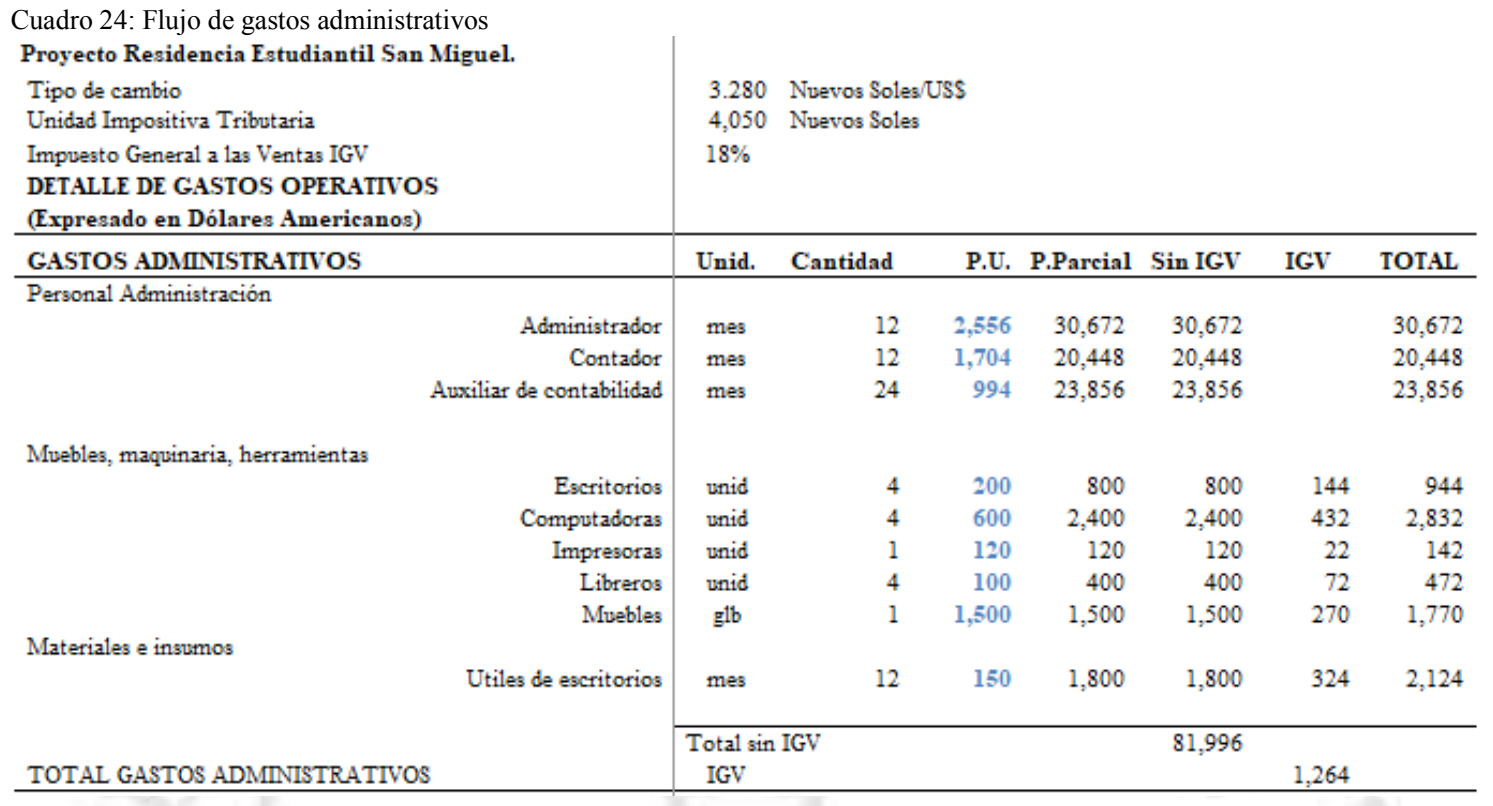

Fuente: Elaboración propia

En los gastos administrativos, ha sido considerado personal, conformado por un administrador, un contador y dos auxiliares de contabilidad. En este rubro también están considerados los muebles, maquinarias, herramientas, materiales e insumos de esta área. En gastos de publicidad, está considerado un Community Manager por un año, junto a un publicista externo por un periodo de cuatro meses. También van a aparecer gastos informáticos como el dominio en internet, y el diseño de la página WEB y la App.

En gastos de limpieza se considera un personal conformado por 4 trabajadores al interior durante el año, 2 para limpieza de exteriores y uno para mantenimiento general de instalaciones sanitarias y eléctricas. También deben considerarse los gastos de muebles, maquinarias, herramientas, materiales e insumos necesarios para la labor. 
Cuadro 25: Flujo de gastos varios.

\begin{tabular}{|c|c|c|c|c|c|c|c|}
\hline GASTOS DE PUBLICIDAD & Unid. & Cantidad & P.U. & P.Parcial & Sin IGV & IGV & TOTAL \\
\hline \multicolumn{8}{|l|}{ Personal } \\
\hline Comunity Mannager & mes & 12 & 1,065 & 12,780 & 12,780 & & 12,780 \\
\hline Publicista externo & trimestrel & 4 & 250 & 1,000 & 1,000 & & 1,000 \\
\hline \multicolumn{8}{|l|}{ Gastos informáticos } \\
\hline Dominio en internet & anual & 1 & 200 & 200 & 200 & 36 & 236 \\
\hline Diseño de págima WEB y diseño de App & glb & 1 & 1,200 & 1,200 & 1,200 & 216 & 1,416 \\
\hline TOTAL GASTOS DE PUBLICIDAD & \multicolumn{4}{|c|}{ Total sin IGV } & 15,180 & \multicolumn{2}{|l|}{252} \\
\hline GASTOS DE LIMPIEZA & Unid. & Cantidad & P.U. & P.Parcial & Sin IGV & IGV & TOTAL \\
\hline \multicolumn{8}{|l|}{ Personal } \\
\hline Personal de limpieza de interiores & mes & 48 & 426 & 20,448 & 20,448 & & 20,448 \\
\hline Personal de limpieza de exteriores & mes & 24 & 426 & 10,224 & 10,224 & & 10,224 \\
\hline Mantenimiento general de IISS e IIEE & mes & 12 & 426 & 5,112 & 5,112 & & 5,112 \\
\hline \multicolumn{8}{|l|}{ Mvebles, maquinaria, herramientas } \\
\hline Aspiradoras industriales & unid & 9 & 650 & 5,850 & 5,850 & 1,053 & 6,903 \\
\hline carros de limpieza & unid & 9 & 160 & 1,440 & 1,440 & 259 & 1,699 \\
\hline \multicolumn{8}{|l|}{ Materiales e insumos } \\
\hline Uniformes & unid & 14 & 100 & 1,400 & 1,400 & 252 & 1,652 \\
\hline \multirow[t]{2}{*}{ Materiales e insumos } & mes & 12 & 700 & 8,400 & 8,400 & 1,512 & 9,912 \\
\hline & \multirow{2}{*}{\multicolumn{4}{|c|}{$\begin{array}{l}\text { Total sin IGV } \\
\text { IGV }\end{array}$}} & 52,874 & \multirow{2}{*}{\multicolumn{2}{|c|}{3,076}} \\
\hline TOTAL GASTOS DE LIMPIEZA. & & & & & & & \\
\hline
\end{tabular}

Fuente: Elaboración propia

El proyecto también debe considerar gastos de seguridad, con 5 trabajadores de seguridad diurna, y 3 de seguridad nocturna al año, junto con las herramientas necesarias para su correcto desempeño.

Luego vienen los gastos de mantenimiento y renovación, los cuales son los más costosos dentro de los gastos operativos. Este rubro comprende materiales, insumos y la mano de obra. Lo más costoso es el pintado de fachadas e interiores cada 4 años, mientras que la renovación de fachadas y arquitectura interior se realiza cada 6 años.

Como último punto a tomar en cuenta, tenemos los gastos de servicios públicos y municipales, entre los que se encuentran los consumos eléctricos, de agua, telefonía e internet, así como también las licencias de funcionamiento, arbitrios y prediales. 
Cuadro 26: Flujo de gastos varios.

\begin{tabular}{|c|c|c|c|c|c|c|c|}
\hline GASTOS DE SEGURIDAD & Unid. & Cantidad & P.U. & P.Parcial & Sin IGV & IGV & TOTAL \\
\hline \multicolumn{8}{|l|}{ Personal } \\
\hline Personal de seguridad diurna & mes & 60 & 568 & 34,080 & 34,080 & & 34,080 \\
\hline Personal de seguridad nocturna & mes & 36 & 639 & 23,004 & 23,004 & & 23,004 \\
\hline \multicolumn{8}{|l|}{ Muebles, maquinaria, herramientas } \\
\hline Intercomunicadores móviles & unid & 10 & 100 & 1,000 & 1,000 & 180 & 1,180 \\
\hline Circuito interno de camaras y monitores & glb & 1 & 22,500 & 22,500 & 22,500 & 4,050 & 26,550 \\
\hline \multicolumn{8}{|l|}{ Materiales e insumos } \\
\hline \multirow[t]{2}{*}{ Uniformes } & unid & 16 & 200 & 3,200 & 3,200 & 576 & 3,776 \\
\hline & \multirow{2}{*}{\multicolumn{2}{|c|}{$\begin{array}{l}\text { Total sin IGV } \\
\text { IGV }\end{array}$}} & \multirow{2}{*}{\multicolumn{5}{|c|}{83,784}} \\
\hline TOTAL GASTOS DE SEGURIDAD & & & & & & & \\
\hline GASTOS DE MANTENIMIIENTO Y RENOVACIÓN & Unid. & Cantidad & P.U. & P.Parcial & Sin IGV & IGV & TOTAL \\
\hline \multicolumn{8}{|l|}{ Materiales e insumos } \\
\hline Renovación de fachadas y arquitectura interir & glb & 1 & 70,000 & 70,000 & 70,000 & 12,600 & 82,600 \\
\hline jardines externo & mes & 12 & 200 & 2,400 & 2,400 & 432 & 2,832 \\
\hline Pintado de fachada & glb & 1 & 45,000 & 45,000 & 45,000 & 8,100 & 53,100 \\
\hline Pintado de Interiores & $\mathrm{glb}$ & 1 & 30,000 & 30,000 & 30,000 & 5,400 & 35,400 \\
\hline Arreglos varios & mes & 12 & 600 & 7,200 & 7,200 & 1,296 & 8,496 \\
\hline TOTAL GASTOS DE MANTENIMIENTO y RENOVACION & \multicolumn{4}{|c|}{$\begin{array}{l}\text { Total sin IGV } \\
\text { IGV }\end{array}$} & 84,600 & 15,228 & 99,828 \\
\hline GASTOS DE SERVICIOS PÚBLICOS Y MUNICIPALES & Unid. & Cantidad & P.U. & P.Parcial & Sin IGV & IGV & TOTAL \\
\hline \multirow{2}{*}{\multicolumn{8}{|c|}{$\begin{array}{l}\text { Materiales e insumos } \\
\text { Consumo de servicios públicos }\end{array}$}} \\
\hline & & & & & & & \\
\hline consumo eléctrico & mes & 12 & 2,500 & 30,000 & 30,000 & 5,400 & 35,400 \\
\hline consumo de agua potable y alcantarillado & mes & 12 & 4,000 & 48,000 & 48,000 & 8,640 & 56,640 \\
\hline consumo de telefonia de administración y seguridad & mes & 12 & 400 & 4,800 & 4,800 & 864 & 5,664 \\
\hline consumo de internet y televisión por cable & mes & 12 & 800 & 9,600 & 9,600 & 1,728 & 11,328 \\
\hline \multicolumn{8}{|l|}{ Gastos municipales y licencias } \\
\hline Licencias de funcionamiento & glb & 1 & 12,000 & 12,000 & 12,000 & & 12,000 \\
\hline arbitrios & año & 1 & 8,000 & 8,000 & 8,000 & & 8,000 \\
\hline \multirow[t]{2}{*}{ Prediales } & año & 1 & 7,000 & 7,000 & 7,000 & & 7,000 \\
\hline & Tota & & & & & & \\
\hline TOTAL GASTOS DE SERVICIOS PÚ & IGY & & & & 119,400 & 16,632 & 136,032 \\
\hline
\end{tabular}

Fuente: Elaboración propia

7.5.2. Alquiler de habitaciones

Este punto habla netamente del alquiler de habitaciones. Para calcular el costo del alquiler de las habitaciones, se considera el precio por $\mathrm{m} 2$ al día de alquiler. Para que el proyecto sea viable, el costo es de $0.70 \$$ el $\mathrm{m} 2$, siendo un total de 21 dólares el metro de alquiler. Así, la habitación más pequeña, de $25 \mathrm{~m} 2$, tiene un costo de 542 dólares, para dos personas, debiendo cada estudiante pagar alrededor de 271 dólares mensuales. El alquiler de habitaciones representa el ingreso más significativo de la residencia. 
Cuadro 27: Flujo de ingreso por habitaciones.

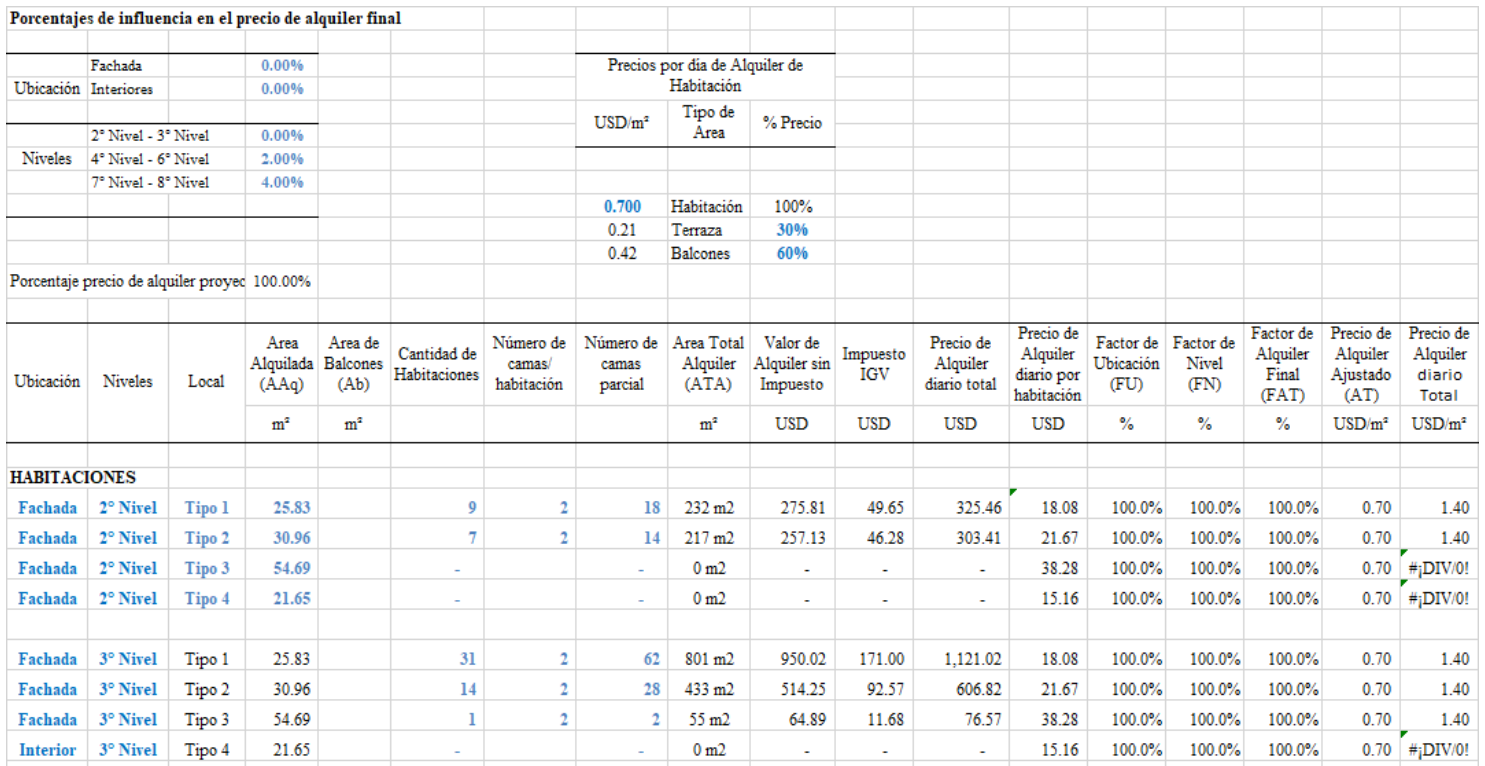

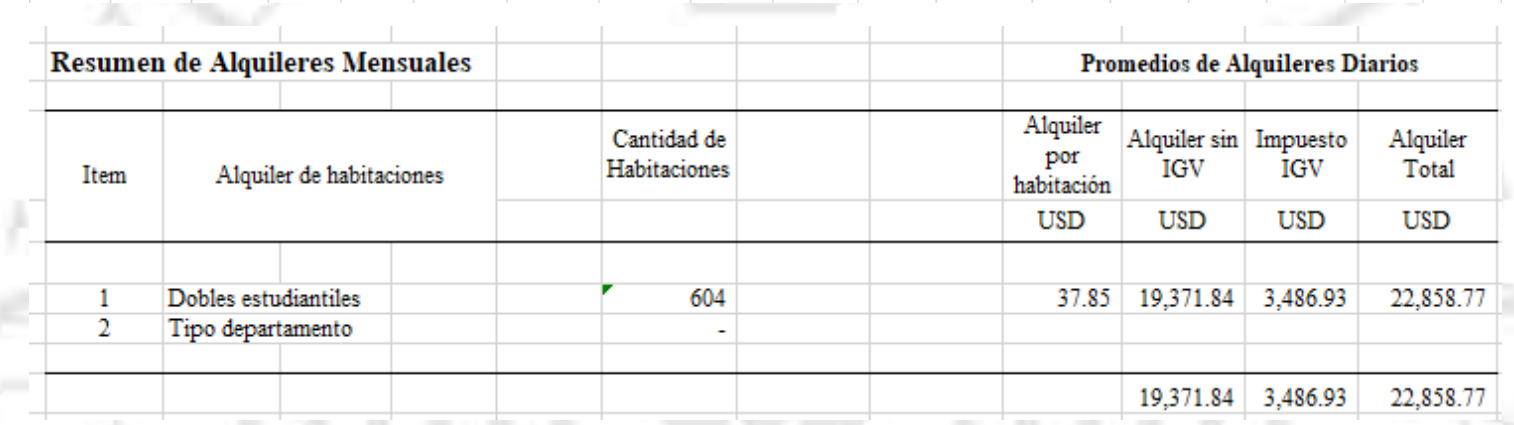

Fuente: Elaboración propia

- Flujo de ingresos 2:

Se evaluó un escenario menos favorable. En este punto se considera el porcentaje de ocupación solo de habitaciones. Teniendo un inicio de proyecto con un $48 \%$ de ocupación, e incrementándose año a año hasta llegar a un máximo de 85\%. Los porcentajes de ocupación se colocaron considerando como se está manejando el mercado en la actualidad. 
Cuadro 28: Ocupación de habitaciones

Proyecto Residencia Universitaria

INGRESO POR OCUPACIÓN DE HABITACIONES Y ESTACIONAMIENTOS

(Expresado en Dólares Americanos)

VAN $\quad-4,093,110 \quad 96 \%$

Impuesto General a las Ventas IGV

$18 \%$

Utilidad $\quad-660,095 \quad 81 \%$

\begin{tabular}{|c|c|c|c|c|c|c|c|}
\hline & $\begin{array}{c}\text { Año } 0 \\
\text { (Construcción) }\end{array}$ & Año 1 & Año 2 & Año 3 & Año 4 & Año 5 & Año 6 \\
\hline \multicolumn{8}{|l|}{ PORCENTAJES DE OCUPACIÓN DE HABITACIONES } \\
\hline Porcentaje promedio de ocupación & $85 \%$ & $48.5 \%$ & $57.0 \%$ & $69.8 \%$ & $85.0 \%$ & $79.0 \%$ & $85.0 \%{ }^{\prime \prime}$ \\
\hline FLUJO DE INGRESOS POR HABITACIONES ( $\sin$ IGV) & USD/año & & & & & & \\
\hline Ingreso anual & $7,070,720$ & $3,429,299$ & $4,030,310$ & $4,931,827$ & $6,010,112$ & $5,585,869$ & $6,010,112$ \\
\hline \multicolumn{8}{|l|}{ PORCENTAJES DE OCUPACIÓN DE ESTACIONAMIENTOS } \\
\hline Porcentaje promedio de ocupación & $85 \%$ & $41 \%$ & $48 \%$ & $59 \%$ & $72 \%$ & $67 \%$ & $72 \%$ \\
\hline FLUJO DE INGRESOS POR ESTACIONAMIENTOS( $\sin$ IGV) & USD/año & & & & & & \\
\hline Ingreso anual & $39,608.3$ & 16,329 & 19,190 & 23,483 & 28,617 & 26,597 & 28,617 \\
\hline \multicolumn{8}{|l|}{ PORCENTAJES DE OCUPACIÓN PARA ALIMENTACIÓN } \\
\hline Porcentaje promedio de ocupación & $85 \%$ & $41.2 \%$ & $48.5 \%$ & $59.3 \%$ & $72.3 \%$ & $67.2 \%$ & $72.3 \%$ \\
\hline FLUJO DE INGRESOS POR ALIMENTACIÓN ( $\sin$ IGV) & USD/año & & & & & & \\
\hline Ingreso anual & $2,591,191.8$ & $1,068,219$ & $1,255,432$ & $1,536,253$ & $1,872,136$ & $1,739,985$ & $1,872,136$ \\
\hline TOTAL INGRESOS ( $\sin$ IGV) & & $4,513,847$ & $5,304,933$ & $6,491,563$ & $7,910,865$ & $7,352,451$ & $7,910,865$ \\
\hline IGV & & 812,492 & 954,888 & $1,168,481$ & $1,423,956$ & $1,323,441$ & $1,423,956$ \\
\hline TOTAL & & $5,326,339$ & $6,259,821$ & $7,660,044$ & $9,334,821$ & $8,675,892$ & $9,334,821$ \\
\hline
\end{tabular}

Fuente: Elaboración propia

\section{- Gastos operativos 2:}

Aparecen también los gastos operativos durante la construcción del proyecto.

Cuadro 29: Gastos operativos durante construcción

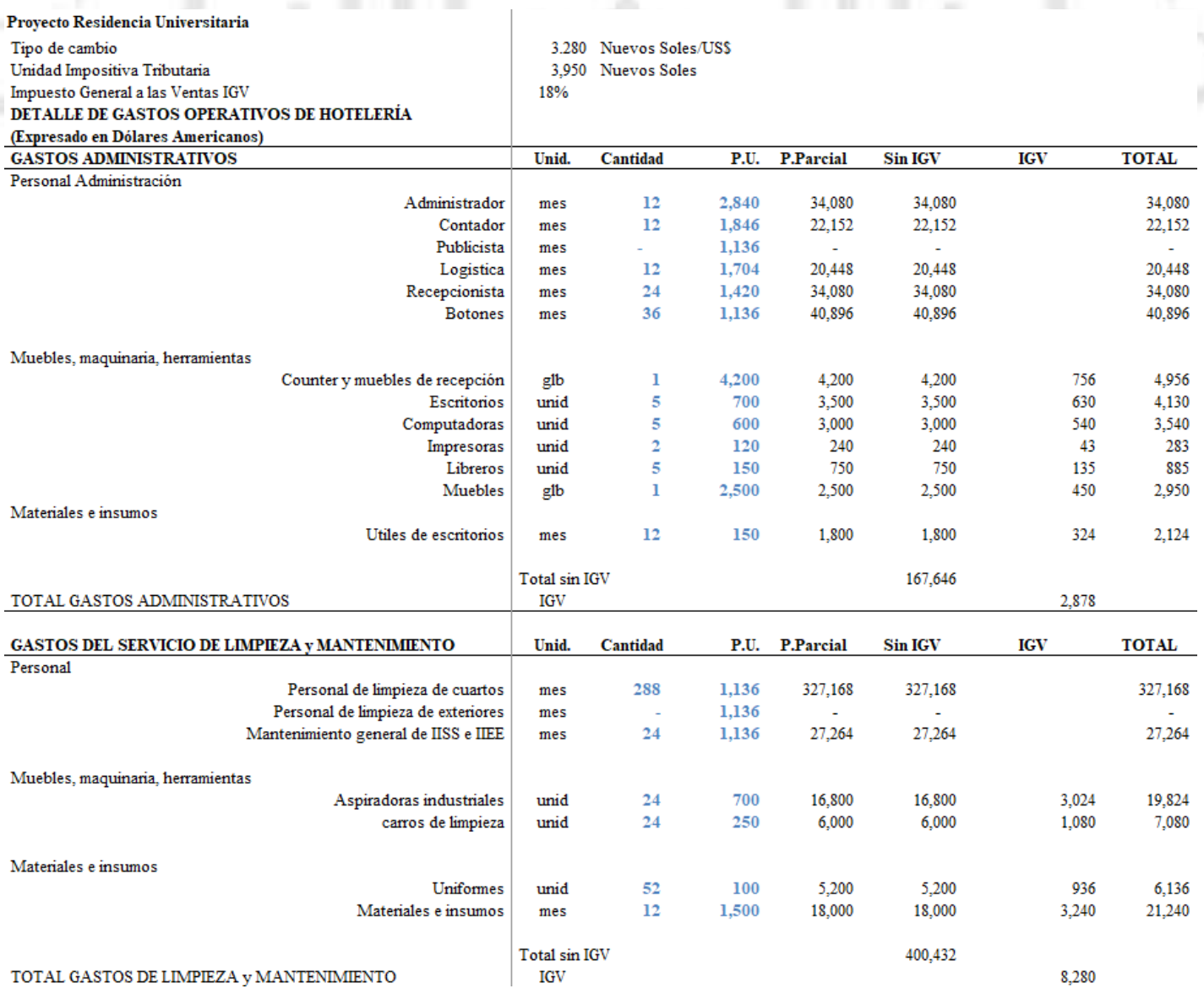

Fuente: Elaboración propia 
Aquí se han considerado los gastos administrativos, de publicidad, de limpieza, de seguridad, de mantenimiento y gastos de servicios públicos y municipales.

En los gastos administrativos, ha sido considerado un personal de administración, conformado por un administrador, un contador, un publicista, un logístico, dos recepcionistas y 3 botones. En este rubro también están considerados los muebles, maquinarias, herramientas, materiales e insumos de esta área.

En gastos de limpieza se considera un personal conformado por 24 trabajadores en limpieza de cuartos y 2 para mantenimiento general de instalaciones sanitarias y eléctricas. También deben considerarse los gastos de muebles, maquinarias, herramientas, materiales e insumos necesarios para la labor.

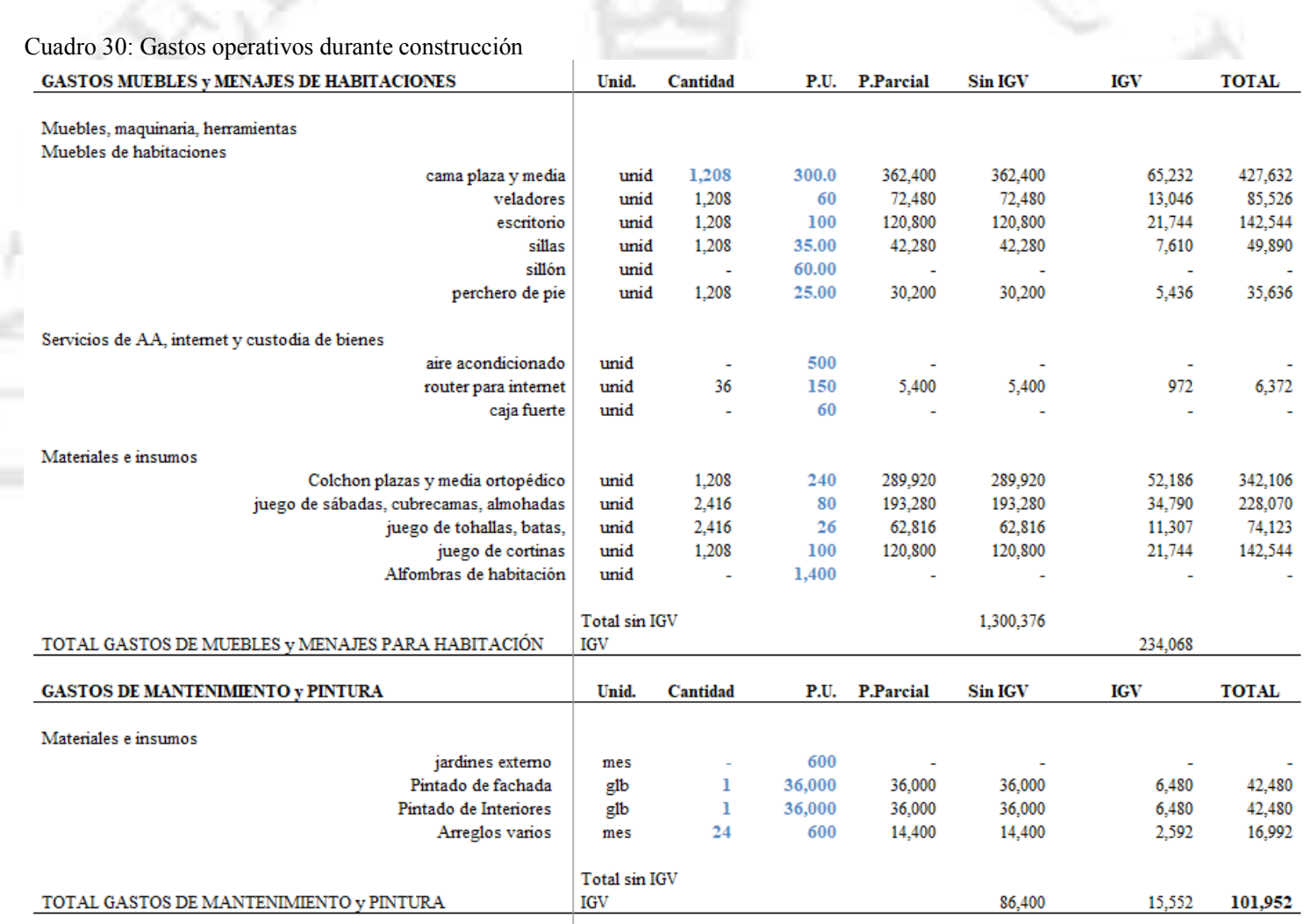

Fuente: Elaboración propia

El proyecto también debe considerar gastos de seguridad, con 4 trabajadores de seguridad diurna, y 2 de seguridad nocturna al año, junto con las herramientas necesarias para su correcto desempeño.

En las zonas de habitaciones, aparecen los gastos de muebles y menajes. Esto comprende muebles, maquinarias, herramientas, servicios de AA, internet y custodio de 
bienes, así como los materiales e insumos respectivos (colchones, sabanas, cubrecamas, etc).

Luego vienen los gastos de mantenimiento y renovación, los cuales son los más costosos dentro de los gastos operativos.

\begin{tabular}{|c|c|c|c|c|c|c|c|}
\hline GASTOS DE SERVICIOS PÚBLICOS Y MUNICIPALES & Unid. & Cantidad & P.U. & P.Parcial & Sin IGV & IGV & TOTAL \\
\hline \multicolumn{8}{|l|}{ Materiales e insumos } \\
\hline \multicolumn{8}{|l|}{ Consumo de servicios públicos } \\
\hline consumo eléctrico & mes & 12 & 12,500 & 150,000 & 150,000 & 27,000 & 177,000 \\
\hline consumo de agua potable y alcantarillado & mes & 12 & 12,500 & 150,000 & 150,000 & 27,000 & 177,000 \\
\hline consumo de telefonia de administración & mes & 12 & 250 & 3,000 & 3,000 & 540 & 3,540 \\
\hline consumo de internet y televisión por cable & mes & 12 & 3,000 & 36,000 & 36,000 & 6,480 & 42,480 \\
\hline \multicolumn{8}{|l|}{ Gastos municipales y licencias } \\
\hline Licencias de funcionamiento & glb & 1 & 10,000 & 10,000 & 10,000 & & 10,000 \\
\hline arbitrios & año & 1 & 10,000 & 10,000 & 10,000 & & 10,000 \\
\hline parques y jardines & año & 1 & 4,500 & 4,500 & 4,500 & & 4,500 \\
\hline TOTAL GASTOS DE SERVICIOS PUBLICOS y MUNICIPALES & \multicolumn{7}{|c|}{ Total $\sin$ IGV } \\
\hline
\end{tabular}

Fuente: Elaboración propia

Como último punto a tomar en cuenta, tenemos los gastos de servicios públicos y municipales, entre los que se encuentran los consumos eléctricos, de agua, telefonía e internet, así como también las licencias de funcionamiento, arbitrios, parques y jardines. El terreno, al pertenecer a la universidad, sería donado por esta, para luego proceder al préstamo bancario en este caso de unos 29 millones de dólares. Además de este préstamo para cubrir gastos directos, se necesitan cubrir los costos indirectos de la construcción y los gastos operativos, los cuáles también serían financiados como préstamo por un valor de 5 millones de dólares, Escenario en el cual el proyecto comienza a ser rentable desde el año 1 de acuerdo al análisis financiero realizado, por lo que se tendría un financiamiento total de 34 millones de dólares.

Este proyecto recupera la inversión en el año 15, con un valor positivo de 7 millones de dólares al término de la deuda, con una ganancia anual de 4 millones. Hay tres tipos de gráficos analizados: 


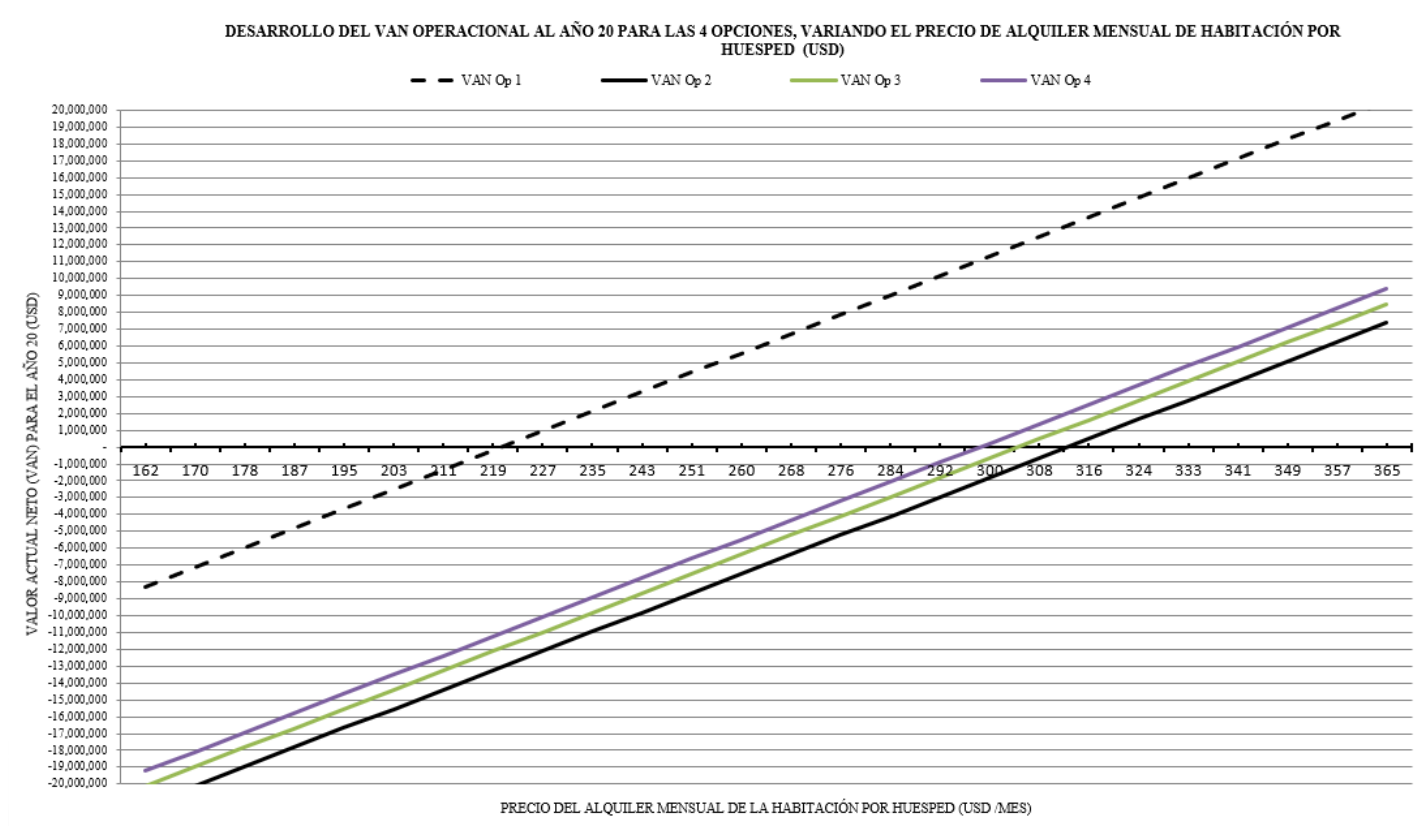

Fuente: Elaboración propia

Este gráfico muestra la variación del VAN (Valor Actual Neto) y de la utilidad del proyecto al año 20 para las 4 opciones. En este caso se utiliza como medidor el precio del alquiler por persona (son 2 personas por habitación). Se puede apreciar en la opción uno que si el alquiler fuera de 220 dólares, al año 20 el VAN estaría en valor neutral Es por esto que el alquiler es de 0.70 por $\mathrm{m} 2$ al día. Dando como resultado 284 dólares mensuales. Permitiendo tener un flujo de caja siempre positivo durante los años de construcción del proyecto. Para que el proyecto sea rentable en las otras opciones, el alquiler debería ser alrededor de 320 dólares mensuales por persona, haciéndolo un precio inviable para los estudiantes. 


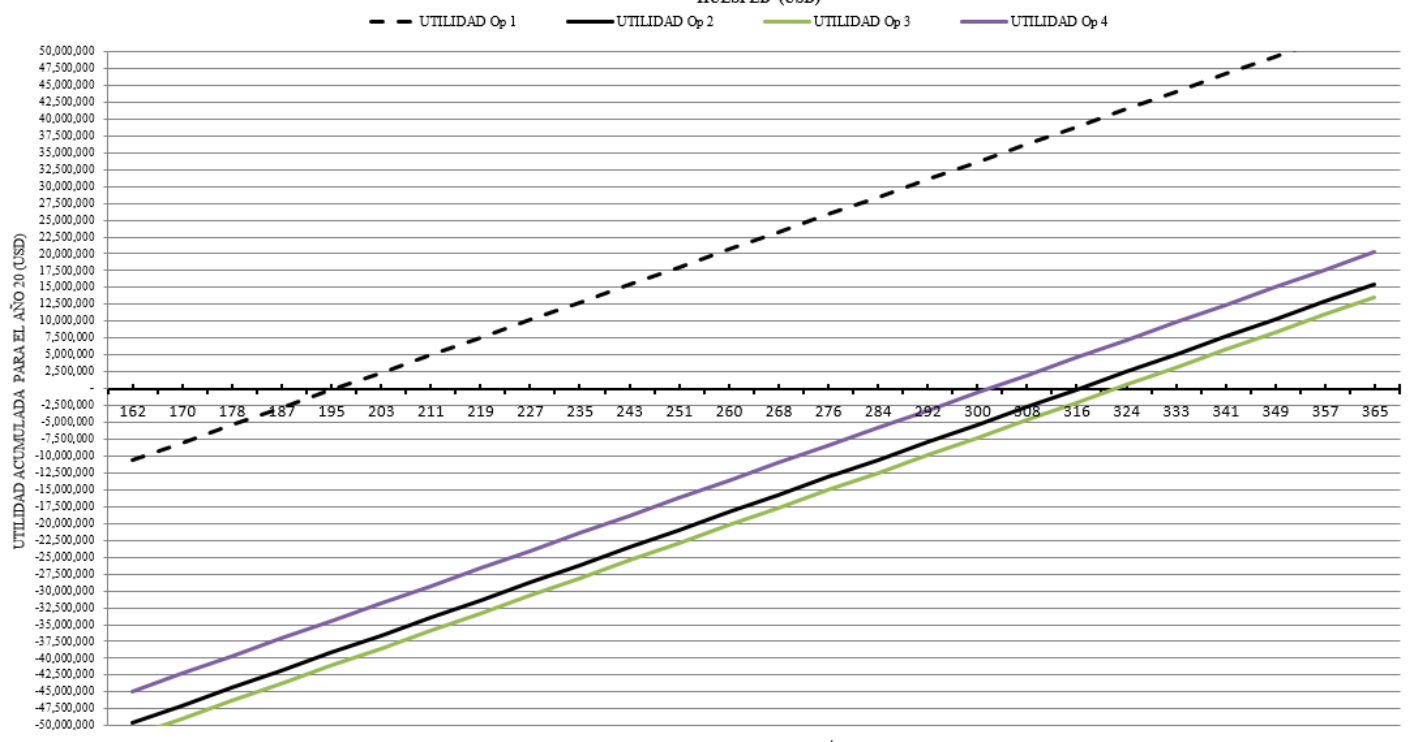
PRECTO DEL ALQUILER MENSUAL DE LA HABITACIÓN POR HUESPED (USD MES)

Fuente: Elaboración propia

Este gráfico muestra la variación de la utilidad del proyecto al año 20 para las 4 opciones. En este caso se utiliza como medidor el precio del alquiler por persona (son 2 personas por habitación). Se puede apreciar en la opción uno que si el alquiler fuera de 190 dólares, al año 20 el proyecto no tendría utilidad. Es por esto que el alquiler es de 0.70 por $\mathrm{m} 2$ al día. Dando como resultado 284 dólares mensuales. Permitiendo tener un flujo de caja siempre positivo durante los años de construcción del proyecto con una utilidad al año 20 de 28 millones de dólares. Para que el proyecto sea rentable en las otras opciones, el alquiler debería ser alrededor de 320 dólares mensuales por persona, haciéndolo un precio inviable para los estudiantes. 


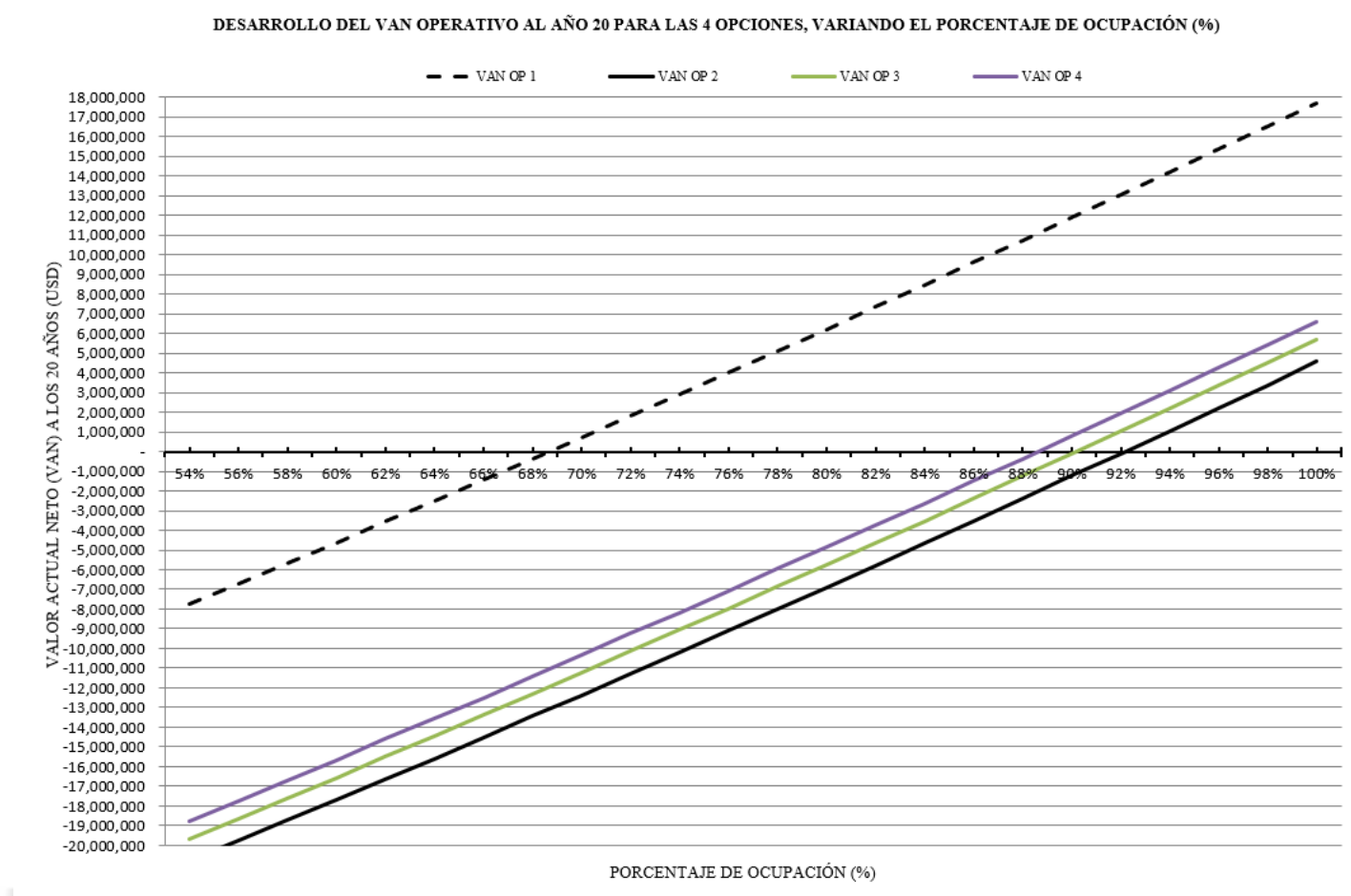

Fuente: Elaboración propia

El gráfico nos muestra que el proyecto necesitaría un mínimo de $65 \%$ de ocupación para que el VAN sea neutral, sin embargo, de acuerdo a la ocupación estimada, al año 20 se tendría un van de 9 millones de dólares. Las otras opciones analizadas necesitarían un $100 \%$ de ocupación. 


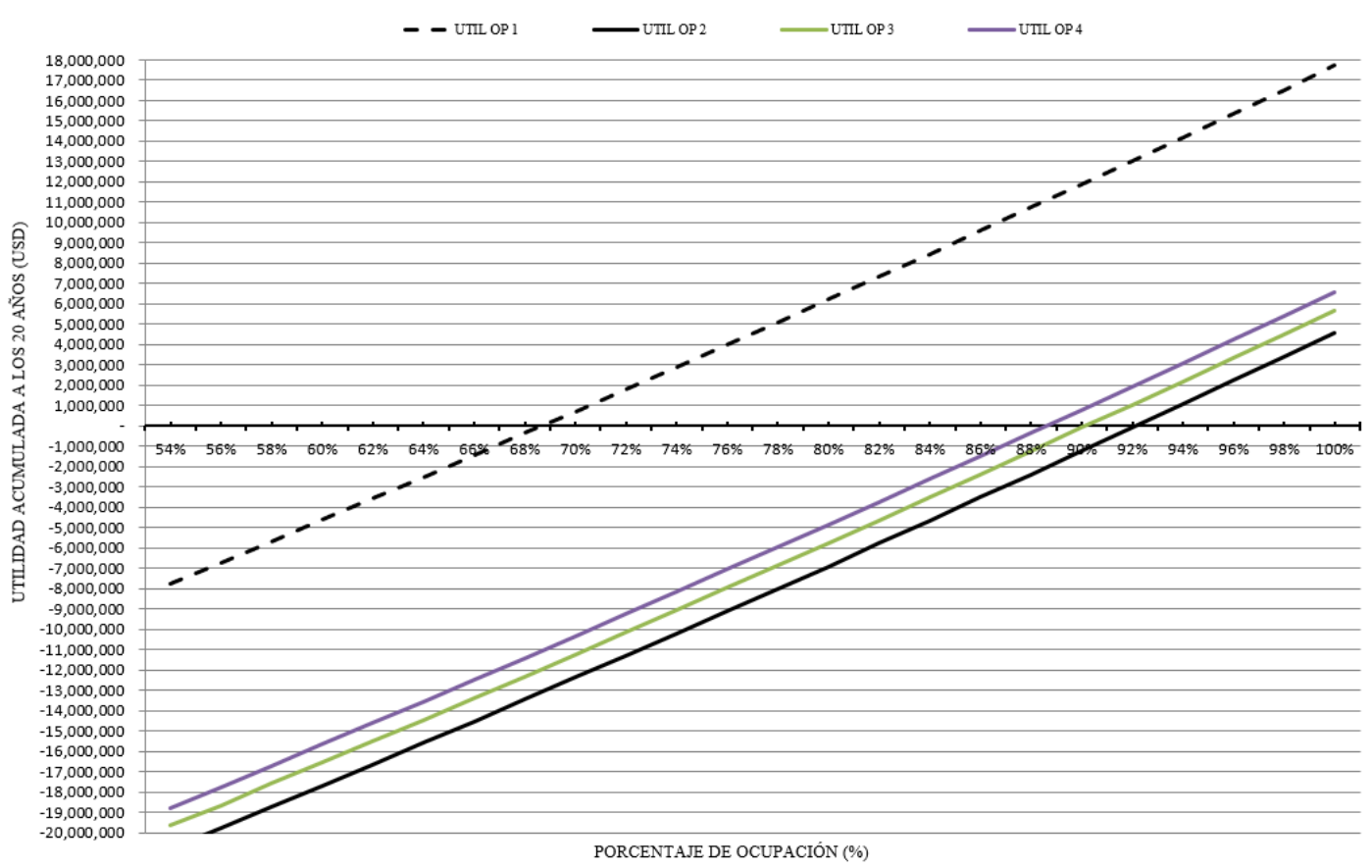

Fuente: Elaboración propia

En el caso de las habitaciones es todo lo contrario. Tomando en cuenta que el $100 \%$ es el porcentaje de habitaciones ocupadas en el año 1 (es el $100 \%$ de lo estimado a ocuparse al inicio, no se refiere al total de habitaciones), vemos que, si este porcentaje bajara al 86 por ciento, el proyecto estaría en quiebra. No hay manera de que el valor incremente ya que el $100 \%$ es el valor absoluto. 
Imagen 138: Desarrollo del VAN operativo variando la tasa de crédito financiero

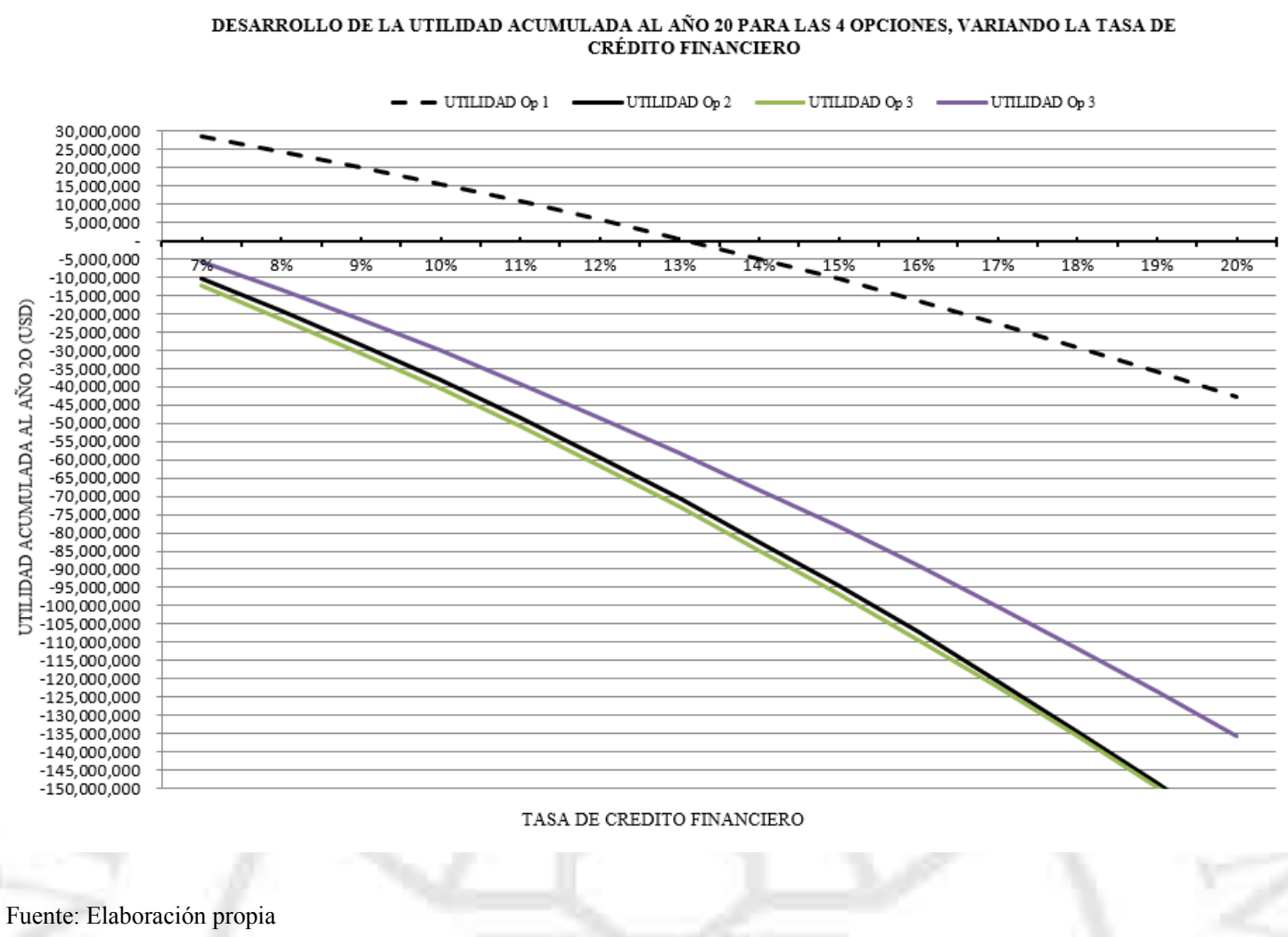

Este cuadro permite analizar la tasa de crédito financiero con una utilidad acumulada al año 20. Se puede ver que mientras mayor sea la tasa de crédito menor será la utilidad. Así, teniendo una tasa de $7 \%$ se tiene una utilidad de 28 millones al año 20 , mientras que una tasa de $13 \%$ dejaría al proyecto sin utilidad al llegar a ese año. Las otras opciones, dejan al proyecto con un saldo negativo, aunque la tasa bancaria sea baja, convirtiéndose en opciones inviables. 


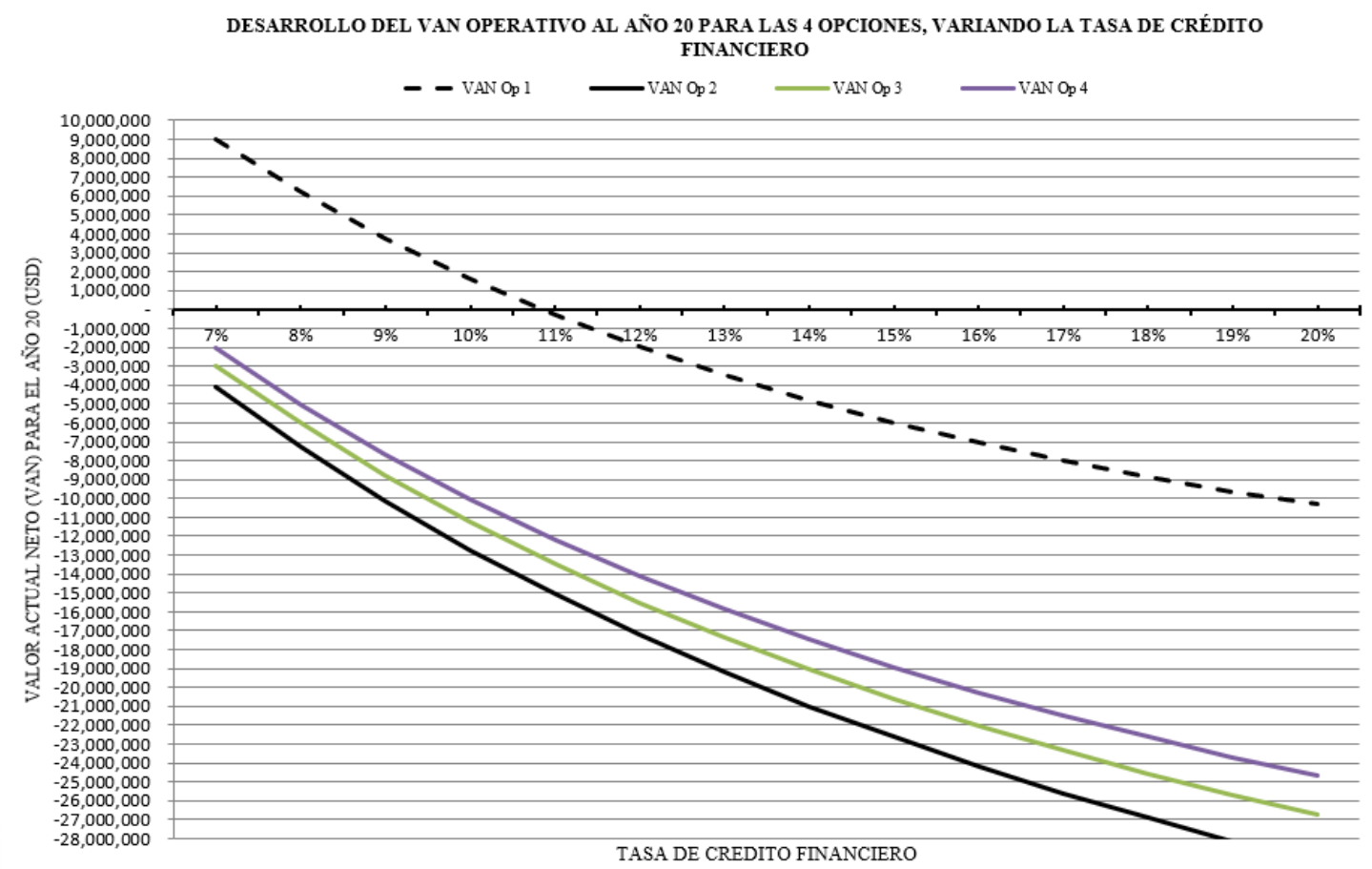

Fuente: Elaboración propia

El último gráfico nos muestra la relación entre la tasa de crédito financiero y el valor actual neto del proyecto al año 20. De manera similar, si la tasa es de 7\% el VAN es de 9 millones mientras que si sube la tasa a $11 \%$ el proyecto no tendría valor, pudiéndose ver que es más sensible el incremento de la tasa respecto al VAN que genera. De la misma forma que el gráfico anterior, las otras opciones no tienen valor ya que el proyecto siempre estaría en negativo.

Teniendo en cuenta esto, el proyecto solo podría funcionar si es que el valor de la tasa no sube a más del $11 \%$ ya que sería inviable por las cuotas a pagar a lo largo de los años. Esto es importante ya que permite saber con exactitud cuál sería el mayor valor de tasa a aceptar por las entidades financieras al momento de decidir realizar el proyecto.

Como conclusiones, podemos notar que la mayor fuente de ingresos de la residencia proviene del alquiler de habitaciones de esta. Si bien es cierto la parte comercial no afecta mucho a la viabilidad del proyecto, genera un gran aporte no solo por lo económico, sino también por el valor que tiene en la residencia.

También es importante recalcar que es posible hacer variaciones de precios y tasa del banco siempre y cuando se mantengan el rango permitido para que el proyecto pueda llevarse a cabo. 


\section{CAPÍTULO VII: CONCLUSIONES FINALES}

- Las residencias universitarias, que en un primer momento aparecieron como viviendas dentro de las universidades, donde las relaciones interpersonales eran entre alumnos y maestros, con el transcurso del tiempo tuvieron que cambiar su concepción frente a la necesidad de adaptarse a las necesidades y cambios que se iban presentando en la sociedad.

- El entorno y la necesidad de relacionarse hacia el exterior, es decir con el contexto y la comunidad, jugaron un papel fundamental en el desarrollo de nuevos planteamientos y diseños en los modelos de residencias universitarias, aun cuando siempre han mantenido su carácter propio.

- El desarrollo de las residencias universitarias en el caso de nuestro país no ha sido muy extenso. Así encontramos unas pocas en provincias, mientras que en Lima sólo funcionan en la actualidad tres, las que se encuentran en la Universidad Nacional Mayor de San Marcos (UNMSM), en la Universidad Nacional de Ingeniería (UNI) y en la Universidad Peruana La Unión (UPEU). Lamentablemente, al menos en el caso de las dos primeras, estas no funcionan de manera adecuada pues no cuentan con una infraestructura ni administración eficiente que les permita brindar adecuados servicios y responder así a las necesidades actuales de los estudiantes.

- Respecto a la utilización de las residencias en Lima, el alojamiento se otorga de manera temporal, teniendo en consideración el nivel socioeconómico del estudiante, así como su rendimiento académico, lo cual restringe la posibilidad de acceso de todos los estudiantes que requieren de dicho servicio.

- Además, cabe precisar, que la capacidad de estudiantes albergados en residencias es muy poca en comparación con la cantidad de estudiantes que buscan alojamiento, lo que nos indica la falta de residencias universitarias. Por citar un ejemplo en la Universidad Nacional Mayor de San Marcos, de un total de 31802 alumnos, 928 alumnos vienen de provincias y del exterior, de los cuales la residencia universitaria solo aloja a 145 , lo que equivale al $0.45 \%$ de su población universitaria. Por ello resulta imperativo la creación de este tipo de infraestructura para cubrir con la demanda no satisfecha de estudiantes. 
- En este contexto, otro aspecto importante a considerar y que sustenta la necesidad del proyecto de residencia universitaria es el incremento de estudiantes que migran de provincias a Lima y que generalmente carecen de un lugar donde hospedarse. Es así que el público usuario objetivo al que está dirigido el proyecto de residencia estaría conformado en su mayoría por estudiantes de provincias. A esto hay que agregarle la demanda de los estudiantes que vienen del extranjero.

- Cabe precisar también que las estadísticas indican que conforme pasan los años la cantidad de estudiantes que no vive con sus padres va en aumento y los jóvenes tienden a vivir en algún otro lugar (ya sea departamentos o casas de estudio) por lo que resulta por demás viable que se hospeden en una residencia universitaria. Así, el porcentaje de estudiantes que vivía en Lima en 1996 con sus padres era de $81 \%$ mientras que en el año 2010 bajo al $76 \%$.

- Por otro lado, las cifras estadísticas indican que el principal aspecto que influye en los estudiantes al momento de elegir una universidad es el prestigio de la misma con un $54 \%$, mientras que la cercanía al domicilio solo el $10 \%$. Esta última preferencia es muy importante ya que nos señala que al $90 \%$ de la población universitaria no le importa la cercanía a su domicilio, lo que indica que la mayoría están dispuestos a ir a una universidad que esté ubicada en un sitio lejano, lo que conlleva la posibilidad que puedan requerir alojarse en una residencia universitaria que se ubique en la cercanía.

- La PUCP y la UNMSM son reconocidas a nivel latinoamericano y ocupan un lugar preferencial en los jóvenes al momento de decidir donde efectuar sus estudios y no cuentan con una residencia universitaria, de ahí que han sido escogidas para desarrollar el proyecto objeto de la presente tesis.

- La gran cantidad de estudiantes de estas universidades -que se encuentran situadas en el distrito de San Miguel- y su demanda cada vez más creciente en busca de alojamiento, nos muestra que es posible establecer una residencia universitaria cerca de la zona.

- La cercanía entre ambos centros de estudios es otro factor esencial que se ha considerado al momento de delimitar la ubicación de la residencia universitaria y la necesidad de que esta se encuentre ubicada fuera de los campus de dichas casas de estudios. 
- Además, otro factor para la inclinación por el desarrollo del modelo de residencia universitaria fuera del campus es su preferencia por los estudiantes, quienes consideran que ello es fundamental para tener mayor independencia.

- En cuanto a los ambientes internos de las residencias, estos deben tener las condiciones mínimas indispensables para que los estudiantes puedan vivir de manera digna, derecho fundamental inherente a la persona humana que se encuentra reconocido en diversos convenios internacionales ratificados por nuestro país. Es así que para que los alumnos se sientan satisfechos en estos alojamientos, las residencias deben hacerlos sentir cómodos, como si constituyeran su segundo hogar. En este contexto, las habitaciones albergarán a un máximo de 2 alumnos.

- Todas las residencias universitarias analizadas tienen en común el recorrido lineal dentro del proyecto. Este recorrido te permite llegar a todos los espacios de manera directa, lo cual puede aplicarse en la residencia que se va a desarrollar, ya que es un modelo que funcionaría a la hora de distribuir los espacios.

- Las residencias universitarias analizadas cuentan con un comedor ya sea dentro de la residencia, o próximo a estas. Dada la importancia de este servicio para los estudiantes debería ser considerado dentro de una residencia universitaria y ser de su uso exclusivo, ya que, al ser subvencionado parte del precio por las universidades, no podría estar disponible al público en general. Esto también debido a que los precios estarían en función al nivel socioeconómico analizado al cual iría dirigida la residencia.

- Luego de comparar las residencias universitarias analizadas en el marco operativo, se sacó un promedio tentativo de porcentajes de áreas que debería tener la residencia universitaria para las universidades de Pueblo Libre. La quinta parte del área debería estar destinada a la circulación dentro del edificio, mientras que otro $22 \%$ debería ser utilizado para las áreas comunes de la residencia. El 45\% para las habitaciones (la parte más importante del proyecto), y dependiendo del área del terreno, esto nos dirá la cantidad de estudiantes que permitirá alojar. Luego en menores proporciones se tiene un 5\% para servicios, $3 \%$ para el hall, y un 1\% para la recepción.

- Dentro de los alcances antes reseñados otro punto a tomar en cuenta es la ubicación de la residencia. El proyecto considera su construcción en un terreno 
que tiene una ubicación ideal pues se encuentra cerca a ambas universidades, así como a zonas de comercio como cafés o restaurantes e instalaciones culturales. Esto ayudará a atraer más estudiantes, volviendo el lugar más llamativo, activando así la residencia en el lugar, ya que estas zonas no serán utilizadas solo por los estudiantes, sino también por las personas de distintas partes de la ciudad.

- El terreno elegido para desarrollar el proyecto destaca por su ubicación y tamaño como principales características, ya que permite el diseño de espacio público. Esto beneficia a la zona, ya que es uno de los puntos que busca el proyecto al querer funcionar como regenerador urbano.

- El terreno, al encontrarse ubicado en una esquina, posee 3 frentes que pueden ser tratadas como parte del diseño, permitiendo así, como una de las características, controlar la penetración de luz por todas las fachadas.

- El terreno posee una cantidad de área considerable para desarrollar el proyecto. Hay suficiente espacio para poder realizar un buen planteamiento del espacio público en la zona, además del desarrollo de una ciclovía que de alguna manera pueda conectarse con la berma central (la cual también contiene una ciclovía) de la avenida Universitaria y pueda continuar su recorrido.

- La inclusión de una zona de comercio en la residencia es un punto muy importante. Esta permite activar la zona ya que atrae gente de los alrededores y simplifica la vida de los estudiantes. Así, ya no tendrán que ir tan lejos cuando necesiten hacer compras, sino que lo podrán realizar en el mismo lugar donde residen. 


\section{Bibliografía}

arq.com.mx. (27 de Noviembre de 2013). Obtenido de Buscador de Arquitectura:

http://noticias.arq.com.mx/Detalles/16471.html\#.Vzwm2_nhCUn

arquitectura blanca. (2006). Obtenido de

http://www.arquitecturablanca.com/fr/verObra.php?id=25

BAKER HOUSE. (7 de Enero de 2011). Obtenido de baker.mit.edu

Casanova, N. (2012). Hacia una teoría arquitectónica del habitar. Montevideo:

Bibliotecaplural.

casiopea. (19 de mayo de 2014). Obtenido de

http://wiki.ead.pucv.cl/index.php/Baker_House,_Massachusetts,_Estados_Unido $\mathrm{s}$

D.K. Ching, F. (1996). ARQUITECTURA FORMA ESPACIO Y ORDEN. Naucalpan: G. Gili.

Decanato de estudiantes. (2002). REGLAMENTO GENERAL DE LAS RESIDENCIAS UNIVERSITARIAS ESTUDIANTILES. Río Piedras: Universidad de Puerto Rico.

Dirección Académica de Relaciones Institucionales. (Octubre de 2017). PUCP.

Obtenido de http://www.pucp.edu.pe/la-universidad/nuestra-universidad/pucpcifras/datos-academicos/?seccion=comunidad-universitaria\&area=estudiantesde-intercambio-int-y-nac

Doberti, R. (2011). Habitar. Montevideo: Nobuko.

Dydak, K. (2014). Planning Housing for International Students. Planning for Higher Education Journal, 76-85.

EcuRed. (2005). Obtenido de https://www.ecured.cu/Mirador_(edificio)

es.wikiarquitectura. (13 de Abril de 2015). Obtenido de https://es.wikiarquitectura.com/index.php/Pabell\%C3\%B3n_Suizo

Evolución de las residencias universitarias. (s.f.). 34-38.

FONDATION LE CORBUSIER. (s.f.). Obtenido de http://www.fondationlecorbusier.fr/corbuweb/morpheus.aspx?sysId=13\&IrisObj ectId $=5108 \&$ sysLanguage $=$ fr-fr\&itemPos $=49 \&$ itemSort $=$ frfr_sort_string1\%20\&itemCount $=78 \&$ sysParentName $=\&$ sysParentId $=64 /$

Gaete, C. M. (18 de Junio de 2015). Plataforma Urbana. Obtenido de http://www.plataformaurbana.cl/archive/2015/06/18/cuatro-elementos-dediseno-para-implementar-la-teoria-de-los-ojos-en-la-calle-de-jane-jacobs/

Garcés, J., Arrascue, O., Ávalos, G., \& Calle, E. (2014). ESTUDIO DE

FACTIBILIDAD PARA LA CREACIÓN DE UNA RESIDENCIA UNIVERSITARIA BRINDADA POR LA UNIVERSIDAD DE PIURA. REPOSITORIO INSTITUCIONAL PIRHUA.

Giedion, S. (2009). Espacio, tiempo y arquitectura. Origen y desarrollo de una nueva tradición. Harvard: Reverté.

Gimenez, A. (s.f.). Valencia: Pencil.

Gómez Pérez, A. (2006). UNA RESIDENCIA UNIVERSITARIA EN UN BARRIO

MARGINADO: La R. U. Flora Tristán en el Polígono Sur de Sevilla. Acciones e investigaciones sociales, 1-16.

Gordon, S. (1974). The Journal of General Education. Londres: Penn State University Press.

Hampton, H. (21 de Junio de 2016). GenslerOn. Obtenido de http://www.gensleron.com/cities/2016/6/21/residence-halls-the-key-to-creatingcommunity-on-college-cam.html

Henley Business School. (s.f.). Obtenido de https://www.henley.ac.uk/people/person/professor-david-clapham/ 
Hites, M. (11 de Febrero de 2014). Archdaily. Obtenido de http://www.archdaily.pe/pe/02-334957/tietgen-dormitory-lundgaard-andtranberg-architects/52f304b5e8e44ea3c5000072-tietgen-dormitory-lundgaardand-tranberg-architects-detail

Hites, M. (11 de Febrero de 2014). Archdaily. Obtenido de http://www.archdaily.pe/pe/02-334957/tietgen-dormitory-lundgaard-andtranberg-architects

Informática, I. N. (11 de Julio de 2014). Instituto Nacional de Estadística e Informática. Obtenido de

https://www.inei.gob.pe/media/MenuRecursivo/publicaciones_digitales/Est/Lib 1251/Libro.pdf

Instituto Nacional de Estadística e Informática. (Enero de 2011). Red Peruana de Universidades. Obtenido de http://rpu.edu.pe/wp-content/uploads/2015/07/IICenso-Nacional-Universitario.pdf

Jacobs, J. (1973). Muerte y vida de las grandes ciudades. Madrid: Ediciones Península. Lidón de Miguel, M. (2015). Aldo van Eyck y el concepto In-between: aplicación en el Orfanato de Amsterdam. Valencia.

López Soria, J. I., Ueda Tsuboyama, A. M., \& Quiñones Tinoco, L. (2012). Historia de la UNI. Lima: Editorial Universitaria.

López Soria, J. I., Ueda Tsuboyama, A. M., \& Quiñones Tinoco, L. (2012). Institucionalización como universidad frente a los retos del desarrollo (19551984). En Historia de la UNI. Lima: Editorial Universitaria.

Matthew, B., Kogan, L., Sánchez, L., \& Villa, J. (2014). Hacia un nuevo modelo de las decisiones de compra: lógicas de consumo en jóvenes universitarios limeños. Lima: Universidad del Pacífico: Centro de Investigación.

Municipalidad distrital de Pueblo Libre. (2010). Plan de Desarrollo Concertado de Pueblo Libre al 2021. Lima.

Naja, R. (06 de Mayo de 2013). Arch Daily. Obtenido de http://www.archdaily.pe/pe/02-257999/clasicos-de-arquitectura-pabellon-suizole-corbusier

Newsletter Semana. (16 de 01 de 2017). Obtenido de Semana: http://www.semana.com/educacion/articulo/universidad-de-los-andes-abreresidencias-universitarias $/ 512341$

NTNU. (s.f.). $N T N U$. Obtenido de https://www.ntnu.edu/employees/terje.andreas.eikemo

NTNU. (s.f.). NTNU. Obtenido de https://www.ntnu.no/ansatte/arnulf.kolstad

Obregón Dionisio, S. (16 de Octubre de 2012). Universidad Nacional Mayor de San Marcos. Obtenido de http://www.unmsm.edu.pe/noticias/ver/2370

Oficina General de Planificación. (2015). Universidad Nacional Mayor de San Marcos. Obtenido de http://ogpl.unmsm.edu.pe/compendios/Compendio\%202015/Cap12.html

Ozden, C., \& Golay, M. (2009). El Derecho a la vivienda. Obtenido de CIDAP: http://www.cidap.org.pe/campanas/derecho-a-la-vivienda

Paredes Albujar, E. (13 de Diciembre de 2012). Universidad Nacional Mayor de San Marcos. Obtenido de http://www.unmsm.edu.pe/noticias/ver/2464

Penven, Stephens, Shushok, \& Keith. (2013). Future of Residential Colleges : Looking Back at S . Stewart Gordon 's " Living and Learning in College ". Journal Of College \& University Student Housing, 114-126.

Públicas, O. G. (Julio de 2002). Sistema de Bibliotecas y Biblioteca Central. Obtenido de 
http://sisbib.unmsm.edu.pe/bibvirtual/publicaciones/actualidad/A\%C3\%B1o2_ N11 2002/vivienda.htm

Quintero, L. A. (2015). LA PERMEABILIDAD DE LAS FORMAS

ARQUITECTÓNICAS. Barcelona: Departament d'Urbanisme i Ordenació del Territori. Universitat Politècnica de Catalunya.

ResearchGate. (s.f.). Obtenido de https://www.researchgate.net/profile/Judith_Thomsen residenciasen.com. (2014). Recuperado el 30 de Abril de 2016, de http://www.residenciasen.com/residencia-estudiantes/123-residenciaestudiantes-definicion.html

Rucrespo. (20 de enero de 2012). CISOLOG ciencia sociologica. Obtenido de http://cisolog.com/sociologia/continuum-social-hipotesis-del-cazador-y-delmono-asesino/

SINTEF. (s.f.). Obtenido de https://www.sintef.no/en/all-employees/?EmpId=4573

THE STUDENT HOTEL. (s.f.). Obtenido de https://www.thestudenthotel.com/

Thomsen, J. E. (2010). Aspects of student housing satisfaction: a quantitative study. $J$. Hous and the Built Environ, 278.

Universidad Nacional de Ingeniería. (2015). Obtenido de http://www.uni.edu.pe/index.php/bienestar-universitario/41-servicios

Universidad Nacional de Ingeniería. (2015). Universidad Nacional de Ingeniería. Obtenido de Oficina de Registro Central y Estadística:

http://www.orce.uni.edu.pe/estadistica_alumnos.php?flag=colegioProcedenciaD epartamentos\&periodo $=20152$

Universidad Nacional Mayor de San Marcos. (2015). Oficina General de Planificación. Obtenido de OGPL - UNMSM: http://ogpl.unmsm.edu.pe/?page_id=1633

University of Victoria. (s.f.). Obtenido de https://www.uvic.ca/socialsciences/psychology/people/facultydirectory/giffordrobert.php

Vargas, J. (2012). Residencia universitaria en Pueblo Libre. Lima: Universidad Peruana de Ciencias Aplicadas -UPC.

Wiki Arquitectura. (2001). Obtenido de http://es.wikiarquitectura.com

Wikiarquitectura. (s.f.). Obtenido de https://es.wikiarquitectura.com/edificio/torrenagakin-capsule/ 
ANEXOS

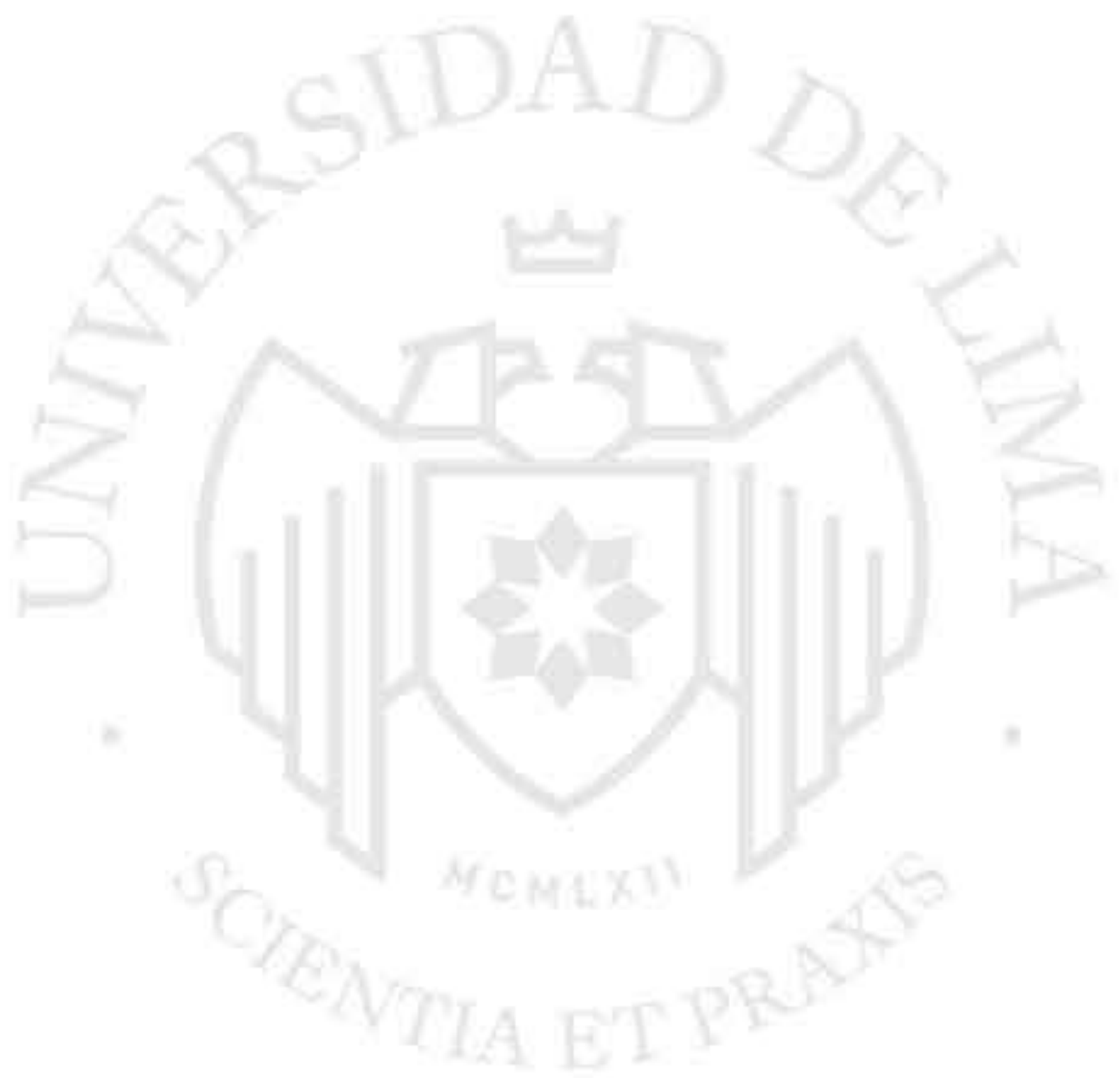



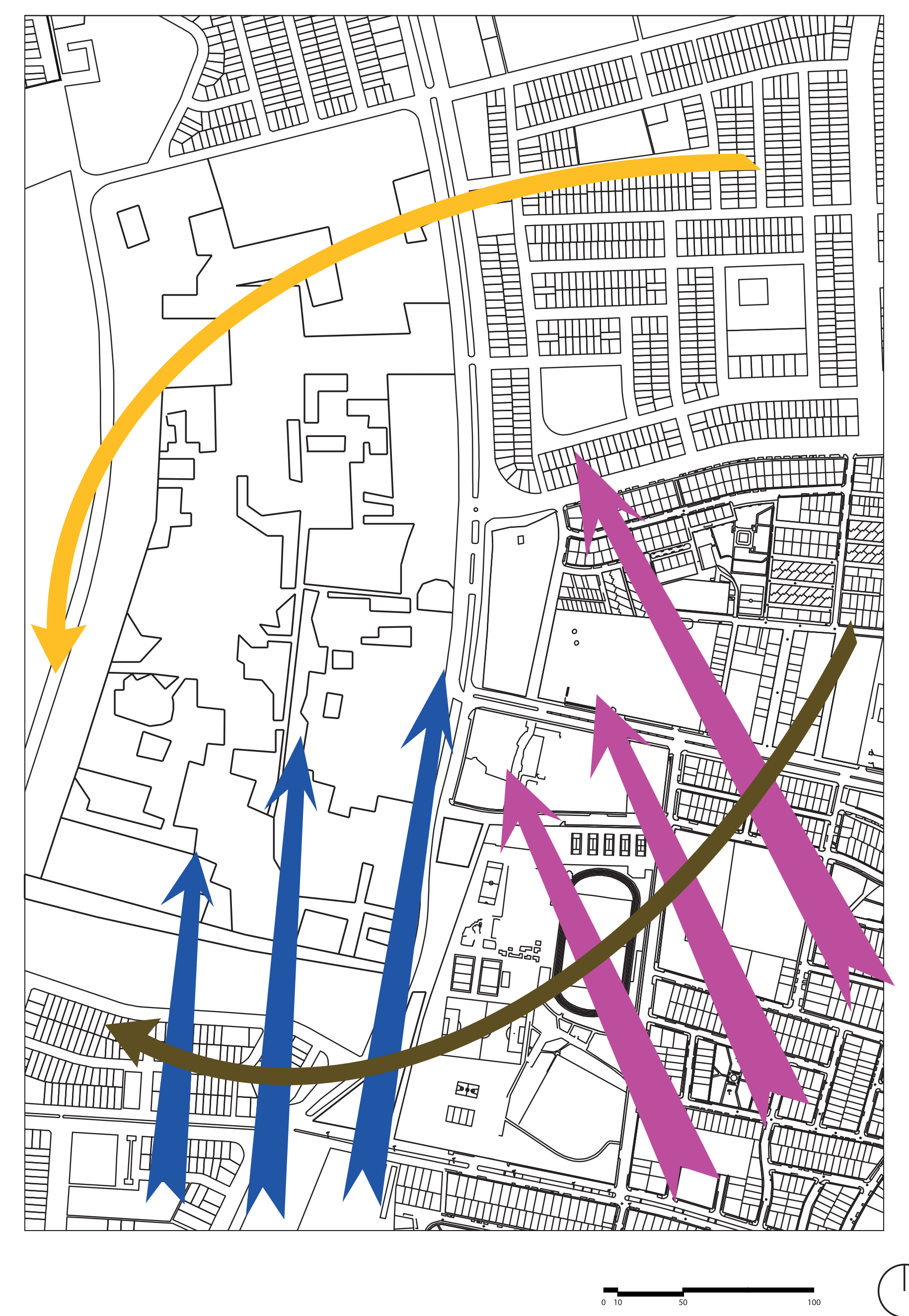

\section{PUEBLO LIBRE}

LATITUD: - 12.068735656184026

LONGITUD: -77.0773945748806

ORIENTACIÓN: S $12^{\circ} 4^{\prime}-0$ 77²
DIRECCIÓN E INTENSIDAD DE VIENTOS DURANTE EL AÑO

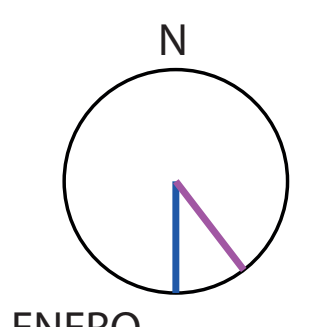

ENERO

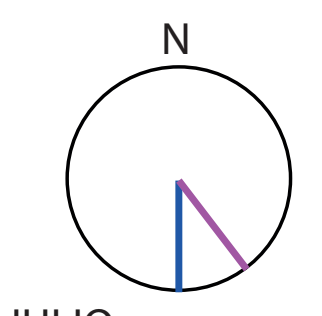

JULIO

Horas:

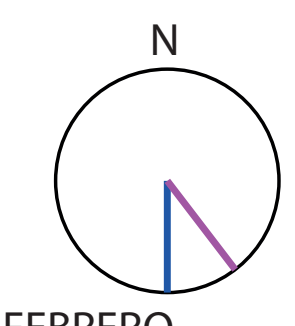

FEBRERO

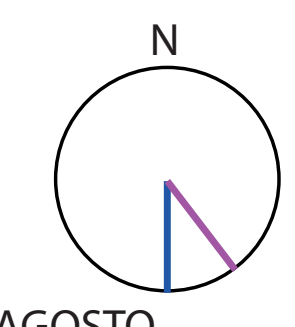

AGOSTO

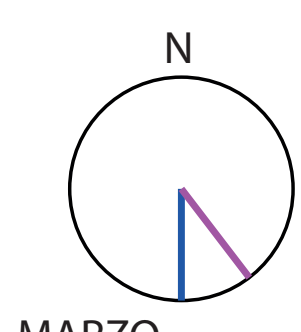

MARZO

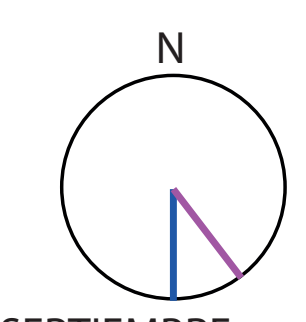

SEPTIEMBRE

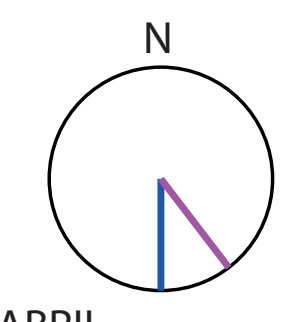

ABRIL

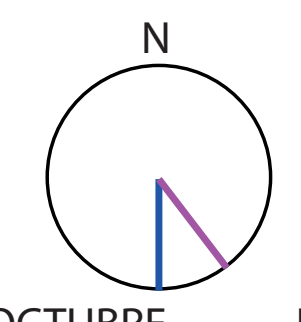

OCTUBRE
PRECIPITACIONES (mm.)

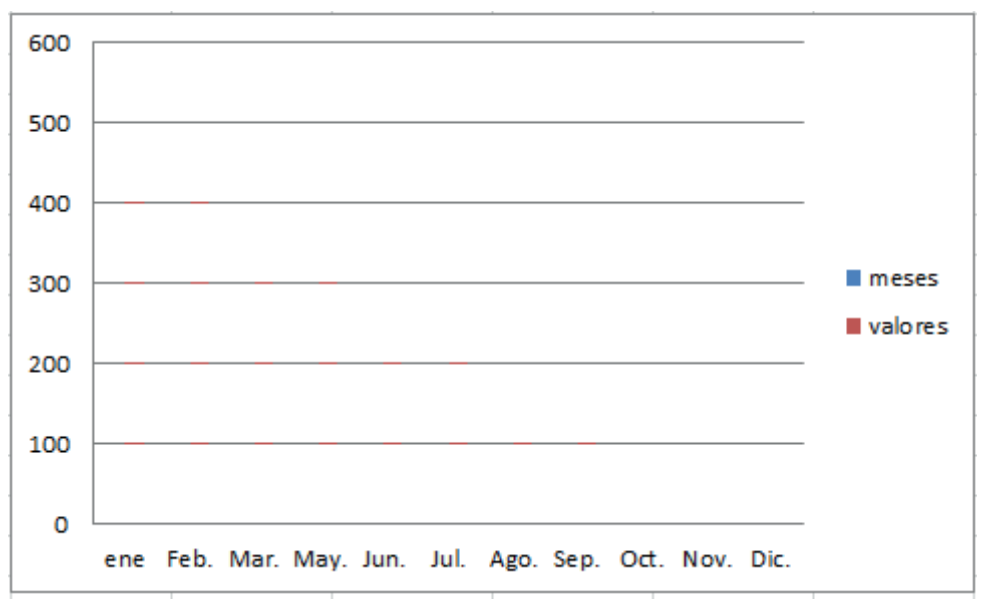

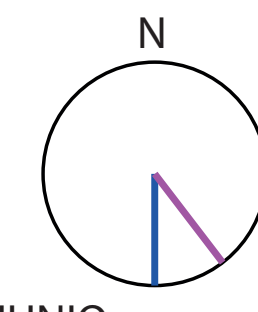

JUNIO

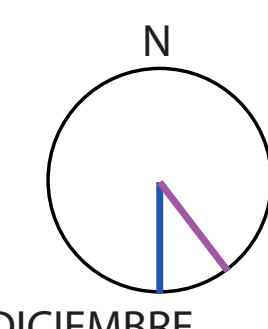
NOVIEMBRE

DICIEMBRE 


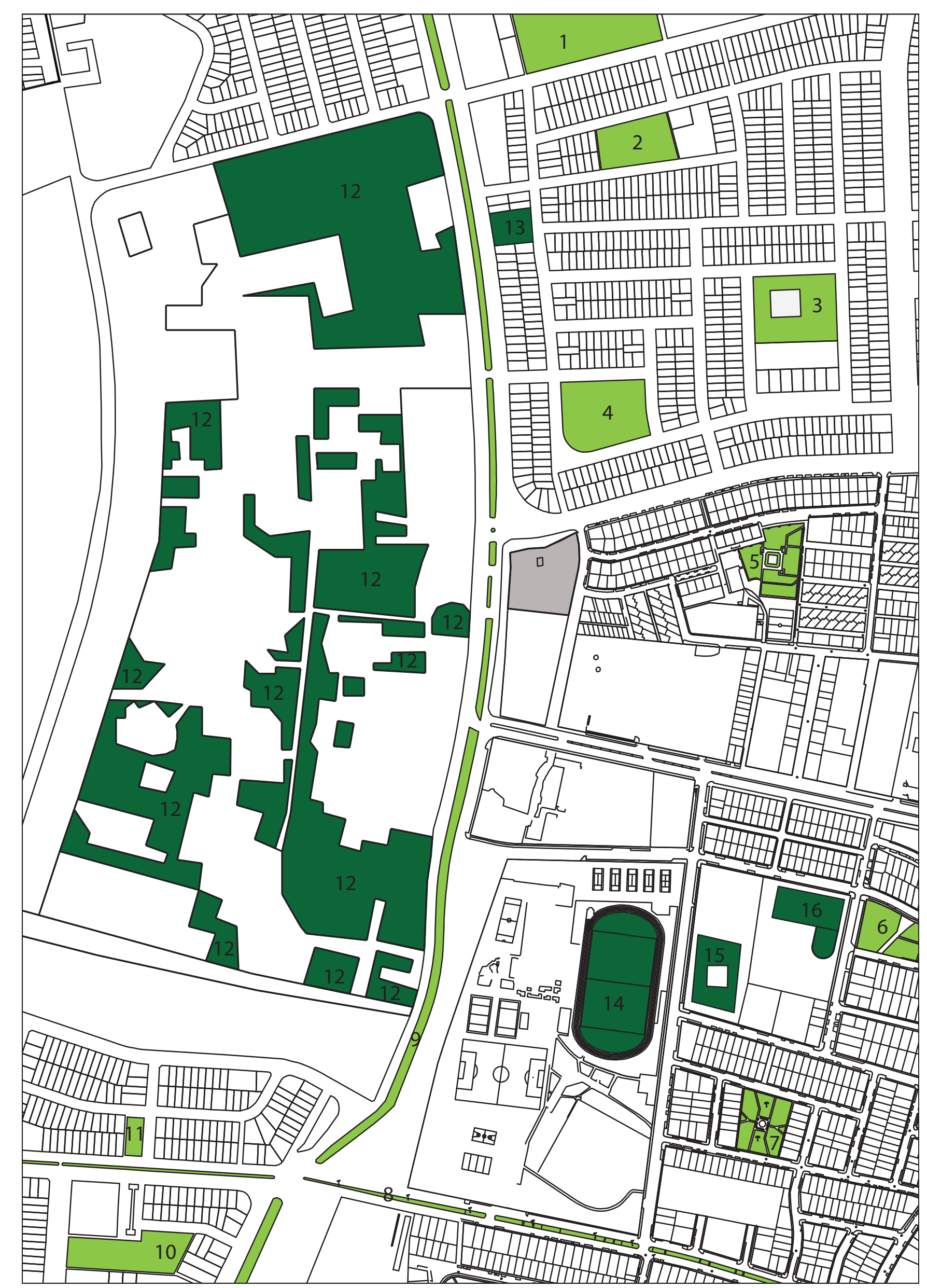

$\square$ Área pública

Terreno

Área privada

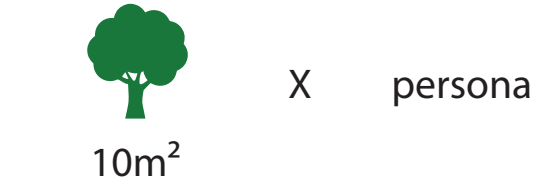

\begin{tabular}{|c|l|l|c|}
\hline & \multicolumn{1}{|c|}{ Privado / Público } & \multicolumn{1}{c|}{ Uso } & \multicolumn{1}{c|}{ Área } \\
\hline 1 & Público (Parque) & Tránsito, urbano & $7204.3863 \mathrm{~m}^{2}$ \\
\hline 2 & Público (Parque) & Tránsito, urbano & $2320.0779 \mathrm{~m}^{2}$ \\
\hline 3 & Público (Parque) & Tránsito, urbano & $3910.8377 \mathrm{~m}^{2}$ \\
\hline 4 & Público (Parque Santa Sofía) & Tránsito, urbano & $3817.0727 \mathrm{~m}^{2}$ \\
\hline 5 & Público (Parque Arco Iris) & Tránsito, urbano & $1800.9919 \mathrm{~m}^{2}$ \\
\hline 6 & Público (Parque) & Tránsito, urbano & $2767.3107 \mathrm{~m}^{2}$ \\
\hline 7 & Público (Parque UNAP) & Tránsito, urbano & $1896.7184 \mathrm{~m}^{2}$ \\
\hline 8 & Público (Av. La Mar) & Tránsito, verma & $1708.5224 \mathrm{~m}^{2}$ \\
\hline 9 & Público (Av. Universitaria) & Tránsito, verma & $6602.3889 \mathrm{~m}^{2}$ \\
\hline 10 & Público (Parque Cultural) & Tránsito, urbano & $2816.3495 \mathrm{~m}^{2}$ \\
\hline 11 & Público (Parque) & Tránsito, urbano & $456.2075 \mathrm{~m}^{2}$ \\
\hline 12 & Privado (PUCP) & Tránsito, césped & $74259.7836 \mathrm{~m}^{2}$ \\
\hline 13 & Privado (Huaca Culebras) & Patrimonio & $940.7283 \mathrm{~m}^{2}$ \\
\hline 14 & Privado (Cancha de fútbol) & Deporte & $5990.3027 \mathrm{~m}^{2}$ \\
\hline 15 & Privado (Colegio Cristo Rey) & Tránsito, césped & $1659.7882 \mathrm{~m}^{2}$ \\
\hline 16 & Privado (Colegio Cristo Rey) & Tránsito, césped & $1911.5675 \mathrm{~m}^{2}$ \\
\hline
\end{tabular}

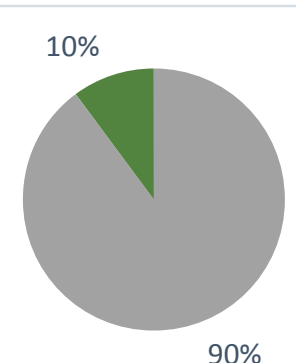

Área verde privada

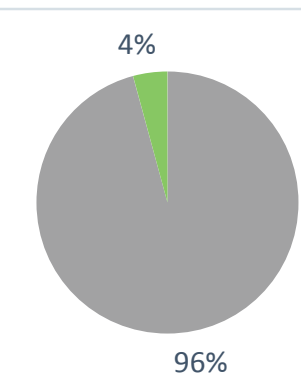

Área verde pública

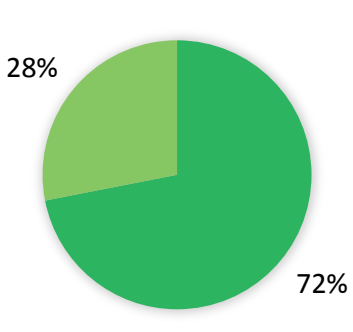

Total de área verde
Al analizar el porcentaje de área verde en la zona, podemos apreciar que hay más área verde privada que pública. En la zona estudiada esto no favorece a la población ya que es una zona netamente residencial, la cual necesita mayor cantidad de área verde en la zona donde viven, no solo dentro de las urbanizaciones, sino también alrededor de las avenidas, así como más parques y lugares donde las personas puedan pasar cierta cantidad de su tiempo. 


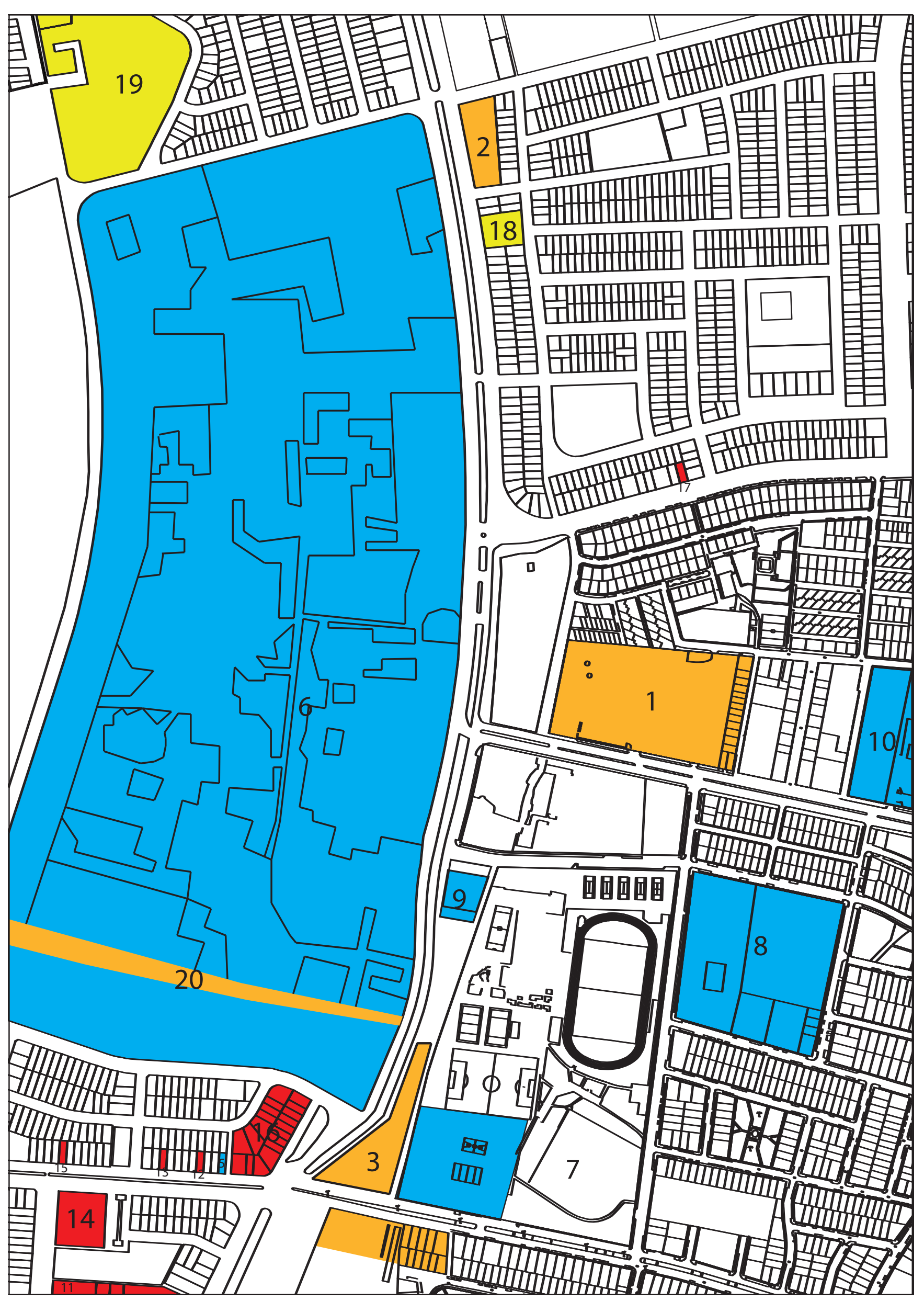

EDIFICIOS PRINCIPALES

POR TAMAÑOY FORMA

-Edificios residenciales

1. Condominio Jardines de la Católica

2. Edificios Urb. El Pando $3^{\circ}$ Etapa

3. Edificios Atlantis

4. Edificios Av. Manuel Cipriani Dulanto

5. Hotel Orquídea

POR USOS

-Edificios Institucionales 6. PUCP

7. Colegio Cristo Rey

8. Colegio La Unión

9. Idiomas Católica

10. Universidad Inca Garcilaso de la Vega

-Comercio

Nivel metropolitano

11. C. C. Plaza San Miguel

Nivel barrial

12. Market

13. Restaurant La Leña

14. Centro comercial San Miguel

15. Restaurant "My Home"

16. Zona de restaurantes "D'Paso"

17. Bodega

\section{-Patrimonio}

18. Monumento arqueológico Culebras

19. Monumento arqueológico Potosí

20. Zona arqueológica PUCP
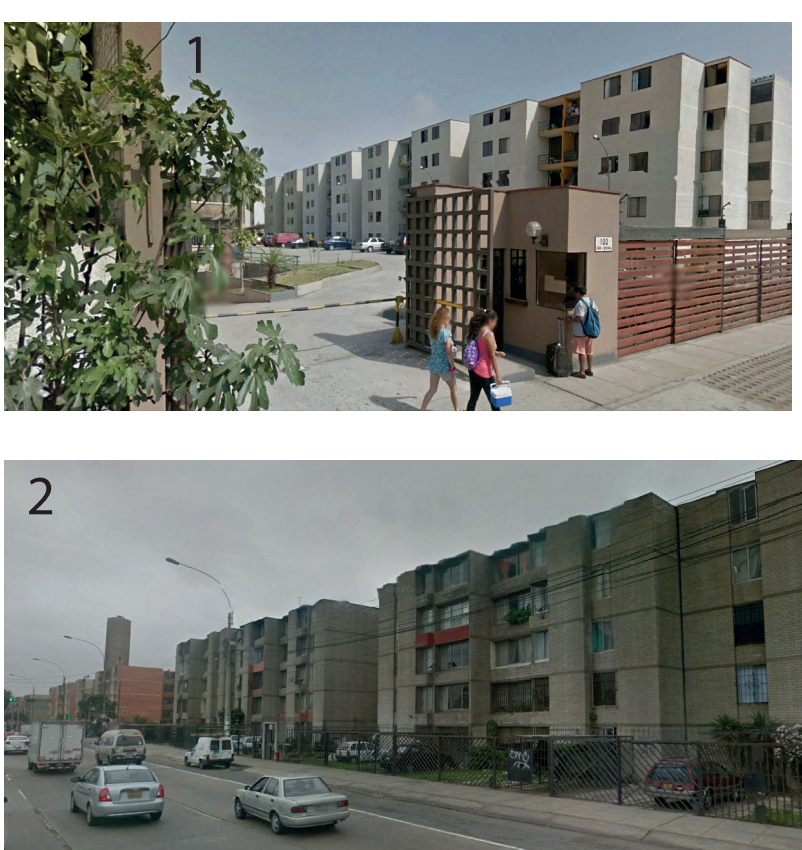

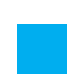

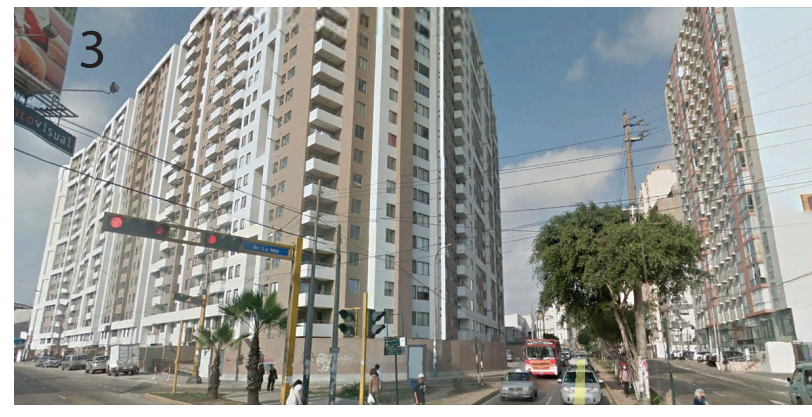

6
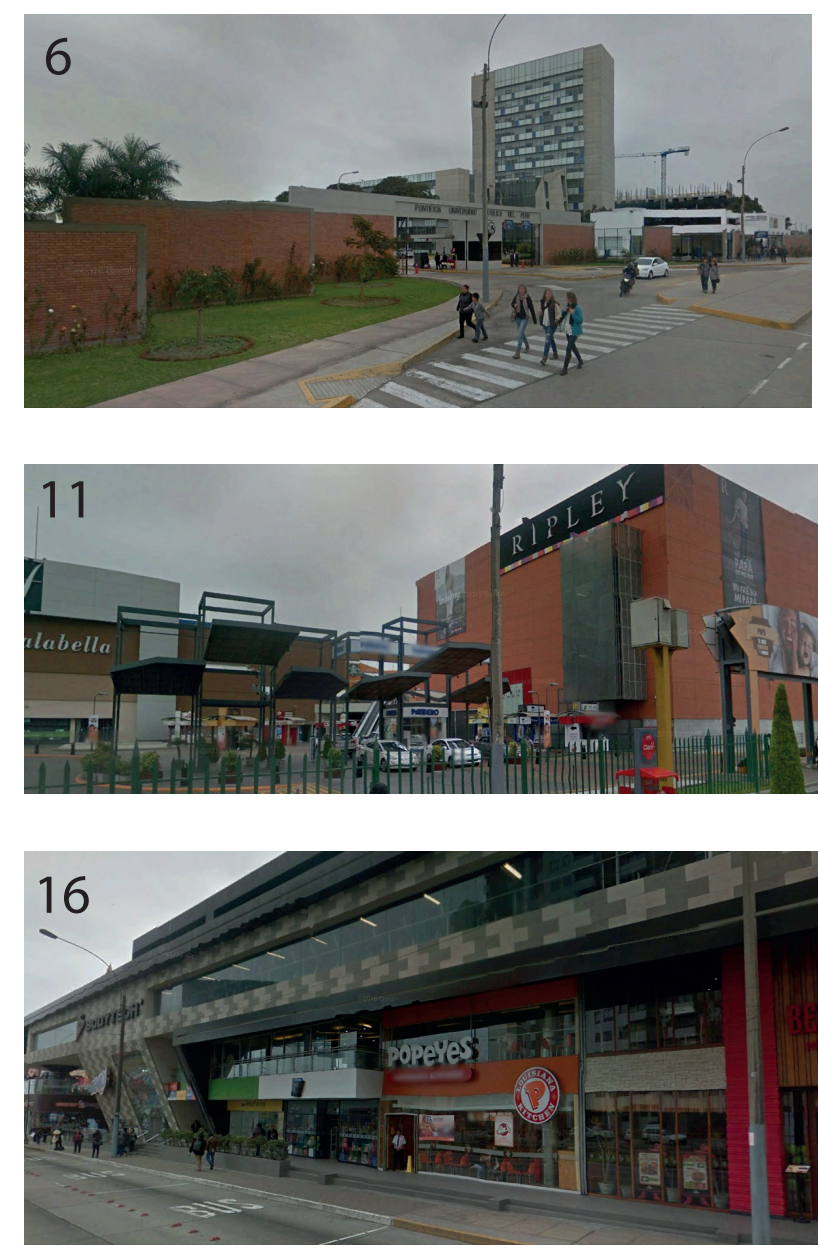


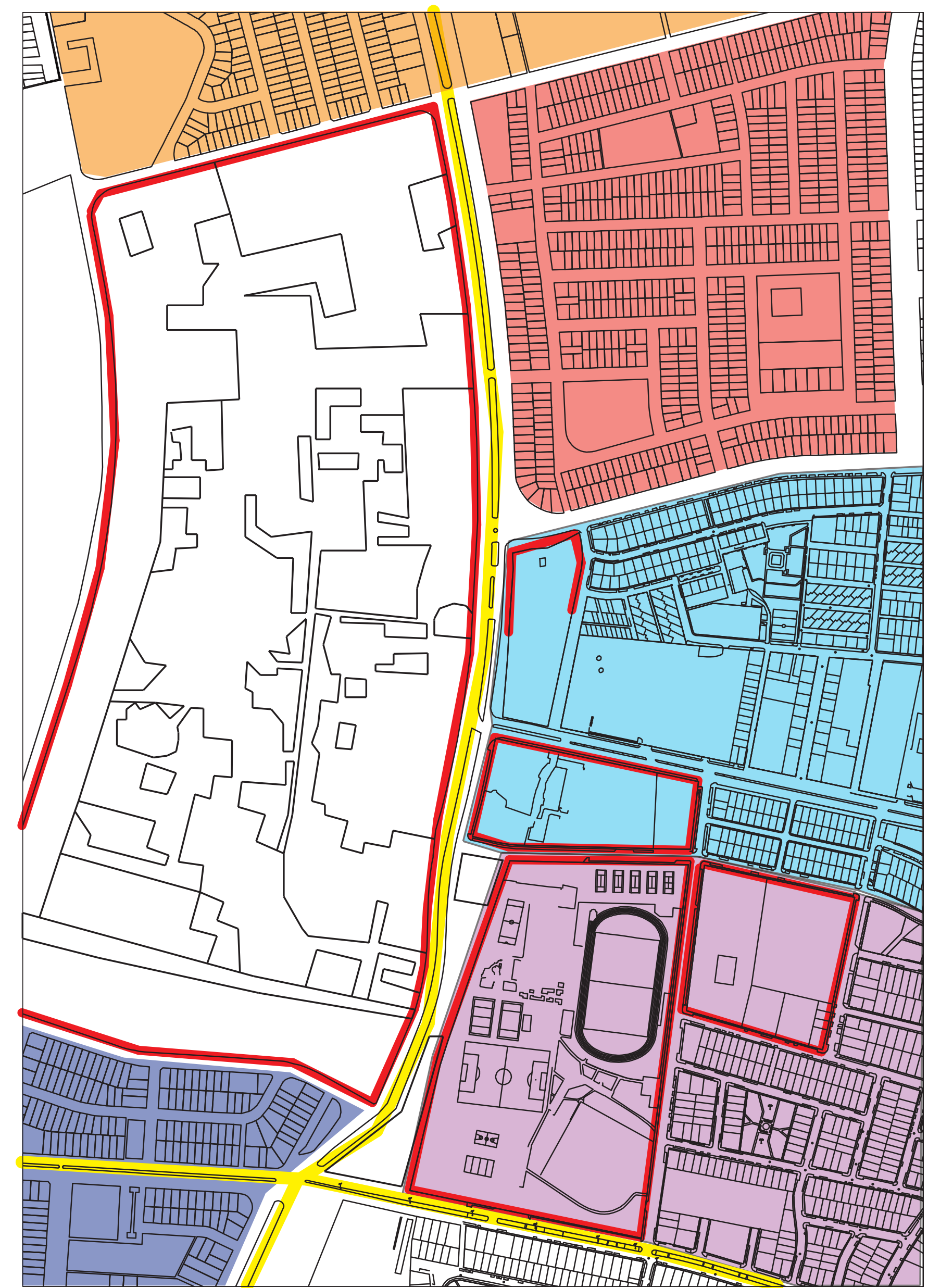

Bordes físicos

Sendas

Muros
BORDE

Es el trazado ya sea físico, natural o virtual que delimita o divida ciertas zonas. Suelen ser sendas como avenidas grandes, muros perimetrales,o configuración de calles lo que demuestra la limitación de un lugar y que puede llegar a ser el perímetro de un barrio.

Borde físico

Es aquel que ha sido construido y que no permite el paso, por lo que resulta impenetrable y delimita una zona.

\section{Borde natural}

Es aquel que se formó debido a la geografía del lugar, y que con el paso del tiempo se mantiene y no ha sido modificado

BARRIO

Son zonas de la ciudad de tamaño medio a grande (varias manzanas), los cuales han sido configurados mediante uno o varios aspectos, como puede ser la historia del barrio, la configuración y tipología de los edificios, la delimitación de las manzanas o los bordes que dividen ciertos lugares. Los barrios se sienten identificados por los transeúntes una vez se encuentran dentro ya que reconocen el carácter comúnque define la zona y que los identifica.

\section{Pando $8^{\circ}$ etapa}

Etapa delimitada por zonas monumentales arqueológicas como son las huacas, además de una avenida. esta etapa está configurada por manzanas ordenadas rectangulares, pero cuyos lotes construidos varian mucho en cuanto a alturas, dando una percepción de desorden desde el punto de vista peatonal. se encuentra cercado con rejas.
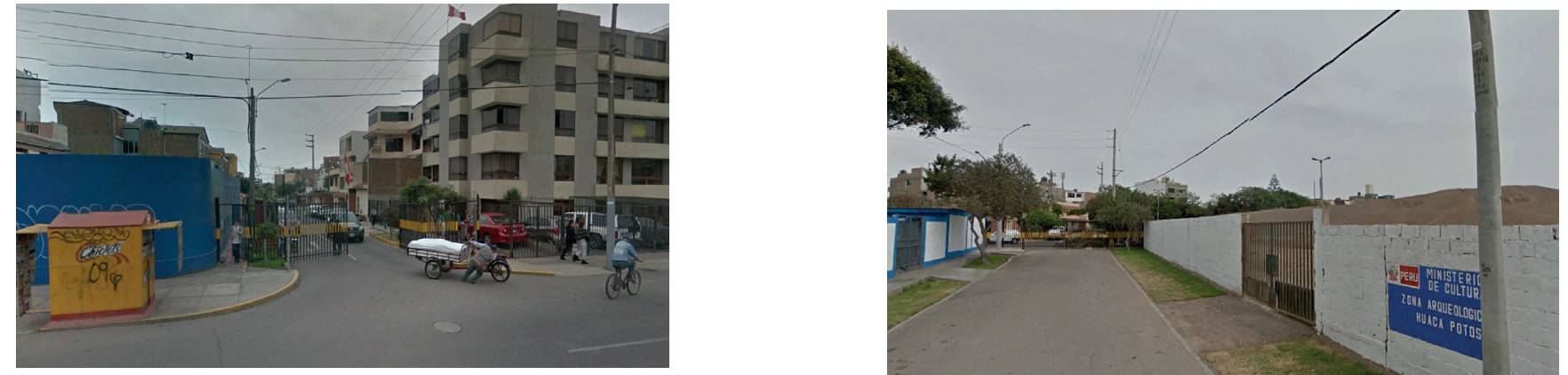

\section{Urbanización Santa Emma}

Organizado mediante la configuración de manzanas de igual tipología, las cuales cierran la urbanización, delimitándola con avenidas. La urbanización tiene manzanas de una sola tipología, con tres parques ubicados a igual distancia de modo que todas las manzanas tengan un rápido acceso al área pública.

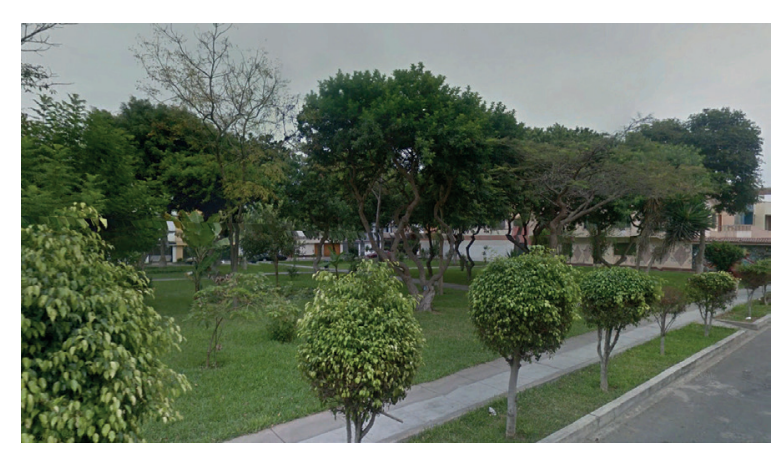




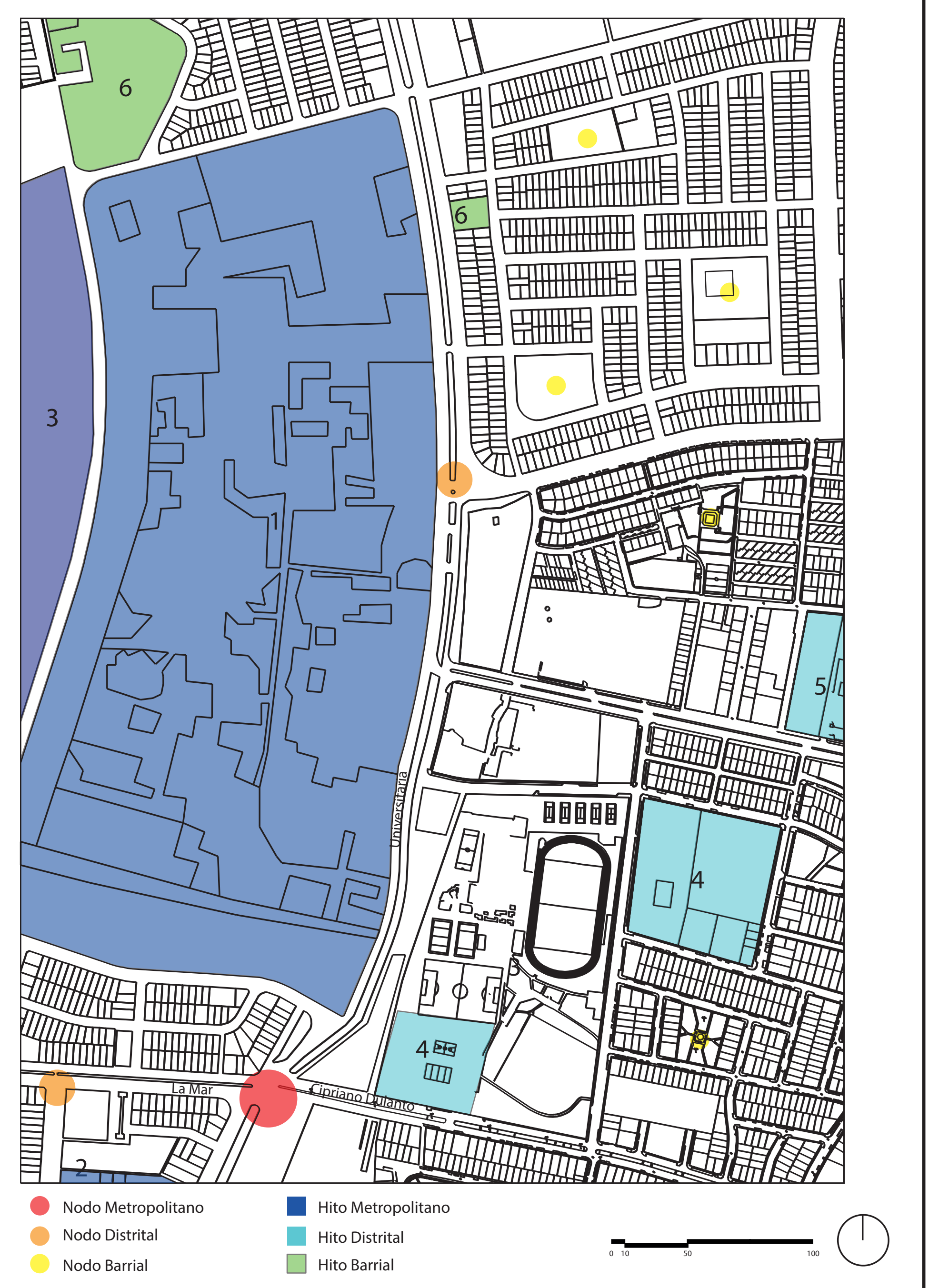

HiTO

Es un punto de referencia, el cual destaca en el lugar donde está emplazado, sirviendo de punto de ubicación para las personas que se encuentran cerca. Pueden considerarse hitos ya sea por tamaño o forma destacada en el lugar donde se encuentran, por su historia o relación con el sitio.

\section{Hitos Metropolitanos:}

1. Pontificia Universidad Católica del Perú

Este hito es el mas importante en la zona de estudio, ya que por su tamaño es muy sencillo ubicarlo, ya que está a lo largo de toda una avenida. Esta universidad atrae estudiantes de distantes partes del peru, asi como otros del extranjero, por lo que es un puntode referencia el cual es importante en la zona.

2. Plaza San Miguel

Si bien se encuentra en el límite de la zona de estudio, es un centro comercial que atrae muchos distritos de Lima sirviendo de referencia para todas las personas por su ubicación en avenidas importantes.

3. Parque de las Leyendas

EI Parque de las Leyendas se encuentra ubicado a espaldas de la PUCP. Es un lugar de recreacion donde acuden cientos de personas día a día, por lo cual es una lugar importante como zona turística del distrito.

\section{Hitos Distritales:}

4. Colegio La Unión - Colegio Cristo Rey

Estos colegios son hitos del distrito, ya que compiten contra la PUCP y Plaza San Miguel. Se encuentran ubicados alrededor de zonas residenciales, ambos adyacentes lo que permite localizarlos de una manera más rápida.

5. Universidad Inca Garcilaso de la Vega

Referente importante del distrito de Pueblo Libre, el cual se encuentra ubicado en la avenida Mariano Cornejo. Este hito destaca más que por su tamaño, por su historia como universidad y por su trascendencia.

\section{Hitos Barriales:}

6. Monumento arqueológico Culebras - Monumento arqueológico Potosí

Estas huacas son hitos en sus barrios respectivamente, ya que al ser de poco tamaño, no son tan marcados en el distrito. ambos están cercados, por lo que forman parte también de los bordes de los barrios a los cuales pertenecen.

NODO

Son los lugares de encuentro de personas en un punto determinado. la importancia del nodo se encuentra definida por la cantidad de personas que convergen en este.

\section{Nodo Metropolitano}

Este nodo es el cruce de las avenidas Universitaria, La Mar y Manuel Cipriano Dulanto, las cuales se encuentran a media cuadra de la Plaza San Miguel y la zona de restaurantes " $D$ ' $P a s o$ ", por lo que atrae a un gran flujo de persona

Nodo Distrital

Los 2 nodos distritales importantes de la zona de estudio se encuentran ubicados en la avenida Universitaria y la avenida La mar. El primero es el ingreso de la PUCP el cual se encuentra frente al terreno escogido, y que concurre en su mayoría a estudiantes, mientras que el segundo nodo está en la parte inferior de la universidad, el cual es una zona comercial local, a espaldas de Plaza San Miguel la cual atrae a muchos vecinos de la zona.

Nodo Barrial

Los nodos barriales a simple vista son los parques de las urbanizaciones. Normalmente se ubican en el centro de estas, siendo el punto medio de encuentro de las personas que viven alrededor. En la zona de estudio se pueden apreciar 4 parques los cuales estan distribuidos en la zona residencial. 


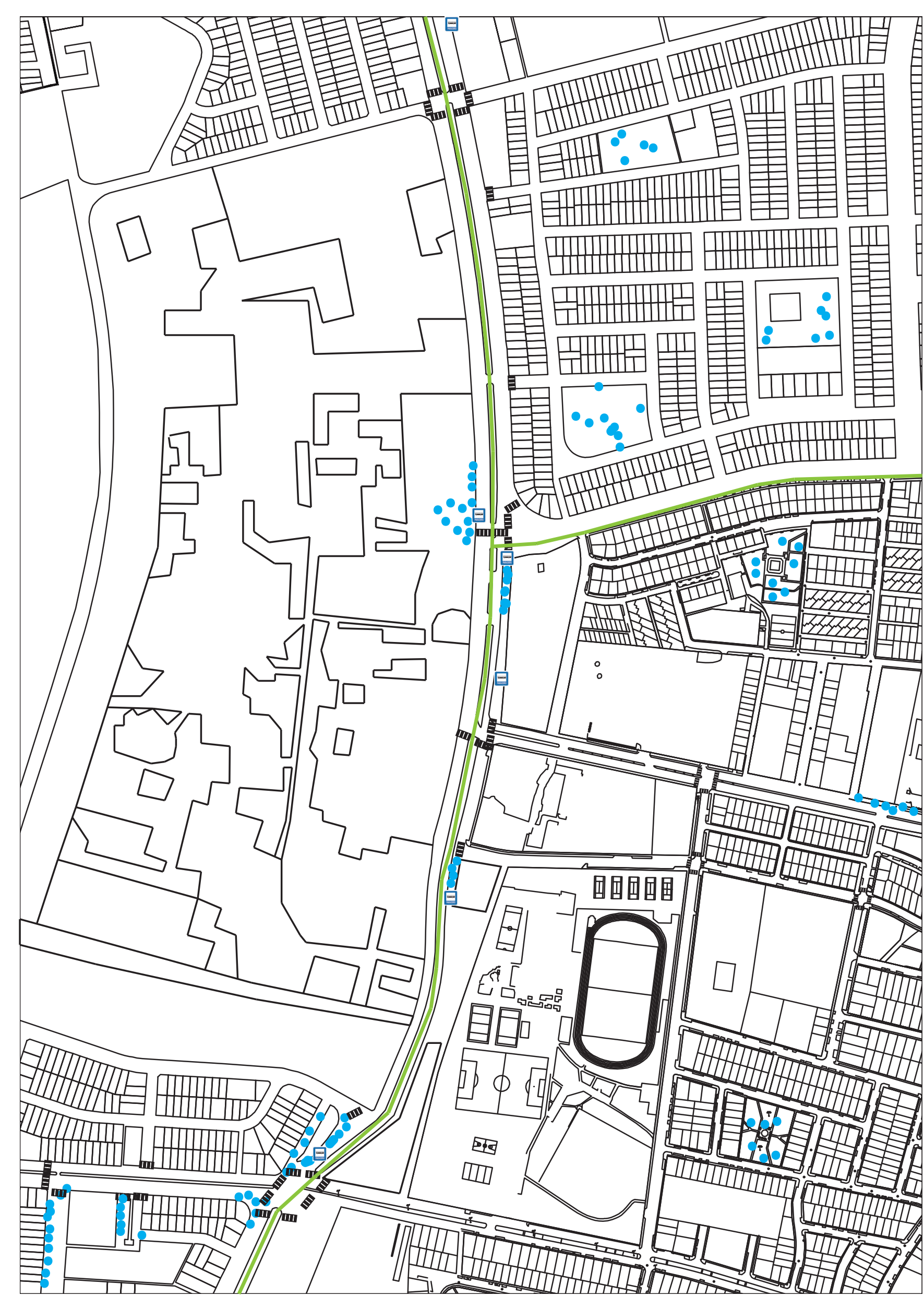

- flujo peatonal

III Cruceros peatonales ciclovías

paraderos
FLUJO PEATONAL

La concentración de personas se da en los paraderos y sobretodo en los ingresos a las edificaciones institucionales. Se puede ver gran concentración de personas en el ingreso a la PUCP, así como también frente a la Universidad Inca Garcilaso de la Vega y frente a la CEPREPUC. Este grado alto de concentración se da en las 3 horas más importantes $(7 \mathrm{am}-1 \mathrm{pm}-7 \mathrm{pm})$, volviéndose más fluido en lo que resta del día. en cuanto a las ubicaciones alejadas de las avenidas principales se puede ver que el flujo de personas se da en las áreas públicas como los parques de las urbanizaciones, siento estos los lugares de descanso para todos los residentes.

O tro punto importante de confluencia de público se da en las zonas comerciales ubicadas en la avenida La Mar. A una cuadra de la avenida Universitaria se asienta una galería comercial cuyo radio se da a nivel distrital. al tener espacio para estacionamientos y un parque cuadra alejada de la zona de estudios.

Los paraderos son un punto a tomar en cuenta ya que la mayoría de personas pasa tiempo en estos lugares esperando el transporte público, y debe tomarse en cuenta que uno de los paraderos se encuentra ubicado en el mismo terreno donde irá ubicada la residencia universitaria.
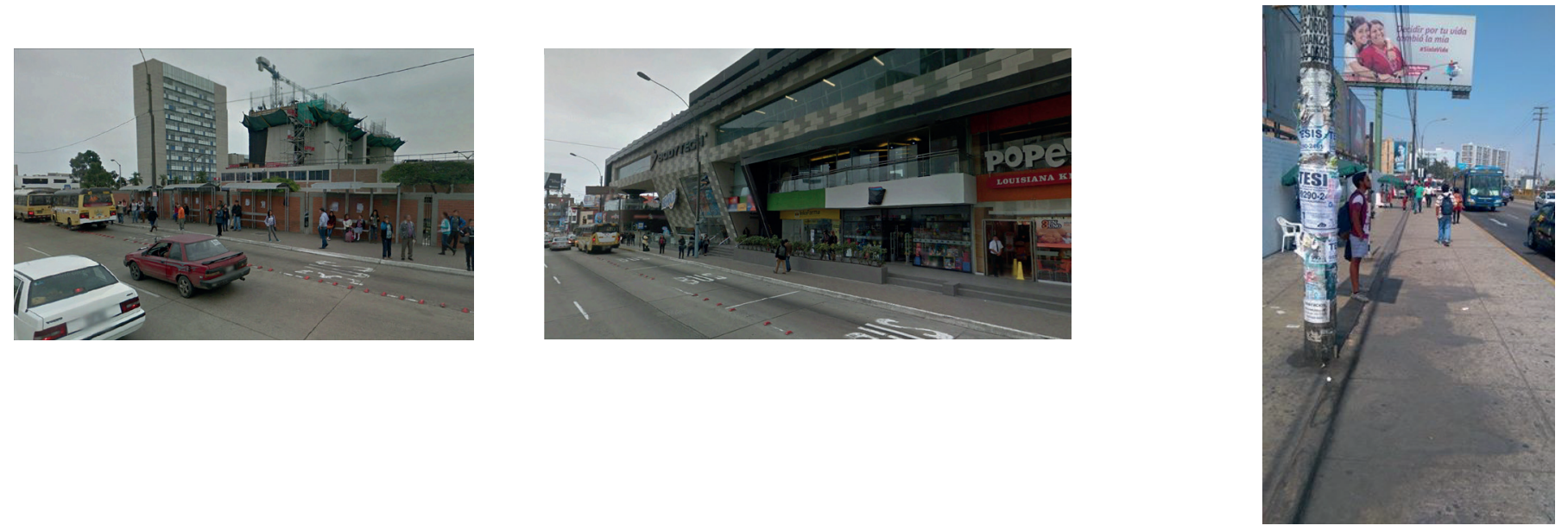

USO DE CICLOVÍAS

Por la ciclovía de la zona aparece una importante ciclovía cuyo recorrido principal se da a lo largo de toda la avenida Universitaria. En esta parte del recorrido se puede apreciar que la ciclovia es de un carril por sentido, y se localiza en la berma central de la avenida, teniendo a los costados porciones de área verde. La ciclovía luego se ramifica por una de las fachadas del terreno, en la avenida Mariano Cornejo, en donde se vuelve más pequena y de un solo sentido.
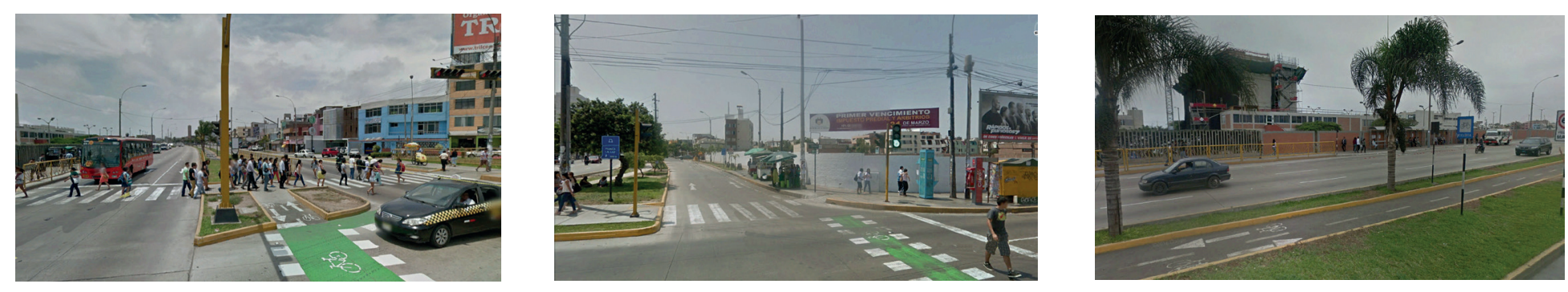

CONCLUSIONES

Podemos concluir que la conglomeración de personas se da en los ingresos a edificaciones instituciones, los paraderos, las áreas públicas y las zonas comerciales. Hay un paradera en el borde del proyecto que puede ser aprovechado. Hay una ciclovía importante que recorre toda la avenida Universitaria y se ramifica en la avenida perpendicular que pasa también por el terreno. Se puede concluir que el terreno
cuenta con todo lo necesario para incentivar el tránsito peatonal y el transporte público y no motorizado de manera que se evite el uso de cuenta con todo lo necesario para incentivar el tránsito peatonal y el transporte público y no motorizado, de manera que se evite el uso de
transporte privado. Al ver flujo de personas en zonas comerciales, es importante integrar una zona comercial al proyecto, ya que al ser un transporte privado. Al ver flujo de personas en zonas comerciales, es importante integrar una zona comercial al proyecto, ya que al ser un área pública, como los parques
la altura de la avenida La Mar. 


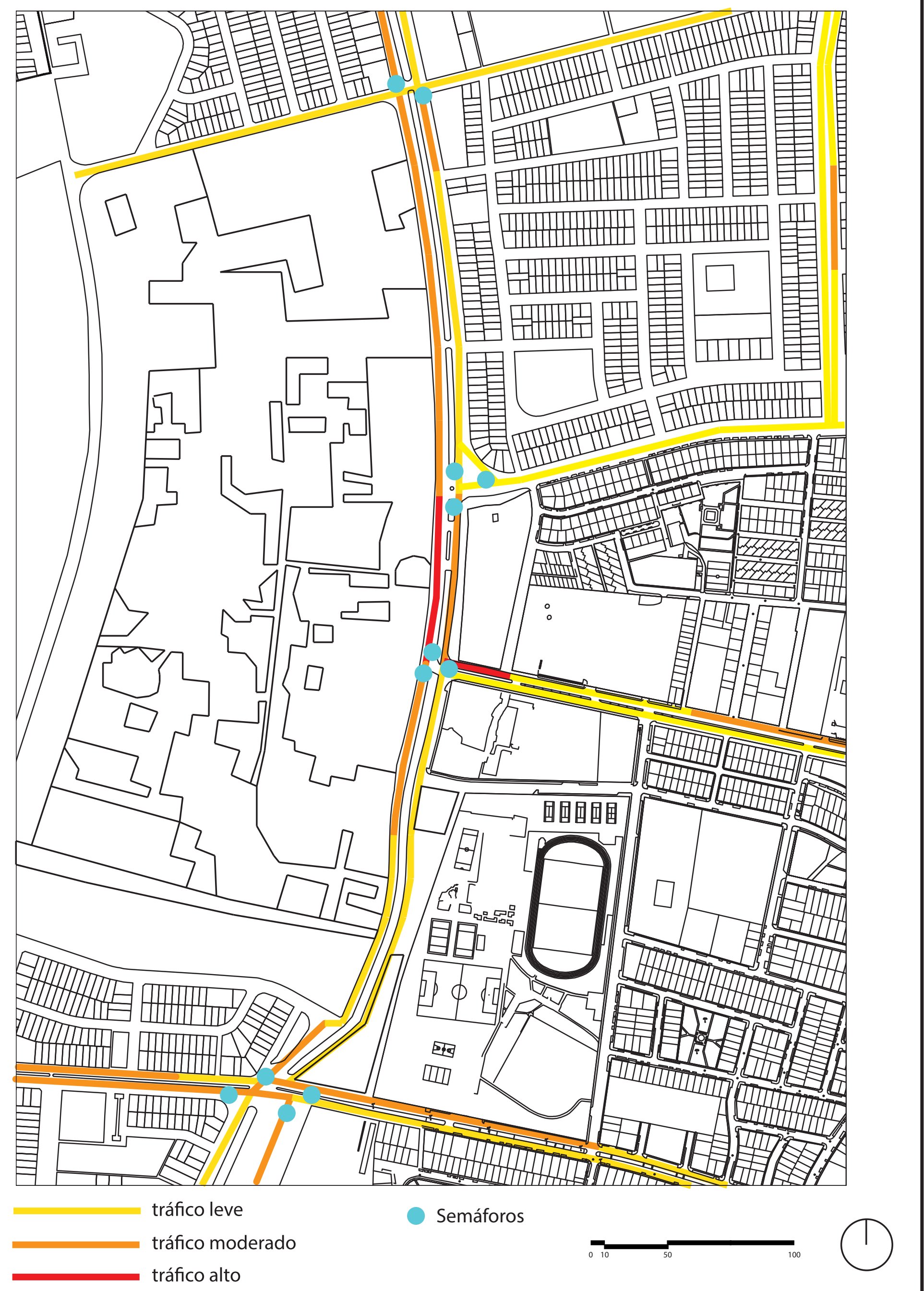

TRANSPORTE PÚBUCO

Las líneas de autobus pasan por las 2 avenidas principales, que son la avenida universitaria y la avenida la Mar, la cual continúa en la avenida Cipriano Dulanto. tienen un recorrido directo y se detienen en los paraderos a lo largo de estas avenidas. Estos autobuses incrementan el tráfico ya que pierden tiempo esperando a los alumnos que salen de la Universidad. Las línas de autobuses solo van hacia la avenida Venezuela, ya que con la implementación del corredor azul, estas solo llegan hasta Plaza San Miguel cuando van en sentido contrario. La línea del corredor azul que transita por ambas avenidas es la 209.
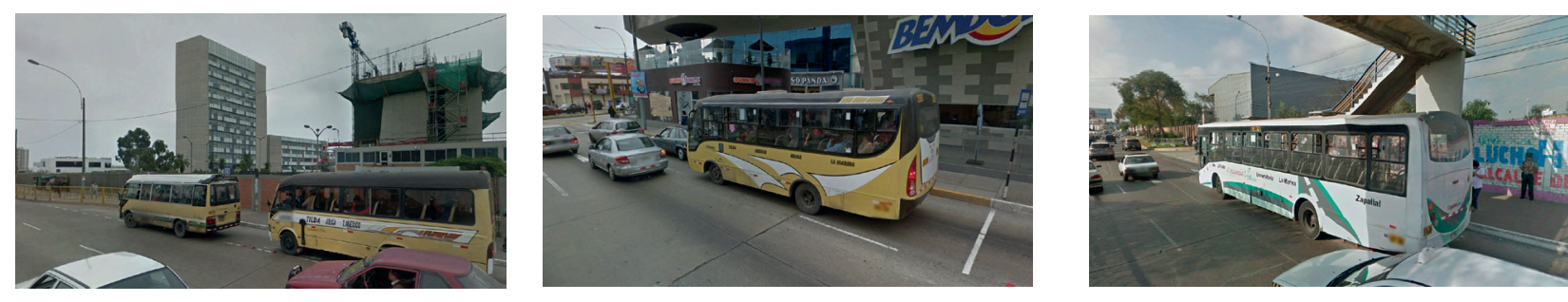

TRÁFICO

La mayor cantidad de tráfico se encuentra concentrada en la entrada de la PUCP, a lo largo de la avenida Universitaria, en las 3 horas puntas $(7 \mathrm{am}, 1 \mathrm{pm}, 6 \mathrm{pm})$. La avenida La Mar con Cipriano Dulanto presenta tráfico moderado debido a que es una zona comercial. El resto de avenidas presentan un tráfico fluido y es posible movilizarse rápidamente a través de estas calles.

\section{PARADEROS}

Hay pocos paraderos en la zona de estudio, el primero se encuentra en la parte superior de la PUCP, al frente, el cual sirve en su mayoría para la gente que vive en la urbanización del costado. El segundo paradero, el más usado, se ubica en el ingreso de la PUCP, el cual es usado por todos los estudiantes y demás personas que transitan por la zona. También hay un paradero al frente, al llegar al terreno del proyecto, para los autos que van en sentido contrario. Antes de llegar al puente que está al sur de la PUCP, hay un paradero para los alumnos de Idiomas Católica. El último paradero visible es el que se encuentra en la plaza de comidas " $\mathrm{D}$ 'Paso", para seguir su recorrido por la avenida La Mar.

SEMÁFOROS

Los Semáforos se encuentran ubicados en los cruces de avenidas importantes y en los cruces con edificios o instituciones importantes como la PUCP o el edificio de El Comercio. Ayudan a regular el tráfico de la avenida Universitaria la cual cuenta con el mayor índice de tráfico en la zona.
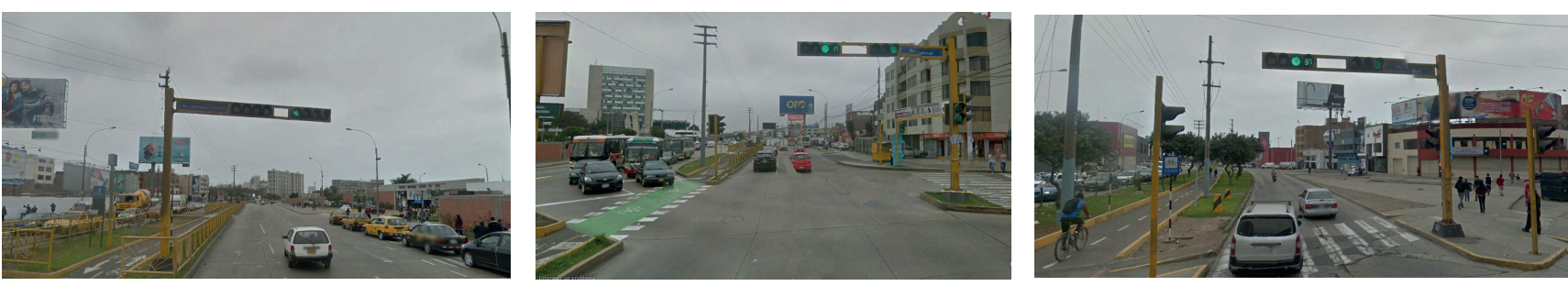

CONCLUSIONES

Il terreno se encuentra ubicado frente al ingreso principal de la PUCP, lugar donde se concentra la mayor cantidad de tráfico en hora punta, por lo cual es importante realizar un diseño en base a la contaminación sonora que se presenta con un adecuado tratamiento de fachadas y del terreno, aprovechando también los frentes donde la circulación es fluida para realizar el emplazamiento del estacionamiento. El terreno se encuentra ubicado en una zona equidistante a los lugares mas importantes de la zona, por lo que incentiva al tránsito peatonal y a uso de la ciclovía, además del paradero que se encuentra frente a una de las fachadas. 


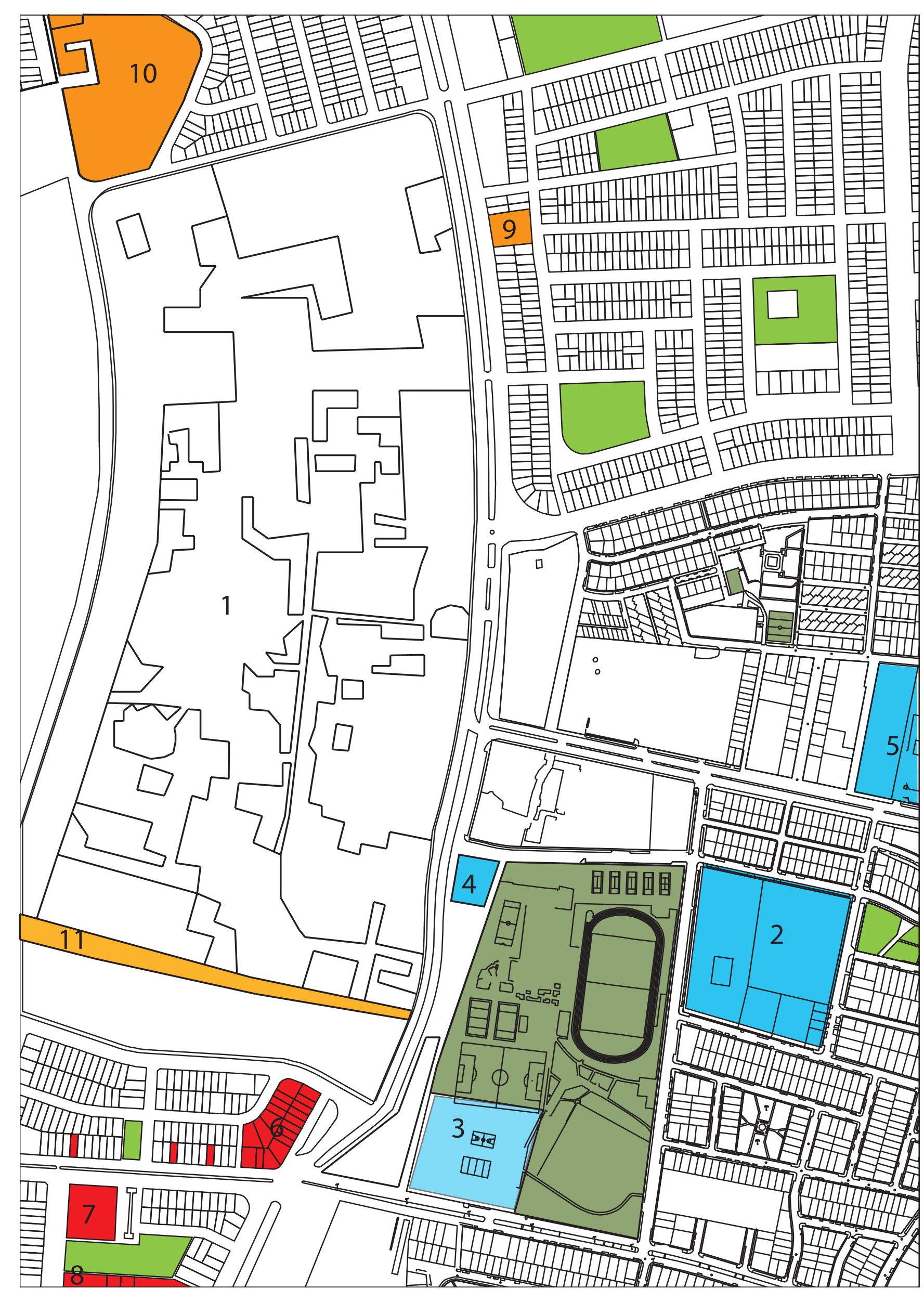

1. PONTIFICIA UNIVERSIDAD CATÓLICA DEL PERÚ $243115.0235 \mathrm{~m}^{2}$

INSTITUCIONES EDUCATIVAS

2. COLEGIO CRISTO REY

$12847.4109 \mathrm{~m}^{2}$

3. COLEGIO LA UNIÓN

$6289.8603 \mathrm{~m}^{2}$

4. IDIOMAS CATÓLICA

$1135.0196 \mathrm{~m}^{2}$

5. UNIVERSIDAD INCA GARCILASO DE LA VEGA $10119.4750 \mathrm{~m}^{2}$

Se puede ver que hay 5 instituciones educativas en la zona de estudio todas ubicadas en la parte inferior exceptuando la PUCP. Esto nos indica la gran demanda de estudiantes que se movilizan por este lugar, la mayor cantidad pertenecientes a la PUCP. Esta es una de las razones por las cuales una residencia universitaria sería viable en el lugar, encontrándose el terreno en el medio de todas estas instituciones. Estos centros de estudio se ubican a pocas cuadras entre sí, por lo que es accesible ir a pie.

\section{ÁREAS COMERCIALES \\ 6. AREA COMERCIAL D'PASO $2952.9545 \mathrm{~m}^{2}$}

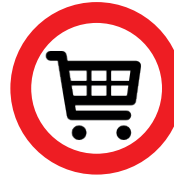

7. GALERÍA COMERCIAL $3063.1824 \mathrm{~m}^{2}$

8. PLAZA SAN MIGUEL $22541.7841 \mathrm{~m}^{2}$

La concentración de zonas comerciales se ubica al sur de la PUCP y del terreno. la primera área comercial es un conjunto de restaurantes donde la gente se dirige a almorzar en la mayoria de los casos. La segunda área comercialse encuentra en la avenida la mar, la cual es una galería comercial, el cual tiene un radio de influencia distrital. Por último se encuentra la Plaza San Miguel el cual tiene un radio de influencia a nivel metropolitano y atrae a una gran cantidad de personas. El proyecto se encuentra en una posicion privilegiada ya que el público objetivo se encontraría cerca de todo lo necesario durantesu tiempo de estadía.

MONUMENTOS ARQUEOLÓGICOS

9. MONUMENTO ARQUEOLOGICO
$2952.9545 \mathrm{~m}^{2}$
10. MONUMENTO ARQUEOLÓGICO
931.6134m²
11. ZONA ARQUEOLÓGICA PUCP
$4848.9946 \mathrm{~m}^{2}$

Hay 3 monumentos arqueológicos ubicados en la zona. El primero se encuentra en la avenida universitaria, el cual está cercado, el segundo arriba de la PUCP, y el tercero dentro de esta universidad, por lo que se encuentra en una zona privada.Si bien estos monumentos arqueológicos o huacas no atraen gente, son patrimonios importantes a tomar en cuenta en el análisis. 


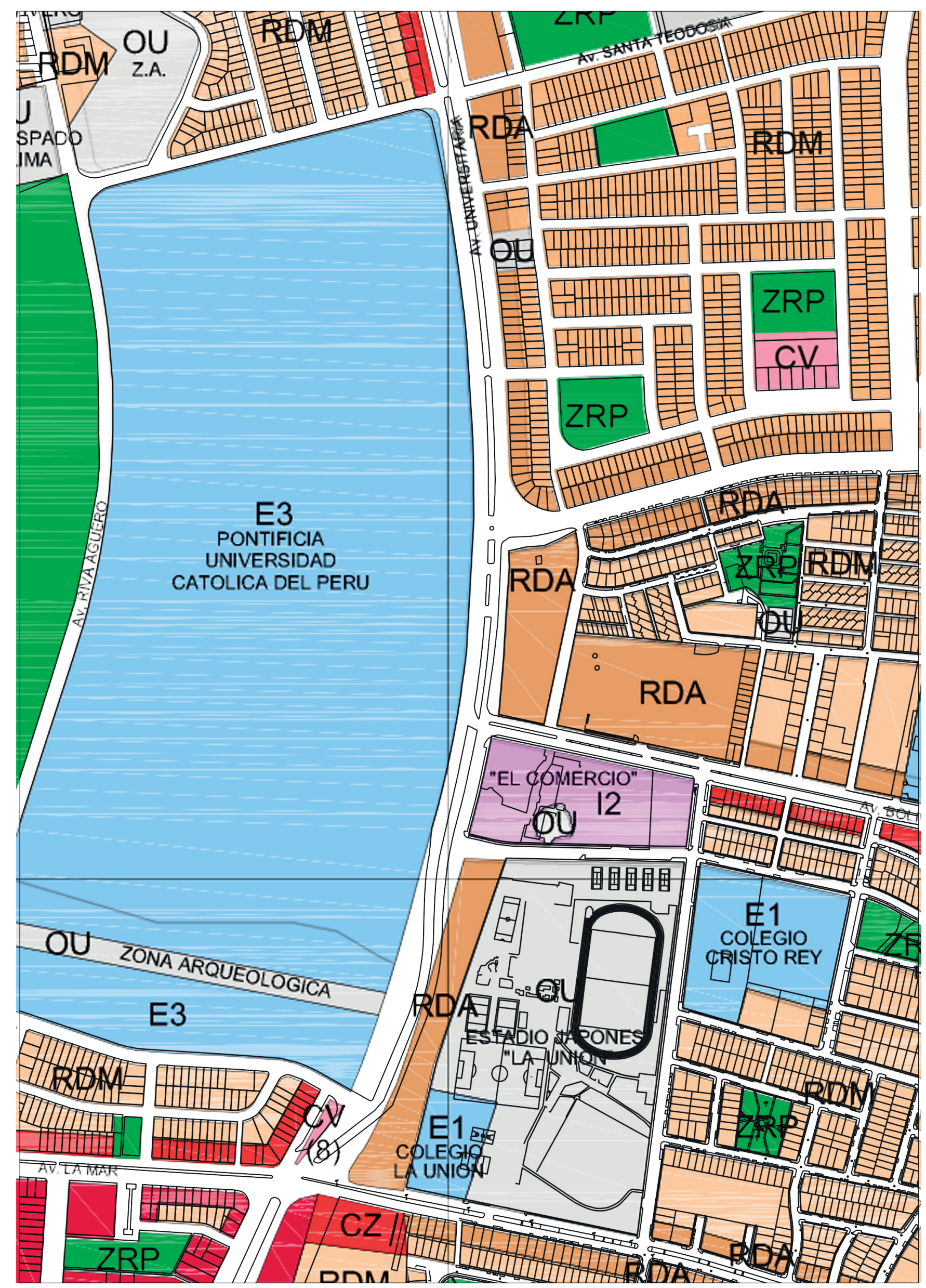

ZONAS RESIDENCIALES

ZONAS INDUSTRIALES

$\square$ RDM Residencial de Densidad Modia $\square$ " Industria Elementaly C Complementaraia

RDA Residencial de Densidad Alla
ZONAS RESIDENCIALES

ZONA VIVIENDA TALLER

The

ZONA RESIDENCIA DE ALTA DENSIDAD:

Es el uso identificado con las vivienndas o residencias tratadas en conjunto que permiten la obtención de una alta concentración poblacional.

ZONA RESIDENCIAL DE MEDIA DENSIDAD:

Es el uso identificado con las viviendas o residencias tratadas individualmente o en conjunto que permiten la oobtención de una concentración poblacional media, a través de undades de vivienda bifamiliares o unifamiliares.

ZONA RESIDENCIAL DE BAJA DENSIDAD:

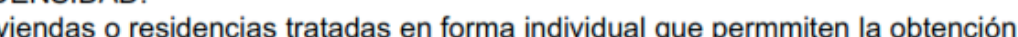
de baja concentración poblacional a través de viviendas unifamiliares.

\begin{tabular}{|c|c|c|c|c|c|c|}
\hline \multicolumn{7}{|c|}{$\begin{array}{l}\text { AREA DE TRATAMIENTO NORMATIVO I" } \\
\text { CUADRO No 01: RESUMEN DE ZONIFICACION RESIDENCIAL }\end{array}$} \\
\hline \multicolumn{7}{|c|}{ ZONIFICACION RESIDENCIAL } \\
\hline ZONIFICACION & usos & $\begin{array}{l}\text { LOTE } \\
\text { MINIMO }\end{array}$ & $\begin{array}{l}\text { FRENTE } \\
\text { MINIMO }\end{array}$ & $\begin{array}{l}\text { ALTURA DE } \\
\text { EDIFICACION }\end{array}$ & $\begin{array}{l}\text { AREA } \\
\text { LIBRE }\end{array}$ & $\begin{array}{l}\text { ESTACIONAMIENTO } \\
\text { MINIMO }\end{array}$ \\
\hline \multirow{5}{*}{$\begin{array}{l}\text { RESIDENCIAL } \\
\text { DE DENSIDAD } \\
\text { MEDIA }\end{array}$} & $\begin{array}{l}\text { UNIFAMILIAR } \\
\text { MULTIFAMILIAR }\end{array}$ & $\begin{array}{l}120.00 \mathrm{~m} 2 \\
120.00 \mathrm{~m} 2\end{array}$ & $\begin{array}{l}6.00 \mathrm{ml} \\
6.00 \mathrm{ml}\end{array}$ & $\begin{array}{l}3 \text { PISOS } \\
3 \text { PISOS }\end{array}$ & $\begin{array}{l}30 \% \\
30 \%\end{array}$ & 1 CADA $1.5 \mathrm{VIV}$. \\
\hline & MULTIFAMILIAR & $150.00 \mathrm{~m} 2$ & $8.00 \mathrm{ml}$. & $\begin{array}{l}4 \text { PISOS } \\
5 \text { PISOS (1) }\end{array}$ & $35 \%$ & 1 CADA $1.5 \mathrm{VIV}$. \\
\hline & MULTIFAMILIAR & $200.00 \mathrm{~m} 2$ & $10.00 \mathrm{ml}$. & $\begin{array}{l}5 \text { PISOS } \\
6 \text { PISOS (1) }\end{array}$ & $35 \%$ & 1 CADA $1.5 \mathrm{VIV}$. \\
\hline & MULTIFAMILIAR & $300.00 \mathrm{~m} 2$ & $10.00 \mathrm{ml}$ & $\begin{array}{l}6 \text { PISOS } \\
7 \text { PISOS (1) }\end{array}$ & $35 \%$ & 1 CADA $1.5 \mathrm{VIV}$. \\
\hline & CONJUNTO RES. & $1600.00 \mathrm{~m} 2$ & $20.00 \mathrm{ml}$. & 8 PISOS & $40 \%$ & 1 CADA $1.5 \mathrm{VIV}$. \\
\hline $\begin{array}{l}\text { VN. -TALLER } \\
\text { VT }\end{array}$ & $\begin{array}{l}\text { UNIFAMILIARY } \\
\text { MULTIFMLLAR }\end{array}$ & $180.00 \mathrm{~m} 2$ & $8.00 \mathrm{ml}$. & $3 \mathrm{PISOS}_{(2)}$ & $35 \%$ & 1 CADA $1.5 \mathrm{VIV}$. \\
\hline \multirow{3}{*}{$\begin{array}{l}\text { RESIDENCIAL } \\
\text { DE DENSIDAD } \\
\text { ALTA } \\
\text { RDA }\end{array}$} & MULTIFAMILIAR & $300.00 \mathrm{~m} 2$ & $10.00 \mathrm{ml}$ & 8 PISOS & $35 \%$ & 1 CADA $1.5 \mathrm{VIV}$. \\
\hline & MULTIFAMILIAR & $450.00 \mathrm{~m} 2$ & $10.00 \mathrm{ml}$. & $1.5(a+r)(3)$ & $40 \%$ & 1 CADA $1.5 \mathrm{VIV}$. \\
\hline & CONJUNTO RES. & $2500.00 \mathrm{~m} 2$ & $25.00 \mathrm{ml}$. & $1.5(\mathrm{a}+\mathrm{r})$ & $50 \%$ & 1 CADA 1.5 VIV. \\
\hline
\end{tabular}

(1) Frente a Parques y Avenicas con ancho mayor a $20 \mathrm{~mm}$

(a)

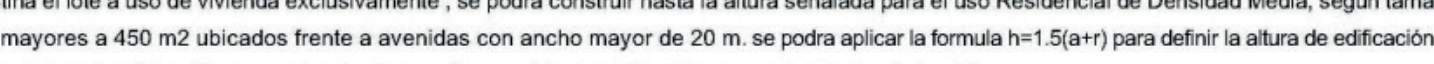

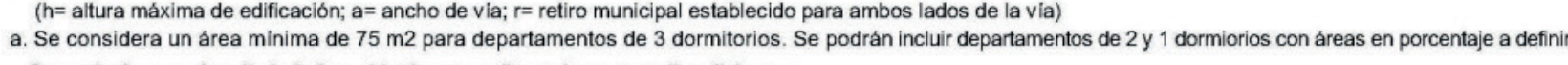
Se contara como dormitorio todo ambiente cuyas dimensiones permitan dicho uso

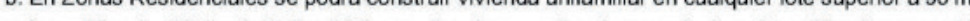

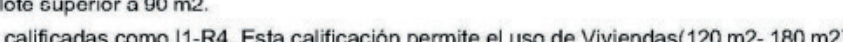
y/o talleres $(150 \mathrm{~m} 2$ - $180 \mathrm{~m} 2)$ segun el indice de Usos y los Niveles Operacionales.

En Zona de Vivienda Taller se permititr la la permanencia de aquellos establecimientos exclusivamente industriales que actualmente existen, los cuales deberán
adeccuarse a las condiciones de funcionamiento y plazos que se definan para tal fetecto. No se permitiran nuevos establecimientos industriales.

\section{ZONAS DE EQUIPAMIENTO}

ZONA DE REGLAMENTACIÓN ESPECIAL:

作 posibiliten un tratamiento a través de progrmas específicos de renovación o rehabilitación urbana.

ZONA RECREACIONAL:

Es la zona en la que se permite el uso recreacional activo y/o pasivo.

Equipamiento recreacional tales como:

Jardines

Lagunas

Bosques
Piscinas

Juegos Infantiles

Se permitirá la instalación de locales complementarios para todo estos usos. 


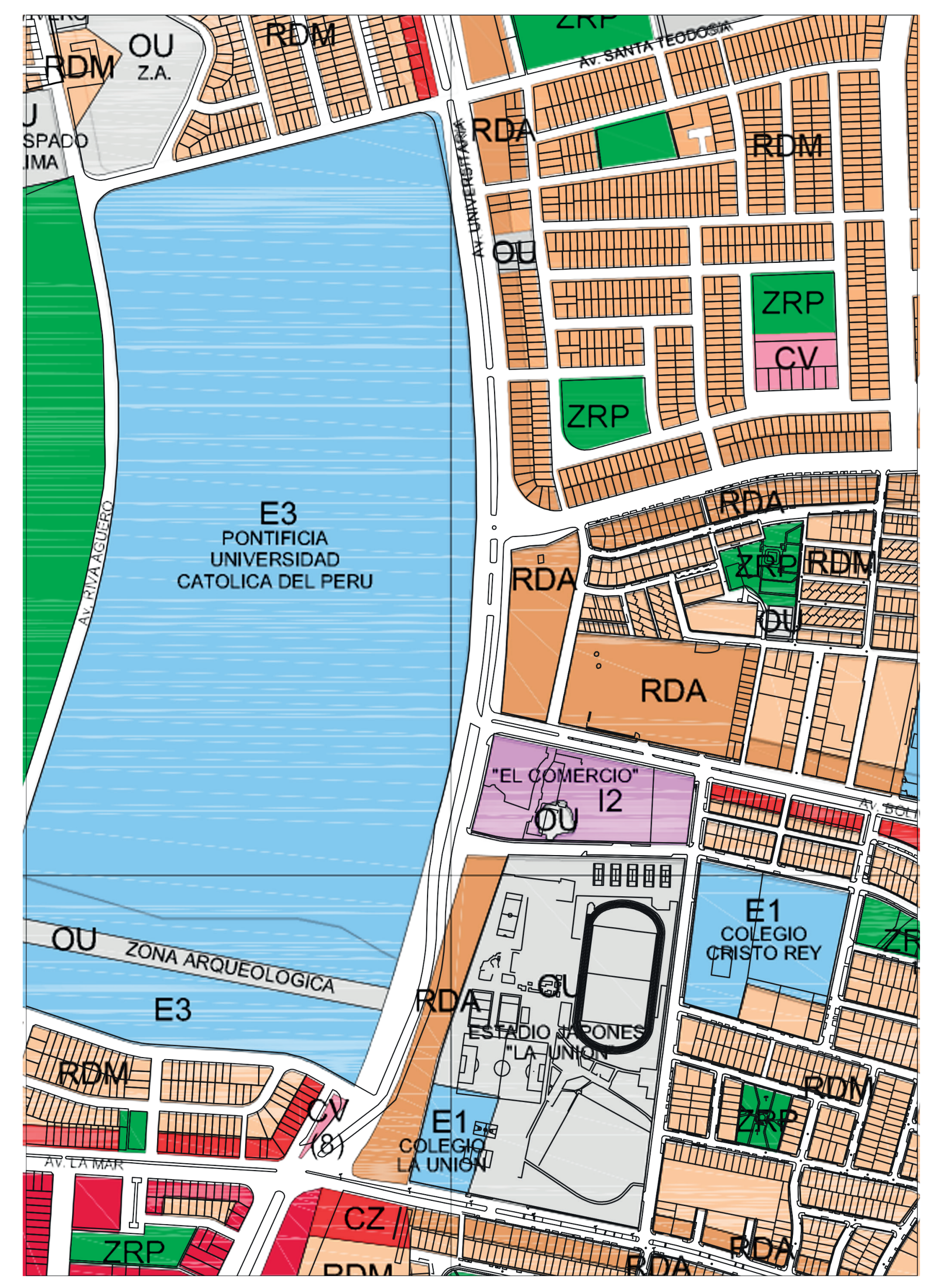

ZONAS COMERCIALES

$\begin{array}{cc}\text { cv } & \text { comercio vecinal } \\ \text { cz } & \text { comercio zonal }\end{array}$ ZONAS DE EQUIPAMIENTO

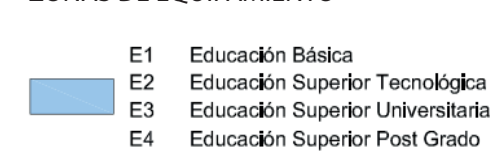

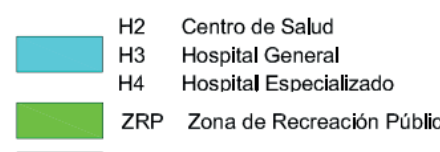

$\square$ ou otros Usos
ZONAS COMERCIALES

ZONA COMERCIO METROPOLITANO: Es el conjunto comercial en el que los establecimientos por su importancia y localización responden a las
necesidades y los recursos de la población metropolitana y su región. Incluye a la mayoría de los servicios comerciales.

ZONA COMERCIAL ZONAL:

Es el tipo de comercio en forma nucleada, en los puntos de intersección de vías importantes, se da en la periferia de los centros comerciales interdistritales. La caracteristica fundamental de este tipo de comercio está dado por
el grado de especialización comercial en función de las áreas de servir: áreas residenciales, áreas industriales. ZONA COMERCIO VECINAL

Es el tipo de comercio destinado a ofrecer bienes de consumo diario especialmente alimentos y articulos o

La cantidad de población a nivel de barrio, a la cual sirve, está comprendida entre 2,500 a 7,500 habitantes, dentro de un radio de influencia de 200 a 400 metros.

\begin{tabular}{|c|c|c|c|c|c|c|}
\hline \multicolumn{7}{|c|}{$\begin{array}{l}\text { CUADRO N 02: RESUMEN DE ZONIFICACION COMERCIAL } \\
\text { AREA DE TRATAMIENTO \| }\end{array}$} \\
\hline & ZONA & \begin{tabular}{l|l} 
ALTURADE \\
EDIFICACION
\end{tabular} & $\begin{array}{l}\text { ISO RESIDENCIAL } \\
\text { COMPATIBLE }\end{array}$ & $\begin{array}{l}\text { TAMAÑO DE } \\
\text { LOTE }\end{array}$ & AREA LIBRE & ESTACIONAMIENTO \\
\hline & $\begin{array}{l}\text { COMERCIO } \\
\text { MEIROPOLITANO }\end{array}$ & $1.5(a+c)$ & RDA & $\begin{array}{l}\text { EXISTENTE O } \\
\text { SEGUN PROYECTO }\end{array}$ & \multirow{3}{*}{$\begin{array}{l}\text { NO EXIGIBLE PARA USO } \\
\text { COMERCIAL } \\
\text { LOS PISOS DESTINADOS A } \\
\text { VIVIENDA DEJARAN EL AREA } \\
\text { LIBRE QUE SE REQUIERE } \\
\text { SEGUN EL USO RESIDENCIAL } \\
\text { COMPATIBLE }\end{array}$} & $\begin{array}{l}\text { 1 CADA } 50 \text { M2 } \\
\text { (2) }\end{array}$ \\
\hline$c z$ & COMERCIO ZONAL & $1.5(a+r)$ & $R D A-R D M$ & $\begin{array}{l}\text { EXISTENTE O } \\
\text { SECOUN PROYECTO }\end{array}$ & & $\begin{array}{l}1 \text { CADA } 50 \mathrm{MR} \\
\text { (2) }\end{array}$ \\
\hline CV & COMERCIO VECINAL & 5 PISOS & RDM & $\begin{array}{r}\text { EXISTENTE O } \\
\text { SEGUN PROYECTO }\end{array}$ & & $\begin{array}{l}1 \text { CADA } 50 \mathrm{M} 2 \\
(2)\end{array}$ \\
\hline
\end{tabular}

(1) Se permitirá hasta 6 pisos de altura en lotes mayores de $200 \mathrm{~m} 2$ ubicados frente a Avenidas con ancho mayor a $20 \mathrm{ml}$. (2) Las Municipalidades Distritales podrán definir requerimintos de estacionamiento distintos al señalado en el presente cuadro para su ratificación por la Municipalidad Metropolitana de Lima.

NOTAS

a. Se permitirá utilizar hasta el $100 \%$ del área de los lotes comerciales, para uso residencial, aplicando los parámetros urbanisticos y edificatorios que le corresponden de acuerdo con la Zonificación Residencial compatible.

b. El requerimiento de estacionamiento para establecimiento especiales se regira por lo señalado en las Especificaciones Normativas.

ZONAS DE EQUIPAMIENTO

USOS ESPECIALES:

Son otros usos diferentes establecidos, tales como:

Centro Administrativo

Centro Deportivo (espectáculo)

Se incluyen asimismo bajo esta denominaton los siguientes servicios pabros cons.

Establecimientos para fines $d e$

Eagares publicos (asilos, orfelinatos)

Estacionamientos para fines religios

Campos deportivos (recreación actios)

Establecimientos educacionales 


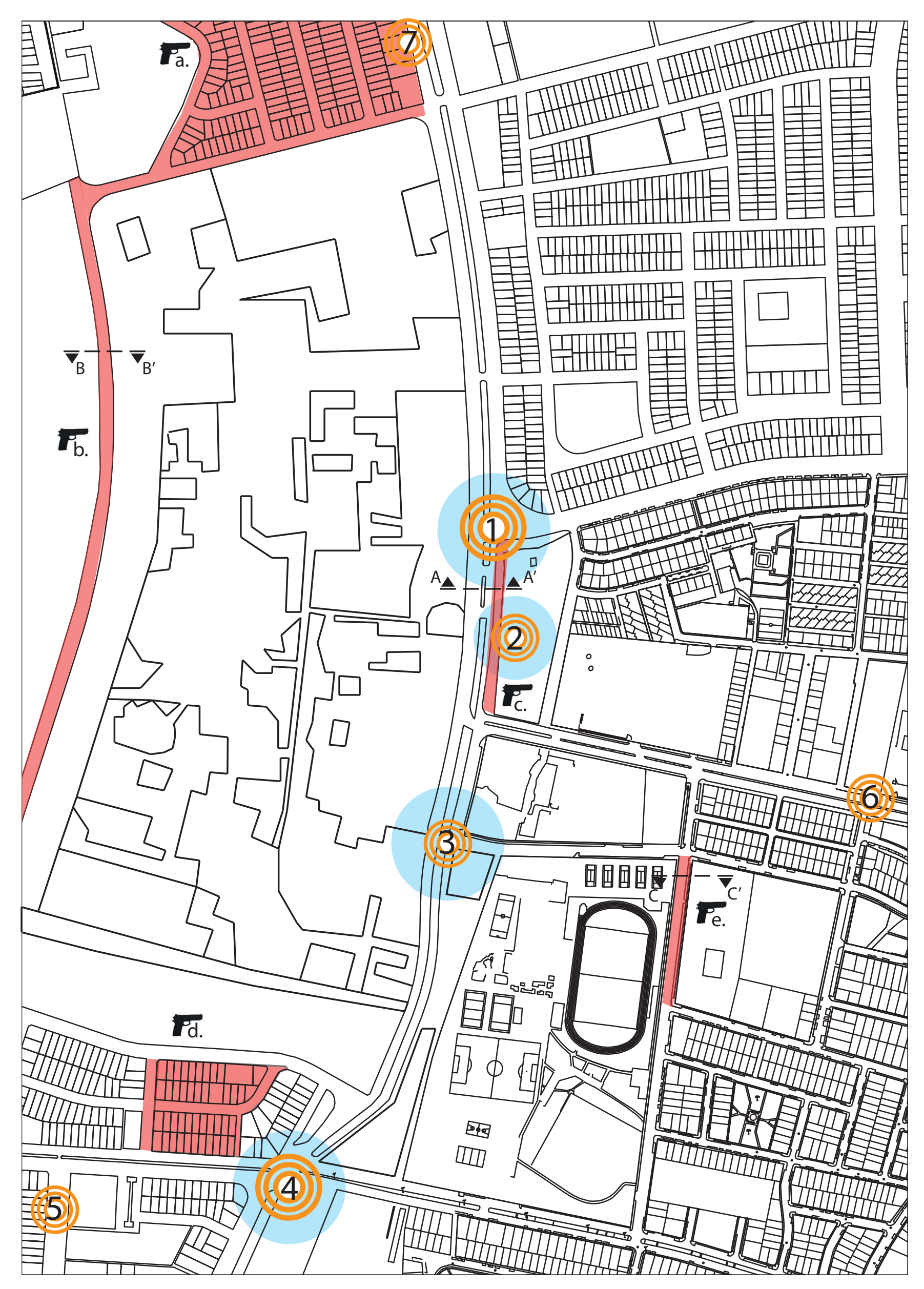

(a)

CONTAMINACIÓN SONORA

1. Este es uno de los puntos donde se genera una gran cantidad de contaminación sonora en la zona de estudio. Esto es debido a la cantidad de transporte que pasa por la zona, sobretodo el transporte público, ya que algunos se estacionan para esperar pasajeros lo cual ocasiona que los vehiculos de atrás comiencen a tocar el claxon generando mucho ruido. Además este es el punto donde los estudiantes de la PUCP salen de la universidad, quedandose en la entrada a conversar o en los paraderos, lo cual tambien genera cierto grado de bulla.

2. Este lugar que se encuentra al sur del terreno, posee pequeños negocios locales, como talleres de autos, los cuales generan ruido al utilizar la maquinaria para hacer su trabajo.

3. La contaminación sonora generada en esta zona, se da debido al paradero ubicado frente a Idiomas Católica, el cual espera a los estudiantes de esta institución, además de ubicarse antes de llegar a un puente el cual normalmente siempre genera más tráfico y bulla.

4. Cruce de las 2 avenidas principales de la zona de estudio, donde transitan muchos vehículos con semáforos en cada frente. Además de esto, hay un paradero ubicado justo en la zona de comidas "D'Paso" donde también los autos tocan el claxon y generan ruido.

5. Zona comercial a espaldas del Centro Comercial Plaza San Miguel. Es una galería la cual cuenta con área privada de estacionamiento al aire libre, además de tener puestos de venta hacia el exterior, gen rando así acumulación de gente en las afueras y por lo tanto, bullicio.

6. Puerta de ingreso y de salida de la Universidad Inca Garcilaso de la Vega, donde se conglomeran estudiantes además de ser un paradero informal para el transporte público ya que ahi es donde recogen a sus pasajeros.

7. Al igual que el punto 2 , son pequeños negocios comerciales, como talleres, los cuales generan mucho ruido al trabajar.

\section{CONTAMINACIÓN VISUAL}

1. Este nodo y punto de encuentro tanto de vehículos como de estudiantes ocasiona contaminación visual al usuario ya que se ve una zona desordenada y esto se transmite como incomodidad. hay paneles publicitarios en algunas partes de la berma central y en algunos lotes de alrededor.

2. La calle detrás del terreno que se encuentra aislada de la avenida Universitaria mediante una berma es una visual desagradable ya que la calle es sucia y no esta ordenada, además de que los pequeños negocios locales son todos desordenados y nodan la confianza de andar seguros por la zona.

3. Contaminación visual al salir o transitar cerca a Idiomas Católica, ya que lo que se puede apreciar es una parte de la PUCP la cual es un muro ciego asi como los costados de Idiomas Católica que se encuentran cercados y no genera seguridad caminar por esta zona. Otra punto que malogra la visual del lugar es la presencia del paradero con las líneas de transporte público las cuales se detienen antes de llegar al puente.

4. Cruce de las avenidas principales con muchos anuncios publicitarios los cuales ensucian la trama y perfil urbano. Hay mucho vehículos los cuales tambien transitan en diagonal, generando tráfico y una visual desordenada a nivel peatonal.

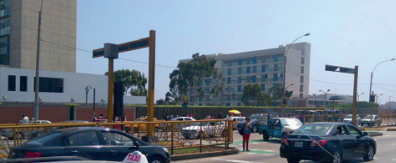 $\Gamma \rightarrow$}
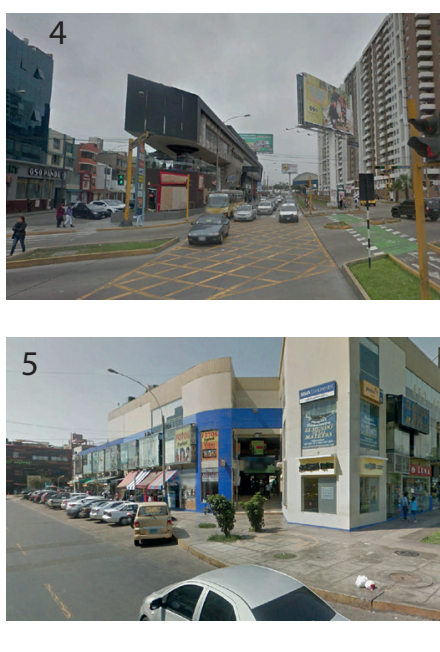

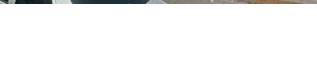




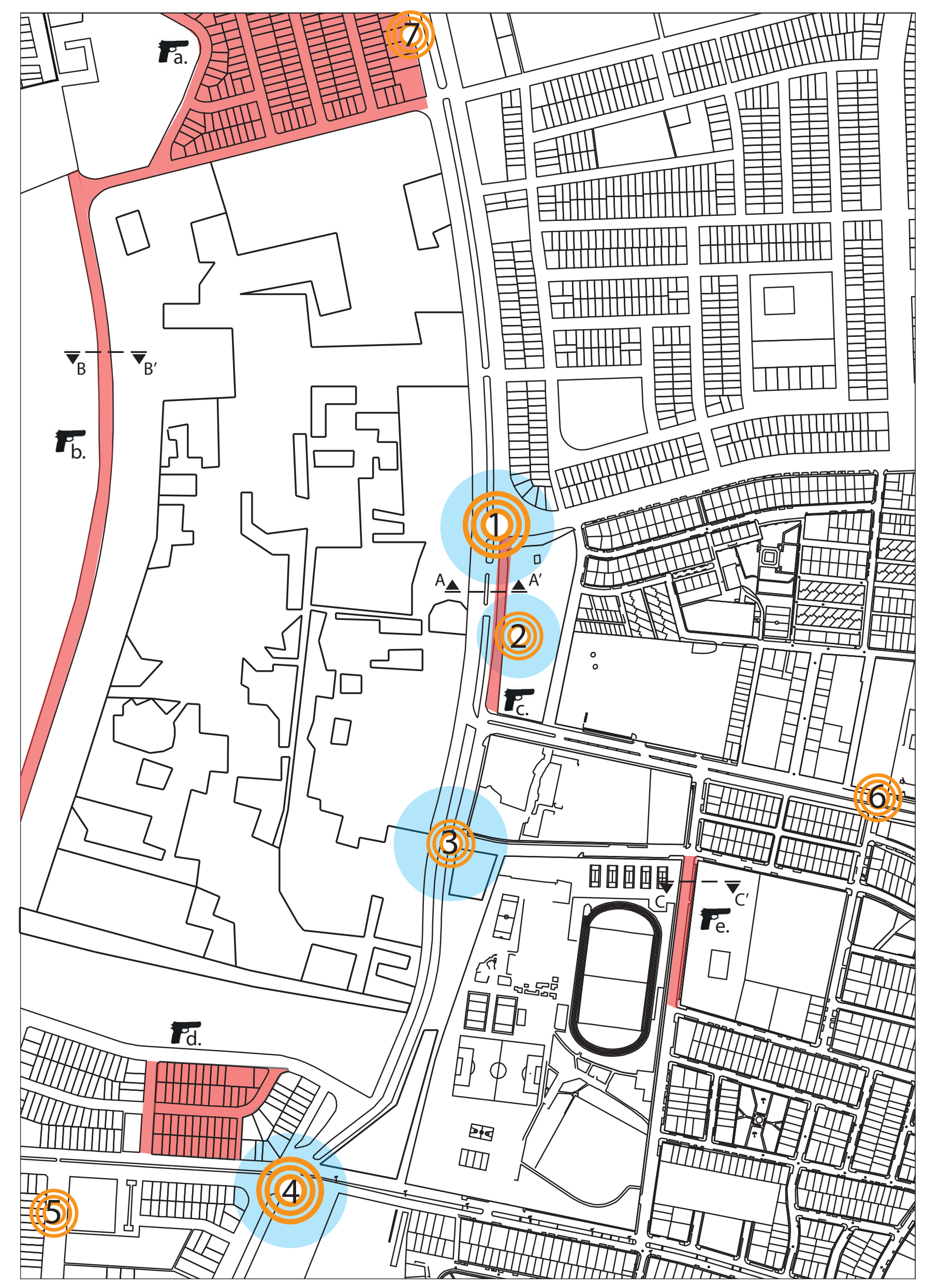

ZONAS DE INSEGURIDAD

Lugares en los que debido a la configuración de las calles, o el perfil urbano, se pueden percibir como inseguros. También los puntos indicados en el mapa del delito que están marcados en el mapa. Este análisis no indica que sean zonas de constante robo, pero si lugares potenciales donde podría ocurrir un delito dadas las condiciones del sitio analizado.

a. Esta zona es un poco insegura ya que se encuentra un poco alejada de la avenida principal. Al estar cerca de la huaca, hay muchas calles con muros ciegos que facilitan los robos. En toda esta zona se pueden ver construcciones informales, además de no contar con un retiro frontal, lo que convierte a estas calles en pasadizos y en algunos casos sin salida debido a rejas.

b. Calle muy abierta, con muros para el lado de la PUCP y rejas para el lado del zoológico. al no tener calles intermedias los transeúntes deben desplazarse manera recta lo que facilita los robos en cualquier parte de esta larga calle.

c. Calle retirada del resto de la manzana, lo que genera un espacio peatonal que lleva a distintos negocios locales y desemboca en el terreno del proyecto el cual esta cercado por un muro ciego en su totalidad. La criminalidad en esta calle severícompletanentel cring al proyecto de la nueva residencia universitaria.

d. Limite entre la PUCP y la zona de comidas ubicadas en la avenida Universitaria, es una zona desolada por las noches. Esto se debe al muro de ciego de la PUCP que delimita su zona privada, y a la poca iluminación que hay en la zona.

e. Calle entre el Club La Unión y el colegio Cristo Rey, ambos con muros que hacen la calle muy pequeña y muy poco segura.

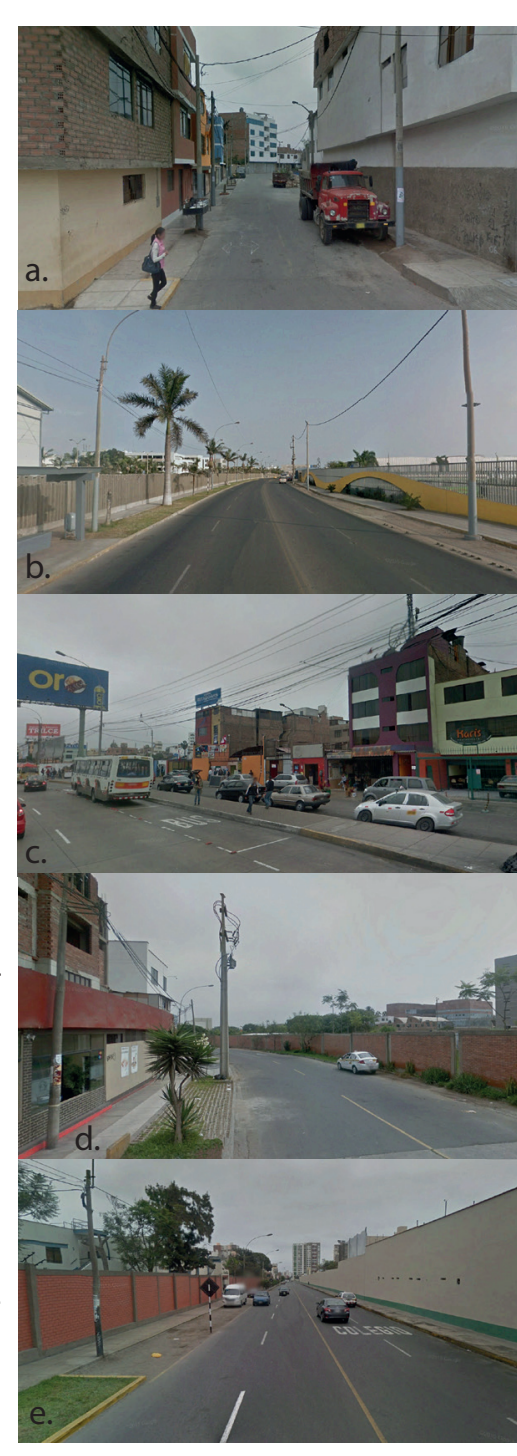

PERCEPCIÓN ESPACIAL

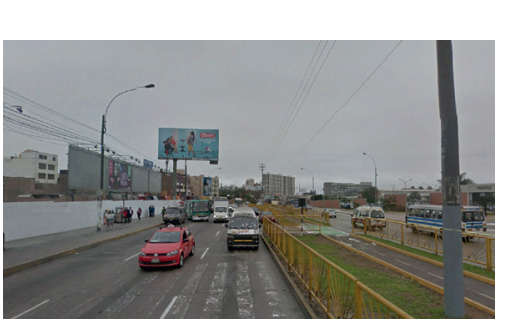

1 CORTE B-B'

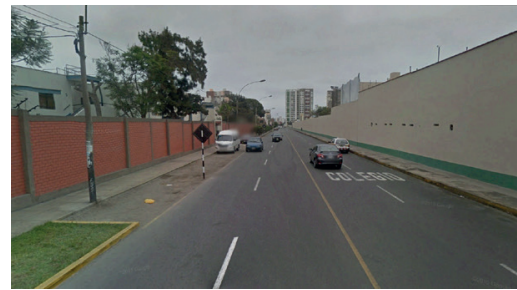

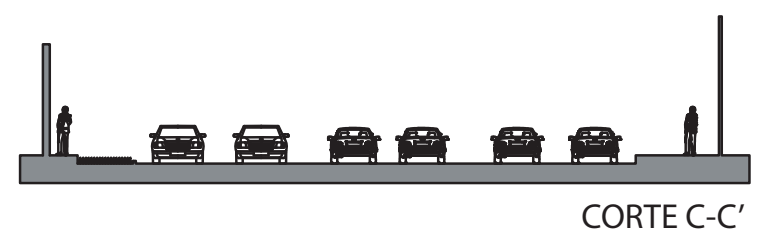

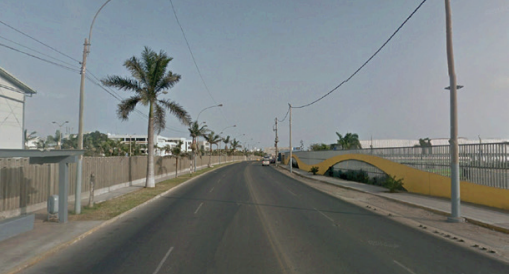




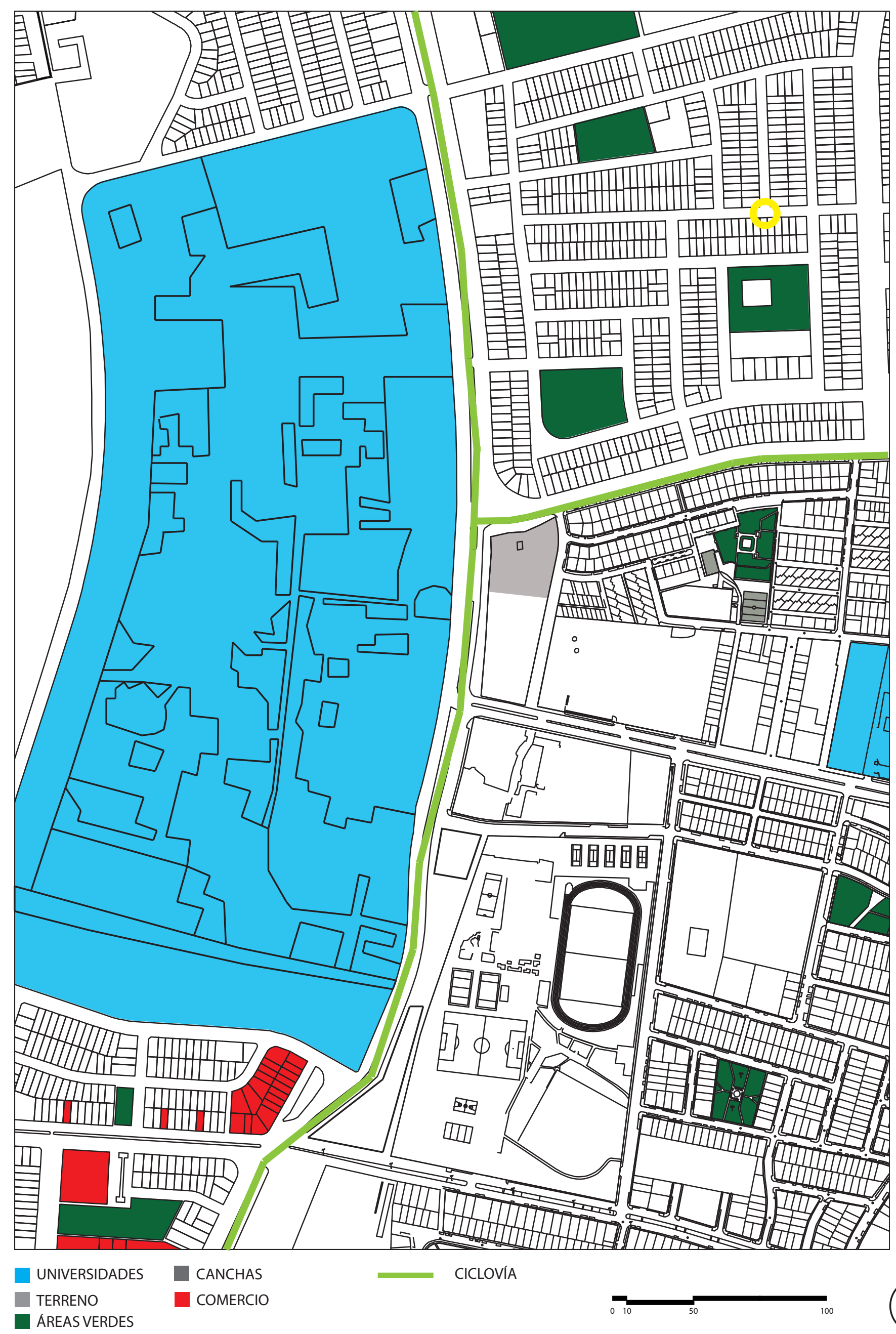

UBICACIÓN

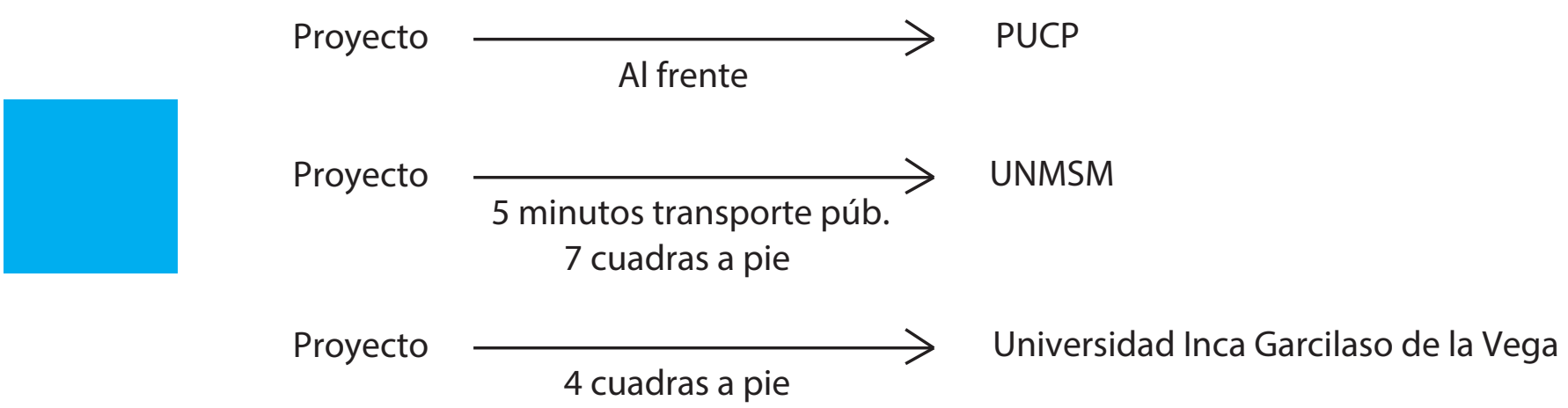

Permite que el público objetivo del proyecto evite el uso del transporte privado, disminyendo así el tráfico, y generando también un ahorro de ingresos

\section{NECESIDAD DE RESIDENCIA}

Casa de estudiantes Santa Susan 15 habitaciones est. nacionales habitaciones est. internacionales

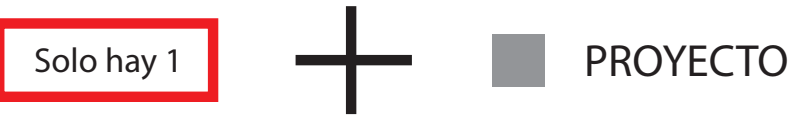

\section{APORTE DE ESPACIO PÚBLICO}

Hay muy poco espacio público para esta zona, por lo que el proyecto generaría un aporte para el lugar al tener 3 frentes disponibles que permiten tratar un espacio público adecuado para todos los residentes de la zona.

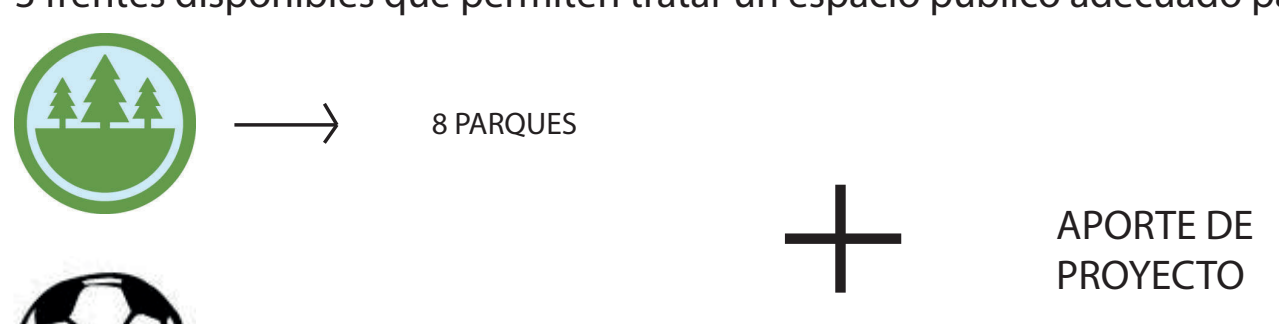

12 ianchasdio

PROYECTO

CICLOVIA

Hay un sistema de ciclovias a lo largo de toda la avenida Universitaria, cuya única ramificación se da en la avenida Mariano Cornejo. Esto nos muestra que la ciclovia recorre dos frentes del proyecto, por lo que puede ser incluído mediante un diseño y propuesta puede ser incluído en el terreno.

$$
\underset{\begin{array}{c}
\text { ciclovía para estudiantes } \\
\text { de la residencia }
\end{array}}{\longrightarrow}
$$

COMERCIO

Área de comercio en la parte sur de

la zona estudiada, incluye centro

comercial de influencia metropolitana.

APORTE COMERCIAL DEL PROYECTO que tenga un radio de influencia barrial, de manera que no compita con la zona sur. 


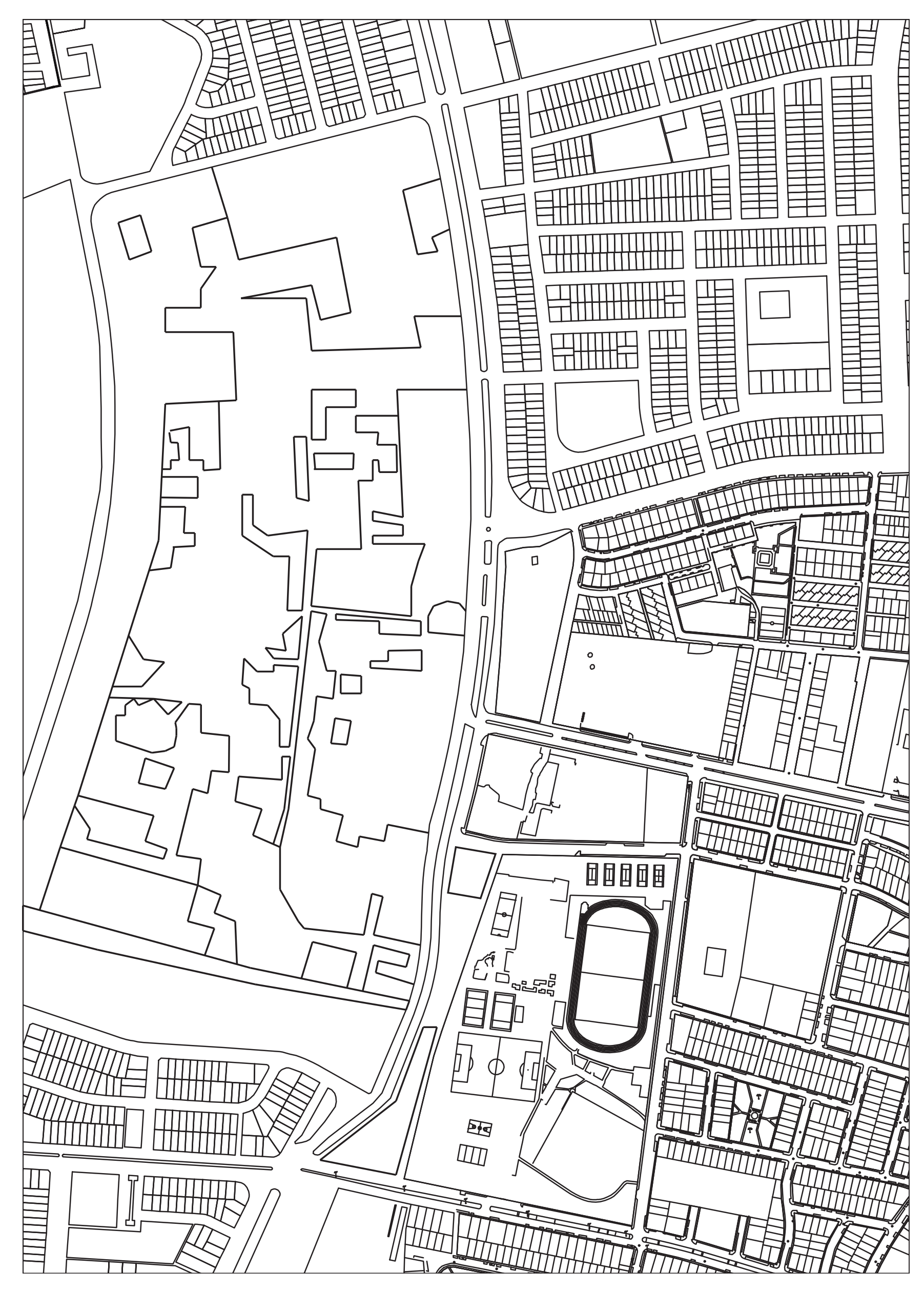

El terreno pertenece a Edelnor, una empresa eléctrica privada que cuenta con una
subestación en la parte norte del terreno, por lo que esta zona no debería manipu-
larse. De todas maneras, el terreno es lo suficientemente grande como para ceder
esta parte. 


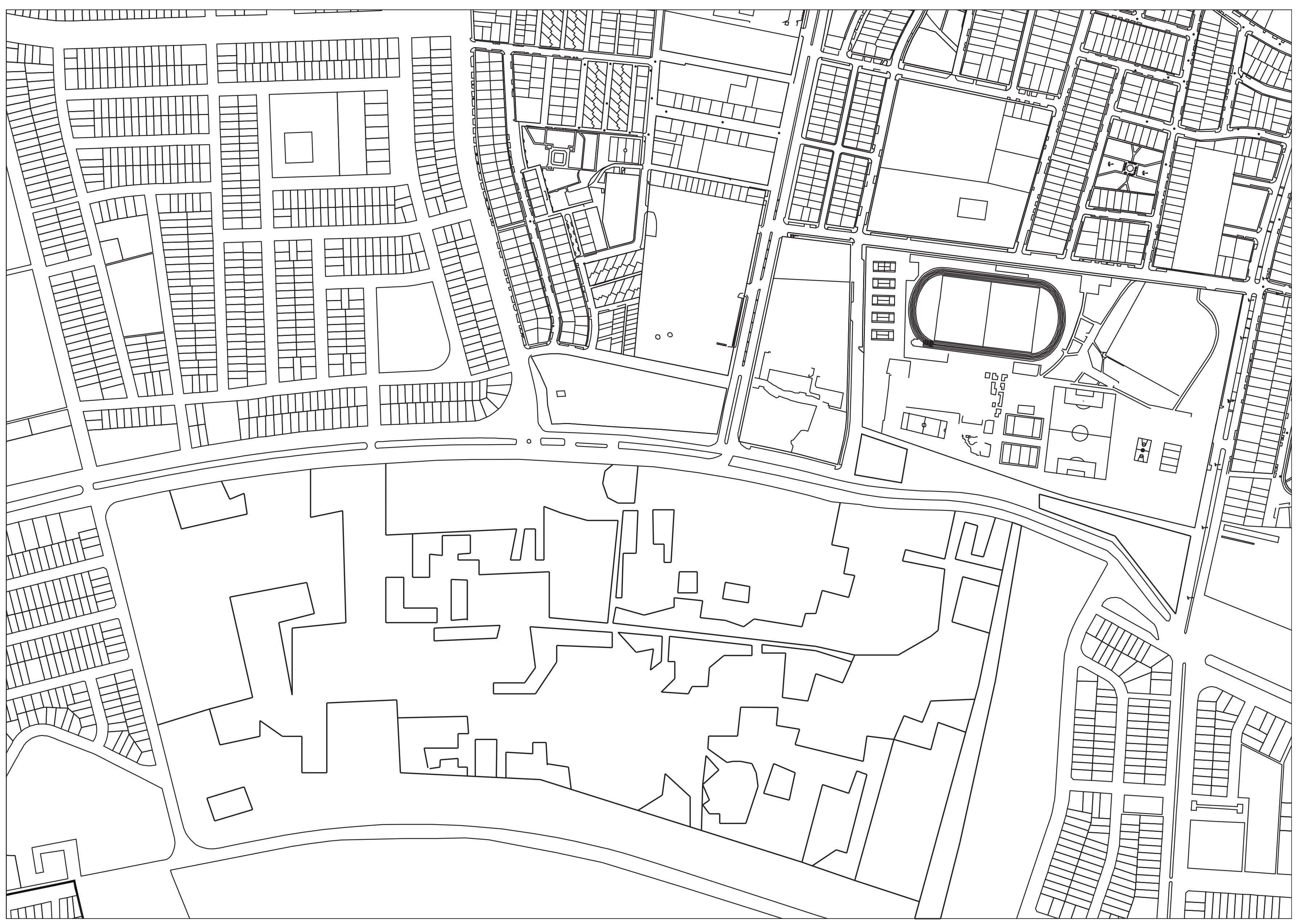




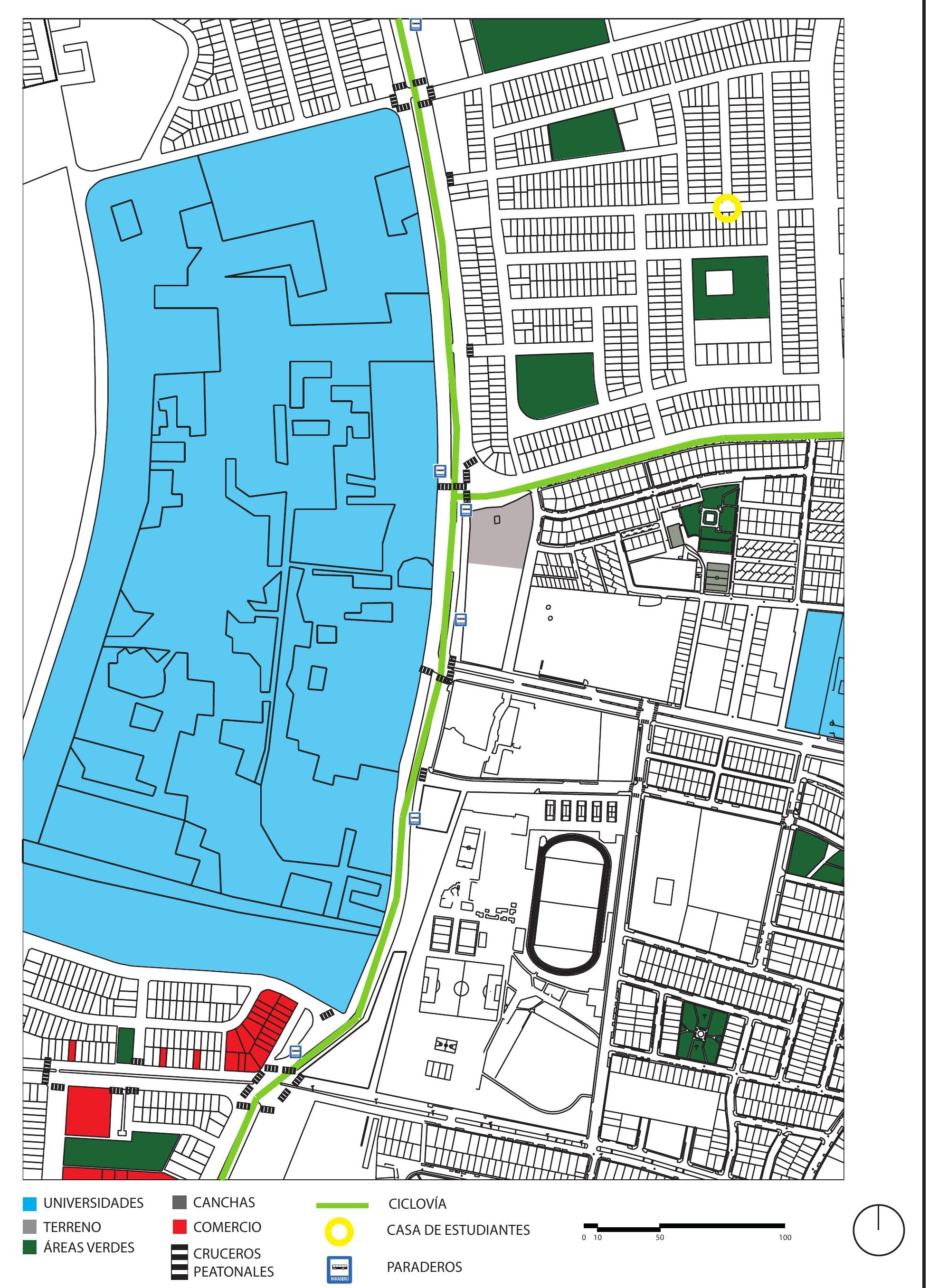

CONCLUSIONES

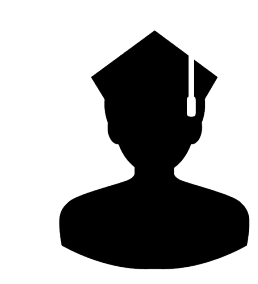

Zona con muchos estudiantes de distintas universidades e institutos

○血

No hay casas de estudio suficientes para suplir demanda de estudiantes que llegan a la zona y que buscan hospedaje

$\sqrt{1}$

Bajo índice de áreas públicas, solo hay parques dentro de urbanizaciones

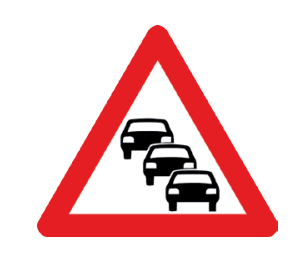

Congestión de tráfico debido a universidades y a paraderos informales. Tráfico frente a proyecto

$\downarrow$ ○ึ

Ciclovía no es aprovechada. Se ramifica por el frente del proyecto. Debería ser integrada para recuperarla

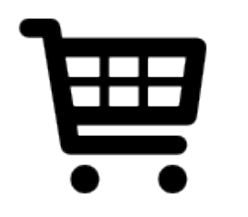

Zona comercial de radio distrital y metropolitano. Debería integrarse una zona comercial de radio local

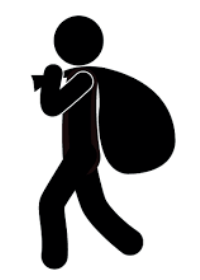

Muros ciegos en varias zonas que generan criminalidad. Eliminar muro en proyecto en la medida de lo posible para bajar el índice de la zona. 